\title{
[-10018-0034
}

DOE/OR/01-2368\&D1

\section{Fiscal Year 2008 Phased Construction Completion Report for EU Z2-33 in Zone 2, East Tennessee Technology Park, Oak Ridge, Tennessee}

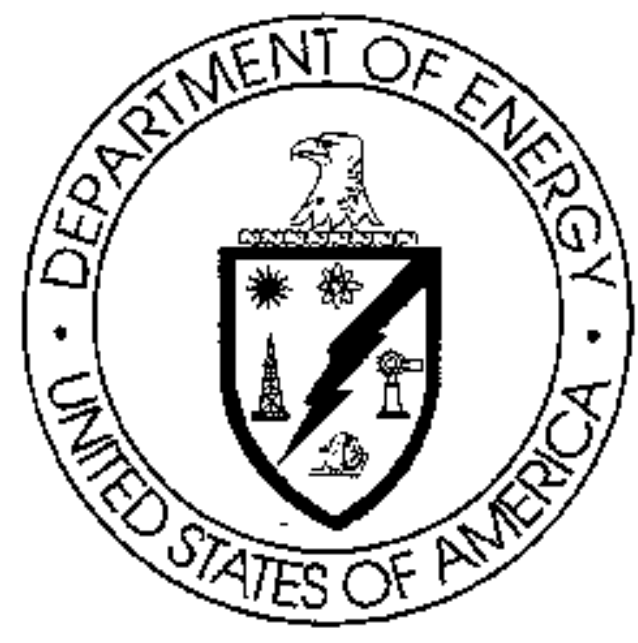

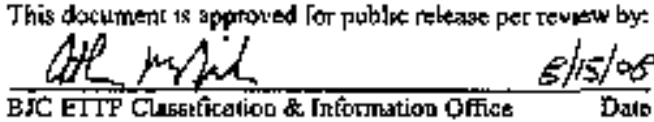




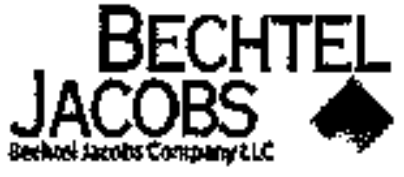

DOE Contract No. DE-AC05-980R22700

Job No. 23900

ETDD-08-0025

September 11, 2008

Mr. Stephen H. McCracken

Contracting Officer's Representative

for Bechtel Jacobs Company LLC

U.S. Department of Energy, EM-90

Post Office Box 2001

Oak Ridge, Tennessee 37831

Dear Mr. McCracken:

DE-AC05-980R22700: H-4 Clause, Government Furnished Services and Items (GFS\&I 8-E-002) Request for Post-Record of Decision (ROD) Comprehensive Environmental Response, Compensation, and Lisbility Act Document Approvals: Fiscal Year 2008 Phased Construction Completion Report for EU Z2-33 in Zone 2, East Tennessee Techuology Park, Oak Ridge, Tentessee (DOE/OR/01-2368\&D1)

Enclosed are 13 copies and two compact disks of the referenced document for transmittal to EPA and TDEC (jointly the Regalators) for their approval. This Phased Construction Completion Report documents that Exposure Unit Z2-33, Balance of Site Laboratories Area is suitable for an unrestricted industrial land use to a depth of ten feet, as required by the Zone 2 ROD. If the Exposure Unit or buildings located on it are leased or transferred, then these agreements must include the land use controls and restrictions required by the Zone 2 ROD.

In accordance with the accelerated approval cycle protocol for post-ROD documents, approval is required within 29 days of DOE receipt of this transmittal, or by Octoter 10, 2008.

Questions or comments should be addressed to Greg Eidam at (865) 576-3393.

Sincerely,

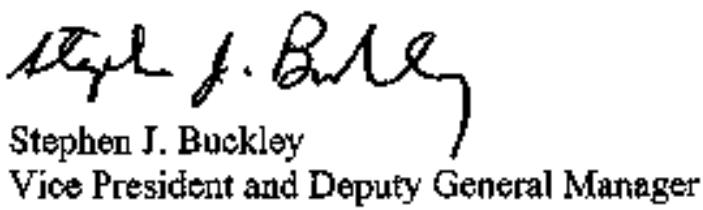

SJB:SBG:sep

Enclosures: As stated

clent: W. J. Biloski

c: S. J. Buckley

L. A. Birk

s. Cange, DOE-ORO

R. R. Butler

P. H. Divjak

R. O. Collins, DOE-ORO

G. R. Eidam

K. R Doughty, DOE-ORO

T. L. Salamacha

S. B. Garland Il

S. K. Shook

J. D. Kopotic, DOE-ORO

R. R. L.ee

File-EMEFDMC-RC 
DOE/OR/11-2368\&D1

Fiscal Year 2008 Phased Construction

Completion Report for EU Z2-33 in Zone 2,

East Tennessee Technology Park, Oak Ridge, Tennessee

Date lssued-September 2008

Prepared for the

U.S. Department of Energy

Office of Environmental Management

BECHTEL JACOBS COMPANY LLC managing the

Accelerated Cleanup Activities at the

East Teruessee Technology Park under contract DE-AC05-980R22700

for the

U.S. DEPARTMENT OF ENERGY 
Reference to any specific commercial product, process or service by trade name, tradematk, manufacturer, or otherwise does not necessarily constitute or imply its endorsement, recommendation, or favoring by the United States Government or any agency thereof or its contractors or subcontractors. 


\section{CONTENTS}

EXECUTME SUMMARY

ES-1

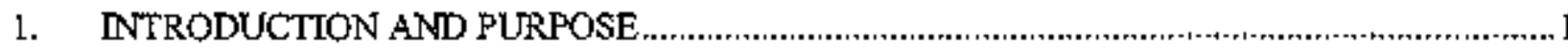

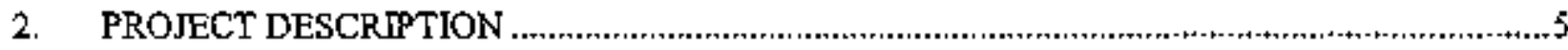

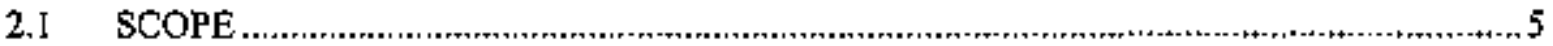

2.1.1 Exposure Unit Groups .................................................................................5

2.1.2 Excluded Acreage .......................................................................................

2.1.3 Data Quality Objectives and Soil Unit Classifications...........................................

2.1.4 Federal Facility Agreement Sites ....................................................................... 7

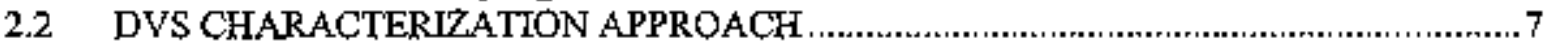

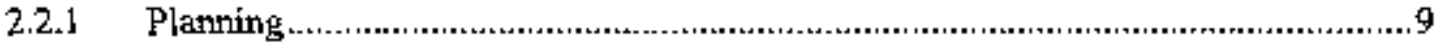

2.2.1.1 SU classification ..............................................................................

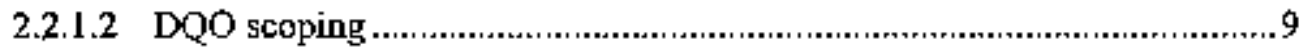

2.2.2 Class 1 and Class 2 SU Characterization Approach..............................................

2.2.3 Class 3 and Chass 4 SU Characterization Approach............................................12

2.2 .4 Program Execution ...................................................................................14

2.2.5 Action/No Further Action Decision/Communication.............................................16

2.2.6 Documentation and Records.................................................................17

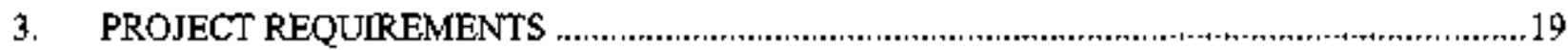

3.1 ZONE 2 RECORD OF DECISION

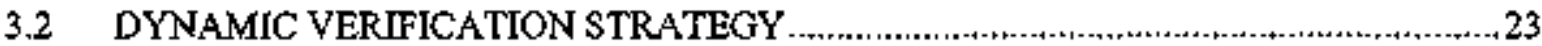

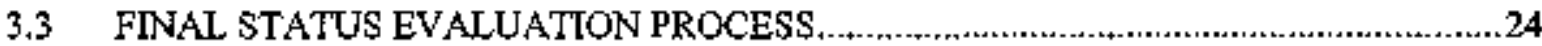

3.3.1 Action/No Further Action Decision …...........................................................24

3.3.2 Special Data Uses and Considerations ..........................................................27

3.3.3 Qualitative Risk Screening for Unrestricted Use ..............................................28

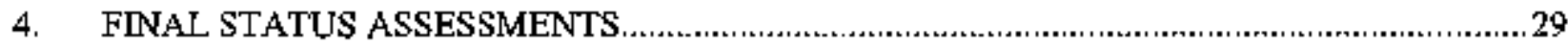

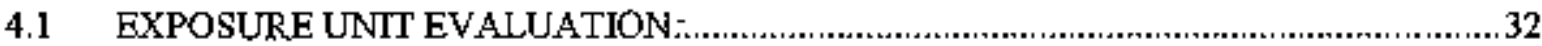

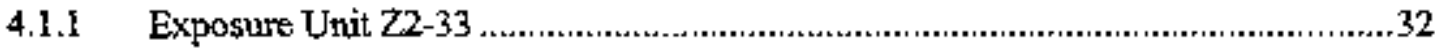

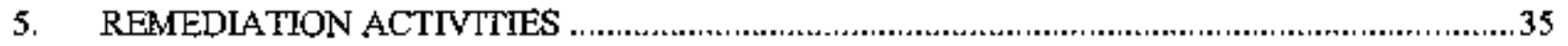

5.1 REMEDIAL ACTION OF BOS LABORATORIES SUBGRADE PTTS ............................35

5.1.1 Facility Descriptions...............................................................................35

5.1.2 Characterization.............................................................................................37

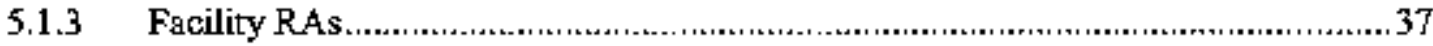

5.1.4 End State..............................................................................................40

5.2 SURFACE SOLS REMEDIAL ACTION SOUTH OF BULLDING K-1004-J

IN EU Z2-33 AND EU Z2-42..................................................................................40

5.2.1 Facility Description and Characterization............................................................40

5.2.2 Soil Remedial Action .......................................................................................40

5.2.3 End State ......................................................................................................4 41

6. DEVIATIONS FROM GOVERNING DOCUMENTS

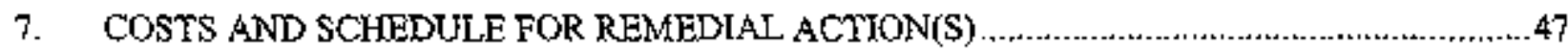


8. WASTE MANAGEMENT ACTIVITIES FOR REMEDIAL ACTION(S) ..............................49

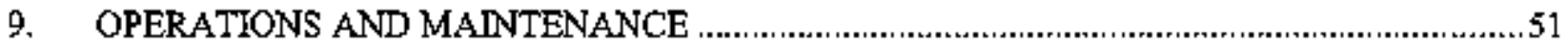

10. MONITORNG SCHEDULE AND/OR EXPECTATIONS

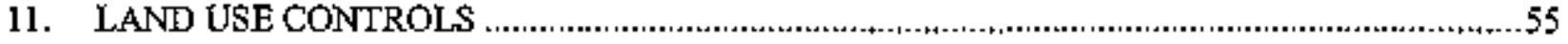

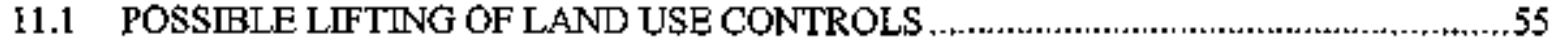

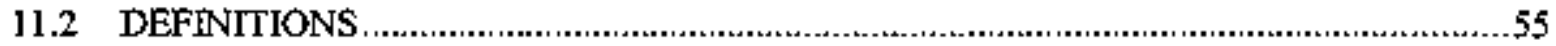

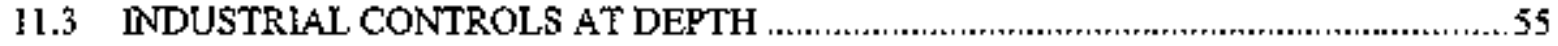

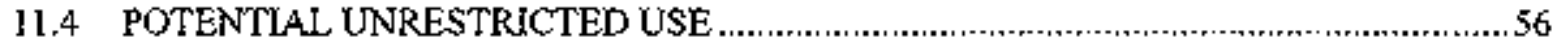

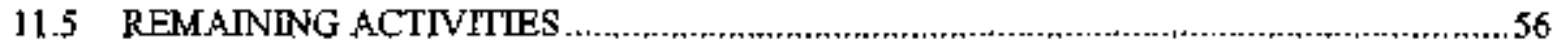

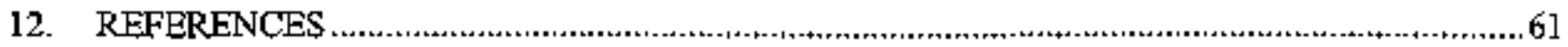

APPENDIX A. EXPOSURE UNIT Z2-33 SOUTH PARK AREA. TECHNICAL MEMORANDUM A-1 


\section{FIGURES}

1. ETTP site map with Zone $2 \mathrm{DQO}$ scoping EU groups and EUs....................................................2

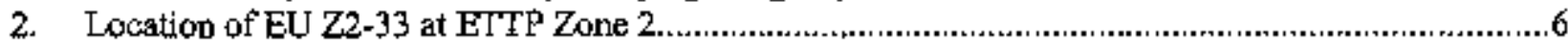

3. Zone 2 DVS Class 1 and Class $2 \mathrm{SU}$ sampting and analysis decision process flow .........................11

4. Zone 2 DVS Class 3 and Class $4 \mathrm{SU}$ sampling and analysis decision process flow......................... 3

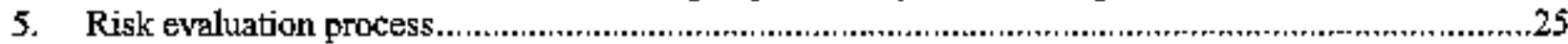

6. Locations of Acid Dilution Pits, K-1015-A Laundry Pit, and soil remedial actionss ........................36

7. K-1004-A, -B, and $-\mathrm{C}$ buil $₫$ ing slab and acid dilution pits prior to remedial action..........................38

8. K-1004-A, B, C building slab and acid dilution pits following remedial .....................................38

9. K-1015 building slab and Laundry Pit prior to remedial action ..................................................39

10. K-1015 butilding slab and Laundry Pit following remedial action.................................................39

11. Confimation radiation survey for area south of the K-1015 Laundry Pit ....................................42

12. Confirmation radiation survey for three locations south of Bldg. K-1004-J..................................43

13. ETTP Zone 2 RA characterization status as of this PCCR .......................................................59

\section{TABLES}

1. Zone 2 EU groups and acreages .............................................................................................5

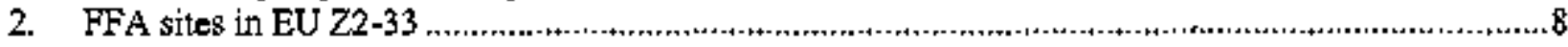

3. RAO and protection goals for Zone 2 .............................................................................19

4. Chemicals and radionuclides required for analysis in Zone 2 DVS samples and their

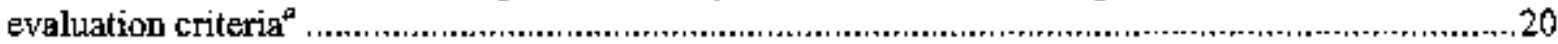

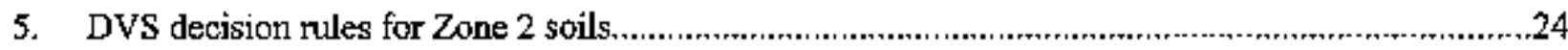

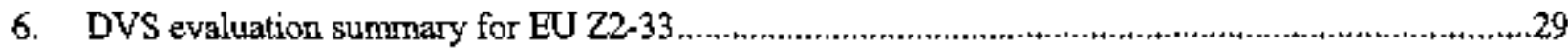

7. Final status assessment summary for EU Z2-33 ..................................................................31

8. Summary of conclusions for EU Z2-33 Zone 2 ROD Appendix A FFA sites ................................32

9. FY 2007 FCNs and concurtenes .......................................................................................45

10. Remedial action cost for EUs Z2-33 and Z2-42 ..........................................................47

11. Waste disposition for EUs Z2-33 and Z2-42 RA .............................................................49 


\section{ACRONYMS}

\begin{tabular}{|c|c|}
\hline $\mathrm{AP}$ & assessment point \\
\hline ARL & average remediation level \\
\hline BAR & biased area remediation \\
\hline BOS & Balance of Site \\
\hline $\mathrm{CD}$ & compact disc \\
\hline $\mathrm{COC}$ & contaminant of concern \\
\hline $\mathrm{D \& D}$ & denctivation and demolition \\
\hline DOE & U.S. Department of Energy \\
\hline DQO & data quality objective \\
\hline DVS & Dynamic Verification Strategy \\
\hline DWP & Dynamic Work Plan \\
\hline ELCR & excess lifetime cancer risk \\
\hline EPA & U.S. Environmental Protection Agency \\
\hline ETTP & East Tennessee Technology Park \\
\hline EU & exposure unit \\
\hline $\mathrm{FCN}$ & Field Change Notice \\
\hline FFA & Federal Facility Agreement \\
\hline FY & fiscal year \\
\hline FIDLER & field instrument for the detection of low energy radiation \\
\hline $\mathrm{HI}$ & hazard index \\
\hline MARSSDM & Multi-Agency Radiation Survey and Site Investigation Marmal \\
\hline MCL & maximum contaminant level \\
\hline MP & mid-point \\
\hline NFA & no further action \\
\hline OREIS & Oak Ridge Environmental Information System \\
\hline $\mathrm{PCB}$ & polychlorinated biphenyl \\
\hline PCCR & Phased Construction Completion Report \\
\hline PRG & preliminary remediation goal \\
\hline QAPP & Quality Assurance Program Plan \\
\hline$Q C$ & quality contsol \\
\hline RA & renuedial action \\
\hline RAO & remedial action objective \\
\hline RAR & Remedial Action Report \\
\hline RDR/RAWP & Remedial Design Report/Remedial Action Work Plan \\
\hline $\mathrm{RCW}$ & recirculating cooling water \\
\hline RL & remediation level \\
\hline $\mathrm{ROD}$ & Record of Decision \\
\hline SL & screening level \\
\hline SOP & standard operating procedure \\
\hline SU & soil unit \\
\hline SVOC & semivolatile organic compound \\
\hline TAL & target analyte list \\
\hline TDEC & Tenressee Department of Environment and Conservation \\
\hline TM & technical memorandum \\
\hline UST & underground storage tank \\
\hline VOC & volatile organic compound \\
\hline
\end{tabular}




\section{EXECUTIVE SUMMARY}

The Record of Dectsion for Soll, Burled Waste, and Subsurface Structure Actions in Zone 2, East Tennessee Technology Park, Oak Ridge, Tennessee (DOE/OR/01-2161\&D2) (Zone 2 ROD) acknowledged that most of the 800 acres in Zone 2 were contaminated, but that sufficient data to confirm the levels of contamination were lacking. The Zone 2 ROD further specified that a sampling strategy for filling the data gaps would bo developed. The Remedial Design Report/Remedial Action Work Plan for Zone 2 Soils, Slabs, and Substayace Structures, East Tennessee Technology Park, Oak Ridge, Tennessee (DOE/OR/01-2224\&D3) (Zone 2 RDR/RAWP) defined the sampling strategy as the Dynamic Verification Strategy (DVS), generally following the approach used for characterization of the Zone 1 exposute units (EUs).

The Zone 2 ROD divided the Zone 2 area into seven geographic areas and 44 EUs. To facilitate the data quality objectives (DQOs) of the DVS process, the Zone 2 RDR/RAWP regrouped the 44 EUs into $12 \mathrm{DQO}$ scoping EU groups. These groups facilitated the DQO process by placing similar facilities and their support facilities together and allowing identification of data gaps. The EU groups were no longer pertinent after DQO planning was completed and characterization was conducted as areas became accessible. As the opportunity to complete characterization became available, the planned DVS program and remedial actions (RAs) were completed for EU Z2-33. Rernedial action was also performed at two additional areas in adjacent EU Z2-42 because of their close proximity and similar nature to a small surface soil RA in EU Z2-33.

Remedial actions for building slabs performed in EU Z2-33 during fiscal year (FY) 2007 were reported in the Fiscal Year 2007 Phased Construction Completion Report for the Zone 2 Soils, Slabs, and Subsurface Structures at East Tennessee Technology Park Oak Rtdge, Temessee (DOE/OR/01-2723\&Dl). Recommended RAs for EU Z2-42 were described in the Ftscal Year 2006 Phased Construction Completion Report for the Zone 2 Soils, Slabs, and Substurface Structures at East Tennessee Technology Park, Oak Ridge, Tennessee (DOE/OR/01-2317\&D2), Remedial actions performed in the Balance of Site (BOS) Laboratory Area of EU Z2-33 and two small areas in EU Z2-42 are described in Sects. 5 througl 10 of this Phased Construction Completion Report (PCCR). The purpose of this PCCR is to address the following:

- Document DVS characterization results for EU Z2-33,

- Describe and document the risk evaluation and determine if the EU meets the Zone 2 ROD requirements for unrestricted industrial use to $10 \mathrm{ft}$ bgs,

- Identify additional areas not defined in the Zone 2 ROD that require remediation based on the DVS evaluation results, and

- Describe RAs performed in the EU Z2-33 BOS Labotatory Area and two small areas in EU Z2-42.

Approximately 18 acres in EU Z2-33 are addressed in this PCCR. Based on the results of the DVS evaluation and RAs performed, all 18 acres are recommended for unrestricted industrial use to $10 \mathrm{ft} b \mathrm{bs}$. Three Federal Facility Agreement sites are addressed and reconsmended for no further action within this acreage, including:

- K-1004-L Recirculating Conling Water Lines Leak Sites,

- K-1044 Heavy Equipment Repair Shop, and

- K-1015-A Laundry Pit. 
Remedial actions for EU Z2-33 were developed in response to DVS characterization results described in the EU Z2-33 Technical Memorandum (Appendix A) and to support reindustrialization of the East Tennessee Technology Park as a commercjal industrial park. Remediation criteria were designed for the protection of a future industrial worker who normally would not have the potential for exposure to soil below $10 \mathrm{ft}$ bgs. Accordingly, the Zone 2 ROD required land use controls to prevent disturbance of soils below $10 \mathrm{ft}$ deep and to restrict future land use to industrial/conmercial activities. In response to stakeholder comments, the U.S. Department of Energy agreed to re-evaluate the need for such land use restrictions. This document includes a screening evaluation to determine the likelihoad of land use controls in EU Z2-33 being modified to: (1) eliminate the restriction on disturbance of soils below $10 \mathrm{ft}$ bgs where data indicate the absence of residual contamination at any depth that would result in an unacceptable risk to the future industrial wokker, and (2) permit altemative land uses that would be protective of future site occupants. Results of this screening evaluation indicate a low probability that restrictions on disturbing soil bilow $10 \mathrm{ft}$ bgs could be safely eliminated for EU Z2-33. A qualitative screening evaluation considered the likelihood of unrestricted land use being protective of future site oceupants. Based on this qualitative assissment, all 18 acres addressed in this PCCR were assigned a low probability for consideration of release for unrestricted land use.

This document contains the main text (Sects. 1 through 13) and one appendix. The main text addresses the purposes for this PCCR and the RAs performed. Additional supporting detail (e.g., field work summaries, maps, survey results, and data summaries) is provided in the EU Z2-33 technical memorandum (Appendix A). The EU Z2-33 Technical Memorandum is prepared from the post-RA perspective, assuming that RA has already been performed. Historical and DVS analytical data used in this PCCR are provided on a compact disc attached to this document and can be accessed through the Oak Ridge Environmental Information System. 


\section{INTRODUCTION AND PURPOSE}

The purpose of this Phased Construction Completion Report (PCCR) is to present fiscal year (FY) 2008 results of Dynamic Verification Strategy (DVS) charecterization activities and remedial actions (RAs) for exposure unit (EU) Z2-33 Balance of Site (BOS) laboratories area and for RA in adjacent EU Z2-42 in Zone 2 at the East Tennessee Technology Park (ETTP). The ETTP is located in the northwest comer of the U.S. Department of Energy (DOE) Oak Ridge Reservation in Oak Ridge, Tennessee and encompasses approximately 5000 acres that have been subdivided into three zonesZone 1 ( $\sim 1400$ acres), Zone 2 ( $~ 800$ acres), and the Boundary Area ( $\sim 2800$ acres).

Zone 2 comprises the highly industrialized portion of ETTP (Fig. 1) and consists of all formerly secured areas of the facility, including the large processing buildings and direct support facilities; experimental laboratories and chemical and materials handling facilities; materials storage and waste disposal facilities; secure document records libraries; and shipping and receiving warehouses. The Record of Decision for Soil Buried Waste, and Stubsurface Structure Actions in Zone 2, East Tennessee Technology Park, Oak Ridge, Tennessee (DOE 2005) (Zone 2 ROD) specifies the future end use for Zone 2 acreage as uncontrolled industrial for the upper $10 \mathrm{ft}$ of soils.

Characterization activities in these areas were conducted in compliance with the Zone 2 ROD and the DVS and data quality objectives (DQOs) presented in the Remedial Design Report/Remedial Action Work Plan for Zone 2 Soils, Slabs, and Subsurface Structures, East Tennessee Technology Park, Oak Ridge, Tentessee (DOE 2007a) (Zone 2 RDR/RAWP). The purpose of this PCCR is to address the following from a post-RA perspective:

- Document EU Z2-33 DVS characterization results;

- Describe and document the risk evaluation and determine if EU Z2-33 meets the Zone 2 ROD requirements for unrestricted industrial use to $10 \mathrm{ft} \mathrm{bgs}$;

- Identify additional areas in EU Z2-33 not defined in the Zone 2 ROD that require remediation based on the DVS evaluation results; and

- Describe RAs performed in EU Z2-33 and two small areas in the adjacent EU Z2-42. Recommended RAs for EU Z2-42 were described in the Fiscal Year 2006 Phased Construction Completion Report for the Zone 2 Soils, Slabs, and Subsurface Structures at East Tennessee Technology Park, Oak Ridge, Tennessee (DOE 2006).

The Zone 2 ROD divided the area into 7 geographic areas and 44 EUs. To facilitate DOOs of the DVS ptocess, the Zone 2 RDRRAWP regrouped the 44 EUs into 12 DQO scoping EU groups. These groups facilitated the DOO process by placing similar facilities and their support facilities fogether and allowing identification of data gaps. The EU groups were no longer pertinent after DQO platuning was completed, and characterization was conducted as EUs became accessible. As the opportunity to complete characterization became available, the planued DVS program and RAs were completed in FY 2008 for EU Z2-33. Two small surface soil RAs were identified in adjacent EU Z2-42 (DOE 2006) that are across the street from and created by the same process as a similar soil area in EU Z2-33. Because of their close proximity and similar nature and extent, the two soil aress were incorporated into the EU Z2-33 RA. 


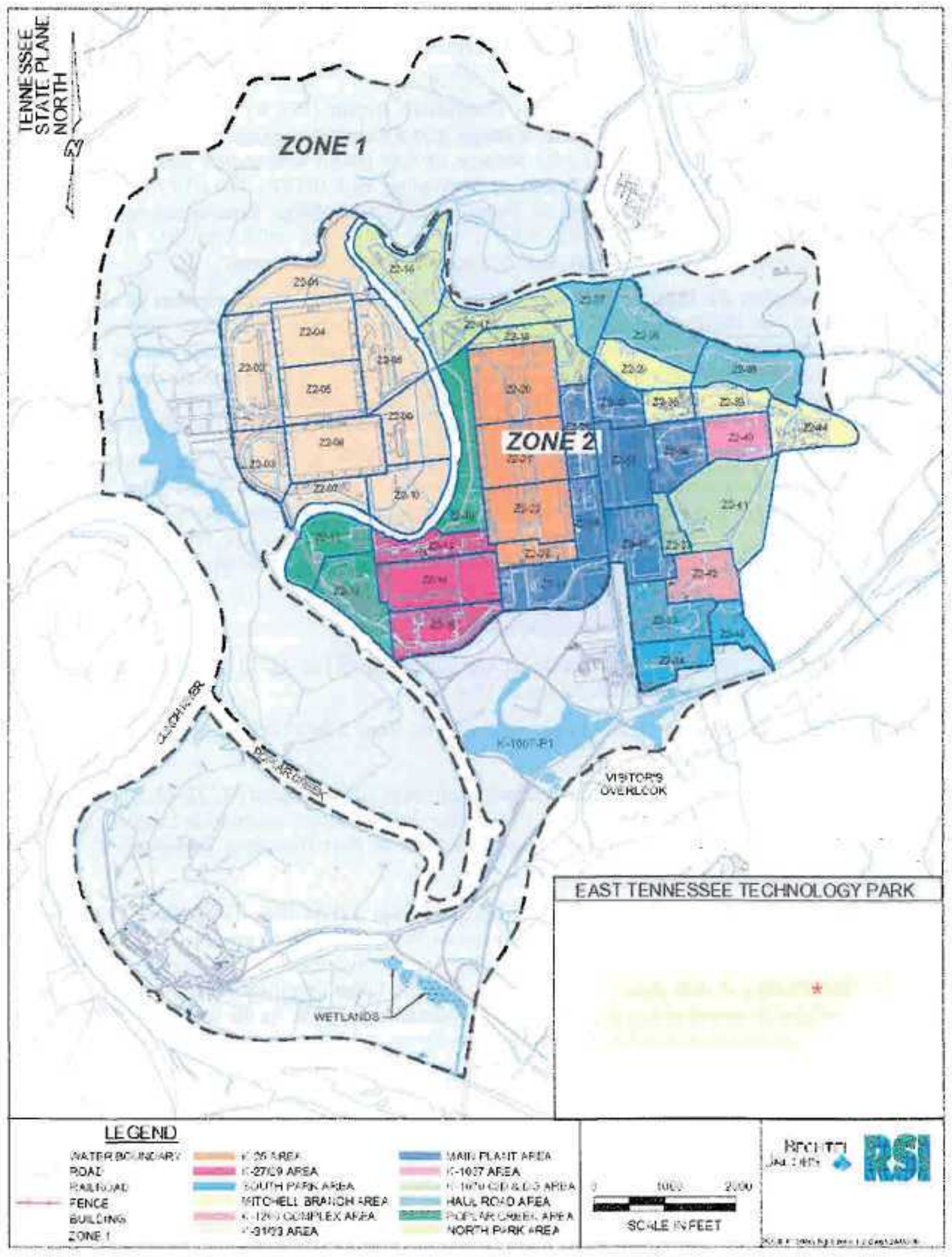

Fig. 1. ETTP site map with Zone 2 DQO scoping EU groups and EUs. 
The main body of this report describes the DVS process, scope of work performed, and RAs completed. The scope and approach for perforning DVS activities that lead to action/no futther action decisions are presented in Sects. 2 through 4 . The remedial action of building slabs performed in EU Z2-33 are reported in Fiscal Year 2007 Phased Construction Completion Report for the Zone 2 Soils, Slabs, and Subsurface Structures at East Tentessee Technology Park Oak Ridge, Tennessee (DOE 2007b). Remedial actions performed in the BOS Laboratory Area of EU Z2-33 and adjacent EU Z2-42 are described in Sects. 5 through 10. Future land use is described in Sect. 11, and the status of all Zone 2 EUs as of this POCR is presented in Sect 12. 


\section{PROJECT DESCRIPTION}

\section{$2.1 \quad$ SCOPE}

\subsubsection{Exposure Unit Groups}

The Zone 2 ROD specified the division of Zone 2 into 44 EUs that range in size from 5.9 acres (EU Z2-37) to 38 acres (EU Z2-41). The location of EU Z2-33 in the South Park Area is shown in Fig. 2. An EU represents a hypothetical area over which an industrial worker could be exposed to contaminated soil in the intervaI 0-10 ft bgs. The acreage of each EU was calculated based on the estimated EU boundaries defined in the Zone 2 ROD. For the Zone 2 DVS characterization program, EU boundaries and acreage calculations were refined. Acreages presented in this document have been rounded to one decimal place. To facilitate DQO development and planuing, the 44 EUs within Zone 2 were divided into 12 EU Groups (DOE 2007a). Field activities were conducted as the opportunity for access to the various areas arose. Coordination between deactivation and demolition (D\&D) activities and assets utilization priorities were the primary drivers in executing the DVS characterization program and RAs. Therefore, EU groups were not completed in their entirety. Evaluation and discussion of the DVS program completed in EU Z2-33 is provided in the technical memorandum (TM) (see Appendix A). The Zone 2 EU groups, EUs, and associated tolal EU group acreages are shown in Table 1.

Table 1, Zone 2 EU groups and acreages

\begin{tabular}{|c|c|c|}
\hline EU Group & EUs & Acreage \\
\hline $\mathrm{K}-3 \mathrm{~L} / \mathrm{K}-33$ Area & $\begin{array}{l}\mathrm{Z} 2-01, \mathrm{Z} 2-02, \mathrm{Z} 2-03, \mathrm{Z2}-04, \mathrm{Z2}-05, \mathrm{Z2}-06, \mathrm{Z2}-07, \mathrm{Z2}-0 \mathrm{~B}, \\
\mathrm{Z} 2-09, \mathrm{Z} 2-10\end{array}$ & 223.6 \\
\hline Poplar Creek Area & $\mathrm{Z} 2-11, \mathrm{Z2}-12, \mathrm{Z2}-19$ & 58.5 \\
\hline K-27/K-29 Area & Z2-13, Z2-14, Z2-15 & 60.5 \\
\hline North Park Area & $Z 2-16, Z 2-17, Z 2-18$ & 62.9 \\
\hline K-25 Area & $\mathrm{Z} 2-20, \mathrm{Z} 2-21, \mathrm{ZZ}-22, \mathrm{Z} 2-23$ & 87.6 \\
\hline Main Plant Area & $\mathrm{Z} 2-24, \mathrm{Z2}-25, \mathrm{ZZ}-26, \mathrm{Z} 2-31, \mathrm{Z2}-32, \mathrm{Z2}-36$ & 100.9 \\
\hline Haul Road Area & $\mathrm{Z2}-27, \mathrm{Z2} \cdot 28, \mathrm{Z2}-38$ & $\$ 2.3$ \\
\hline Mitchell Branch Area & $Z 2-29, Z 2-30, Z 2-35, Z 2-39, Z 2-44$ & 59.7 \\
\hline K-1037 Area & $22-40$ & 13.8 \\
\hline K-1070-CD and Downgradient Area & $Z 2-37,72-41$ & 44.0 \\
\hline K-1200 Complex Area & $22-42$ & 15.5 \\
\hline \multirow[t]{2}{*}{ South Park Area } & $\mathrm{Z} 2.33, \mathrm{Z2}-34, \mathrm{Z2}-43$ & 39.7 \\
\hline & Total acreage & 819.0 \\
\hline
\end{tabular}




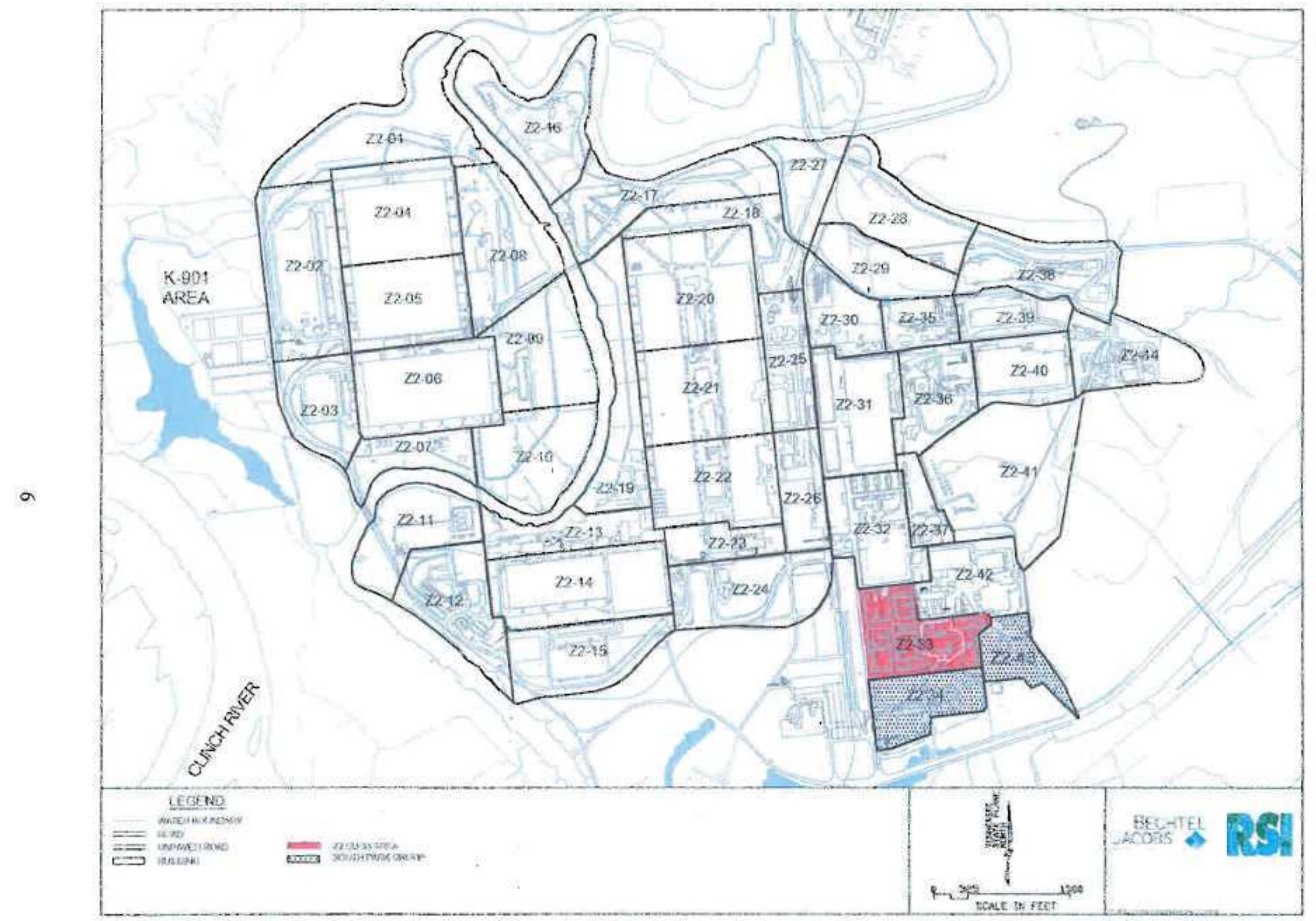

Fig. 2. Location of EU Z2-33 at ETTP Zone 2.

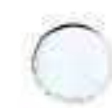




\subsubsection{Ercluded Acreage}

Concrete slab removal at Bldgs. K-1004-A, K-1004-B, K-1004-C, K-1004-D, and K-1004-L (and a small soil RA adjacent to K-1004-L) presented in the FY 2007 Zone 2 PCCR (DOE 2007b) is excluded from this document.

\subsubsection{Data Qaality Objectives and Soil Unit Classifications}

The fust action taken under the DVS characterization program was to assemble the DQO scoping packages, which are Core Team documents that give a compilation and evaluation of facility records and present the results of previous sampling that provided the bases for soil unit (SU) classification and determination of additional sampling needs. The Multi-Agency Radiation Survey and site Investigation Manual (MARSSIM), which describes the probability that an area has been impacted and the extent to which the impact forms the basis for classification, was generally followed for SU classification. The SU classification was used to develop a graded approach to the level of scrutiny so that soils with the highest probability of contamination received the highest level of scrutiny and those with the lowest probability of contamination received the lowest level of scrutiny. The SUs were classified as follows:

- Class 1 -high to moderate probability that contaninants exceed remedial action objectives (RAOs),

- Class 2-moderate to $13 \mathrm{w}$ probability that contarninants excecd RAOS,

- Class 3-impacted areas with low probability of contamination above RAOs, or

- Class 4-no impact from anthropogenic activities (no Class 4 SU areas were identified in Zone 2).

The soil classification breakdown for acreage in EU Z2-33 included the following:

- 0.4 acres in Class 1 SUs,

- 3.9 acres in Class 2 SUs,

- $\quad \mathbf{3} .5$ acres in Class 3 \$Us, and

- 0 acres in Class $4 \mathrm{SU}_{\mathrm{S}}$

In each case, the probability of contamination was based on a thorough review of historical data, aerial photographs, records, and personnel interviews. Soil sampling activities under the DVS focused primarily on Class 1 and Class 2 SUs. The SUs were evaluated by walkover assessments, which included historic photograph analysis, records research, visual inspection, limited radiological survey, and selected biased sampling based on walkover assessment observations and measurements.

\subsubsection{Federal Facility Agreement Sites}

There are three Federal Facitity Agreement (FFA) sites (DOE 1992) in EU Z2-33 that are addressed in this PCCR. Final status assessments for these sites are summarized in Table 2.

\subsection{DVS CHARACTERIZATION APPROACH}

The DVS approach to soils characterization and the rationale to support conclusions drawn from the characterization results are presented in this section. Through characterization activities, DVS provides the necessary information to support decisions on whether an action is required. Additionally, DVS supports decisions on the extent of an action and, through confinnation sampling, whether the action is 
Table 2. FFA sites in EU Z2-33

\begin{tabular}{lccc}
\hline \multicolumn{1}{c}{ FFA site } & EU & $\begin{array}{c}\text { Final status assessed } \\
\text { in this PCCR? }\end{array}$ & Explanation, if not assessed \\
\hline K-1004-L RCW Lines Leak Sites & $Z 2-33$ & Yes \\
K-1044 Heary Equipment Repair Shop & $Z 2-33$ & Yes \\
K-1015-A Laundry Pit & $22-33$ & Yes & \\
\hline
\end{tabular}

E! $x$ exposurt urit

PCCR = Phased Construction Codipletion Report

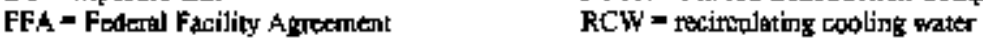

complete. In this section, the characterization approach and communications necessary to make key decisions throughout the DVS process are discussed. Decisions and communicarions required during remediation also are discussed. The DVS process was further defined in the Zone 2 RDRRAWP (DOE 2007).

The DVS process was designed to provide sufficient data to determine if a RA is needed. To meet this goal, a sampling strategy was developed based on the likelihood of RA being required. The DVS characterization approach has six key components, which include the following:

- Plaming (Sect. 2.2.1), including acreage classification (Sect. 2.2.1.1) and DQO scoping (Sect. 2.2.1.2);

- Class 1 and Class 2 SU characterization approBch (Sect. 2.2.2);

- Class 3 and Class 4 SU characterization approach (Sect. 2.2.3);

- Program execution (Sect. 2.2.4);

- Action/no further action (NFA) decision/communication (Sect. 2.2.5); and

- Documentation and records (Sect, 2.2.6).

During the planning stage (first component), the acres of interest were classified into SUs according to their potential level of contamination as described in Sect. 2.1.3, and the DQOs were applied to develop a sampling plan. Because of different probabilities for the presence of contanination, SU classifications had different characterization strategies (second and third component). However, a base survey and sampling program was developed for all SU classifications and presented during DQO scoping. This base program was modified during field implementation as work was conducted and additional characterization needs were identified. The Class 1 and Class $2 \mathrm{SU}$ base program consisted of radiological walkover and geophysical surveys, where appropriate, and systematic sampling supplemented by biased sampling. The Class 3 and Class 4 SU base program primarily consisted of visual itspections and radiological screening surveys with bissed sampling conducted based on inspection and survey observations. Execution techniques to accomplish SU characterization were carried out in the field (fourth component). The final stage included RA Core Team decision making and communication, which was associated with all sampling programs (fifth component).

The RA Core Team was created to streamline planning and accelerate the completion of all actions at ETTP to accelerate site closure. The RA. Core Team approach is a formalized, consensus-based process where members reach agreement on key closure issues and strategies. The RA Tean consists of representatives from parties to the FFA-DOE, U.S. Environmental Protection Agency (EPA), and Tennessee Department of Environment and Conservation (TDEC) as well as DOE's accelerated closure contractor. The phimary function of the RA Core Team is to make programuatic decisions that facilitate and guide specific projects as ETTP progresses toward closure.

The following subsections provide an overview of the first four DVS characterization process components. 


\subsubsection{Planning}

The two key parts of the planning component included soil unit classification and DQO scoping for sampling plan development, both of which required RA Core Team concurrence.

\subsubsection{SU classification}

To begin planning, the land area within each EU Group was classified as either impacted or non-impacted by ETTP plant activities. This initial classification included compilation and reviev of existing information from historic aerial photographs, maps, drawings, and other facility records. After classification as impacted/non-impacted, land areas were assigned SU classifications as defined in Sect. 2.1.3. (FFA sites were typically designated as Class 1 or Class 2 SUs.)

\subsubsection{DQO scoping}

Once the area under consideration was classified into a SU, the quantity and quality of existing data and other information was evaluated against the DQO requirements for sufficiency and quality, and a DQO scoping plan for base program surveying, sampling, and analysis was developed. Some of the work described below (e.g, field survey results) was used to design the DQO scoping plan and was considered part of the planning process. A DQO scoping plan, including the SU classifications, was presented to the RA. Core Team for concurrence and documented in the Dynamic Work Plan (DWP), which identified sample locations and analysis requirements, and included the use of real-time field measurements where applicable. Any additional sampling and analysis was addect to the program with RA Core Team concurrence. The DQO scoping meeting for work described in this PCCR was conducted on January 19, 2005, and the applicable DWP is the Zone 2 Dynamic Work Plan, East Tennessee Technology Pank, Oak Ridge, Tennessee (BJC 2007).

Per the DVS process, a portion of characterization samples were analyzed for an extensive list of potential contaminants. Fixed laboratory analyses were performed for a suite of analytes [\%olatile organic compounds (VOCs), semivolatile organic compounds (SVOCs), target andyte list (TAL) metals, polychioninated biphenyls (PCBs), and a radiological analytical suite that included gamma spectroscopy, alpha spectroscopy, thoriun-isotopic, uranium-isotopic, lechnetium- 99 , and radium-specific analyses].

All identified contamination was evaluated to detemine if action was needed for the EU, including the following:

- Primary and secondary contaminants of concen (COCs), which are identified in the Zone 2 ROD;

- Contaminants of potential concern, which are identified during the risk evaluation process; and

- EU-specific COCs, which are contaminants identified during characterization that result in an unacceptable EU tisk.

The documentation included a summary of existing data, assessment of data gaps in DQO scoping packages, and documentation of the base survey and sampling program in the Zone 2 DWP. Conourrence on the base program was reached by the Core Team and documented on concurrence forms.

\subsubsection{Class 1 and Class 2 SU Characterization Approach}

Implementation of the Class 1 and Class $2 \mathrm{SU}$ characterization program included the steps Histed below. Details on each step are provided in Seck. A.8 of the Qtality Assurance Project Plan for Soil Characterization Activities under the Dynamic Verification Strategy at the East Tennessee Technology Park, Oak Ridge, Tennessee (QAPP), which is included as Appendix A in the Zone 2 RDRRAWP (DOE 2007a). 
- Step 1 (not applicable in Zone 2)-Complete an ecological impact assessment prior to significant disturbance.

- Step 2 (not applicable in Zone 2)—Clear to provide access (as required).

- Step 3-Perform radiological walkover surveys (where historic surveys are unavailable) and geophysical surveys [burial sites and underground storage tank (UST) sites].

- Step 4-Select systematic sampling locations and additional biased sampling locations based on survey results.

- Step 5-Perform base program and initial biased sampling.

- Step 6-Evaluate field and laboratory data.

- Step 7-Select additional biased sampling locations based on field measurements and laboratory results.

A flow diagram outtining the details of this characterization approach and associated decisions made for Class 1 and Class 2 SUs is shown in Fig. 3. Along with the planning component (acreage classification and DOOs) defined in Sects. 2.2.1.1 and 2.2.1.2, Steps 1 through 4 above constitute the base program for characterizing Class 1 and Class 2 SUs.

Field radiological and -geophysical surveys (Step 3) were performed prior to the actual sempling activity. A lead time of several weeks to months allowed for the evaluation of survey data and supported selection of a set of biased sampling locations to evaluate the results. Geophystcal surveys were used to define the boundaries of buried waste at landfill disposal sites or the presence of other buried objects (USTs) and materials.

Radiological walkover surveys were used to define the limits of radiological contamination in surface soils. The decision to have biased sampling locations where elevated radiological readings or geophysical anomalies were encountered (Step 4) was made after reviewing results of the radiological walkover and geophysical surveys. (These survey results were used later during the confimation sampling phase to assist in identifying potential excavation boundaries.) After concurrence from the RA Cote Team, any biased sampling locations identified from these survey results were included in the base sampling program.

Characterization field work began (Step 5 ) after the base program was defined and agreed to by the RA Core Team. Each EU Group was characterixed according to the specific details presented during DQO scoping and finalized in the DWP. Soil sampling was performed using standard field methods and following EPA Region IV standard operating procedures (SOPs).

The predorinant method of sample acquisition for subsurface soil to depths up to $30 \mathrm{ft}$ was Geoprobei sampling. Surface and shallow interval soil sampling was performed predominantly using hand augers. The standard DVS sampling methodology cals for composite samples to be taken from the 0- to 6-in. interval, 6-in to 2-ft interval, and 2- to 10-ft interval. The sample composite protocol is presented in Attachment $C$ to the QAPP [Appendix A in the Zone 2 RDR/RAWP (DOE 2007a)]. Discrete interval samples were collected based on the following two criteria (Steps 5, 6, and 7):

- Field screening method showed an elevated level for a COC in a segment of a core; or

- Initial analytical results from samples submitted to a laboratory showed an action level [25\% of an average remediation level (ARL)] for one or more COCs was exceeded in the composited sample (Steps 6 and 7). 

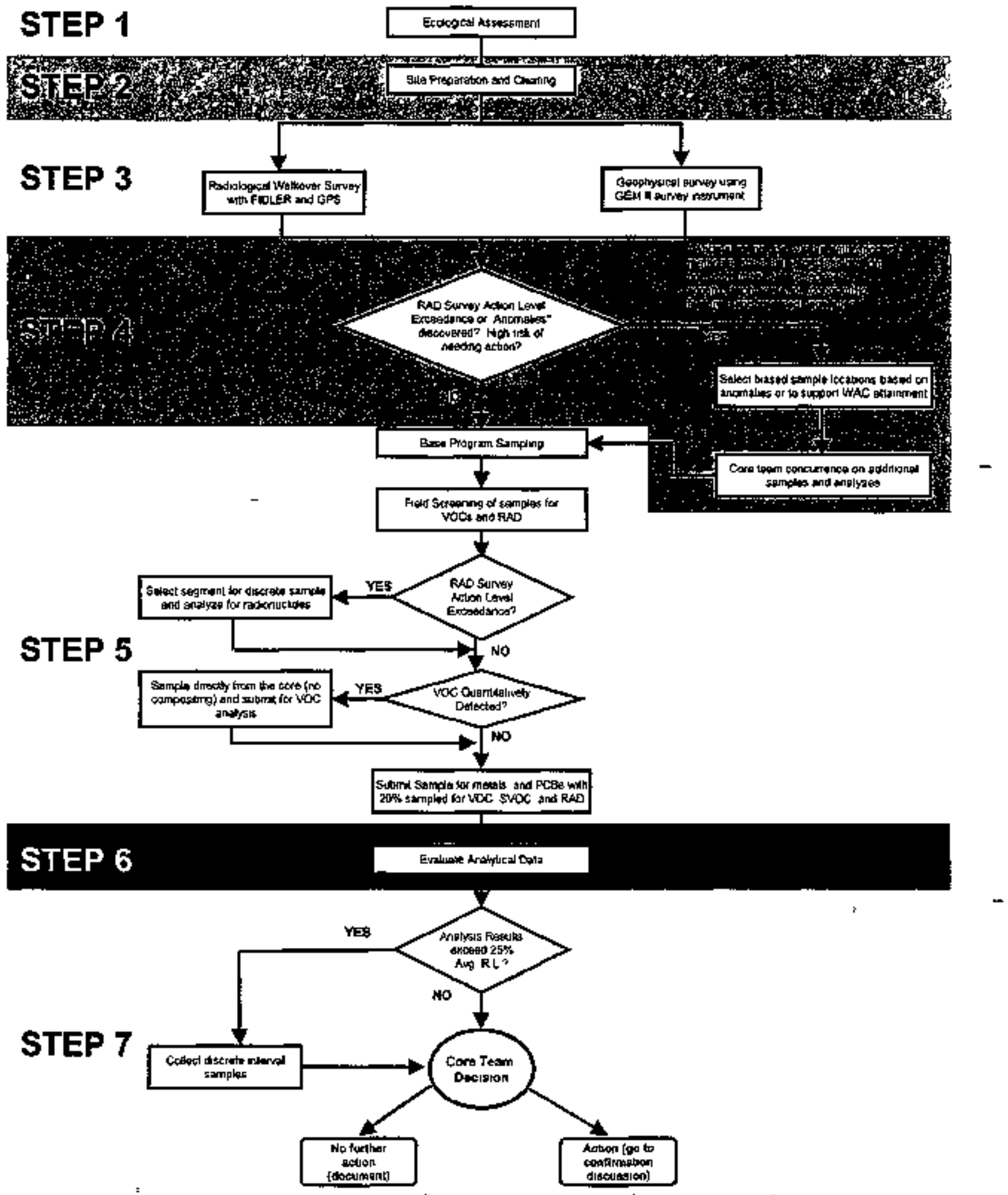

Fig. 3. Zone 2 DVS Class I and Class 2 SU sampling and analysis decision process flow. 
For the first criterion, field screening methods were used as part of the field characterization activity (Step 5). Two field screening methods used on soil cores included (1) VOC sereening using hand-held meters, and (2) radiological screening using core-scanning devices developed specifically for the DVS program. Field screening allowed sample collection for laboratory analysis of the core intervals most likely to have contamination in addition to collection of the composited sample. Collection of the most-likely contaminated segment of the core ensured existing contamination was represented in the analytical results. Recognution of potential VOC contamination also allowed the segment of the core to be collected for VOC analysis prior to compositing. VOCs were not analyzed for in composite samples.

The second criterion was based on analysis of laboratory results. The base program required all samples to be analyzed for TAL metals and PCBs. To support the risk assessment, a randomly selected $20 \%$ of all samples also were analyzed for VOC (discrete interval), SVOC, and radiological analyses (Step 5). If laboratory-reported results indicated action levels were exceeded in any of the randomly selected samples, the location with elevated results was resampled for the specific parameters of concem and three discrete intervals [0-6 in., $6 \mathrm{in}-2 \mathrm{ft}$, and a selected interval in the 2-10 $\mathrm{ft}$ interval (Steps 6 and 7)] were sent for analysis.

Current EPA laboratory analytical methods were used to provide risk assessment quality data as required by the DQO process and as stipulated in the DWP for all composite samples, discrete samples, and samples sent for full-suite analysis. All of the information collected is documented in the EU Z2-33 TM (Appendix A).

\subsubsection{Class 3 and Class 4 SU Characterization Approach}

A flow diagram outlining the characterization approach taken and the associated decisions made for Class 3 and Class 4 SUs is presented in Fig. 4. Note that no Class 4 SUs are present in EU Z2-33. The following statements were considered during decision making:

- Are there anthropogenic features, areas of elevated radiation, or sediment accumalation areas that require biased sampling and analysis?

- Does the EU exceed RAOs stated in the Zone 2 ROD and, therefore, require action? (Results from Class 1 and $2 \mathrm{SU}$ evaluations, if applicable, are needed to make this final EU-level assessment.)

Assessment of the Class 3 and Class 4 SU acreage proceeded independently of the Class 1 and Class 2 SU investigations and were perfomed during the winter, when possible, to facilitate inspection of those portions of Zone 2 with heavy vegetation. These assessments were conducted in accordance with the Class 3 and Class 4 Soil Unit Walkover Assessment Protocol (DOE 2007a, Attachment C). The approach began with visual walkover inspections conducted to systematically irspect Class 3 and Class 4 SUs along transects to cstablished systematic grid assessment locations, map observed features, ard collect radiological screening data to support the action/NFA decision.

These assessments focused on jdentifying antbropogenic features, delineating boundaries of the features, and determining if sampling of the features was warranted Anthropogenic features identifted in the Class 3 and Class 4 SUs were broadly inclusive of anything present as the result of any human activity. Identifying any unnatural conditions in the remote areas of the site where little to no industrial activity occurred was a very conservative approach to the site assessment protocol for clearing large tracts of peripheral lands in Zone 2. Anthropogenic features as defined in the Class 3 and Class 4 SU walkover assessment protocol were to include areas of radiation survey anomalous readings (above two times area background), visible anthropogenic materials (such as concrete, asphalt, metal debris, rubble, and rubbish), soil staining or discoloration, and/or stressed vegetation. In addition, crews were instructed to identify areas of unusual topographic relief, low areas where sediment would accumulate, and mounds of soil that appeared to be unusual for the local topographic conditions. This very brosd definition of anthropogenic features provided a thorough assessment of the Class 3 and Class 4 SUs in Zone 2 . 


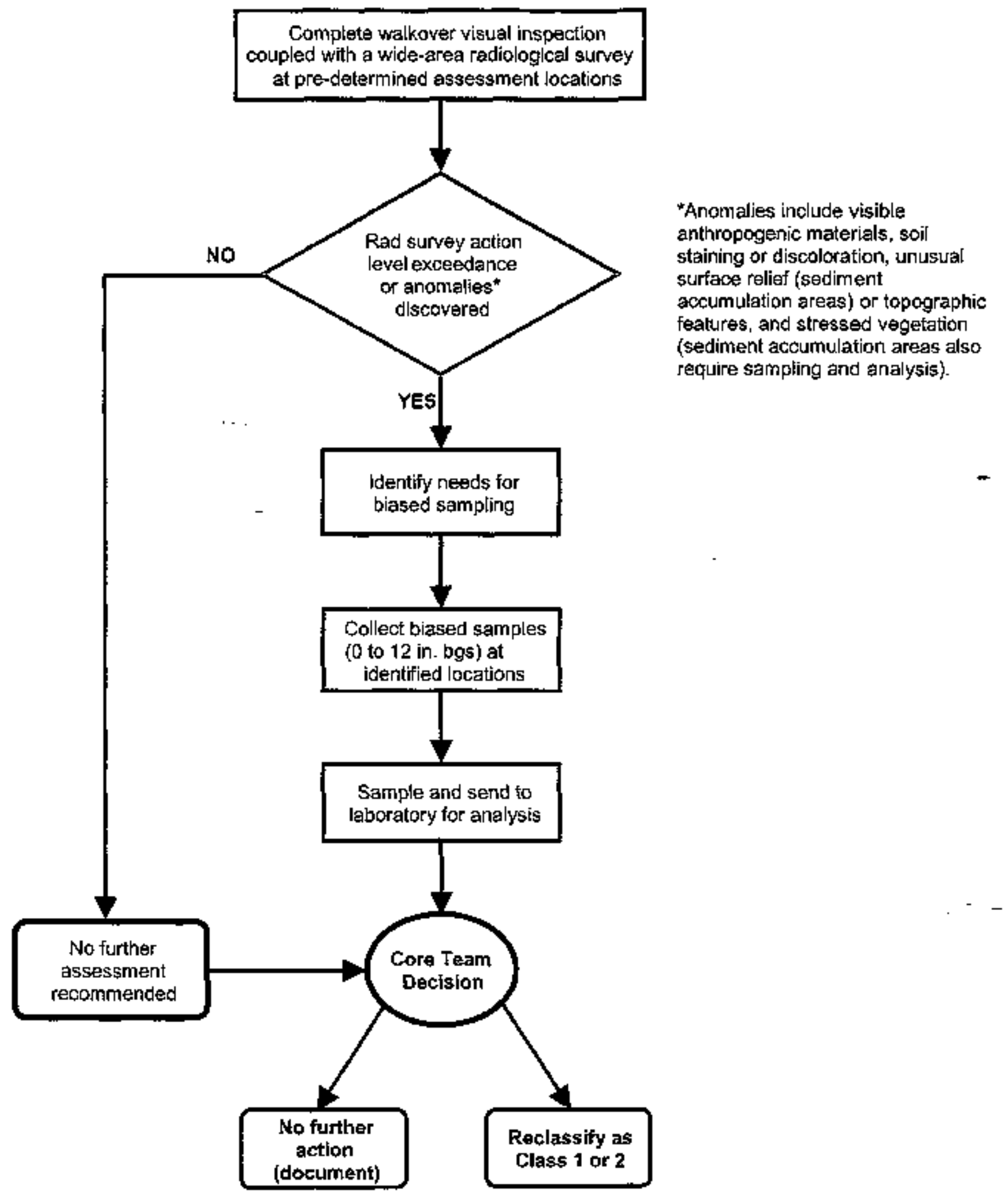

Fig, 4. Zone 2 DVS Class 3 and Cless 4 SU sampling and analysis decision process flow. 
A systematic grid with a random starting point was used to establish each assessment point (AP), with approximately one point per acre. A field instrument for detection of low-energy radiation (FDLER) (Ludlumin 44-17 detector, 2 in. $\times 2$ mm) was used by the survey crews. Background conditions were established for the EU group based on the Class 3 and Class 4 Soil Unit Walkover Assessment Protocol (DOE 2007a, Attachment C). The screening level (SL), which determined the need for further consideration and detajled evaluation, was twice the group mean background value. Approximately halfway to each AP, a mid-point (MP) was counted and surface features described. Class 3 and Class 4 SU radiological surveys were conducted at APs, MPs, and discretionary points during the SU walkover assessments. Anthropogenic features or areas of elevated activity away from APs and MPs were also characterized with 30-second counts of the FIDLER as a discretionary survey point.

Biased soil samples from identified anomalies were collected and analyzed for metals, radionuclides, and PCBs. Approximately $20 \%$ of the biased samples were analyzed for a larger suite of analytes to aid in identifying potentially unrecognized, site-related soil contaminants.

Biased sampling lockations also were identified in sediment accumulation areas, which are defined as areas where runoff from large portions of the SU and surrounding areas converge and have the potential for sediment deposition. The chemical and radiological composition of sediment accumulation area soils or sediments is representative of the upstream conditions, and elevated levels of contamination are indicative of an upgradient source. Biased samples collected from sediment accumulation areas were sent to a laboratory for radionuclide, metal, VOC, SVOC, and PCB analysis to identify previously unrecognized site-related soil contaminants.

\subsubsection{Program Execution}

Soil sample collection was performed following EPA Region IV standard sampling methods and SOPs. The DVS base program sampling was tailored to site-specific conditions and samples were collected in the 0 - to 10 -ft depth in all Class 1 and Class 2 SUs. There were several conceptual site models in Zone 2 that included surface and subsurface models describing the potential contaminant source and potential release to the environment.

The DVS program for the Class 1 and 2 SUs required at least $20 \%$ of all sample locations be drilled and sampled to a depth of $10 \mathrm{ft}$ bgs. Sample borings were completed using Geoprober direct-push equipment (Models 54DT and 54LT) and were collected in acetate liners and capped upon recovery. All boreholes were logged and described according to EPA Region IV guidance (EPA 2002), and all soil cores were scanned in the field for the presence of radioactive contaminants using the Model $T$ Radiological Soil Core Screening System. The core screening action level was set to comespond with approximately $80 \%$ of the ARL for U-238 (40 pCV/g). The SL for the core scanner was based on a background soil core for which a daily baseline value was detemined. The SL varied slightly from day to day in response to local ambient radiological conditions and natural activity of the background soils specific for the EU Group. Screening levels were set at the observed daily baseline (commonly in the range of $135-150 \mathrm{cpm})$, plus $65 \mathrm{cpm}$, and were in the range of $200 \mathrm{cpm}( \pm 20 \mathrm{cpm})$, which provided $100 \%$ accuracy for identifying gamma-emitting radioactive contamination in soils in excess of $40 \mathrm{pCi} / \mathrm{g}$.

Results of field activities completed in this PCCR indicate the SLs of baseline plus $65 \mathrm{cpm}$ were consistently identifying radiological constituents at $10 \mathrm{pCi} / \mathrm{g}$ or greater in soil corts. When the SL was exceeded, a discrete interval soil sample was collected for radiological analysis.

The acetate liners were split in the field and the core was screened for the presence of VOCs. If VOCs were detected above $5 \mathrm{ppm}$ using a hand-held photojonization detector, a discrete interval soil. sample was collected for VOC analyses using EnCoreßi samplers. At a burial trench site (e.g., EU Z2-41), the waste matrix was commonly comprised of course materials, debris, rubble, and fill materials, which precluded the use of EnCored samplers for VOC analysis. Approved sample containers were used at these sites and managed according to EPA Region IV protocols (EPA 2002). 
At base progran sampling locations, three intervals of the soil core were composited according to the protocol described in the QAPP (DOE 2007a, Appendix C). The compositing procedure stipulates that equal volumes of soil from the surface to 0.5 -ft interval, 0.5- to 2-ft interval, and a selected section of core in the 2- to 10-ft interval be collected and thoroughly mixed to form a composite soil sample. The interval selected for inclusion in the soil composite was based on visual observation of the sample and targeted to select the most contaminated portion of the soil core. Selection was made based on visual observations such as staining, odor, soil contacts, obvious waste, or the presence of unnatural materials. This compositing methodology provided a physical conposite that represented the average contaminant profile for the entire 0 - to I0-ft interval. All base program composite samples were analyzed for PCBs and TAL metals and screened in the field for the presence of VOCs $>5$ ppm) and radioactivity (in excess of two times background). Discrete interval samples were collected for VOC and radiological analyses if field SLs were exceded [tefer to the Zone 2 QAPP (DOE 2007a) for specific procedwes].

The DVS program requires $20 \%$ of all sample locations be drilled and sampled to $10 \mathrm{ft}$ bgs. At surface contamination sites, the base program focused on the 0 - to 2 - $\mathrm{ft}$ interval where contaminant releases would have occurred. However, $20 \%$ of the locations were drilled and sampled to $10 \mathrm{ft} \mathrm{bgs.} \mathrm{At}$ the UST sites and buried utilities and infrastructure sites, all borings were drilled and sampled to $10 \mathrm{ft}$ bgs or to native material, whichever was deeper. The program also requires at least $20 \%$ of all samples be analyzed for a full suite of COCs, including VOCs, SVOCs, metals, PCBs, and radioisotopes. Locations to be drilled to depth and samples for full suite analyses are randomly selected. This selection process results in full suite analyses-being performed on both surface and shallow interval samples as well as on some deep soil samples.

Changes to the base program plan included dropping inaccessible sample locations (e.g., areas of steep slopes or obstructions such as roads or heavy dead fall areas) and moving locations due to shallow refusal (e.g., buried concrete and metallic debris and rubble). These changes were documented on Field Change Notice (FCN) forms and presented to the Core Team for concurrence. Drops and moves occurred at $<5 \%$ of the planned locations. Locations moved more than $5 \mathrm{ft}$ from the planned grid node were identified by the inclusion of an " $M$ " character in the location ID (e.g., Z2-EU33M-206).

At surface contarnination sites, the base program plan stipulated sampling the 0 - to 2 -ft interval to focus in the interval where contamination levels were assumed to be the highest. Sampling in these areas was performed using the Geoprobe( equipment and 0- to 2-fh, two-interval composite samples using the standard sampling method. In these areas, $20 \%$ of the base program sample locations were drilled to $10 \mathrm{ft}$ at randomly selected jocations and $20 \%$ of all locations ( 0 to 2 th and to depth) were analyzed for a full suite of constituents. Soil cotes at these sites also were screened in the field for VOC and radiological contamination.

Biased sampling was performed in addition to base program sampling. These locations were selected based on the results of geophysical surveys, radiological watkover surveys, and "step-out" locations to base program samples that indicated significant concentrations of contamination occurred. Biased sanples drilled to $10 \mathrm{ft}$ were collected in three discrete intervals (from the 0.5-ft interval, 0.5- to 2-ft interval, and a selected section of core in the 2- to 10 -ft interval). Surface soil samples were generally collected as five-point conposite samples to provide area coverage of radiological surface anomaltes, surface-distributed mounds of soils, or small waste piles. The intent of surface compositing was to provide an average contaminant profile for a localized surface area.

Sampling procedures and methods were complied using EPA Region $\Gamma$ guldance. Sampling equipment, shipping containers, and quality assurance/quality control (QC) requirements also followed EPA Region N guidance. Standard laboratory aralytical methods were used, and data management and QC procedures were complied with EPA criteria Detailed discussion of field and laboratory requirements is included in the Zone 2 RDRRAWP (DOE 2007a). 


\subsubsection{Action/No Further Action Decision/Communication}

Once results of field and analytical work were received, the RA Core Team evaluated the data and decided on an appropriate action. The action/NFA decision was based on one or more of the following criteria:

- Exceedance of a maximum remediation level (RL) at any location,

- Exceedance of an average RL across the EU,

- Unacceptable future threat to groundwater, and/or

- Unacceptable cumulative excess lifetime cancer risk (ELCR) of $>1 \times 10^{-4}$ and hazard index (HI) of $>1$ across the EU.

Sample results were evaluated for the 0 - to 10 -ft soil interval and were not depth dependent. Contamination anywhere within the 0 - to 10 -fi interval had equal weighting in the risk assessment and was presumed equally accessible to an industrial worker. Soil sample compositing provided data representative of the 0 - to 10 -ft interval. Discrete interval sampling was selected based on the field screening for VOCs and radioactivity identified by soil core screening. This approach provided a very conservative evaluation of soil conditions and had an equivalent consideration in the risk assessment methodology. Selection of intervals for inclusion in soil core composite samples was based on visual observation and included the portion of the soil core with the highest probability of contanination. Visual cues included but were not limited to bedding contacts, porous and permeable intervals, staining, and odor. Discrete sample interval depth information is included in the data set on the compact dise provided with this document. Major stratigraphic differences (i.e., $2 \mathrm{ft}$ of cover material over fill) are referenced in the text where appropriate.

An area-weighted mean of the data in each EU was used to compare the average composition of the EU to the average RLs. Risk was evaluated by area-weighting the results. Beckuse data within an EU was unevenly distributed across the SUs (i.e., SUs with greater probability of contamination had a higher density of samples), weighting was based on the areal extent of the SUs. For \$Us with little probability of contamination and, therefore, few, if any, sample results (i.e., Class 3 SUs), background concentrations of COCs as defined in the Soil Background Supplemental Dato Set for the East Tenmessee Technology Park. Oak Ridge, Tennessee (DOE 2003) were used in the weighted average calculations for the EU risk assessments and comparison to average RLs.

Data collected for the original background data set for ETTP (DOE 1993a) was not representative of EITP site soils, nor were the associated statistical calculations performed in accordance with then curtent EPA guidance. To resolve the issues, additional samples were collected and statistics were recalculated to comply with EPA guidance. Samples were collected from the B soil horizon of the Rome and Upper Knox formations to supplement the original data set. These samples were collected from approximately 12-24 in. bgs and analyzed only for radiological constituents and inorganic elements. The comparison of site data versus background data was made using methods from Guidance for Comparing Background and Chemical Concentrations in Soil for CERCLA Sites (EPA 2002). Soil background data used in this report was presented in the document Soil Background Supplemental Data Set for the East Tennessee Technology Park, Oak Ridge, Tennessee (DOE 2003) and not from the earlier report.

If elevated concentrations (i.e., above background) were found, sample results were used (even if sparse) after the $S U$ was reclassified as a Class 1 or Class 2 SU. Results of the actionNFA evaluation were documented in the EU Group TM, which were provided to the RA Core Team for early teview but formally submitted for approval as appendices to this PCCR. Data, maps, cross sections, and other useful information also were provided on the project webpage to facilitate decision making.

The risk RAO was developed in the Zone 2 ROD to identify new COCs because of the uncertainty that all COCs had been identified in the historical data sets. If the risk assessment identified contaminants 
requiring remediation that did not have associated RLs, remediation was recommended if the risk was found to be unacceptable.

\subsubsection{Documentation and Records}

All information, data, documents, and records necessary to support the decisions presented in this PCCR will be transfered to the post-decision document file upon approval of the PCCR. A list of referenced documents that becomes part of the ffle is provided in Sect. 12. Additional records contained within the file but not listed in Sect. 12 include but are not limited to FCNs, Core Team concurrence forms, and analytical data packages. The post-decision document file is available to the public through the DOE Oak Ridge Office Infomation Center. Analytical data, field data, and sample location maps are archived in and made available to the public through the Oak Ridge Environmental Information System (OREIS). 


\section{PROJECT REQUIREMENTS}

Requirements for the characterization activities, fmal status assessments, and RAs originated in the Zone $2 \mathrm{ROD}$, which presents specific soil RAs required in Zone 2 and provides general guidelines for addressing the remainder of the soils. In response to the guidelines for addressing Zone 2 soils, DVS was developed to present specific requirements for addressing soils and making action/NFA decisions. It is further stated in Sect. 1.5 of the Zone 2 ROD that additional contaminants could be identified during remedy implementation or confirmation.

\subsection{ZONE 2 RECORD OF DECISION}

The Zone 2 ROD presents the selected remedy for environmental remediation of contaminated areas within Zone 2 at ETTP. An evaluation of existing data performed in the Zone 2 ROD determined the following sites either had sufficient characterization data to demonstrate unacceptable risk, warrant additional characterization, and/or selection of an action for soil:

- K-1070-B Old Burial Ground,

- K-1420 Facility Area,

- K-1004-J Lab Complex Area,

- K-1401 Facility Area,

- K-1070-CD Area, and

- Zone 2 miscellaneous soils.

In addition, the ROD specifies that a DVS should be developed to address the characterization of soils in other areas in the Zone with insufficient data to determine if an action is required. As discussed in the ROD, the key criterion for an action/NFA decision and a successful RA is the RAO, which is presented in Table 3 .

Table 3. RAO and protection goals for Zone 2

\begin{tabular}{ll}
\hline \multicolumn{1}{c}{ Remedlation issue } & \multicolumn{1}{c}{ Protection roal } \\
\hline Future land use & $\begin{array}{l}\text { Protect human health under an unrestricted industrial land use to a risk level not to } \\
\text { exceet } 1 \times 10^{-1}\end{array}$ \\
Groundwater resoutces & $\begin{array}{l}\text { Control leaching and nigration from contaminated soil to help minimize further } \\
\text { impacts to groundwater }\end{array}$ \\
\hline
\end{tabular}

RAO $\times$ remmedial aclion abjextive

Other key parts of the ROD include determining future land use as unrestricted industrial to $10 \mathrm{ft}$ bgs, protecting the industrial worker from soil exposure identified as the primary risk driver, developing a risk assessment methodology based on EUs, and defuning soil COCs with corresponding soil RLs (two RLs were established for each COC in the ROD). The maximum RL is the concentration that a COC may not exceed at any location within an $\mathrm{EU}$. The average $R L$ is the average $O O C$ concentration within an $\mathrm{EU}$ that, when exceeded, means the RAO risk protection goal has not been met. The Zone 2 ROD COCs, chemicals, and radionuclides required for analysis and associated RLs are presented in Table 4. 
Table 4. Chemicals and radionaclides required for analysis in

Zone 2 DVS samples and their evaluation criterta

\begin{tabular}{|c|c|c|c|c|c|c|}
\hline $\begin{array}{l}\text { Chemicals and } \\
\text { radionucidies }\end{array}$ & $\begin{array}{c}\text { Maximum } \\
\text { RL }\end{array}$ & $\begin{array}{l}\text { Average } \\
\text { RL }\end{array}$ & $\begin{array}{l}\text { Indnstrial } \\
\text { PRG (10) }\end{array}$ & Background & $\begin{array}{c}\text { Groundwater } \\
\text { SL }^{b}\end{array}$ & $\begin{array}{l}\text { Residentsal } \\
\text { PRG }\left(10^{-5}\right)\end{array}$ \\
\hline \multicolumn{7}{|c|}{ Metals $(m g / k g)$ (ng $g / L$ for grouthdwater) } \\
\hline Alaninum & & & 100,000 & 40,300 & & 7,614 \\
\hline Antimony & & & 410 & 1.52 & 144 & 3.1 \\
\hline Arsenjc ${ }^{c}$ & 900 & 300 & 16 & $\mathbf{j} 4.95$ & 66.3 & 0.39 \\
\hline Barium & & & 67,000 & 124.93 & 9,150 & 537 \\
\hline Berylium & 6,000 & 2,000 & 1,900 & 2.20 & & 15 \\
\hline Boton & & & 100,000 & & & 1,600 \\
\hline Cadmium & & & 450 & $0.22 \mathrm{U}$ & & 3.7 \\
\hline Calcium & & & & 2400 & & \\
\hline Chromium & & & 640 & 44.88 & 172 & 22 \\
\hline Cobalt & & & 130,000 & 42.00 & & 138 \\
\hline Copper & & & 41,000 & 22.48 & & 313 \\
\hline Iton & & & 100,000 & 58,600 & & 2,346 . \\
\hline Lead & & & 800 & 37.91 & 3,370 & 400 \\
\hline Lithium & & & 20,000 & 48.94 & & I56 \\
\hline Magoesium & & & & 3,300 & & \\
\hline Manganese & - & & 19,000 & 2,200 & & 176 \\
\hline Mercury & 1,800 & 600 & 310 & 0.17 & & 2.35 \\
\hline Molybdenum & & & 5,100 & & - & 39 \\
\hline Nickel & & & 20,000 & 26.07 & & 156 \\
\hline Potassium & & & & $5,074.69$ & & \\
\hline Selenium & & & 5,100 & 1.47 & & 39 \\
\hline Silver & & & 5,100 & $0.6 \mathrm{U}$ & & 39 \\
\hline Sodium & & & & 497 & & \\
\hline Thallium & & & 67 & $0.4 U^{U}$ & 10.8 & 0.52 \\
\hline Uranium & & & 200 & & & 1.56 \\
\hline Vanadium & & & 1,000 & 65.47 & & 7.8 \\
\hline Zine & & & 100,000 & 89.70 & & 2,346 \\
\hline \multicolumn{7}{|c|}{ Radionuclides (pCi/gl (wo/L for gronthdwater) } \\
\hline Cesium $-137^{c}$ & 20 & 2 & 1.1 & & & 0.06 \\
\hline Cobalt -60 & & & 0.6 & & & 0.04 \\
\hline $\begin{array}{l}\text { Gross alpha activity } \\
\text { Gross beta activity }\end{array}$ & & & & & & \\
\hline Neptunium-237 & 50 & 5 & 2.7 & & & 0.13 \\
\hline Potassium-40 & & & 2.7 & 32.12 & & 0.11 \\
\hline Radiuna-226 $6^{c, d}$ & 15 & 5 & 0.26 & 1.25 & & 0.01 \\
\hline Technnetium-99 & & & 9,000 & & & 0.25 \\
\hline Thorium- $230^{\text {c,d }}$ & 15 & 5 & 210 & 1.20 & & 3.5 \\
\hline Thorium-232e,d & 15 & 5 & 0.176 & 1.95 & & 0.01 \\
\hline Uranium-234 & 7,000 & 700 & 330 & 1.47 & 61.1 & 4.02 \\
\hline Uranium $-235^{c . d}$ & 80 & 8 & 4.0 & & 61.1 & 0.2 \\
\hline Utanium-238 & 500 & 50 & 18 & 1.47 & 61.1 & 0.74 \\
\hline \multicolumn{7}{|l|}{ Pesticides and PCBs (ug/kg) } \\
\hline PCB- $1016^{\circ}$ & 100,000 & 10,000 & 37,000 & & & 393 \\
\hline PCB-1221 ${ }^{c}$ & 100,000 & 10,000 & 7,436 & & & 112 \\
\hline PCB $-1232^{c}$ & 100,000 & 10,000 & 7,436 & & & 112 \\
\hline $\mathrm{PCB}-1242^{\circ}$ & 100,000 & 10,000 & 7,436 & & & 112 \\
\hline РСB-1248 & 100,000 & 10,000 & 7,436 & & & 112 \\
\hline $\mathrm{PCB}-1254^{6}$ & 100,000 & 10,000 & 7,436 & & & 112 \\
\hline $\mathrm{PCB}-1260^{\circ}$ & 100,000 & 10,000 & 7,436 & & & 112 \\
\hline Polychlorinated biphenyl' & 100,000 & 10,000 & 7,436 & & & 112 \\
\hline
\end{tabular}


Table 4. (contipned)

\begin{tabular}{|c|c|c|c|c|c|c|}
\hline $\begin{array}{l}\text { Chemicals and } \\
\text { radionnclides }\end{array}$ & $\begin{array}{l}\text { Maximum } \\
\text { RI }\end{array}$ & $\begin{array}{c}\text { Average } \\
\text { RL }\end{array}$ & $\begin{array}{l}\text { Indestrial } \\
\text { PRG }\left(10^{-5}\right)\end{array}$ & Background & $\begin{array}{c}\text { Groondwater } \\
\text { SL }^{\phi}\end{array}$ & $\begin{array}{l}\text { Restidential } \\
\text { PRG }\left(10^{-5}\right)\end{array}$ \\
\hline \multicolumn{7}{|c|}{ Sentivolatile Organic Compounds (kg/kz) (ug/L for gronntwater) } \\
\hline 1,2,4-Trichlorobenzene & & & 220,000 & & & 6,216 \\
\hline 1,2-Dichlorobenzene & & & 600,000 & & & 110,330 \\
\hline 1,3-Dichlombenzene & & & 600,000 & & & 53,135 \\
\hline 1,4-Dichlorobenzente & & & 79,000 & & & 3,447 \\
\hline $2,3,4,6$-Tetrachlorophenol & & & $18,000,000$ & & & 183,309 \\
\hline $2,4,5-$ Trichtorophenol & & & $62,000,000$ & & & 611,031 \\
\hline 2,4,6-Trichlorophend & & & 62,000 & & & 611 \\
\hline 2,4-Dichlorophenol & & & $1,800,000$ & & & 18,331 \\
\hline 2,4-Dimethylphenol & & & $12,000,000$ & & & 122,206 \\
\hline 2,4-Dinitrophenol & & & $1,200,600$ & & & 12,221 \\
\hline 2,4-Dinitrotoluene & & & 25,000 & & & 715 \\
\hline 2,6-Dinitrotoluene & & & 25,000 & & & 715 \\
\hline 2-Chloronaphthalene & & & $23,000,000$ & & & 493,664 \\
\hline 2-Chlorophenol I. & & & 240,000 & & & 6,340 \\
\hline 2-Metbyl-4,6-dinitrophenol & & & 62,000 & & & 611 \\
\hline 2-Methylnaphthalene & & & 190,000 & & & 5,592 \\
\hline 2-Methyiphenol & & & $31,000,000$ & & & 305,515 \\
\hline 2-Nitrobenzenamine & - & & $1,800,000$ & & & 18,277 \\
\hline \multicolumn{7}{|l|}{ 2-Nitrophenol } \\
\hline 3,3'-Dichlorobenzidine & & & 38,000 & & & 1,081 \\
\hline 3-Nitrobenzenamine & & & 18,000 & & & 1,833 \\
\hline \multicolumn{7}{|l|}{$\begin{array}{l}\text { 4-Bromophenyl phenyl } \\
\text { ether }\end{array}$} \\
\hline \multicolumn{7}{|l|}{ 4Chloro-3-methylphenol } \\
\hline 4-Chlorobenzenamine & & & $2,500,000$ & & & 24,441 \\
\hline \multicolumn{7}{|l|}{$\begin{array}{l}\text { 4-Chlorophenyl phenyl } \\
\text { ether }\end{array}$} \\
\hline 4-Methylphenol & & & $3,100,000$ & & & 310,000 \\
\hline 4-Nitrobenzenamine & & & 180,000 & & & 18,330 \\
\hline \multicolumn{7}{|l|}{ 4-Nitrophenol } \\
\hline Acenaphthene & & & $29,000,000$ & & & 370,000 \\
\hline Acenaphthylene & & & $29,000,000$ & & & 370,000 \\
\hline Aniline & & & $3,000,000$ & & & 42,742 \\
\hline Aлthracene & & & $100,000,000$ & & & $2,200,000$ \\
\hline Benz(a)enthracenc & & & 21,000 & & & 621 \\
\hline Benzenemethanol & & & $100,000,000$ & & & 1,833 \\
\hline Benzo(a)pyrent & & & 2,100 & & & 62 \\
\hline Benzo(b)fluoranthene & & & 21,000 & & & 621 \\
\hline Benzo(ghi)perylene & & & $29,000,000$ & & & 231,595 \\
\hline Benzo(k)fluoranthene & & & 210,000 & & & 6,215 \\
\hline Benzoic acid & & & $100,000,000$ & & & $24,000,000$ \\
\hline \multirow{2}{*}{\multicolumn{7}{|c|}{$\begin{array}{l}\text { Bis(2-chlorothoxy) } \\
\text { methane }\end{array}$}} \\
\hline & & & & & & \\
\hline $\mathrm{Bis}$ (2-chloroethyl) ether & & & 5,800 & & & 218 \\
\hline \multicolumn{7}{|l|}{ Bis(2-chloroisopropyl) } \\
\hline ether & & & 74,000 & & & 2,884 \\
\hline Bis(2-elhylhexyl)phthalate & & & $1,200,000$ & & $2,350,000$ & 34,741 \\
\hline Butyl benzyl phthalate & & & $100,000,000$ & & & $1,200,000$ \\
\hline Carbazole & & & 860,000 & & & 24,319 \\
\hline Chrysene & & & $2,100,000$ & & & 62,146 \\
\hline Di-n-butyl phthalate & & & $62,000,000$ & & & 611,000 \\
\hline Di-n-octylphthalate & & & $25,000,000$ & & & 244,000 \\
\hline
\end{tabular}


Table 4. (continued)

\begin{tabular}{|c|c|c|c|c|c|c|}
\hline $\begin{array}{l}\text { Chenicals and } \\
\text { radionuelides }\end{array}$ & $\begin{array}{l}\text { Maximana } \\
\text { RL }\end{array}$ & $\begin{array}{l}\text { Average } \\
\text { RL } \\
\end{array}$ & $\begin{array}{l}\text { Industrial } \\
\text { PRG (100) }\end{array}$ & Backsponnd & $\begin{array}{c}\text { Groondwater } \\
\text { SL }^{*}\end{array}$ & $\begin{array}{l}\text { Residenttal } \\
\text { PRG }\left(10^{-6}\right)\end{array}$ \\
\hline Dibenz(a,b)anthracene & & & 2,100 & & & 62 \\
\hline Dibenzofurán & & & $1,600,000$ & & & 14,526 \\
\hline Diethyl phthalate & & & $100,000,000$ & & & $4,900,000$ \\
\hline Dimethyl phthajale & & & $100,000,000$ & & & $61,000,000$ \\
\hline Diphernyldiazene & & & 160,000 & & & 4,422 \\
\hline Fluoranthene & & & $22,000,000$ & & & 230,000 \\
\hline Fluorene & & & $26,000,000$ & & & 275,000 \\
\hline Hexachlorobenzene & & & I 1,000 & & & 304 \\
\hline Hexachlorobutadiene & & & 180,000 & & & 1,833 \\
\hline \multicolumn{7}{|l|}{ Hexachloro- } \\
\hline cyclopentadiene & & & $3,700,000$ & & & 36,550 \\
\hline Hexachloroethane & & & 620,000 & & & 6,110 \\
\hline Indeno $(1,2,3-c d) p y r e n e$ & & & 21,000 & & & 621 \\
\hline Isophorone & & & $5,100,000$ & & & 512,000 \\
\hline \multicolumn{7}{|l|}{ N-Ni(roso-di-n- } \\
\hline propylamine & & & 2,500 & & & 69.5 \\
\hline N-Nitrosodimethylamine & & & 340 & & & 9.54 \\
\hline N-Nitrosodipherylamine & & & $3,500,000$ & & & 99,261 \\
\hline Naphthalene & - & & 190,000 & & & 5,592 \\
\hline Nilrobenzene & & & 100,000 & & & 1,964 \\
\hline Pentachlorophendl & & & 90,000 & & · & 2,979 \\
\hline Phenanthrene & & & $29,000,000$ & & & 23,160 \\
\hline Pbenol & & & $100,000,000$ & & & $1,800,000$ \\
\hline Pyrene & & & $29,000,000$ & & & 231,600 \\
\hline Pyridıne & & & 620,000 & & & 6,110 \\
\hline \multicolumn{7}{|c|}{ Volntile Organtc Componds (ug/kg) (ug/L for groundwater) } \\
\hline 1,1,1-Trichloroetbane & & & $1,200,000$ & & 97,900 & 198,200 \\
\hline $1,1,2,2$-Tetrachloroethane & & & 9,300 & & & 408 \\
\hline 1,1,2-Trichloroethane & & & 16,000 & & 1,370 & 729 \\
\hline 1,1-Dicbloroethane & & & $1,700,000$ & & & 50,640 \\
\hline 1,5-Dichloroethene & & & 410,000 & & 1,750 & 12,350 \\
\hline 1,2-Dichloroethane & & & 6,000 & & 729 & 278 \\
\hline 1,2-Dichloropropane & & & $-7,000$ & & & $\mathbf{3 4 2}$ \\
\hline 2-Bulanone & & & $110,000,000$ & & & $2,230,000$ \\
\hline \multicolumn{7}{|l|}{ 2-Hexanone } \\
\hline 4-Methyl-2-pentanone & & & $47,000,000$ & & & 528,100 \\
\hline Acetone & & & $54,000,000$ & & & $1,413,000$ \\
\hline Benzene & & & 14,000 & & 1,150 & 643 \\
\hline Bromodichloromethane & & & 18,000 & & & 824 \\
\hline Bromoform & & & $2,200,000$ & & & 61,570 \\
\hline Bromomethane & & & 13,000 & & & 390 \\
\hline Carbon disulfide & & & 720,000 & & & 35,530 \\
\hline Carbon tetrachloride & & & 5,500 & & 2,770 & 217 \\
\hline Chlorobenzene & & & 530,000 & & & 15,070 \\
\hline Chlorothane & & & 65,000 & & & 3,026 \\
\hline Chloroform & & & 4,700 & & 1230 & 221 \\
\hline Chloromethane & & & 160,000 & & & 4,685 \\
\hline Dibromocbloromethane & & & 26,000 & & & 1,109 \\
\hline Ethylbenzene & & & 400,000 & & & 186,400 \\
\hline Methylene chlonde & & & 210,000 & & 241 & 9,107 \\
\hline Styтene & & & $1,700,000$ & & & 438,210 \\
\hline Tetrachloroethene & & & 13,000 & & 4,720 & 484 \\
\hline Toluent & & & 520,000 & & 502,000 & 65,600 \\
\hline
\end{tabular}


Tabie 4, (continued)

\begin{tabular}{|c|c|c|c|c|c|c|}
\hline $\begin{array}{l}\text { Chemicals and } \\
\text { radionaclides }\end{array}$ & $\begin{array}{l}\text { Maxinumin } \\
\text { RL }\end{array}$ & $\begin{array}{c}\text { Average } \\
\text { RL }\end{array}$ & $\begin{array}{l}\text { Industrial } \\
\text { PRG }\left(10^{-5}\right)\end{array}$ & Background & $\begin{array}{c}\text { Groundwater } \\
\text { SL }\end{array}$ & $\begin{array}{l}\text { Residential } \\
\text { PRG }\left(10^{-5}\right)\end{array}$ \\
\hline Total Xylene & & & 420,000 & & & 27,000 \\
\hline Trichlorgethene & & & 1,100 & & 1,720 & 53 \\
\hline Vinyl chloride & & & 7,500 & & 176 & 79 \\
\hline cis-1,2-Dichlorothene & & & 150,000 & & & 4,294 \\
\hline cis-1,3-Dichloropropene & & & 18,000 & & & 777 \\
\hline trans-1,2-Dichloroethene & & & 230,000 & & & 6,949 \\
\hline trans-1,3-Dichloropropene & & & 18,000 & & & 777 \\
\hline D'esel Range Organics" & & & & & $100 \mathrm{mg} / \mathrm{kg}$ & \\
\hline Gasoline Range Organics" & & & & & $100 \mathrm{mg} / \mathrm{kg}$ & \\
\hline
\end{tabular}

"Chemicats and radiomuclides listed include all of the 20ue 2 soik COCs axd pother chemical and raditanaclides considered to be potential eantaminants at ETTP. Abalytical laboralories for DVS samples often report the results for chemicols and radionuclides not listed here and historical data may include anslyser for chemicals and radionuelides not reponted in DVS faroples. When there is a detetion in either a DVS or historical sample af a

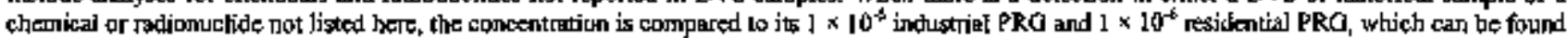
in the Zone 2 RDR/RAWP (DOE 2007a).

Referred to as soil exposure contemeraibss in the Zone 2 ROD.

'Zont 2 ROD conkamirast of concers

${ }^{4}$ Radiurt-226, Thorium-230, and Thorium-232 are evaluated by a computational method that determines the primary RAD constituent and the daughers of the primary radionatlide; the total activity of the primarry plus daughters is then compared to establighed Zone 2 RLs that are listed in the Zone 2 RDR/RAWP (DOE 2007a).

'Dicsel-range organics and gasoline-range arganics apply when there is an UST under investigation. The 100-mug/kg limit for protextion of froundwater is based on State of Tensessee UST regulations.

COC- tombarinant of concern DVS * Dynamic Verification Strategy ETTP = East Tennessee Techrology Park PRG = prelimiraty rentéfitation gosl

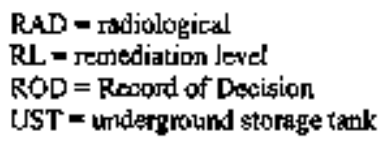

As specified in the Zone 2 ROD, all of Zone 2 should be evaluated for unrestricted use with data from the industrial use scenario. In areas where information indicates there is little chance for unacceptable contamination, restrictions will not be imposed (see Sect. 11).

\section{3,2 DYNAMIC VERIFICATION STRATEGY}

The DVS was developed as required by the Zone 2 ROD and designed to provide sufficient data to fill data gaps, conduct final status assessments for all of Zone 2, and to facilitate real-time decision making. This strategy focused on the soil characterization portion of the Zone 2 ROD to determine where action was needed. Acreage classification was used to progressively focus the investigation efforts in areas with a moderate to high probability of soil contamination (see Sect. 2.1.3). The DVS also helped verify information from previous investigations to incorporate flexibility to facilitate rapid collection of additional data based on data results. The strategy was to gather adequate data with minimal iterations of site investigation planning and mobilization.

The DVS addressed requirements of the Zone 2 ROD RAO with the DQO process. Step 5 of the DVS DQOs presented four decision rules whereby any particular land area in Zone 2 was deemed to have met the $\mathrm{RAO}$ requirements (see Table 5). 
Table 5. DVS fecision rules for Zone 2 soils

\begin{tabular}{|c|c|c|c|}
\hline $\begin{array}{c}\text { Decision } \\
\text { Rule }\end{array}$ & If & Then & Otherwise \\
\hline 1 & $\begin{array}{l}\text { Concentration of any COC in a } \\
\text { localized area ("hot spot" nominally } \\
50 \text {-ft radius) within an EU to a depth } \\
\text { of } 10 \mathrm{ft} \text { exceeds the maximum } \mathrm{RL}\end{array}$ & $\begin{array}{l}\text { Remediate localized area of elevated } \\
\text { contamination until the COC concentration is } \\
\text { less than the maximum RL }\end{array}$ & $\begin{array}{l}\text { NFA for } \\
\text { protection of } \\
\text { industrial worker }\end{array}$ \\
\hline 2 & $\begin{array}{l}\text { Mear concentration value of any soil } \\
\text { COC to a depth of } 10 \mathrm{ft} \text { exceeds the } \\
\text { average RL within an EU }\end{array}$ & $\begin{array}{l}\text { Remediate elevaled areas of contamination } \\
\text { until the mean COC concentrolion over the EU } \\
\text { is less than the respective } R L\end{array}$ & $\begin{array}{l}\text { NFA for } \\
\text { protection of } \\
\text { industrial worker }\end{array}$ \\
\hline 3 & $\begin{array}{l}\text { Industrial risk across the EU to a depth } \\
\text { of } 10 \mathrm{ft} \text { is }>1 \times 10^{4} \text { ELCR or target } \\
\text { organ HIs exceed l }\end{array}$ & $\begin{array}{l}\text { Remediate elevated areas of contarination } \\
\text { until residual risk over the EU is below the risk } \\
\text { levels. Evaluatc the need for action if target } \\
\text { HIs exceed } 1\end{array}$ & $\begin{array}{l}\text { NFA tor } \\
\text { protection of } \\
\text { industrial worker }\end{array}$ \\
\hline 4 & $\begin{array}{l}\text { Site-specific contaminants in } \\
\text { groundwater exceed MCL or } \\
\text { site-specifie, mass-based soil SL } 8^{\circ} \\
\text { oalculated for a site for the protection } \\
\text { of groundwater are exceeded above } \\
\text { the water table or bedrock surface } \\
\text { (whichever is shallower) }\end{array}$ & Evaluate the impacts of remediating the site & $\begin{array}{l}\text { NFA for the } \\
\text { protection of } \\
\text { groundwater }\end{array}$ \\
\hline
\end{tabular}

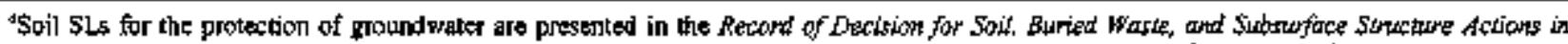

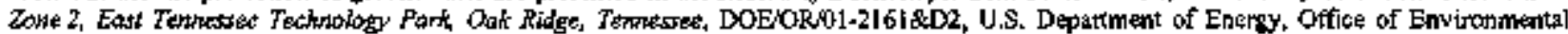
Manggettert, Oak Ridge, TT.

COC $=$ contamingint of concern DVS = Dynamic Verifieation Strategy

ELCR- excess lifetume cancer risk

EU $=$ exposure unit

$M C L=$ jusximum sontamirianu level

NFA $=$ no funthet action

$R L=$ rearediation kerel

$\mathrm{HI}=$ hazard index

SI = serętening level

\section{FINAL STATUS EVALUATION PROCESS}

The firal status recommendation for action/NFA of each EU as presented in this PCCR was determined by evaluating the EU in terms of the four decision rules. Descriptions of the action/NFA evaluation processes for each decision rule are presented in Sect. 3.3.1. A discussion of special data uses and considerations in the action/NFA evaluations is included in Sect. 3.3.2. As defined in the Zone 2 ROD, a risk screening was performed to evaluate the industrial land use of each EU, A qualitative risk screening also was conducted against $1 \times 10^{-6}$ residential preliminary remediation goals (PRGs) to evaluate the unrestricted use of each EU. A description of this evaluation is presented in Sect. 3.3.3.

\subsubsection{Action/No Further Action Decision}

The process whereby EUs are evaluated against the four DVS decision nules (see Sect. 3.2) is described in the following text and presented graphically in Fig. 5 as Steps 1 through 4.

Decision Rule 1-Maximum RE Evaluation. Zone 2 soils chemical and radionuclide $C O C$ concentrations are screened against their maximum (not to exceed) RLs as defined in the Zone 2 ROD. If any compound is detected at a concentration above its maximum $\mathrm{RL}$, an action is required. Maximum RIs and the COCs they are applied to are presented in Table 4. 


\section{STEP 1}

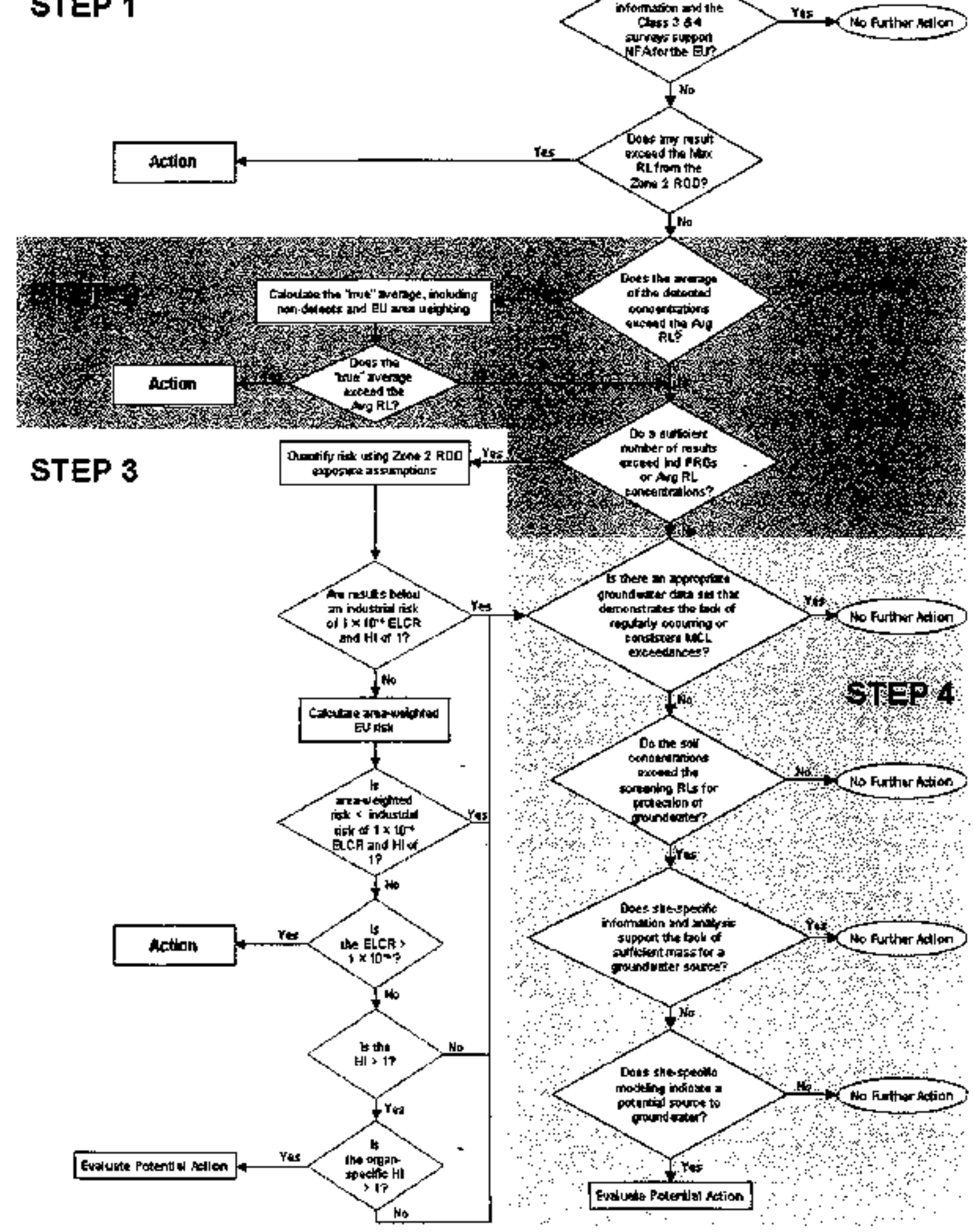

Fig. 5. Risk evaluation protess. 
Decision Rule 2-Average RL Evaluation. The mean value of the detected concentrations for each Zone 2 soil $O O C$ across an EU is screened against the respective average $R L$. If the average detected concentration of any $\mathrm{COC}$ across an EU is less than the average RI for that $\mathrm{COC}$, then the overall average concentration of the $\mathrm{COC}$ (which includes non-detected results and area weighting) must also be below the average $R L$.

If the EU average detected concentration of soils $C O C$ exceeds the average $R L$ for that $C O C$, then the EU average is calculated using the detected values and half the detection limit for all the non-detect results. If the EU average for this calculation is still in excess of the Zone 2 average RLs, then an aren-weighted mean for the EU is calculated (see Sect. 3.3.2). If the area-weighted mean concentration of the $C O C$ is above the Zone 2 average $R L$ for the $C O C$, then an action is required. Average $R L s$ and the COCs they are applied to are presented in Table 4.

Decision Rule 3"-Cumulative Rìsk Assessment. The first step in evaluating the cumulative risk associaled with an EU is to perform a risk screen to determine if further assessment in the form of a risk calculation is required. The risk screen consists of comparing the data to average RLs and an EPA Region LX ELCR $<1 \times 10^{-5}$ or $\mathrm{HI}$ of 1 . If the concentration of any chemical or radionuclide exceeds either an average $R L$ or an industrial PRG (except as described in Sect. 3.3.2), then the complete EU data set is evaluated to determine if the cumblative effect of all chemicals and radionuclides in the EU would cause the EU to fail the $1 \times 10^{-4}$ risk criterion established in the Zone 2 ROD. If such a detennination is made, a risk calculation is conducted as described below. Additional detail on the risk calculation is documented in Supporing Documentation for Preliminary Remediation Goals Used in the Dynamic Verification Strategy Sampling Program, East Tennessee Technology Pank, Oak Ridge, TN (BJC 2006). U.S. Environmental Protection Agency Region IX $1 \times 10^{-5}$ industrial PRGs for chemicals and radionuclides analyzed under the DVS are presented in Table 4.

If it is determined by the risk screen that a risk calculation is required, then the risk is calculated in accordance with the Zone 2 ROD by first calculating the risk based on the available EU data. If the calculated risk is below an industrial $1 \times 10^{-4}$ ELCR or target organ $\mathrm{HI}$ of 1 , then NFA is appropriate. If not, EU area-weighted calculations are performed.

Because data collection is focused on areas of potential contamination, the resultant data population is more representative of specific portions of an EU than the total EU, and it is the total EU over which risk is to be evaluated according to the Zone 2 ROD. To account for this over emphasis of potentially contaminated areas, an area-weighted risk calculation is perfonned for the $\mathrm{EU}$. An area-weighted average is calculated for each chemical and radionuclide in the EU according to the area-weighted averaging method described in Sect. 3.3.2, and the cumulative risk is calculated on the area-weighted averages according to the guidelines in the Zone 2 RDR/RAWP (DOE 2007).

If the area-weighted calculation results is an acceptable ELCR $\left(<1 \times 10^{-4}\right)$ and HI $(<1)$, a NFA determination can be made. However, if the area-weighted calculation results in an unacceptable ELCR $\left(>1 \times 10^{-4}\right)$, the EU cannot be cleared for industrial land use and an action detemination is made. If the aren-weighted approach results in an unacceptable $\mathrm{HI}(>1)$, an individual target organ $\mathrm{HI}$ review is conducted. If individual target organ HIs exceed 1 , an assessment on the need for action is conducted in accordance with the Zone 2 RDR/RAWP (DOE 2007a).

Decision Rale 4-Threat to groundwater. A threat to groundwater by Zone 2 soils is evaluated by reviewing existing area groundwater data for maximum contaninant level (MCL) exceedances that occur on a regular basis. If the groundwater data are sufficient and there are no consistent MCL exceedances,

\footnotetext{
${ }^{a}$ Radium and thoriun isotopes are excluded from the risk evalualion (see Sext 3.3.2 for further discussion).

Number of semples to adequately charaterize the EU and evaluate risk is detenined in the DQO scoping proctest with the Core Team. Available DVS ard historical data are used when risk calculations are performed.
} 
then NFA is appropriate. If the groundwater data ate insufficient to discem regular MCL exceedances, or the data are sufficient and regular MCL excedances are observed, then soil concentrations are screened against the SLs for the protection of groundwater as defined in the Zone 2 ROD (DOE 2005). Based on the screening, site-specific modeling may be conducted if additional evaluation is required. Consideration of an action is required if modeling results indicate a site may be a potential source of contamination to groundwater. The sitewide ROD evaluates available site data for threats to groundwater. Data generated from the DVS process will be included in this ROD. Groundwater SLS for chemicals and radionuclides analyzed under the DVS are presented in Table 4.

The Zone 2 ROD specifically addresses USTs at ETTP, including those in Zone 1 and Zone 2. State UST regulations are applicable or relevant and appropriate regulations for all ETTP tanks according to the Zone 2 ROD. Therefore, closure will be performed according to State of Tennessee regulations. Tanks that are demongtrated to be clean (i.e., containing no flujds that could adversely effect groundwater) and have no soil contamination present to indicate a leak will be closed in place by filling. Tanks that contain residual fluid and/or where soll contamination indicates a leak will be removed according to state UST regulations.

\subsubsection{Special Data Uses and Considerations}

Circumstances requiring special data uses and considerations during EU action/NFA evaluations fall into three categories: (1) evaluation of Class 3 and Class 4 SUs that may not have any analytical data, (2) area-weighted averages, and (3) chemicals and radionuclides with regulatory limit concentrations less than or similar in value to background concentrations.

Class 3 and Class 4 SU Evaluations-Some EUs have historical information and the Class 3 and Class 4 SU walkover assessments provide sufficient information to support the NFA determination. Class 3 and Class 4 SU walkover assessments include visual observations of the SU acreage, collection of radiological survey data, and selected biased sampling where survey results or observations indicate the presence of impacted soils.

Area-weighted Averages-Area-weighted averaging is accomplished by calculating the fraction of the total area of the EU that contains contaminated soil (called a contaminant area fraction). The remaining area of the EU constitutes a remaining acreage area fraction. The average concentration of soil constituents in the area of contanination is calculated and then multiplied by the contaminant area fraction. Average soil concentrations are calculated for the remaining acteage area of the EU using all available sample results or, if no sample data are availabie, background concentrations. These average concentrations are multjplied by the remaining acreage area fraction. The area-weighted EU average then is calculated as the sum-of-the-fractions.

Regulatory Limit versus Background Concentrations-The industrial PRGs for arsenic, Cs-137, $\mathrm{K}-40$, Ra-226, Th-228, and Th-232 are less than or simjlar in value to their respective background concentrations, which results in the industrial PRGs exceeding all or most instances where the chemical or radionuclide is detected. It was concluded in the Zone 2 ROD that data for Ra-226, Th-228, and Th-232 will not be used for risk calculations. Instead, health hazards associated with the presence of these radionuclides in Zone 2 soils will be evaluated by comparison to the RLs for Ra-226 and Th-232 (which contains Th-228 in its decay chain).

When a risk screen is conducted as part of the Decision Rule 3 evaluation (Sect. 3.3.I), secondary concentration comparisons are made in response to PRG exceedances by arsenic, $\mathrm{Cs}-137$, and $\mathrm{K}-40$ before proceeding with the cumulative effects evaluation, which may lead to performing risk calculations for the EU. The industrial PRG for arsenic $(15.9 \mathrm{mg} / \mathrm{kg})$ was very close in value to the arsenic background concentration (14.95 $\mathrm{mg} / \mathrm{kg}$ ). Although no local background value exists, the industrial PRG for $\mathrm{Cs}-137$ (1.13 pCi/g) was low enough that this ubiquitous nuclear fallout radionucljde exceeded its 
PRG in most instances where detected, and the industrial PRG for $\mathrm{K}-40(2.73 \mathrm{pCi} / \mathrm{g})$ was less than the background concentration for K-40 (32.12 pCi/g). Secondary concentration comparisons that were performed included arsenic concentrations to the arsenic Zone 2 soils average RL, Cs-137 concentrations to the Cs-137 Zone 2 soils average $\mathrm{RL}$, and $\mathrm{K}-40$ concentrations to the $\mathrm{K}-40$ background value. If any of these secondary concentration comparisons resulted in an excedance, then the complete EU dataset was evaluated for cumulative effects as described in Sect. 3.3.1.

Ra/Th Decay Series Calculation. Becsuse the carcinogenic risk associated with the concentrations of radium and thorium isotopes in the natural background at ETTP exceed the cumulative risk goal of $1 \times 10^{-4}$, RL values for these radionuclides were based on alternative concentration levels rather than risk. The altemative concentration levels of $5 \mathrm{pCi} / \mathrm{g}$ above background (average $\mathrm{RL}$ ) and $15 \mathrm{pCi} / \mathrm{g}$ above background (maximum RL) were set as low as reasonably achievable under the site-specific conditions. Concentrations of these radionuclides and their decay series were not considered in the risk estimates because site-specific background concentralions of the radionuclides exceeded the target risk range.

The Zone 2 ROD states that average RL and maximum $R L$ excedances by $R a-226$, Th- 230 , and $\mathrm{Tb}-232$ are to be evaluated by summing above-background concentrations ' of the greater of Ra-226 or Th-230 with the above-background concentrations of Th-232, and comparing the results to $5 \mathrm{pCi} / \mathrm{g}$ (average RL) and $15 \mathrm{pCi} / \mathrm{g}$ (maximum RL). These calculations were performed by subtracting the background values of $\mathrm{Ra}-226$, Th-230, and Th-232 from the analytical result. $\mathrm{A}$ Ra/Th decay sertes value then was calculated for each sample by selecting the larger of the Ra-226 or Th-230 value and summing the seiected value with the $T h-232$ value.

The Ra/Th decay series was considered to be analyzed in a sample if one or more of the three radionuclides it comprised were analyzed for in the sample. Also, this decay series was considered to be detected in a sample if one or more of the three radionuclides it comprised were detected in a sample. It is possible that a $\mathrm{Ra} / \mathrm{Th}$ decay series detected value could equal zero.

\subsubsection{Qutalitative Risk Screening for Unrestricted Use}

While not required by the Zone 2 ROD, a qualitative tisk screening for unrestricted use was conducted to determine the possibility of releasing the EUs without institutional controls. These results are provided for information only and do not form the basis for action (see Sect. 11). For this screening, average concentrations were compared to $1 \times 10^{\text {st }}$ residential PRGs and ETTP soils background values from Table 4 in Soil Background Supplemental Data Set for the East Tennessee Technology Park, Oak Ridge, Tennessee (DOE 2003). EPA Region DX residential PRGs $1 \times 10^{-6}$ and ETTP soil background values for the chemicals and radionuclides analyzed for under the DVS are presented in Table 4. 


\section{FINAL STATUS ASSESSMENTS}

This section presents the DVS evaluation results for EU Z2-33 and the final status assessment based on that evaluation. Guidelines for the evaluation are presented in Sect. 2 and for preparing the final status assessment are presented in Sect. 3. A high-Ievel summary of the DVS evaluation is presented in Table 6.

The final status assessment conclusions for EU Z2-33 are presented in Table 7, which is followed by a summary of the evaluation and conclusions. The conclusions and summaries presented in Table 8 were based on the evaluation of existing information in terms of the four DVS decision rules described in Sect. 3. Table 7 provides the information by EU and includes the EU acreage, Class 1 and Class 2 SU acreage, Class $3 \mathrm{SU}$ acreage, and FFA sites in each EU.

Because all samples within the 0-to 10 -ft soil interval were considered equally in the risk assessment, there was no differentiation of the contamination information by depth. Any contamination in the 0 - to 10 -ft interval was considered to be equally accessible to an industrial worker. Depth information for discrete interval samples, including all VOC samples and the majority of the radiological samples, is provided in the accompanying compact disc (CD). Because there is no depth differentiation of the potential impact of contamination, details regarding sample intervals were not included in the EU evaluation presented in the following text.

Details of the material presented in Tables 6 and 7 and the associated summaries are presented in the EU Z2-33 TM (see Appendix A). Analytical data summary tables are also presented in the TM. The complete set of analytical data used to generate the summary data tables is provided in the CD attached to this PCCR. Data are also available in the OREIS database, which can be accessed by contacting DOE.

Recommendations for the Zone 2 ROD Appendix A FFA sites are summarized in Table 8 . Characterization, evaluation, and remediation of these sites will be used as a metric for the closure of ETTP. If the evaluation of all avaitable data for an EU supported a NFA deternination at the EU level, then all FFA sites within that EU were considered NFA by inclusion. If a limited set of data resulted in an action being required within an EU, then the final status of the EU and all included FFA sites was deferred until the action was complete and an EU-level NFA deternination was made. The EU Z2-33 Techrical Memoratidur was prepared from the post-RA perspective.

Table 6. DVS evaluation summary for EU Z2-33

\begin{tabular}{ll}
\hline Bulk acreage summary & \\
\hline Total acreage in Zone 2 & 819 \\
Acreage included in this PCCR & 18 \\
Acreage for NFA - no RA & 18 \\
Acreage for NFA - post RA & 0 \\
Acreage of RAs conducted & $<1$ \\
Acreage of RAs to be conducted & 0 \\
\hline SU classincation summary for acreage in the PCCR & \\
\hline Class 1 SU acreage & 0.4 \\
Class 2 SU acreage & 3.9 \\
Class 3 SU acreage & 13.5 \\
Class 4 SU acreage & 0 \\
\hline
\end{tabular}


Tahle 6. (continued)

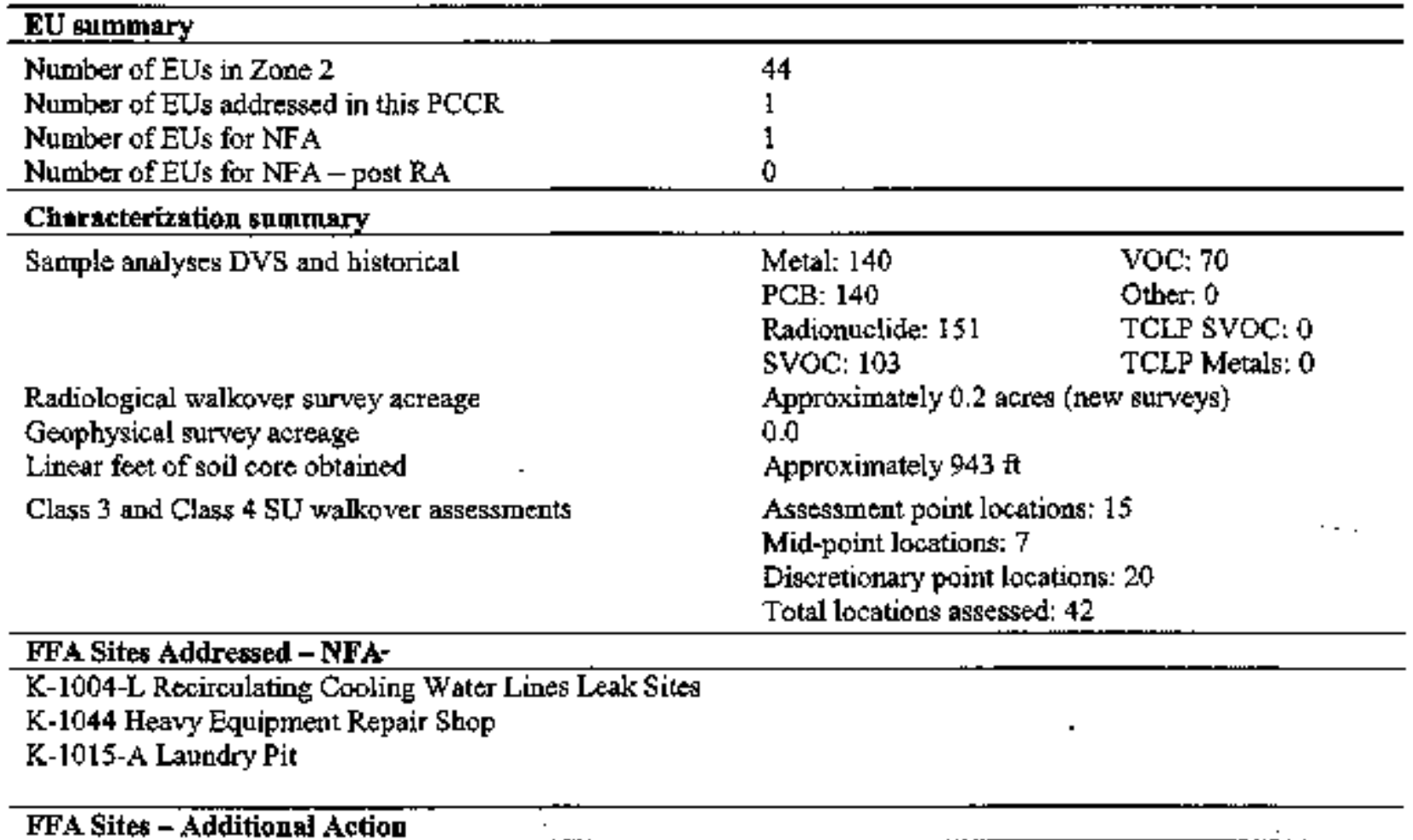

The need for RA aryobece in as EU indicated the NFA decision could not be made for the whole EU until the action was couplete. Final Etatus of FFA sites within an EU where an action was planened was contingent an completion of the RA. "Acrtage for NFA-post RA" indicates the sum of acreages in which a RA was to be conducted "Acreages of RAg to be conducted" indicates the sum af acreages of the actions themsedves.

DVS = Dynamic Verification Strategry

$\mathrm{EV}=$ exposure unit

FFA = Federal Facility Agreement

$N F A=$ ac furtber extion

PCG = polychlorinated biphertyl

PCCR = Phased Construction Corngletion Report

\author{
$\mathrm{RA}=$ ramedial action \\ $\mathrm{SU}=$ soil wnit \\ SVOC = setrivolatile organis tompound \\ TCLP - wxicily characteristic leaching procedure \\ $\checkmark O C=$ volatile orpanic compound
}


Table 7. Final status assessment sumnuary for EU Z2-33

\begin{tabular}{|c|c|c|c|c|c|c|c|}
\hline $\begin{array}{l}\text { EU size } \\
\text { (acres) }\end{array}$ & EU Group & $\begin{array}{c}\text { Zone } 2 \text { ROD } \\
\text { Appendix A EFA sites }\end{array}$ & $\begin{array}{c}\text { Class I and } 2 \\
\text { SU area } \\
\text { (meres) }\end{array}$ & $\begin{array}{c}\text { Class } 3 \text { and } 4 \\
\text { SU area } \\
\text { (acres) } \\
\end{array}$ & Risk evafuation & $\begin{array}{c}\text { Decision rule } \\
\text { evalugition }\end{array}$ & $\begin{array}{c}\text { Final status } \\
\text { decision }\end{array}$ \\
\hline \multirow[t]{3}{*}{18} & South Park & $\begin{array}{l}\text { K-l004-L Recirculating } \\
\text { Cooling Water Lints Leak } \\
\text { Sites }\end{array}$ & -- & -- & Passes risk screen & $\begin{array}{l}\text { Max RL: NFA } \\
\text { Avg RL: NFA } \\
\text { Risk: NFA } \\
\text { GW: NFA }\end{array}$ & NFA for soils \\
\hline & & $\begin{array}{l}\text { K-1044 Heavy Equipinent } \\
\text { Repair Shop }\end{array}$ & & & Passes risk screen & $\begin{array}{l}\text { Max RL: NFA } \\
\text { Avg RL: NFA } \\
\text { Risk: NFA } \\
\text { GW: NFA }\end{array}$ & NFA for soils \\
\hline & & K-1015-A Laundry Pit & & & Passes risk screen & $\begin{array}{l}\text { Max RL: NFA } \\
\text { Avg RL: NFA } \\
\text { Risk: NFA } \\
\text { GW: NFA }\end{array}$ & NFA for soils \\
\hline $\begin{array}{l}\mathrm{Avg}=\text { aver } \\
\mathrm{EU}=\operatorname{evpos} \\
\mathrm{GW}=\text { grout } \\
\mathrm{Max}-\operatorname{mat}\end{array}$ & $\begin{array}{l}\text { canit } \\
\text { water } \\
\text { umt }\end{array}$ & $\begin{array}{l}\text { NFA }=\text { no fur } \\
R L=\text { recredis } \\
R O D=\text { Recor } \\
\text { SU }=\text { soil unf }\end{array}$ & $\begin{array}{l}\text { cetion } \\
\text { Eecl } \\
\text { Vecision }\end{array}$ & & & & \\
\hline
\end{tabular}


Table 8. Summary of conclusions for EL Z2-33 Zone 2 ROD Appendix A FFA sites

\begin{tabular}{lc}
\hline \multicolumn{1}{c}{ Zone 2 ROD Appendix A FFA Site } & Recommendation \\
\hline K-1004-L Recirculating Cooling Water Lines Leak Sites & NFA \\
K-1044 Heavy Equiprnent Repair Shop & NFA \\
K-1015-A Laundry Pit & NFA \\
\hline
\end{tabular}

$\mathrm{EU}=\mathrm{expos}$ (NF) unit $\quad$ NFA $=$ no further action

FFA - Foderal Facility Agreement $\quad$ ROD $\sim$ Reoord of Decision

\subsection{EXPOSURE UNIT EVALUATION}

The following section surmmarizes the cvaluation and conclusions for EU Z2-33. Details of the malerial presented in Tabjes 6,7 , and $B$, and the following section, are presented in Appendix A. The evaluation is performed and presented from a post-RA perspective by removing from the analysis data from all locations where RA. was performed.

\subsubsection{Exposure Unit Z2.33}

EU Z2-33 is located along the south boundary of Zone 2 in the South Park EU Group (Fig. 1), and is bounded on the north by EU Z2-32 and EU Z2-42, on the east by EU Z2-43 and Zone 1, on the south by EU Z2-34, and on the west by Zone 1. All of the land area in this EU has been impacted by site operations. Impacts to the EU included construction of buildings, roads, parking lots, and sidewalks. EU Z2-33 is the heart of what is commonly referred to as the administrative section of ETTP, which generally housed offices and laboratories.

Exposure unit Z2-33 has three FFA sites that are listed in Appendix A of the Zone 2 ROD (Fig. 2):

- K-1004-L Recirculating Cooling Water (RCW) Lines Leak Sites,

- K-1015-A Laundry Pit, and

- K-1044 Heavy Equipment Repair Shop.

Two conceptual models apply to EU Z2-33. The conceptual model for the Class 1 SUs is a surface . release model of radiological contamination. The model defines limited mobility through the soil column and identifies the most probable mode of secondary transport as suspended solids in surface water. The conceptual model for the acid dilution pits is a point source release to underlying soils and potentially to local groundwater.

EU Z2-33 contains Class 1, Class 2, and Class 3 SUs. The Class 1 SUs include the K-1004-3 Lab South Class I SU, which is an area of approximately 0.4 acres located along the northem boundary of EU 22-33 with C8-137 maximum RL exceedances in historical samples. The othet is the K-1015 Class $1 \mathrm{SU}$, which is a small arca of soil south of the K-1015 Laundry Pit with historic Cs-137, U-234, U-235, and U-238 average RL exceedances and U-235 maximum RL exceedances. Radiological walkover surveys and sampling were performed in these SUs.

The Class 2 SUs include the K-1004 Area Drain Line Class 2 SU with a high degree of uncertainty regarding the impact of the K-1004 Area Drain Line to EU soils and two small areas centered around histonical sample locations KAH-\$S-B22 and KAH-SS-S31. Ratiological walkover surveys and sampling were performed in these SUs. 
The rempinder of EU Z2-33 is a Class 3 SU where walkover assessments and biased sampling was performed

The following is a summary of the data evaluation for EU Z2-33.

\begin{tabular}{cccccc}
\hline EU \# & $\begin{array}{c}\text { Max RL } \\
\text { exceeded? }\end{array}$ & $\begin{array}{c}\text { Average RL over } \\
\text { EU excoeded? }\end{array}$ & $\begin{array}{c}\text { Industrist risk } \\
\text { above } 1 \times 10^{-4} \text { ? }\end{array}$ & $\begin{array}{c}\text { Potential source } \\
\text { to gronndwater? }\end{array}$ & $\begin{array}{c}\text { Action } \\
\text { required? }\end{array}$ \\
\hline $22-33$ & No & No & No & No & No \\
\hline
\end{tabular}

- The only Max RL exceedance was from a Ra/Th decay series exceedance in two samples of sediment collected from the K-1006 north sump, which is an active facility. The RA Core Team agreed the K-1006 north sump would not be addressed at this time.

- No average COC concentration across EU Z2-33 exceeded its Avg RL.

- The industrial tisk for EU Z2-33 was calculated to be $<1 \times 10^{4}$ ELCR, with a target organ HI of 1 .

- The soils do not pose a threat to groundwater.

- No further action is necessary to meet industrial land use.

- There was a low probability that EU Z2-33 acreage could be released with no land use restrictions. Avg RL exceedances for radionuclides and PCBs, and hnd and Res PRG exceedances for metals, radionuclides, PCBs, SVOCs, and VOCs occurred in this EU. 


\section{REMEDIATION ACTIVITYES}

Remedial actions presented in this PCCR for EU Z2-33 and EU Z2-42 include the following:

- BOS laboratories below grade pits, and

- Surface soils south of Bldg. K-l004-J in EU Z2-33 and EU Z2-42. Recommended RAs for EU 22-42 were described in the Fiscal Year 2006 Phased Construction Completion Report for the Zone 2 Soils, Slabs, and Subsufface Structures at East Tennessee Technology Park, Oak Ridge, Tennessee (DOE 2006). The RA in EU Z2-42 is described in the 2006 Zone 2 PCCR.

The following sections present the characterization findings that led to the RAs and a description of the RAs. The locations of the below grade pits and soil RAs are shown in Fig. 6. With the exception of the K-1015 Laundry Pit, the pits had no urique identifiers and were assigned numbers based on DVS walkover assessment discretionary point sample location $\mathrm{D}$ number (c.g., pit 318 is named for sample location ID EU33D-318),

The final teport for the RAs listed above is described in this section and Sects. 6, 7, and 8.

\subsection{REMEDIAL ACTION OF BOS LABORATORIES SUBGRADE PITS}

The BOS laboratories below grade pits RAs included:

- Excavating and removing six acid difution pits (318,329, 330, 331, 332 and 335);

- Closing pit 304 in place;

- Excavating and removing the K-1015 Laundry Pit;

- Excavating the inlet pipes to pits 330 and 332 ; and

- Excavating two small areas of soil adjacent to pit 329 and the K-1015 Laundry Pit.

\subsubsection{Facility Descriptions}

The acid dilution pits and K-1015-A Laundry Pit FFA site were subsurface structures contained in the EU Z2-33 BOS Labs Area. The pits were reinforced concrete shells with acid-brick linings that had tops located near ground surface and depths extending to $\sim 8 \mathrm{ft}$. The acid dilution pits received laboratory liquid wastes that were neutralized in the pits and discharged to the storm sewer system. The K-1015-A Laundry Pijt FFA site was located south of the K-1015 Laundry. Wash waler from the laundry flowed to the pit to allow particulates (mostly fibrous) to settle prior to discharge to the sarjitary sewer system in an adjacent thanhole.

Use of the acid dilution pits and laundry pit was discontinued in 1985 and 1996, tespectively. These pits were identified for RA because of maximum RL and groundwater exceedances for radionuclides, metals, VOCs, and PCBs of their solids contents from DVS characterization activities described in the EU Z2-33 Techrical Memorandum (see Appendix A). Example contaminants and their concentrations included PCB-1260 (1,000,000 ug/kg), Cs-137 (215 pCi/g), mercury ( $3120 \mathrm{mg} / \mathrm{kg}$ ), benzene $(640,000 \mathrm{ug} / \mathrm{kg})$, carbon tetrachloride $(11,000,000 \mathrm{ug} / \mathrm{kg})$, and TCE $(1,400,000,000 \mathrm{ug} / \mathrm{kg})$. 


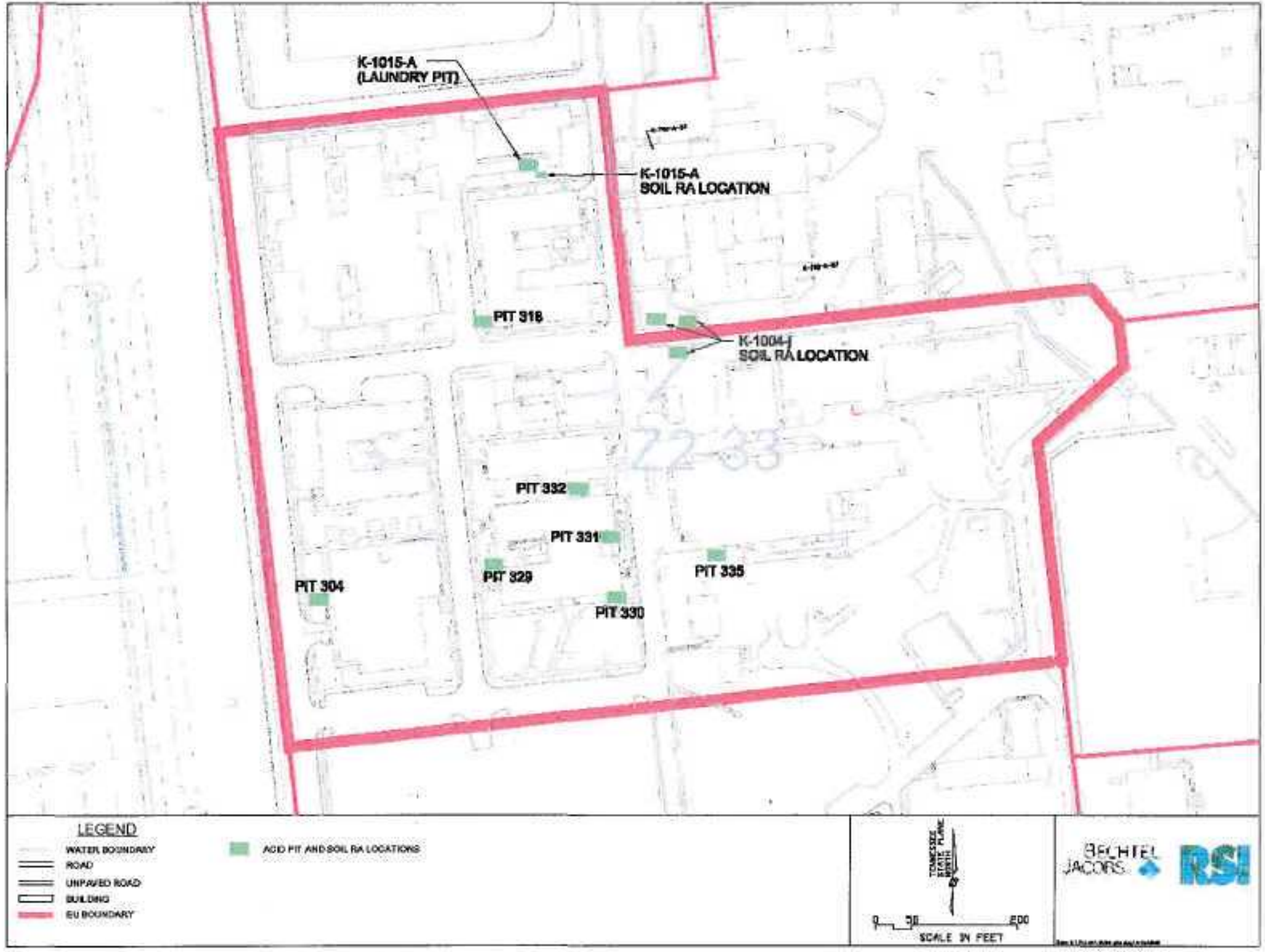

Fig. 6. Locations of Acid Dilution Pits, K-1015-A Laundry Pit, and soil remedial actions. 


\subsubsection{Characterization}

Pit liquid and solid contents were sampled to establish facility safaty basis and waste disposition pathways prior to RA. DVS characterization biased sampling of the soil immediately adjacent to and downgradient of each pit was sampled from the depth of each pit bottom to bedrock to assess any potential pit leakage. Sample results indicated groundwater SL exceedances for VOCs (TCE at $50,000 \mathrm{ug} / \mathrm{kg}$, chloroform at $31,000 \mathrm{ug} / \mathrm{kg}$, and PERC at $300,000 \mathrm{ug} / \mathrm{kg}$ ) in soil adjacent to pit 329 , which suggested it had leaked in the past. Step-out sampling was perfomed $12.5 \mathrm{ft}$ downgradient of the pit to define the areal and vertical extent of contamingtion. These sampling results indicated lateral migration had not occurred and the contaminated soil was limited to the area immediately downgradient and adjacent to the pit.

Two historic sample locations adjacent to the K-1015-A Laundry Pit (KAH-SS-B12 and $\mathrm{KAH}-\mathrm{SS}-\mathrm{B} 13)$ with $\mathrm{U}-235$ maximum RL exceedances in shallow soil $(94.5 \mathrm{pCi} / \mathrm{g}$ and $149 \mathrm{pCi} / \mathrm{g}$, respectively) were identified during DVS characterization. After conducting a biased area remediation (BAR) survey, it was determined that a small area $\left(\sim 200 \mathrm{ft}^{2}\right)$ exceeded the $2688 \mathrm{cpm}$ action level. Sampling outside of the BAR survey area confinmed the boundary definition.

Inlet and outlet pipes. were exposed near each pit, severed, and their contents sampled. After sampling, the pipe ends were plugged with mortar. Analytical results from the inlet pipes to pits 330 and 332 found PCB $(5.2 \mathrm{ug} / \mathrm{kg}$ at location Z2-EU33B-243, $10.0 \mathrm{ug} / \mathrm{kg}$ at location EU33B-310) and radionuclide $(3.3 \mathrm{pCi} / \mathrm{g} \mathrm{Cs}-137$ at location $\mathrm{Z2}-\mathrm{EU} 33 \mathrm{~B}-241,11.9 \mathrm{pCi} / \mathrm{g}$ Thorium-232 at location EU33B-243) maximum RL excesdances.

\subsubsection{Facility RAs}

Two inlet pipes to pits 330 and 332 were removed in their entirety from the pit to where they exited Bldess. K-1004-A and K-1004-B, respectively. Adjacent and underlying soil was removed, and composite confirmation samples obtained from the remaining soil indicated an absence of residual soil contamination requining additional removal. The excavations were backfilled with clean native soil and seeded with donestic grass as an erosion control meastare until native grass seeding occurs.

After the inlet and outlet pipes were severed-and plugged, pit RA was accomplished by removing or solidifying the contents in place, excavating around each pit, and intact pit removal. Removed pits were placed on plastic sheeting laid on the ground, crushed, and the debris was placed in waste containers. Pit 335 and the K-1015-A Laundry Pit broke apart during removal and were removed in large pieces. Consistent with FCN-ETTP-Zone 2-053, confirmation samples were not obtained from the excavations where DVS characterization data indicated an absence of contamination and from pits that were removed intact. However, four-point confirmation samples were obtained from pit 335 and the K-1015-A Laundry Pit excavations, and those sample results exhibited no elevated contaminant levels. Clean native soil was used to fill the excavations, which were seeded with domestic grass as an erosion control measure until native grass seeding occurs.

$A$ view of the K-1004-A, -B, and $-C$ building slab and acid dilution pit locations prior to their removal is shown in Fig. 7. A view of the area after completion of RA and prior to seeding is shown in Fig. 8. The K-1015 building slab and Laundry Pit are shown prior to RA in Fig. 9 and after slab and laundry pit RA in Fig. 10. Rernedial action of the building slab is described in the FY 2007 PCCR for Zone 2 (DOE 2007b). 


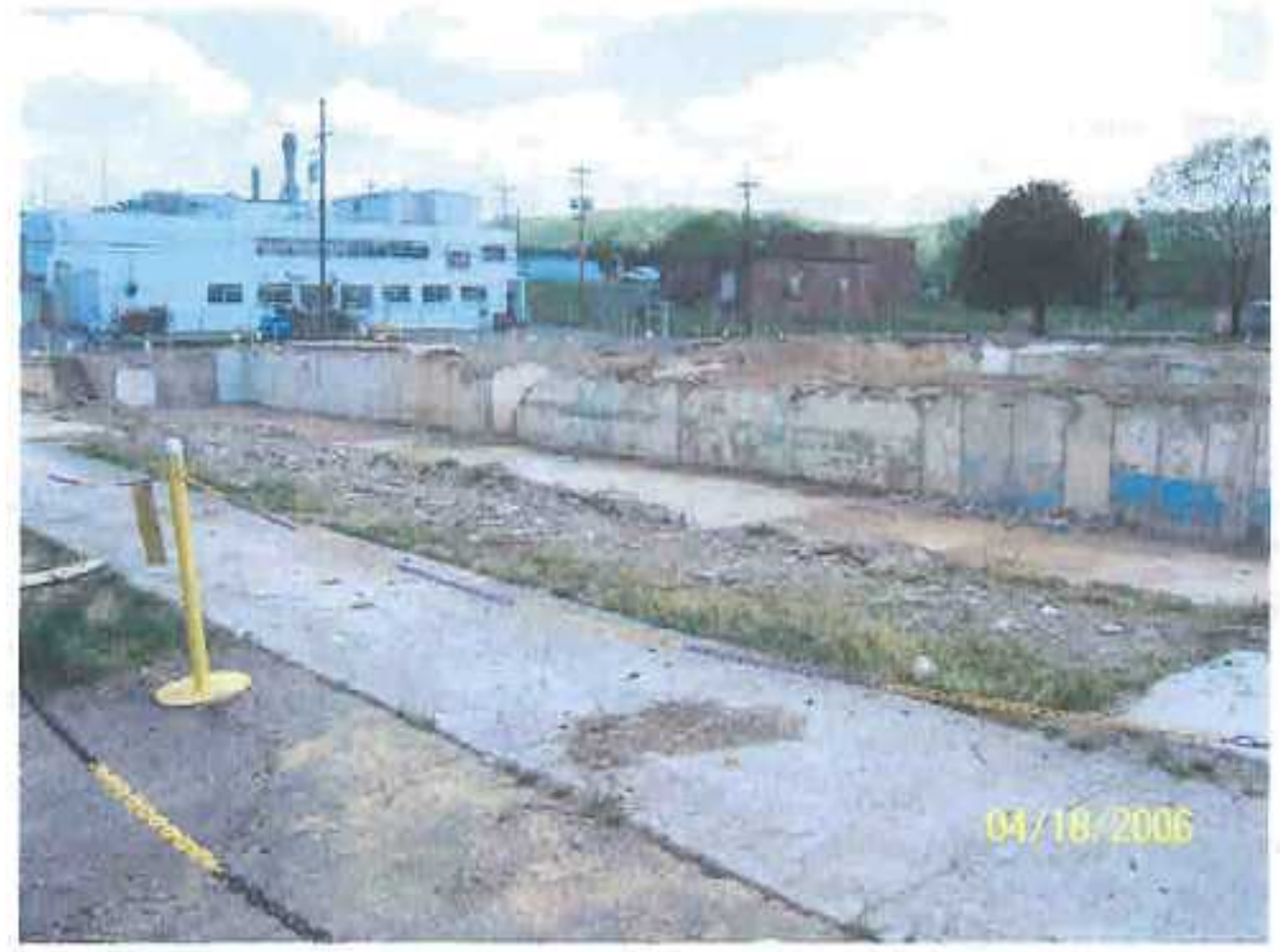

Fig. 7. K-1004-A, $-\mathrm{B}$, and $-\mathrm{C}$ building slab and acid dilution pits 330, 331, and 332 prior to remedial action.

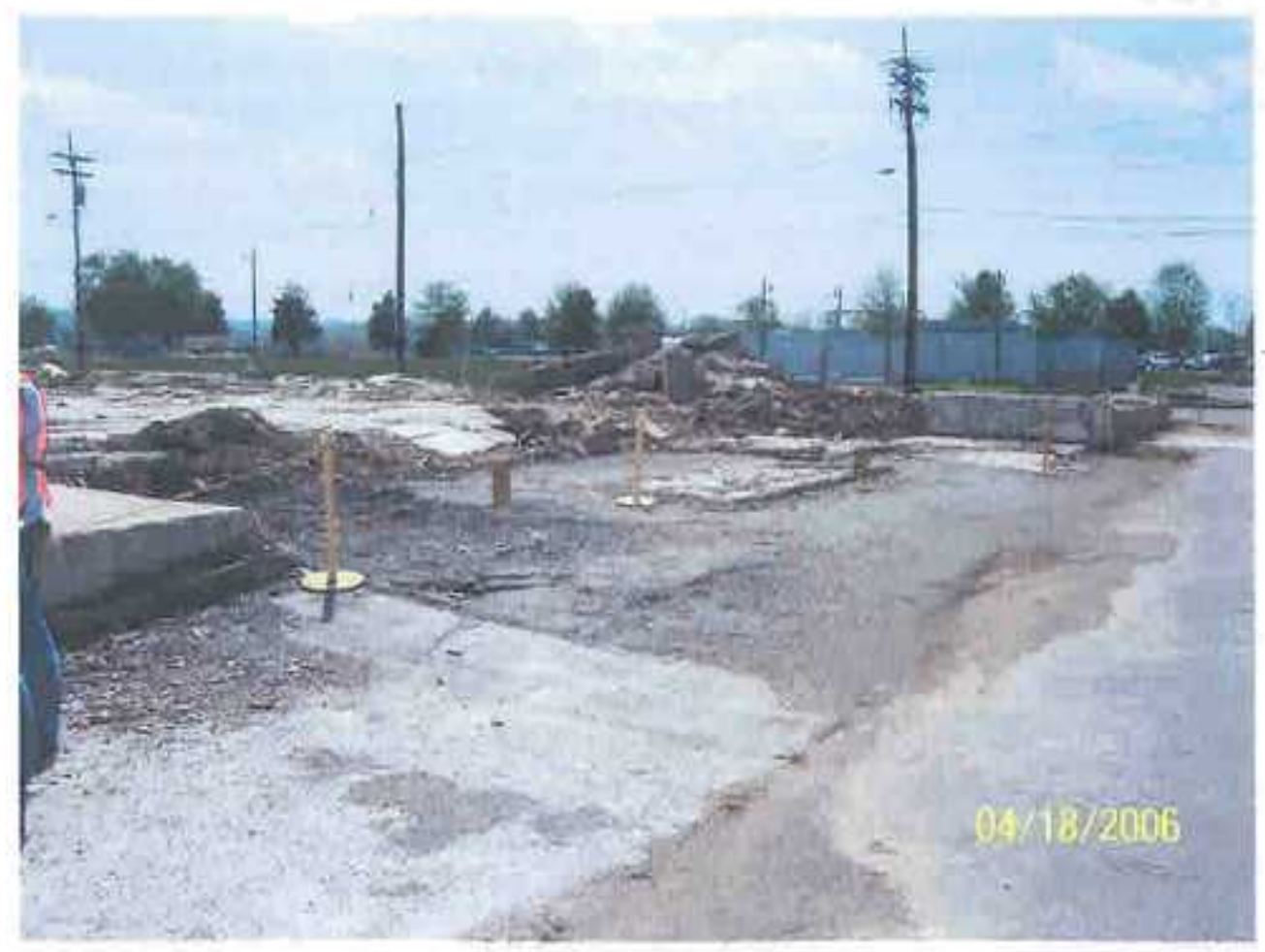

Fig. 8. K-1004-A, B, C building slab and acid dilution pits 330,331 , and 332 following remedial action. 


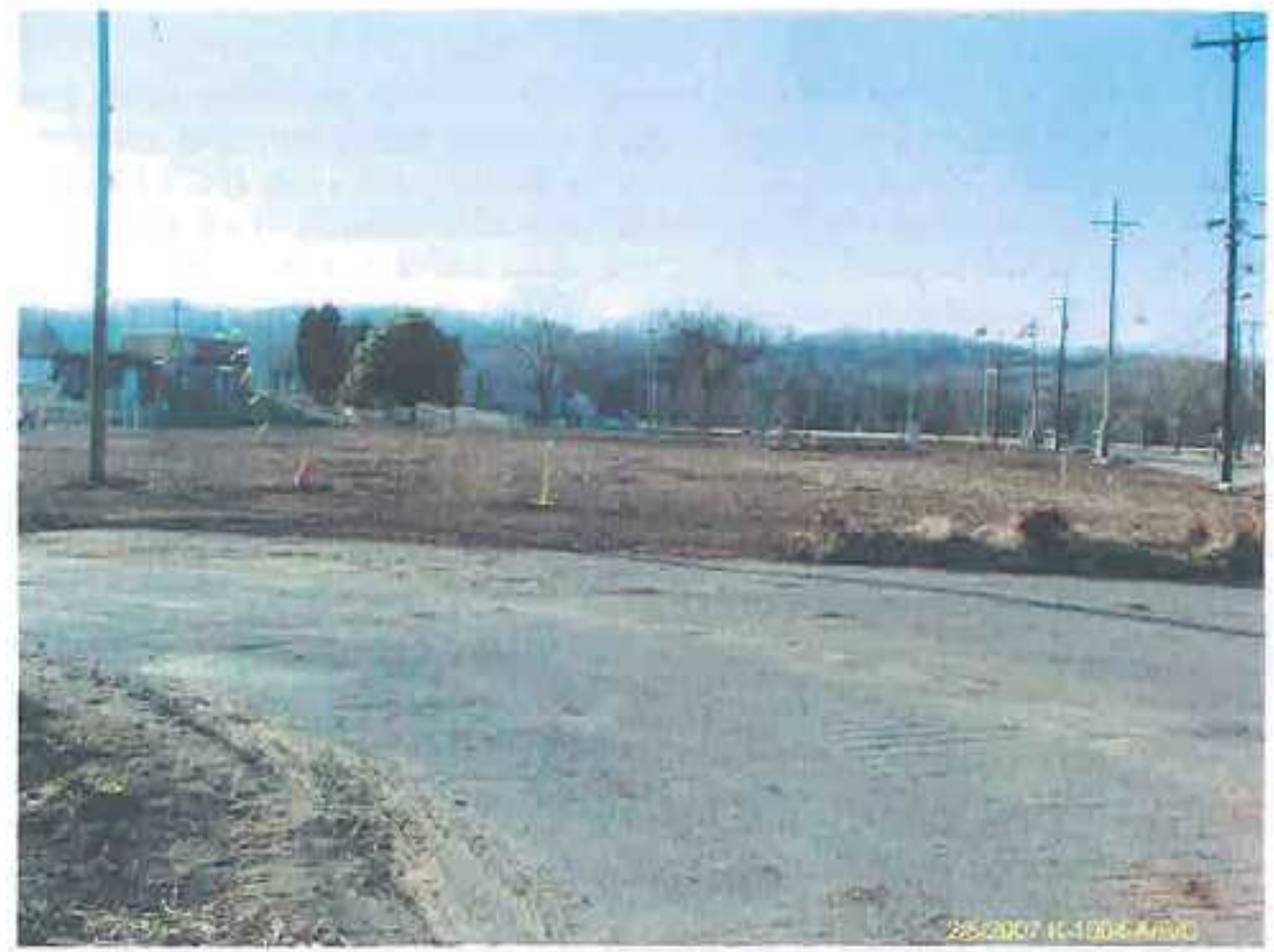

Fig. 9. K-1015 building slab and Laundry Pit prior to remedial action.

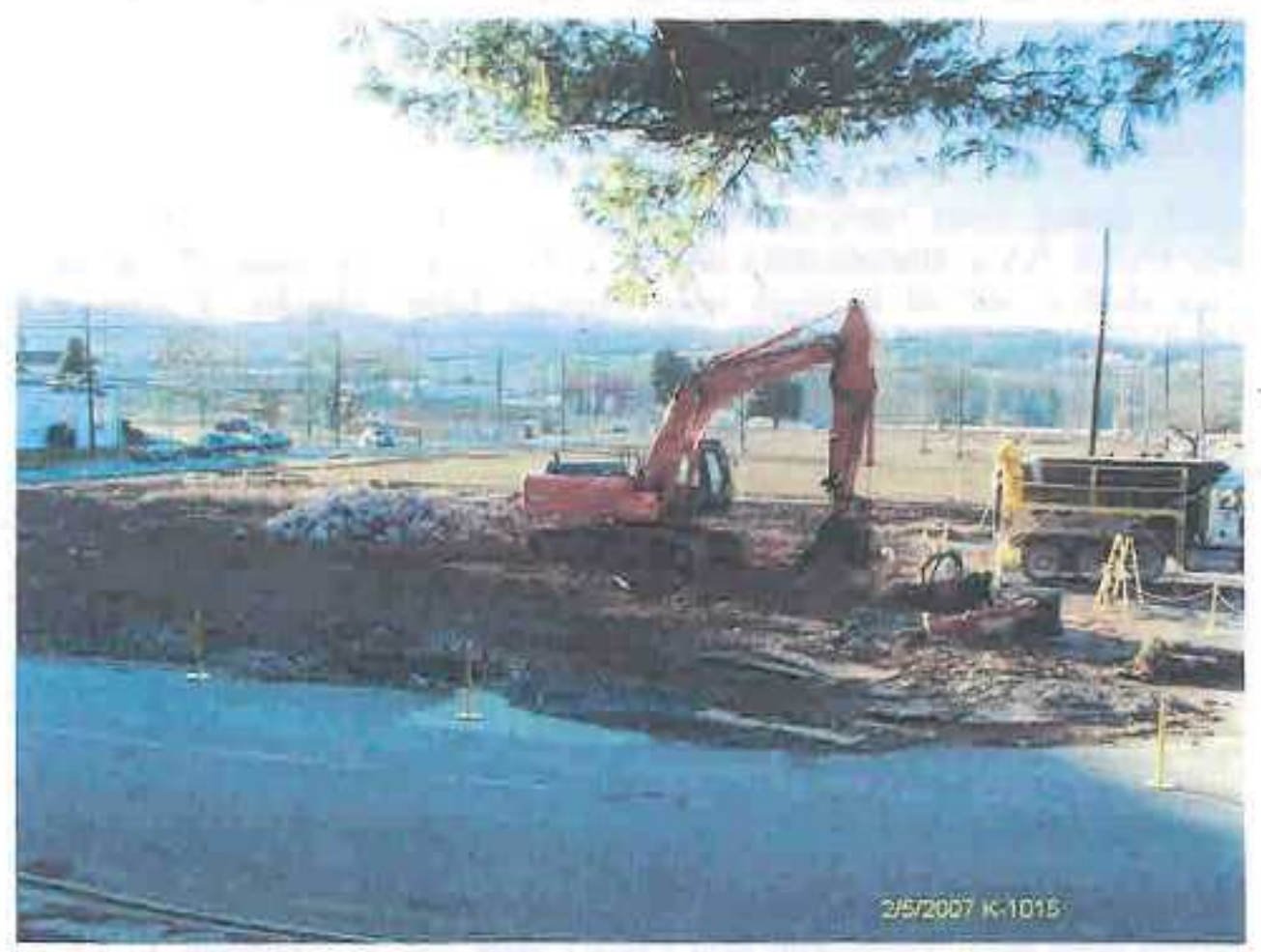

Fig. 10. K-1015 building slab and Laundry Pit following remedial action. 
The 304 acid dilution pit interior had been coated with a coal-tar derivative epoxy product called Tarset, which is typically used to line storage tanks containing highly corrosive material to prevent compromising the storage tank integrity. It was agreed by the RA Core Team (FCN-ETTP-Zone 2-064) that if visual inspection demonstrated Tarset material integrity after the contents were removed and the pit rinsed, the pit could be closed in place and filled with clean native soil or grout. These actions were performed and the pit was grouted to the surface.

Soil RAs occurred adjacent to pit 329 and adjacent to the K-1015-A Laundry Pit simultaneously with pit removal. The 329 pit location was excavated approximately $10 \mathrm{ft}$ downgradient and to a depth of approximately $10.5 \mathrm{ft}$. Confirmation sampling at the base of the excavation revealed an exceedance of the groundwater SL for carbon letrachloride $(5700 \mathrm{ug} / \mathrm{kg})$. Because of this exceedance, the excavation was extended to a depth of approximately $12 \mathrm{ft}$, where carbon tetrachloride was not detected.

The roughly $200 \mathrm{ft}^{2}$ area south of the K-1015 Laundry Pit was excavated to a nominal depth of $1 \mathrm{t}$ Results from the confirmation radiation survey (Fig. II) indicated all the soil requiring RA bad been removed.

\subsubsection{End State}

Native grasses, which require no maintenance, were planted in the BOS Labs area prior to the RAs. These grasses failed to grow because of the very dry 2007 spring and sumner. A decision on when to replant has not been made, but domestic grass that will require mowing has been planted as an erosion control measure.

\subsection{SURFACE SOLS REMEDLAL ACTION SOUTH OF BULDING K-IO04-J IN EU Z2-33 AND EU Z2-42}

\subsubsection{Facility Description and Characterization}

Three small grassy areas encompassing roughly $3500 \mathrm{ft}^{2}$ were identified during DVS characterization. During RA characterization of EU Z2-33, Cs-137 maximum RL exceedances were identified in the shallow soil of a grassy area south of Bldg. K-1004-J (215 pCV/g at location Z2-EU33B-313, 65.9 pCi/g at location Z2-EU33B-241, and 24.6 pCi/g at location Z2-EU33B-106). The Cs-137 maximum RL, value was also exceeded in four samples in EU Z2-42 (327 pCi/g at location Z2-EU42B-1 13, 58.1 pCifg at location Z2-EU42B-114, $21.2 \mathrm{pCi} / \mathrm{g}$ at location Z2-EU33B-315, and $44.5 \mathrm{pCi} / \mathrm{g}$ at location Z2-EU42B-102), and BAR surveys were performed to describe the RA areas. The Cs-137 maximum RL exceedances and BAR survey in EU Z2-33 are described in Appendix A. The surface soil RA for EU Z2-42 was prescribed by the Cs-137 maximum RL excecdance and BAR survey described in Fiscal Year 2006 Phased Construction completion Report for the Zone 2 Soils, Slabs, and Subsurface Structures (DOE 2006, Appendix F). The source of contanination was deemed to be the $\mathrm{K}$, 1004-J Underground Tank (R074) FFA site, which is an underground low-level waste storage tank for contaminated liquids that was decontaninated and filled with sand under previous actions.

\subsubsection{Soil Remedial Action}

The upper nominal $\mathrm{l} f \mathrm{f}$ of soil was removed fiom the three locations south of BIdg. K-1004-J between November 2-12, 2007. Consistent with the FY 2006 PCCR, Appendix F (DOE 2006) and FCN-ETTP-Zone 2-053, confirmation was performed using a radiation survey and composite sample from the three excavated areas. Results from the radiation survey and analytical results indicated all the soil requiring RA had been removed (see Fig. 12). 


\subsubsection{End State}

Domestic grass that will requite mowing was planted at the thre sufface soil RA areas south of Bldg. K-1004-J. 


\section{EU Z2-33, Biased Area Radiation Survey KAH-SS-B13 \& KAH-SS-B12 Post Remediation Survey Date 10/22/2007 985 Data Points, $\sim 800$ Square Feet}
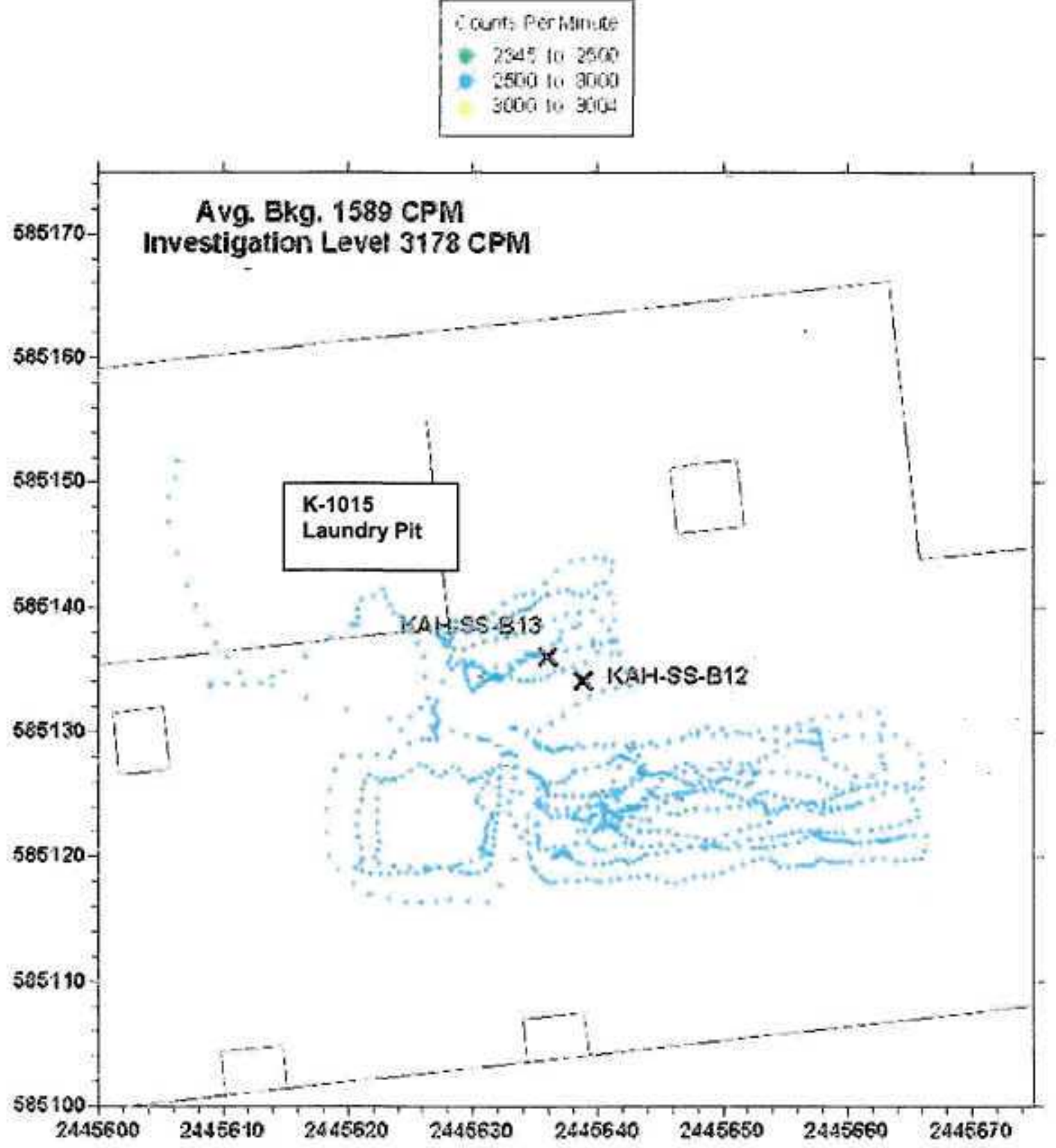

Fig. 11. Confirmation radiation survey for area south of the K-1015 Laundry Pit. 
EU Z2-33 \& EU Z2-42

Biased Area Radiation Survey

Post Final Excavation

Survey Dates 11/02/07 - 11/13/07

3366 Data Points

-4216 Square Feet

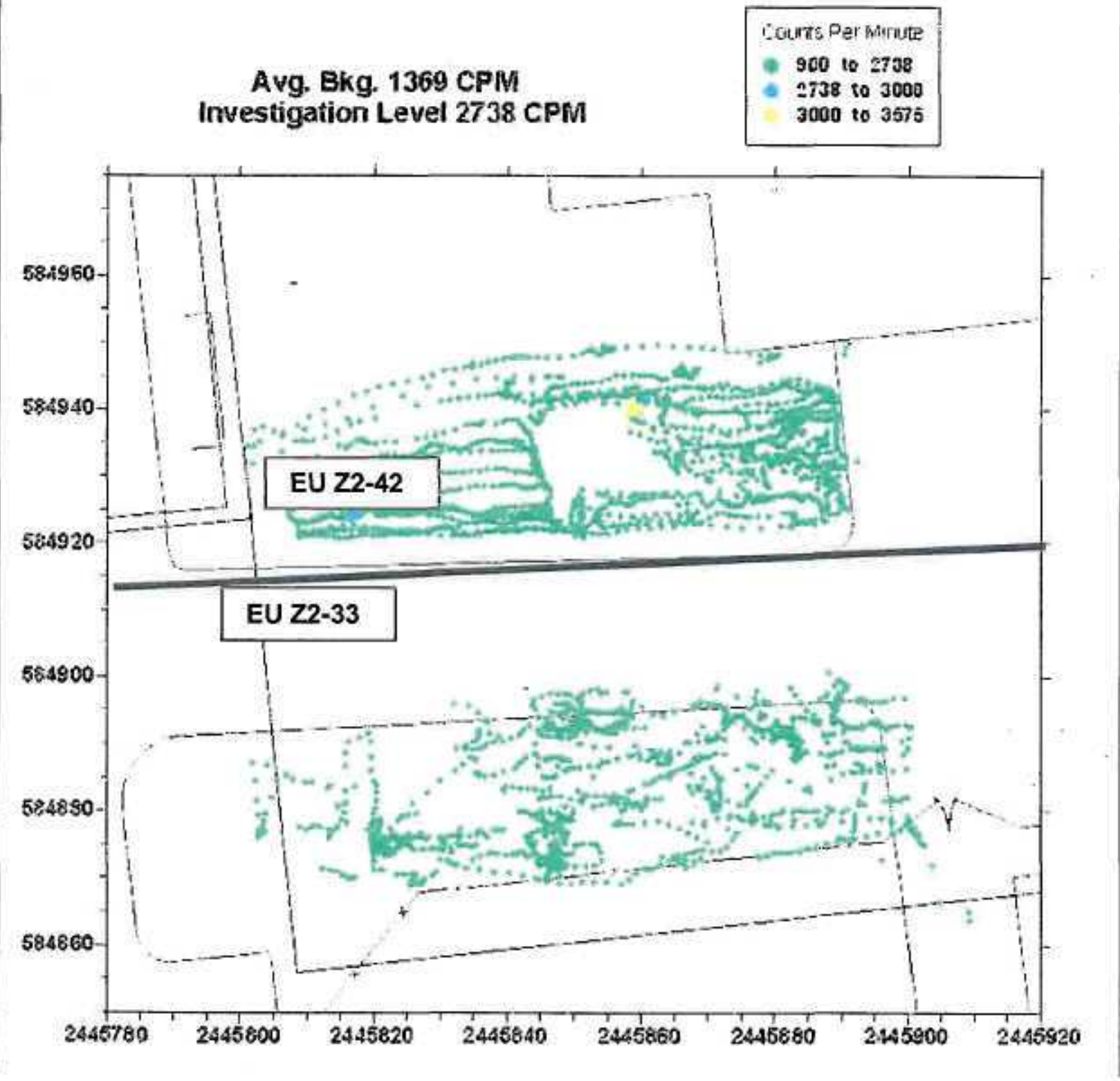

Fig. 12. Confirmation radiation survey for three locations south of Bldg. K-1004-J. 


\section{DEVLATIONS FROM GOVERNING DOCUMENTS}

Zone 2 was divided into 7 geographic areas and 44 EUs in the ROD (DOE 2005). To facilitate the DQOs, the Zone 2 RDR/RAWP (DOE 2007a) regouped the 44 EUs into 12 DQO scoping EU groups, which facilitated the 100 process by placing similar facilities and their support facilities together and allowing identification of data gaps.

It is not uncommon for EU acseages reported in PCCRs to differ from that reported in the ROD because of boundary refinement and an increased level of accuracy. In the case of EU Z2-33, however, the 18 acres used in this PCCR is the same as that reported in the ROD.

The RA Core Team concurrence process is an integral part of DVS implementation, which allows actions such as revising sampling locations or RA implementation based on field conditions encountered. Table 9 lists the FCNs and concumences submitted to and reached by the RA Core Team pertaining to the DVS characterization and RAs assessed in this PCCR.

Table 9. FY 2007 FCNs and concurrences

\begin{tabular}{|c|c|c|c|}
\hline RCN number & Title or description & $\begin{array}{c}\text { Date } \\
\text { subnitted }\end{array}$ & $\begin{array}{c}\text { Date } \\
\text { approved }\end{array}$ \\
\hline FCN-ETTP-Zone 2-017 & $\begin{array}{l}\text { South Park Area EU Group DQO Scoping Package Class } \\
\text { I Sample Additions (Z2-EU33, EU34, EU43) }\end{array}$ & $8 \overline{8} 1 / 2006$ & $9 / 13 / 66$ \\
\hline FCN-ETTP-Zone $2-019$ & $\begin{array}{l}\text { South Park Area EU Group DQO Scoping Package } \\
\text { Sample Classification Changes (Z2-EU33) }\end{array}$ & $1 \mathrm{t} / 3 / 2006$ & $11 / 13 / 2006$ \\
\hline FCN-ETTP-Zone 2-020 & $\begin{array}{l}\text { South Park Area EU Group DQO Scoping Package RAB } \\
\text { Definition in arta South of K-1004-J (Z2-EU33) }\end{array}$ & $11 / 3 / 2006$ & $11 / 8 / 2006$ \\
\hline FCN-ETTP-Zone 2-021 & $\begin{array}{l}\text { South Park Area EU Group DQO Scoping Package Acid } \\
\text { Dilution Pit Sample Additions (Z2-EU33) }\end{array}$ & $12 / 5 / 2006$ & $1 / 5 / 2007$ \\
\hline FCN-ETTP-Zone 2-029 & $\begin{array}{l}\text { South Park Area EU Group DQO Scoping Package } \\
\text { limited soll remediation at K-1004-L (Z2-EU33) }\end{array}$ & $1 / 5 / 2007$ & $1 / 5 / 2007$ \\
\hline FCN-ETTP-Zone 2-039 & $\begin{array}{l}\text { South Park Area EU Group DQO Scoping Package for } \\
\text { biased sampling adjacent to K-1225 (22-EU33) }\end{array}$ & $4 / 4 / 2007$ & $4 / 23 / 2007$ \\
\hline FCN-ETTP-Zone 2-1045 & $\begin{array}{l}\text { South Park Area EU Group DQO Scoping Package for } \\
\text { step out sampling downgradient of the K-1004 dilution } \\
\text { pits (Z2-EU33) }\end{array}$ & $5 / 15 / 2007$ & $5 / 24 / 2007$ \\
\hline FCN-ETTP-Zone 2-046 & $\begin{array}{l}\text { South Park Area EU Group DQO Scoping Package for } \\
\text { sarmpling the K-1006 dilution pit (Z2-EU33) }\end{array}$ & $5 / 18 / 2007$ & $5 / 22 / 2007$ \\
\hline FCN-ETTP-Zone 2-063 & $\begin{array}{l}\text { South Park Area EU Group DQO Scoping Package for } \\
\text { adding BOS Labs dilution pit waste to the Zone } 2 \text { WHP } \\
\text { (Z2-EU33) }\end{array}$ & $8 / 16 / 2007$ & $9 / 5 / 2007$ \\
\hline FCN-ETTP-Zone 2-053 & $\begin{array}{l}\text { South Park Area EU Group DQO Scoping Package for } \\
\text { EU } 33 \text { dilution pits RA }\end{array}$ & $6 / 21 / 2007$ & $7 / 3 / 2007$ \\
\hline
\end{tabular}


Table 9. (continned)

\begin{tabular}{|c|c|c|c|}
\hline FCN number & Title or description & $\begin{array}{c}\text { Date } \\
\text { oubaitted }\end{array}$ & $\begin{array}{c}\text { Date } \\
\text { approved }\end{array}$ \\
\hline $\begin{array}{l}\text { FCN-ETTP-Zone 2-053 } \\
\text { Amendment }\end{array}$ & $\begin{array}{l}\text { South Park Area EU Group DQO Scoping Package } \\
\text { Amendment for pits } 313 \text { and } 314 \text { inlet pipe RA, } \\
\text { omitting pit confirmation sampling, and closing } \\
373 \text { pit in place }\end{array}$ & $10 / 5 / 2007$ & $10 / 30 / 2007$ \\
\hline FCN-ETTP-Zone 2-054 & $\begin{array}{l}\text { South Park Area EU Group DQO Scoping Package } \\
\text { for biased sarupling in Marhole (MH) } 057 \\
\text { (Z2-EU33) }\end{array}$ & $\begin{array}{l}7 / 2 / 2007 \\
\text { revision } \\
7 / 23 / 2007\end{array}$ & $8 / 21 / 2007$ \\
\hline FCN-ETTP-Zone 2-063 & $\begin{array}{l}\text { South Park Area EU Group DQO Scoping Package } \\
\text { for adding BOS Labs dilution pit waste to the } \\
\text { Zone } 2 \text { WHP (Z2-EU33) }\end{array}$ & $8 / 16 / 2007$ & $9 / 5 / 2007$ \\
\hline FCN-ETTP-Zone 2-064 & $\begin{array}{l}\text { South Park Area EU Group DQO Scoping Packige } \\
\text { for closing BOS Labs dikution pit at } K_{n}-1006 \text { in } \\
\text { place (Z2-EU33) }\end{array}$ & $8 / 23 / 2007$ & $9 / 5 / 2007$ \\
\hline
\end{tabular}

BOS - Balances of Sitis

ORR = Oak Ridxe Regurvaluon

$\mathrm{DQD}=$ date quality objestive

$R A$ - remedial action

ETTP $=$ East Tennesset Technobogy Park

EMWMF - Eayironruental Managenent Waste Management Facily

RAB i radiation area boumdary

BU $a$ expostare uait

FCN = Field Change Notice

FY $=$ fiscal year

RCW = recirculating wator

UST = uroderground storage tank

WAC $=$ wastc acceptance erileria

HVSS = Happy Valley Service Station

WHP = Waste Hatdling Plats 


\section{COSTS AND SCHEDULE FOR REMEDIAL ACTION(S)}

Remedial action of the BOS labs dilution pits began on August 7, 2007, and was completed in August 2008 when the last of the waste was shipped off site. Remedial action of the soils south of K-1004-J was performed from November 1-13,2007.

The costs for performing RAs in EUs Z2-33 and Z2-42 are presented in Table 10.

Table 10. Remedial action cost for EUs Z2-33 and Z2-42

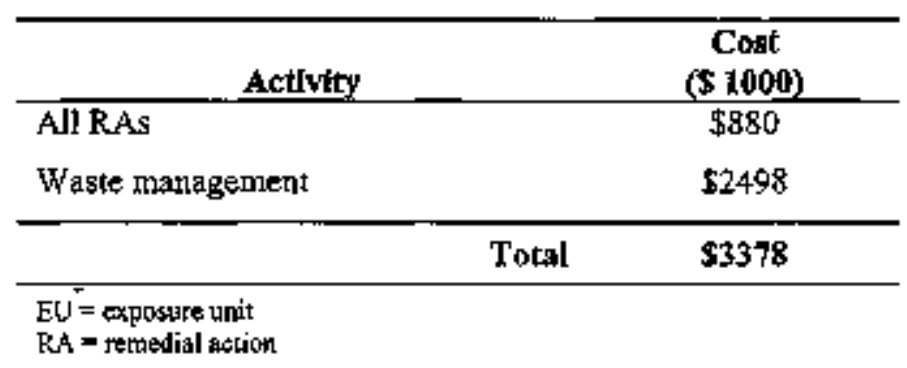




\section{WASTE MANAGEMENT ACTIVITIES FOR REMEDIAL ACTION(S)}

A summary of waste disposition for the RAs performed in EUs Z2-33 and EU Z2-42 is shown in Table 11. The waste disposal at EMWMF was included in Waste Lot 155.5, Soils from BOS Laboratories, which was shipped in September 2008.

Tabie I1. Waste disposition for EUs Z2-33 and Z2-42 RA

\begin{tabular}{|c|c|c|c|}
\hline RA & Waste stream & Dispostal facility & Volame \\
\hline BOS laboratorits bolow-grade pits & $\begin{array}{c}\text { Soljds } \\
\text { Liquids }\end{array}$ & $\begin{array}{l}\text { Energy Solutions } \\
\text { Energy Solutions }\end{array}$ & $\begin{array}{c}51 \mathrm{yd}^{3} \\
2424 \mathrm{gal}^{2}\end{array}$ \\
\hline $\begin{array}{l}\text { Surface soils south of Bldg. K-1004-J } \\
\text { jn EUs } 72-33 \text { and } 22-42\end{array}$ & Soil & EMWMF & $106 y^{3}$ \\
\hline$\ldots$ & & Total volume & $157 \mathrm{yd}^{3}$ \\
\hline
\end{tabular}




\section{OPERATIONS AND MAINTENANCE}

Aside from mowing, no operations and maintenance is required for the RAs performed. 


\section{MONITORING SCHEDULE AND/OR EXPECTATIONS}

There are no monitoring requirements for the RAs performed in EUs 22-33 and 22-42. 


\section{LAND USE CONTROLS}

This section discusses general land use controls for the EUs in Zone 2 at ETTP. Details of the controls will be presented in the Remedial Action Report. An assessment for possible unrestricted use of EU Z2-33 is presented in Sect. 11.4.

Dynamic Verification Strategy characterization of EU Z2-33 was conducted in accordance with the requirements of the Zone 2 ROD and RDR/RAWP. The goal of characterization was to gather sufficient information to evaluate the EU against the four decision rules developed in the DVS DQOS (Table 5) and arrive at an action/NFA decision. The decision rule evaluation process used in this PCCR is described in Sect. 3. Consistent with the Zone 2 ROD, a NFA decision neans an EU is available for unrestricted industrial use to a depth of $10 \mathrm{ft}$ bgs.

\subsection{POSSIBLE LIFTING OF LAND USE CONTROLS}

As required by the Zone $2 \mathrm{ROD}$, this section presents an evaluation of EU Z2-33 for the possible Jifting of the following two land use controls:

- Industrial land use controls below $10 \mathrm{ft}$ bgs, and

- Making the EU available for unrestricted land use.

The DVS process and EU status assessment presented in this PCCR for EU Z2-33 can assign a high, nedium, or low qualitative probability of lifting land use controls.

\subsection{DEFINITIONS}

High probability-This designation indicates no identified areas of contaminated soils and there are tho significant disposal or landfill operations observed in the EU. Dynamic Verification Strategy evaluations indicate no identified impact within the EU and a high probability the acreage could be released with no land use controls following appropriate evaluation.

Medium probability-This designation indicates an identifiable impact from facility operations to some portion of acreage in the EU. This impact may be visible rubbish and debris, concentrations of several metals and/or radionuclides above background levels, and/or the detection of organic compounds in a few samples within the EU. Based on the observations and sample results, the impact appears to be minor and limited in extent. There is a moderate probability the acreage could be releaced following appropriate evaluation.

Low Probabjlity - This designation indicates a clearly identified impact to substantial portions of acreage within the EU. Metals and radionuclides are commonly above background levels and organic compounds may be present in several samples within the EU at levels above $1 \times 10^{-6}$ residential PRGs. The probability of unrestricted use of the acreage is low.

\subsection{INDUSTRIAL CONTROLS AT DEPTH}

An evaluation was performed to determine if EU Z2-33 would require industrial controls below $10 \mathrm{ft}$ bgs. The DVS program was designed to assure the top $10 \mathrm{ft}$ of soil meet industrial criteria. However, sufficient infonmation exists to make reasonable conclusions regarding the need for land use controls below 10 ft of soil. A VOC groundwater plume is known to exist in the central portion of EU Z2-33 at a 
depth of $+/-25 \mathrm{ft}$ below ground surface. Therefore, it is proposed to retain land use restrictions below $10 \mathrm{ft}$ for EU Z2-33.

\subsection{POTENTLAL UNRESTRICTED USE}

To conduct the evaluation and determine the probability of lifting land use controls, EU Z2.33 analytical data were compared to background concentrations and $1 \times 10^{6}$ residential PRGs. A qualitative assessment of the comparison results applicability to the whole EU was made. DVS sampling is biased to areas with relatively high probabilities of contamination being present (i.e., DVS systematic sampling is focused on Class 1 and Class 2 SUs and DVS biased sampling is conducted in all SUs based on a determination from visual and screening assessments that there is a likelihood of confamination). As a result, the presence of background or $1 \times 10^{-6}$ residential-use PRG concentration exceedances in the data set does not automatically preclude the possibility of lifting industrial land use controls. The probability of lifting land use controls for acreage in Zone 2 is generally low because it has been extensively impacted by the construction of ETTP facilities, infrastructure, and heavy industrial activities. Sample results consistently indicate impact to area soils above background levels and commonly above industrial use PRGs. Also, unrestricted use of Zone 2 acreage is an unlikely alternative because there are many small structures and abandoned infrastructures in the area.

Further evaluation is recommended before a final conclusion can be made conceming lifting industrial land use controls because the DVS process was designed around requirements of the Zone 2 ROD, which specifies an unrestricted industrial land use.

To evaluate for umestricted use, appropriate DQOs were developed that considered but were not limited to the following:

- Calculated RLs consistent with the risk management requirements of an unrestricted land use scenario,

- Remedjation levels for chenicals and radionuclides where background concentrations are greater than residential PRGs (i.e., aluminum, arsenic, iron, manganese, K-40, Ra-226, Th-228, and Th-232),

- Remediation levels for Cs-137, a ubiquitous fallout radionuclide that does not have a determined background concentration but typically exceeds its residential PRG when detected, and

- EU size.

Taking the above information into account, results of the evaluation process determined there is a low probability that land use controls can be lifted at EU Z2-33. Several $1 \times 10^{\circ 6}$ residential PRGs were exceeded in this EU by metals, $\mathrm{PCB}$, and radionuclides.

\subsection{REMAINING ACTIVITIES}

This section summarizes activities remaining to be completed in Zone 2 . The rationale for these activities falls into the following four categories:

- Remaining activity is an action to be performed,

- Remaining activity awaits a risk management decision,

- Remaining activity is part of a larger infastructure investigation to be conducted at a later date, or

- Remaining activity awaits D\&D to make soils accessible. 
The status of each EU in Zone 2 is presented in Table 12. The status of Zone 2 RA characterization as of this PCCR is shown in Fig. 13. As shown in Fig. 13, characterization has been completed in 18 of 44 Zone 2 EUs ( 328 of 800 acres).

Table 12. Status of Zone 2 EUs

\begin{tabular}{|c|c|c|c|c|c|c|}
\hline $\mathbf{E U}$ & $\begin{array}{c}\text { Characterization } \\
\text { complete? }\end{array}$ & $\begin{array}{l}\text { NRA on soll } \\
\text { appropriate? }\end{array}$ & $\begin{array}{c}\text { NFA on } \\
\text { Infrastrncture } \\
\text { appropriate? }\end{array}$ & $\begin{array}{l}\text { Actlon } \\
\text { required? }\end{array}$ & $\begin{array}{c}\text { Closure } \\
\text { documentstion? }\end{array}$ & $\begin{array}{l}\text { Comment' } \\
\text { explandtínn }\end{array}$ \\
\hline $\mathrm{Z2} 201$ & -7 & $\checkmark$ & $\sqrt{5}$ & & FY 2007 PCCR & \\
\hline$z 2-02$ & $\checkmark$ & $\checkmark$ & $\checkmark$ & & FY 2006 PCCR & \\
\hline Z2-03 & $\checkmark$ & $\checkmark$ & $\checkmark$ & & FY 2007 PCCR & \\
\hline $22-04$ & & & & & PCCR or Zone 2 RAR & \\
\hline $22-05$ & & & & & PCCR or Zone 2 RAR & \\
\hline $\mathrm{Z} 2-06$ & & & & & PCCR or Zone 2 RAR & \\
\hline$z 2-07$ & $\checkmark$ & $\checkmark$ & $\checkmark$ & & FY 2006 PCCR & \\
\hline $\mathrm{z} 2-0 \mathrm{~g}$ & $\checkmark$ & $\checkmark$ & $\checkmark$ & & FY 2007 PCCR & \\
\hline $\mathrm{Z} 2-09$ & $\checkmark$ & $\checkmark$ & $r$ & & FY $2006 \mathrm{PCCR}$ & \\
\hline $22-10$ & $r$ & $\checkmark$ & $\checkmark$ & & FY 2006 PCCR & \\
\hline $22-11$ & & & & & PCCR or Zone 2 RAR & \\
\hline $\mathrm{Z2}-\mathrm{I} 2$ & & & & & PCCR or Zone 2 RAR & \\
\hline $\mathrm{Z} 2-13$ & & & & & PCCR or Zone 2 RaR & \\
\hline 22.14 & & & & & PCCR or Zone 2 RAR & \\
\hline $22-15$ & & & & & PCCR or Zone 2 RAR & \\
\hline $22-16$ & & & & & POCR or Zone 2 RAR & \\
\hline $\mathrm{Z} 2-17$ & & & & & POCR or Zont 2 RAR & \\
\hline $22-18$ & & & & & PCCR or Zone 2 RAR & \\
\hline $22-19$ & & & & & PCCR or Zone 2 RAR & \\
\hline$Z 2-20$ & & & & & PCCR or Zone 2 RAR & \\
\hline $\mathrm{Z} 2-21$ & & & , & & PCCR or Zone 2 RAR & \\
\hline $22-22$ & & & & & PCCR or Zone 2 RAR & \\
\hline $22-23$ & $\checkmark$ & $\checkmark$ & $\checkmark$ & & FX $2007 \mathrm{PCCR}$ & \\
\hline $\mathrm{Z} 2-24$ & $\checkmark$ & $\checkmark$ & $\checkmark$ & & FY 2007 PCCR & $\cdot$ \\
\hline $22-25$ & & & & & PCCR or Zone 2 RAR & \\
\hline $22-26$ & & & & & PCCR or Zone 2 RAR & \\
\hline
\end{tabular}


Table 12. (continted)

\begin{tabular}{|c|c|c|c|c|c|c|}
\hline $\mathbf{E U}$ & $\begin{array}{l}\text { Characterization } \\
\text { complete? }\end{array}$ & $\begin{array}{l}\text { NKA on soil } \\
\text { appropriate? }\end{array}$ & $\begin{array}{c}\text { NFA on } \\
\text { infrastructare } \\
\text { approprtate?" }\end{array}$ & $\begin{array}{l}\text { Action } \\
\text { requfred? }\end{array}$ & $\begin{array}{c}\text { Closure } \\
\text { documentation? }\end{array}$ & $\begin{array}{l}\text { Comment' } \\
\text { Explangtion }\end{array}$ \\
\hline $\mathrm{Z} 2-27$ & $\checkmark$ & $\checkmark$ & $\checkmark$ & & FY 2006 PCCR & \\
\hline $22-28$ & $\checkmark$ & $\checkmark$ & $\checkmark$ & $\checkmark$ & FX 2007 PCCR & \\
\hline $72-29$ & & & & & PCCR or Zone 2 RAR & \\
\hline $\mathrm{Z2}-30$ & & & & & POCR or Zone 2 RAR & \\
\hline $22-31$ & & & & & PCCR or Zone 2 RAR & \\
\hline $22-32$ & & & & & PCCR or Zone 2 RAR & \\
\hline $22-33$ & $\checkmark$ & $\checkmark$ & $\checkmark$ & & $\begin{array}{l}\text { FY } 2008 \text { EU Z2-33 } \\
\text { PCCR }\end{array}$ & $\begin{array}{l}\text { Buildings K- } \\
1225 \text { and K- } \\
1006 \text { are } \\
\text { leased } \\
\text { facilities }\end{array}$ \\
\hline $22-34$ & $\checkmark$ & $\checkmark$ & $\checkmark$ & & FY 2007 PCCR & \\
\hline $22-35$ & & & & & PCCR or Zone 2 RAR & \\
\hline$z 2-36$ & & - & & & PCCR or Zone 2 RAR & \\
\hline $\mathrm{Z} 2-37$ & $\checkmark$ & $\checkmark$ & $\checkmark$ & & FY 2007 PCCR & \\
\hline $\mathrm{Z2}-38$ & & & & & PCCR or Zone 2 RAR & \\
\hline$Z 2-39$ & & & & & PCCR or Zone 2 RAR & \\
\hline$Z 2-40$ & & & & & PCCR or Zone 2 RAR & \\
\hline $22-41$ & $\checkmark$ & $\checkmark$ & $\checkmark$ & $\checkmark$ & FY $2007 \mathrm{PCCR}$ & \\
\hline $22-42$ & $\checkmark$ & $\checkmark$ & $\checkmark$ & $\checkmark$ & PCCR or Zone 2 RAR & $\begin{array}{l}\text { Soil RA } \\
\text { Dorrylete; } \\
\text { K-1004-I } \\
\text { Vaults FFA } \\
\text { Site requires } \\
\text { RA }\end{array}$ \\
\hline 22.43 & $\checkmark$ & $\checkmark$ & $\checkmark$ & & FY 2007 PCCR & \\
\hline$Z 2-44$ & $\checkmark$ & $\checkmark$ & $\checkmark$ & & FY 2907 PCCR & \\
\hline
\end{tabular}

The check mark in this coltumb indicates ejther the infrastruedre has beent evaluated or there it no infrastructure requiriug evaluarion

EU = Exposure urit

FFA = Federal Fycility A greerment

FY = fiscal year

POCR $=$ Pheged Construction Completion Report

$\mathrm{RA}$ - retredial action

RAR = Remedial Attion Report

$\mathrm{NF} A=$ no further action 


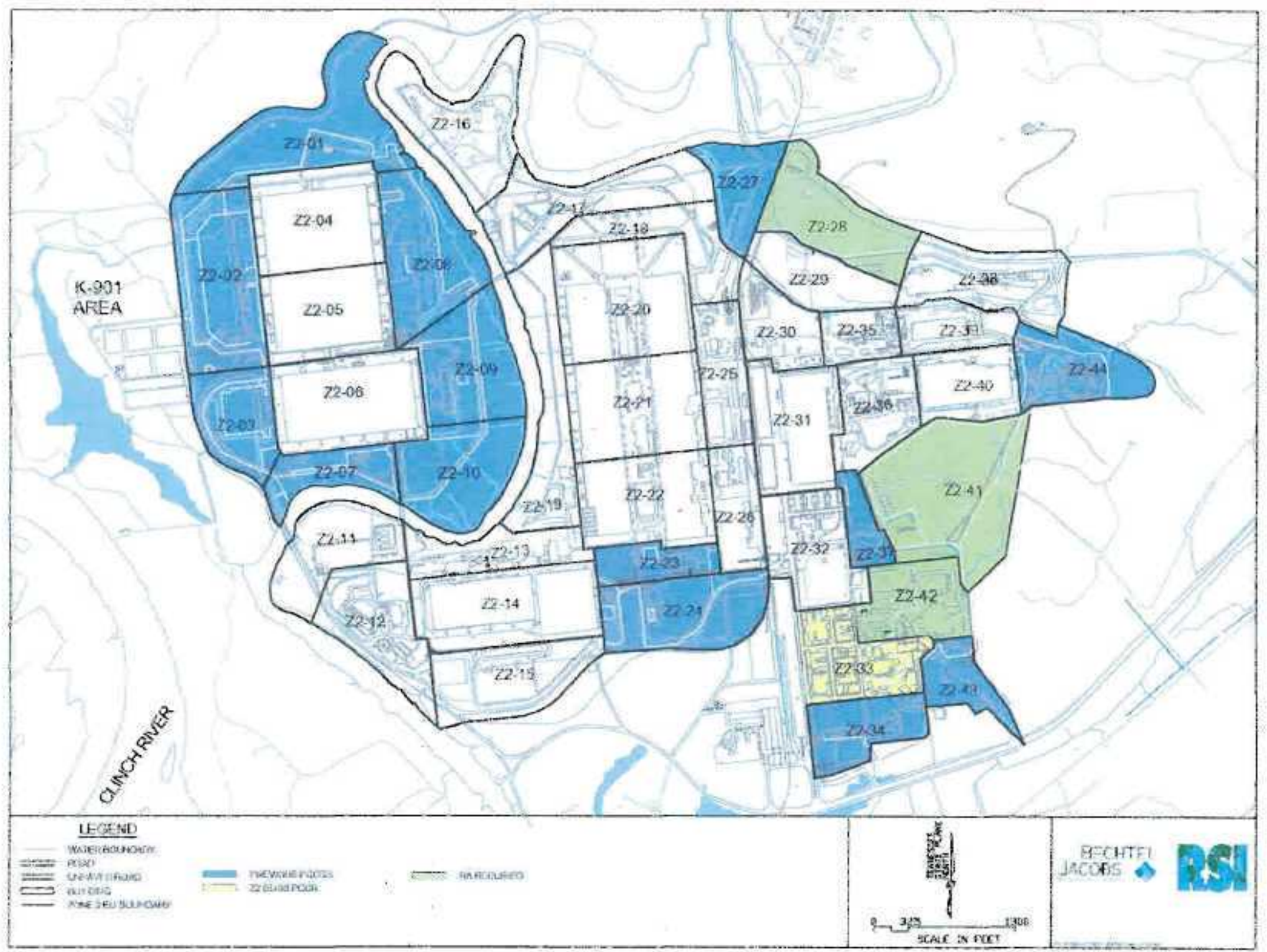

Fig. 13. ETTP Zone 2 RA characterization status as of this PCCR. 


\section{REFERENCES}

BJC 2006. Supporting Documentation for Preliminary Remediation Goals Used in the Dynamic Verification Strategy Sampling Program, East Tennessee Technology Pank, Oak Riage, TN, BJCJOR-2383, Bechtel Jacobs Company LLC, Oak Ridge, TN.

BJC 2007. Zone 2 Dynamic Work Plan, East Tennessee Technology Park, Oak Ridge, Tennessee, BJCKOR-2373/R1.

DOE 1992. Federal Facility Agreement for the Oak Ridge Reservation, DOE/OR-1014, EPA-Region 4. DOE, and TDEC, Washington, D.C.

DOE 1993a Final Report on the Background Soil Characterization Project at the Oak Ridge Reservation, Oak Ridge, Tennesse, Volume I - Results of Field Sampling Program, DOE/OR/01-1175/V1, October.

DOE 1993b. Radiation Protection of the Public and the Enviromment, DOE 0 5400.5, Change 2, U.S. Department of Energy, Washington, D.C.

DOE 2003. Soil Background Supplemental Data Set for the East Tennessee Technology Park, Oak Ridge, Tennessee, DOE/OR/01-2105\&D1, U.S. Department of Energy, Office of Environmental Management, Oak Ridge, TN.

DOE 2005. Record of Decision for Soil, Buried Waste, and Subsurface Structure Actions in Zone 2, East Tennessee Technology Park, Oak Ridge, Tennessee, DOE/OR/1-2161\&D2, U.S. Department of Energy, Office of Environmental Management, Oak Ridge, TN.

DOE 2006. Fiscal Year 2006 Phased Construction Completion Report for the Zone 2 Soils, Slabs, and Substrface Structures at East Tennessee Technology Part, Oak Ridge, Tennessee, DOE/OR01-2317\&D2, U.S. Department of Energy, Office of Environmental Management, Oak. Ridge, TN.

DOE 2007a. Remedial Design Report/Remedial Action Work Plan for Zone 2 Solls, Slabs, and Substrface Structures, East Tennessee Technology Park, Oak Ridge, Tennessee, DOE/OR01-2224\&D3, U.S. Department of Energy, Office of Environmental Management, Oak Ridge, TN.

DOE 2007b. Fiscal Year 2007 Phased Constrution Completion Report for the Zone 2 Soils, Stabs, and Stbstuflace Structures at East Temessee Technology Park, Oak Ridge, Tennessee, DOE/OR/01-2723\&D1, U.S. Department of Energy, Office of Environmental Management, Oak Ridge, TN, September.

EPA 1989. Rish Assessment for Superfund, Vol, I, Human Health Evaluation Manual (Part A), EPA/540/1-89/002, U.S. Environmental Protection Agency, Washington, D.C.

EPA 2002. Gtidance for Comparing Backgrotsnd and Chemical Concentrations in Soil for CERCLA Sites, EPA-540-R-01 -003, EPA Region IV, Washington, D.C.

MMES 1994. Cable Instalation PCB Analysis, Internal Correspondence, Martin Marietta Energy Systerns, Inc., February 28, 1994. 
ORISE 2000. Polychlorinated Biphenyl and Asbestos Sampling and Analysis Report for the K-762 and K-792 Switchyard Site, East Tennessee Technology Park, Oak Ridge, Tennessee (Draft), Oak Ridge Institute for Science and Education, December 14, 2000. 


\section{APPENDIX A. \\ EXPOSURE UNIT Z2-33 SOUTH PARK AREA TECHNICAL MEMORANDUM}




\section{TABLES}

A.1. EU Z2-33 facility and FFA site list ........................................................................... A-81

A.2. EU Z2-33 sample summary ……………..................................................................... A-83

A.3. EU Z2-33 sample locations removed during remedial actions and D\&D .................................. A.93

A.4. EU Z2-33 data summary for soil samples collected from 0 to $10 \mathrm{ft}$ below ground surface ......... A-95

A.5. EU Z2-33 concrete data summary .................................................................................... A-101

A.6. EU Z2-33 data summary for soil samples collected from $\geq 10 \mathrm{ft}$ below ground surface ........... A-105

\section{FIGURES}

A.1. EU Z2-33 location map ……...................................................................................... A-64

A.2. EU Z2-33 boundary location map ............................................................................. 65

A.3. EU Z2-33 BAR survey locations ............................................................................ A-66

A.4. EU Z2-42 injtíal BAR survey results..................................................................... A-67

A.5. EU Z2-42 post-RA BAR survey results ................................................................ A-68

A.6. K-1004-J Lab South Class I SU pre-RA BAR survey results................................................ A-69

A.7. K-1004-J Lab South Class I SU post-RA BAR survey results ............................................... A-70

A.8. K-1015 pre-RA BAR survey results..................................................................... A-71

A.9. K-1015 post-RA BAR survey results ........................................................................ A-72

A.10. K-1004-L gravel wash area post-RA BAR survey results ..................................................... A-77

A.11. BAR survey for KAH-SS-B22 …….......................................................................... A-74

A.12. BAR survey for KAH-SS-S31 ................................................................................. A-75

A.13. EU Z2-33 assessment locations ..................................................................................... A-76

A.14. All EU Z2-33 DVS and historical sample locations from all depths..................................... A-77

A.15. EU Z2-33 DVS and historical sample locations representative of current conditions ................. A-78

A.16. EU Z2-33 sample locations removed during a remedial action or D\&D ................................... A-79

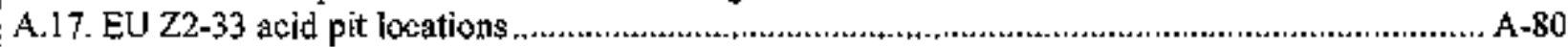




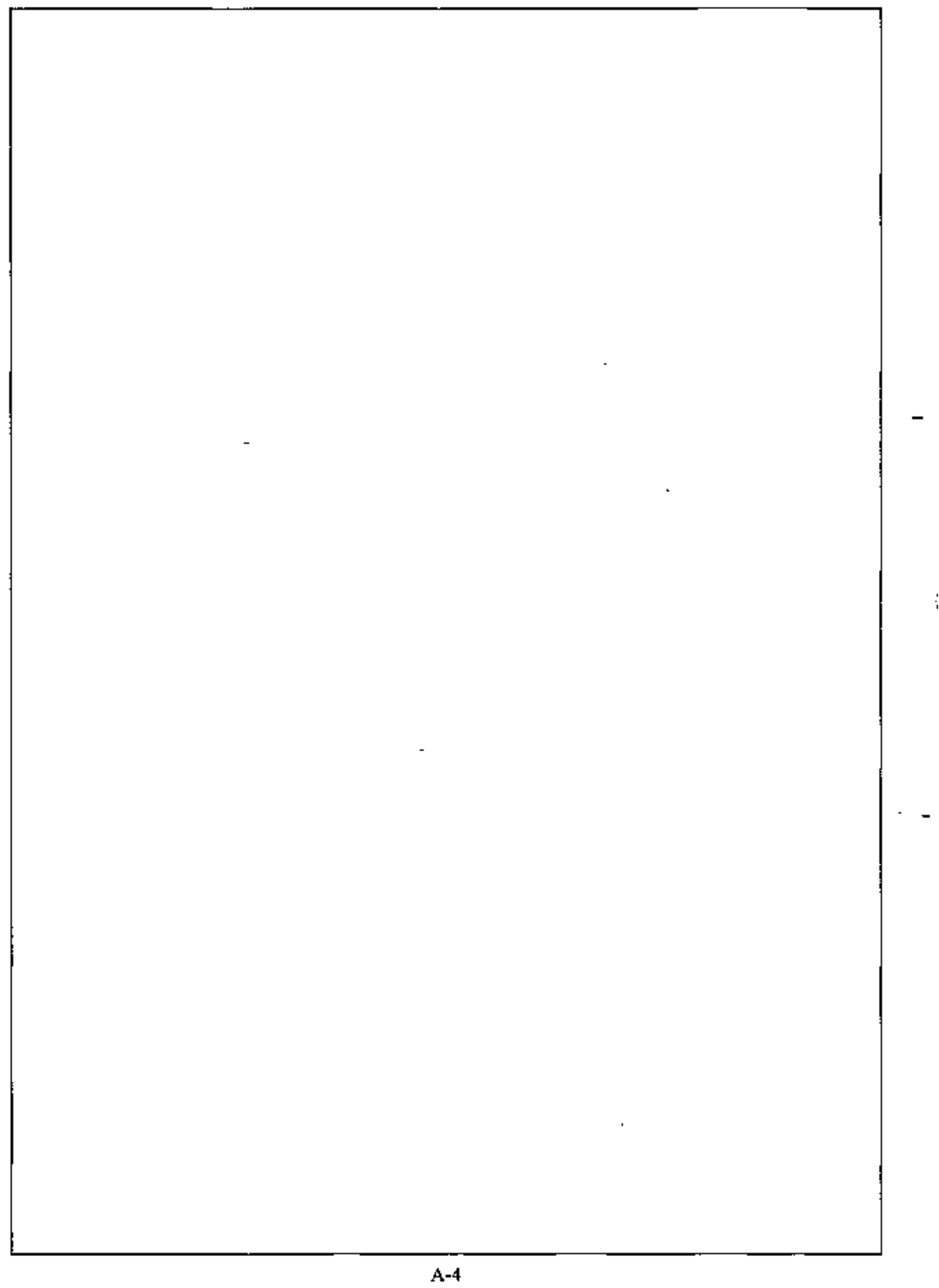




\begin{tabular}{|c|c|}
\hline \multicolumn{2}{|r|}{$\begin{array}{l}\text { DYNAMIC VERIFICATION STRATEGY (DVS) } \\
\text { TECHNICAL MEMORANDUM }\end{array}$} \\
\hline \multicolumn{2}{|r|}{ EXPOSURE UNTT (EU) GROUP: Zone 2 South Park Group EU 33} \\
\hline & INTRODUCTION \\
\hline \multicolumn{2}{|c|}{ 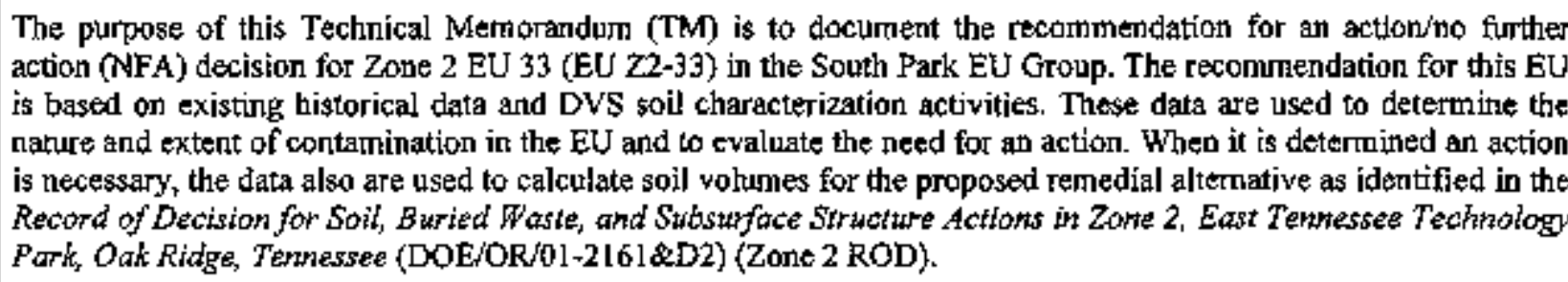 } \\
\hline 1.0 & BACKGROUND AND EU SUMMARY \\
\hline 1.1 & LOCATION AT EAST TENREGSEE TECHNOLOGY PARK (ETTP) \\
\hline \multicolumn{2}{|c|}{$\begin{array}{l}\text { EU Z2.33 is located along the south boundary of Zone } 2 \text { in the South Park EU Group (Fig. A.1). It is bounded on } \\
\text { the north by EU Z2-32 and EU Z2-42, on the east by EU } Z 2-43 \text { and Zone } 1 \text {, on the south by EU Z2-34, and on the } \\
\text { west by Zone } 1 \text {. }\end{array}$} \\
\hline 1.2 & EU ZZZ33 ACREAGE \\
\hline \multicolumn{2}{|c|}{ EU Z2-33 has an area of approxinnately I8 acres (Fig. A.2). } \\
\hline 1.3 & SUMMARY DESCAIPJION \\
\hline \multicolumn{2}{|c|}{$\begin{array}{l}\text { Site operations impacted all of the land area in EU Z2-33. Impacts to the EU included construction of buildings, } \\
\text { roads, parking lots, and sidewalks. EU Z2-33 was the heart of what is commonly referred to as the administrative } \\
\text { section of EITP, which generally housed office and laboratery buildings. }\end{array}$} \\
\hline 1.4 & SOIL UNITS (SUs) \\
\hline \multicolumn{2}{|c|}{$\begin{array}{l}\text { Class } 1 \mathrm{SU}: 0.4 \text { acres } \\
\text { Class } 2 \mathrm{SU}: 3.9 \text { acres } \\
\text { Class } 3 \text { SU: } 13.5 \text { acres } \\
\text { Class } 4 \mathrm{SU}: \text { Note } \\
\text { The EU Z2-33 soil unit boundaries are shown on Fig. A.2. }\end{array}$} \\
\hline 1.5 & ZONE 2 ROD APPENDCX A FEDER $\lambda$ L FACILITY AGREEMENT (FFA) SITES \\
\hline \multicolumn{2}{|c|}{$\begin{array}{l}\text { There are three FFA sites in EU Z2-33 that are listed in Appendix A of the Zone } 2 \text { ROD (Fig. A.2): } \\
\text { - K-1004-L Recirculating Cooling Water (RCW) Lines Leak Sites, } \\
\text { - K-1015-A Laendry Pjt, and } \\
\text { - K-1044 Heavy Equipment Repair Shop. } \\
\text { The Data Quality Objective (DQO) Scoping Package for the South Park EU Group lists } 56 \text { facilities in EU Z2-33 } \\
\text { (see Table 1). }\end{array}$} \\
\hline
\end{tabular}




\begin{tabular}{|l|l|}
\hline 2.0 & DVS INVESTIG ATIONS AND RESULTS \\
\hline 2.1 & DVS FIELD ACTIVITIES \\
\hline
\end{tabular}

DVS activities were conducted in accordance with the Remedial Design ReportRemedial Action Work Plan for Zone 2 Soils, Slabs, and Infrostructure, East Tennessee Technology Park Oak Ridge, Tennessee (DOE/OR/01-2224\&D3) (Zone 2 RDRRAWP).

\section{\begin{tabular}{l|l} 
2.1.1 & CEASS 1 SUS
\end{tabular}}

K-1004-J Lab South Class I SU: An area of approximately 0.4 acres was classified as a Class 1 SU. The K-1004-J Lab South Class I SU is located aiong the northern boundary of EU Z2-33 and lies directly south of the K-1004-J Laboratory, which is in EU Z2-42. There were Cs-137 maximum remediation level (RL) exceedances in historical sampies from EU Z2-33 and soil contamination at the K-1004-J Laboratory SU. An action for these exceedances and contamination was documented in the EU Z2-42 Technical Memporandum, The contaninated soils tn EU Z2-42 were contiguous with the Class I SU in EU Z2-33. Historical sample locations with maximum RL exceedances were RAD18, RAD19, RAD20, and RAD21, and early characterization location Z2-EU33B-111.

K-1015 Class 1 SU: A small area of soil south of the K-1015 Laundry Pit was classified as a Class 1 SU. The $\mathrm{K}-1015$ Laundry $\mathrm{P}_{\mathrm{it}}$ is an FFA site and is included in the Zone 2 ROD for a remedjal action. Two historical sarnples located immediately south of the Laundry Pit, KAH-SS-B12 and KAH-SS-B13, had Cs-137, U-234, U-235, and U-238 average RL exceedances and U-235 maximum RL exceedances. A third sample, Z2-BU33-2019, was noted in the DQO Scoping Package as having a U-235 average RL exceedance. However, review of the historical data showed that gamma spectroscopy analysis resulted in an average RL exceedance while alpha spectroscopy analysis did not. Consistent with the data evaluation process for uranium isotopes presented in the Zone 2 RDR/RAWP, the elpha spectroscopy arlalysis was accepted over the gamma spectroscopy analysis.

\subsubsection{1 CLASS 1 SU RADTOLCGICAL WALKOVER SURVEY}

Biased area radiation (BAR) survtys were conducted over three areas in EU Z2-33 to delineate remedial action boundaries and docunzent current conditions following remedial actions. The K-1004-J Lab South Class 1 SU and the K-1015 Class $1 \mathrm{SU}$ were surveyed. The third surveyed area was in a Class $3 \mathrm{SU}$ but is included in this section because its purpose was to delineate possible remedial action boundaries around a maximum RL exceedance discovered as a result of the Class 3 SU walkover assessment (Sect. 2.3.1).

In addition to the BAR surveys conducted in EU Z2-33, the results of pre- and post-remedial action BAR surveys for a single location in EU Z2-42 are also reported The area strveyed in EU Z2-42 was focated directly north of the EU Z2-33 K-1004-J Lab South Class I SU and was the northern extent of the area of soil contanination associated with the K-1004-J Lab. The surveyed area was contigurous with the K-1004-J Lab South Class $1 \mathrm{SU}$, except for a road separating the two areas. As documented in the EU Z2-42 TM, the soil contaminant was Cs-137.

The BAR surveys were conducted according to the Class 1 and Class 2 Soil Unit Radiological Investigation and Biased Area Radiation Survey Protocol, which is included in the Zone 2 RDR/RAWP. Results of the BAR surveys, including the BAR surveys in EU Z2-42, are presented in Walkover Inspections and Radiological Surveys for FY2007 Exposure Units in Zone2, East Tennessee Technology Park Oak Ridge, Tennessee (BJC/OR-269]) and șummarized below. BAR survey locations are shown on Fig. A.3.

K-1004-J Lab in EU Z2-42: Pre-remedial action BAR surveys were conducted in EU 22-42 on August 25, 2005 and January 25, 2006, south of the K-1004-J Laboratory and immediately north of the K-1004-J Lab South Class 1 SU. The land area surveyed in EU 22-42 was contiguous with the K-1004-J Lab South Class 1 SU, except for a road separating the wo areas, which is coincident with the boundary between EU Z2-33 and EU Z2-42. Results of the pfe-remedjal action BAR survey are shown graphically on Fig. A.4. Two areas with action level (AL) exceedances were observed during the BAR survey and are delineated on Fig. A.4 with red boxes. Radiation measurements during the pre-remedial action BAR survey attalned a maximum $21,118 \mathrm{cpm}$ in the eastern part of the two areas. The two areas were excayated and replaced with clean soil in October 2007.

Post-remedial action BAR surveys were conducted at the K-J004-J Laboratory area in EU 22-42 on November 2 and 8, 2007, prior to filling with ciean soil (see Fig. A.5). Survey results showed that the contaminated soil was effectively removed. Two spots of elevated radiation are apparent in Fig. A.5 -one on the northwest comer of the eastern excavation and the other on the southwest corner of the western excavation. Based on a comparison of count rates from the pre-remedial action BAR surveys with analytical results, it was determined the maximum count rate 
during the post-remedial action BAR surveys, $3574 \mathrm{cpm}$, represented a Cs-137 concentration at or less than the Cs-137 average RL concentration. Because the area of raximum elevated radioactivity at the easters excavation was \$mall (approximately I ft by $1 \mathrm{ft}$ ), no additional excavation was conducted.

K-1004J Lab South Class I SU: A pre-remedial action BAR survey was conducted in this Class 1 SU on August 25,2005 , to delineate possible remedial action boundaries for the area of soil contamination. Results of the BAR survey showed elevated radiation measurements over almost the entire approximately $2400 \mathrm{ft}^{2}$ area (see Fig. A.6). The surveyed area was excavated and replaced with clean soil in October 2007.

Post-remedial action BAR surveys were conducted over the excavated area on November 2, 8, 12, and 13, 2007, prior to filling with ciean soil. Results of the post-remedial action BAR surveys demonstrated that the remedial action was successful in removing the contanninated soil (see Fig. A.7).

K-1015 Class 1 SU: A BAR survey was conducted in this Class 1 SU on July 6, 2006, to delineate possible remedial action boundaries for a soil area located south of and adjacent to the K-HOLS Laundry Pit FFA site. Results showed ar area approximately $20 \mathrm{ft}$ long and $10 \mathrm{ft}$ wide (approximately $200 \mathrm{f}^{2}$ ) extending to the south of the K-1015 Laundry Pit with radialion measurements in excess of the AL (see Fig. A.8).

A post-remedial action BAR survey was conducted in this SU on October 22, 2007 (see Fig. A.9). No radiation in excess of the AL was detected.

Gravel Wash Ares: A gravel-covered area located south of the K-1004-L pad was used to rinse radionuclide-contaminated filters. The area was identified as having radiation in excess of the screening level (SL) during the Class 3 SU walkover assessment (Sect. 2,1,3.1). Analytical results from biased sampling showed U-234, UJ-235, and U-238 in excess of their average RLs and U-238 in excess of its maximum RL. The gravel wash area was excayated and a follow-up BAR survey was conducted January $19,2007$.

The BAR survey results for this area showed an approximately 10 -ft by 10 -ft area (approximately $100 \mathrm{ft}^{2}$ ) with radiation measurements excooding the AL (see Fig. A. 10).

\begin{tabular}{|l|l|}
\hline $2,1,1,2$ & CLASS I SU GEOPHYSICAL SURVEY \\
\hline None &
\end{tabular}

\section{\begin{tabular}{l|l} 
2.t.1.3 & CLASS I SU SOIJ, SAMPLING \\
\hline
\end{tabular}}

DVS biased sampling in the EU Z2-33 Class 1 SUs was conducted as described below.

K-1004-J Lab South Class 1 SU: There were tive DVS sample locations in the K-1004-J Lab South Class 1 SU that included two systematic grid sample locations identified during DQO scoping, one historical confirmation sample, and two 4-point composite step-out samples. One of the systematic grid samples coincided with the highest radiation measurement obtained during the pre-remedial action BAR surveys (Sect 2.1.1.1). As agreed to by the Core Team, confirmation sampling was conducted at only one historical sample location in the SU (RAD20) because the four historical sample locations were closely spaced and fell within the area of AL exceedances defined during the preremedial action BAR surveys. Step-out sampling was conducted both within and outside the area of AL exceedances defined during the BAR surveys.

K-1015 Class 1 SSU: There were seven DVS sample locations in the K-1015 Classs 1 SU. DVS sample locations included confimation locations for historical locations KAH-SS-B12, KAH-SS-B 13, and 22-EU33-2019, and four locations selected outside the BAR survey area of radiation exceeding the AL (Sect. 2.1.i.1) to confirm the boundaries of radiplogical contamination.

Details of the actual sampling and analysis in the Class I SUs, including depths, analytes, and deviations from planned sampling, are presented in Table 2.

\section{\begin{tabular}{l|l}
2.1 .2 & CLASS 2 SUS
\end{tabular}}

The K-1004 Area Drain Line Class 2 SU in EU Z2-33 was defined to address a high degree of uncertainty regarding the impact of the K-1004 Area Drait Line to EU soils. In addition, two small areas centered around historical sample locations KAH-SS-B22 and KAH-SS-\$3 I were defined during DQO scoping to delineate the extent of $\mathrm{Cs}-137$ average $R L$ exceedances. 
Two BAR surveys were conducted to delineate the extent of radionuclide average $R L$ exceedances at historical sample locations KAH-SS-B22 and KAH-SS-S31. The BAR surveys were conducted according to the Class $I$ and Class 2 Soil Unit Radiological Investigation and Biased Area Radiation Survey Protocol, which is included in the Zone 2 RDR/RAWP. Results of the BAR surveys are presented in Walkover Inspections and Radiological Surveys for FY2007 Exposture Units in Zone 2, East Tennessee Technology Park, Oat Ridge, Tennessee (BJClOR-2691) and surnmarized below.

Results of the Class 2 SU BAR surveys are presented graphically on Figs. A.1 I and A.12, respectively. The AL was not exceeded at either of the two locations.

\begin{tabular}{|l|l|}
\hline $\mathbf{2 . 1 . 2 . 2}$ & CLASS 2 SU GEOPHYSICAL SURVEY \\
\hline None & \\
\hline $\mathbf{2 . 1 . 2 3}$ & CLASS 2 SU SOHL SAMPLING \\
\hline
\end{tabular}

Seventeen DVS systematic grid sample locations were identified during DQO scoping and sampled in the Class 2 SU of EU Z2-33. Also, confirmation samples were collected at historical sample locations KA.H-SS-B22 and KAH-\$S-S3 1 with Cs-137 average RL exceedances.

\section{\begin{tabular}{l|l}
2.1 .3 & CLASS 3 AND CLASS 4 SU WALKOVER ASSTESSMENT
\end{tabular}}

The protocol for addressing the Class 3 and Class 4 SUs in EU Z2-33 is the Class 3 and Class 4 Soll Unil Walkover Inspection Protocol Rev 01 (found in Appendix A of the Zone 2 RDRRAWP). The purpose of the Class 3 SU walkover assessments is to systematically inspect Class 3 SUs by visual observation along transects to established grid assessment locations, map observed features, and collect radiological screening data at grid and discretionary locations. The details of the walkover assessment results for EU Z2-33 are presented in the document Walkover Inspections and Radiologicol Surveys for FY2007 Exposure Units in Zone 2, East Tennessee Technology Park, Oak Ridge, Tennessee (BJC/OR-2691) (Assessment Report). A summary of the report results is presented below in Sects. 2.1.3.1 and 2.1.3.2. The assessment point (AP), mid-point (MP), and discretionary point (DP) locations are shown on Fig. A.13.

A total of 15 APs were identified in EU Z2-33 prior to the start of fieldwork and are documented in the DQO Scoping Package. The actual number of APs evaluated in EU Z2-33 corresponds to the uumber planned.

In addition to the APs, the field team made assessments at seven MP locations, which are selected in the field and located approximately half way berween APs, and conducted discretionary surveys at a total of 20 locations (see below). Mid-point and DP locations were not specified in planning tocuments.

\begin{tabular}{lccc}
\hline & Number of APs & Number of MPs & Number of DP5 \\
\hline EU 22-33 & 15 & 7 & 20 \\
\hline$A P=$ assessment poutl & $\mathrm{EU}$ m exposure unt & & \\
$\mathrm{DP}=$ diseretupnary pont & $\mathrm{MP}=$ mid-point & &
\end{tabular}

\subsubsection{CLASS 3 AND CLASS 4 SU RADIOLOGICAL SURVEY SUMMARY}

Sereening level (SL): $3892 \mathrm{cpar}$

SL exceedances: One

The radiation SL was exceeded at a DP located in what was identified in the Assessment Report as a gravel wash area south of the $\mathrm{K}-1004-\mathrm{L}$ pad.

\section{\begin{tabular}{l|l} 
2.1.3.2 & CLASS 3 AND CLASE 4 SU ANTHROPOGENIC FEATURES \\
\hline
\end{tabular}}

Number of identified anth ropogenic features: 19 
Exposure unit Z2-33 is located in an industrialized pontion of ETTP, which included numerous anthropogenic features such as facilities and associated constructed features such as roads, sidewalks, and paved areas. Plant facilities and their associated constructed features were assessed as part of the Class 3 and Class 4 SU walkover assessment protocol and are reported in Sect. 2.1.3.3. Other than plant facilities atd associated constructed features, 19 anthropogenic features were identified in EU 22-33 during the Class 3 SU walkover assessment. The anthropogenic features listed below consist of a brief description and DP identifier, both taken from the Assessment Report.

1) Valve Vault, north side of Avenue $E$ and 3rd Street (DP EU33-316);

2) Difution Pit southwest of K-1004-D (DP EU33-318);

3) Storm Drain, west of K-13 10-D (DP EU33-319);

4) Valve Vault, northwest comer of K-1310-JX on A venue E (DP EU33-320);

5) Valve Vault, southeast comer of K-1006 on Avenue E (DP EU33-321);

6) Steam Vault, on A venue E north of intersection with 3rd Street (DP EU33-322);

7) Storm Drain, south of K-1004-B (DP EU33-323);

8) Storm Drain, south of southeast corner of K-1004-B (DP EU33-324);

9) Storm Drain, southwest corner of Avenue D and 5th Street (DP EU33-325);

10) Valve Vault, west of K-1205-A (DP EU33-326);

II) Vault, $-80 \mathrm{ft}$ southwest of K-1039-1 and $-35 \mathrm{ft}$ east of K-13 10-JK (DP EU33-327);

12) K-1004-A,B,C dilution pit west (DP EU33-329);

13) K-1004-A,B,C dilution pit south (DP EU33-330);

14) K-1004-A,B,C dilution pit east (DP EU33-331);

15) $K-1004-A, B, C$ dilution pifeast center (DP EU33-332);

16) Grave] wash area south of the K-1004-L pad (DP EU33-333);

17) Brick-lined drain pit adjacent to gravel wash area (DP EU33-334);

18) Acid dilution pit south of K-1004-L (DP EU33-335); and

19) Bottle area at the northwest corner of K-1004-L pad (DP EU33-336).

As stated in Sect. 2.1.3.I, the radiation SL was exceeded at the gravel wash arte south of the K-1004-L pad. Nine anthropogenic features were selected for biased sampling based on the radiation SL exceedance, visual observations indicative of possible chemical contamination, and on-site history (Sect. 2.1.3.4).

In addition to the anthropogenic features listed above, sedinent accumulation area DP EU33-317 was identified in EU Z2-33 during the Class $3 \mathrm{SU}$ walkover assessment.

\subsubsection{CLASS 3 SU FACILITIES ASSESSMENTS}

According to the DQO Scoping Package, 51 facilities were located in EU Z2-33. Thirty-one facilities were assessed during the Class $3 \mathrm{SU}$ walkover assessment (Table 1), including four facilities not identified in the Scoping Package, and were reported in the Assessment Report. In summary, one facility was selected for biased sampling based on a radiation SL exceedance and eight other facilities were selected for biased sampling based on vistal evidence of possible chernical contamination and process knowledge (Sect. 2,1.3.4).

\subsubsection{4 $\quad$ CLASS 3 aND CLASS 4 SU BIASED SAMPLING}

Based on the visual observations and radiation surveys of each anthropogenic feature as well as process knowledge, biased sampling was conducted at nine anthropogenic features. These features are listed below with brief descriptions taken from the Assessment Report and the DP location identifier.

- Dilution pit southwest of K-1004-D (EU33D-318);

- K-1004-A, B, C dilution pit west (EU33D-329);

- K-1004-A, B, C dilution pít south (EU33D-330);

- K-1004-A, B, C dilution pit east (EU33D-331);

- K-l004-A, B, C dilution pit east central (EU33D-332)

- Gravel wash area south of the K-I004-L pad (EU33D-333);

- Brick-tjned drain pit adjacent to the gravel wash area (EU3JD-334);

- Acid dilution pit south of K-1004-L (EU33D-335); and

- Bottle area at the northwest comer of the K-1004-L pad (EU33D-336). 
Based on yisual observations and radiation surveys as well as process knowledge, biassed sampling was conducted at the following facilities:

- K-1003 Dispensary,

- K-1004-F Laboratory Storage Building,

- K-1004-L,

- K-1004-M Former Electrical Switchgear Room,

- K-1006 Development Laboratory,

- K-1015 Laundry Facility.

- Kn-700-A-13 Substation,

- K-700-A-17 Substation, and

- K-700-A-74 Substation.

Biased sampling was recommended in the Assessment Report for a sediment accumulation area located east of K-1310-D, but a sample was not colbected because of accessibility problems arising from decontanination and decommissioning (D\&D) activities. Because of the high density of sample locations in EU Z2-33, a sample from] this sediment accumulation area would provide no new information regarding potential source areas in the EU and no new sampling is planned at this location. A different sediment accumulation sample location located east of the K-1004-J Lab South Class I SU was identified and sampled during DVS sampling. This location received runoff from a $\mathrm{D} \& \mathrm{D}$ truck wash contamination area.

2,2 DVS AND HistóRICAL, SAMPLE RESULTS

Sample locations with samples from all depth intervats were assigned to applicable focused investigation areas (SUs, DPs, facikilies, and FFA sites). Then, consistent with requirements of the Zone 2 ROD, soil and concrete, including brick and mortar, data from the 0 to $10 \mathrm{ft}$ depth interval (i.e., any sample with a starting depth < $10 \mathrm{ft} b \mathrm{gs}$ ) were evaluated by focused investigation area (see Sects. 2.2.5 and 2.2.6). The sample locations presented in Sects. 2.2.I through 2.2.3 are ali historieal and DVS soil and concrete sample locations in EV Z2-33. However, in response to analytical results from DVS sampling the RA Core Tearn concurred that several remetial actions needed to be conducted in EU Z2-33. As a result of the remedial actions, several DVS and historical sample locations were removed. In addition, several EU Z2-33 tacilities were undergoing D\&D during the time of DVS characterization activities that resulted in additional removal of DVS and historical sample locations. Table 3 summarizes remedial action and D\&D activities in EU Z2-33, and details soil and concrete sample locitions that were removed and sample locations representative of current conditions at focused investigation areas impacted by remedial actions and D\&D actjities. In some cases, representative sampling was conducted in the $>10$ ft depth interval as confirnation following a remedial action or to determine if leakage from a subsurface structure had introduced contaminants into the subsurface. These sample locations are shown in Table 3 and the analytical results are included in Sects. 22.5 and 2.2.6. Only those focused investigation areas listed in Table 3 were impacted as just described. The sample kocations for focused investigation areas not listed in Table 3 are presented in Sects. 2.2.1 through 2.2.3.

Analytical results for soil samples representative of current conditions and collected from the 0 to $10 \mathrm{ft}$ depth interval are summarized in Table A. Analytical data representative of current conditions for concrete and related material (e.g., brick, mortar) are summarized in Table 5. The full data set for EU Z2-33 contains several soil samples collected from depths up to $23 \mathrm{ft}$ bgs. Results for samples collected from $\geq 10 \mathrm{ft}$ bgs and representative of current conditions at that depth are summarized in Table 6. A compact disc containing electronic files for the historical and DVS analytical data used to generate the data tables is provided with this Phased Constuction Completion Report (PCCR). All DVS and historical soil and concrete sample locations, regardless of depth, are shown on Fig. A.14 (location ID numbers not included for figure legibility). Dynamic Verification Strategy and historical soil and concrele sample locations representative of current conditions are shown on Fig. A.I5. Several samples from locations shown on Fig. A.14 were collected from a depth of $\geq 10 \mathrm{ft}$ because they help define current conditions. Soil and concrete sample locations removed during \& remedial action or D\&D are shown on Fig. A.16.

\section{\begin{tabular}{l|l} 
2.2.1 & CLASS 1 SUS
\end{tabular}}

There were 27 DVS and historical samplo locations in the EU Z2-33 Class l SUs. All soil, concrete and concrete-related material sample Jocations with samples from all depth intervals are presented below [some sample 
locations are no longer representative of curent conditions (see Table 3)]. Historical sample locations Z2-EU33B-1 10 and Z2-EU33B-2019 were sampled in the 0 to $10 \mathrm{ft}$ depth interval and the $\geq 10 \mathrm{ft}$ interval.

\begin{tabular}{|c|c|}
\hline DVs sample Jocations & Fistorical sample locations \\
\hline \multicolumn{2}{|l|}{ Locations with samples collected from of to 10 fo bos } \\
\hline $\begin{array}{l}\text { K-1004-J Lab South Class } 1 \text { SU Systematic Grid } \\
\text { Locationș (Z2-EU33B-105, Z2-EU33B-106) }\end{array}$ & $\begin{array}{l}\text { K-1004-J Lab South Class } 1 \text { SU (RAD18, RAD19, } \\
\text { RAD20, RAD21, Z2-EU33-2026, Z2-EU33-2027, } \\
\text { Z2-EU33B-110, Z2-EU33B-111) }\end{array}$ \\
\hline $\begin{array}{l}\text { K-1004-J Lab South Class I SU Historical Sampit } \\
\text { Confirmation Location (Z2-EU33B-103) }\end{array}$ & $\begin{array}{l}\text { K-1015 Class } 1 \text { SU (KAH-SS-B12, KAH-SS-B13, } \\
\text { Z2-EU33-2019) }\end{array}$ \\
\hline \multicolumn{2}{|l|}{$\begin{array}{l}\text { K-1004-J Lab South Class } 1 \text { SU Step-out Locations } \\
\text { (Z2-EU33B-129, Z2-EU33B-130) }\end{array}$} \\
\hline \multicolumn{2}{|l|}{$\begin{array}{l}\text { K- I004-J Lab South Class I SU Post-RA } \\
\text { Confürmation Location (Z2-EU33B-380) }\end{array}$} \\
\hline \multicolumn{2}{|l|}{$\begin{array}{l}\text { K-1015 Class } 1 \text { SU Historical Sample Confirmation } \\
\text { Sample Locations (Z2-EU33B-108, Z2-EU33B-109, } \\
\text { Z2-EU33B-220 ) }\end{array}$} \\
\hline \multicolumn{2}{|l|}{$\begin{array}{l}\text { K-1015 Class } 1 \text { SU Boundary Confirmation Sample } \\
\text { Locations }{ }^{2} \text { (Z2-EU33B-306, Z2-EU33B-307, } \\
\text { 22-EU33B-308, Z2-EU33B-309) }\end{array}$} \\
\hline \multicolumn{2}{|c|}{ Locations with samples collected from the $\geq 10$ ft depth interval } \\
\hline $\begin{array}{l}\text { K-1015 Class I SU Post-RA Confirmation Location } \\
\text { (22-EU33B-382) }\end{array}$ & K-1004-J Lab South Class I SU (Z2-EU33B-I I0) \\
\hline \multicolumn{2}{|c|}{ 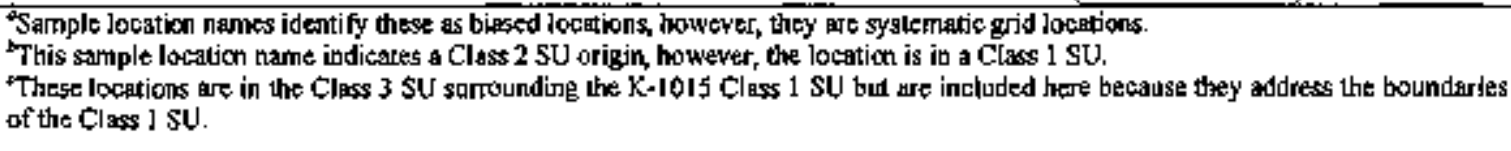 } \\
\hline 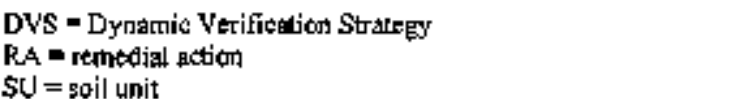 & \\
\hline
\end{tabular}

Sampling and analytical details for each sample location are presented in Table 2. The analytical data for samples representative of current conditions in the 0 to $10 \mathrm{ft}$ depth interval are evaluated in Sect 2.2.5. Numbers of analyses conducted for all samples from all sampie depths in the Class 1 SUs are presented below by analyte group.

\begin{tabular}{lcccc}
\hline Metals & PPCBs & Radiontelides & SVOCs & VOCs \\
\hline 12 & 10 & 25 & 9 & 3 \\
\hline PPCB = pesticide and polychlorinated biphenyl \\
SYOC = semivotatlle organc compound \\
WOC = valatile treganis compound
\end{tabular}

\section{\begin{tabular}{l|l}
2.2 .2 & CLASS 2 SUS \\
\hline
\end{tabular}}

There were 23 DVS and historical sample locations in the EU Z2-33 Class 2 SUs (summarized below). All samples in the Class 2 SUs were collected from the 0 to $10 \mathrm{ft}$ depth interval. 


\begin{tabular}{|c|c|}
\hline DVS sample locations & Histarical sample bocatlons \\
\hline $\begin{array}{l}\text { Z2-EU33-203, Z2-EU33-204, Z2-EU33-205, } \\
\text { Z2-EU33M-206, Z2-EU33M-207, Z2-EU33M-208, } \\
\text { Z2-EU33M-209, Z2-EU33-210, Z2-EU33-211, } \\
\text { Z2-EU33M-212, Z2-EU33M-213, Z2-EU33M-214, } \\
\text { Z2-EU33-215, Z2-EU33-216, Z2-EU33-217) }\end{array}$ & $\begin{array}{l}\text { KAH-SS-B22 Class } 2 \text { SU (KAH-SS-B22) } \\
\text { KAH-SS-S3 I Class } 2 \text { SU (KAH-SS-S31) }\end{array}$ \\
\hline $\begin{array}{l}\text { KAH-SS-B22 Class } 2 \text { SU Historical Sample } \\
\text { Confirmation Location (Z2-EU33B-221) }\end{array}$ & \\
\hline $\begin{array}{l}\text { KAH-SS-S3 I Class } 2 \text { SU Historical Sample } \\
\text { Confïmation Location (Z2-EU33B-222) }\end{array}$ & \\
\hline
\end{tabular}

Sampling and analytical details for each sample location are presented in Table 2 and analytical data are evaluated in Sect. 2.2.5. The number of analyses conducted in the Class 2 SUs is presented below by analyte group.

\begin{tabular}{|c|c|c|c|c|}
\hline Metabs & PPCBs & Radionuclufes & SVOCs & VOCs \\
\hline 17 & 17 & 12 & 17 & 4 \\
\hline
\end{tabular}

PPCB = pesticide and polychlonnated binhenyl SYOC = semivolatıle organc compound $\mathrm{YOC}-\mathrm{volat}$ le of ganic compound

\section{\begin{tabular}{l|l}
\hline 2.2 .3 & CLASS 3 AND CLASS 4 SUS \\
\hline
\end{tabular}}

There were 135 DVS and historical sample locations used to characterize the EU Z2-33 Class 3 SU, including II locations in the K-1015 Class 1 SU that bounded conditions in the adjacent K-1015-A Laundry Pit FFA site. All soil, concrete and concrete-related material sample locations with samples from all depth intervals are presented below. Some of these sample locations are no longer representative of current conditions (see Table 3). DVS sampling used biased sampling and was conducted in response to DQO scoping requlrements and DP and facility observations made during the Class 3 SU walkover assessment (Sect. 2.1.3.4). Historical sample locations were assigned to $\mathrm{DPs}$, fatilities, and other features based on proximity. Several sample locations presented in this section were in the Class 2 SU but are presented here because they were identified during the Class 3 SU walkover assessment ( $\mathrm{Fig}$. A.13). Samples were collected from both the 0 to $10 \mathrm{ft}$ depth interval and $\geq 10 \mathrm{ft}$ interval at three sample locations presented below $(424,425$, and Z2-EU33B-2019).

\begin{tabular}{|c|c|}
\hline DVS sample locations & Historical sample locations \\
\hline \multicolumn{2}{|l|}{ Locations with samples collected from 0 to $10 \mathrm{ft}$ bos } \\
\hline 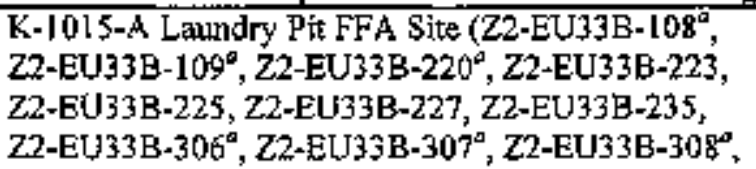 & 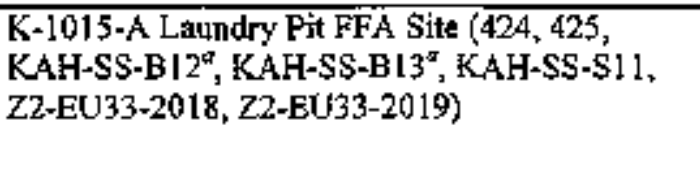 \\
\hline 22-EU33B-309 & $\begin{array}{l}\text { K-1004-D Facility Locations (K-1004D-S1, } \\
\text { K-1003D-S2, K-1004D-S3, KAH-SS-S41, }\end{array}$ \\
\hline $\begin{array}{l}\text { K-1044 Heavy Equipment Repair Shop FFA Site } \\
\text { (Z2-EU33B-232, Z2-EU33B-233) }\end{array}$ & $\begin{array}{l}\text { Z2-EU33-2004, Z2-EU33-2005, Z2-EU33-2006, } \\
\text { Z2-EU33-2007, Z2-EU33-2008, Z2-EU33-2009, } \\
\text { Z2-EU33-2010, Z2-EU33-2011, }\end{array}$ \\
\hline Sedimont Accumulation Area (Z2-EU33B-342) & Z2EU33-K1004D) \\
\hline $\begin{array}{l}\text { Dilution Pil SW of K-1004-D (DP EU33D-318) } \\
\text { (Z2-EU33B-113, Z2-EU33B-310, Z2-EU33B-311) }\end{array}$ & $\begin{array}{l}\text { K-1004-P Facility Locations (Z2-EU33-2012, } \\
\text { Z2-EU33-2013) }\end{array}$ \\
\hline $\begin{array}{l}\text { K-I004-A,B,C Dilution Pit West (DP EU33D-329) } \\
\text { (Z2-EU33B-125, Z2-EU33B-131, Z2-EU33B-137, } \\
\text { Z2-EU33B-I 40, Z2-EU33B-141, Z2-EU33B-316) }\end{array}$ & $\begin{array}{l}\text { K-1006 Facility Locations (K-3006-01, } \\
\text { K-1006-02, K-1006-09, KAH-SS-S81) }\end{array}$ \\
\hline
\end{tabular}




\begin{tabular}{l} 
DVS sample locations \\
\hline K-1004-A,B,C Dilution Pit South (DP EU33D-330) \\
(Z2-EU33B-122, Z2-EU33B-314, Z2-EU33B-315, \\
Z2-EU33B-379) \\
K-3004-A,B,C Dilution Pit East (DP EU33D-33L) \\
(Z2-EU33B-1 16)
\end{tabular}

K-1004-A,B,C Dilution Pit East Conter (DP EU33D-332) (Z2-EU33B-119, Z2-EU33B-313, 22-EU33B-378)

Gravel Wash Area (EU33D-333) (Z2-EU33B-333, Z2-EU33B-359, Z2-EU33B-3601, Z2-EU33B-361, Z2-EU33B-368, Z2-EU33B-369, Z2-EU33B-370, Z2-EU33B-37I, Z2-EU33B-372)

Brick-Lined Drain Pit (EU33D-334)

(Z2-EU33B-334)

Acid Ditution Pit South of K-1004-L (EU33D-335) (Z2-EU333B-335, Z2-EU33B-365)

Bottle Area Near K-I 1004-L (EU33D-336)

(Z2-EU33B-336)

K-1003 Facility Location (Z2-EU33B-326)

K-1004-F Facility Locations (Z2-EU33B-325, Z2-EU33B-329, Z2-EU33B-330, Z2-EU33B-331, Z2-EU33B-332)

K-1004-L Facility Lucations (Z2-EU33B-337, Z2-EU33B-339, Z2-EU33B-340, Z2-EU33B-341, Z2-EU33B-343, Z2-EU33B-344, Z2-EU33B-346, Z2-EU33B-348, Z2-EU33B-349, Z2-EU33B-350, Z2-EU33B-351, Z2-EU33B-352, Z2-EU33B-353,Z2-EU33B-354, Z2-EU33B-356, Z2-EU33B-357, Z2-EU33B-358, Z2-EU33B-362, Z2-EU33B-363, Z2-EU33B-364)

K-1004-M Facility Locations (Z2-EU33B-338, 22-EU33B-345, 22-EU33B-347)

K-1006 Facility Locations (Z2-EU33B-128, Z2-EU33B-327, Z2-EU33B-328, Z2-EU33B-373)

K-I015 Laundry Facility Locations (Z2-EU33B-301, Z2-EU33B-302, Z2-EU33B-303)

K-700-A-13 Substation Facility Location (Z2-EU33B-317)

K-700-A-17 Substation Facility Location (Z2-EU33B-320)
K-1015 Laumdry Facility Locations

(Z2-EU33-2014, Z2-EU33-2015, Z2-EU33-2016, Z2-EU33-2017)

K-1205-A Facility Locations (22-EU33-2001, Z2-EU33-2002, Z2-EU33-2003)

Other Class 3 SU Historical Locations $(414,415$, 416, KAH-SS-S21) 
K-700-A-74 Substation Facility Location

(22-EU33日-323)

Locations with samiples collected from $\geq 10$ ft depth interval

K-1015-A Laundry Pit FFA Site (Z2-EU33B-229, K-1015 Laundry Pit FFA Site (424, 425, Z2-EU33B-230, Z2-EU33B-382) 22-EU33-2019

Dilution Pit SW of K-1004-D (DP EU33D-318) (22-

EU33B-114)

K-1004-A,B,C Dilution Pit West (DP EU33D-329)

(Z2-EU33B-126, Z2-EU33B-132, 22-EU33B-138,

Z2-EU33B-377, Z2-EU33B-383)

K-1004-A,B,C Dilution Pit South (DP EU33D-330)

(Z2-EU33B-123)

K-1004-A,B,C Dilutions Pit East (DP EU33D-331)

(Z2-EU33B-117)

K-1004-A,B,C Dilution Pit East Center (DP EU33D-

332) (Z2-EL33B-120)

Acid Dilution Pit South of K-1004-L (EU33D-335)

(Z2-EU33B-381)

K-1004-L Facility Locations (Z2-EU33B-355)

K-1006 Facility Locations (Z2-EU33B-374)

"These Class I SU sample locations assigned to the K-lo1s-A Laundry Pit FFA site are also incleded in the K.1015 Class I SU (see Sect. 2.2.I) which is adjacent to the K-1015-A Laundry Pit FFA site. These bocations are listed here because they bound the condicions in K-10] 5 Layndry Pit FFA site.

'This sample localion was removed when sediment frosh the sewer ejector sump pil was semoved by DeD Operations after production of the first draft or this TMM.

Sampling and analytical details for each sample location are presented in Table 2 . Analytical data for samples representative of current conditions in the 0 to $10 \mathrm{ft}$ depth interval are evaluated in Sect. 2.2.5. The number of analyses conducted for all samples frorn all sample depths in the Class 3 SUs is presented below by analyte group. This analyte tally does not include analytes from K-1015-A Laundry Pit FFA site locations that are also included in the K-1015 Class $1 \mathrm{SU}$ (Sect. 2.2.1).

\begin{tabular}{cccccc}
\hline Metak & $\begin{array}{c}\text { Other } \\
\text { Organies }\end{array}$ & PPCBs $^{\$}$ & Radtonuclides & SVOCs & VOCs \\
\hline 110 & 4 & 112 & 111 & 74 & 64 \\
\hline
\end{tabular}

Inciudtes diesel range orsanics ant pasoline range organics

the watal count is for PCBs but incledes 13 pesticide analyses.

PPCB = pesticide and polychlotinated biphenyl

SVOC $=5$ semiYo| Atile orgaric compound

VOC = yolatile organic wongand

\section{\begin{tabular}{|l|l} 
2.2.4 & INFRASTRUCTURE \\
\hline
\end{tabular}}

The K-1004 Area Drain Line Class 2 SU sampling in EU Z2-33 was designed to test the impact of plant infrastructure on $\$ U$ soils. 
In this section, characterization data and other information are evaluated for EL Z2-33. Aralytical data in the following summartes are presented by analyte group and results for a particular analyte group are summarized only if that group was analyzed in the samples from the unit being summarized. Within each summary, the data are evaluated by comparing to certais criteria, includiag the Zone 2 soils maximurn remediation ievel (Max RL), Zone 2 soils average remediation level (Avg RL), $1 \times 10^{-5}$ industrial preliminary remediation goal (Ind PRG), ETTP soils background composition (BkE), Zone 2 groundwater screening levels (GW SL), and $1 \times 10^{-6}$ residential preliminary remediation goal (Res PRG). If a particular criterion does not apply to any member of an analyte group, it is not tabulated for that analyte group; if a particular criterion does not apply to all analytes within an analyte group, those analytes to which it does not apply were notated with NA (not applicable). Individual metals and radionuclides, which are naturally occurring, are reported in the sumbarjes only if one or more criterion is exceeded. Organic chemicals, which are not naturally occurring, are reported if they are detected even if no criteria are exceeded. The Max RL, Avg RL, Ind PRG, Bkg, GW SL, and Res PRG criteria values as they pertain to the analytes listed in Appendix A of the RDR/RAWP (i.e., the QAPP) are presented in Sect, 3.1 of this FCCR.

Because the carcinogente risk associated with the concentrations of radium and thortum isotopes in the natural background at ETTP exceeds the cumulative risk goal of $1 \times 10^{-1}$, RL values for these radionuclides are based on alterriative concentration levels rather than risk. The alternative concentration levels of $\$ \mathrm{pCi} / \mathrm{s}$ above background (Avg RL) and $15 \mathrm{pCi} / \mathrm{g}$ above background (Max RL) were set as low as reasonably achievable under the site-specific conditions. Because site-specific backeround concentrations of these radionuclides exceed the target risk range, residual concentrations of these radionuclides and their decay series are not considered in estimates of residual risk following any remedial action.

The Zone 2 ROD states that Avg RL and Max RL exceedances by Ra-226, Th-230, and Th-232 will be evaluated by summing above-background concentrations of the greater of Ra-226 or Th-230 with the above-background concentrations of Th-232 and comparing the results to $5 \mathrm{pCi} g$ (average RL) and $15 \mathrm{pCi} / \mathrm{g}$ (maxinum RL). These required calculations have been performed. Average and Max RL exceedances for these radionuclides, if any, are reported in the TM data summaries below and in Table $2 \mathrm{as}$ "Ra/Th decay series", and individual RL exceedances by Ra-226, Th-230, and Th-232 are reported as NA. The Ra/Th decay series data are summarized in the sections that follow only if an Avg or Max RL has been exceeded, consistent with the description in the preceding paragraph for reporting radionuclides. Discussion of the Ra/Th decay series calculation, including the manner in which the calculation is performed, is presented in Sect. 3.3 of this PCCR.

\section{EU Z2-33 Conceptua] Site Model (CSM)}

Land classification as proposed in the DOO Scoping Package identified two Class 1 SUs within EU Z2-33. One Class I SU is associated with surface soils near the K-1015-A Lanndry Pit and the other is an area of soil contaminated by a Cs-137 spill south of the K-1004-J Laboratory. The Class 1 SU near the K-1004-J Laboratory also included the K-J004-H concrete pad located northwest of the K-1004-L Facility. Historical samples from these two SUs had reported radioactive contamination above Max RLs. Radiological surveys and verification sampling was planned at these two Cless $1 \mathrm{SUs}$. The conceptual model for both $\mathrm{SUl}$ is a surface release model of radiological contamination. The model defunes limited mobility through the soil column and identifies the most probable mode of secondary transport as suspended solids in surface water. Radiological survey and sampling in the areas confirmed the extent of impact and showed no lateral transport beyond the release point.

Land classification as proposed in the DQO Scoping Package identified a Class 2 SU along the utjlity corridors that are in proximity to all of the labs within the EU. A broad range of chemicals and radioisotopes had been used in the labs and discharged into acid pits and sumps that connected into the local stom drain systoms. The classification of the utility corridors was based on the presumption that line breaks and leaks could have occurred in these systems and released contaminants to soils along the corridors. Because releases would have occurred underground from the buried pipes, sampling was targeted at the base of the utility corridor in the underlying native soil.

The remainder of the EU was classified as a Class $3 \mathrm{SU}$ and evaluated using the Class 3 and Class $\mathrm{A}$ SU walkover assessment protocol, which is presented in the RDRRAWP. During the Class 3 SU walkover assessments and associated facility assessments, six acid pits were inspected and found to contain residual solids and liquids. These materials were sompled to determine if they had exceeded any Zone 2 evaluation criteria. These materials did exceed one or more Zone 2 Max RLs and had high concentrations of polychlorinated biphenyls (PCBs), mercury, 
uranium isotopes, Cs-137 and several volatile organic compounds (VOCs). Analytical results from the acid pit samples indicated removal actions were necessary. Liquids and semi-solid sludges were removed from the pits and all but one of the pit stuctures were excavated for off-site disposal; the exception was closed in place. The concepnal model for these structures was a point source release to underlying soils and potentially to loca] groundwater. Sampling around these structures consisted of close proximity borings that recovered soil cores to depths equal to and deeper than the base of the structures. These close off-set lacations were placed in a groundwater downgradient direction from the structures and samples were collected and analyzed for full-suite analyses. In all except one case, sample results indicated the pits had not teaked to the underlying soils. Therefore, no significant contaminant mass was present that would pose a threat to local groundwater. At one location, soil contamination was present in samples at the off-set location and soils were excavated around the pit A confurmation sample was collected following RA to confinm the contamination had been removed.

\section{EU 22-33 Groundwater Evaluation}

There are 12 gtoundwater monitoring weils in EU Z2-33, to bedrock wells, and 2 unconsolidated zone wells. Ten of the 12 wells are located in proximity 10 the K-1004-L Facility and in open areas to the south of the facility. Two bedrock wells are located in the westem portion of the EU northwest and southeast of the K-1006 Facility. Water levels in these wells ranged from 13-25 ft bgs. Both unconsolidated zone wells were consistently dry, which indicates flow in the area is predominantly in the bedrock formations. Flow in the area is toward the K-1007-P Ponds to the south and southwest of the EU. Conduit flow predominates within the Chickamalga limestone units urderlying this portion of the site.

Several of the bedrock wells south of the K-1004-L Facility bave reported VOCs abowe MCLs. Two recently completed weIls to the south in EU Z2-34 also have reported low-level detections of VOCs. The highest reported concentrations were from a bedrock well location near the K-1004-L Facility acid sump.(BRW-038). This well was placed in proximity to the acid sump in 1989 and has consistently reported elevated PCE and TCE detections in groundwater during the monitoring period of 1989-1995. The last sampling event at this location was in 1995 and reported concentrations of $17 \mathrm{ppb}$ PCE and $120 \mathrm{ppb}$ TCE. Montioring was performed under a previous grounowater monitoring program (IWQP) that has been discontinued. The existing data are insufficient to adequately assess the importance of the PCE and TCE detections. The concentration trends for these chemicals have been clearly declining since the first round of sampling performed in 1989. Concentrations of these chemicals in the wells to the south are an order of magnitude lower than the BRW-038 samples. The BRW-038 well was damaged some time after 1995 and was inaccessible for further sampling. Off-set soil sarmpling downgradient of the acid pits was performed as part of the DVS characterization program in 2007. At the K-1004-L locations, VOC contamination was not observed at the off-set sampling location. One soil boring near the acid pit on the west side of the K-1004-B lab did detect VOCs. Step-out locations $12.5 \mathrm{ft}$ around this location did not detect contamination, which indicates the possibte source was very small in lateral extent.

Soil sampling in EU Z2-33 investigated the acid sumps, which were cotnsidered possible point sources of VOCs. Samples from the off-set locations and confimmation sampling at several of the pit locations following removal of the sumps demonstrated no significant mass of contaminated soil that would pose a threal to local groundwater.

\section{EU Z2-33 Sampling Results}

Exposure unit Z2-33 (18 acres) was classified into Class 1,2, and 3 SUs. Approximately 0.5 acres were classified as Class 1 SUs, including the K-1004-J Lab South Class 1 SU (0.4 acres) located south of the K-1004-J Laboratory and classified during DQO scoping. Sampling tn the K-1004-J Lab Solth Class 1 SU included historical sampling, DVS systernatic grid sampling, DVS confirmation sampling, and DVS step-out sampling for boundary definition (Sect. 2.2.I) A BAR survey was conducted in the K-1004-J L.Bb South Class 1 SU and area of AL exceedance was identified (Sect. 2.1.1.1). An additional approximately 0.I acres of soil located around the K-1015-A Laundry Pjt is also addressed in this Technical Memorandurn as the K-1015 Class 1 SU. Sampling in the K-1015 Class I SU included historical sampling, DVS confïmation sampling, and DVS boundary definition sampling (Sect. 2.2.1). A BAR survoy was conducted in the K-1015 Class I SU and an ared of AL exceedarice was identified (Sect. 2.1.1.1). Class 1 SU boundaries are shown on Fig. A.2 and sample locations are shown on Fig. A.I4.

The Class 2 SUs consisted of the large K-1004 Area Drain Line Class 2 SU, which encompassed almost the entire 3.9 acres of Class 2 SU acreage. These SUs were located along the utility line corridors in the southeast/central portion of the site (Fig. A.2). The purpose of this SU was to determine the impact of utility lines to EU soils, including the K-1004 Area Drain Line. 
Sampling in the K-1004 Area Driin Line Class 2 SU included historical sampling and DVS systematic grid sampling (Sect. 2,2.2). Two small Class 2 SUs, KAH-\$S-B22 and KAH-\$S-\$31, were identified during DQO scoping to delineate the extent of Cs-137 Avg RL exceedance. Sampling in these two SUs included DVS confimmation sampling. BAR surveys also were conducted in these SUs but no AL exceedance was observed (Sect. 2.1.2.1). Class 2 SU boundaries are shown on Fig. A.2 and sample locations are shown in Fig. A.14.

The remaining 13.5 acres of EU 22-39 were classified a Class 3 SU so a Class 3 SU walkover assessment was conducted. Because EU Z2-33 is located in an industrialized portion of ETTP, there are many anthropogenic features, sone of these being facilities. Thity-one of these facilities were evaluated as part of the Class $3 \mathrm{SU}$ walkover assessment (Sect. 2.1.3.3). Biased sampling was conducted around nine facilities (Sect. 2.1.3.4) based on assessment conclusions that these facilities were potential sources of contamination. In addition, early characterization sampling was conducted aroumd three other facilities (Sect. 2.2.3). Nineteen non-facility, anthropogenic features were identified (Sect. 2.1.3.2) and seven anthropogenic features were selected for birsed sampling based on radiation survey results or visual evaluations (Sect. 2.1.3.4). A sediment accumulation area was identified during the Class $3 \mathrm{SU}$ walkover assessment but the area was inaccessible for sampling. Irstead, a sample was collected from another sediment accurnulation area identified by the sampling crew. Class $3 \mathrm{SU}$ boundaries are sbown on Fig. A.2 and sample locations are shown on Fig. A.14.

A summary of sampling results for EU Z2-33 is provided in the following sections. Data summarized are for samples collected at the locations presented in Sects. 2.2.1, 2.2.2, and 2.2.3. For sites afready addressed by a remedial action or $D \& D$, only date from sample locations representative of the current conditions were summarized (Table 3). This surnmary begins with a presentation of analytical results for the focused investigation areas in the EU ard concludes with an overall summary for EU Z2-33. The focused investigation areas discussed below include the Class 1 and Class 2 SUs, DPs and facilities selected for bjased sampling based on recommendations in the Assessment Report, and a sediment accumulation area. This section concludes with data summary tables and a writter description of the nature and extent of the chemicals and radionuclides observed. The EU Z2-33 summary also includes analytical data for the FFA sites summarized in Sett. 2.2.6. Analytical results in this section are generally from semples collected from the 0-10 ft depth interval. In a few cases, samples collected from $\geq 10 \mathrm{ft}$ are included if they represented cutrent conditions that have been addressed by a remedial action or D\&D (Table 3). Sample locations representative of current conditions are shown on Fig. A.I5. The Class I and Class 2 SU RA locations are shown on Fig. A.17.

K-1004-J Lab South Class 1 SU: As defined in the DQO Scoping Packase, this area has known radionuclide soil contanination that originated from the K-I004-J Laboratory in EU Z2-42. There were eight historical sample locations in this Class $1 \mathrm{SU}$ (see Sect. 2.2.1) and four Cs-137 Max RL exceedances in these locations (Sect. 2.1.1). Concrete sampling was conducted at two historical sample locations on the K-1004-H pad. An area of AL exceedances was described (Sect. 2.1.1.1) after completion of the BA.R survey. Only one DVS confirmation sample Iocation (RAD20) (Sect. 2.2.1) was identified because of the proximity of the four historical locations to each other. DVS step-out sampling was conducted within (location Z2-EU33B-129) and outside (location Z2-EU33B-130) the BAR survey area of AL exceedances. In adfition to the biased DVS sample locations, two DVS systernatic grid locations were identified during DQO scoping (Sect. 2.2.1).

A remedial action was conducted at this $\$ \mathrm{U}$, end several of the histortcal and DVS sample locations have been removed (see Table 3). Five sample locations that defined conditions in this SU following remedial action included two concrete locations from the K-1004-H pad (Z2-EU33-2026 and Z2-EU33-2027), a systematic grid location (Z2-EU33B-105), the composited step-out samples from outside the area of contamination (Z2-EU33B-130), and a composited confirmation sample from the excavator bucket representing the last soils excayated during the remedial aetion (Z2-EU33B-380) (see Table 3). Analytical results summarized below are from sample locations representative of current conditions that showed a Cs-137 Avg RL exceedance in the step-out sample, radionuclide lnd PRG exceedances, metal and radionuclide Bkg exceedances, and semivolatile organic compound (SVOC) delection. 
EU Z2-33 K-1004J LAB SOUTH CLASS I SU METALS WTTH BACKCROUND, PRG, GW SL, AND/OR RL EXCEEDANCES (m $/ 20$ ) (t-10 ft

\begin{tabular}{|c|c|c|c|c|c|c|c|c|c|c|c|}
\hline \multirow[b]{2}{*}{ Analyte } & \multirow[b]{2}{*}{$\begin{array}{c}\text { Detect } \\
\text { frequency }\end{array}$} & \multirow[b]{2}{*}{$\begin{array}{l}\text { Mifhimum } \\
\text { detect }\end{array}$} & \multirow{2}{*}{ Marinum } & \multirow{2}{*}{$\begin{array}{l}\text { Location(b) of } \\
\text { maximum } \\
\text { detect }\end{array}$} & \multirow{2}{*}{$\begin{array}{l}\text { Av́rage } \\
\text { detected } \\
\text { reult }\end{array}$} & \multicolumn{6}{|c|}{ Number of anslyses awceeding criteria } \\
\hline & & & & & & Max & $\begin{array}{l}\text { AVg } \\
\text { RL }\end{array}$ & $\begin{array}{l}\text { Led } \\
\text { PRG }\end{array}$ & Bkg & $\begin{array}{l}\text { GW } \\
\text { SL }\end{array}$ & $\begin{array}{l}\text { Rea } \\
\text { PRG }\end{array}$ \\
\hline Arsenic & $2 / 2$ & 41 & 49 & Z2-EU33-2027 & 45 & 0 & 0 & 0 & 0 & 0 & 2 \\
\hline Cadmuım & 217 & 092 & 12 & Z2-EU33-2027 & 106 & NA & NA & 0 & 2 & Na & 0 \\
\hline Calcaum & $2 / 2$ & 170,000 & 180,000 & Z2-EU33.2026 & 175,000 & NA & NA & NA & 2 & NA & NA \\
\hline Iron & $2 \Omega$ & 4,700 & 5,400 & Z2-EU33-202\} & 5,050 & NA & NA & 0 & 0 & $\mathrm{NA}$ & 2 \\
\hline Magnesiurti & $2 / 2$ & 58.000 & 63,0000 & $22-E 0333-2026$ & 60.500 & $N A$ & $\mathrm{NA}$ & NA & 2 & $\mathrm{NA}$ & $N A$ \\
\hline Vangduum & $2 / 2$ & 11 & II & $\begin{array}{l}\text { Z2-EU33-2026 } \\
\text { Z2EU33-2027 }\end{array}$ & 11 & NA & NA & 0 & 0 & $N A$ & 2 \\
\hline \multicolumn{2}{|c|}{$\begin{array}{l}\text { Avg = average } \\
\text { Bkg = background } \\
\text { EU = exposute Unit } \\
G W=\text { ground water } \\
\text { lid = indugtrig } \\
\text { Max = maxhmum }\end{array}$} & \multicolumn{10}{|c|}{ 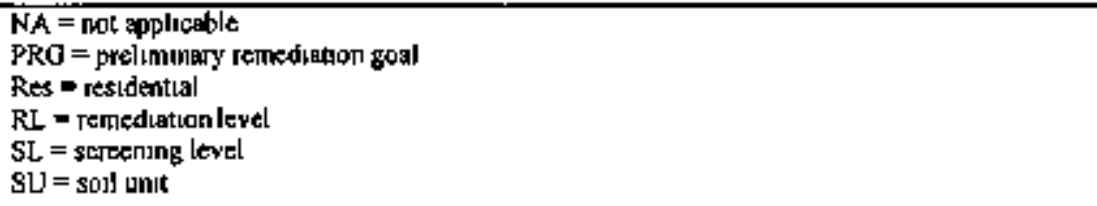 } \\
\hline
\end{tabular}

EU Z2-33 K-1004-J LAB SOUEH CLASS 1 SU PPCB DETECTS (Logk) 0-10 it

\begin{tabular}{|c|c|c|c|c|c|c|c|c|c|}
\hline \multirow[b]{2}{*}{ Anolyte } & \multirow[b]{2}{*}{$\begin{array}{l}\text { Detect } \\
\text { Irequency. }\end{array}$} & \multirow[b]{2}{*}{$\begin{array}{l}\text { Miphajum } \\
\ddot{z} \text { detecs }\end{array}$} & \multirow[b]{2}{*}{$\begin{array}{l}\text { Mfatioum } \\
\text { detect }\end{array}$} & \multirow{2}{*}{$\begin{array}{c}\text { Location(o) of } \\
\text { maximan } \\
\text { detect }\end{array}$} & \multirow{2}{*}{$\begin{array}{l}\text { '" } \\
\text { Averugt } \\
\text { dęfectod" } \\
\text { refult }\end{array}$} & \multicolumn{4}{|c|}{$\begin{array}{l}\text { Nunber of analysed } \\
\text { erropeding criterit. }\end{array}$} \\
\hline & & & & & & $\begin{array}{r}\text { MAr } \\
\text { RE. }\end{array}$ & $\begin{array}{l}\text { Avg } \\
\text { +RL. }\end{array}$ & $\begin{array}{c}\text { lad } \\
\text { PRG }\end{array}$ & $\begin{array}{l}\text { Res: } \\
\text { PRR }\end{array}$ \\
\hline $\mathrm{PCB}-1260$ & $2 / 2$ & 695 & $|4|$ & 22-EU33-2026 & 105 & 0 & 0 & 0 & 0 \\
\hline Potythlorintaled Biphetuyl & $2 / 2$ & 691 & I4J & 22-EU33-2016 & 105 & 0 & 0 & 0 & 0 \\
\hline $\begin{array}{l}\text { Ayg = ayerage } \\
\text { EU = exposarc umt } \\
\text { lnd = industrjal } \\
\text { J = andyte vras ıdentufied } \\
\text { Max = maximum }\end{array}$ & and resull is a & eptoximare c & concentertion & $\begin{array}{l}\text { PPCB = pest } \\
P R G=\text { prel It } \\
\text { Res = resıden } \\
\text { RL = remedı } \\
\$ \mathrm{~L}=\text { gDd un! }\end{array}$ & $\begin{array}{l}\text { tade and p } \\
\text { mirary reme } \\
\text { atual } \\
\text { ation leyed } \\
\text { t }\end{array}$ & $\begin{array}{l}\text { olychio } \\
\text { edsalpon }\end{array}$ & $\begin{array}{l}\text { rinated } \\
\text { goal }\end{array}$ & bipher & nyl \\
\hline
\end{tabular}

EU 72-33 K-10014-I LAB SOUTH CLASS I SU RADIONUCLIDES WITH BACKGROUND, PRG, AND $/ O R$ RL EXCEEDANCES (pCig) t 10 it

\begin{tabular}{|c|c|c|c|c|c|c|c|c|c|c|c|}
\hline \multirow[b]{2}{*}{ Antelytt } & \multirow[b]{2}{*}{ Ditequed } & \multirow[b]{2}{*}{$\underset{\text { detect }}{\text { Minimum }}$} & \multirow[b]{2}{*}{$\begin{array}{c}\text { Maxtmun } \\
\text { detect }\end{array}$} & \multirow[b]{2}{*}{$\begin{array}{l}\text { Location(s) of } \\
\text { moyluum detect }\end{array}$} & \multirow{2}{*}{$\begin{array}{l}\text { Average } \\
\text { detteted } \\
\text {. restalt }\end{array}$} & \multicolumn{6}{|c|}{ Number of and byses exceeding exiterte } \\
\hline & & & & & & $\underset{\mathrm{ML}}{\mathrm{RL}}$ & AYg & $\begin{array}{l}\text { Ind } \\
\text { PRG }\end{array}$ & Buse & $\begin{array}{l}\text { GW } \\
\mathbf{S L}\end{array}$ & $\begin{array}{r}\text { - Res } \\
\text { PRG }\end{array}$ \\
\hline Ces|um-137 & $2 \sqrt{5}$ & 174 & $\$ 4 \mathrm{~L}$ & 22-EU333-130 & 358 & 0 & $T$ & $\overline{2}$ & NA & $\overline{N A}$ & 2 \\
\hline Potassıuın-40 & $3 / 4$ & 933 & 121 & Z2-EU33E-105 & 109 & NA & NA & 3 & 0 & $\mathrm{NA}$ & 3 \\
\hline Radium-226 & $2 / 3$ & 0256 & 107 & Z2-ĒU33B-10S & 0663 & NA & NA & 1 & 0 & NA & 2 \\
\hline Thonum-228 & $2 / 4$ & 1 & 303 & Z2-Eบ330-130 & 102 & NA & NA & 2 & 0 & $\mathbf{N A}$ & 2 \\
\hline Thonum-232 & $3 / 4$ & 0179 & $10 B$ & Z2-EU33B-130 & 0706 & NA & $\mathrm{NA}$ & 3 & 0 & NA & 3 \\
\hline Uranjum-234 & $4 / 4$ & 03921 & 544 & $22-E U 33 \mathrm{~B}-130$ & 189 & 0 & 0 & 0 & NA & 0 & $\mathbf{1}$ \\
\hline Uranım-23B & $4 / 4$ & 0419 & 332 & Z2EU33B-130 & 127 & 0 & 0 & 0 & 6 & 0 & 2 \\
\hline
\end{tabular}

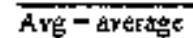

$\mathrm{Bkg}=$ beckground

EU $=$ expositre unit

$G W=$ groundwater

lnd $m$ industrut

Max $=\operatorname{maxm} u m$
NA $=$ mot appliceble

$\mathrm{PRO}=$ prel | imipary remediatron goal

Res = residential

RL = remediation level

SL - scractung level

$\$ \bigvee=$ soll unit

EU Z2-33 K-1004-J LAB SOUTH CLASS 1 SU SVOC DETECTS (4g/kg) th-10 ft

\begin{tabular}{|c|c|c|c|c|c|c|c|c|}
\hline \multirow[b]{2}{*}{ Anelyte } & \multirow[b]{2}{*}{$\begin{array}{c}\text { Detect } \\
\text { frequency }\end{array}$} & \multirow{2}{*}{$\begin{array}{c}\text { MFiminum } \\
\text { deteck }\end{array}$} & \multirow{2}{*}{$\begin{array}{c}\text { Maxirann } \\
\text { deteet }\end{array}$} & \multirow[b]{2}{*}{$\begin{array}{l}\text { Lasation(s) of } \\
\text { marimum detect }\end{array}$} & \multirow{2}{*}{$\begin{array}{l}\text { Aytragt } \\
\text { fettetted } \\
\text { resnlt }\end{array}$} & \multicolumn{3}{|c|}{$\begin{array}{l}\text { Number of atsalyses } \\
\text { exceceding triteris }\end{array}$} \\
\hline & & & & & & $\begin{array}{l}\text { Ind } \\
\text { PRG }\end{array}$ & $\begin{array}{l}\text { GW } \\
\text { gi }\end{array}$ & $\begin{array}{l}\text { REt } \\
\text { PRG }\end{array}$ \\
\hline B15(2-ethylinexyl)phthalate & is & 2005 & 200J & $\overline{\mathrm{Z}} \overline{2}-\mathrm{E} U 33-2027$ & 200 & 0 & 0 & 0 \\
\hline 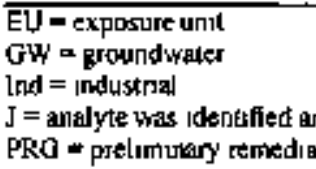 & $\begin{array}{l}\text { I result is a| } \\
\text { on god }\end{array}$ & proxumate & concentrat & \multicolumn{2}{|c|}{$\begin{array}{l}\text { Res = residential } \\
\text { RL = remediation level } \\
\text { SL = screcnug Jevel } \\
\text { SU = soil unit } \\
\text { SVOC = semivolgtale arg }\end{array}$} & & & \\
\hline
\end{tabular}


K-1015 Class 1 SU: Although this Cless I SU was not defined during DQO scoping, it was addressed under DVS as a Class 1 SU because of maximum RL exceedances in historical samples from the area. This Class 1 SU is located in the K-1015 Laundry Pit FFA site (Sect. 2.2.6) and had three bistorical sample locations (Sect. 2.2.1) with radionuclide maximum RLs exceeded at two of the locations (Sect 2.1.1). A BAR survey was conducted to determine the area of AL exceedances (Sect. 2.1.1.1) and DVS confirmation sample locations were selected at the historical locations with Max RL exceedances. A third DVS confinmation sample location was selected at historical saniple location 22-EU33B-2019 (Sect, 2.2.1) and fow DVS boundary confirmation sample locations were selected in the Class 3 SU surrounding this Class 1 SU. The boundary confirmation sample locations were not step-out locattons. Al] sample locations it this SU are presented in Stet. 2.2.I.

A remedial action was conducted at this SU, and several of the historical and DVS sample locations have been removed (see Table 3). Sample locations that defined current conditions in the SU included four historical locations (see Table 3 and Sect. 2.2.1), four DVS sample locations (Z2-EU33B-306 through Z2-EU33B-309) that defined the areal extert of the SU as well as the extent of possible soil contamination in the K-1015-A Laundry Pit FFA site (Sect, 2,2,6), and one location (Z2-EU33B-229) sampled at a dept > $10 \mathrm{ft}$ bgs to bound the vertical extent of soil contamination in the K-1015 Class 1 SU and K-1015-A Laundry Pit FFA site (Sect. 2.2.6). Analytical results summarized below showed radıonuclide Ind PRG exceedances, a U-234 GW SL exceedance, metal and radionuclide Bkg exceedances, and $S V O C$ and $V O C$ detections.

EU Z,-33 K-1015 CLASS I SU METALS WTTH BACKCROUND, PRG, GW SL, AND/OR RL EXCEEDANCES ímg/kg) (- $10 \mathrm{ft}$

\begin{tabular}{|c|c|c|c|c|c|c|c|c|c|c|c|}
\hline \multirow[b]{2}{*}{ Anabyte } & \multirow[b]{2}{*}{$\begin{array}{c}\text { Detect } \\
\text { trequency }\end{array}$} & \multirow{2}{*}{$\begin{array}{l}\text { Mirimam } \\
\text { detect }\end{array}$} & \multirow[b]{2}{*}{$\begin{array}{c}\text { Maximum } \\
\text { detect }\end{array}$} & \multirow{2}{*}{$\begin{array}{c}\text { Lecetion(s) of } \\
\text { maximum } \\
\text { detioct }\end{array}$} & \multirow{2}{*}{$\begin{array}{l}\text { Averitge } \\
\text { detectod } \\
\text { result }\end{array}$} & \multicolumn{6}{|c|}{ Number of analyses excoeding crtterig } \\
\hline & & & & & & $\begin{array}{c}\text { Max } \\
\text { Rl }\end{array}$ & $\begin{array}{l}\text { AvB } \\
\text { RE }\end{array}$ & $\begin{array}{c}\text { Ind } \\
\text { PRG }\end{array}$ & Algg & $\begin{array}{l}\text { GW } \\
\text { SL }\end{array}$ & $\begin{array}{r}\text { Res } \\
\text { PRG }\end{array}$ \\
\hline Aluminutr & $8 / 8$ & $7,600 \mathrm{~J}$ & 18,8001 & $27-6 U 13 \mathrm{~B}-309$ & 13,063 & $\mathrm{NA}$ & $\mathrm{NA}$ & 0 & 0 & $\mathrm{NA}$ & 7 \\
\hline Arsenic & $8 / 8$ & 3 IJ & $7 \mathrm{~B}$ & Z2-EU33-2018 & 473 & 0 & 0 & 0 & (1) & 0 & 8 \\
\hline Barıाn & $8 / 8$ & 507 & $170 \mathrm{~J}$ & $\mathrm{Z2}-\mathrm{EU} 33 \mathrm{~B}-279$ & 104 & NA & NA & 0 & 2 & 0 & 0 \\
\hline Beryllım & $8 / 8$ & 033 & 23 & $22-E \cup 93 B-229$ & 103 & 0 & 0 & 0 & ] & NA & 0 \\
\hline Cadmutem & $6 / s$ & 0079 & 39 & Z2-EU33-2018 & 0,772 & $N_{A}$ & $\mathrm{NA}$ & 0 & 1 & $\mathrm{NA}$ & l \\
\hline Calcium & $\mathrm{B} / 8$ & $1,140 \mathrm{~J}$ & 65,200 & 22-EU93B-306 & 16.495 & NA & NA & NA & 6 & $\mathrm{NA}$ & NA \\
\hline Chsorntum & 818 & I2I & 343 & 425 & 207 & $M A$ & NA & 0 & 0 & 0 & 3 \\
\hline Сояगका & $8 / 8$ & 80 & $33 \mathrm{~J}$ & 22-EU33B-229 & 18 & NA & NA & 0 & 2 & NA & 0 \\
\hline [ron & $8 / 8$ & $16,040 \mathrm{~J}$ & $57,000 \mathrm{~J}$ & Z2-EU33B-229 & 32,550 & $\mathrm{NA}$ & NA & 0 & 0 & NA & 8 \\
\hline Lead & $8 f$ & 16.85 & \$1] & Z2-EU33B-309 & 300 & $\mathrm{NA}$ & NA & 0 & 3 & 0 & 0 \\
\hline Mangmese & $8 / 8$ & 320. & 3510 & Z2-EUj3B-309 & 1432 & NA & $\mathrm{NA}$ & 0 & 2 & $\mathrm{NA}$ & 8 \\
\hline Mercuiy & $7 / 7$ & $0053 \mathrm{~J}$ & $12 \mathrm{~J}$ & Z2-EU33B-307 & 0275 & 0 & 0 & 0 & 3 & $\mathrm{NA}$ & 0 \\
\hline Nicke] & $8 / 8$ & 6 & 57 & $22-E \bigcup 33-2018$ & 242 & $\mathrm{NA}$ & NA & 6 & 4 & NA & 0 \\
\hline S.lYer & 518 & 0032 & 12 & 22-EU33-2018 & 0313 & NA & NA & 0 & 1 & $N A$ & 0 \\
\hline Uranjum & $6 / 6$ & 04 & 34 & Z2-EU33-2018 & 140 & $\mathrm{NA}$ & $\mathrm{NA}$ & 0 & $N A$ & $N A$ & 3 \\
\hline Venedtum & $8 / 8$ & 33 & 405 & $22-E U 338-300$ & 260 & $\mathrm{MA}$ & NA & 0 & 0 & NA & 8 \\
\hline \multicolumn{10}{|c|}{ 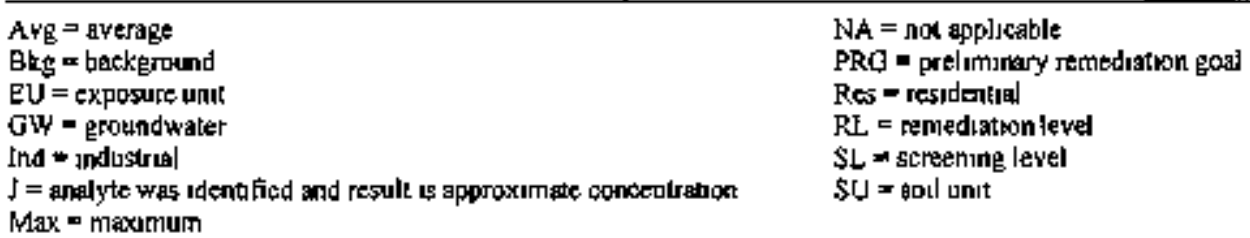 } & & \\
\hline
\end{tabular}

PCBs were analyzed for in six samples but wete not detected.

EU ZZ-13 K-101S CLASS I \$U RADIONUCLIDES WITIT BACKGROUND, PRG, AND/OR RL EXCEEDANCES (pCCLg) 0.10 ft

\begin{tabular}{|c|c|c|c|c|c|c|c|c|c|c|c|}
\hline \multirow[b]{2}{*}{ Analyte } & \multirow[b]{2}{*}{$\begin{array}{c}\text { Detect } \\
\text { Irequeney }\end{array}$} & \multirow[b]{2}{*}{$\begin{array}{c}\text { Miphmum } \\
\text { detext }\end{array}$} & \multirow[b]{2}{*}{$\begin{array}{c}\text { Maximu } \\
\text { detect }\end{array}$} & \multirow[b]{2}{*}{$\begin{array}{l}\text { Location(s) of } \\
\text { maximag detect }\end{array}$} & \multirow{2}{*}{$\begin{array}{l}\text { Averabe } \\
\text { detected } \\
\text { result }\end{array}$} & \multicolumn{6}{|c|}{ Number of andigres excetedieg eriteria } \\
\hline & & & & & & $\underset{\text { RL }}{M a x}$ & $\begin{array}{l}\text { Awg } \\
\text { RL }\end{array}$ & $\begin{array}{l}\text { lnd } \\
\text { PREF }\end{array}$ & Bkg & $\begin{array}{l}\text { GW } \\
\text { SL }\end{array}$ & $\underset{\text { PRG }}{\text { Pog }}$ \\
\hline Ces $14 m \cdot 137$ & $1 \overline{10}$ & 0564 & 0564 & KAH-SS-SI 1 & 0564 & 0 & 0 & 0 & Na & NA & I \\
\hline Neptunıтm-23? & $1 / 7$ & 05896 & 05896 & KAH-\$S-\$II & 0590 & 0 & 0 & 0 & NA & NA & $\mathbf{1}$ \\
\hline Polagsitum-40 & $6 / 6$ & 71 & 278 & Z2-FE33B-229 & 199 & NA & NA & 6 & 0 & $\mathrm{NA}$ & 6 \\
\hline
\end{tabular}


EU Z2-\$3 K-1O1S CLASS I SU RADIONUCMDES WTTH BACKGROUND, PRG, ANDAR RL EXCEEDANCES ( 0 Clíg) 0-10 ft (ant'd)

\begin{tabular}{|c|c|c|c|c|c|c|c|c|c|c|c|}
\hline \multirow[b]{2}{*}{ Analfete } & \multirow[b]{2}{*}{$\begin{array}{l}\text { Detect } \\
\text { frequency }\end{array}$} & \multirow[b]{2}{*}{$\begin{array}{l}\text { Mfipinu o } \\
\text { detect }\end{array}$} & \multirow[b]{2}{*}{$\begin{array}{l}\text { Maximur } \\
\text { detect }\end{array}$} & \multirow[b]{2}{*}{$\begin{array}{l}\text { Location(0) of } \\
\text { maximan detect }\end{array}$} & \multirow{2}{*}{$\begin{array}{l}\text { Averays } \\
\text { defactip } \\
\text { result }\end{array}$} & \multicolumn{6}{|c|}{ Number of andyses exceedidg crletrla } \\
\hline & & & & & & $\begin{array}{c}\text { Max } \\
\text { RL }\end{array}$ & $\begin{array}{l}\text { Avg } \\
\text { RL }\end{array}$ & $\begin{array}{l}\text { Ind } \\
\text { PRG }\end{array}$ & Blcg & $\begin{array}{l}\text { CW } \\
5 \mathrm{~L}\end{array}$ & $\begin{array}{l}\text { Rt: } \\
\text { PRE }\end{array}$ \\
\hline Radium-226 & $5 / 5$ & 0776 & 099 & $22-E U 338-309$ & 0899 & NA & $N A$ & 5 & 0 & NA & 5 \\
\hline Techuletuadis-99 & $1 / 9$ & 03807 & 03807 & KAH-SS-SIJ & 0381 & $N A$ & NA & 0 & $\mathbf{N A}$ & NA & I \\
\hline Thanยm-22\$ & פو & 0723 & 178 & 22-EU33日-229 & 130 & $N_{A}$ & NA & 9 & 0 & NA & 9 \\
\hline Thorium-230 & 919 & 0452 & 6148 & KAH-SS-S1I & 153 & NA & NA & 0 & 3 & $N A$ & $\mathbf{I}$ \\
\hline Thonime-23,2 & 919 & 0,543 & 149 & $22-E U 33 B-229$ & 116 & NA & $N_{A}$ & 9 & 0 & $N_{A}$ & 9 \\
\hline Uranıum-234 & 9 & 0735 & 8379 & KAH-SS-SII & 115 & 0 & 0 & 1) & $N A$ & 1 & I \\
\hline Eranium-235 & $5 \times$ & 0058 & 2956 & $\mathrm{KAH}-\mathrm{SS}-\mathrm{S} 1 \mathrm{I}$ & 0694 & 0 & 0 & 0 & NA & $\theta$ & I \\
\hline 1) & 9 & 0321 & 2047 & $\mathrm{KAH}-\$ \$ \$ \$ 11$ & 316 & 0 & 0 & I & 2 & $\theta$ & 7 \\
\hline
\end{tabular}

Avg = average $\quad N A=$ nol applicale

Ekg $=$ background $\quad$ PRO $=$ prelimitary temedialion gool

EU = ExposuTe unit Re5 = residential

GW = groundwater $\quad \mathrm{RL}=$ remedianion level

lnd = Industrial $\quad \mathrm{SL}=$ soreening $|c y c|$

Max $=\max i m u m \quad S U=$ soil uhit

EU Z2-33 K-1015 CLASS 1 SU SVOC DETECTS (U2-1kg) 0-10 of

\begin{tabular}{|c|c|c|c|c|c|c|c|c|}
\hline \multirow[b]{2}{*}{ Anolytr } & \multirow[b]{2}{*}{$\begin{array}{c}\text { betece } \\
\text { frequecticy }\end{array}$} & \multirow[b]{2}{*}{$\begin{array}{c}\text { Mininumon } \\
\text { detest }\end{array}$} & \multirow[b]{2}{*}{$\begin{array}{l}\text { Maximum } \\
\text { detect }\end{array}$} & \multirow[b]{2}{*}{$\begin{array}{l}\text { Locetion(s) of } \\
\text { meximera dotect }\end{array}$} & \multirow{2}{*}{$\begin{array}{l}\text { Avernge } \\
\text { detected } \\
\text { result }\end{array}$} & \multicolumn{3}{|c|}{ Number of unsiystes } \\
\hline & & & & & & $\begin{array}{c}\text { Ind } \\
\text { PRE }\end{array}$ & $\begin{array}{l}\text { GH } \\
\text { SL }\end{array}$ & $\begin{array}{c}\text { Res } \\
\text { PRG }\end{array}$ \\
\hline Acerraphithene & $1 / 3$ & TRJ & 78 & 22-EU33B-307 & 78 & 0 & $\mathrm{NA}$ & 0 \\
\hline Anthracene & 13 & נסונ & I10J & 22-EU33B-307 & $1 \mathrm{tt}$ & 0 & NA & 0 \\
\hline Benc(a)finthracetse & $\mathrm{L} / 3$ & 2403 & $240 J$ & 22.EU33B-307 & 240 & 0 & $H A$ & 0 \\
\hline Benzo(a)py]tne & $1 \sqrt{3}$ & $180 \mathrm{~J}$ & $180 J$ & $22 \cdot E U 33 \mathrm{~B}-347$ & 180 & 0 & $N A$ & $⺊$ \\
\hline Eenzo(b)fluoranthene & $1 / 3$ & $210\}$ & 2101 & Z2-E】33B-307 & 210 & 0 & $\mathrm{NA}$ & 0 \\
\hline Benzo(ghi)perylene & $1 / 3$ & 130נ & $130 J$ & Z2.EU33B-3Q? & 130 & 0 & $N A$ & 0 \\
\hline Bentzo(k)luarandhente & $1 \sqrt{3}$ & 1901 & 1901 & $22 \cdot E U 33 B-307$ & 190 & 0 & $N A_{2}$ & 0 \\
\hline Bis\{z-ethy[hexyl\}phthal site & $1 / 3$ & $1 \$ 00$ & 1800 & 22-EU33-2018 & 1,800 & 0 & 0 & 0 \\
\hline Buty] benzyl phithalate & $1 / 3$ & $69 \mathrm{~J}$ & $69 \mathrm{~J}$ & $22-5 U 33-2018$ & 69 & 0 & $N A$ & 0 \\
\hline Cenbazole & $1 \sqrt{3}$ & 785 & $78 \mathrm{~J}$ & 22-EU33B-307 & 78 & 0 & NA & 0 \\
\hline Chrysens & 13 & 280 & $2 \% 01$ & Z2-FU33В-307 & 280 & 0 & NA & 0 \\
\hline Dl-1-octylpholate & $1 \sqrt{3}$ & 1201 & 1201 & 22.EU33-2018 & 120 & 0 & NA & 0 \\
\hline Fuprasthęா & $1 / 3$ & 590 & $\$ 40$ & 22-EЏ33日-307 & 590 & 0 & $N A$ & 0 \\
\hline Fluorethe & $1 \sqrt{3}$ & 63J & 63. & $22 \cdot E U 33 B \cdot 30 ?$ & 69 & 0 & NA & 0 \\
\hline Jndenta (1,2,3-cd)pyrene & $1 / 3$ & $120 \mathrm{~J}$ & ${ }^{-} 120 \mathrm{~J}$ & 22-EU33B-307 & 120 & 0 & $N A$ & 0 \\
\hline Phereanthrene & {$[\Omega$} & 520 & 520 & 72-EU33B-30? & 520 & 0 & NA & 0 \\
\hline Pyrene & $1 / 3$ & 470 & 470 & $22 \cdot E U 33 B-307$ & 470 & 0 & $N A$ & 0 \\
\hline
\end{tabular}

$E Џ=$ expasure unul

GW = groumdwaler

Ind = ind astrial

] = analyte was idenglied and result is approxumate concentration

PRG = predumintery remicdıation god

Res = res1dential

$\mathrm{SL}=$ screening lewel

NA = not applicable

SU - soil unst

\$WOC = semivolahle arganc tompound

EU 22-33 K-1015 CLASS I SU VOC DETECTS (ug/kg) 0-10 ft

\begin{tabular}{|c|c|c|c|c|c|c|c|c|}
\hline \multirow[b]{2}{*}{ Analyte } & \multirow[b]{2}{*}{$\begin{array}{l}\text { Deteet } \\
\text { Greepuency }\end{array}$} & \multirow[b]{2}{*}{$\begin{array}{c}\text { Minhruum } \\
\text { deItett }\end{array}$} & \multirow[b]{2}{*}{$\begin{array}{l}\text { Marinum } \\
\text { defect }\end{array}$} & \multirow[b]{2}{*}{$\begin{array}{l}\text { Locstion(s) of } \\
\text { axrimun detect }\end{array}$} & \multirow{2}{*}{$\begin{array}{l}\text { Avcrage } \\
\text { detected } \\
\text { rtsult }\end{array}$} & \multicolumn{3}{|c|}{$\begin{array}{l}\text { Nowher of anslyses } \\
\text { excecting eriteris }\end{array}$} \\
\hline & & & & & & $\begin{array}{l}\text { Ind } \\
\text { PRG }\end{array}$ & SW & $\begin{array}{l}\text { Res } \\
\text { PRG }\end{array}$ \\
\hline $\begin{array}{l}\text { 1,1,2-Tnchloto-1,2,2- } \\
\text { urfluortethant }\end{array}$ & $1 / 4$ & 21 & 21 & 424 & $2 !$ & 0 & NA & 0 \\
\hline Toluene & $2 / 4$ & 9 & 22 & 425 & 155 & 0 & 0 & o \\
\hline $\begin{array}{l}\text { EU = exposure unit } \\
\text { GW = erroundwaler } \\
\text { Ind = industrtal } \\
\text { NA = nol spplicable } \\
\text { PRG = prel rminary Jer }\end{array}$ & allon goal & \multicolumn{3}{|c|}{$\begin{array}{l}\text { Res = residential } \\
\text { SL = screening level } \\
\text { SU = soll tuic } \\
\text { VOC = yolatile orgene compound }\end{array}$} & & & & \\
\hline
\end{tabular}


K-1004 Area Drain Lime Class 2 SU: Seventeen DVS systematic grid sample locations were identified in this SU (see Sect. $2.2,2$ ) to address the impacts of the K-1004 Area Drain Line and other utitities to the EU soils. Also, there were two historical sample locations in this SU (Sech 2.2.2). Analytical results surnmarized below from DVS and historical sampling in this SU did show Ind PRG exceedances for one metal, several radionuclides, and one SVOC; thetal and radionuclide Bkg exceedances; and PCB, SVOC, and VOC detections.

LU Z2-33 K-J004 AREA DRAIN LUVE CLASS 2 SU METALS WITH BACKGROUND, PRG, GW SL, AND/OR RL EXCEEDANCES (me/2R) 0-10 it

\begin{tabular}{|c|c|c|c|c|c|c|c|c|c|c|c|}
\hline \multirow[b]{2}{*}{ Analyite } & \multirow[b]{2}{*}{$\begin{array}{c}\text { Dettect } \\
\text { frequency }\end{array}$} & \multirow[b]{2}{*}{$\underset{\substack{\text { Miminam } \\
\text { detect }}}{ }$} & \multirow[b]{2}{*}{$\begin{array}{l}\text { Maximium } \\
\text { detect }\end{array}$} & \multirow{2}{*}{$\begin{array}{l}\text { Loction (g) of } \\
\text { maximuin } \\
\text { detect }\end{array}$} & \multirow{2}{*}{$\begin{array}{l}\text { Averaje } \\
\text { detected } \\
\text { resalt }\end{array}$} & \multicolumn{6}{|c|}{ Number of anslyga crcesoileng criteria } \\
\hline & & & & & & $\begin{array}{c}\text { Wax } \\
\text { Rl }\end{array}$ & $\begin{array}{l}\text { AvE } \\
\text { RL }\end{array}$ & $\begin{array}{l}\text { Ind } \\
\text { PRG }\end{array}$ & 旦殁 & $\begin{array}{l}\text { GW } \\
\text { SLL }\end{array}$ & $\begin{array}{c}\text { Res } \\
\text { PREG }\end{array}$ \\
\hline Aluminum & $17 / 17$ & $7,940 \mathrm{~J}$ & $15,900 \mathrm{~J}$ & 22-EU33-216 & 10.724 & NA & NA & 0 & 0 & NA & 17 \\
\hline Atsenic & $\lg / 7$ & [3] & {$[76$} & Z2-EU33-203 & 539 & 0 & 0 & I & $l$ & 0 & 17 \\
\hline Banutn & 1717 & 358 & 222 & $22-E[33-216$ & 942 & $\mathrm{NA}$ & NA & 0 & 2 & 0 & 0 \\
\hline Cadmtum & $17 / 17$ & $0028 \mathrm{~J}$ & $1 \mathfrak{3}$ & Z2-EU33M-207 & 0256 & NA & NA & 0 & 6 & NA & 0 \\
\hline Calcuam & $\mid 7 / I\}$ & $767\rfloor$ & 161,000 & Z2-EU33M-214 & 25,660 & $N_{A}$ & NA & $\mathrm{NA}$ & 14 & NA & NA \\
\hline Chromium & $13 / 17$ & $98 J$ & $27 〕$ & z2-EU33-203 & 180 & $\mathrm{NA}$ & NA & 0 & 0 & 0 & 3 \\
\hline Cobalt & $17 / 7$ & $47 J$ & 283] & Z2-EU33M-2I227 & 27 & $\mathrm{NA}$ & NA & 0 & $\mathrm{l}$ & NA & ] \\
\hline Copper & $1] /] 7$ & $3 \mathrm{gJ}$ & 4281 & 22 -EU33-205 & 146 & $\mathrm{NA}$ & NA & 0 & 2 & NA & 0 \\
\hline [ron & 1317 & 13,200 & 46,300 & Z2-EU35-203 & 22,994 & NA & $\mathrm{NA}$ & 0 & 0 & NA & 17 \\
\hline Lead & $17 / 17$ & $143 \mathrm{~J}$ & $274 \mathrm{~J}$ & Z2-EU33M-21350 & 601 & $\mathrm{~N} \wedge$ & $\mathrm{NA}$ & 0 & 5 & 0 & 0 \\
\hline Megnnessum & $\mid] / 1\}$ & 43 이 & $2,210,0 J$ & Z2-EU33M-203 & 6,096 & NA & $N_{A}$ & $\mathrm{NA}$ & 7 & NA & $\mathbf{N A}$ \\
\hline Mangamlese & $1 \pi 17$ & $=115 \mathrm{~J}$ & 2,1601 & Z2-EU33-216 & 969 & $\mathrm{NA}$ & NA & 0 & 0 & NA & 16 \\
\hline Mercury & $12 / 17$ & bol3J & $044 \mathrm{~J}$ & Z2-EU33M-213 & 0204 & 0 & 0 & 0 & 7 & $N A$ & 0 \\
\hline Nuckel & []$\left.^{\prime}\right] 7$ & 49 & $453 \mathrm{~J}$ & 22-EU33-205 & 166 & NA & NA & 0 & 2 & NA & 0 \\
\hline Selenung & $7 / 17$ & $015 \mathrm{~J}$ & 15.5 & Z2-EU33-203 & 0443 & NA & NA & 0 & 1 & NA & 0 \\
\hline Sılver & $16 / 17$ & $0083 \mathrm{~J}$ & $19 \mathrm{~J}$ & Z2-EU33M-2I4 & 03 L0 & $\mathrm{MA}$ & $\mathrm{NA}$ & 0 & 2 & NA & 0 \\
\hline Uтвпmurn & $17 / 7$ & $0.64 . J$ & 381 & 22-EU33M-20073 & 72 & NA & NA & 0 & NA & $N_{A}$ & 8 \\
\hline Vanadnm & $17 f 17$ & 147 & 42 d] & Z2-EU633-2013 & 227 & NA & NA & ڤ & 9 & $N A$ & 13 \\
\hline Zinc & \{\}$/ 1\}$ & נו & $377 \mathrm{~J}$ & 22-EU3J-205 & 594 & NA & NA & 0 & 2 & NA & 0 \\
\hline
\end{tabular}

$A Y g=$ average

$\mathrm{Bkg}=$ bakckground

EU $=$ exposure unst

OTH = Evondwater

[rtd = industra!

NA $=$ not apdicable

$\mathrm{PRC}=$ prelımınary semedirtion goal

Res $=$ residentıl $]$

RL a remediation level

SL - strtening level

$M a x=$ maxumum

$\mathbf{S U}=\mathbf{S O}$; ।

EU 2:-33 K-L094 AREA GRAIN LINE CLASS 2 8U PPCH DETECTS (ug/kg) 0-10 fl

\begin{tabular}{|c|c|c|c|c|c|c|c|c|c|}
\hline \multirow[b]{2}{*}{ Andlyte } & \multirow[b]{2}{*}{$\begin{array}{c}\text { Deftet } \\
\text { frequency }\end{array}$} & \multirow[b]{2}{*}{$\begin{array}{l}\text { Mindmum } \\
\text { detect }\end{array}$} & \multirow[b]{2}{*}{$\begin{array}{l}\text { Mayinatun } \\
\text { idetect }\end{array}$} & \multirow{2}{*}{$\begin{array}{c}\text { Locktion(s) of } \\
\text { mevlmum } \\
\text { detert }\end{array}$} & \multirow{2}{*}{$\begin{array}{l}\text { Average } \\
\text { detected } \\
\text { result }\end{array}$} & \multicolumn{4}{|c|}{$\begin{array}{l}\text { Number of nnalyses } \\
\text { excetufine criteris }\end{array}$} \\
\hline & & & & & & $\underset{\text { ML }}{\operatorname{Max}}$ & $\begin{array}{l}\text { AFg } \\
\text { FI }\end{array}$ & $\begin{array}{l}\text { Ind } \\
\text { PEG }\end{array}$ & $\begin{array}{l}\text { Res } \\
\text { PRG }\end{array}$ \\
\hline$\overline{\mathrm{PCE}}-1254$ & $3 \sqrt{17}$ & $60^{\circ}$ & 1201 & Z2-EU33M-207 & 853 & 0 & 0 & 0 & 1 \\
\hline PCB. 1260 & 217 & S4J & 60 & Z2-EU33-205 & 57 & 0 & 0 & to & 0 \\
\hline Polychlorinated Bipheny] & $3 / 1]$ & 76 & $170 \mathrm{~J}$ & Z2-EU33M-207 & 122 & 0 & 0 & 6 & 2 \\
\hline 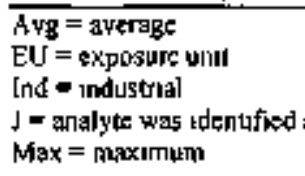 & & & & \multicolumn{6}{|c|}{ 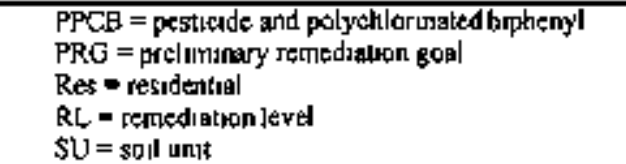 } \\
\hline
\end{tabular}


EU Z2-33 K-1004 AREA DRAIN LINE CLASS 2 5U RADHONLCLTOES WITH BACKCROUND, PRG, ANDHOR RL EXCEEDANCES (pCig) b-L0 It

\begin{tabular}{|c|c|c|c|c|c|c|c|c|c|c|c|}
\hline \multirow[b]{2}{*}{ Anglyte } & \multirow[b]{2}{*}{$\begin{array}{c}\text { Dotect } \\
\text { frequency }\end{array}$} & \multirow[b]{2}{*}{$\begin{array}{l}\text { Midinam } \\
\text { dettect }\end{array}$} & \multirow[b]{2}{*}{$\begin{array}{c}\text { Marim Ko } \\
\text { delect }\end{array}$} & \multirow[b]{2}{*}{$\begin{array}{l}\text { Locndlon(b) of } \\
\text { mrafmum detec| }\end{array}$} & \multirow{2}{*}{$\begin{array}{c}\text { Average } \\
\text { detected } \\
\text { result }\end{array}$} & \multicolumn{6}{|c|}{ Nember of enalyses exceeding eriterla } \\
\hline & & & & & & $\begin{array}{c}\text { Max } \\
\text { RL }\end{array}$ & $\begin{array}{l}\text { ATr } \\
\text { RL }\end{array}$ & $\begin{array}{l}\text { Ind } \\
\text { PRG }\end{array}$ & BEI & $\begin{array}{l}\text { GW } \\
\text { SL }\end{array}$ & $\begin{array}{l}\text { Res } \\
\text { PRG }\end{array}$ \\
\hline Сeงเนก-137 & $3 / 8$ & $02715 \mathrm{~J}$ & 06505 & KAH.SSSGI & 0451 & 0 & 0 & 0 & NA & $\overline{N A}$ & 3 \\
\hline Potassgutm-40 & $6 / 6$ & 16 & 255 & $22-E U 33-2] 1$ & 212 & NA & $N_{A}$ & 6 & 0 & NA & 6 \\
\hline Radium-226 & 616 & $071 \mathrm{~J}$ & 118 & Z2-EU33-202 & 0.987 & NA & NA & 6 & 0 & NA & 6 \\
\hline Technediurt-99 & 28 & 058 & 128 & Z2-EU33M-207 & 093 & NA & $N_{A}$ & 0 & NA & NA & 2 \\
\hline Thenum-228 & 88 & $0 B I J$ & 184 & 22-EU33M-212 & 132 & $\mathrm{NA}$ & $\mathrm{NA}$ & 8 & 0 & $\mathbf{R}$ & $B$ \\
\hline Thoriutr-230 & 848 & $068 \mathrm{~J}$ & 15 & Z2-E\33M-20r & ! It & $\mathrm{NA}$ & NA & 0 & 3 & NA & 0 \\
\hline Thorium-232 & $8 / 8$ & 0855 & 162 & 22-EU33-21! & 123 & NA & $\mathrm{NA}$ & 8 & 0 & NA & 8 \\
\hline Uraniem-234 & 88 & 117 & 424 & Z2-EU33.217 & 108 & 0 & 0 & 0 & NA & 0 & 2 \\
\hline Uranitum-235 & $1 / 8$ & 004 & 243 & 22-EL53-213 & 0741 & 0 & $\theta$ & 0 & NA & 0 & 3 \\
\hline Lranıum-238 & 89 & 115 & 414 & $22-E U 33-217$ & 955 & 0 & 0 & 2 & 6 & 0 & $\$$ \\
\hline
\end{tabular}

Avg = average

$\mathrm{Bkg}=$ background

$\mathrm{EU}$ a exposure unt

$G W=$ groundwater

NA = not spplicatgie

$\operatorname{PR} \theta=$ pteliminary remediauon goal

Ind $=$ וndus|r|al

I = analye was identufied and result is approximale concentratuon

Res I residentual

RL = Temediation leved

SL = screening IEvẹl

$M a x=$ maxımum

SU $=$ sosl unit

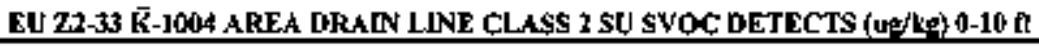

\begin{tabular}{|c|c|c|c|c|c|c|c|c|}
\hline \multirow[b]{2}{*}{ Analyte } & \multirow[b]{2}{*}{$\begin{array}{l}\text { Detwet } \\
\text { Irequency }\end{array}$} & \multirow[b]{2}{*}{$\begin{array}{l}\text { Minimson } \\
\text { detect }\end{array}$} & \multirow[b]{2}{*}{$\begin{array}{l}\text { Mnximum } \\
\text { detect }\end{array}$} & \multirow[b]{2}{*}{$\begin{array}{l}\text { Location(s) of } \\
\text { meximuin detect }\end{array}$} & \multirow{2}{*}{$\begin{array}{l}\text { A peratge } \\
\text { defected } \\
\text { repult }\end{array}$} & \multicolumn{3}{|c|}{ 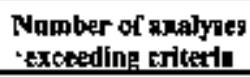 } \\
\hline & & & & & & $\begin{array}{l}\text { Ind } \\
\text { PRG }\end{array}$ & $\begin{array}{l}\text { GW } \\
\text { SL }\end{array}$ & $\begin{array}{l}\text { Res } \\
\text { PRG }\end{array}$ \\
\hline 2-Methylnaphthalene & $2 / 37$ & $46 \mathrm{~J}$ & 850 & Z2-EU33M-12I2 & 448 & 0 & $\overline{N A}$ & NA \\
\hline Acenaptithene & $4 / 17$ & $5 \mathrm{~J}$ & 1000 & 22-EU33M-2!2 & 311 & 0 & $\mathrm{NA}$ & 0 \\
\hline Acenaphthylens: & 2177 & $260 \mathrm{~J}$ & 670 & Z2-EU33-209 & 465 & 0 & NA & 0 \\
\hline Anthrakene & $5 / 17$ & $46 \mathrm{~J}$ & $2,800 \mathrm{~J}$ & Z2.EU33M-212 & 810 & 0 & NA & 0 \\
\hline Benz(a) вnthr вcene & jort? & 461 & $\exists, 900]$ & 22-EU33M-2:2 & 796 & 0 & NA & 2 \\
\hline Benzo(a)pyrene & ]l/7 & 45J & $2,900 \mathrm{~J}$ & Z2.EU33M-232 & 552 & 1 & NA & 6 \\
\hline Benzo(b) Invoranthene & Jois & $4 \$$ & 4,900 & $27-\mathrm{E} \cup 33-203$ & 898 & 0 & NA & 2 \\
\hline Велzв(ghi)pery|ene & $8 / 17$ & $d 21$ & 2,100 & Z2-EU33-203 & 502 & 0 & NA & 0 \\
\hline Benzo\{k\}fluorandhene & $8 / 77$ & 571 & 2,400 & Z2.EU3334-212 & 458 & 0 & NA & 0 \\
\hline$B_{15}(2-e$ thylhexyl)phthel ate & $4 / 17$ & $69 \mathrm{~J}$ & 1 เป็ & 22-EU13-202 & St & 0 & 0 & 0 \\
\hline Butyl bendy| phthalate & $1 / 7$ & $49 J$ & $.49 \mathrm{~J}$ & Z2-EU33M-208 & 49 & 0 & NA & 0 \\
\hline Carbazole & $4 / 17$ & 54J & 1600 & Z2.EU333M-232 & 494 & 0 & NA & 0 \\
\hline Chrysene & 1217 & $44 J$ & $3,500 \mathrm{~J}$ & Z2-EU33M-212 & 626 & 0 & NA & 0 \\
\hline Dibenz(ah)anthtacene & $3 / 17$ & $94 J$ & $540 \mathrm{~J}$ & 22-EU33-203 & 255 & 0 & NA & 3 \\
\hline Dibenzafuras & $3 / 17$ & 555 & 1300 & 22-EU3JM-212 & 508 & 0 & NA & 0 \\
\hline Fluoranthene & ]U/T & 73J & $10,0,0 \times 0 \mathrm{~J}$ & Z2.EU33M-2]2 & 1,840 & 0 & $N A$ & 0 \\
\hline Fluorene & $5 / 17$ & $\$ 2 J$ & 2,300 너 & $22-E_{3} 3 \mathrm{M}-212$ & 602 & 0 & NA & 0 \\
\hline Indeпo $(1,2,3-c$-cd)pyrent & $7 / 17$ & $49 J$ & 1,900 & $Z 2-E U 33-203$ & 549 & 0 & NA & 7 \\
\hline Naphthalene & $2 / 17$ & $57]$ & $1,400 \mathrm{~J}$ & Z2-EU33M-212 & 729 & $\theta$ & NA & 0 \\
\hline Phentulhrene & 8117 & 611 & $12,000 \mathrm{~J}$ & $22-E U 3 ; 1 M-2] 2$ & 2162 & 0 & NA & 0 \\
\hline Pyrene & $11 / 17$ & $50 \mathrm{~J}$ & $8,600 \mathrm{~J}$ & Z2-EU33M-212 & 1,447 & 0 & $N A$ & 0 \\
\hline $\begin{array}{l}\text { EU = exposure unit } \\
\text { GW = eroudnd trater } \\
\text { [nd m Jndustrial } \\
J=\text { analyte was Ident fied an } \\
N A=\text { not applicsble }\end{array}$ & result & mats & Icentrat & $\begin{array}{l}\text { PRG - prelımim } \\
\text { Res = rtisident } \\
\text { SL = screcning } \\
\text { SU = soil unit } \\
\text { SVOC - stmit }\end{array}$ & $\begin{array}{l}\text { ary remed } \\
\text { al } \\
\text { Ievel } \\
\text { olatule orge }\end{array}$ & Le com & & \\
\hline
\end{tabular}




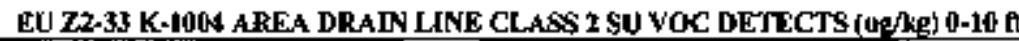

\begin{tabular}{|c|c|c|c|c|c|c|c|c|}
\hline \multirow[b]{2}{*}{ Anstyte } & \multirow[b]{2}{*}{$\begin{array}{c}\text { Detest } \\
\text { Ireguenty }\end{array}$} & \multirow[b]{2}{*}{$\begin{array}{l}\text { Mialnum } \\
\text { detect }\end{array}$} & \multirow[b]{2}{*}{$\begin{array}{c}\text { Maximnm } \\
\text { detect }\end{array}$} & \multirow{2}{*}{$\begin{array}{c}\text { Eoction(s) of } \\
\text { inazinum detect }\end{array}$} & \multirow{2}{*}{$\begin{array}{l}\text { Aperige } \\
\text { detected } \\
\text { resili }\end{array}$} & \multicolumn{3}{|c|}{$\begin{array}{l}\text { Nmober of dunflysed } \\
\text { exceeding criterla }\end{array}$} \\
\hline & & & & & & $\begin{array}{l}\text { Fod } \\
\text { PRG }\end{array}$ & $\begin{array}{l}\text { GHY } \\
\text { 8L }\end{array}$ & $\begin{array}{l}\text { Res } \\
\text { PRG }\end{array}$ \\
\hline 2-Butantust & $1 / 4$ & $16 j^{\circ}$ & I6J & 22-E\33-2I\} & 16 & 0 & $N A$ & 0 \\
\hline Acetone & $2 / 4$ & 37 & $43 J$ & $\mathrm{Z2}-\mathrm{EU} 33 \cdot 217$ & 40 & 0 & $\mathrm{NA}$ & 0 \\
\hline Benzent & $1 / 4$ & $22 \mathrm{~J}$ & $22 J$ & 22-E【39-217 & 22 & 0 & 0 & 0 \\
\hline cIs-1,2-Dichloroethens & $2 / 4$ & $12 \mathrm{~J}$ & $39 \mathrm{~J}$ & Z2-EU33-21] & 255 & 0 & $N A$ & 0 \\
\hline Tolkrene & $1 / 4$ & $16]$ & $16 \mathrm{~J}$ & 22-EЏ33-217 & 16 & 0 & 0 & 0 \\
\hline Trichlorocthene & $3 / 4$ & $19 \mathrm{~J}$ & $19 \mathrm{~J}$ & Z2-EU33-217 & 19 & 0 & $\theta$ & 0 \\
\hline Wony] shorids & $2 / 4$ & 82 & $37 J$ & 22-EU33-217 & 226 & 0 & th & 0 \\
\hline $\begin{array}{l}\text { EU = exposure unit } \\
\text { GW = groundwater } \\
\text { Ind = Industrial } \\
J=\text { analyte was jdentfie } \\
\text { NA = uot applicable }\end{array}$ & Ind resute is a & proxumate & Centration & \multicolumn{3}{|c|}{ 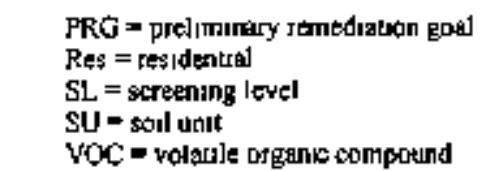 } & & \\
\hline
\end{tabular}

KAH-SS-B22 Class 2 SU: This Class 2 SU was defined to delineate the extent of a Cs-137 Avg RL exceedance at historical sample location KAH-SS-B22 (Sect. 2.I.2). Also, a BAR survey was conducted but no AL exceedances were observed (Stet. 2.1.2.1). A DVS confirmation sample location was selected at the historical sample location (Sect. 2.2.2) but analytical results did not confirm the Avg RL, exceedance. Analytical results summarized below for the DVS confirmation sample did show radionuclide Ind PRG and Bkg exceedances.

EU 72-33 KAH-\$S-R2Z CLASS 2 SU RADIONUCLJDES WITH BACKGROUND, PRG, AND/OR RL EXCEEDANCES (pCL/e) 0-11) It

\begin{tabular}{|c|c|c|c|c|c|c|c|c|c|c|c|}
\hline \multirow[b]{2}{*}{ Analyyte } & \multirow[b]{2}{*}{$\begin{array}{c}\text { Detiet } \\
\text { Irequency }\end{array}$} & \multirow[b]{2}{*}{$\begin{array}{l}\text { Minimum } \\
\text { detect }\end{array}$} & \multirow[b]{2}{*}{$\begin{array}{l}\text { Maxineuw } \\
\text { detert }\end{array}$} & \multirow[b]{2}{*}{$\begin{array}{l}\text { Location(3) of } \\
\text { maximand delect }\end{array}$} & \multirow{2}{*}{$\begin{array}{l}\text { Average } \\
\text { detected } \\
\text { resclt }\end{array}$} & \multicolumn{6}{|c|}{ Nunber of etalytes excesding criterin } \\
\hline & & & & & & Re & $\begin{array}{l}\text { Aves } \\
\text { RII }\end{array}$ & $\begin{array}{l}\text { Ind } \\
\text { PRG }\end{array}$ & Bkg & $\begin{array}{l}\text { GW } \\
\text { SL }\end{array}$ & $\begin{array}{l}\text { Ret } \\
\text { PRC }\end{array}$ \\
\hline Potag514m-40 & I/] & 231 & 234 & Z2-EU\$3B-22] & 234 & NA & $\mathrm{NA}$ & I & 0 & NA & I \\
\hline R.:01um-226 & $1 / 1$ & 091 & 091 & Z2-EU33B-221 & 091 & NA & NA & $\mathbf{I}$ & 0 & $\mathrm{NA}$ & 1 \\
\hline Tharium-228 & $|f|$ & 132 & 132 & 22-EU33B-221 & 132 & NA & NA & $\mathbf{I}$ & 0 & NA & \rfloor \\
\hline Thorium-230 & I $/$ & 122 & 122 & Z2-EU33B-221 & 122 & $\mathrm{NA}$ & NA & 0 & $\mathbf{I}$ & NA & 0 \\
\hline Thorumam=232 & $\mathbf{I} / \mathbf{I}$ & 132 & 132 & Z2-EU33B-221 & 132 & NA & NA & I & o & $N A$ & i \\
\hline Uranı:4m-238 & UI & 102 & 02 & Z2-EU3эB-22I & 102 & 0 & 0 & 0 & 0 & 0 & ! \\
\hline
\end{tabular}

\begin{tabular}{|c|c|}
\hline $\begin{array}{l}\text { Avg = average } \\
\text { Bke = backgrotand } \\
\text { EU = exposure untt } \\
\text { GW = groundwater } \\
\text { Ithd = industral } \\
\text { Max = meximum }\end{array}$ & 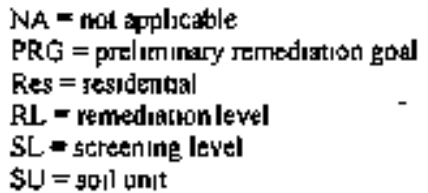 \\
\hline
\end{tabular}

KAH-SS-S31 Class 2 SU: This Class 2 SU was defined to delineate the extent of a C $5-137$ Avg RL exceedance at historical sample location KAH-SS-\$3 I (Sect 2.1.2). Also, a BAR survey was conducted but tho AL exceedances were observed (Sect. 2.1.2.1) A DVS confirmation sample location was selected at the historical sample location (Sect. 2.2.2) but analytical results did not confum the Avg $\mathrm{RL}$ exceedance. Analytical results summarized below for the DVS confirmation sample did show rodionuclide Ind PRG and Bkg exceedances.

EU Z2-33 KAH-55-S3] CLASS I SU RADIONUCLIPES WITH BACKGROUND, PRG, AND/OR RL EXCEETHANCES (pClig) 0-10 ft

\begin{tabular}{|c|c|c|c|c|c|c|c|c|c|c|c|}
\hline \multirow[b]{2}{*}{ Analyte } & \multirow[b]{2}{*}{$\begin{array}{l}\text { Detect } \\
\text { frequency }\end{array}$} & \multirow[b]{2}{*}{$\begin{array}{c}\text { Miniraum } \\
\text { delect }\end{array}$} & \multirow[b]{2}{*}{$\begin{array}{l}\text { Maxim nu } \\
\text { deteet }\end{array}$} & \multirow[b]{2}{*}{$\begin{array}{l}\text { Location(s) of } \\
\text { maximum distect }\end{array}$} & \multirow{2}{*}{$\begin{array}{c}\text { Aversigt } \\
\text { drteited } \\
\text { restlt }\end{array}$} & \multicolumn{6}{|c|}{ Number af intyses excesitine criterio } \\
\hline & & & & & & $\underset{\text { RL }}{\text { Max }}$ & Ave & $\begin{array}{l}\text { IntI } \\
\text { PRG }\end{array}$ & Blog & GW & $\begin{array}{l}\text { Res } \\
\text { PRG }\end{array}$ \\
\hline Potø5 5um-40 & $1 / 1$ & 154 & 154 & Z2-EU33B-222 & 154 & $\mathrm{NA}$ & NA & I & 0 & NA & I \\
\hline Radnum.226 & 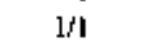 & 084 & 084 & Z2-EU33B-222 & 084 & $\mathrm{NA}$ & NA & $\mathbf{I}$ & 0 & $\mathrm{NA}$ & $\mathbf{I}$ \\
\hline Therium-228 & $1 / 1$ & 13 & 115 & Z2-EU33B-272 & 115 & NA & NA & 1 & 0 & $\mathrm{NA}$ & $\mathbf{I}$ \\
\hline Thor:um-230 & $\mathbf{W} \mathbf{l}$ & 147 & 147 & Z2-EU33B-222 & 147 & NA & NA & 0 & $\mathbf{I}$ & NA. & 0 \\
\hline
\end{tabular}


EU Z2-33 KAH-SS-S3I CLASS 2 SU RADIONUCEIDES WITH BACKGROUND,

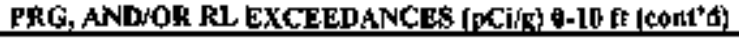

\begin{tabular}{|c|c|c|c|c|c|c|c|c|c|c|c|}
\hline \multirow[b]{2}{*}{ Analyte } & \multirow[b]{2}{*}{$\begin{array}{c}\text { Detred } \\
\text { frétuenty }\end{array}$} & \multirow[b]{2}{*}{$\begin{array}{l}\text { Minimum } \\
\text { detect }\end{array}$} & \multirow[b]{2}{*}{$\begin{array}{c}\text { Maximun } \\
\text { deteet }\end{array}$} & \multirow[b]{2}{*}{$\begin{array}{l}\text { Luction(s) aC } \\
\text { meriouan detett }\end{array}$} & \multirow{2}{*}{$\begin{array}{l}\text { Averuge } \\
\text { detected } \\
\text { rebult }\end{array}$} & \multicolumn{6}{|c|}{ Nomber of andyses exceding crjtetds } \\
\hline & & & & & & $\underset{\text { RI }}{\text { Max }}$ & $\begin{array}{l}\text { Avg } \\
\text { RL. }\end{array}$ & $\begin{array}{l}\text { Ind } \\
\text { PRG }\end{array}$ & Bky & $\begin{array}{l}\text { GW } \\
\text { SL }\end{array}$ & $\begin{array}{c}\text { Res } \\
\text { PRQ }\end{array}$ \\
\hline Thoпum-237 & $|/|$ & I 05 & 105 & 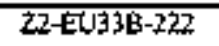 & 105 & $\mathbf{N A}$ & $\widehat{N A}$ & 1 & i & $\mathrm{NA}$ & I \\
\hline Lranium-23B & Itl & $10]$ & 101 & Z2-EU33B-222 & [ 01 & 0 & 0 & 0 & 0 & 0 & 1 \\
\hline $\begin{array}{l}\text { Avg = gverage } \\
\text { Bkg = background } \\
\text { EU = exposure uril } \\
\text { GW = groundwater } \\
\text { End = inkustrial } \\
\text { Max = maxımum }\end{array}$ & $\begin{array}{l}\text { NA } \\
\text { PRG } \\
\text { ReS } \\
\text { RL= } \\
\text { SL } \\
\text { SU. }\end{array}$ & $\begin{array}{l}\text { - not spplic: } \\
\text { n prelıming } \\
=\text { residertal } \\
=\text { remediatuo } \\
\text { screening I } \\
\text { saril unit }\end{array}$ & 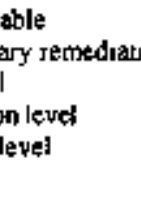 & Ion gpal & & & & & & & \\
\hline
\end{tabular}

Sediment Accumulation Area: Sediment accumulation area DP EU33D-316 was identified during the Class 3 SU walkover assessment However, upon retuming to collect a sample, the area was inaccessible as a result of D\&D activities. In its place, a DVS biased sample was collected from an area with accurnulated sediment from the D\&D truck wash station east of the K-1004-J Lab South Class 1 SU. This sample was analyzed for radionuclides to investigate possible radiological contamination resulting from runoff from the truck wash station. Analytical results summanzed below showed Ind PRG exceedances for radum and therium isotopes and K-40 but no evidence that runoff from the truck wash statton resulted in an accumulation of radjonuclides.

\begin{tabular}{|c|c|c|c|c|c|c|c|c|c|c|c|}
\hline \multicolumn{12}{|c|}{ 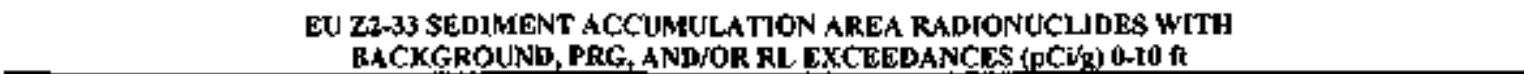 } \\
\hline \multirow[b]{2}{*}{ Angłyte } & \multirow[b]{2}{*}{$\begin{array}{l}\text { Detect } \\
\text { Ireguency }\end{array}$} & \multirow[b]{2}{*}{$\begin{array}{l}\text { Mtiptomum } \\
\text { detect }\end{array}$} & \multirow[b]{2}{*}{$\begin{array}{l}\text { Maximan } \\
\text { detect }\end{array}$} & \multirow{2}{*}{$\begin{array}{c}r_{1} \\
\text { Eocation(s) of } \\
\text { maxilnzun deted }\end{array}$} & \multirow{2}{*}{$\begin{array}{l}\text { Averaget } \\
\text { detecited } \\
\text { result }\end{array}$} & \multicolumn{6}{|c|}{ Namber of analyas exteedlnE criterta } \\
\hline & & & & & & Mxis & $\begin{array}{l}\text { Ave } \\
\text { RU }\end{array}$ & $\begin{array}{l}\text { Ind } \\
\text { PRG }\end{array}$ & Bt女 & SW & $\begin{array}{l}\text { Rea } \\
\text { PRG }\end{array}$ \\
\hline$\overline{C e s t u m=137}$ & $\mathrm{I} / 1$ & 039 & 039 & 22-EU33B-342 & 039 & 0 & 0 & 0 & NA & NA & 1 \\
\hline Porassumb 40 & $1 / 1$ & 143 & 143 & Z2.EU33B-342 & 143 & NA & NA & i & 0 & $\mathrm{NA}$ & I \\
\hline Radinum-226 & $\mu$ & 189 & 089 & $2,2-E \cup 1330-342$ & 089 & MA & NA. & [ & 0 & NA & $\mathbf{I}$ \\
\hline Therium-22s & $1 / \pi$ & 157 & $1 \$ 7$ & 27-EUß3B-3d2 & 157 & NA & NA & ! & 0 & NA & $\mathbf{I}$ \\
\hline Thosumin-232 & {$[/]$} & 117 & 117 & Z2-EU33B-342 & 117 & $\mathrm{NA}$ & NA & 1 & 0 & NA & t \\
\hline Utanıum-734 & $|/|$ & 451 & $4 s l$ & Z2-EU33B-3-AZ & 451 & 0 & 0 & 0 & $\mathrm{NA}$ & 0 & $\mathrm{t}$ \\
\hline Uran!นm-238 & I/1 & 288 & 288 & Z2-EU33B-342 & 288 & 0 & 0 & 0 & I & 0 & i \\
\hline
\end{tabular}

Avg $=$ average NA - not applicable

$\mathrm{BkB}=$ background $\quad$ PRG = prelıminary remediaten goal

$E U=$ exposure tnat $\quad$ Res $=$ residantıo

$\mathrm{GW}=$ groundwater $\quad \mathrm{RL}=$ remediation level

Ind = industrits $\quad S L=$ streteinge level

Mex $=$ maxımum

Dilution Pit Soutbwest of K-1004-D (DP EU33D-318): Biased sampling was recommended in the Assessment Report for this site based on the Class $35 \mathrm{~S}$ walkover assessment visual obseryations. A sediment sample collected from the pit exceeded multiple evaluation criteria for metals, PCBs, radionuclides, and VOCs. Two soil samples collected outside the dilution pit and at the pit's base level were analyzed for metals, PCBs, radionuclides, SVOCs, and VOCs. A. 10 -ft composite sample location was located in the groundwater downgradient direction from the dilution pit and analyzed for metais, PCBs, radionuclide, SVOCs, and VOCs. Analytical results from these samples located outside the dilution pit showed contaminants had not leaked from the pit. The dilution pit was removed during a remedial action that also removed the sediment sample location (Table 3). Soil sample locations

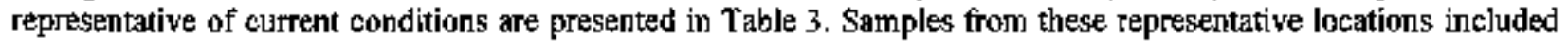
the two from the base level of the dilution pit (Z2-EU33B-113 and Z2-EU33B-1 14), one that was collected from a depth $>10 \mathrm{ft}$ bgs (Table 3 ), and the sample location in the groundwater downgradient direction from the dilution pit (Z2-EU33B-311). Analytical results summarized below for locations representative of curtent conditions showed radionuclide Ind PRG exceedances, metal and radionuclide Bkg exceedances, and SVOC and VOC detections. 
EU $22-333$ DILUTION PIT SOUTHWEST OF K-1004-D METALS WJFH BACKGROUND, PRG, GW SL, ANDOOR RL EXCEEDANCES (mg/kg) -10 ft

\begin{tabular}{|c|c|c|c|c|c|c|c|c|c|c|c|}
\hline \multirow[b]{2}{*}{ Analyte } & \multirow[b]{2}{*}{$\begin{array}{c}\text { Detect } \\
\text { frequency }\end{array}$} & \multirow[b]{2}{*}{$\begin{array}{c}\text { Melninum } \\
\text { detoct }\end{array}$} & \multirow[b]{2}{*}{$\begin{array}{c}\text { Maximain } \\
\text { acteat }\end{array}$} & \multirow{2}{*}{$\begin{array}{c}\text { Locsibon(s) of } \\
\text { maximum } \\
\text { detesf }\end{array}$} & \multirow{2}{*}{$\begin{array}{c}\text { Average } \\
\text { detected } \\
\text { rault }\end{array}$} & \multicolumn{6}{|c|}{ Number of and pats exreeding criterit. } \\
\hline & & & & & & $\begin{array}{l}\text { Max } \\
R L\end{array}$ & $\begin{array}{l}\text { AvE } \\
\text { RL }\end{array}$ & $\begin{array}{c}\text { lnd } \\
\text { PRG }\end{array}$ & Bleg & $\begin{array}{l}\text { GW' } \\
\text { SL }\end{array}$ & $\begin{array}{l}\text { Res } \\
\text { PRG }\end{array}$ \\
\hline A.luminum & $3 \beta$ & 6,100 & 16,000 & $22-5033 B-114$ & 9,670 & NA & NA & $\overline{0}$ & 0 & NA & 1 \\
\hline Arsensc & $3 / 3$ & 12 & 41 & Z2-EU33B-114 & 257 & 0 & 0 & $\theta$ & 0 & 0 & 3 \\
\hline Ceadmum & $3 / 3$ & 0054 & 026 & 22-E133B-114 & 0161 & NA & NA & 0 & $\mathbf{I}$ & NA & 0 \\
\hline Cی|ç⿰m & $3 / 3$ & $2290 \mathrm{~J}$ & 5,300 & Z2-EU33B-113 & 3497 & NA & $\mathrm{NA}$ & $N_{A}$ & 2 & NA & $\mathrm{NA}$ \\
\hline Copper & $3 / 3$ & 8. & $34 \mathrm{~J}$ & Z2-EU33B-113 & 223 & NA & NA & 0 & 2 & NA & 0 \\
\hline tran & $3 / 3$ & $12,9000 \mathrm{~J}$ & $50,000 \mathrm{~J}$ & $27-E U 33 B-11 A$ & 25,300 & $N_{A}$ & NA & 0 & 0 & $\mathrm{NA}$ & 3 \\
\hline Manganese & $3 \sqrt{3}$ & 1203 & $1,400 \mathrm{~J}$ & 22-EU33B-114 & 634 & NA & NA & 0 & 0 & NA & 2 \\
\hline Mercury & $3 \sqrt{3}$ & $0025]$ & 097 & Z2-EU33B-113 & 0378 & 0 & 0 & 0 & $\mathbf{I}$ & NA & 0 \\
\hline Nickel & $3 / 3$ & 91 & 31 & 22-EปЭ33-114 & 168 & NA & NA & 0 & $\mathbf{I}$ & NA & 0 \\
\hline Nicke] & $3 / 3$ & $9 \mathrm{I}$ & 3] & 23.Ev93B-114 & 168 & $\mathbf{N A}$ & $\mathrm{NA}$ & 0 & I & $\mathrm{NA}$ & 0 \\
\hline Sejenıum & $3 \sqrt{3}$ & $018 \mathrm{~J}$ & 37 & Z2-EU33B-114 & 151 & NA & NA & 0 & $\mathbf{I}$ & NA & 0 \\
\hline Uranıum & $3 / 3$ & 089 & 8 & Z2-EU33B-\{13 & 346 & NA & $N A$ & 0 & $\mathrm{NA}$ & $\mathrm{NA}$ & 1 \\
\hline Vantadium & $3 / 3$ & $\mathrm{ksg}$ & $31 \mathrm{~J}$ & 22-E033B-l14 & 219 & NA & $\mathrm{NAA}$ & 0 & 0 & $\mathrm{NA}$ & 3 \\
\hline
\end{tabular}

$\begin{array}{ll}\text { Avg }=\text { average } & \text { Max a maximum } \\ \text { Bkg }=\text { background } & \text { NA = nol applicable } \\ \text { EU }=\text { exposure untt } & \text { PRO = preluminary te }\end{array}$

EU = exposure unit

$0 W=$ eroundwąler

PRO - prelniminery femediation goal

Ind = induțtral

$\mathrm{J}=$ analyte was identafled and Jesult is approxumate concentralion

$\mathrm{R \perp}=$ remediatipn level

$\mathrm{SL}=$ sereming |evel

PCBs were for analyzed in three samples but were not detected

EUZ2-33 DLLETION PIT SOUTHWEST OF K-J\$04-D RADIONUCLIDES WITH BACKGROUND, PRG, AND/OR RL EXCEEDANCES (PCDg) 0-10 it

\begin{tabular}{|c|c|c|c|c|c|c|c|c|c|c|c|}
\hline \multirow[b]{2}{*}{ Anolyte } & \multirow[b]{2}{*}{$\begin{array}{l}\text { Detect } \\
\text { Ireguency }\end{array}$} & \multirow[b]{2}{*}{$\begin{array}{l}\text { Minimnm } \\
\text { deteat }\end{array}$} & \multirow[b]{2}{*}{$\begin{array}{l}\text { Marimum } \\
\text { detect }\end{array}$} & \multirow[b]{2}{*}{$\begin{array}{l}\text { Location(s) of } \\
\text { maximum detect }\end{array}$} & \multirow{2}{*}{$\begin{array}{l}\text { Arerage } \\
\text { detectid } \\
\text { result }\end{array}$} & \multicolumn{6}{|c|}{ Number of analyses sxuetilna eriteria } \\
\hline & & & & & & $\begin{array}{l}\text { Max } \\
\text { RL }\end{array}$ & $\begin{array}{l}\text { AYE } \\
\text { RL }\end{array}$ & $\begin{array}{l}\text { Ind } \\
\text { Pagr }\end{array}$ & Bleg & $\begin{array}{l}\text { SW } \\
\text { sL }\end{array}$ & $\begin{array}{l}\text { Res } \\
\text { PRG }\end{array}$ \\
\hline Potzosium 40 & $3 / 3$ & 10 & 272 & Z2-EL33B-1[4 & 169 & $\mathrm{NA}$ & $\mathrm{NA}$ & 3 & 0 & WA & 3 \\
\hline Radıum-226 & M & 095 & 095 & Z2-EЏ33B-311 & 095 & NA & $N A$ & $\mathrm{l}$ & 0 & NA & I \\
\hline Thpnum-278 & $3 \Omega$ & 124 & 199 & Z2-EU3引日次 14 & 153 & NA & NA & 3 & l & $N A$ & 3 \\
\hline Thorium-230 & $3 \sqrt{3}$ & 134 & 155 & 22-Eป33B-1 14 & 131 & NA & NA & 0 & 2 & NA & 0 \\
\hline Thonum-232 & $3 / 3$ & I & 132 & Z7-EU33B-I l4 & 132 & $N A$ & NA & 3 & 0 & NA & 3 \\
\hline Uranıum-234 & $3 / 3$ & 105 & 438 & Z2-EU33日-113 & 236 & 0 & 0 & 0 & NA & 0 & 1 \\
\hline Uranlum-235 & 23 & 01085 & $022 \mathrm{~J}$ & 22-EU33B.I 13 & 0164 & 0 & 0 & 0 & $N A$ & 0 & 1 \\
\hline Urantum-2938 & $3 / 3$ & 136 & 292 & 22-EU33B-I13 & ] $\$ 9$ & 0 & 0 & 0 & 1 & 0 & $\exists$ \\
\hline 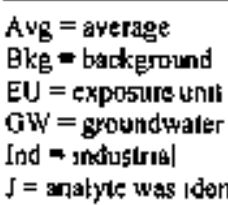 & ntofied and? & sult is appor & imate wnoen & & \multicolumn{7}{|c|}{ 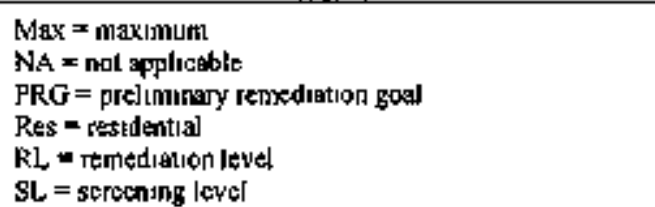 } \\
\hline
\end{tabular}

EU Z2-33 DELITJON PIT SOUTHWEST OF K-1004-D SVOC DETECTS (4.8/kg) 0.10 th

\begin{tabular}{|c|c|c|c|c|c|c|c|c|}
\hline \multirow[b]{2}{*}{ Analyte } & \multirow[b]{2}{*}{$\begin{array}{c}\text { Detect } \\
\text { frequency }\end{array}$} & \multirow[b]{2}{*}{$\begin{array}{c}\text { Mininum } \\
\text { detect }\end{array}$} & \multirow[b]{2}{*}{$\begin{array}{l}\text { Maximung } \\
\text { detect }\end{array}$} & \multirow[b]{2}{*}{$\begin{array}{l}\text { Locestion(s) of } \\
\text { meximum detext }\end{array}$} & \multirow{2}{*}{$\begin{array}{l}\text { Average } \\
\text { detected } \\
\text { renuli }\end{array}$} & \multicolumn{3}{|c|}{$\begin{array}{l}\text { Number of amalyses } \\
\text { exceeding arterit }\end{array}$} \\
\hline & & & & & & $\begin{array}{l}\text { ind } \\
\text { PRG }\end{array}$ & SW & $\begin{array}{l}\text { Res } \\
\text { PRG }\end{array}$ \\
\hline Benz(a)anthracene & $1 / 3$ & $93 \mathrm{~J}$ & 93J & 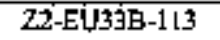 & 93 & 0 & NA & 0 \\
\hline Benzo(g)pyғате & $1 / 3$ & $48 J$ & 48] & 20า-EU33B-키I & 48 & 0 & NA & 0 \\
\hline Benzo(b)fluoranthene & $2 / 3$ & $73 \mathrm{~J}$ & 94.] & Z2-EU33B-113 & 835 & 0 & $\mathrm{NA}$ & 0 \\
\hline Benzo(ghu)perylene & 13 & $83\rfloor$ & B3] & Z2-Eり33B-3!I & 83 & 0 & $N A$ & 0 \\
\hline Benzo(k)fluoranhene & $1 / 3$ & 615 & GIJ & 22-EU33E-3II & 61 & 0 & NA & 0 \\
\hline Chrysente & $2 / 3$ & $57 \mathrm{~J}$ & $92 \mathrm{~J}$ & 22.EU33B-113 & 745 & 0 & NA & D \\
\hline Fluoranthene & $1 \sqrt{3}$ & $250 \mathrm{~J}$ & 2501 & Z2-EU33日-113 & 250 & 0 & NA & 0 \\
\hline Indeno( $(1,2,3-c d)$ pyrene & 13 & $58 \mathrm{~J}$ & $58]$ & 22-EU33B-311 & 58 & 0 & NA & 0 \\
\hline
\end{tabular}




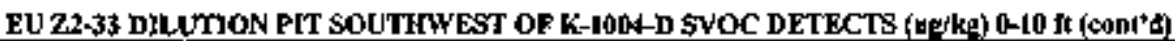

\begin{tabular}{|c|c|c|c|c|c|c|c|c|}
\hline \multirow[b]{2}{*}{ Anclyte } & \multirow[b]{2}{*}{$\begin{array}{l}\text { Detect } \\
\text { Irequedsy }\end{array}$} & \multirow[b]{2}{*}{$\begin{array}{l}\text { Maimum } \\
\text { detect }\end{array}$} & \multirow{2}{*}{$\begin{array}{c}\text { Marrimuni } \\
\text { detect }\end{array}$} & \multirow{2}{*}{$\begin{array}{l}\text { Location(s) of } \\
\text { maxtmum detect }\end{array}$} & \multirow{2}{*}{$\begin{array}{l}\text { Average } \\
\text { detected } \\
\text { result }\end{array}$} & \multicolumn{3}{|c|}{$\begin{array}{l}\text { Number ox annlyses } \\
\text { ercoeding eriteran }\end{array}$} \\
\hline & & & & & & $\begin{array}{l}\text { Ind } \\
\text { PRG }\end{array}$ & $\begin{array}{l}\text { GW } \\
\text { SL }\end{array}$ & $\begin{array}{l}\text { Res } \\
\text { PRG }\end{array}$ \\
\hline Nophlbaletse & I/S & 94 & 94 & $22-\mathrm{U} / 33 \mathrm{~B}-113$ & 94 & 0 & $\mathrm{NA}$ & 0 \\
\hline 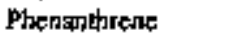 & $1 / 3$ & $87 J$ & 873 & $22-E U 33 E-113$ & 87 & 0 & NA & 0 \\
\hline Pyrene & $2 \sqrt{3}$ & 43J & $\mathrm{J} B 0 \mathrm{~J}$ & 22-EU338-113 & 112 & 0 & NA & 0 \\
\hline 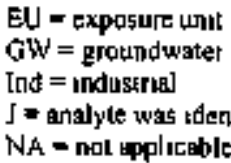 & egult is 的 & 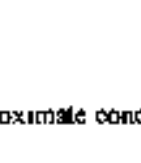 & & \multicolumn{5}{|c|}{ 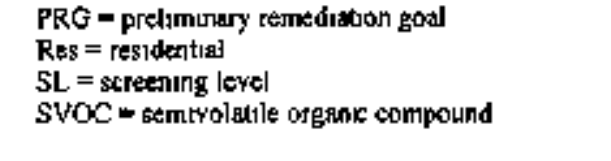 } \\
\hline
\end{tabular}

EU Z2-33 DILUTJON PIT SOUTHWWEST OF K-I004-D VOC DETECTS (un/kg) 0-10 ft

\begin{tabular}{|c|c|c|c|c|c|c|c|c|}
\hline \multirow[b]{2}{*}{ Analytc } & \multirow[b]{2}{*}{$\begin{array}{c}\text { Detect } \\
\text { frequency }\end{array}$} & \multirow[b]{2}{*}{$\begin{array}{l}\text { Minimum } \\
\text { detect }\end{array}$} & \multirow[b]{2}{*}{$\begin{array}{l}\text { Marlinam } \\
\text { detect }\end{array}$} & \multirow[b]{2}{*}{$\begin{array}{l}\text { Latstian(s) or } \\
\text { maxi num detert }\end{array}$} & \multirow{2}{*}{$\begin{array}{l}\text { Averıge } \\
\text { detected } \\
\text { rasult }\end{array}$} & \multicolumn{3}{|c|}{$\begin{array}{c}\text { Number of analyses } \\
\text { exceedtug eriteris }\end{array}$} \\
\hline & & & & & & $\begin{array}{l}\text { Ind } \\
\text { PRG }\end{array}$ & GW & REG \\
\hline I,I,I-Trichlorothane & $2 / 3$ & 96 & 4,300 & 22-EU33B-[1] & 2,198 & 0 & 0 & 0 \\
\hline $\begin{array}{l}\text { I, I,2-Trichloro-1,2,2- } \\
\text { [rifuwnelbant }\end{array}$ & $\begin{array}{l}2 \sqrt{2} \\
=\end{array}$ & 255 & 150 & 22-EL33B-113 & 763 & (1) & $N A$ & 0 \\
\hline I,I,2-Truchloroethane & $1 / 3$ & 74 & 74 & 2.2-EU33B-113 & 74 & 0 & 0 & 0 \\
\hline I,I-Dhch|orothant & $2 / 3$ & 42 & $\mathbf{4} 80$ & 22-EU33B-113 & $26]$ & 0 & $\mathrm{NA}$ & 0 \\
\hline I,I-Dishlorosthens & $2 / 3$ & 37 & 320 & Z2-EU33B-[13 & 179 & 0 & 0 & 0 \\
\hline 1,2-Dhchlarothint & $1 / 3$ & $\mathbf{I I}$ & 11 & 27-EU33B-113 & 11 & 0 & $B A$ & 0 \\
\hline Acetone & $2 / 3$ & [0] & 64 & 23-EU\$3B-โI & 37 & 0 & NA & 0 \\
\hline Cabon disulfide & $1 / 3$ & 69 & 69 & Z2-EU33B-113 & 69 & 0 & NA & 0 \\
\hline Chloroform & $1 / 3$ & 41 & 41 & 22-EU33B-113 & 41 & 0 & 0 & 0 \\
\hline cடs-I,2-Diciloroethene & 23 & 98 & 99 & 22-EU33B-ן13 & 965 & 0 & JAA & 0 \\
\hline Methylene chlonde & $2 / 3$ & 71 & 40 & Z2-EU33B-!13 & 236 & 0 & 0 & 0 \\
\hline Tetrachkorosthene & $1 / 3$ & 77 & 77 & 22-EU33E-[13 & 77 & 0 & 0 & 0 \\
\hline Toluene & ]$/ 3$ & 30 & 30 & 27-EU33B-[13 & 30 & 0 & 0 & 0 \\
\hline trans-],2-Dichloroethere & $1 / 3$ & 235 & $23 \mathrm{~J}$ & Z2-EU33B-!I3 & 23 & 0 & $\mathrm{NA}$ & 0 \\
\hline Tnchlorpethene & $2 \pi$ & 29 & 5 觔 & $22-E 133 B+13$ & 305 & $\theta$ & 0 & 1 \\
\hline 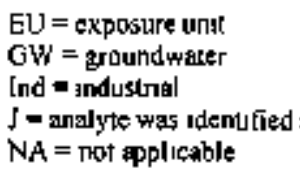 & ad result is & proximate & centran & \multicolumn{3}{|c|}{$\begin{array}{l}\text { PRG = preiminary remediahon goal } \\
\text { Res = Jesidential } \\
\text { SL = screenulg level } \\
\text { VOC = volatilt organc compound }\end{array}$} & & \\
\hline
\end{tabular}

K-I004-A,B,C Dilution Pit West (DP EU33D-329): Biased sampling was recommended in the Assessment Report for this site based on Class $3 \mathrm{SU}$ walkover assessment visual observations. A sediment sample collected from the pit exceeded multiple metal, PCB, radionuclide, and VOC evaluation criteria. Two soil samples collected outside the dilution ptt and af the pit's base level were analyzed for metals, PCBs, radionuclides, SVOCs, and VoCs. Four addjtional soil samples were collected in a step-wise manner in the groundwater downgradient direction from the dilution pit and analyzed for VOCs. Analytical results from these samples showed elevated VOCs in the pit base level samples but not in the downgradient samples. Interpretation of these analytical results determined metaI, PCB, and radionuclide contaminants had been contsined within the pit and only VOCs had migrated out of the pit. The dilution pit was removed during a remedial action that atso removed the original sediment sample location and the two pit base level soil sample locations (Table 3). Confirmation sample 22-EU33B-377 was collected following the remedial action and analyzed for VOCs. Analytical results showed elevated VOCs resulting in additional soil being excavated, removal of the confirmation sample location (Table 3), and collection of a confirmation sample to be analyzed for VOCs for the second excavation. Soil sample locations representative of current conditions at the K-1004-A,B,C Dilution Pit West are presented in Table 3. These loctations included downgradient sample locations Z2-EU33B-131, Z2-EU33B-137, Z2-EU33B-140, and Z2-EU33B-141 and final confirmation sample Z2-EU33B-383, which were collected from a depth $>10 \mathrm{ft}$ bgs. All samples from the representative sample 
locations were analyzed for VOCs only. Analytical results summarized below from the sample locations representetive of curent conditions show VOC detections.

EU Z2-33 K-1004-A,B,C DILUTLON PCT WEST YOC DETECTS (ugskg) 0-1 if

\begin{tabular}{|c|c|c|c|c|c|c|c|c|}
\hline \multirow[b]{2}{*}{ Anolyte } & \multirow[b]{2}{*}{$\begin{array}{c}\text { Detect } \\
\text { frequency }\end{array}$} & \multirow[b]{2}{*}{$\begin{array}{c}\text { Mininum } \\
\text { detect }\end{array}$} & \multirow[b]{2}{*}{$\begin{array}{c}\text { Maximug } \\
\text { detect }\end{array}$} & \multirow[b]{2}{*}{$\begin{array}{l}\text { Location(s) of } \\
\text { neximum detoct }\end{array}$} & \multirow{2}{*}{$\begin{array}{c}\text { Average } \\
\text { detected } \\
\text { resuli }\end{array}$} & \multicolumn{3}{|c|}{$\begin{array}{l}\text { Number of nolyses } \\
\text { erokedine siftria }\end{array}$} \\
\hline & & & & & & $\begin{array}{l}\text { Ind } \\
\text { PRG }\end{array}$ & $\begin{array}{l}\text { GW } \\
\text { SLL }\end{array}$ & $\begin{array}{l}\text { Ret } \\
\text { PRG }\end{array}$ \\
\hline I,I-D|chlotothene & $1 / 5$ & $31 \mathrm{~J}$ & $3 ! \mathrm{J}$ & Z2.EU33B-3B3 & 31 & 0 & 0 & 0 \\
\hline Acelont & $1 / 5$ & 110 & 110 & 22-EU33日-390 & 110 & 0 & NA & 0 \\
\hline Carbon disulfide & $1 / 5$ & 12 & 12 & Z2.EU33B-383 & 12 & 0 & $\mathrm{NA}$ & 0 \\
\hline Chloroform & $1 / 5$ & 140 & 140 & Z2-EU33B-383 & 140 & 0 & $\rightarrow$ & 0 \\
\hline c1s-l,2-Dich|oroethere & $2 / 5$ & 570 & 1,300 & 22-EU33日-363 & 935 & 0 & NA & 0 \\
\hline Tetrachlorosthene & $2 / 5$ & $23 \mathrm{~J}$ & 29 & Z2.EU33B-3B3 & 157 & 0 & 0 & 0 \\
\hline Toluente & $1 / 5$ & $26]$ & $26 J$ & Z2-EU33E-383 & 26 & 0 & 0 & 0 \\
\hline tranns-1.2-Dichlorothene & $2+5$ & $25 \mathrm{~J}$ & 11 & Z2-EU33B-383 & 675 & 0 & NA & 0 \\
\hline Trichloroellhente & $2 / 5$ & 431 & 170 & $22 \cdot E U 33 E-383$ & 872 & 0 & 0 & $\mathbf{I}$ \\
\hline Vungl chloride & $1 / 5$ & 120 & 120 & Z2-EU33B-383 & 120 & 0 & 0 & $\mathbf{I}$ \\
\hline
\end{tabular}

EU = expesure unit

GW $=$ gtoundwater

Ind = Indurtinal

J - andyte was identified and result 19 appreximate concentrition:

NA $=$ not applicable

PRG = prel Iminary remed Iation go日|

Res = residentual

$S L=$ scretring level

VOC = volatıle organc compound

K-J004-A,B,C Dilution Pit South (DP EU33D-330): Biased sampling was recommended in the Assessment Report for this site based on Class 3 SU walkover assessment visual observations. A sediment sample collected from the pit exceeded multiple metal, PCB, radionuelide, SVOC, and VOC evaluation criteria. Two soil samples collected outside the dilution pit and at the pit's base level were analyzed for metals, PCBs, radionuclides, SVOCs, and VOCs. An additional l0-ft composite sample was collected southwest of the pit Analytical results from these samples showed contaminants had been contained by the dilution pit, which was removed duing a remedial action that also removed the original sediment sample location (Table 3). A confirmation sample was collected from the excavation at the end of the remedial action. Sample locations representative of current conditions at the $K_{-}-1004-A, B, C$ Dilution Pit South are presented in Table 3. These locations included samples Z2-EU33B-122 and Z2-EU33B-I23 from the base level of the pit [one sample was at a depth $>10 \mathrm{ft}$ bgs (see Table 3)], 10-ft composite sample Z2-EU33B-315 southwest of the pit, and confirmation sample Z2-EU33B-379. Analytical results summarized below show radionuclide Ind PRG exceedances, metal and radionuclide Bkg exceedances, and PCB, SVOC, and VOC detections.

EU Z2-33 K-1004-A,B,C IHLUTION PIT SOUTH METALS WITH BACKGROUNO, PRG, GW 8L, AND/OR RL EXCEEDANCES (m)

\begin{tabular}{|c|c|c|c|c|c|c|c|c|c|c|c|}
\hline \multirow[b]{2}{*}{ Amabyte } & \multirow[b]{2}{*}{$\begin{array}{c}\text { Detect } \\
\text { Treglesacy }\end{array}$} & \multirow[b]{2}{*}{$\begin{array}{c}\text { Mindonum } \\
\text { detect }\end{array}$} & \multirow[b]{2}{*}{$\begin{array}{l}\text { Maxiluinm } \\
\text { detect }\end{array}$} & \multirow{2}{*}{$\begin{array}{c}\text { Loestan(s) of } \\
\text { maximum } \\
\text { detect }\end{array}$} & \multirow{2}{*}{$\begin{array}{l}\text { Average } \\
\text { detectisd } \\
\text { regult }\end{array}$} & \multicolumn{6}{|c|}{ Number of apalyges exceting criterin } \\
\hline & & & & & & $\underset{\text { Rl }}{\operatorname{Max}}$ & $\begin{array}{l}\text { Avg } \\
\text { RL }\end{array}$ & $\begin{array}{l}\text { lnd } \\
\text { PRG }\end{array}$ & Gkes & $\begin{array}{l}\text { GFY } \\
\mathbb{S L}\end{array}$ & $\begin{array}{l}\text { Res } \\
\text { PRG }\end{array}$ \\
\hline A.뺘mเnum & $4 / 4$ & 10,6 서이 & 22,000 & Z2-6U33B-122 & 16,9000 & $\mathrm{NA}$ & $N A$ & 0 & 0 & $\mathrm{NA}$ & 4 \\
\hline Arstenit & $4 / 4$ & $4 \mathrm{IJ}$ & 64 & Z2-EU33B-122 & 54 & 0 & 0 & 0 & 0 & 0 & 4 \\
\hline Barmam & $4 / 4$ & $31 \mathrm{~J}$ & 132 & 22-EU33B-315 & 668 & NA & $N_{A}$ & 0 & 1 & 0 & 0 \\
\hline Cadmum & $4 / 4$ & 02 & 069 & Z2-EU33B-I23 & 0338 & NiA & NA & 0 & 2 & NA & 0 \\
\hline Calcium & $4 / 4$ & 2,200 & 21,300 & 22-EU33B-315 & 11,275 & NA & NA & $N_{A}$ & 3 & $\mathrm{NA}$ & NA \\
\hline Chromium & d/4 & $19 \mathrm{~d}$ & 130 & ट2-EUग3B-I23 & 395 & $\mathrm{NA}$ & NA & 0 & 2 & 0 & 2 \\
\hline Copper & $4 / 4$ & 195 & $33 \mathrm{~J}$ & Z2-EU33B-123 & 234 & NA & $\mathrm{NA}$ & 0 & 2 & NA & 0 \\
\hline Iron & $4 / 4$ & 18,600 & $52,0,00$ & $\begin{array}{l}Z 2-E U 33 B-122 \\
Z 2-E U 33 B-123\end{array}$ & 41,150 & $\mathrm{NA}$ & NA & 0 & 0 & NA & 4 \\
\hline Lead & $4 / 4$ & 2651 & 61 & Z2.EU33B-123 & 376 & NA & NA & 0 & 1 & 0 & 0 \\
\hline Mangénese & 4/4 & $310 \Gamma$ & 1,030 & 22-EU33B-315 & 913 & $\mathrm{NA}$ & $\mathrm{NA}$ & 0 & 0 & NA & 4 \\
\hline Merçury & $4 / 4$ & 0085 & 0865 & $22-E U 33 B-122$ & 0474 & 0 & 0 & 0 & 3 & $N A$ & 0 \\
\hline Selenıum & $3 / 4$ & 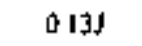 & 42 & Z2-EU33B-123 & 268 & NA & NA & 0 & 2 & NA & 0 \\
\hline Silver & $2 / 4$ & $0.45 J$ & 21 & Z2-EU33B-123 & 123 & $\mathrm{NA}$ & $\mathrm{NA}$ & 0 & 1 & NA & 0 \\
\hline
\end{tabular}


EU Z2-3ł K-1004-A,B,C DILUTION PIT SOUTH METALS WITH BACKGROUND, PRG, GW SL AND/OR RL EXCERDANCES (nIg/kg) 0-10 it (conl'd)

\begin{tabular}{|c|c|c|c|c|c|c|c|c|c|c|c|}
\hline \multirow[b]{2}{*}{ Analyte } & \multirow[b]{2}{*}{$\begin{array}{c}\text { Detect } \\
\text { frequency }\end{array}$} & \multirow[b]{2}{*}{$\begin{array}{c}\text { Minimum } \\
\text { detect }\end{array}$} & \multirow[b]{2}{*}{$\begin{array}{c}\text { Maxirmum } \\
\text { detect }\end{array}$} & \multirow{2}{*}{$\begin{array}{l}\text { Lacation(s) of } \\
\text { marimum } \\
\text { detect }\end{array}$} & \multirow{2}{*}{$\begin{array}{l}\text { Average } \\
\text { detected } \\
\text { result }\end{array}$} & \multicolumn{6}{|c|}{ Number of andyses exceedlof criterle } \\
\hline & & & & & & $\begin{array}{c}\text { Max } \\
\text { RE }\end{array}$ & $\begin{array}{l}\text { A } \\
\text { RL }\end{array}$ & $\begin{array}{l}\text { Ind } \\
\text { PRG }\end{array}$ & 明. & $\begin{array}{l}\text { GW } \\
\text { SL }\end{array}$ & $\begin{array}{l}\text { Ales } \\
\text { PRG }\end{array}$ \\
\hline Uranium & $4 \sqrt{4}$ & 088 & 15 & Z2-EU33B-123 & 505 & NA & $N A$ & 0 & $\mathrm{NA}$ & NA & 3 \\
\hline Veromdım & $4 / 4$ & 204 & $67 J$ & Z2-EU33B-122 & 421 & NA & $\mathrm{NA}$ & 0 & 1 & NA & 4 \\
\hline \multicolumn{5}{|c|}{ 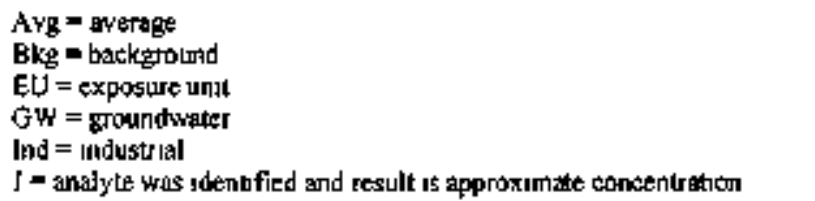 } & \multicolumn{7}{|c|}{ 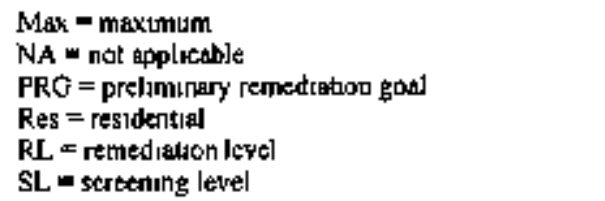 } \\
\hline
\end{tabular}

EU Z2-33 K-1004-A,B,C DHLUTION PIT SOUTH PPCB DETECTS (ng/kg) 0-]0 it

\begin{tabular}{|c|c|c|c|c|c|c|c|c|c|}
\hline \multirow[b]{2}{*}{ Avalyte } & \multirow[b]{2}{*}{$\begin{array}{l}\text { Detect } \\
\text { Irequency }\end{array}$} & \multirow[b]{2}{*}{ Minimum } & \multirow[b]{2}{*}{$\begin{array}{l}\text { Maximum } \\
\text { detect }\end{array}$} & \multirow{2}{*}{$\begin{array}{l}\text { Locetion(s) or } \\
\text { entximur } \\
\text { detect }\end{array}$} & \multirow{2}{*}{$\begin{array}{l}\text { Average } \\
\text { deteteted } \\
\text { regitit }\end{array}$} & \multicolumn{4}{|c|}{$\begin{array}{l}\text { Number of analyse: } \\
\text { exceediex criterba }\end{array}$} \\
\hline & & & & & & $\begin{array}{l}\text { Mar } \\
\text { RL }\end{array}$ & $\begin{array}{l}\text { AYg } \\
\text { RL }\end{array}$ & $\begin{array}{l}\text { Ind } \\
\text { Pkg }\end{array}$ & $\begin{array}{l}\text { Res } \\
\text { PRG }\end{array}$ \\
\hline$\overline{P C B}-[254$ & $2 / 4$ & 24 & 60 & $22-E U 338-123$ & 42 & 0 & 0 & 0 & 4 \\
\hline Polychlorinated Biphenyl & $2 / 4$ & 24 & 60 & Z2.EU33B-123 & 42 & 0 & 0 & 0 & $\theta$ \\
\hline
\end{tabular}

\begin{tabular}{|c|c|}
\hline $\begin{array}{l}\text { Aqg = average } \\
\text { EU }=\text { exposure un!t } \\
\text { Ind = Industal | }\end{array}$ & 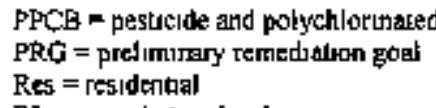 \\
\hline
\end{tabular}

Max = maximurn $\quad$ RL $=$ remediation leved

EU 22-33 K-1004-A,B,C DILUTION PT SOUTH RADIONUCE NDES WITH BACKGROUND, PRG, ANDJOR RL EXCEEDANCES (pCV/) 0-J0 ft

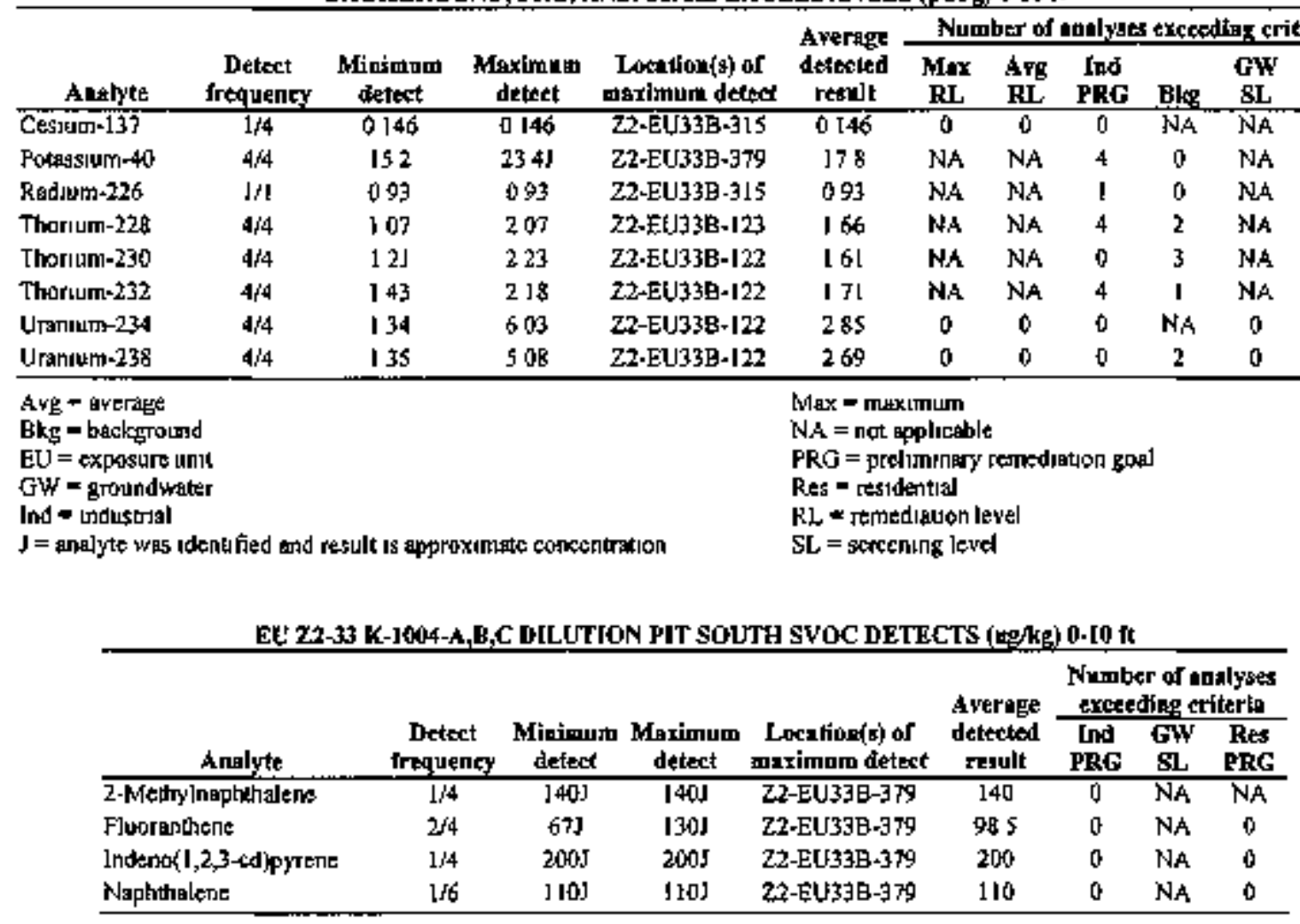


EU Z2-33 K-1004-A,BC. DILUTION RIT SOUTH SVOC DETECTS (äg/kE) 0-k0 it (cont'd)

\begin{tabular}{|c|c|c|c|c|c|c|c|c|}
\hline \multirow[b]{2}{*}{ Anglyte } & \multirow[b]{2}{*}{$\begin{array}{c}\text { Betect } \\
\text { Irequenky }\end{array}$} & \multirow[b]{2}{*}{$\begin{array}{l}\text { Mtipinum } \\
\text { detect }\end{array}$} & \multirow[b]{2}{*}{$\begin{array}{l}\text { Meximum } \\
\text { deteet }\end{array}$} & \multirow[b]{2}{*}{$\begin{array}{l}\text { Location(s) of } \\
\text { mardmum deteet }\end{array}$} & \multirow{2}{*}{$\begin{array}{l}\text { Average } \\
\text { detecled } \\
\text { resull }\end{array}$} & \multicolumn{3}{|c|}{$\begin{array}{l}\text { Nomber of anglysed } \\
\text { exeexdlue eriferia }\end{array}$} \\
\hline & & & & & & $\begin{array}{l}\text { Ind } \\
\text { P\&G }\end{array}$ & GW & $\begin{array}{l}\text { Res } \\
\text { PRG }\end{array}$ \\
\hline Phenirithrent & 214 & $45 \mathrm{~J}$ & $120 \mathrm{~J}$ & Z2-EU333-379 & 825 & 0 & NA & 0 \\
\hline Pyrene & $2 / 4$ & $48 \mathrm{~J}$ & 1005 & Z2-EU33B-379 & 74 & 0 & $N A$ & 0 \\
\hline $\begin{array}{l}\text { EU = exposure unit } \\
\text { GW = groundweter } \\
\text { lnd = mdustnal } \\
\text { J = analyte was idet } \\
\text { NA = noL gppticable }\end{array}$ & result is a & roxim, gate 0 & concertrahon & \multicolumn{4}{|c|}{ 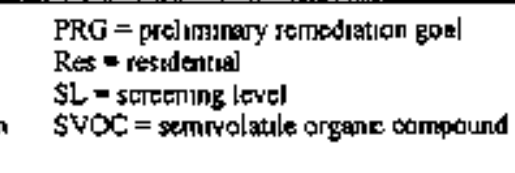 } & \\
\hline
\end{tabular}

EU Z2-33 K-1094-A,B,C DILUTJON PIT \&OUTH VOC, DETECTS (ue/kg) 0-10 it

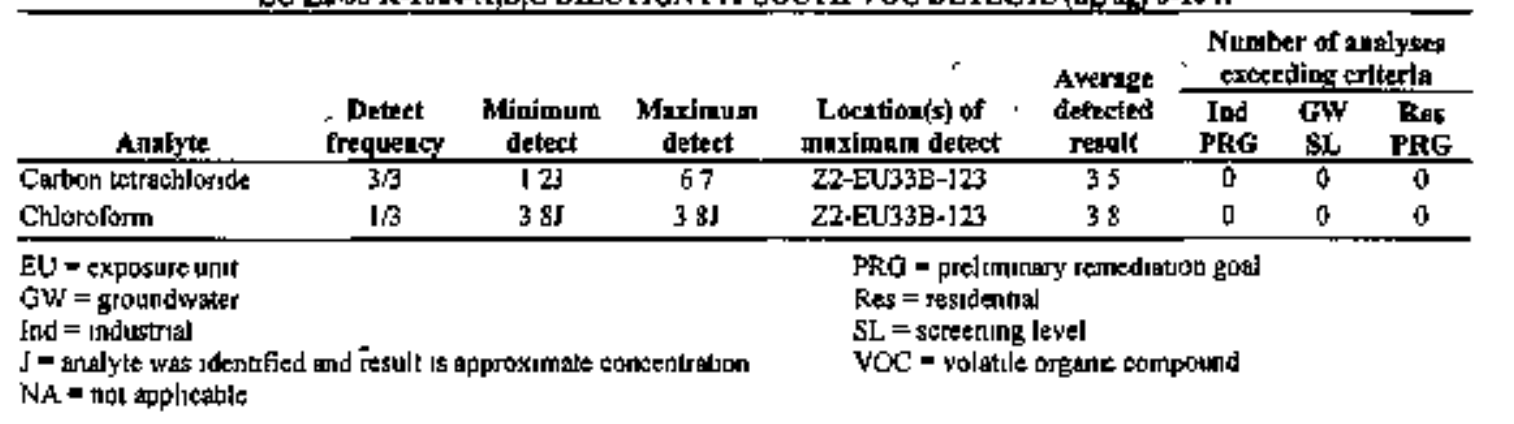

K-1014-A,B,C Dilution Pit East (DP EU33D-33L); Biased sampling was recomnended for this site in the Assessment Report based on Class 3 SU walkover assessment visual observations. A sediment sample could not be collected from the pit because it was filled with construction debris. Two soil samples collected outside the ditution pit and at the pit's base level were analyzed for metals, PCBs, radionuclides, SVOCs, and VOCs. Although a sample from the pit was nol collected and the two base-level samples showed no criteria exceedances, the pit was removed during a rechedial action. Because the pit was removed during a remedial action, the inability to collect a sediment sample from the pit has no impact on the understanding of current conditions. Sample locations representative of current conditions are presented in Table 3. These tocations included two samples from the pit's base level (one collected form a depth $>10 \mathrm{ft}$ bes). Analytical results summarized below for sample locations represencative of current conditions show radionuclide Ind PRG exceedances, metal and radionuclide Bkg exceedances, and PCB, SVOC, and VOC detections.

EU Z2-33 K-1004-A,B,C DILUTION PIT EAST METALS WTTH BACKGROUND, PRG, GW BL, ANDHOR RL EXCEEIANCES (me/ke) 0-10 n

\begin{tabular}{|c|c|c|c|c|c|c|c|c|c|c|c|}
\hline \multirow[b]{2}{*}{ Analyte } & \multirow[b]{2}{*}{$\begin{array}{l}\text { Petecl } \\
\text { frequency }\end{array}$} & \multirow[b]{2}{*}{$\begin{array}{c}\text { Miaimum } \\
\text { detec1 }\end{array}$} & \multirow[b]{2}{*}{$\begin{array}{c}\text { Maximinirt } \\
\text { detect }\end{array}$} & \multirow{2}{*}{$\begin{array}{l}\text { Location }(\mathrm{s}) \text { of } \\
\text { maxlmumm } \\
\text { defect }\end{array}$} & \multirow{2}{*}{$\begin{array}{l}\text { Average } \\
\text { detected } \\
\text { result }\end{array}$} & \multicolumn{6}{|c|}{ Number of andlyses texteding eriterin } \\
\hline & & & & & & $\begin{array}{l}\text { Max } \\
\text { RL }\end{array}$ & $\begin{array}{l}\text { AYg } \\
\text { RL }\end{array}$ & $\begin{array}{l}\text { Ind } \\
\text { PRG }\end{array}$ & BAfig & $\begin{array}{l}\text { GW } \\
\text { SL }\end{array}$ & $\begin{array}{l}\text { Reg } \\
\text { PRG }\end{array}$ \\
\hline Alumitudin & $2 / 2$ & 11,000 & 18,000 & $27 . E U 33 B-116$ & 14,500 & NA & NA. & 0 & $\theta$ & $\mathrm{NA}$ & 2 \\
\hline Arsemic & $2 / 2$ & 36 & 12 & 22-EU33B-116 & 78 & 0 & 0 & 0 & 0 & 0 & 2 \\
\hline Cadmutem & $1 / 2$ & 039 & 039 & $22-E U 33 B-116$ & 039 & NA & NA. & 0 & 1 & $N_{A}$ & 0 \\
\hline Calaum & $2 / 2$ & 1,900 & 5,300 & $22-E) 33 B-116$ & 3,600 & $\mathrm{~N} \AA$ & NA & NA & 1 & NA & $N A$ \\
\hline Chromidum & $2 / 2$ & 22 & 29 & Z2-EU33B-116 & 255 & NA & NA & 0 & 0 & 0 & $\mathbf{I}$ \\
\hline Copper & $2 / 2$ & 78 & 391 & $22-E U 33 B-116$ & 234 & NA & NA & 0 & 1 & $N_{A}$ & 0 \\
\hline Jron & $2 / 2$ & 38,0005 & $74,000 \mathrm{~J}$ & Z2-EU33B-116 & $56,(x) 0$ & NA & NA & 0 & l & $\mathrm{NA}$ & 2 \\
\hline Lead & $2 / 2$ & 26 & 73 & $22-E=1333-116$ & 495 & $\mathrm{NA}$ & NA & 0 & 1 & 0 & 0 \\
\hline Manganege & $2 / 2$ & I & $1,4(00)$ & 22-EU33B-116 & 995 & NA & NA & $\theta$ & 0 & $N A$ & 2 \\
\hline Seleniwm & $2 / 2$ & $2 B$ & 41 & Z2-EU33B-116 & 345 & NA & NA & 0 & 2 & NA & 0 \\
\hline Thallium & $2 \pi$ & (1) & [ 49] & $2 \geq-E U 33 B_{1}-116$ & 033 & $N A$ & NA & 0 & 1 & 0 & 0 \\
\hline Qranium & $2 / 2$ & 13 & 36 & $22-E U 33 B-116$ & 245 & $\mathrm{NA}_{\mathrm{A}}$ & NA & 0 & NA & NA & ] \\
\hline
\end{tabular}


EU 22-33 K-1004-A,B,C DILUTION PIT EAST METALS WTTH BACKGROUND, PRG, GW SL, ANDJOR RL EXCEEDANCES (mE/Ne) 0.10 ft (cont'd)

\begin{tabular}{|c|c|c|c|c|c|c|c|c|c|c|c|}
\hline \multirow[b]{2}{*}{ Auslyte } & \multirow[b]{2}{*}{$\begin{array}{c}\text { Defect } \\
\text { fireguteycy }\end{array}$} & \multirow[b]{2}{*}{$\begin{array}{l}\text { Munimur: } \\
\text { detect }\end{array}$} & \multirow[b]{2}{*}{$\begin{array}{c}\text { Movinum } \\
\text { detect }\end{array}$} & \multirow{2}{*}{$\begin{array}{l}\text { Lacathatas or } \\
\text { maxioum } \\
\text { detect }\end{array}$} & \multirow{2}{*}{$\begin{array}{l}\text { Average } \\
\text { detected } \\
\text { result }\end{array}$} & \multicolumn{6}{|c|}{ Nomber of angiyges excetiline criterla } \\
\hline & & & & & & $\begin{array}{l}\text { Mex } \\
\mathbf{R L}^{-}\end{array}$ & Arg & PRA & Elg. & $\begin{array}{l}\text { GW } \\
\text { SL }\end{array}$ & $\begin{array}{l}\text { Res } \\
\text { PRG }\end{array}$ \\
\hline$\overline{\text { Dranium }}$ & $2 / 2$ & 13 & 36 & $22-E \mathbf{U} 33 \mathrm{~B}-11 \overline{6}$ & 245 & NA & NA & 0 & NA & $\mathrm{NA}$ & 1 \\
\hline Vanadnum & $2 \pi$ & 32J & $75 \mathrm{~J}$ & Z2-EU\$3B-1 I6 & 535 & NA & NA & 0 & $\mathbf{I}$ & Na & 2 \\
\hline Zin: & $2 \sqrt{2}$ & 25 & 120 & $22-E U 33 B-[16$ & 725 & NA & NA & 0 & $\mathbf{I}$ & NA & 0 \\
\hline
\end{tabular}

Avg $=$ average

Bkg = backgroumd

EU = exposare unit

GW = groundwater

Ind = Industrial

J = analyte wat identfied and result is approxmate concentrathon:

$M a x=$ maxımum

$\mathrm{NA}=$ not applicelble

PRG = pred imtary remedratons goal

Res - ressdentid

$\mathrm{RL}=\mathrm{sem}$ ediduou leve

SL - screening level

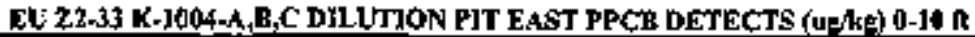

\begin{tabular}{|c|c|c|c|c|c|c|c|c|c|}
\hline \multirow[b]{2}{*}{ Aasyte } & \multirow[b]{2}{*}{$\begin{array}{c}\text { Detect } \\
\text { treqpency }\end{array}$} & \multirow[b]{2}{*}{$\begin{array}{l}\text { Mlimiran ra } \\
\text { detect }\end{array}$} & \multirow[b]{2}{*}{$\begin{array}{c}\text { Mayimum } \\
\text { detect }\end{array}$} & \multirow{2}{*}{$\begin{array}{c}\text { Locition(s) of } \\
\text { maxinum } \\
\text { detect }\end{array}$} & \multirow{2}{*}{$\begin{array}{l}\text { Average } \\
\text { detected } \\
\text { rapult }\end{array}$} & \multicolumn{4}{|c|}{$\begin{array}{l}\text { Number of ogalyers } \\
\text { exceedisg critern }\end{array}$} \\
\hline & & & & & & $\begin{array}{c}\text { Mgx } \\
\text { RL }\end{array}$ & $\begin{array}{l}\text { Avg } \\
\text { RL }\end{array}$ & $\begin{array}{c}\text { Ind } \\
\text { PRG }\end{array}$ & $\begin{array}{l}\text { Reg } \\
\text { PRG }\end{array}$ \\
\hline PCB-1260 & $2 / 2$ & $6 I I$ & $20 \mathrm{~J}$ & 22-EU33B-117 & $-\sqrt{31}$ & 0 & $\theta$ & 0 & 0 \\
\hline Polychlonnated Biphetyl & $2 / 2$ & $61 J$ & 201 & Z2-EU33B-II7 & 131 & 0 & 0 & 0 & 0 \\
\hline
\end{tabular}

Axg $=$ average

EU $=$ exposure unt

Ind = industrial

$\mathrm{J}$ - malyte was idenufied and result is approximate concentration

PPCB = pestuade and pobychlorinated biphenyl

PRG = prel ImInary retrediahon goal

Ris $=$ restidentıal

Max = maxisnum

$\mathrm{RL}=$ remediation level

EU Z2-33 K-1004-A,B,C DILUTION PIT EASTT RADKONUCLIDES WITH

BACKGROUND, PRG, AND/OR RL EXCEEDANCES (pCV/g) 0-10 it

\begin{tabular}{|c|c|c|c|c|c|c|c|c|c|c|c|}
\hline \multirow[b]{2}{*}{ Anglyit } & \multirow[b]{2}{*}{$\begin{array}{c}\text { Detect } \\
\text { frequericy }\end{array}$} & \multirow[b]{2}{*}{$\begin{array}{c}\text { Minimum } \\
\text { detett }\end{array}$} & \multirow[b]{2}{*}{$\underset{\text { Meximud }}{\operatorname{Man}}$} & \multirow[b]{2}{*}{$\begin{array}{l}\text { Losullon(s) of } \\
\text { maximum detcet }\end{array}$} & \multirow{2}{*}{$\begin{array}{l}\text { Average } \\
\text { detected } \\
\text { result }\end{array}$} & \multicolumn{6}{|c|}{ Nunber of inalyset croced ding enleria } \\
\hline & & & & & & $\begin{array}{l}\text { Mnx } \\
\text { RL }\end{array}$ & $\begin{array}{l}\text { Avg } \\
\text { RI }\end{array}$ & $\begin{array}{l}\text { Ind } \\
\text { PRG }\end{array}$ & 8kg & $\begin{array}{l}\text { GW } \\
\text { SL }\end{array}$ & $\begin{array}{l}\text { Res } \\
\text { PRG }\end{array}$ \\
\hline Potassium-40 & $2 / 2$ & 138 & 184 & 22-EU33B-JI? & 161 & NA & $\overline{N A}$ & 2 & 0 & NA & 2 \\
\hline Thpriłm-278 & $2 / 2$ & 125 & 169 & $22-E \cup 33 B-116$ & 147 & NA & NA & 2 & 0 & $\mathrm{NA}$ & 2 \\
\hline Thoritum.230 & $2 / 2$ & 0874 & 24 & $22-E U 33 B-116$ & 164 & NA & NA & 0 & 1 & $\mathbf{N A}$ & $\theta$ \\
\hline Thurıemr-232 & $2 / 2$ & 124 & $\mathbf{1} 71$ & Z2-EU33B-116 & 548 & NA & NA & 2 & 0 & $\mathrm{MA}$ & 2 \\
\hline Uranıum-238 & $2 \sqrt{2}$ & $1] 4$ & 221 & Z2-EU33B-116 & 168 & 0 & 0 & 0 & l & 0 & 2 \\
\hline
\end{tabular}

\begin{tabular}{|c|c|c|}
\hline $\begin{array}{l}\text { AYg - average } \\
\text { Bkg = baskground } \\
\text { EU - exposure unit } \\
\text { GW = groundwater }\end{array}$ & $\begin{array}{l}\text { lnd - endusirual } \\
\text { Max = maximum } \\
\text { NA - no[ appletib]e } \\
\text { PRG = prelumirary remedration gall }\end{array}$ & $\begin{array}{l}\text { Res " residential } \\
\text { RL = remedialion level. } \\
\text { SL = scteening leyel }\end{array}$ \\
\hline
\end{tabular}

EU Z2-33 K+1004-A,B,C DILUTION PIT EAST SVOC DETECTS (ug/kg) 0-10 it

\begin{tabular}{|c|c|c|c|c|c|c|c|c|}
\hline \multirow[b]{2}{*}{ Anglyte } & \multirow[b]{2}{*}{$\begin{array}{c}\text { Detcet } \\
\text { freguepcy }\end{array}$} & \multirow[b]{2}{*}{$\begin{array}{c}\text { Mhninnm } \\
\text { detect }\end{array}$} & \multirow[b]{2}{*}{$\begin{array}{c}\text { Morminum } \\
\text { dereset }\end{array}$} & \multirow[b]{2}{*}{$\begin{array}{l}\text { Location(b) of } \\
\text { naximnn detect }\end{array}$} & \multirow{2}{*}{$\begin{array}{l}\text { Average } \\
\text { detected } \\
\text { result }\end{array}$} & \multicolumn{3}{|c|}{$\begin{array}{l}\text { Nondber of anglyses } \\
\text { exceeing critera }\end{array}$} \\
\hline & & & & & & $\begin{array}{l}\text { Ind } \\
\text { PRC }\end{array}$ & $\begin{array}{l}\text { GW } \\
\text { SL }\end{array}$ & $\begin{array}{l}\text { RE: } \\
\text { PRG }\end{array}$ \\
\hline Benz(a)tan'thracene & $1 n$ & $100 \mathrm{~J}$ & $100 \mathrm{~J}$ & 22-EU33B-116 & 100 & 0 & $\mathrm{NA}$ & 0 \\
\hline 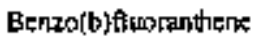 & $1 / 2$ & Ilt & 1 & Z7-EU33E-116 & 110 & 0 & NA & 0 \\
\hline Fluoranthene & $\mathrm{I} / 2$ & $270 \mathrm{~J}$ & $270 \mathrm{~J}$ & 22-EU33B-1]6 & 270 & 0 & NA & 0 \\
\hline Naphthelene & $1 / 4$ & 160 & 360 & 22-EU33B-116 & 160 & 0 & NA & 0 \\
\hline Phenanthrene & $1 / 2$ & 2301 & $230 \mathrm{~J}$ & $22 . E U 333.116$ & 230 & $\square$ & $\mathrm{NA}$ & 0 \\
\hline Pyrene & $1 / 2$ & I90J & 」90J & Z2-EU338-116 & 190 & 0 & NA & 0 \\
\hline
\end{tabular}

$\mathrm{EU}=$ cxposure un: $1 \mathrm{t}$

$G W=$ groundwater

Ind - undustral

PRG = prelim Lxery remsilatop̣ goal

Res $=$ TEMldent $\mid$ al

J a analyte was identufied erid resule ts approximae concentration

$\mathrm{SL}=$ screenthg leqel

$\mathrm{NA}=$ not applicable

SVOC = semuYolatule organc compound 
EU 22-33 K-1004-A,B,C DILUT]ON PJT RAST VOC DETECTS (-

\begin{tabular}{|c|c|c|c|c|c|c|c|}
\hline \multirow[b]{2}{*}{ Analyte } & \multirow[b]{2}{*}{$\begin{array}{c}\text { Minimum } \\
\text { Detert }\end{array}$} & \multirow[b]{2}{*}{$\begin{array}{c}\text { Meximan } \\
\text { Petcet }\end{array}$} & \multirow[b]{2}{*}{$\begin{array}{l}\text { Locrtion(g) of } \\
\text { Maxitand Beftect }\end{array}$} & \multirow{2}{*}{$\begin{array}{c}\text { Awerogt } \\
\text { Dettelted } \\
\text { Result }\end{array}$} & \multicolumn{3}{|c|}{$\begin{array}{l}\text { Nonaber of } A \text { ralyos } \\
\text { Irceediog Criteris }\end{array}$} \\
\hline & & & & & $\begin{array}{l}\text { Ind } \\
\text { PRG }\end{array}$ & $\begin{array}{l}9 \% \\
91\end{array}$ & $\begin{array}{l}\text { Res } \\
\text { PRG }\end{array}$ \\
\hline 1,2,3-Trucblorabenzene & $27 \mathrm{~J}$ & 27 & 22.EU33B-117 & 27 & $\mathbf{N A}$ & $\mathrm{NA}$ & $\mathrm{NA}$ \\
\hline 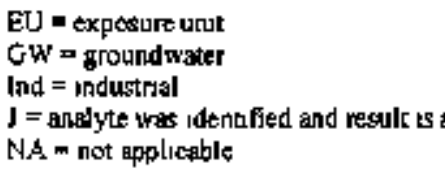 & ppoximare c & icentration & $\begin{array}{l}\text { PRG = prelisanar } \\
\text { Res = resendential } \\
\text { BL = screentsig lo } \\
\text { VOC = voletule or }\end{array}$ & $\begin{array}{l}\text { retinedjalior } \\
\text { ganx cormpa }\end{array}$ & & & \\
\hline
\end{tabular}

K-1004-A,B,C Dilution Pit East Center (DP EU33D-332): Biased sampling was reconmended for this site in the Assessment Report based on Class 3 SU walkover assessment visual observations. A sediment sample collected from the pil exceeded multiple metal, PCB, radionuelide, and VOC evaluation criteria. Two soil samples collected outside the dilution pit and at the pit's base level were analyzed for metals, PCBs, radionuclides, SVOCs, and VOCs. Analytical resules from the two samples collected at the base level of the pit showed no contamination had leaked from the pit. A remedial action conducted in this area removed the dilution pit and the sediment sample location (Table 3). A confilmation sample was collected following the remedial action. Sample locations representative of eurrent conditions at the K-1004-A,B,C Dilution Pit East Center are presented in Table 3. These locations included samples Z2-EU33B-1 19, 22-EU33B-120 from the base level of the pit [one sample was at a depth of $\geq 10 \mathrm{ft}$ (Table 3)] and confirmation sample location Z2-EU33B-378. Analytical results summarized below from the sample locations representative of current conditions show radionuclide Ind PRG exceedances, metal and radionuclide Bkg exceedances, and one VOC detection.

EU 22-33 K-1004-A,B,C DILUTION PCT EAST CENTER NETALS WTTH BACKGROUND, PRG, GW SL, AND/OR RL EXCEEDANCES (mL/4P) 0-10 ft

\begin{tabular}{|c|c|c|c|c|c|c|c|c|c|c|c|}
\hline \multirow[b]{2}{*}{ Anslytt } & \multirow[b]{2}{*}{$\begin{array}{c}\text { Deteet } \\
\text { trequetury }\end{array}$} & \multirow[b]{2}{*}{$\begin{array}{c}\text { MLinum } \\
\text { delect }\end{array}$} & \multirow[b]{2}{*}{$\begin{array}{c}\text { Mazinam } \\
\text { detect }\end{array}$} & \multirow{2}{*}{$\begin{array}{c}\text { Loeation(s) of } \\
\text { marimum } \\
\text { detect }\end{array}$} & \multirow{2}{*}{$\begin{array}{l}\text { Average } \\
\text { detected } \\
\text { renult }\end{array}$} & \multicolumn{6}{|c|}{ Number of andyses exceedlue crifterg } \\
\hline & & & & & & $\begin{array}{c}\text { Max } \\
\text { RL }\end{array}$ & $\begin{array}{l}\text { Avg } \\
\text { RL }\end{array}$ & $\begin{array}{l}\text { Ind } \\
\text { PRG }\end{array}$ & Bkg & $\begin{array}{l}\text { GW } \\
\text { SL }\end{array}$ & $\begin{array}{l}\text { REs } \\
\text { PRG }\end{array}$ \\
\hline Aluminumin & $3 / 3$ & 7,500 & 15,000 & Z2-EU33B-378 & 10,733 & $\mathbf{N A}$ & NA & 0 & 0 & NA & 2 \\
\hline Arserlc & $3 / 3$ & I 7 & II & 2Z-EU33B-378 & 567 & 0 & 0 & 0 & 0 & $\mathbf{0}$ & 3 \\
\hline Cadmım & $2 / 3$ & 015 & 031 & Z2-EU33B-378 & 023 & NA & NA & 0 & 1 & Nk & 0 \\
\hline Calaum & $3 \sqrt[3]{3}$ & 1,200 & 43,000 & Z2-EU338-119 & 17,667 & NA & $N \AA$ & NA & 2 & $\mathrm{NA}$ & NA \\
\hline Chromium & $3 A$ & 13 & 25 & $22-E 0193 B-119$ & 20 & $N A$ & NA & 0 & 4 & 0 & $\mathbf{I}$ \\
\hline Copper & $3 / 3$ & $42 J$ & $25 \mathrm{~J}$ & Z2-ẼU33B-378 & 137 & NA & $\mathrm{NA}$ & 0 & 1 & $\mathrm{NA}$ & 0 \\
\hline tran & $3 A$ & $21,0<0)$ & $46,000)$ & Z2-EนJ3B-378 & 31,667 & $\mathrm{NA}$ & NA & 0 & 0 & NA & 3 \\
\hline Maggnesumm & $3 / 9$ & 570 & 23,000 & Z2-EU33B-H 19 & 9,090 & NA & $\mathrm{NA}$ & $N A$ & 2 & NA & $\mathrm{NA}$ \\
\hline Mangencese & $3 / 9$ & 6401 & 6801 & 22-EU33B-I20 & 657 & NA & NA & 0 & 0 & NA & 3 \\
\hline Mercury & 33 & $0 ! 2 J$ & $T \mathrm{JJ}$ & Z2-EU33B-379 & 245 & 0 & 0 & 0 & 1 & $N A$ & 1 \\
\hline Selentum & $2 / 3$ & 19 & 19 & $\begin{array}{l}\text { Z2-EU33B-1 19 } \\
\text { Z2-EU33B-120 }\end{array}$ & 19 & NA & NA & $\theta$ & 2 & NA & 0 \\
\hline Urastaum & $3 / 3$ & 078 & 25 & Z2-EU33B-1t9 & 196 & $\mathrm{NA}$ & $N A$ & $\theta$ & $N A$ & $N A$ & 2 \\
\hline Vanadium & $3 / 3$ & 23.5 & 54 & Z2-EU33B- 378 & 35 & NA & NA & 0 & 0 & NA & 3 \\
\hline \multicolumn{5}{|c|}{$\begin{array}{l}\text { Ayg = arerage } \\
\text { Bkg = backsroumd } \\
\text { EU = exposure undt } \\
\text { GW = groupdurater } \\
\text { lod = Industrial } \\
\mathrm{J}=\text { analyte was identied a }\end{array}$} & \multicolumn{7}{|c|}{ 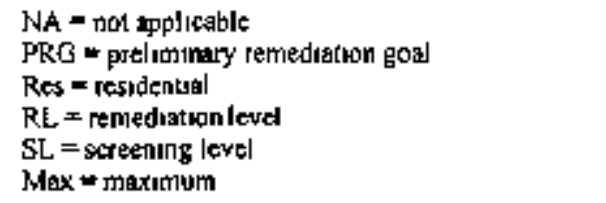 } \\
\hline
\end{tabular}

Polychlorunated biphenyls were analyzed for in the three samples but were not detected. 
EU 22-33 K-1004-A,B,C DILUTHOA PIT EAST CENTER RADIONUCEIDES WTTH BACKCROUND, PRO, AND/OR RL EXCEEDANCES (pC//z) (0-1) ft

\begin{tabular}{|c|c|c|c|c|c|c|c|c|c|c|c|}
\hline \multirow[b]{2}{*}{ Ausyte } & \multirow[b]{2}{*}{$\begin{array}{c}\text { Detect } \\
\text { frequency }\end{array}$} & \multirow[b]{2}{*}{$\begin{array}{c}\text { Mininum } \\
\text { detret }\end{array}$} & \multirow[b]{2}{*}{$\begin{array}{c}\text { Masioinm } \\
\text { detect }\end{array}$} & \multirow[b]{2}{*}{$\begin{array}{l}\text { Locstiou(b) of } \\
\text { naximum detcet }\end{array}$} & \multirow{2}{*}{$\begin{array}{l}\text { Average } \\
\text { delteted } \\
\text { regelt }\end{array}$} & \multicolumn{6}{|c|}{ Number of anahosed exces: ing criterle } \\
\hline & & & & & & $\operatorname{Mrx}$ & $\begin{array}{l}\text { Avg } \\
\text { RL }\end{array}$ & $\begin{array}{l}\text { Ind } \\
\text { PRG }\end{array}$ & Bkg & $\begin{array}{l}\text { 5W } \\
\text { SL }\end{array}$ & $\begin{array}{l}\text { Res } \\
\text { PRG }\end{array}$ \\
\hline CEsium-137 & IA & 02975 & 0297 & 22-EU33B-378 & 0297 & 0 & 0 & 0 & NA & NA & 1 \\
\hline Potassum -40 & $3 / 3$ & II 2 & $158 \mathrm{~J}$ & Z2-EU33B-378 & 142 & NA & NA & 3 & 0 & NA & 3 \\
\hline Thontm-228 & $3 / 3$ & 12 & 194 & 22-EL33B-378 & 162 & NA & NA & 3 & 1 & NA & 3 \\
\hline Thonum-230 & $3 / 3$ & 135 & 205 & 22-EU33日-119 & 170 & $\mathrm{NA}$ & NA & 0 & 3 & NA & 0 \\
\hline Thontm-232 & $3 / 3$ & 124 & 149 & Z2-EU33B-376 & 136 & $\mathrm{NA}$ & NA & 3 & 0 & NA & $\mathbf{3}$ \\
\hline Uranium-234 & $3 / 3$ & 437 & 839 & 22-EU3白-119 & 675 & 0 & 0 & 0 & $\mathrm{NA}$ & 0 & 3 \\
\hline Uranıum-235 & $3 / 3$ & $0141 \mathrm{~J}$ & $037 ! 1$ & Z2-EU33B-119 & 0276 & 0 & 0 & 0 & NA & 0 & 2 \\
\hline Uranium-238 & $3 / 3$ & 14 & 252 & 22-EU133B-3/8 & 211 & 0 & 0 & 0 & 2 & 0 & 3 \\
\hline
\end{tabular}

AYB $=$ ayeragc

$\mathbf{B k g}=$ background

EU $=$ expostur ant

$G W *$ groundwater

Ind = indugmal

$J=$ analyte was Identılied and resulf us approx.|make combentration
NA = noi applicable

PRG = prej Lainary remediaton pool

Res = residenttal

RL = remedtatoon level

$\$ L$ a screening level

Max $=$ max $\mid$ mutn

Semivolatile organic compounds were analyzed for in two samples but were not detected.

EU Z2-33 K-IO04-A,B,C DILUTIOA PIT EAST CENTER VOC DETECTS (OE/Kg) 0-10 ft

\begin{tabular}{|c|c|c|c|c|c|c|c|c|}
\hline \multirow{2}{*}{ Alalyte } & \multirow[b]{2}{*}{$\begin{array}{l}\text { Detect } \\
\text { frequency }\end{array}$} & \multirow[b]{2}{*}{$\begin{array}{l}\text { Mininum } \\
\text { detect }\end{array}$} & \multirow[b]{2}{*}{$\begin{array}{l}\text { Maximan } \\
\text { detect }\end{array}$} & \multirow{2}{*}{$\begin{array}{l}\text { Locintion(s) of } \\
\text { Innyiungen detect }\end{array}$} & \multirow{2}{*}{$\begin{array}{l}\text { Average } \\
\text { detectod } \\
\text { rebult }\end{array}$} & \multicolumn{3}{|c|}{$\begin{array}{l}\text { Nember of antlyes } \\
\text { excetiding suiterls }\end{array}$} \\
\hline & & & & & & $\begin{array}{l}\text { Ind } \\
\text { PRG }\end{array}$ & SL. & $\begin{array}{l}\text { Ret } \\
\text { PRG }\end{array}$ \\
\hline Trushlotocthene & $\mathrm{I} / \boldsymbol{Z}$ & $26 \mathrm{~J}$ & $26 \mathrm{~J}$ & Z2-EU33B-I19 & 26 & 0 & 0 & 0 \\
\hline $\begin{array}{l}\text { EU = exposure un| } \\
\text { GW - groundwate } \\
\text { Ind = industral } \\
J=\text { analyte was ide }\end{array}$ & Ad result is & & & $\begin{array}{l}\text { PRG = prelim } \\
\text { Res = ressdent } \\
\text { SL = scretnin } \\
\text { YOC = yolalul }\end{array}$ & $\begin{array}{l}\text { iry remediat } \\
\text { evel } \\
\text { organis com }\end{array}$ & & & \\
\hline
\end{tabular}

Gravel Wash Area (EU33D-333): This area is located south and adjacent to the former K-1004-L concrete pad and was reported to have been used for rinsing filters. Biased sampling for this site was recomrnended in the Assesstnent Report based on a radiation measurement that exceeded the SL. The boundaries of the gravel wash area were delineated visually and three soil sample locations were identified along the eastern, southern, and western boundaries (K-1004-L concrete pad was the northen boundary), and one sample location was identified inside the gravel wash area. The U-234 and U-238 Avg RLs and-U-238 Max RL were exceeded at the sample location inside the gravel wash area and the PCB-1254 Avg RL was exceeded at the eastem boundary sample location. The gravel wash area was removed during a remedial action that also removed all four sample locations. A follow-up BAR survey identtfied a small area with residual radiation in excess of the AL (Sect. 2.1.1.1) and additional soils were excavated. Following the remedial action, five confmmation samples were collected from the excavation and analyzed for uranium isotopes. Sample locations that represent current conditions are presented in Table 3. Analytical results summarized below from the sample locations representative of current conditions show two U-238 Bkg exceedarices.

EU Z3-33 GRAVEL WASH AREA RADIONUCLDES WITH BACKGROUND, PRG, ANB/OR RL EXCEEDANCES (pC//g) 0-10 i1

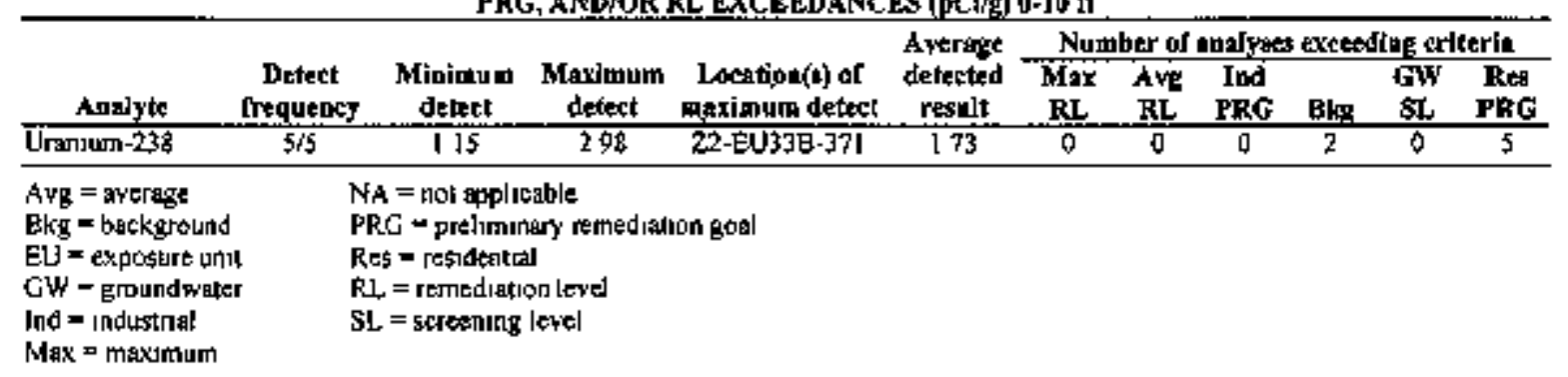


Brick-Lined Drain Pit (EU33D-334): This pit is a storm drain that received runoff from the Gravel Wash Area (EU33D-333) and was recommended for biased sampling in the Assessment Report. A DVS biased sample location was identified (Sect 2.2.3) and a sample of sediment from the storm drain was collected. Analytical results summarized below show U-235 and U-238 Avg RL exceedances; one metal and several radionuclide and SVOC Ind PRG exceedances; metal and radionuclide Bkg exceedances; U-234 and U-238 GW SL exceedances; and PCB, SVOC, and VOC detections.

EU 22-33 BRICK-LINE[ IBRAIN PIT METALS WITH BACKGROUND,

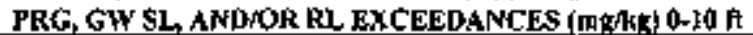

\begin{tabular}{|c|c|c|c|c|c|c|c|c|c|c|c|}
\hline \multirow[b]{2}{*}{ Anabyte } & \multirow[b]{2}{*}{$\begin{array}{c}\text { Detest } \\
\text { trequency }\end{array}$} & \multirow[b]{2}{*}{$\begin{array}{l}\text { Miluituum } \\
\text { dettoct }\end{array}$} & \multirow[b]{2}{*}{$\begin{array}{l}\text { Mavilnum } \\
\text { detect }\end{array}$} & \multirow{2}{*}{$\begin{array}{c}\text { Location(s) of } \\
\text { maximum } \\
\text { detext }\end{array}$} & \multirow{2}{*}{$\begin{array}{l}\text { Aperage } \\
\text { Actected } \\
\text { restlt }\end{array}$} & \multicolumn{6}{|c|}{ Namber of englyses exceeding criteris } \\
\hline & & & & & & Min & $\begin{array}{l}\text { Avg } \\
\text { RL }\end{array}$ & $\begin{array}{l}\text { Ind } \\
\text { PRG }\end{array}$ & Elsu & $\begin{array}{l}\text { GW } \\
\text { SL }\end{array}$ & $\begin{array}{l}\text { Reg } \\
\text { PRG }\end{array}$ \\
\hline Alumınum & $3 / 1$ & $8,1,0$ & 8,180 & $22-E \bigcup 33 \mathrm{~B} \cdot 334$ & $B, 180$ & NA & $N_{A}$ & 0 & 0 & $\mathrm{NA}$ & 1 \\
\hline Arsenic & 川 & 10 J & 10 叮 & 22-EU33B-334 & 109 & 0 & 0 & 0 & 0 & 0 & 1 \\
\hline Bgritum & lUI & 24BJ & 248J & Z2-EU33B-334 & 248 & $\mathrm{NA}$ & NA & 0 & $\mathbf{I}$ & a & 0 \\
\hline Cadminum & $\boldsymbol{T} \boldsymbol{H}$ & 651 & 6.5 .5 & 22-EU33日-334 & 65 & NA & NA & 0 & $\mathbf{I}$ & $\mathrm{NA}$ & $\mathrm{l}$ \\
\hline Calcium & $1 / 1$ & $89,6000)$ & $39,6000 \mathrm{~J}$ & Z2-EU33B-334 & 89,600 & NA & $\mathrm{NA}$ & $\mathrm{NA}$ & I & $\mathrm{NA}$ & $\mathrm{NA}$ \\
\hline Chromierm & $\mathbf{I} / \mathbf{I}$ & 100 & 100 & 22-EU33B-334 & 100 & NA & NA & 0 & $\mathbf{I}$ & 0 & l \\
\hline Copper & $|\boldsymbol{I}|$ & 191 & 191 & 22-EU33B-934 & 191 & NA & $\mathrm{N} \cdot \mathrm{A}$ & 0 & $\mathbf{I}$ & NA & 0 \\
\hline ]ron & $\boldsymbol{b} \boldsymbol{I}$ & $15,800 \mathrm{~J}$ & $\mid 5,800)$ & Z2-EU33B-334 & 15,800 & NA & NA & 0 & 0 & NA & $!$ \\
\hline Leat & $\mathrm{E} / \mathbf{I}$ & $236 J$ & $236 \mathrm{~J}$ & 22-EU33B-334 & 236 & NA & NA & 0 & $\mathbf{I}$ & 4 & 0 \\
\hline Magnesiurd & VI & ]1.200J & $11,200 \mathrm{~J}$ & 22-EU33E-334 & 11,200 & $N A$ & NA & $N A$ & $\mathbf{I}$ & $\mathrm{NA}$ & NA \\
\hline Mauganese & IfI & -3711 & $37 ! J$ & Z2-EU33B-334 & 371 & NA & NA & 0 & 0 & $N A$ & 1 \\
\hline Mtercury & 1 I & 1331 & 1333 & Z2-EU33日-334 & 133 & 0 & 0 & 0 & $\mathbf{I}$ & NA & 1 \\
\hline Nickel & $1 \|$ & $100 \mathrm{~J}$ & $107 \mathrm{~J}$ & Z2-EU1336-334 & 107 & $N_{A}$ & NA & 0 & $\mathbf{I}$ & NA & 0 \\
\hline Silyet & Wl & 611 & $6 \mathrm{ld}$ & Z2-EU33B-334 & 61 & NA & NA & 0 & 1 & $N A$ & 0 \\
\hline Sodjum & $1 / 1$ & 1,260 & 1,260 & 22-EЏ33B-334 & 1,260 & $N A$ & NA & $\mathrm{NA}$ & $\mathbf{I}$ & NA & NA \\
\hline Uran:ium & III & 6921 & 6921 & Z2-EU33日-334 & 692 & NA & NA & I & WA & NA & 1 \\
\hline Yanadium & UI & ll & 11 & Z2-EU33B-334 & 11 & $\mathrm{NA}$ & NA & 0 & 0 & $N /$ & 1 \\
\hline Zınc & UI & 797 & 797 & 27-EU33B-334 & 797 & NA & $N A$ & 0 & $\mathbf{I}$ & NA & 0 \\
\hline \multicolumn{5}{|c|}{$\begin{array}{l}\text { Avg = gverage } \\
\text { Bke = beckground } \\
\text { EU - exposure unit } \\
G W=\text { groundwatef } \\
\text { Ind = uidusirial } \\
\text { = analyte was dentufi }\end{array}$} & \multicolumn{7}{|c|}{$\begin{array}{l}\text { Max = maxumum } \\
\text { NAA = not applicable } \\
\text { PRG = preintunary remedialeon goul } \\
\text { Res = residentıat } \\
\text { RL a remediation leyed } \\
\text { SL = sereening ievel }\end{array}$} \\
\hline
\end{tabular}

EU Z2-13 BRICK-LJNEI DRA]N PIT PPCB DETECTS (EfK:) 0-t0 it

\begin{tabular}{|c|c|c|c|c|c|c|c|c|c|}
\hline \multirow[b]{2}{*}{ Analyfe } & \multirow[b]{2}{*}{$\begin{array}{l}\text { Detect } \\
\text { Jrequency }\end{array}$} & \multirow[b]{2}{*}{$\begin{array}{l}\text { Minimum } \\
\text { detect }\end{array}$} & \multirow[b]{2}{*}{$\begin{array}{l}\text { Maximpar } \\
\text { detect }\end{array}$} & \multirow{2}{*}{$\begin{array}{c}\text { Loention(s) of } \\
\text { maxtimum } \\
\text { detect }\end{array}$} & \multirow{2}{*}{$\begin{array}{l}\text { Apersige } \\
\text { detected } \\
\text { renult }\end{array}$} & \multicolumn{4}{|c|}{ 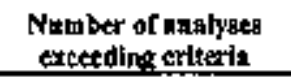 } \\
\hline & & & & & & $\begin{array}{l}\text { Mar } \\
\text { AL }\end{array}$ & $\begin{array}{l}\text { Ave } \\
\text { RL }\end{array}$ & $\begin{array}{l}\text { lod } \\
\text { PRG }\end{array}$ & $\underset{\text { PRts }}{\text { PRt: }}$ \\
\hline $\mathrm{PCB}-1254$ & $1 / 1$ & 2.300 & 2.300 & Z2-EU33B-334 & 2,300 & 0 & 0 & 0 & ] \\
\hline $\mathrm{PCB}=1260$ & $1 / 1$ & $920 \mathrm{~J}$ & $920 \mathrm{~J}$ & 22-EU33B-334 & 920 & 0 & 0 & 0 & $\mathbf{I}$ \\
\hline Poilychlorınaled Bipheny| & III & $3,300 \mathrm{~J}$ & $3,300 \mathrm{~J}$ & Z2-EU33B-3344 & 3,300 & 0 & 0 & 0 & 1 \\
\hline
\end{tabular}

A $Y \mathrm{P}=$ average

EU - exposure unut

Ind = Indust $\sqcap$ \&F

$J=$ anglyte was identified and result is approximale concentration

Max = maxirnum

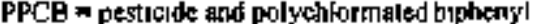

PRG = prelumistary remediatori sod

Res $=$ residential

RL = remedıatuon level 
EU Z2-33 BRICK-LINED DRAIN PIT RADJONUCLIDES WTTH RACKGROUND, PRG, ANBHOR RL, EXCEEDANCES (pClg) 0-10 it

\begin{tabular}{|c|c|c|c|c|c|c|c|c|c|c|c|}
\hline \multirow[b]{2}{*}{ Anabyte } & \multirow[b]{2}{*}{$\begin{array}{c}\text { Detect } \\
\text { irequency }\end{array}$} & \multirow[b]{2}{*}{$\begin{array}{c}\text { Mininum } \\
\text { deted }\end{array}$} & \multirow[b]{2}{*}{$\begin{array}{l}\text { Maximum } \\
\text { detest }\end{array}$} & \multirow[b]{2}{*}{$\begin{array}{c}\text { Loshinon(g) of } \\
\text { maximun detect }\end{array}$} & \multirow{2}{*}{$\begin{array}{c}\text { Afercoge } \\
\text { detected } \\
\text { result }\end{array}$} & \multicolumn{6}{|c|}{ Nugher of anabgac excetodig ariteria } \\
\hline & & & & & & $\begin{array}{l}\text { Max } \\
\text { RL }\end{array}$ & AYg & $\begin{array}{l}\text { Ipd } \\
\text { PRG }\end{array}$ & B $k g$ & $\begin{array}{l}\text { GW } \\
\text { SL }\end{array}$ & $\begin{array}{l}\text { Res } \\
\text { PRG }\end{array}$ \\
\hline Polassitum.40 & 1 1 & 73 & 73 & $22 \cdot E \backslash 33 \mathrm{~B}-334$ & 73 & NA & NA & 1 & 0 & $\mathrm{NA}$ & I \\
\hline Radium-226 & WI & 065 & 065 & 22-EU33B-334 & 065 & $\mathrm{NA}$ & NA & 1 & 0 & NA & $\mathbf{I}$ \\
\hline Technetnun-99 & $1 / 1$ & $1 ! 6$ & 116 & Z2-EU33B-334 & 116 & NA & NA & 0 & $\mathrm{NA}$ & NA & 1 \\
\hline Tharımm-27\% & U & $0 \$ 2$ & $0 \$ 2$ & 2A-El/33B-334 & $0 \$ 2$ & NA & NA & 1 & 0 & NA & 1 \\
\hline Thoriun-232 & $1 / 1$ & 067 & 063 & Z2-EU33B-334 & 067 & NA & NA & 1 & 0 & NA & $\mathbf{i}$ \\
\hline Џгепाитा-234 & lfI & 227 & 223 & 22-EU33日-334 & 227 & 0 & 0 & 0 & NA & 1 & 1 \\
\hline Urantum-235 & $|f|$ & 115 & $11 \mathrm{~s}$ & Z2-EU33B-334 & 115 & 0 & I & J & $\mathrm{NA}$ & 0 & ] \\
\hline Uranium-238 & $H^{\prime \prime}$ & 244 & 244 & Z2-EU33B-334 & 244 & 0 & $\mathbf{I}$ & l & ] & $\mathbf{I}$ & 1 \\
\hline
\end{tabular}

Ave = urecage $\quad$ NA $=$ nol applicible

Bkg = background $\quad$ PRO $=$ prel|minary remedisturn goal

$E U=$ expossure unit Res $=$ residential

$\mathrm{G} W=$ grotundwater $\quad \mathrm{RL}=$ remediation lovel

3nd = induseral $\quad \$ L=$ screnting level

Max m maximum

EU Z2.33 BRICK-LINED DRATN PIT SVOC DETECTS (ug/kg) 0-10 ft

\begin{tabular}{|c|c|c|c|c|c|c|c|c|}
\hline \multirow[b]{2}{*}{ Analyte } & \multirow[b]{2}{*}{$\begin{array}{c}\text { Detect } \\
\text { frepuency }\end{array}$} & \multirow[b]{2}{*}{$\begin{array}{l}\text { Minirrun } \\
\text { detext }\end{array}$} & \multirow[b]{2}{*}{$\begin{array}{l}\text { Maninum } \\
\text { detec1 }\end{array}$} & \multirow[b]{2}{*}{$\begin{array}{l}\text { Lacition(s) of } \\
\text { manmon fetect }\end{array}$} & \multirow{2}{*}{$\begin{array}{l}\text { A verdiqt } \\
\text { detectid } \\
\text { result }\end{array}$} & \multicolumn{3}{|c|}{$\begin{array}{l}\text { Namber of amolyes } \\
\text { erceediag criteru }\end{array}$} \\
\hline & & & & & & $\begin{array}{l}\text { Ind } \\
\text { PAg }\end{array}$ & SL & $\begin{array}{l}\text { REG } \\
\text { PRG }\end{array}$ \\
\hline 2-J4echylnaphthalene & bII & 11,000 & 11,000 & 22-EU33B-334 & 11,900 & 0 & $\mathrm{NA}$ & NA \\
\hline Acenaphthene & II & 38,000 & 38,000 & $22-E Џ 33 B-334$ & 38,000 & 0 & NA & 0 \\
\hline Anthracenc & |リ & 82,000 & 82000 & 22-EU33日-334 & 82,000 & 0 & $\mathrm{NA}$ & 0 \\
\hline Benz(a)anthtacene & I/I & 190.000 & 190,000 & Z2.EU33B-334 & 190,000 & $\mathbf{I}$ & NA & $\mathbf{I}$ \\
\hline Bentzo(a)pyrente & $|H|$ & 170,000 & 170,000 & Z2-EU33B-334 & 170,000 & 1 & $\mathrm{NA}$ & I \\
\hline Benzo(b)fluor क्षhorent & WI & 170,000 & 170,000 & 22-EU33日-334 & 170,000 & 1 & NA & $\mathbf{I}$ \\
\hline Benzo(ghi)perylene & $|\boldsymbol{J}|$ & 92,600 & $92,0 \mathrm{k} 10$ & Z2-EU33B-334 & 92,900 & 0 & NA & $\square$ \\
\hline Benzo(k)filuprenthene & W/ & 170,000 & 170,000 & Z2-EU33B-334 & 170,000 & 0 & $\mathrm{NA}$ & $\mathbf{I}$ \\
\hline BLs(2-ethylhexyl)phthalate & |ノ & 18,000 & 18,000 & Z2-EU33日-334 & 18,000 & 0 & 0 & 0 \\
\hline Bucyl betroyl plathalate & $\mid \boldsymbol{|}$ & 19,000 & 19,000 & Z2-EU39B-334 & 19,400 & 0 & NA & 0 \\
\hline Cartoazole & $\mathbf{M}$ & 53,000 & 53,000 & 22-EU33B-334 & $53,0,00$ & 0 & NA & $\mathbf{I}$ \\
\hline Chrysene & $\mid \boldsymbol{I S I}$ & 220,060 & 220,0001 & Z2-EU33B-334 & 220,000 & 0 & NA & $\mathbf{I}$ \\
\hline Doberre(a)h)anthracene & $\mathbf{1} /$ & 23,000 & 23,000 & Z2-EU33B-334 & 23,600 & 1 & $\mathrm{NA}$ & $\mathbf{I}$ \\
\hline Dibenzofurap & $\mid \boldsymbol{|}$ & 23,000 & $23,0 \times 0$ & Z2. EU 33 B -334 & 23,000 & 0 & NA & $\mathbf{I}$ \\
\hline Fluoranthene & $|/|$ & 500,0000 & 590,000 & Z2-EU33B-334 & 500,000 & 0 & NA & $\mathbf{I}$ \\
\hline Fuकrene & I'I & 29,000 & 29,000 & 22-EU33.3-334 & 29,000 & 0 & NA & 0 \\
\hline Indeno( $(1,2,3-c d)$ pyfene & $|/|$ & 77,000 & 37,000 & Z2-EU33B-33A & 77,000 & 1 & NA & $\mathbf{I}$ \\
\hline m+p Methylphenot & If & $450 \mathrm{~S}$ & 45口j & Z2-EU33B-334 & 450 & $\mathrm{NA}$ & NA & NA \\
\hline Naphthalents & 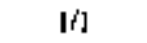 & 31,0000 & $31, \infty 0$ & 22-EU33B-33A & 31,000 & 0 & NA & $\mathbf{I}$ \\
\hline Phenanthrene & $\mid f^{\prime \prime}$ & 370,000 & 370,000 & Z2-EU33B-334 & 370,000 & 0 & NA & $\mathbf{I}$ \\
\hline Phemol & {$[r]$} & $260 \mathrm{~J}$ & $260 \mathrm{~J}$ & 22-EU333-334 & 260 & 0 & NA & 0 \\
\hline Pytene & {$[/]$} & 340,000 & 340,000 & Z2-EU33B-334 & 340,000 & 0 & NA & 子 \\
\hline
\end{tabular}

EU $=$ exposure unit

GW $=$ groundwale

PRO = preluminary temediatuon goal

Ind = andustrial

Res = reșidenbal

$\mathrm{J}=$ dnatyle was identefied and result is approximute conkentrabon

SL = screening level

$\mathrm{NA}=$ not applicteble

SVOC - semirolatile orgarue compound 
EU Z2-33 BRICK-LINED DRAIN PIT VOC DETECTS (ng/kg) 0 -10 ft

\begin{tabular}{|c|c|c|c|c|c|c|c|c|}
\hline \multirow[b]{2}{*}{ Anelyte } & \multirow[b]{2}{*}{$\begin{array}{c}\text { Detect } \\
\text { Irequency. }\end{array}$} & \multirow[b]{2}{*}{$\begin{array}{l}\text { Mifpiomum } \\
\text { detect }\end{array}$} & \multirow{2}{*}{$\underset{\substack{\text { Getect } \\
\text { Medmunin }}}{-}$} & \multirow{2}{*}{$\begin{array}{c}* \\
\text { Locution(j) of } \\
\text { neximmo detect }\end{array}$} & \multirow{2}{*}{$\begin{array}{c}\text { Average } \\
\text { defecled } \\
\text { redalt }\end{array}$} & \multicolumn{3}{|c|}{$\begin{array}{l}\text { Nomber or aualysea } \\
\text { ercetuting criterla }\end{array}$} \\
\hline & & & & & & $\begin{array}{l}\text { Ind } \\
\text { PRG }\end{array}$ & $\begin{array}{l}\text { GH } \\
\text { SL }\end{array}$ & $\begin{array}{l}\text { Res } \\
\text { PRG }\end{array}$ \\
\hline els-1,2-Dethlorogthent & III & $91 \mathrm{~J}$ & 95. & Z2.EU33B-334 & 91 & 0 & $\mathrm{NA}$ & 0 \\
\hline Truchloroethert & It) & Id아 & I40T & 22-EU33日-334 & 140 & 0 & 0 & 1 \\
\hline 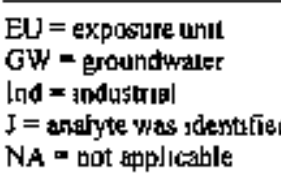 & and result is & proxsmate & centration & \multicolumn{5}{|c|}{ 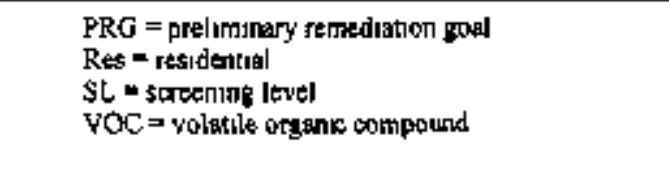 } \\
\hline
\end{tabular}

Acid Dilution Pit South of K-1004-L (EU33D-335): Biased sarnpling was recommended for this site in the Assessment Report based on Class 3 SU walkover assessment visual observations summarized. A sediment sample

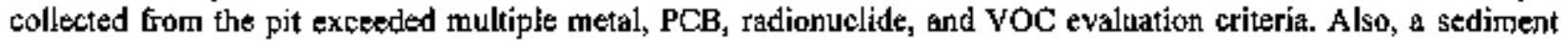
sample was collected from a manhole adjacent to pit. Analytical results from the manhole sample showed arsenic and iron ind PRG exceedances and a chromjum GW SL exceedance. The pit was removed during a remedial action that also removed the sedtrment sample location (Tabie 3). Following the remedial action, a confirmation sampie was collected from a depth $>10 \mathrm{ft}$ bgs. Sample locations representative of current conditions are presented in Table 3 and include sediment sample Z2-EU33B-365 inside the manhole and confirmation sample Z2-EU33B-381. Analytical results summarized below from the sample locations representative of cument conditions show two metal and three redionuclide Ind PRG exceedances, a chromium GW SL exceedance, metal and radionucide Bkg exceedances, and one SVOC and one VOC detection.

EU Z2-33 ACID DIUUTION PJT SOUTH OF K-1004-L METALS WITH BACKGROUND, PRG, GW SL, AND/OR RL EXCEEDANCES (m/ME) 0-10 fi

\begin{tabular}{|c|c|c|c|c|c|c|c|c|c|c|c|}
\hline \multirow[b]{2}{*}{ Andifyte } & \multirow[b]{2}{*}{$\begin{array}{c}\text { Deteet } \\
\text { frequency }\end{array}$} & \multirow[b]{2}{*}{$\begin{array}{c}\text { Minignum } \\
\text { deted }\end{array}$} & \multirow[b]{2}{*}{$\begin{array}{l}\text { Maximon } \\
\text { detect }\end{array}$} & \multirow{2}{*}{$\begin{array}{l}\text { Locition(a) of } \\
\text { maximum } \\
\text { delect }\end{array}$} & \multirow{2}{*}{$\begin{array}{l}\text { Average } \\
\text { detected } \\
\text { resuli }\end{array}$} & \multicolumn{6}{|c|}{ Number of nalyses excesiding criterla } \\
\hline & & & & & & $\begin{array}{l}\text { Mrx } \\
\text { RL }\end{array}$ & $\begin{array}{l}\text { Aw } \\
\text { RL }\end{array}$ & $\begin{array}{l}\text { Ind } \\
\text { PRC }\end{array}$ & Bkg & $\begin{array}{l}\text { GW } \\
\text { SL }\end{array}$ & $\begin{array}{c}\text { Reg } \\
\text { PRG }\end{array}$ \\
\hline Aluminum & $2 / 2$ & $5,330 \mathrm{~J}$ & 13,000 & Z2-EU338-38I & 9,165 & $N A$ & $N A$ & 0 & 0 & NA & I \\
\hline Antmonony & $1 / 2$ & $35 J$ & $35 \mathbf{J}$ & Z2-EU $338-36.5$ & 35 & $\mathrm{NA}$ & NA & 0 & 1 & 0 & $\mathbf{I}$ \\
\hline Arsentc & $2 / 2$ & 48 & $2 \mathrm{I} 5 \mathrm{~J}$ & Z2-EU33B-365 & 132 & 0 & 0 & ] & ] & 0 & 2 \\
\hline Cadmum & $2 / 2$ & 031 & 3 & Z2-EU33B-365 & 16.5 & NA & $\mathrm{NA}$ & 0 & 2 & $N A$ & 0 \\
\hline Crecum & $2 / 2$ & 1,10 어 & $16,000 \mathrm{~J}$ & Z2-EU33B-3\$1 & 8,550 & NA & $\mathrm{NA}$ & $\mathrm{NA}$ & 1 & NA & $\mathrm{NA}$ \\
\hline Chromitum & $2 n$ & $23 \mathrm{~J}$ & 213J & Z2-EU33B-365 & 118 & $\mathrm{NA}$ & NA & 0 & 1 & l & 2 \\
\hline Copper & $2 / 2$ & 19 & 24,0005 & $22-\mathrm{E} U 333-365$ & 12,010 & NA & NA & 0 & 1 & NA & 1 \\
\hline Iron & $2 / 2$ & 33,000 & $433,600 \mathrm{~d}$ & Z2-EU33B-365 & 233.000 & NA & $\mathrm{NA}$ & 1 & ] & $N A$ & 2 \\
\hline Lesd & $2 \pi$ & 25 & 538 & 22-ELJ33B-365 & 282 & NA & $N A$ & 0 & 1 & 0 & 1 \\
\hline MagnKs|uni & $2 / 2$ & ]$_{1} 6010$ & 3,8901 & Z2-EU33B-365 & 2.745 & NA & $\mathrm{NA}$ & $N A$ & ] & $N A$ & $\mathrm{NA}$ \\
\hline Ménganteser & $2 / 2$ & $589 J$ & $620 J$ & 22-EU33B.381 & 605 & NA & NA & 0 & 0 & $N A$ & 2 \\
\hline Mercury & $2 / 2$ & 01 & $0(64)$ & Z2-EUJ33B-365 & 037 & 0 & 0 & 0 & 1 & NA & 0 \\
\hline Nicke] & $2 / 2$ & 23 & $976]$ & Z2-EU33B-365 & 603 & NA & $\mathrm{NA}$ & 0 & ] & $\mathrm{NA}$ & 0 \\
\hline Selenıाum & $1 / 2$ & 17 & $1 T$ & 22-EU]3B-381 & 17 & NA & NA & 0 & 1 & $\mathrm{NA}$ & 0 \\
\hline SIlver & $1 / 2$ & 173 & 173 & Z2-EU33B-365 & 173 & $\mathrm{NA}$ & NA & $\theta$ & 1 & NA & 0 \\
\hline Urünım & $2 / 2$ & $15 !$ & $34 !$ & Z2-EU33E-365 & 245 & $N A$ & NA & 0 & $N A$ & $\mathrm{NA}$ & $\mathbf{I}$ \\
\hline Vanad|um & $2 / 2$ & 1721 & 25 & $22-E v 33 B-331$ & 211 & $N A$ & NA & 0 & 0 & $N_{A}$ & 2 \\
\hline Zinc & $2 \pi$ & 51 & $6.56 \mathrm{~J}$ & Z2-EU33B-365 & 354 & $\mathrm{Na}$ & NA & 0 & ] & NA & 0 \\
\hline \multicolumn{5}{|c|}{ 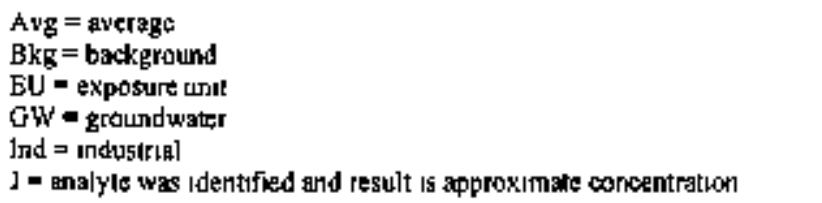 } & \multicolumn{5}{|c|}{$\begin{array}{l}\text { Max = maximumn } \\
\text { N,A = not applicable } \\
\text { PRG - prelimuntry remtdiation goal } \\
\text { Res = residantual } \\
\text { RL = remediation level } \\
\text { SL = sereenang ievel }\end{array}$} & & \\
\hline
\end{tabular}


EU Z2-33 ACID DILUTTON PIT SOUTH OF K-1004-L PPCB DETECTS (Ug/kg) 0-10 at

\begin{tabular}{|c|c|c|c|c|c|c|c|}
\hline \multirow[b]{2}{*}{ Antalyte } & \multirow[b]{2}{*}{$\begin{array}{c}\text { Detect } \\
\text { frequerey }\end{array}$} & \multicolumn{2}{|l|}{, } & \multirow{2}{*}{ 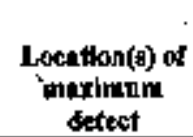 } & \multirow{2}{*}{$\begin{array}{l}\text { Aperage } \\
\text { detected } \\
\text { resilt }\end{array}$} & \multicolumn{2}{|c|}{$\begin{array}{l}\text { Nambet of analysct } \\
\text { excesding criterta }\end{array}$} \\
\hline & & $\begin{array}{c}\text { MInlmoni } \\
\text { ilstect }\end{array}$ & $\begin{array}{l}\text { Marimnn } \\
\text { deteret }\end{array}$ & & & $\begin{array}{l}\text { Max Avg } \\
\text { RL }, \mathbf{R L}\end{array}$ & $\begin{array}{l}\text { Int Res } \\
\text { PRG PRG }\end{array}$ \\
\hline PCB-1260 & $1 / 2$ & I9J & 1क] & Z2-Eしふ3B-361 & 19 & $\theta$ & 0 द \\
\hline Polychloringted Biphemyl & $1 / 2$ & 191 & $19 \mathrm{~J}$ & 22-EU33E-381 & 19 & $\theta$ & 0 \\
\hline $\begin{array}{l}\text { Avg = average } \\
\text { EU = exposure unit } \\
\text { Ind a industrial } \\
\text { J m enolyute wos idents fied } \\
\text { Mex = maximum }\end{array}$ & and result is & proxitmale & oncentralion & $\begin{array}{l}\text { PPCB }=p t \\
\text { PRG = pre } \\
\text { Res = tessi } \\
\text { RL = reme }\end{array}$ & $\begin{array}{l}\text { aticide and } \\
\text { Jummiary res } \\
\text { feitial } \\
\text { diation leve }\end{array}$ & $\begin{array}{l}\text { polychlonnate } \\
\text { mediation goil }\end{array}$ & d biphenyl \\
\hline
\end{tabular}

EU 22-33 ACIU DILUTION PJT SOUTH OF K-1004-L RADIONUCLIDES WITH BACKGROUND, PRG, AND/OR RL EXCERDANCES (pCLe) 0-10 At

\begin{tabular}{|c|c|c|c|c|c|c|c|c|c|c|c|}
\hline \multirow[b]{2}{*}{ Anelyte } & \multirow[b]{2}{*}{$\begin{array}{c}\text { Detect } \\
\text { Prequency }\end{array}$} & \multirow[b]{2}{*}{$\begin{array}{c}\text { Mlnimum } \\
\text { Detect }\end{array}$} & \multirow[b]{2}{*}{$\begin{array}{c}\text { Maximum } \\
\text { Detect }\end{array}$} & \multirow{2}{*}{$\begin{array}{c}\text { Locmtion(s) of } \\
\text { Maximug } \\
\text { Detect }\end{array}$} & \multirow{2}{*}{$\begin{array}{l}\text { Averuge } \\
\text { Detected } \\
\text { Regult }\end{array}$} & \multicolumn{6}{|c|}{ Noinbet of Analytes Erreeding Criteria } \\
\hline & & & & & & $\begin{array}{l}\text { trax } \\
\text { RL }\end{array}$ & AYt & $\begin{array}{l}\text { Inil } \\
\text { PRGG }\end{array}$ & 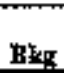 & $\begin{array}{l}\text { GW } \\
\text { SE }\end{array}$ & $\begin{array}{l}\text { Res } \\
\text { PRGG }\end{array}$ \\
\hline Neptarpum-237 & $\frac{13}{18}$ & II] & 12 & Z2-E】33B-365 & 12 & 0 & 0 & 0 & $\mathrm{NA}$ & $\mathrm{NA}$ & 1 \\
\hline Potassiumeri=40 & $1 / 2$ & 223 & 223 & Z2-EU33B-38I & 223 & NA & $N_{A}$ & I & 0 & NA & 1 \\
\hline Thonum-228 & $\boldsymbol{E} \boldsymbol{z}$ & 13 & 13 & Z2-EU33B-381 & 13 & $N A$ & NA & ! & 0 & $\mathrm{~N} / \mathrm{N}$ & l \\
\hline Thonum-232 & 12 & 0775 & 0775 & Z2-Еџ33B-79: & 0775 & NA & NA & 1 & 0 & $\mathrm{NA}$ & 1 \\
\hline Uranım-238 & $2 \Omega$ & .067 & 148 & Z2-EU33B-38I & 1075 & 0 & 0 & 0 & I & 0 & l \\
\hline \multicolumn{10}{|c|}{ 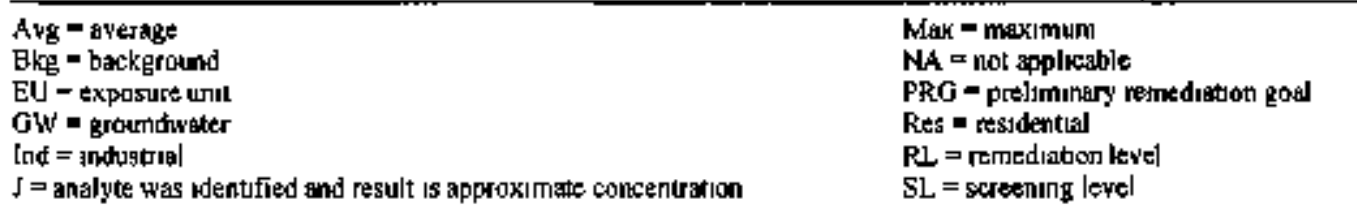 } & & \\
\hline
\end{tabular}

EU Z2-33 ACID DILUTION PIT BOUTH OF K-1004-L SVOC DETECTS (Lu/kg) 0-18 ft

\begin{tabular}{|c|c|c|c|c|c|c|c|c|}
\hline \multirow[b]{2}{*}{ Analyte } & \multirow{2}{*}{$\begin{array}{c}\text { Detect } \\
\text { frequency }\end{array}$} & \multirow{2}{*}{$\begin{array}{c}\text { Mustoum } \\
\text { detect }\end{array}$} & \multirow[b]{2}{*}{$\begin{array}{c}\text { Maxlmum } \\
\text { detect }\end{array}$} & \multirow[b]{2}{*}{$\begin{array}{l}\text { Locention[s) of } \\
\text { maximint detedt }\end{array}$} & \multirow{2}{*}{$\begin{array}{c}\text { Afrroge } \\
\text { detected } \\
\text { resulp }\end{array}$} & \multicolumn{3}{|c|}{$\begin{array}{c}\text { Number of pnalyses } \\
\text { excetiding erfferta }\end{array}$} \\
\hline & & & & & & $\begin{array}{l}\text { Ind } \\
\text { PRG }\end{array}$ & $\begin{array}{l}\text { GW } \\
\text { SL }\end{array}$ & $\begin{array}{l}\text { Res } \\
\text { PRG }\end{array}$ \\
\hline E1s(2-thylhexyl)phthelate & 11 & $3+0$ & $370 \mathrm{~J}$ & Z2-EU33B-365 & 370 & 0 & 0 & 0 \\
\hline
\end{tabular}

EU = expogure ungt $\quad$ PRG $=$ predimesary remedcation gat

GWi $=$ groundwgter

Res $=$ Eesjdential

Ind = indusutial

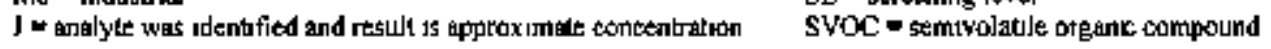

EU Z2-33 ACID DILUTION PIT SOUTH OF K-1004-L VOC DETECTS (ug/kg) 0-10 ft

\begin{tabular}{|c|c|c|c|c|c|c|c|}
\hline \multirow[b]{2}{*}{ Analyte } & \multirow[b]{2}{*}{$\begin{array}{l}\text { Minimum } \\
\text { detect }\end{array}$} & \multirow[b]{2}{*}{$\begin{array}{l}\text { Maxtmum } \\
\text { detect }\end{array}$} & \multirow[b]{2}{*}{$\begin{array}{l}\text { Locntfon(s) of } \\
\text { mavlnom detect }\end{array}$} & \multirow{2}{*}{$\begin{array}{c}\text { Averago } \\
\text { detected } \\
\text { result }\end{array}$} & \multicolumn{3}{|c|}{$\begin{array}{l}\text { Number of anelybes } \\
\text { ercetdling critexia }\end{array}$} \\
\hline & & & & & $\begin{array}{l}\text { Ind } \\
\text { PRG }\end{array}$ & $\begin{array}{l}\text { GW } \\
\text { SL }\end{array}$ & $\begin{array}{l}\text { Res } \\
\text { PRG }\end{array}$ \\
\hline Truchlorothene & $300 \mathrm{~J}$ & $300 \mathrm{~J}$ & 22-EU33B-38i & 300 & 0 & 0 & 1 \\
\hline $\begin{array}{l}\text { UJ }=\text { expossure unit } \\
G W=\text { groundwater } \\
\text { Ind = Industrial } \\
\text { J } \times \text { analyle was idenufied and result is }\end{array}$ & pproxımate c & חitentraliou & \multicolumn{5}{|c|}{$\begin{array}{l}\text { PRG = preliminary rectedlapon goal } \\
\text { Res = regidential } \\
\text { SL = screeneng leve } \\
\text { VOC - volarile organe compound }\end{array}$} \\
\hline
\end{tabular}

Bottle Area Near K-1004-L (EU33D-336): This area was located on the north side of the former K-1004-L concrete pad and was used to store bottles for K-1004-L Laboratory operations. This area was removed when the K-1004-L pad was removed during D\&D. Analytical results from the sample locations representative of current conditions at the former K-1004-L pad (see Table 3) are surmarized below in the K-1004-L Facility summary.

K-1003 Facility: Biased sampling was recommended for this site in the Assessment Report (former K-1003 Dispensary) based on stte knowledge and visual inspection performed during the Class 3 SU walkover assessment. 
One DVS biased sample location was identified (Sect. 2.2.3). Analytical results summarized below show metal Bkg exceedances and SVOC detections.

EU Z2-33 K-1003 FACILITY METALS WTTH BACKGROUND, PRG, GW SL, ANDHOR RL EXCEEDANCES ime/kgi 0-10 ft

\begin{tabular}{|c|c|c|c|c|c|c|c|c|c|c|c|}
\hline \multirow[b]{2}{*}{ Andiby } & \multirow[b]{2}{*}{$\begin{array}{c}\text { Deltet } \\
\text { frequency }\end{array}$} & \multirow[b]{2}{*}{$\begin{array}{c}\text { Miduum } \\
\text { detect }\end{array}$} & \multirow[b]{2}{*}{$\begin{array}{l}\text { Martmum } \\
\text { detect }\end{array}$} & \multirow{2}{*}{$\begin{array}{c}\text { Lacekfonis of of } \\
\text { moxitmum } \\
\text { detect }\end{array}$} & \multirow{2}{*}{$\begin{array}{l}\text { Average } \\
\text { detected } \\
\text { requilt }\end{array}$} & \multicolumn{6}{|c|}{ Number o[ anghyses exceejing uritarla } \\
\hline & & & & & & $\begin{array}{l}\text { Max } \\
\text { RI }\end{array}$ & $\begin{array}{l}\text { Ave } \\
\text { RL }\end{array}$ & $\begin{array}{l}\text { Ind } \\
\text { PRG }\end{array}$ & Bkx & $\begin{array}{l}\text { GW } \\
\text { ȘL }\end{array}$ & $\begin{array}{l}\text { Fes } \\
\text { PEG }\end{array}$ \\
\hline Aluminum & If] & $12.200 \mathrm{~J}$ & $12,200,5$ & Z2-EU338-326 & 12,200 & NA & NA & 0 & 0 & $\overline{N A}$ & ] \\
\hline Arstencic & It & 66 & $66 \mathrm{~J}$ & 22-EU33B-326 & 66 & 0 & 0 & 0 & 0 & 0 & 1 \\
\hline Cadminm & III & [03] & 031 & Z2-EVJ3B-326 & {$\left[\begin{array}{l}3 \\
3\end{array}\right.$} & $\mathrm{NA}_{\mathrm{A}}$ & NA & 0 & [ & NA & 0 \\
\hline Calcium & $|/|$ & $10,100 \mathrm{~J}$ & $10,100 \mathrm{~J}$ & Z2-EU33B-326 & 10.100 & NA & NA & NA & l & NA & NA \\
\hline Copper & $1 / 1$ & $265 \mathrm{~J}$ & $265 \mathrm{~J}$ & 22-EU33B-326 & 265 & $N A$ & $\mathrm{NA}$ & 0 & l & NA & 0 \\
\hline lron & III & 31,500 & 31,500 & Z2-EU33B-326 & 31,500 & NA & NA & 0 & 0 & NA & $\mathbf{I}$ \\
\hline Lead & $\mid \mathbf{I}^{\prime}$ & $118 J$ & [18] & Z2-EU33B-326 & 118 & NA & NA & 0 & l & 0 & 0 \\
\hline Mangariese & IfI & 403 & 403 & 22-EU33B-326 & 403 & NA & NA & 0 & 0 & NA & 1 \\
\hline Mercury & $|r|$ & 021 & 021 & Z2-EUJ3B-326 & 021 & 0 & 0 & 0 & l & NA & 0 \\
\hline Yamadıum & 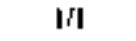 & 2573 & 2571 & Z2-EU33B-326 & 257 & NA & $N A$ & 0 & 0 & NA & I \\
\hline Zinc & lil & [47] & 1473 & 22-EЏ33日-326 & 147 & NA & $\mathrm{NA}$ & 0 & 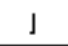 & NA & 0 \\
\hline
\end{tabular}

Avg $\times$ average $\quad$ Max $=\max \mid$ mum

Bkg $m$ background $\quad$ NA $=$ not applicable

EU - exposute unit $\quad$ PRG = prelutisinary remednatuon goal

OW $x$ groundwarter $\quad$ Res 3 Tesdential

Ind = induglisial $\quad R L=$ remeediabon tevel

$\mathrm{J}=$ analyte was identified and resujt as approximase concentration $\mathrm{SL}=$ jcreening level

PCBs were analyzed for but were not detected.

EU Z2-33 K-JBO3 FACILITY SVOC DETECTS (Lg/kg) 0.10 it

\begin{tabular}{|c|c|c|c|c|c|c|c|c|}
\hline \multirow[b]{2}{*}{ Anglyte } & \multirow[b]{2}{*}{$\begin{array}{l}\text { Detect } \\
\text { freyucticy }\end{array}$} & \multirow[b]{2}{*}{$\begin{array}{c}\text { Minimum } \\
\text { detedt }\end{array}$} & \multirow[b]{2}{*}{$\begin{array}{l}\text { Mavimum } \\
\text { detect }\end{array}$} & \multirow[b]{2}{*}{$\begin{array}{l}\text { Loctalion(g) of } \\
\text { maxictem detect }\end{array}$} & \multirow{2}{*}{$\begin{array}{c}\text { Avernge } \\
\text { detected } \\
\text { restult }\end{array}$} & \multicolumn{3}{|c|}{$\begin{array}{l}\text { Namber of analyses } \\
\text { exceedilug criteria }\end{array}$} \\
\hline & & & & & & $\begin{array}{l}\text { LBd } \\
\text { PRG }\end{array}$ & $\begin{array}{l}\text { GWY } \\
\text { SL }\end{array}$ & $\begin{array}{r}\text { Rts } \\
\text { PrtG }\end{array}$ \\
\hline Acenaphthylene & III & $75 \mathrm{~J}$ & $75 \mathrm{~J}$ & Z2-EV133-326 & $7 \$$ & 0 & NA & 0 \\
\hline Benz(a)anthracene & lll & 3709 & 3701 & Z2-EU33B-326 & 370 & 0 & NA & 0 \\
\hline Eenteo(i)pyrtent & $1 / 1$ & 4001 & $400 \mathrm{~J}$ & Z2-EU33B-326 & 460 & 0 & NA & 1 \\
\hline Benzo(b)tluoranthene & $1 / 1$ & 730 & 730 & Z2-EU33B-326 & 730 & 0 & NA & 1 \\
\hline Benzo(ghi)perylene & $1 / 1$ & $290 j$ & -2900 & Z2-EU338-326 & 290 & 0 & $\mathrm{NA}$ & 0 \\
\hline E|s(2-ethylhexyl)phths $\left.\right|_{\text {ete }}$ & $1 / \pi$ & $34\rfloor$ & $54]$ & Z2-EVI33B-326 & 54 & 0 & 0 & 0 \\
\hline Butyl benzyd phthal ate & ]$/ l$ & $79 \mathrm{~J}$ & 793 & Z2-EU33B-326 & 79 & 0 & NA & 0 \\
\hline Chrysene & $1 / 1$ & $460 J$ & $460 \mathrm{~J}$ & Z2-EU33B-326 & 460 & 0 & $\mathrm{NA}$ & 0 \\
\hline Dibenz(ah) anthragcene & $1 / l$ & $8] J$ & BIJ & Z2-EU/33B-326 & 83 & 0 & NA & ] \\
\hline Flvorantlene & $1 / \mathrm{h}$ & $520 J$ & $520 \mathrm{~J}$ & 22-EU33B-326 & 520 & 0 & $\mathrm{NA}$ & 0 \\
\hline Indeло (1,23,3-cd)pyгепе & WI & $260 \mathrm{~J}$ & $260 \mathrm{~J}$ & Z2-EU33日-326 & 260 & 0 & NA & 0 \\
\hline Pyrene & $\mathrm{b} / \mathrm{I}$ & $470 \mathrm{~J}$ & $470 \mathrm{~J}$ & Z2-EU33B-326 & 470 & $\theta$ & $N A$ & 0 \\
\hline
\end{tabular}

EW - exposure unil $\quad$ PRO = predimentry remediatoon goul

GW = groundwatar $\quad$ Reg $=$ residentis]

lnd = industral $\quad$ SL = screening level

$\mathrm{J}$ * analyle was ident fied and regult is approximate concentration SVOC - semivalatile orobanc compoud

NA $=$ not Éplicable

K-1004-D Facillty: The K-1004-D facility basement and pad were not recommended for biased sampling in the Assesstient Report. However, there were several historical spil (including sewer ejector sump pit sediment) and concrete sample locations around K-1004-D (Sect. 2.2.3) that are included in this section. Analytical results for the historical soil and concrete samples summarized below show PCB Avg RL exceedances in three concrete samples from the facility's basement; metal, PCB, and radiontelide Ind PRG exceedances; metal and radionuclide Bkg exceedances; and diesel-range organic (DRO), gasoline-range organic (GRO), PCB, pesticide, and SVOC detections. (Note: DRO and GRO were detected in a sedjunent sample fron the șewer ejector sump pit located in the 
basement of Bldg. K-1004-D. The sediment was removed from the sump pit by D\&D Operations after production of the first draft of this TM).

EU Z2-33 K.]004-D FACILITY METALS WITH BACKTROUND, PRG, GW SL ANDJOR RL EXCEEDANCES (mg/kg) 0-10 A

\begin{tabular}{|c|c|c|c|c|c|c|c|c|c|c|c|}
\hline \multirow[b]{2}{*}{ Andyet } & \multirow[b]{2}{*}{$\begin{array}{c}\text { Detect } \\
\text { Frequenticy }\end{array}$} & \multirow[b]{2}{*}{$\begin{array}{l}\text { Minimum } \\
\text { Detect }\end{array}$} & \multirow[b]{2}{*}{$\begin{array}{c}\text { Morimum } \\
\text { Detect }\end{array}$} & \multirow[b]{2}{*}{$\begin{array}{l}\text { Locathon(s) of } \\
\text { Maxdaum bettet }\end{array}$} & \multirow{2}{*}{$\begin{array}{l}\text { Average } \\
\text { Dotected } \\
\text { Result }\end{array}$} & \multicolumn{6}{|c|}{ Number of Analyses Erceedios Criterln } \\
\hline & & & & & & $\begin{array}{c}\operatorname{Max} \\
\operatorname{RL}\end{array}$ & $\begin{array}{l}\text { Ave } \\
\text { Rl }\end{array}$ & $\begin{array}{l}\text { - Ind } \\
\text { PRE }\end{array}$ & Bke & $\begin{array}{l}\text { GW } \\
\text { SEL }\end{array}$ & $\begin{array}{r}\text { Res } \\
\text { PRG }\end{array}$ \\
\hline Al lamminam & $\mid 7 / 1\}$ & $5,0 \overline{00}$ & 29,430 & K]OOAD-\$় & 13,094 & NA & $\mathrm{NA}$ & 0 & 6 & NA & 11 \\
\hline Antumpny & $16 / 17$ & 0018 & 19 & Z2EU39-K 1004D & 132 & NA & NA & 0 & 1 & 0 & $\mathbf{I}$ \\
\hline Arsemic & $17 / 7$ & 2 & 31 & 22EU33-K1004D & $5 \$ 3$ & 0 & 0 & I & 1 & 0 & 17 \\
\hline Barıum & $17 / 1]$ & 40 & 269 & KJOOAD-S3 & III & NA & NA & 0 & 5 & 0 & 0 \\
\hline Beryllium & $17 / 7$ & 035 & 3 I & 22-EU33-2006 & 150 & 0 & 0 & 0 & 4 & NA & 0 \\
\hline Cadmium & Ints & 023 & 13 & Z2-EU133-2006 & 368 & NA & $\mathrm{NA}$ & 0 & 17 & NA & 4 \\
\hline Calcnum & $17 / 1 ?$ & 1,990 & 210,000 & 22-EU33-2006 & 61,071 & NA & NA & NA & 16 & NA & NA \\
\hline Chromium & דונדנ & 7 & $140 \mathrm{~J}$ & Z2EU33-KIOX4D & 266 & NA & NA & 0 & 1 & 0 & 4 \\
\hline Copper & $17 / 17$ & 66 & 1,100 & 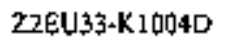 & 933 & NA & NA & 0 & 6 & NA & $\mathbf{I}$ \\
\hline Iron & 1317 & 4,900 & $5] 0,0001$ & 22EU33-K100dD & 48,724 & NA & $\mathrm{NA}$ & ] & ] & NA & 17 \\
\hline LFad & $17 / 17$ & 37 & 1,300 & Z2EU33-K $1004 \mathrm{D}$ & 139 & NA & $\mathrm{NA}$ & ] & 5 & 0 & 2 \\
\hline Mrgnesum & $17 / 17$ & 1,6001 & 63,000 & 22-EU33-2006 & 13,185 & $\mathrm{NA}$ & $\mathrm{NA}$ & NA. & 8 & NA & $\mathrm{NA}$ \\
\hline Manganesse & IT/17 & 2701 & 4,350 & Kit(0040-53 & 959 & NA & NA & 0 & ] & NA & 17 \\
\hline Merally & $\mid 4 / J 5$ & 00121 & 30 & Z2EU33-KJ 004[D & 237 & 0 & 0 & 0 & 8 & NA & $\mathbf{I}$ \\
\hline Nickel & $\mid 7 / 1]$ & $6-51$ & 452 & $K 10040-\$ 3$ & 671 & NA. & NA & 0 & 5 & NA & 2 \\
\hline Selenıum & S/ET & 0228 & $14\rfloor$ & Z2EU33-K1DQ4D & 319 & NA & $N A$ & 0 & 1 & NA & 0 \\
\hline Silvęr & $4 / 7$ & 011 & 130 & 22EU33-K.1004D & 435 & NA & $\mathrm{NA}$ & 0 & 2 & NA & 2 \\
\hline Sodtum & $17 / 7$ & $67]$ & 820 & 22-EU33-2004 & 259 & NA & NA & NA & 2 & NA & NA \\
\hline The日|lim & 1717 & $0019 J$ & 0439 & KI004D-S2 & 0193 & NA & $\mathrm{NA}$ & 0 & 1 & 0 & 0 \\
\hline Uraninutit & 1414 & 056 & \& & Z2EU33-KJ004D & 222 & $\mathrm{NA}$ & $\mathrm{NA}$ & 0 & NA & NA & 5 \\
\hline Vandoum & $\mid 7 / 1\}$ & 73] & 391 & K1004D-\$3 & 188 & NA & NA & 0 & 0 & NA. & 14 \\
\hline Zinc & $1 T H 17$ & Jפו & 1,9001 & Z2-EU33-2006 & 392 & NA & NA & 0 & 8 & NA & 0 \\
\hline
\end{tabular}

AYg $=$ ayerage

Bkg = background

Max $=$ maximlim

EU - exposure umt

NA $=$ not applictable

$\mathrm{GW}=$ groundwater

PRG = prellminary remedisbon goal

Ind = industral

Res $=$ Tesiderit|al

$J=$ atalyte wras idertified and result is approxumate concentralion

$\mathrm{RL}=$ rernediation ievel

SL = screenting level

EU 22-33 K-1004-D SOIL OTFER ORGANICS DETECTS (mR/tigl 0.10 ft

\begin{tabular}{|c|c|c|c|c|c|}
\hline Anglyte & $\begin{array}{c}\text { Detect } \\
\text { frequency }\end{array}$ & $\begin{array}{c}\text { Minimnon } \\
\text { deteet }\end{array}$ & $\begin{array}{c}\text { Maxinum } \\
\text { itetect }\end{array}$ & $\begin{array}{l}\text { Location(c) of } \\
\text { maximum defect }\end{array}$ & $\begin{array}{l}\text { Aferage } \\
\text { detected } \\
\text { resalt }\end{array}$ \\
\hline Dresel Range OTganics & lll & $7.50 \mathrm{k}$ & 7,500 & Z2EU33-K.1004D & 7.500 \\
\hline Gaspoline Range Organks & d & 0473 & 0471 & Z2EU\$3.K-K1004D & 043 \\
\hline
\end{tabular}

EL: 22-33 K-1004-D FACFLITY PPCB DETECTS (u化多) 0-10 it

\begin{tabular}{|c|c|c|c|c|c|c|c|c|c|}
\hline \multirow[b]{2}{*}{ Andlyte } & \multirow[b]{2}{*}{$\begin{array}{c}\text { Detect } \\
\text { Frequesesy }\end{array}$} & \multirow[b]{2}{*}{$\begin{array}{c}\text { Minimum } \\
\text { Detect }\end{array}$} & \multirow[b]{2}{*}{$\begin{array}{c}\text { Marimum } \\
\text { Detect }\end{array}$} & \multirow{2}{*}{$\begin{array}{c}\text { Location(g) of } \\
\text { Moximen } \\
\text { Detect }\end{array}$} & \multirow{2}{*}{$\begin{array}{l}\text { Average } \\
\text { Deterted } \\
\text { Resull }\end{array}$} & \multicolumn{4}{|c|}{$\begin{array}{l}\text { Number of Anatyges } \\
\text { Exceedlug Crlterie }\end{array}$} \\
\hline & & & & & & $\underset{\mathrm{ML}}{\mathrm{Mnx}}$ & $\begin{array}{l}\text { Ang } \\
\text { RL }\end{array}$ & $\begin{array}{l}\text { Ind } \\
\text { PRG }\end{array}$ & $\begin{array}{l}\text { Reg } \\
\text { PRG }\end{array}$ \\
\hline $4,4^{\prime}-$ DDE & $1 / 6$ & 150 & 150 & K1004D-S3 & 150 & NA & NA & 0 & NA \\
\hline 4,4'-Ob' & $3 / 6$ & $110 \mathrm{~J}$ & 230 נח & K1004D.S] & 187 & NA & NA & 0 & NA \\
\hline alpha-Culordane & $1 / 6$ & $85 \mathrm{~J}$ & B 5J & KI004D-S] & 85 & NA & NA & $\theta$ & NA \\
\hline gamma-Chlordane & $1 / 6$ & 65 & $6 !$ & $\mathrm{K} 1004 \mathrm{D} \cdot \mathrm{S} 1$ & 6 & NA & $\mathrm{NA}$ & 0 & NA \\
\hline Endasulfan sulfate & $1 / 6$ & 2501 & 25 [t] & K1004D-\$1 & 250 & NA & NA & 0 & NA \\
\hline Endrın & 26 & $86 \mathrm{~J}$ & $230 \mathrm{~J}$ & Klo04D-S2 & 158 & NA & $\mathrm{NA}$ & 0 & NA \\
\hline Heptachlor & $1 \%$ & 655 & 653 & K1004D-S1 & 65 & NA & NA & 0 & $N A$ \\
\hline Heplachlor epoxide & 316 & 355 & 95 & K1004D-\$2 & 307 & NA & NA & 0 & NA \\
\hline
\end{tabular}


EU 72-33 K-1004-D FACTLITY PYCA BETECTS (ug/kg) 0-10 ft (cont'd)

\begin{tabular}{|c|c|c|c|c|c|c|c|c|c|}
\hline \multirow[b]{2}{*}{ Arstyte } & \multirow[b]{2}{*}{$\begin{array}{l}\text { Detoct } \\
\text { Frequency }\end{array}$} & \multirow{2}{*}{$\underset{\substack{\text { Mizulishum } \\
\text { Detect }}}{\vec{n}}$} & \multirow[b]{2}{*}{$\begin{array}{c}\text { Mnximum } \\
\text { Detect }\end{array}$} & \multirow{2}{*}{ 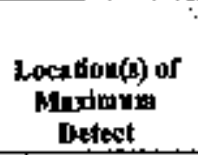 } & \multirow{2}{*}{$\begin{array}{c}\text { Average } \\
\text { Detected } \\
\text { Resalt }\end{array}$} & \multicolumn{4}{|c|}{$\begin{array}{l}\text { Numbar of Anntysta } \\
\text { Exceedins Criterix }\end{array}$} \\
\hline & & & & & & Max & Aq & $\begin{array}{l}\text { Ind } \\
\text { PRG }\end{array}$ & $\begin{array}{l}\text { Res } \\
\text { PRG }\end{array}$ \\
\hline 4,4'-DDE & 116 & 150 & 150 & K1004D-S3 & 150 & $\mathrm{NA}$ & NA & 0 & NA \\
\hline $4,4^{\prime}-\mathrm{DDT}$ & 36 & $110 \mathrm{f}$ & 2301 & K1004D-SI & לל & NA & NA & 0 & NA \\
\hline a'pha-chlordane & $1 / 6$ & $85 \mathrm{~J}$ & $85 j$ & K1004D-SI & 85 & NA & $\mathrm{NA}$ & 0 & NA \\
\hline gatumb-Chlordant & $1 / 6$ & $6 \mathrm{~J}$ & $6 \mathrm{~J}$ & K1004D-SI & 6 & NA & $\mathrm{NA}$ & 0 & NA \\
\hline Endosutfan suffate & $1 / 6$ & $250 \mathrm{~J}$ & $250 \mathrm{~J}$ & K] $004 D-\$ 1$ & 250 & NA & $N A$ & 0 & NA \\
\hline Endпा & $2 / 6$ & $86]$ & $230 J$ & K1004D-S2 & $15 \%$ & NA & NA & 0 & NA \\
\hline Heptactilor & 沙 & $65 J$ & $65 J$ & KLOC4D-S] & 65 & NA & $N A$ & 0 & NA \\
\hline Heptach]or epoxidt & $3 / 6$ & 3.55 & 95 & K10040\$2 & 707 & NA & $N A$ & 0 & NA \\
\hline PCB-I254 & $10 \prime 17$ & $42 \mathrm{~J}$ & $S I, 0$ OCO & Z2-EU33-2004 & 9.951 & 0 & 3 & 3 & 9 \\
\hline Polychlorutatted Biphenyl & $7 / 4$ & $42 \mathrm{~J}$ & 51,000 & 22-EU33-2004 & 13,736 & 0 & 3 & 3 & 6 \\
\hline
\end{tabular}

Avg = àverage

EU = exposure unil

Ind = andustrial

$J=$ analyte tras identfied and result is approximate concentration

Miax = maxumtion
PPCB = pesucte atud polychlónnered buphebyl PRG = prelımısery remediation pod

Res $=$ residential

RL = remediason level

EU 22-33 K-10.04-D RADIONUCLJDES WTTH BACKGROUND, PRG, AND/OR RL EXCEEDANCRS (pCJ/g) 0-10 I

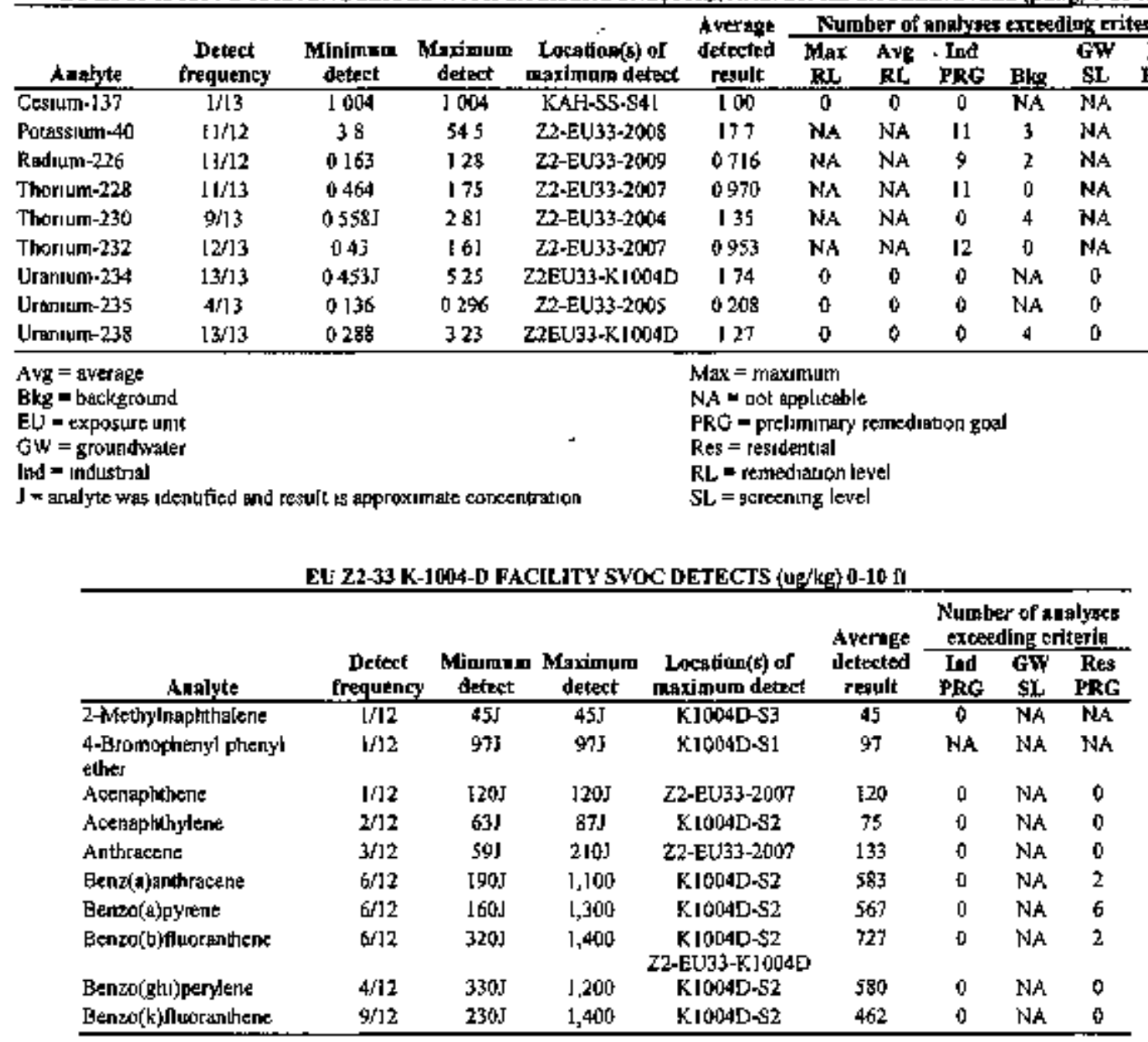




\begin{tabular}{|c|c|c|c|c|c|c|c|c|}
\hline \multirow[b]{2}{*}{ Analyte } & \multirow[b]{2}{*}{$\begin{array}{c}\text { Detect } \\
\text { frequency }\end{array}$} & \multirow[b]{2}{*}{$\begin{array}{c}\text { Mipinge } \\
\text { deteet }\end{array}$} & \multirow[b]{2}{*}{$\begin{array}{l}\text { Menimum } \\
\text { detect }\end{array}$} & \multirow[b]{2}{*}{$\begin{array}{c}\text { Locstion(s) of } \\
\text { meximam dtteet }\end{array}$} & \multirow{2}{*}{$\begin{array}{l}\text { Average } \\
\text { dectected } \\
\text { reqult }\end{array}$} & \multicolumn{3}{|c|}{$\begin{array}{l}\text { Number of analyses } \\
\text { excedine criterta }\end{array}$} \\
\hline & & & & & & $\begin{array}{c}\text { Jnd } \\
\text { PRG }\end{array}$ & $\begin{array}{l}\text { GW } \\
\text { SL }\end{array}$ & $\begin{array}{l}\text { Res } \\
\text { PRG }\end{array}$ \\
\hline 2-Methylniephehalene & [/12 & $45 !$ & $4 S \mathrm{~J}$ & K1004D-S3 & 45 & 0 & NA & NA \\
\hline $\begin{array}{l}\text { A-Broprophenyl phenyl } \\
\text { ethej }\end{array}$ & $|J| 2$ & 975 & $97 \mathrm{~J}$ & KI004D-S1 & 97 & NA & NA & $N A$ \\
\hline Actenaphtivene & $w 12$ & $120 \mathrm{~J}$ & $120 \mathrm{~J}$ & 22-EU33-200T & 120 & 0 & NA & 0 \\
\hline Acenaphtlyylene & $2 / 2$ & $63 \mathrm{~J}$ & $87 \mathrm{~J}$ & K1004D-S2 & 75 & 0 & $\mathrm{NA}$ & 0 \\
\hline Anthracene & 312 & 391 & $210 \mathrm{~J}$ & Z2-Eบ33-2007 & 133 & 0 & $\mathrm{NA}$ & 0 \\
\hline Genz(B)anthracene & $6 / 2$ & $190 \mathrm{~J}$ & 1,100 & K1004D-\$2 & 583 & 0 & $\mathrm{NA}$ & 2 \\
\hline Benzo(a)pyene & $\left.6{ }^{\prime}\right] 2$ & 160.5 & 1,300 & K $1004 D-52$ & 567 & 10 & NA & 6 \\
\hline Betszo(b) fluosentheste & $6 / 2$ & $320 \mathrm{~s}$ & 1,400 & $\begin{array}{c}\text { KIO04D-S2 } \\
\text { 22-EU93-K1004D }\end{array}$ & 727 & 0 & $N A$ & 2 \\
\hline 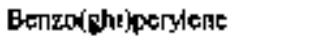 & $4 / 12$ & $330 \mathrm{~J}$ & 1,200 & KIO04D-S? & 580 & 0 & NA & 0 \\
\hline Beinzo(k)fluosanthene & $\left.9 f^{\prime}\right] 2$ & 2300 & $t, 400$ & K1004D-S2 & 462 & 0 & NA & 0 \\
\hline Bis(2-ethylhexyl)phthaldate & $S / 12$ & $160 \mathrm{~J}$ & $B, 800$ & 22EU33-K100\$D & 2,016 & 0 & 0 & 0 \\
\hline Butyl benzyl ghthalato & $2 / 12$ & $240]$ & $430 \mathrm{~J}$ & 22-EU $33-2007$ & 335 & 0 & NA & 0 \\
\hline Carbazole & $4 / 12$ & $44 f$ & $180 J$ & K1004D-S2 & 105 & 0 & NA & 0 \\
\hline Chrysene & $6 / 32$ & $290 \mathrm{~J}$ & 1,800 & KIODAD-\$2 & 757 & 0 & NA & 0 \\
\hline Dibenz $(a, h)$ andhracenc & $3 / 2$ & 835 & $300 \mathrm{~J}$ & K1004D-52 & 158 & 0 & $\mathrm{NA}$ & $\mathfrak{3}$ \\
\hline Dy-s-butyl pheholate & $4 / 12$ & $110 \mathrm{~J}$ & $590 \mathrm{~J}$ & Z2-EU33-2004 & 270 & 0 & $\mathrm{NA}$ & 0 \\
\hline Flupranthene & $/ 12$ & $170 \mathrm{~J}$ & 2,800 & K1004D-s2 & 1,163 & 0 & NA & 0 \\
\hline Fluorene & $W 12$ & $11(t)]$ & 4,100 & Z2EU33-K I004D & 2,105 & 0 & NA & 0 \\
\hline [ndeno(1,2,3-odipyrene & $4 / 12$ & $390 \mathrm{~J}$ & 1,300 & K.1004D-52 & 630 & 0 & $\mathrm{NA}$ & $\mathrm{t}$ \\
\hline Pentachloropheno1 & $H / 2$ & $74 I$ & 745 & KJ004D-92 & 34 & 0 & NA & 0 \\
\hline Phẹnanthrẹne & $6 / 2$ & $120 \mathrm{~J}$ & 1,2000 & 22-EU33-2007 & 482 & 0 & NA & 0 \\
\hline Phenol & $2 / 12$ & $96 \mathrm{~J}$ & 1702 & 22-EU33-2010 & 133 & 0 & NA & 0 \\
\hline Pyrente & $6 / 12$ & $150 \mathrm{~J}$ & 2,300 & KJ004D-S2 & 868 & 0 & $\mathrm{NA}$ & 0 \\
\hline $\begin{array}{l}\text { EU = exposure unit } \\
\text { GW = groundwater } \\
\text { Ind = Industonal } \\
J \text { = antalyte wase identifited a } \\
\text { NA = not applicable }\end{array}$ & 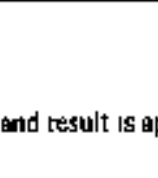 & & 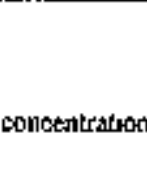 & $\begin{array}{l}\text { PRG = prelumb } \\
\text { Res = resident } \\
\text { SL = screening } \\
\text { SVOC = semI4 }\end{array}$ & $\begin{array}{l}\text { nary remed } \\
\text { ad } \\
\text { |cwel } \\
\text { olatle orge }\end{array}$ & nic com! & & \\
\hline
\end{tabular}

VOCs were analyzed for in four samples but were not detected.

K-1004-F Facility: Biased sampling was recommended for this site in the Assessment Report based on site knowledge regarditg fotmer use of the facility. Five DVS biased sample locations were identified (Sect. 2.2.3). The $\mathrm{K}-1004-\mathrm{F}$ pad was removet during $\mathrm{D} \& \mathrm{D}$ alo ng with four concrete sample locations removed in the process (Table 3) since the Class $3 \mathrm{SU}$ walkover assessment. The remaining soil sample location (Table 3 ) is representative of curtent conditions. Analytical results summarized below show one SVOC Ind PRG exceedance, metal Bkg exceedances, and detections of PCBs and SVOCs.

EU Z2-33 K-10D4-F FACILITY' SOIL METALS WITTI BACKGROUND, PRG, GW SL, AND/OR RL EXCEEDANCES (mg/kg) 0-I0 It

\begin{tabular}{|c|c|c|c|c|c|c|c|c|c|c|c|}
\hline \multirow[b]{2}{*}{ Analyte } & \multirow[b]{2}{*}{$\begin{array}{c}\text { Detect } \\
\text { frequenty }\end{array}$} & \multirow[b]{2}{*}{$\begin{array}{l}\text { MAnimam } \\
\text { detect }\end{array}$} & \multirow[b]{2}{*}{$\begin{array}{c}\text { Mariminm } \\
\text { detect }\end{array}$} & \multirow{2}{*}{$\begin{array}{c}\text { Lacalion(s) of } \\
\text { maximid al } \\
\text { detect }\end{array}$} & \multirow{2}{*}{$\begin{array}{l}\text { Average } \\
\text { defected } \\
\text { resuli }\end{array}$} & \multicolumn{6}{|c|}{ Nipmber of auslyses excedilnt trittrin } \\
\hline & & & & & & $\begin{array}{c}\text { Max } \\
\text { RL }\end{array}$ & $\begin{array}{l}\text { AFg } \\
\text { RL }\end{array}$ & $\begin{array}{l}\text { Žnd } \\
\text { Pkg }\end{array}$ & Blgg & $\begin{array}{l}\text { GW } \\
\text { SL }\end{array}$ & $\begin{array}{l}\text { REy } \\
\text { PRG }\end{array}$ \\
\hline Arsenic & $1 / \mathbf{1}$ & 103 & 103 & $\overline{Z 2-E U 33 B-325}$ & 103 & 0 & 0 & 0 & 0 & 0 & I \\
\hline Cadmum & U1 & 037 & 037 & Z2.EU33B-325 & 037 & NA & NA & 0 & 1 & NA & 0 \\
\hline Calc|um & $\mathbf{I} / 1$ & 62,3001 & $62,300 \mathrm{~J}$ & $22-E U 33$ B- 325 & 62,300 & NA & WA & NA & $\mathbf{I}$ & NA & $\mathrm{NA}$ \\
\hline Maģnesoutr & $1 / 1$ & $17,200]$ & $17,200 \mathrm{~J}$ & Z2-EU133B-325 & 17,200 & NA & NA & NA & ! & NA & NA \\
\hline Iron & ! $/ 1$ & $12,300]$ & $12,300,1$ & Z2-EU33B-325 & 12,300 & $\mathrm{NA}$ & NA & 0 & 口 & $N A$ & 1 \\
\hline Mangentese & $9 / 1$ & $626 \mathrm{~J}$ & $626 \mathrm{~J}$ & Z2-EU33E-325 & 626 & $\mathrm{NA}$ & NA & 0 & 0 & $\mathrm{~N} / \mathrm{A}$ & 1 \\
\hline Nickel & $1 / 1$ & d) 4J & $414 J$ & 2.2-EU33B-325 & 414 & $N_{A}$ & NA & a & 1 & NA & 0 \\
\hline Uransum & $1 / 1$ & 23 & 23 & Z2-EU33B-325 & 23 & $\mathrm{NA}$ & NA & V & NA & NA & 1 \\
\hline
\end{tabular}


EU Z2-33 K-1004-F FACILLTY SOIL METALS W]TH BACKGROUND, PRG, GW SL, AND/OR RL EXCEEDANCES (mg/kg) 0.10 (t (cont'd)

\begin{tabular}{|c|c|c|c|c|c|c|c|c|c|c|c|}
\hline \multirow[b]{2}{*}{ Anabyé } & \multirow[b]{2}{*}{$\begin{array}{c}\text { Detect } \\
\text { Irequepcy }\end{array}$} & \multirow[b]{2}{*}{$\begin{array}{l}\text { Mililtaum } \\
\text { detect }\end{array}$} & \multirow[b]{2}{*}{$\begin{array}{c}\text { Maximi:an } \\
\text { detect }\end{array}$} & \multirow{2}{*}{$\begin{array}{c}\text { Loeation(s) of } \\
\text { maximum } \\
\text { detect }\end{array}$} & \multirow{2}{*}{$\begin{array}{l}\text { Ayeraget } \\
\text { detected } \\
\text { resilt }\end{array}$} & \multicolumn{6}{|c|}{ Number of andyses eretedine erittria } \\
\hline & & & & & & $\begin{array}{l}\operatorname{Min} x \\
\text { RL }\end{array}$ & AW & $\begin{array}{l}\text { Ind } \\
\text { Pitec }\end{array}$ & Bkgs & $\begin{array}{l}\text { GYY } \\
\text { SL }\end{array}$ & $\begin{array}{l}\text { Res } \\
\text { PRC }\end{array}$ \\
\hline Vanadım & lll & 156 & 156 & Z2-EU338.325 & 156 & NA & NA & 0 & D & $N / A$ & 1 \\
\hline Zutc & \ا & |63] & 1635 & Z2-EU33B-325 & 163 & NA & NA & 0 & I & $\mathrm{NA}$ & $\mathbf{0}$ \\
\hline
\end{tabular}

Avg $=$ avergeg

Bkg = backeround

Max = maximunat

$\mathrm{EU}=$ exposure imıt

GLW $n$ eroumdwater

NA $x$ not applicable

lnd = Industrial

$\mathrm{J}=$ analyte was tdentufied and result is approximate concentration

PRG - prelıminary remsediation goal

Res = residontıal

$R L=$ rcmediation level

SL = screenitg level

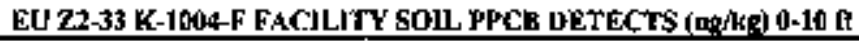

\begin{tabular}{|c|c|c|c|c|c|c|c|c|c|}
\hline \multirow[b]{2}{*}{ Analyte } & \multirow[b]{2}{*}{$\begin{array}{c}\text { Detect } \\
\text { frequexicy }\end{array}$} & \multirow[b]{2}{*}{$\begin{array}{l}\text { Minim:un } \\
\text { detect }\end{array}$} & \multirow[b]{2}{*}{$\begin{array}{l}\text { Maximun } \\
\text { detect }\end{array}$} & \multirow{2}{*}{$\begin{array}{c}\text { Locntion(s) os } \\
\text { mading } \\
\text { detert }\end{array}$} & \multirow{2}{*}{$\begin{array}{l}\text { AFtrifigt } \\
\text { detected } \\
\text { regult }\end{array}$} & \multicolumn{4}{|c|}{$\begin{array}{l}\text { Nomber of a ralyzes } \\
\text { ex teedlore eriterle }\end{array}$} \\
\hline & & & & & & $\begin{array}{c}\text { Mtax } \\
\text { RL }\end{array}$ & $\begin{array}{l}\text { Avg } \\
\text { RI }\end{array}$ & $\begin{array}{c}\text { Ind } \\
\text { PRG }\end{array}$ & $\begin{array}{l}\text { Res } \\
\text { PRG }\end{array}$ \\
\hline PCB-1254 & $|f|$ & 48 & 48 & Z2.EU33B-325 & 48 & 0 & 0 & 0 & 0 \\
\hline$P C B-1260$ & $|/|$ & 23] & $27 \mathrm{~J}$ & Z2.EU/33E-325 & 27 & $\theta$ & 0 & 0 & 0 \\
\hline Polychlorenated Biphersyl & $|f|$ & $75]$ & $75\rfloor$ & 22-EU33B-325 & 75 & 0 & 0 & 0 & 0 \\
\hline $\begin{array}{l}\text { AYg = ayergge } \\
\text { EU = exporture unit } \\
\text { Ind = Industial } \\
\text { J = analyte was Identhied } \\
\text { Mgx = maximum }\end{array}$ & d regult is & 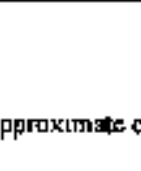 & encentrathon & \multicolumn{6}{|c|}{$\begin{array}{l}\text { PPCB = pesticide and polychloniatedbiphenyl } \\
\text { PRC * prelımisary remediation goal } \\
\text { Res = resideribal } \\
\text { RL = remediatuon tevel }\end{array}$} \\
\hline
\end{tabular}

EU Z2-33 K-1004-F FACIITY SOLL SVOC DETECTS (ug/kg) 0-10 ft

\begin{tabular}{|c|c|c|c|c|c|c|c|c|}
\hline \multirow[b]{2}{*}{ Anabyte } & \multirow[b]{2}{*}{$\begin{array}{c}\text { Detect } \\
\text { Fisequency }\end{array}$} & \multirow[b]{2}{*}{$\begin{array}{l}\text { Mlnimum } \\
\text { Detect }\end{array}$} & \multirow[b]{2}{*}{$\begin{array}{l}\text { Maximom } \\
\text { Detect }\end{array}$} & \multirow[b]{2}{*}{$\begin{array}{l}\text { Location[s] of } \\
\text { Maxtraum Detect }\end{array}$} & \multirow{2}{*}{$\begin{array}{c}\text { Average } \\
\text { Deteteded } \\
\text { Retult }\end{array}$} & \multicolumn{3}{|c|}{$\begin{array}{l}\text { Number of Annlyses } \\
\text { Exoeeding Criterin }\end{array}$} \\
\hline & & & & & & $\begin{array}{l}\text { Ind } \\
\text { PRG }\end{array}$ & $\begin{array}{l}\text { GW } \\
\text { SL }\end{array}$ & $\begin{array}{l}\text { Reg } \\
\text { PRG }\end{array}$ \\
\hline Acenaphthylene & $\bar{l} f \bar{c}$ & 1,400 & $1,400^{\circ}$ & Z2-E\Э3B-325 & 1,400 & 0 & $\mathrm{NA}$ & $\dot{0}$ \\
\hline Anthracene & $1 /$ & 450 & 450 & Z2-EU33B-325 & $4 \$ 0$ & 0 & NA & 0 \\
\hline Benz(a)anthratent & $1 / 1$ & 3,100 & 3,100 & 22-EU33B-325 & 3,100 & 0 & NA & $\mathbf{I}$ \\
\hline Benzo(a)pyादne & $1 / l$ & 4,600 & 4,600 & Z2-EU93B-325 & 4,600 & ] & NA & l \\
\hline Berazo(b)tluoranthene & lfl & 5,300 & $-5,300$ & Z2-EU33B-325 & 5,300 & 6 & NA & 1 \\
\hline Benzo(ghi)petylene & UI & 3,500 & 3,500 & Z2-EU33B-325 & 3,500 & 0 & $\mathrm{NA}$ & 0 \\
\hline Benzo(k) fluoremthene & L/I & 3,500 & $3,5 \% 0$ & Z2-EU33B-325 & 3.500 & 0 & $\mathrm{NA}$ & 0 \\
\hline Carhnzole & $|f|$ & Iloj & IJUJ & Z2-EVJ33B-325 & 110 & 0 & NA & 0 \\
\hline Chrysene & LI & 3,200 & 3,200 & Z2-EU33B-325 & 3,200 & 0 & NA & 0 \\
\hline Dutenz(ah)an/hrapene & $\mathrm{u} / \mathbf{I}$ & 900 & 900 & Z2-EU33B-325 & 900 & 0 & NA & $\mathbf{I}$ \\
\hline Fluoranthens & $|/|$ & 4,600 & 4,600 & Z2-EUJ33B-325 & 4,600 & 0 & NA & 1) \\
\hline Fluorene & U! & 48J & $48 J$ & 22-EU33B-325 & 48 & 0 & NA & 0 \\
\hline Indesop $(1,2,3-c d) p y r e n t$ & $1 / k$ & 3,400 & 3,400 & 22-E[333B-325 & 3,400 & 0 & NA & $\mathbf{I}$ \\
\hline Phenarsthrene & $\mathrm{Lt}$ & $9 B 0$ & 980 & Z2-EU33B-325 & 980 & 0 & NA & 0 \\
\hline Pyтепе & 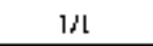 & 4,800 & 4,800 & Z2-EU33B-325 & 4,8000 & 6 & NA & 0 \\
\hline
\end{tabular}

EJ = exposute tritt

GW a proundwaler

Ind = indugtr|al

J = analyte was idenitied and result is approximate concentratron

$N A=$ not applucable

PRG = prelimınary remsd tabon goal

Res - residentual

SL = screenıng level

SYOC = sem IYolatle oreanc compound

K-1004-L Facility: Biased sampling was recommended in the Assessment Report for this tacility based on site knowledge regarding activitjes conducted in the former K-1004-L Laboratory and on elevated radiation measurements and visual observations made during the Class 3 SU walkover assessment. Dynamic Verification Strategy and historical sample locations pertaining to the K-J004-L pad are presented in Sect. 2.2.3. The K-J004-L 
pad was removed during D\&D along with the process, soil, sediment, concrete, and asphalt sample locations (Table 3) sinee the Class $3 \mathrm{SU}$ walkover assessment Soil sample localions representative of current conditions at the former facility are presented in Table 3. Analytical results from the sample locations representative of current conditions at the former K-1004-L pad summarized below show radionuclide Ind PRG exceedances, metal and tadionuclide Bkg exceedances, and PCB, SVOC, and VOC detections.

QU Z2-33 K-1104-L FACILRT FOIL METALS WIIH BACKGROUND, PRG, GW SL, ANDJOR RL EXCEEDANCES (mp/kg) 0-10 ft

\begin{tabular}{|c|c|c|c|c|c|c|c|c|c|c|c|}
\hline \multirow[b]{2}{*}{ Analyte } & \multirow[b]{2}{*}{$\begin{array}{c}\text { Detect } \\
\text { frequency }\end{array}$} & \multirow[b]{2}{*}{$\begin{array}{l}\text { Minimtum } \\
\text { detoct }\end{array}$} & \multirow[b]{2}{*}{$\begin{array}{l}\text { Marimannt } \\
\text { andtect }^{2}\end{array}$} & \multirow{2}{*}{$\begin{array}{c}\text { Labation(t) af } \\
\text { maximan } \\
\text { detect }\end{array}$} & \multirow{2}{*}{$\begin{array}{l}\text { Average } \\
\text { deterted } \\
\text { rescit }\end{array}$} & \multicolumn{6}{|c|}{ Number of andyan erceetiog criterio } \\
\hline & & & & & & $\begin{array}{l}\text { MaY } \\
\text { RL }\end{array}$ & $\begin{array}{l}\text { AvE } \\
\text { RL }\end{array}$ & $\begin{array}{l}\text { Ind } \\
\text { PRG }\end{array}$ & 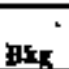 & $\begin{array}{l}\text { GW } \\
\text { SL }\end{array}$ & $\begin{array}{l}\text { Res } \\
\text { PRG }\end{array}$ \\
\hline 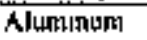 & $5 / 5$ & 2,5201 & 14,800 & Z2-EU33白-346 & 9,892 & NA & $\overline{\text { NA. }}$ & 0 & 0 & $\overline{N A}$ & 4 \\
\hline Arsenic & $5 / 5$ & $23 \mathrm{~J}$ & 78 & Z2-EU33B-362 & 498 & 0 & 0 & 0 & 0 & 0 & 5 \\
\hline Barnum & $5 / 5$ & 458 & 161 & 22-EЏ33B-364 & 908 & $\mathrm{NA}$ & NA & 0 & 1 & 0 & 0 \\
\hline Cadmitam & $5 / 3$ & 0 059 & 082 & z2-eU33日-364 & 0278 & $N A$ & NA & 0 & 2 & $\mathrm{NA}$ & 0 \\
\hline Câlesum & $5 / 5$ & $2,710 \mathrm{~J}$ & 291,0001 & Z2-EU33B-364 & 63,898 & NA & NA & NA & 5 & NA & $\mathrm{NA}$ \\
\hline Chromnum & $5 / 5$ & (0) & 4 [9] & 22-EU33B-362 & 20.4 & NA & NA & 0 & 0 & 0 & 1 \\
\hline Iron & $5 / 5$ & $9,230 \mathrm{~J}$ & $30,700 \mathrm{~J}$ & Z2-EU33B-346 & 21,066 & NA & NA & 0 & 0 & NA & 5 \\
\hline Lead & $\$ / 5$ & $1 \mid 8 J$ & $4 \mid 2 J$ & 22-EU33B-362 & 231 & NA & NA & 0 & 1 & 0 & 0 \\
\hline M㫨пеgлшा & $5 / 5$ & 779 & $59,600 \mathrm{~J}$ & 22-EV133日-364 & $13,78]$ & NA & NA & $\mathrm{NA}$ & 2 & $\mathrm{NA}$ & NA \\
\hline Manganese & $5 / 5$ & $2 d 2 J$ & $1,290]$ & 22-EU33B-362 & 605 & NA & NA & 0 & 0 & NA & 5 \\
\hline Mersury & $3 / 5$ & $0074 \mathrm{~J}$ & 665 & Z2-EU33B-362 & 0345 & 0 & 0 & 0 & 2 & NA & 0 \\
\hline Uranium & $5 / 5$ & $=\quad \mathrm{IJ}$ & 9431 & 22-EU33日-362 & 222 & NA & $\mathrm{NA}$ & 0 & $N A$ & $\mathrm{NA}$ & 4 \\
\hline Y'gnाadnum: & $5 / 3$ & $86]$ & 28 & Z2-EU39日-346 & 203 & NA & $\mathrm{NA}$ & 0 & 0 & NA & 5 \\
\hline Zunc & $5 / 5$ & $224 J$ & $405 \mathrm{~J}$ & Z2-EU33B-364 & 119 & NA & NA & 0 & 1 & NA & 0 \\
\hline
\end{tabular}

Avg $=$ average

Bke $=$ background

EU = exposure tant:

$\mathrm{GW}=$ groundwater

Max = makimum

Ind $=$ industrial

NA - nal epplictbl

PRG = prediminary Jeirkediatoon goal

Reg $=$ residentilil

$J=$ anelyle was iderified and result is approxumate concentration

$R L=$ remediation level

\$L = screerung kevel

EU Z2-33 K-1004-L FACILITY SOL PPCB DETECTS fug/hg) 0-10 ft

\begin{tabular}{|c|c|c|c|c|c|c|c|c|c|}
\hline \multirow[b]{2}{*}{ Analyte } & \multirow[b]{2}{*}{$\begin{array}{c}\text { Dettect } \\
\text { frequency }\end{array}$} & \multirow[b]{2}{*}{$\begin{array}{c}\text { Minimam } \\
\text { detect }\end{array}$} & \multirow[b]{2}{*}{$\begin{array}{c}\text { Maximan } \\
\text { detect }\end{array}$} & \multirow{2}{*}{$\begin{array}{l}\text { Lochefion(s) of } \\
\text { nuximum } \\
\text { detect }\end{array}$} & \multirow{2}{*}{$\begin{array}{c}\text { Average } \\
\text { detected } \\
\text { result }\end{array}$} & \multicolumn{4}{|c|}{$\begin{array}{c}\text { Number of analyses } \\
\text { excepding criteria }\end{array}$} \\
\hline & & & & & & $\begin{array}{l}\text { Max } \\
\text { RL }\end{array}$ & $\begin{array}{l}\text { Ave } \\
\text { RL }\end{array}$ & $\begin{array}{l}\text { Ind } \\
\text { preg }\end{array}$ & $\begin{array}{l}\text { Res } \\
\text { PRG }\end{array}$ \\
\hline$\overline{\mathrm{PCB}}-1254$ & $1 / 5$ & 670 & 570 & Z2-EW33B-364 & 670 & 0 & 0 & 0 & 1 \\
\hline Polychlorınated Bıphenyl & $\mathrm{J} / \mathrm{s}$ & 670 & 670 & 22-EU33B-364 & 670 & (1) & 0 & 0 & $\downarrow$ \\
\hline $\begin{array}{l}\text { Avg = averges } \\
\text { eU = exposure unil } \\
\text { [nd = indust'ial } \\
\text { Max = meximum }\end{array}$ & $\begin{array}{l}\text { PPCB = } \\
\text { PRQ }=\mathrm{P} \\
\mathrm{Res}=\mathrm{re} \\
\mathrm{RL}=\mathrm{rer}\end{array}$ & $\begin{array}{l}\text { eesuerde and } \\
\text { eluminary ren } \\
\text { idential } \\
\text { iediadion leve }\end{array}$ & $\begin{array}{l}\text { palychlaru } \\
\text { med/Athon \& }\end{array}$ & d bupheryt & & & & & \\
\hline
\end{tabular}

EU Z2-33 K-1094-L FACLUTY SOLL RADIONUCLIDES WITH BACKGROUND, PRG, AND/OR RL EXCEEDANCES (pCifg) 0-1 it it

\begin{tabular}{|c|c|c|c|c|c|c|c|c|c|c|c|}
\hline \multirow[b]{2}{*}{ Aasiyte } & & \multirow{2}{*}{$\begin{array}{l}\text { Maxibum } \\
\text { detect }\end{array}$} & \multirow[b]{2}{*}{$\begin{array}{c}\text { Locstion(g) of } \\
\text { maximant detect }\end{array}$} & \multirow{2}{*}{$\begin{array}{l}\text { : } \\
\text { Awergge } \\
\text { setected } \\
\text { resplt }\end{array}$} & \multicolumn{6}{|c|}{ Number of and tox excedtupe criteria } \\
\hline & $\begin{array}{c}\text { Detect } \\
\text { irequency }\end{array}$ & $\begin{array}{c}\text { Minlman } \\
\text { detect }\end{array}$ & & & & $\underset{\text { RL }}{\operatorname{Mnx}}$ & $\begin{array}{l}\text { Avg } \\
\text { RE }\end{array}$ & $\begin{array}{l}\text { Ind } \\
\text { PRG }\end{array}$ & Blgg & $\begin{array}{l}\text { GW } \\
\text { SL }\end{array}$ & $\begin{array}{l}\text { Res } \\
\text { PRG }\end{array}$ \\
\hline Cesium-ijy & L15 & 0.83 & $0 \sqrt{83}$ & $22-E \cup 3312-363$ & 0183 & 0 & $\overline{0}$ & 0 & NA & NA & 1 \\
\hline Potassitum-40 & 515 & 56 & 234 & Z2-EU33日-352 & 139 & NA & NA & $\$$ & 0 & NA & 5 \\
\hline Radıum·226 & $5 / 5$ & 026 & 098 & Z2-EU33B-346 & 0724 & NA & $\mathrm{N}_{\Lambda}$ & 4 & 0 & NA & 5 \\
\hline Technttiun-99 & 2! & 13 & AB 7 & 22-EU33B-363 & 25 & NA & $\mathrm{NA}$ & 0 & NA & NA & 2 \\
\hline Thorlum-228 & $5 / 5$ & 017 & 147 & Z2-EU33B-35Z & 0968 & NA & NA & 4 & 0 & NA & 5 \\
\hline Thorium-230 & $5 / 5$ & 06 & I 41 & 22-EU33B-346 & 118 & NA & NA & 0 & 4 & NA & 0 \\
\hline Thorıum-232 & 515 & 026 & 138 & $22-e \cup 33 B-352$ & 103 & $\mathrm{NA}$ & NA & $\$$ & 0 & NA & $\$$ \\
\hline Utanumin-234 & $5 / 5$ & 152 & 44 & Z2-EU33B-362 & 196 & 0 & 0 & 0 & $\mathrm{NA}$ & 0 & 3 \\
\hline Utanium-235 & $5 / 5$ & 0132 & 326 & 22-EU33B-346 & 129 & 0 & 0 & 0 & $\mathrm{NA}$ & 0 & 3 \\
\hline
\end{tabular}


EU Z2-33 K-10104-L FACTLITY SOIL RADIONUCLIDES WITH BACKGROUND, PRG, ANDFOR RL EXCEEDANCES \{pCifi) 0-10 ft (sant'd)

\begin{tabular}{|c|c|c|c|c|c|c|c|c|c|c|}
\hline \multirow[b]{2}{*}{ Analyte } & \multirow[b]{2}{*}{$\begin{array}{c}\text { Bettet } \\
\text { Irequewey }\end{array}$} & \multirow[b]{2}{*}{$\begin{array}{l}\text { Milolmum } \\
\text { detect }\end{array}$} & \multirow[b]{2}{*}{$\begin{array}{l}\text { Modimum } \\
\text { delest }\end{array}$} & \multirow[b]{2}{*}{$\begin{array}{l}\text { Latation(s) of } \\
\text { maribuju detcet }\end{array}$} & \multirow{2}{*}{$\begin{array}{c}\text { Apergagt } \\
\text { detected } \\
\text { respilt }\end{array}$} & \multicolumn{5}{|c|}{ 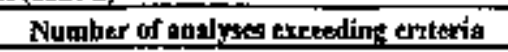 } \\
\hline & & & & & & $\underset{\text { RL }}{\text { Max }}$ & ${ }_{\text {RI }}^{\text {AYE }}-$ Ind & Bkg? & $\begin{array}{l}\text { GW } \\
\text { SL }\end{array}$ & $\begin{array}{l}\text { Rea } \\
\text { PRG }\end{array}$ \\
\hline Dranigm-238 & $5 / 5$ & 154 & 456 & $22-E U 33 B-362$ & 207 & 0 & $0-2$ & 5 & 0 & 5 \\
\hline $\begin{array}{l}\text { Avg = average } \\
\text { Bkg = background } \\
\text { EU = exposuct unt } \\
\text { GW = groundwater }\end{array}$ & $\begin{array}{l}\text { Ind } \\
\text { Mas } \\
\text { NA } \\
\text { PRC }\end{array}$ & 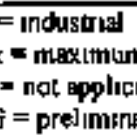 & $\begin{array}{l}\text { n } \\
\text { ary remed }\end{array}$ & OA goal & $\begin{array}{l}\text { Res = reside } \\
\mathrm{RL}=\text { remed } \\
\mathrm{SL}=5 \text { croen }\end{array}$ & $\begin{array}{l}\text { itul } \\
\text { atoon le } \\
\text { gg level }\end{array}$ & & & & \\
\hline
\end{tabular}

EU Z1-33 K-1004-L FAClLMV SOLk SVOC DETECTS (uK/kg) 0-10 \&!

\begin{tabular}{|c|c|c|c|c|c|c|c|c|}
\hline \multirow[b]{2}{*}{ Analyte } & \multirow[b]{2}{*}{$\begin{array}{c}\text { Detect } \\
\text { frequency }\end{array}$} & \multirow[b]{2}{*}{$\begin{array}{l}\text { Minimug } \\
\text { detert }\end{array}$} & \multirow[b]{2}{*}{$\begin{array}{l}\text { Maximuth } \\
\text { ifctect }\end{array}$} & \multirow[b]{2}{*}{$\begin{array}{l}\text { Locetion(s) of } \\
\text { onnximene detect }\end{array}$} & \multirow{2}{*}{$\begin{array}{c}\text { Average } \\
\text { detected } \\
\text { rosult }\end{array}$} & \multicolumn{3}{|c|}{$\begin{array}{l}\text { Number of anulges } \\
\text { exceodlag crifterth }\end{array}$} \\
\hline & & & & & & $\begin{array}{l}\text { Ind } \\
\text { PRG }\end{array}$ & $\begin{array}{l}\text { GW } \\
\text { SL }\end{array}$ & $\begin{array}{l}\overline{\mathbf{R}} \text { es } \\
\text { PRG }\end{array}$ \\
\hline Acensphthene & $1 / 4$ & 919 & 915 & $27-E \sqrt{3} 3 \mathrm{~B}-364$ & 91 & 0 & $\mathrm{NA}$ & 0 \\
\hline Anthracene & {$[/ 4$} & $140 \mathrm{~J}$ & $140 \mathrm{~J}$ & 22-EU33B-364 & 140 & 0 & $\mathrm{NA}$ & 0 \\
\hline Betez(a)emrhractent & $2 / 4$ & $110 \mathrm{~J}$ & 430 & $22-E \bigcup 33 \mathrm{~B}-364$ & 270 & 0 & NA & 0 \\
\hline Вепzо(в)ругеле & $2 \sqrt{4}$ & $100 \mathrm{~J}$ & 410 & $22-E / \sqrt{33} \mathrm{~B}-364$ & 255 & th & NAA & 2 \\
\hline Btazo(b)flutortanthent & $2 / 4$ & 931 & 540 & Z2-EU33E-364 & 317 & 0 & NA & 0 \\
\hline Benza(ght)perylene & $2 / 4$ & 69J & $340 \mathrm{~J}$ & 22-EU33B-364 & 202 & 0 & $\mathrm{NA}$ & 0 \\
\hline Benzo(k)filworanthene - & $2 / 4$ & ]00 J & $d 70$ & Z2-EU33B-364 & 285 & 0 & NA & 0 \\
\hline Bis(2-2thylhexyy) phethalate & $2 / 4$ & $44 J$ & $370 \mathrm{~J}$ & $\mathrm{Z2}-\mathrm{EU} 33 \mathrm{~B}-364$ & 207 & 0 & 0 & 0 \\
\hline Butyl benzyl phthalate & 14 & $160 \mathrm{~J}$ & 1601 & 22-EU33B-364 & 160 & 0 & NA & 0 \\
\hline Carbazole & $1 / 4$ & $160 \mathrm{~J}$ & $160 J$ & Z2-E1/33B-364 & 160 & a & NA & 0 \\
\hline Chrysene & $2 / 4$ & $130 \mathrm{~J}$ & 610 & Z2-EU33B-364 & 370 & 0 & NA & 0 \\
\hline Dibenz(a,h)anthracent & $1 / 4$ & $160]$ & $160 \mathrm{~J}$ & Z2.EU33B-364 & 160 & 0 & NA & $\mathbf{I}$ \\
\hline Ditxnzofuran & $1 / 4$ & $66]$ & 669 & Z2-EU93B-364 & 66 & 0 & NA & 0 \\
\hline Fluoranthente & $2 / 4$ & $260 \mathrm{~J}$ & 1500 & Z2-EU33B-364 & 880 & 0 & NA & 0 \\
\hline Flugre़ne & $1 / 4$ & $76 J$ & $76 \pi$ & 22-EU33B-364 & 36 & 0 & ita & 0 \\
\hline lndeno(1,2,3-cd)pyrente & $2 \sqrt{4}$ & $6.1 J$ & 2901 & Z2-EU33B-364 & 176 & 0 & $\mathrm{NA}$ & 0 \\
\hline Naphthalene & $1 / 4$ & रा J & 675 & $22-8 U 338-364$ & 67 & 0 & NA & ot \\
\hline Phenanthrene & $2 / 4$ & $170 \mathrm{~J}$ & 980 & Z2-EU33B-364 & 575 & 0 & NA & 0 \\
\hline PyTtene & $2 / 4$ & $2200]$ & 950 & 22-EU33B-364 & 585 & 0 & NA & 0 \\
\hline 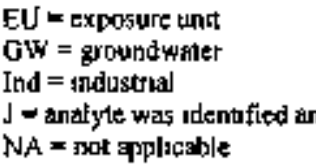 & 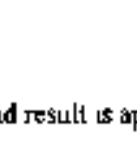 & 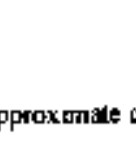 & - & 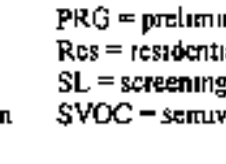 & $\begin{array}{l}\text { mary remed } \\
\text { ab } \\
\text {; level } \\
\text { rdalife org }\end{array}$ & Lon $\mathrm{gC}$ & ound & \\
\hline
\end{tabular}

EU Z2-33 K-1004-L FACILITY SOIL VOC DETECTS (ugikg) 0-18 ft

\begin{tabular}{|c|c|c|c|c|c|c|c|c|}
\hline \multirow[b]{2}{*}{ Analyte } & \multirow[b]{2}{*}{$\begin{array}{c}\text { Defect } \\
\text { frequency }\end{array}$} & \multirow[b]{2}{*}{$\begin{array}{l}\text { Mininum } \\
\text { detect }\end{array}$} & \multirow[b]{2}{*}{$\begin{array}{c}\text { Morimum } \\
\text { defect }\end{array}$} & \multirow[b]{2}{*}{$\begin{array}{l}\text { Locedton[s] of } \\
\text { maxipum detcet }\end{array}$} & \multirow{2}{*}{$\begin{array}{l}\text { Averibe } \\
\text { detected } \\
\text { retult }\end{array}$} & \multicolumn{3}{|c|}{$\begin{array}{l}\text { Numbes of ansigyes } \\
\text { exceeding criterift }\end{array}$} \\
\hline & & & & & & $\begin{array}{l}\text { Ind } \\
\text { PRG }\end{array}$ & $\begin{array}{l}\text { GW } \\
\text { SL }\end{array}$ & $\begin{array}{l}\text { Res } \\
\text { PRG }\end{array}$ \\
\hline Eenzene & $1 \sqrt{3}$ & 351 & 351 & Z2-Eบ33B-346 & 35 & 0 & 0 & 0 \\
\hline cis-1,2-Dichloroetliene & $1 / 3$ & 27 & 273 & Z2.-EU33B-346 & 27 & 0 & NA & 0 \\
\hline Ethylbenzene & $1 / 3$ & 74 & 74 & 22-EU33B-346 & 74 & 0 & NA & 0 \\
\hline Toluene & $1 / 3$ & $\mathcal{u}$ & 2 & 22-EU33日-346 & 2 & 0 & 0 & 0 \\
\hline Total Xylene & $1 / 3$ & $\mathrm{JB}$ & 18 & Z2-EU33B-346 & 18 & 0 & NA & NA \\
\hline Luns-I, 7 -Dichloroethene & 13 & ( I) & $1 \tau \boldsymbol{J}$ & Z2-E\33B-346 & 17 & 0 & NA & 0 \\
\hline Trisluorothenc & $1 / 3$ & 17 & 17 & Z2-EU93B-364 & 17 & 0 & 0 & 0 \\
\hline Vinyl thlonde & $1 / 3$ & 17 & 17 & Z2-EU33B-3-46 & 17 & 0 & 0 & 0 \\
\hline \multicolumn{4}{|c|}{ 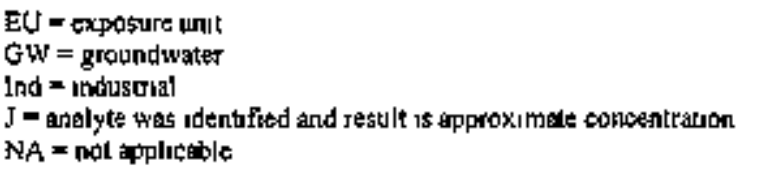 } & \multicolumn{5}{|c|}{ 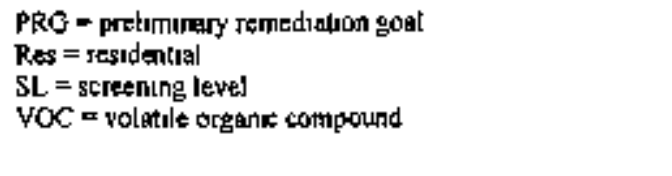 } \\
\hline
\end{tabular}


K-1004-M Facility: Biased sampling was recommended in the Assessment Report based on site knowledge regarding former use of the facility. Three DVS biased sample locations were identified (Sect. 2.2.3), including two locations in the concrete trench surrounding the slab where concrete and sediment samples were collected and one location where a concrete samiple was collected. Average RI exceedances of U-234 and U-238 were observed in the two sediment samples from the drainage trench sumounding the slab. Since the time of sample collection, the K-1004-M slab, including the drainage trench, was removed during D\&D along with all sample locations. The former K-1004-M slab was adjacent to the K-1004-L slab and current conditions at the K-1004-L slab (see above) are representative of current conditions at the site of the K-1004-M slab.

K-1004-P Facility Lotations: Biased sampling was not recommended for these sites in the Assessinent Report. However, there were several historical sample locations around K-1004-P (Sect. 2.2.3) that are included in this section. Analytical results for these historical samples summarized below show radionuclide Ind PRG exceedances, metal Bkg exceedances, and PCB and SVOC detections.

EU 22-33 K-1004-P FACILITY SOIL METALS WTTH BACKGROUND, PRG, GW SL, AND/OR RL EXCEEDANCES (m/kg) 0-10 f!

\begin{tabular}{|c|c|c|c|c|c|c|c|c|c|c|c|}
\hline \multirow[b]{2}{*}{ Anelyte } & \multirow[b]{2}{*}{$\begin{array}{l}\text { Detect } \\
\text { Erequeney }\end{array}$} & \multirow[b]{2}{*}{$\begin{array}{c}\text { Minimum } \\
\text { detect }\end{array}$} & \multirow[b]{2}{*}{$\underset{\text { detect }}{\text { Mariman }}$} & \multirow{2}{*}{$\begin{array}{c}\text { Locations(s) or } \\
\text { maximan* } \\
\text { detect }\end{array}$} & \multirow{2}{*}{$\begin{array}{l}\text { Average } \\
\text { detected } \\
\text { resuil }\end{array}$} & \multicolumn{6}{|c|}{ Number of analyses erceodtug criteris } \\
\hline & & & & & & $\begin{array}{c}\text { Max } \\
\text { RL }\end{array}$ & $\begin{array}{l}\text { AYg } \\
\text { RL }\end{array}$ & PRG & BkE & $\begin{array}{l}\text { GW } \\
\text { Sll }\end{array}$ & $\begin{array}{c}\text { Res } \\
\text { PRG }\end{array}$ \\
\hline Aluntietium & $2 \pi$ & 12,000 & $17,0,00$ & $22-\mathrm{EU} 33-2013$ & 14,500 & $N A$ & NA & 0 & 0 & NA & 2 \\
\hline Arstenנsc & $2 / 2$ & $=69$ & 71 & 22.EU33-2012 & $y$ & 0 & 0 & 0 & 0 & 0 & 2 \\
\hline Cadm1um & $2 / 2$ & 12 & [ 4 & 22-EU⿻3 2013 & 13 & NA & NA & 0 & 2 & NA & 0 \\
\hline Calçum & $2 / 2$ & $2,400 \mathrm{~J}$ & $14,020 \mathrm{~J}$ & Z2-EU33-2012 & $B, 200$ & NA & NA & $N A$ & ] & NA & NA \\
\hline Chromıur & $2 \sqrt{2}$ & 21 & 25 & $22-E U 13-2013$ & 23 & NA & NA & $\dot{0}$ & 0 & 0 & $\mathbf{I}$ \\
\hline Coppes & $2 / 2$ & 201 & $25 \mathrm{IJ}$ & $22-E U 33-2013$ & 225 & NA & $N A$ & 0 & 1 & NA & 0 \\
\hline [ron & $2 / 2$ & 43,000 & 58,0030 & Z2-EU33-2013 & 50,500 & NA & $\mathrm{NA}$ & 0 & 0 & NA & 2 \\
\hline Manganese & $2 / 2$ & $I 60$ & 180 & 22-EU33-2012 & 170 & NA. & NA & 0 & 0 & NA & $\mathbf{I}$ \\
\hline Vantadium & $2 \Omega$ & 30 & 38 & $22-E U 33-2013$ & 34 & NA & $\mathrm{NA}$ & 0 & 0 & NA & 2 \\
\hline
\end{tabular}

\section{AYg - averege}

Bkg $=$ barkgromind

EU - exposure unit

$G W=$ groundwaler

ind = industrial

$J=$ antalyle was identified and tesult is approximate concentration

\section{Max $=$ maxumum}

NA $=$ not appliteble

PRG = prejumotary remediation gotal

Res = resldental

RL = remediation level

SL $m$ screesung lewel

EU Z2-33 K-10IM-P FACILITY SOJL, PPCB DETECTS (az/Lis) 0-10 A

\begin{tabular}{|c|c|c|c|c|c|c|c|c|c|}
\hline \multirow[b]{2}{*}{ Analgte } & \multirow[b]{2}{*}{$\begin{array}{c}\text { Detect } \\
\text { Prequency }\end{array}$} & \multirow[b]{2}{*}{$\begin{array}{l}\text { Mfinimen } \\
\text { dętert }\end{array}$} & \multirow[b]{2}{*}{$\begin{array}{l}\text { Maximan } \\
\text { detect }\end{array}$} & \multirow{2}{*}{$\begin{array}{l}\text { Lacaluon(s) of } \\
\text { maximnm } \\
\text { detect }\end{array}$} & \multirow{2}{*}{$\begin{array}{l}\text { Average } \\
\text { detected } \\
\text { result }\end{array}$} & \multicolumn{4}{|c|}{$\begin{array}{l}\text { Number of analyses } \\
\text { excetediag criterto }\end{array}$} \\
\hline & & & & & & $\begin{array}{c}\text { Max } \\
\text { RL }\end{array}$ & $\begin{array}{l}\text { Ave } \\
\text { RL }\end{array}$ & $\begin{array}{l}\text { Ind } \\
\text { PRe I }\end{array}$ & $\begin{array}{c}\text { Res } \\
\text { PRE } \\
\end{array}$ \\
\hline $\mathrm{PCB}-1260$ & 12 & $17 J$ & 17] & $22 \cdot E V 33-2012$ & 17 & 0 & D & 1) & 0 \\
\hline Polychlorinated Bıptenyl & $1 / 2$ & $17 J$ & $17 \mathrm{~J}$ & Z2-EU33-2012 & 17 & $\$$ & 0 & 0 & 0 \\
\hline $\begin{array}{l}\text { Avg }=\text { average } \\
\text { EU = exposure untt } \\
\text { 1nd = Industral } \\
\text { J m anglyte wes udenufied } \\
\text { Max = maximum }\end{array}$ & ind restult is & proxtriale & concentration & \multicolumn{6}{|c|}{$\begin{array}{l}\text { PPCB = pestucide and polyctlomnated biphenyl } \\
\text { PRG = prediminary semedirtion god } \\
\text { Res = residential } \\
\text { RL = remedtation level }\end{array}$} \\
\hline
\end{tabular}

EU Z2-33 K-1004-P FACILITY SOIL RADLONUCLIDES WITH BACKGROUND, PRG, ANDHOR RL DXCEEDANCES (pCi/g) 0-10 ft

\begin{tabular}{|c|c|c|c|c|c|c|c|c|c|c|c|}
\hline \multirow[b]{2}{*}{ Arstyte } & \multirow[b]{2}{*}{$\begin{array}{c}\text { Detect } \\
\text { Irequebey }\end{array}$} & \multirow[b]{2}{*}{$\begin{array}{c}\text { Minimen } \\
\text { derect }\end{array}$} & \multirow[b]{2}{*}{$\begin{array}{l}\text { Muxidinum } \\
\text { detect }\end{array}$} & \multirow[b]{2}{*}{$\begin{array}{l}\text { Lotedanf(s) of } \\
\text { marinum Jeteel }\end{array}$} & \multirow{2}{*}{$\begin{array}{l}\text { Average } \\
\text { deterted } \\
\text { refult }\end{array}$} & \multicolumn{6}{|c|}{ Number of nalyben tucetedine sritcria } \\
\hline & & & & & & $\begin{array}{c}\text { Max } \\
\text { RL. }\end{array}$ & $\begin{array}{l}\text { Aqg } \\
\text { RLE }\end{array}$ & $\begin{array}{l}\text { Ind } \\
\text { PEG }\end{array}$ & BAtg & $\begin{array}{l}\text { GW } \\
\text { sl. }\end{array}$ & $\begin{array}{l}\text { Res } \\
\text { PRG }\end{array}$ \\
\hline Potas5ium-40 & d!l & 156 & 156 & Z2-Eบ33-2012 & 156 & NA & NA & 1 & t) & NA & I \\
\hline Radium-226 & $\mu$ & 0879 & 0879 & Z2-EU33-2012 & 0879 & NA & NA & 1 & 0 & NA & । \\
\hline Thortum-228 & $1 / 1$ & 12 & 12 & Z2-EU33-2012 & โ 2 & NA & NA & 1 & 0 & NA & 1 \\
\hline Thorium-232 & $|/|$ & I is & 118 & Z2-EU33-2012 & I I8 & NA & $\mathrm{NA}$ & 1 & 0 & NA & 1 \\
\hline
\end{tabular}


EU 22-33 K-[004-P FACTLITY SOIL RADIONUCLLDES WTTH BACKGROUND, PRG, AND/OR RL EXCEEDANCES (pCl/g) (n-10 ft (cobl'd)

\begin{tabular}{|c|c|c|c|c|c|c|c|c|c|c|c|}
\hline \multirow[b]{2}{*}{ Analyte } & \multirow[b]{2}{*}{$\begin{array}{l}\text { Detret } \\
\text { frequency }\end{array}$} & \multirow[b]{2}{*}{ Misimum } & \multirow[b]{2}{*}{$\begin{array}{l}\text { Maxintun } \\
\text { detert }\end{array}$} & \multirow[b]{2}{*}{$\begin{array}{l}\text { Locstion(s) of } \\
\text { mutringan detect }\end{array}$} & \multirow{2}{*}{$\begin{array}{l}\text { Averape } \\
\text { detected } \\
\text { regult }\end{array}$} & \multicolumn{6}{|c|}{ Number of anabybes excetaling criterix } \\
\hline & & & & & & ML & Alv & $\begin{array}{l}\text { Ind } \\
\text { PRGG }\end{array}$ & Blkg & Git & $\begin{array}{l}\text { ReE } \\
\text { PRG }\end{array}$ \\
\hline Urantum-238 & WI & 116 & 116 & Z2-EU33-2012 & 116 & 0 & 0 & 0 & 0 & 0 & I \\
\hline
\end{tabular}

\begin{tabular}{|c|c|}
\hline 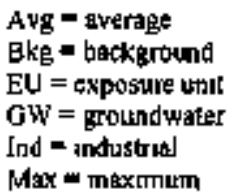 & $\begin{array}{l}\text { NA = nod aplicable } \\
\text { PRG = prelıminary remedıation god } \\
\text { Res = resıdentual } \\
\text { RL = remediation level } \\
\$ L=\text { sercening leycl }\end{array}$ \\
\hline
\end{tabular}

EU Z2-33 K-1004-P FACILTY SOLL SVOC DETECTS (UEAgg) 0-16 ft

\begin{tabular}{|c|c|c|c|c|c|c|c|}
\hline \multirow[b]{2}{*}{ Annfyte } & \multirow{2}{*}{$\begin{array}{c}\text { Detcet } \\
\text { Fropotetcy }\end{array}$} & \multirow{2}{*}{$\begin{array}{c}\text { Mftaimun } \\
\text { Delect }\end{array}$} & \multirow{2}{*}{ Metect } & \multirow{2}{*}{$\begin{array}{l}\text { Losation(s) of } \\
\text { Matumum tithet }\end{array}$} & \multirow{2}{*}{$\begin{array}{l}\text { Averigo } \\
\text { Detected } \\
\text { Rtondt }\end{array}$} & \multicolumn{2}{|c|}{ 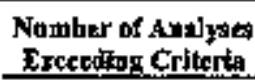 } \\
\hline & & & & & & $\begin{array}{l}\text { Ind } \\
\text { PRG } \\
\end{array}$ & $\begin{array}{l}\text { Res } \\
\text { RRG } \\
\end{array}$ \\
\hline N-Nitrosodiphenyiamine & {$[/]$} & 17 & 175 & $22-E U 33-2012$ & 17 & $\mathrm{NA}$ & 0 \\
\hline 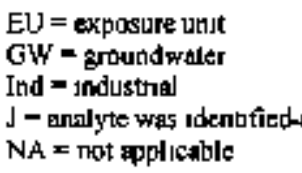 & d result t5 ap & pprokimate & oncentration & \multicolumn{4}{|c|}{ 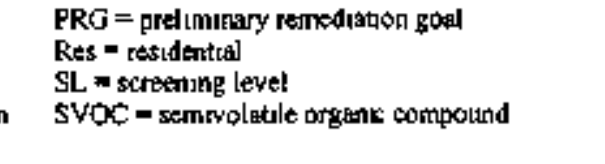 } \\
\hline
\end{tabular}

VOCs were analyzed for but were not detected.

K-1006 Facllity: The K-1006 Development Laboratory is an active facility. Biased sampling was recommended in the Assessment Report based on its current and hustoric use. Dynamic Verification Strategy biased sample locations were identified at the busiding sump on the north end of the facility, building sump on the south end of the facility, and acid drain pit located to the west of the facility. In addition, there are several historical sample locations associated with the K-1006 facility. DVS and historical sample locations are presented in Sect. 2.2.3

Three DVS biased sample locations characterize building sumps Z2-EU33B-128 and Z2-EU33B-327 on the north end and 22-EU33B-328 on the south. All three locations represent sediment samples from the sunips. Analytical results for the sump samples summarzed below show two Ra/Th decay series Max and Avg RL exceedances in the noth sump. PCB and U-238 Avg RL exceedances it the north sump, metal and radionuclide ind PRG and Bkg exceedances in both sumps, PCB Ind PRG exceedances in the north sump, metal and radionuclide GW SL exceedances in the north sump, and detections of PCBs, SVOCs, and VOCs in both sumps.

EU Z2.33 K-1006 FACILITY \$UMP METAES WTTH BACKGROUND, PRG, GW SL, ANDFOR RL EXCEEDANCES (me/kg) 0-10 ft

\begin{tabular}{|c|c|c|c|c|c|c|c|c|c|c|c|}
\hline \multirow[b]{2}{*}{ Ansalyte } & \multirow[b]{2}{*}{$\begin{array}{c}\text { Detect } \\
\text { Irequexsy }\end{array}$} & \multirow[b]{2}{*}{$\begin{array}{c}\text { Minimum } \\
\text { detect }\end{array}$} & \multirow[b]{2}{*}{$\begin{array}{l}\text { Marlmún } \\
\text { dexpet }\end{array}$} & \multirow{2}{*}{$\begin{array}{c}\text { Locatiom(s) of } \\
\text { ntatimunt } \\
\text { detest }\end{array}$} & \multirow{2}{*}{$\begin{array}{l}\text { Average } \\
\text { detected } \\
\text { resalt }\end{array}$} & \multicolumn{6}{|c|}{ Number of anolyses exeeedlug criterta } \\
\hline & & & & & & $\begin{array}{c}\operatorname{Max} \\
\mathrm{RL}\end{array}$ & $\begin{array}{l}\text { Ave } \\
\text { RL }\end{array}$ & $\begin{array}{l}\text { Ind } \\
\text { PRG }\end{array}$ & Bks: & $\begin{array}{l}\text { GW } \\
\text { SL }\end{array}$ & $\begin{array}{l}\text { Res } \\
\text { PBG }\end{array}$ \\
\hline Antımony & $2 / 2$ & 17 & उय & $22-E \cup 33 B-327$ & 245 & $\mathrm{NA}$ & $\mathrm{NA}$ & 0 & $\dot{i}$ & 0 & 1 \\
\hline Arsenic & 22 & 92 & $93]$ & $Z 2-E U 33 B-32]$ & 512 & 0 & 0 & 1 & 1 & 1 & 2 \\
\hline Barnum & $2 /$ & 472 & 346 & Z2-EU33B-327 & 197 & $N_{A}$ & NA & 0 & ] & 0 & 0 \\
\hline Cadmelam & $2 / 2$ & 19 & 242 & Z2-EU 3 BB-32] & 216 & $\mathrm{NA}$ & NA & 0 & 2 & NA & 2 \\
\hline Calcium & $2 / 2$ & $\$ 1,500 \mathrm{~J}$ & $T 2,400$, & 22-EU33B-328 & 51,950 & $\mathrm{NA}$ & NA. & $\mathrm{NA}$ & 2 & NA & NA \\
\hline Chromsum, & $2 / 2$ & $588 \mathrm{~J}$ & 2383 & Z2-E033B-327 & 148 & NA & NA & 0 & 2 & 1 & 2 \\
\hline Copper & $2 / 2$ & 5565 & $1,0 \mid 0)$ & Z2-EU33B-328 & J83 & $\mathrm{NA}$ & $\mathrm{NA}$ & 0 & 2 & NA & 2 \\
\hline iron & $2 / 2$ & 270,000 & 300,000 & 22-EU33B-328 & 291,000 & $\mathrm{NA}$ & NA & 2 & 2 & $N A$ & 2 \\
\hline Lend & $2 / 2$ & 123J & 1341 & Z2-EU33B-327 & 279 & $N A$ & NA & $\theta$ & 2 & 0 & $\mathbf{I}$ \\
\hline Lith1um & $2 \sqrt{2}$ & 4575 & 515 & 22-EU33B-32? & 486 & Net & NA & 0 & i & NA & 0 \\
\hline Magneร़แm & $2 / 2$ & $1,140 \mathrm{~J}$ & $22,600 \mathrm{~J}$ & $22-E 033 B-328$ & 11,870 & $\mathrm{NA}$ & NA & $\mathrm{NA}$ & $\mathbf{t}$ & NA & NA \\
\hline Manganese & $2 / 2$ & 1,090 & 2,110 & Z2-EU33B-327 & 1,600 & NA & NA & 0 & 0 & NA & 2 \\
\hline Mescury & $2 \pi$ & 086 & 16 & Z2-EU33B-327 & 123 & 0 & 0 & 0 & 2 & $\mathrm{NA}$ & 0 \\
\hline Nıctketl & $2 / 2$ & 846 & 215 & Z2-EU33B-327 & 150 & $\mathrm{NA}$ & NA & 0 & 2 & $N A$ & I \\
\hline
\end{tabular}


EU 22-33 K-1006 FACILITY SUMP METALS WITH BACKGROUND,

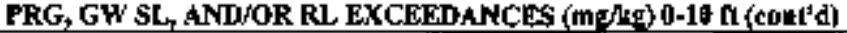

\begin{tabular}{|c|c|c|c|c|c|c|c|c|c|c|c|}
\hline \multirow[b]{2}{*}{ Aselyyte } & \multirow[b]{2}{*}{$\begin{array}{c}\text { Dettet } \\
\text { frequency }\end{array}$} & \multirow[b]{2}{*}{$\underset{\text { Meteet }}{\text { Mummum }}$} & \multirow{2}{*}{$\begin{array}{c}\text { Marionidn } \\
\text { detect }\end{array}$} & \multirow{2}{*}{$\begin{array}{c}\text { Locution(s) of } \\
\text { mayinen } \\
\text { detect }\end{array}$} & \multirow{2}{*}{$\begin{array}{l}\text { Averight } \\
\text { detected } \\
\text { "result }\end{array}$} & \multicolumn{6}{|c|}{ 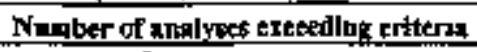 } \\
\hline & & & & & & $\underset{\text { RL }}{\text { Max }}$ & 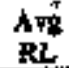 & $\begin{array}{l}\text { Ind } \\
\text { ext' }\end{array}$ & BLs: & $\begin{array}{l}\text { GW } \\
\text { SL }\end{array}$ & $\begin{array}{l}\text { Res } \\
\text { PRC }\end{array}$ \\
\hline Silver & $2 / 2$ & 62 & 125 & Z2-EU33B-327 & 656 & $\overline{N A}$ & NA & 0 & 2 & $\mathrm{NA}$ & l \\
\hline Urantum & $2 \Omega$ & 128 & 878 & Z2-EU33B-327 & $\$ 03$ & NA & NA & 0 & $\mathbf{N A}$ & NA & 2 \\
\hline Vanadium & $2 / 2$ & $54 \$$ & $303 \mathrm{~J}$ & $22-E$ U13 $3 B-328$ & 179 & NA & NA & 0 & 0 & $\mathrm{NA}$ & 1 \\
\hline Zink & $2 / 2$ & I52J & $605]$ & Z2-EU33B-327 & 379 & $\mathrm{NA}$ & NiA & 0 & 2 & NA & 0 \\
\hline
\end{tabular}

Avg $=$ avtrapge

$B \mathrm{~kg}=$ backgroumd

$\mathrm{EU}=$ s.xposure uail

GW' = ground water

isd = industrisl

J - amalyte was identafed and restlt ds approxtmete concterstratkon

Mex $=$ maximum

NA $=$ not appincable

PRG = preliminary' remediaton goal

Res = tesidentud

RL = remequatunn level

SL - screenıng level

EU Z2-333 K-1006 FACJLIJY \$̦UMP PPCB DETECTS (ug/kg) 0-10 ft

\begin{tabular}{|c|c|c|c|c|c|c|c|c|c|}
\hline \multirow[b]{2}{*}{ Andylyte } & \multirow[b]{2}{*}{$\begin{array}{c}\text { Detect } \\
\text { Irequency }\end{array}$} & \multirow[b]{2}{*}{$\begin{array}{l}\text { Mfipinam } \\
\text { detest }\end{array}$} & \multirow[b]{2}{*}{$\begin{array}{c}\text { Meriopar } \\
\text { deted }\end{array}$} & \multirow{2}{*}{$\begin{array}{l}\text { Location(g) of } \\
\text { andmum } \\
\text { detect }\end{array}$} & \multirow{2}{*}{$\begin{array}{l}\text { Arerage } \\
\text { detected } \\
\text { restilt }\end{array}$} & \multicolumn{4}{|c|}{$\begin{array}{l}\text { Number of snalyses } \\
\text { treteding eriters }\end{array}$} \\
\hline & & & & & & $\begin{array}{c}\text { Max } \\
\mathbf{R L}\end{array}$ & $\begin{array}{l}\text { AVg } \\
\text { RI. }\end{array}$ & $\begin{array}{l}\text { Ind } \\
\text { PRG }\end{array}$ & $\begin{array}{l}\text { Res } \\
\text { PRG }\end{array}$ \\
\hline PCB.1254 & $-1 / 2$ & 23,0001 & 23, (XDOt] & 72-EU33B-327 & 23,000 & 0 & l & 1 & ] \\
\hline Polychlonnated B।phenyl & $1 / 2$ & 23,0000 & $23,000 \mathrm{~J}$ & Z2-Eบ引33-327 & 23,000 & 0 & $\mathrm{t}$ & $\mathbf{I}$ & 1 \\
\hline
\end{tabular}

Ayg = average

EU = exposture untt

Ind = Industrial

$J$ = analyte was idenufied and tesult is approxımase concentration

Max = maxımum
PPCB = pesticide and poilychlonnated biphersyl

PRG = prelımınary remedioton goal

Res a residentid

RL — remedsation level

CU $22-33$ K-1006 FACILCT SUMP RADIONUCLIDES WITH BACKGKOLND, PRG, AND/OR RL EXCEEDANCES (pCug) 0-10 fi

\begin{tabular}{|c|c|c|c|c|c|c|c|c|c|c|c|}
\hline \multirow[b]{2}{*}{ Anajyte } & \multirow[b]{2}{*}{$\begin{array}{c}\text { Detect } \\
\text { frequency }\end{array}$} & \multirow[b]{2}{*}{$\begin{array}{l}\text { Monitum } \\
\text { detect }\end{array}$} & \multirow[b]{2}{*}{$\begin{array}{l}\text { Magnana } \\
\text { detect }\end{array}$} & \multirow[b]{2}{*}{$\begin{array}{l}\text { Loctation(s) of } \\
\text { maxamun detect }\end{array}$} & \multirow{2}{*}{$\begin{array}{l}\text { Averige } \\
\text { detected } \\
\text { result }\end{array}$} & \multicolumn{6}{|c|}{ Maribert of andpses excecilina eriteria } \\
\hline & & & & & & Max & $\begin{array}{l}\text { At? } \\
\text { Rl }\end{array}$ & Imd & Bhg. & 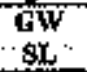 & $\begin{array}{c}\text { Red } \\
\text { PRG }\end{array}$ \\
\hline Cesilam-137 & $2 / 2$ & 0 il7 & 023 & Z2-EU33B-327 & 0]74 & 0 & 6 & 0 & NA & NA & 2 \\
\hline Nephmium-27? & $1 / 2$ & 13 & 13 & 22-EL133B-327 & 13 & 0 & 0 & 0 & NA & NA & I \\
\hline Potassnum 40 & III & 38 & 38 & Z2-EU33B-328 & 38 & $\mathrm{NA}$ & NA & 1 & 0 & NA & 1 \\
\hline Radum-226 & $3 / 3$ & 012 & 218 & 22-EU33B-327 & 106 & $\mathrm{NA}$ & $N A$ & 3 & 1 & $N A$ & 3 \\
\hline Techretium-99 & $2 \pi$ & 242 & 267 & Z2-Eบ33B-327 & 146 & $N A$ & NA & 0 & $\mathrm{NA}$ & $N A_{2}$ & 2 \\
\hline Thonum-228 & $3 / 3$ & 024 & 385 & 22-Eบ33B-327 & 179 & NA & $N A$ & 3 & $\mathbf{I}$ & NA & 3 \\
\hline Thonum-230 & $2 / 3$ & 2211 & 405 & 22-EU33B-327 & 313 & NA & NA & 0 & 2 & $N A$ & 2 \\
\hline Thюnџm-232 & $3 / 3$ & 0215 & 429 & 22-EU33B-327 & 197 & $\mathbf{N A}$ & NA & 3 & I & $\mathrm{NA}$ & 3 \\
\hline EarTh decay stenes & $3 / 3$ & 0 & 4164 & Z2-EU33E-327 & 313 & 2 & 2 & NA & NA & NA & $N A$ \\
\hline Џranım-2引4 & $2 / 2$ & 182 & 102 & 22-EL133B-327 & 601 & 0 & 0 & 0 & $N A$ & 1 & 2 \\
\hline Uran|um-235 & $2 \sqrt{2}$ & 114 & 58 & 22-EU33B-327 & 347 & 0 & 0 & 1 & NA & 0 & 2 \\
\hline Urantum-23B & $2 / 2$ & 115 & 116 & Z2-EU33B-327 & 638 & 0 & 1 & l & 2 & 1 & 2 \\
\hline $\begin{array}{l}\text { Avg = avcrage } \\
\text { Bkg = background } \\
\text { EU = exposturt unit } \\
\text { GW' = groundwater } \\
\text { [nd = industral } \\
\text { J c analyte was rdent }\end{array}$ & ified and rest & It & tho & rahon & \multicolumn{7}{|c|}{ 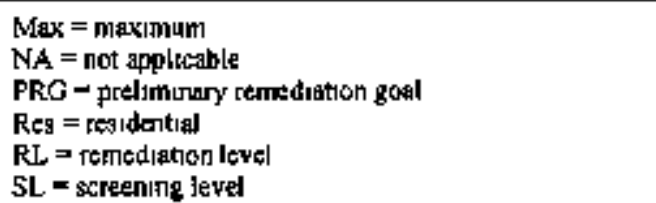 } \\
\hline
\end{tabular}




\begin{tabular}{|c|c|c|c|c|c|c|c|c|}
\hline \multirow[b]{2}{*}{ Antyle } & \multirow[b]{2}{*}{$\begin{array}{l}\text { Detett } \\
\text { frequency }\end{array}$} & \multirow[b]{2}{*}{$\begin{array}{l}\text { Minumum } \\
\text { deteet }\end{array}$} & \multicolumn{2}{|l|}{ ' } & \multirow{2}{*}{$\begin{array}{c}\text { Aperuge } \\
\text { defected } \\
\text { refult }\end{array}$} & \multicolumn{3}{|c|}{$\begin{array}{l}\text { Nomber of anglyget } \\
\text { expetilub eriferit }\end{array}$} \\
\hline & & & $\begin{array}{c}\text { Mexunam } \\
\text { detett }\end{array}$ & $\begin{array}{l}\text { Locabon(t) of } \\
\text { naranum deltei }\end{array}$ & & $\begin{array}{l}\text { Ind } \\
\text { PRG }\end{array}$ & $\begin{array}{l}\text { GW } \\
\text { SL }\end{array}$ & $\begin{array}{l}\text { Res } \\
\text { PRG }\end{array}$ \\
\hline 1,2,4-Tachlorobenzene & $1 / 2$ & $15,000 \mathrm{~J}$ & $15,000 \mathrm{~J}$ & Z2.-EU33B-327 & 15,000 & 0 & NA & 1 \\
\hline 1,2-Dichlorobenzene & 12 & 831 & $83]$ & $22-E U 338-327$ & 83 & 0 & NA. & 0 \\
\hline 1,4-Dictlotobenzene & $1 / 2$ & $160 \mathrm{~J}$ & $160 \mathrm{~J}$ & Z2-EU33B-327 & 160 & 0 & $N A$ & 0 \\
\hline 2-Metby|naptaha|ene & $I / 2$ & 64. & 641 & $22-E U 33 B-327$ & 64 & 4 & NA & NA \\
\hline Benzolc axid & $1 / 2$ & 5,500 & 5,500 & Z2-EU33B-327 & 5,500 & 0 & NA & 0 \\
\hline BLS(2-ethylhexyl)phthalate & 22 & $660 \mathrm{~J}$ & $66,000 \mathrm{~J}$ & Z2-EU33B-327 & 33,330 & 0 & 0 & 1 \\
\hline Butyl henzyl phthalate & 17 & 29,0001 & $29.000 \mathrm{~J}$ & 己2-EU33B-32? & $29, \infty 0$ & 0 & NA & 0 \\
\hline Di-T-butyl phthalate & $1 / 2$ & $1,200 \mathrm{~J}$ & $1,200 \mathrm{~J}$ & Z2-EU33B-327 & 1,200 & 0 & NA & 0 \\
\hline Di-n-actylphthatate & $1 / 2$ & 1,400 & 1,400 & 22 -EU333-32\} & 1,400 & 0 & NA & 0 \\
\hline Fluoranthene & $1 / 2$ & 83. & 83 & Z2-EU33B-32? & 83 & $\theta$ & $\mathrm{NA}$ & 0 \\
\hline Hexachlorobenzene & $\mathrm{L} / 2$ & $340 \mathrm{~J}$ & $340 \mathrm{~J}$ & Z2-EU33B.327 & 340 & 0 & NA & 1 \\
\hline Naphthalene & $\mathrm{l} / \mathrm{Z}$ & 160009 & 16,0001 & Z2-EU33B-32\} & 16,000 & 0 & NA & 1 \\
\hline Phenanuhrene & $1 / 2$ & 623 & 621 & 22-EU33B-327 & 62 & 0 & NA & 0 \\
\hline Pyrene & $1 / 2$ & $70 \mathrm{~J}$ & $70 \mathrm{~J}$ & Z2-EU33B-327 & 70 & $q$ & NA & 0 \\
\hline
\end{tabular}

EU $=$ exposure uhit

GW - e proundwater

Ind = Industinal

$J=$ analytc was identhied and regu|t is approximate concentration

$N A=$ not plicable

PRG a prelumutnary remedcation god

Res - residentut|

$S L$ a scretening levd

SVOC = semrvo[atile organic compound

EU Z2-33 K-10e6 FAClLITY SUMP VOC DETECTS (Ug,

\begin{tabular}{|c|c|c|c|c|c|c|c|c|}
\hline \multirow[b]{2}{*}{ Ambyits } & \multirow[b]{2}{*}{$\begin{array}{c}\text { Detest } \\
\text { freguenty }\end{array}$} & \multirow[b]{2}{*}{$\underset{\text { detect }}{\text { Minimum }}$} & \multirow[b]{2}{*}{ S Marimam } & \multirow{2}{*}{$\begin{array}{l}= \\
\text { Locaton(s) of } \\
\text { mavenum detect }\end{array}$} & \multirow{2}{*}{$\begin{array}{l}\text { Averuge } \\
\text { detected } \\
\text { réíull }\end{array}$} & \multicolumn{3}{|c|}{$\begin{array}{l}\text { Number of analfacel } \\
\text { excenting criterla }\end{array}$} \\
\hline & & & & & & $\begin{array}{l}\text { Ind } \\
\text { PRG }\end{array}$ & $\begin{array}{l}\text { GW } \\
\text { SL }\end{array}$ & $\begin{array}{l}\text { Reg } \\
\text { PRG }\end{array}$ \\
\hline Carbon teuachlonde & $1 / 2$ & 可 & $\overline{3 j}$ & $\mathrm{Z2}-\overline{\mathrm{E}} \mathrm{133 \textrm {B } - 3 2 8}$ & 3 & 0 & 0 & 0 \\
\hline Chloroform & $1 / 2$ & 3 I & $39 \mathrm{~J}$ & Z2-EU33B-327 & 39 & 0 & 0 & 0 \\
\hline e1s-1,2-Dxchlorot thene & $1 / 2$ & $91 J$ & 915 & 22-EU33B-327 & 91 & 0 & NA & 0 \\
\hline Evhylbenzene & $1 / 2$ & $30 \mathrm{~b}$ & $30 \mathrm{j}$ & 22-EU33B-32J & 30 & 0 & NA & 0 \\
\hline Metbyjene chlortde & $1 / 2$ & $31 \mathrm{~J}$ & $39 \mathrm{~J}$ & Z2-EU33B-327 & 3] & 0 & $\square$ & 0 \\
\hline Tetrachlorethent & $1 / 2$ & $26]$ & $26 \mathrm{~J}$ & Z2-EU33B-327 & 26 & 0 & 0 & 0 \\
\hline Toluene & $2 / 2$ & u & $20 \mathrm{~J}$ & Z2'-EU33B-327 & 105 & 0 & 0 & 0 \\
\hline Total Xylent & $1 / 2$ & $290 \mathrm{~J}$ & $290 \mathrm{~J}$ & 22-EU33B-327 & 290 & 0 & NA & NA \\
\hline
\end{tabular}

EU $=$ exposure unıt

$G W=$ groundwater

Ind a induserial

$J=$ analyle was tdentefied and jesult is approximate toncentration

PRC = preliminary remedlatapa goal

NA = пе4 applicable

Res = residentilel

SL $=$ scteening levei

VOC $=$ volatile organk compoumd

A sedıment sample collected from the acid drau pit located west of K-1006 exceeded multiple metal, radionuclude, and VOC evaluation criteria A soll sample was collected from $>10 \mathrm{ft}$ bgs outsıde and below the base level of the pit in a groundwater downgradient direction from the pit Aratytical results from this sample showed contaminants had not leaked from the pit Inlet and outlet pipes were severed and plugged, and the pit was trole mnsed and backfilled to the surface with grout The sample location representative of current conditions at the $\mathrm{K}-1006$ acid dratn pit (Table 3) is located in a groundwater downgradient directoon from the pit Analytical "results from the sample location representative of current condstions summarzed below show radionuclide Ind PRG exceedances, metal Bkg exceedances, and one SVOC detecton 
EU 22-33 K-1006 FACILITY ACIU DRAIN PIT METALS WITH BACKGROUND, PKG, OW SL, ANDJOR RL EXCEEDANCES (adkg) 0-10 it

\begin{tabular}{|c|c|c|c|c|c|c|c|c|c|c|c|}
\hline \multirow[b]{2}{*}{ Anglyte } & \multirow[b]{2}{*}{$\begin{array}{l}\text { Defect } \\
\text { frequetopy }\end{array}$} & \multirow{2}{*}{. Minimum } & \multirow[b]{2}{*}{$\begin{array}{l}\text { Minimim } \\
\text { detect }\end{array}$} & \multirow{2}{*}{$\begin{array}{l}\text { Lotadion(B) of } \\
\text { moximnm } \\
\text { deftert }\end{array}$} & \multirow{2}{*}{$\begin{array}{l}\text { Averege } \\
\text { detritted } \\
\text { regplt }\end{array}$} & \multicolumn{6}{|c|}{ Number of andrises erceedios criterin. } \\
\hline & & & & & & $\begin{array}{l}\text { Max } \\
\text { RL' }\end{array}$ & $\begin{array}{l}\text { Av! } \\
\text { RL }\end{array}$ & $\begin{array}{l}\text { lnd } \\
\text { PRG }\end{array}$ & Buts: & $\begin{array}{l}\text { GW } \\
\text { SL }\end{array}$ & $\begin{array}{l}\text { Res } \\
\text { PRG }\end{array}$ \\
\hline 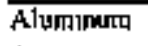 & $\mathrm{I} / 1$ & 16,000 & 16,000 & 22-Eu33B-374 & 16,000 & WA & $\mathrm{NA}$ & 0 & 0 & $\mathrm{NA}$ & I \\
\hline Afsenic & I/1 & 361 & $36 \mathrm{~J}$ & Z2-EU33B-374 & 36 & 0 & $\theta$ & 0 & 0 & 0 & $\mathbf{I}$ \\
\hline 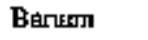 & th & 130 & 130 & Z2-EU333-37A & 130 & NA & NA & 0 & 1 & 1) & 0 \\
\hline Cqlcıum & $1 / 1$ & $15,000 \mathrm{~J}$ & 15,000t & 22-EU33B-374 & 15,000 & NA & NA & NA & 1 & NA & NA \\
\hline Iron & It] & 40,000 & 40,600 & 22-EЏ33B-374 & 40,000 & NA & NA & 0 & 0 & NA & l \\
\hline Mangenese & $\mathrm{I} / 1$ & $730 \mathrm{~J}$ & $730 \mathrm{~J}$ & Z2-EU33E-374 & 730 & NA & NA & 0 & 0 & NA & i \\
\hline Vantadium & If1 & 26 & 26 & Z2-EU33B-374 & 26 & NA & $\mathrm{NA}$ & B & 0 & $\mathrm{NA}$ & I \\
\hline
\end{tabular}

$\mathrm{Avg}=$ arenge

Bkp $=$ back soumd

ED = exposure unit

$G W=$ growndwatex

Ind = Industnal

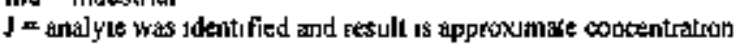

Max $=$ maxumum

NA $=$ not applicable

PRG = prediminary remediabion gool

Reg $=$ resident $t$ il

$R L=$ remedigtion leved

SL = scretsing level

PCBs were analyzed for but were not detected.

EU 2.2-33 K-1006 FACILITY ACID DRAIN PIT RADIONDCLIDES WITH BACKGROUND, PRG, ANDIOR RL EXCEEDANCES (pCí) Q 0-10 ft

\begin{tabular}{|c|c|c|c|c|c|c|c|c|c|c|c|}
\hline \multirow[b]{2}{*}{ Auabyte } & \multirow[b]{2}{*}{$\begin{array}{l}\text { Defext } \\
\text { freqpency }\end{array}$} & \multirow[b]{2}{*}{$\begin{array}{c}\text { Minimu:m } \\
\text { dettet. }\end{array}$} & \multirow[b]{2}{*}{$\begin{array}{c}\text { Marimum } \\
\text { detert }\end{array}$} & \multirow[b]{2}{*}{$\begin{array}{l}\text { Location(s) of } \\
\text { maximunt defoct }\end{array}$} & \multirow{2}{*}{$\begin{array}{l}\text { Aferkge } \\
\text { détecied' } \\
\text { resalt }\end{array}$} & \multicolumn{6}{|c|}{ Number of andyass exceddlit criterie } \\
\hline & & & & & & $\begin{array}{c}\text { Max } \\
\text { RL }\end{array}$ & $\begin{array}{l}\text { Avg } \\
\text { RL }\end{array}$ & $\begin{array}{l}\text { Ind } \\
\text { PRG }\end{array}$ & Blog. & $\begin{array}{l}\text { GW } \\
\text { SL }\end{array}$ & $\begin{array}{l}\text { Res } \\
\text { PRG }\end{array}$ \\
\hline Pothissiunin 40 & $\overline{\mathrm{J} / \mathrm{I}}$ & 133 & 133 & 22 -E[-33B-374 & 133 & $\overline{N A}$ & NA & l & 0 & NA & I \\
\hline Thorrum-228 & $1 / !$ & $164 !$ & $164 J$ & Z2-EU33E-374 & 164 & $\mathrm{NA}$ & NA & $t$ & 0 & NA & I \\
\hline Thorium-232 & $1 / 1$ & I $46 \mathrm{~J}$ & {$[46]$} & Z2-EU33B-374 & I 46 & NA & NA & $!$ & 0 & NA & $\mathbf{I}$ \\
\hline Uranıum-238 & $1 / \mathrm{t}$ & $0937 \mathrm{~J}$ & 09371 & 22-E\33B-374 & 0937 & 0 & $\theta$ & 0 & 0 & 0 & $\mathbf{I}$ \\
\hline
\end{tabular}

AYg $=$ arerage

Blcg $=$ background

EL - exposure unנt

$G$ W $=$ goundwater

Ind = industrol|

$J=$ analyte was identified and result is approximate corcentration

$\mathrm{Max}=$ maxımum

$\mathrm{NA}=$ not applicable

PRG a prelımitary remedtation goal

Res = resıdental

RL - remediathon level

SL = screenting leque

EU Z1-33 K-1006 FACILITY ACID DRAIN PIT SVOC DETECTS (ug/kg) 0-10 ft

\begin{tabular}{|c|c|c|c|c|c|c|c|}
\hline \multirow[b]{2}{*}{ Arabyte } & \multirow[b]{2}{*}{$\begin{array}{c}\text { Detect } \\
\text { Preguency }\end{array}$} & \multirow[b]{2}{*}{$\begin{array}{l}\text { Mlsidaum } \\
\text { detect }\end{array}$} & \multirow[b]{2}{*}{$\begin{array}{c}\text { Maximuw } \\
\text { delect }\end{array}$} & \multirow{2}{*}{$\begin{array}{l}\therefore \\
\text { Locntion(s) of } \\
\text { narimumen detect }\end{array}$} & \multirow{2}{*}{$\begin{array}{l}\text { Average } \\
\text { detected } \\
\text { resurt }\end{array}$} & \multicolumn{2}{|c|}{$\begin{array}{l}\text { Number of arblyose } \\
\text { excesiding criterla }\end{array}$} \\
\hline & & & & & & $\begin{array}{l}\text { Ind GW } \\
\text { PRG, SL }\end{array}$ & $\begin{array}{c}\text { Res } \\
\text { PRG }\end{array}$ \\
\hline 3-Methylphenol & 111 & I30J & 1305 & $\mathrm{Z} 2-\mathrm{E} U 133 \mathrm{~B}-374$ & 130 & $0 \quad \mathrm{NA}$ & 0 \\
\hline $\begin{array}{l}\text { EU = exposure ur } \\
\text { GWi a groundwat } \\
\text { lid = industind } \\
J=\text { ara|yle was N } \\
\text { NA = not Atphlce. }\end{array}$ & and resul & ApDrnx m & te ronce & \multicolumn{4}{|c|}{ 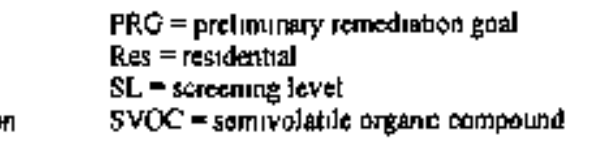 } \\
\hline
\end{tabular}

VOCs were analyzed for but were not detected.

Fistorical sample locations at the K-1006 facility are all soil sample locations around the facility. Analytical results summarized below show radionuclide Ind PRG exceedances, metal and radionuclide Bkg exceedances, and PCB, pesticide, and SVOC detections. 
EU Z2-33 K-1096 FACILTYY HISTOKJCAL SOIE METALS WITH BACKCROUND, PRG, GW SL, ANBSOR RL EXCEEDANCES (1⿴囗大)/ $\mathrm{kg})$ 0-10 it

\begin{tabular}{|c|c|c|c|c|c|c|c|c|c|c|c|}
\hline \multirow[b]{2}{*}{ Andyte } & \multirow[b]{2}{*}{$\begin{array}{c}\text { Detect } \\
\text { frequency }\end{array}$} & \multirow[b]{2}{*}{$\begin{array}{c}\text { Minimum } \\
\text { ittetet }\end{array}$} & \multirow[b]{2}{*}{$\begin{array}{c}\text { Mosinum } \\
\text { dttert }\end{array}$} & \multirow{2}{*}{$\begin{array}{c}\text { Location(s) of } \\
\text { maxingtan } \\
\text { detect }\end{array}$} & \multirow{2}{*}{$\begin{array}{l}\text { Aversigt } \\
\text { detteted } \\
\text { renralt }\end{array}$} & \multicolumn{6}{|c|}{ Namber of abolyses exceeding criterte } \\
\hline & & & & & & $\begin{array}{l}\text { Max } \\
R L\end{array}$ & AL & $\begin{array}{l}\text { Ind } \\
\text { phes }\end{array}$ & Bles & $\begin{array}{l}\text { GW } \\
\text { SL }\end{array}$ & PRG \\
\hline 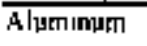 & $3 / 3$ & 16,800 & 20,500 & K1006-01 & 18,667 & $N A$ & NA & 0 & 0 & NA & 3 \\
\hline Assenjc & $3 / 3$ & 4873 & $598 \mathrm{~J}$ & $K 1006001$ & 532 & 0 & 0 & 0 & 0 & 0 & 3 \\
\hline Barnum & $3 / 3$ & 737 & 126 & KIDOG-OI & 967 & $\mathrm{NA}$ & NA & D & $\mathbf{I}$ & 0 & 0 \\
\hline Cadming & $3 / 3$ & 1080 & 16 & $\mathrm{~K} 1006 \cdot 93$ & 131 & $N A$ & NA & 0 & 3 & $\mathrm{NA}$ & 0 \\
\hline Calcium & $3 / 3$ & 4,540 & 7,360 & $\mathrm{~K}_{100<-02}$ & 6,300 & $\mathrm{NA}$ & NA & $N_{A}$ & 3 & $\mathrm{NA}$ & $\mathrm{NA}$ \\
\hline Chromarts & $3 B$ & $24 \tau$ & 304 & $\mathrm{~K} 1006-0 \mathrm{l}$ & 276 & $\mathrm{NA}$ & NA & 0 & 만 & 0 & 3 \\
\hline Copper & $3 / 3$ & 246 & 413 & KJ006-0I & 304 & NA & $\mathrm{NA}$ & 0 & 3 & $\mathrm{NA}$ & 0 \\
\hline Eran & $3 / 3$ & 23,800 & 35,000 & $k 1006-03$ & 27,567 & NA & $W_{A}$ & 0 & 0 & NA & 3 \\
\hline Mangarese & $3 / 3$ & 950 & 1,130 & KJ006-0I & 1.027 & $\mathrm{NA}$ & $\mathrm{NA}$ & 0 & 0 & $\mathrm{NA}$ & 3 \\
\hline Nickel & $3 / 3$ & 226 & 463 & $\mathrm{~K} 1006-01$ & 335 & NA & NÁ & 0 & 2 & $\mathrm{NA}$ & 0 \\
\hline Veneduum & $3 / 3$ & 22 & 275 & K.006-03 & 245 & NA & $\mathbf{N A}$ & 0 & 0 & NA & 3 \\
\hline ZIne & $3 / 3$ & 742 & 194 & K.1006-41 & 122 & $\mathrm{NA}$ & $\mathrm{NA}$ & 0 & 2 & $N A$ & 0 \\
\hline
\end{tabular}

AYg- syerage

Bkg - background

EU $=$ exposure unit

GW = g्रoundwater

Ind $\times$ industnal

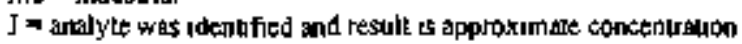

Max $=$ maximum

NA $=$ not applictible

PRG = prelutrinary remediatum gool

Res $=$ residential

RL = remedistıon level

\$L $=$ streesung level

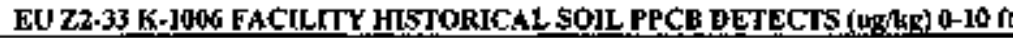

\begin{tabular}{|c|c|c|c|c|c|c|c|c|c|}
\hline \multirow[b]{2}{*}{ Anulfite } & \multirow[b]{2}{*}{$\begin{array}{l}\text { Detret } \\
\text { fiegnexpy }\end{array}$} & \multirow{2}{*}{$\begin{array}{c}\text { Minimum } \\
\text { detect }\end{array}$} & \multirow[b]{2}{*}{$\begin{array}{c}\text { Mininam } \\
\text { detect }\end{array}$} & \multirow{2}{*}{$\begin{array}{l}\text { Losation(s) of } \\
\text { ntarimiut } \\
\text { detect }\end{array}$} & \multirow{2}{*}{$\begin{array}{l}\text { Average } \\
\text { defteted } \\
\text { result }\end{array}$} & \multicolumn{4}{|c|}{ 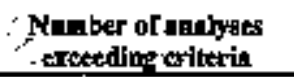 } \\
\hline & & & & & & $\begin{array}{l}\text { Max } \\
\text { EL }\end{array}$ & $\begin{array}{l}\text { Av: } \\
\text { RLi }\end{array}$ & Ind & $\begin{array}{l}\text { Rer } \\
\text { PRG }\end{array}$ \\
\hline $4,4-D D T$ & I及 & I\$J & 190 & KIO06-0] & 19 & NA & NA & 0 & $\mathrm{NA}$ \\
\hline Endrun & $1 / 3$ & $20 \mathrm{~J}$ & $20 \mathrm{~J}$ & $\mathrm{~K} I 006001$ & 20 & $N A$ & $N A$ & 0 & NA \\
\hline PCE-1260 & $1 / 3$ & $91 \mathrm{~J}$ & 911 & $x \mid 006-01$ & 91 & 0 & 0 & 0 & 0 \\
\hline 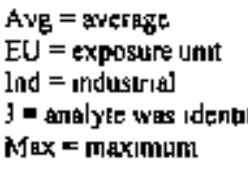 & and resulf is $x$ & Prond & concentration & $\begin{array}{l}\text { NA = noi a } \\
\text { PPCB = pes } \\
\text { PRG = prel } \\
\text { Res = resd } \\
\text { RL = remed }\end{array}$ & $\begin{array}{l}\text { pplicable } \\
\text { sticude and } \\
\text { utinary sec } \\
\text { entul } \\
\text { diation leve }\end{array}$ & $\begin{array}{l}\text { polychl } \\
\text { itediatro }\end{array}$ & $\begin{array}{l}\text { oringatc } \\
\text { n goal }\end{array}$ & d biphe & nyl \\
\hline
\end{tabular}

EU Z2-33 K-L006 FACILITY HISTORJCAL SOIL RADIONUCLIDES WITH BACKGROUNO, PKG, AND/OR RL EXCEEDANCES (PCHS) $010 \mathrm{ft}$

\begin{tabular}{|c|c|c|c|c|c|c|c|c|c|c|c|}
\hline \multirow[b]{2}{*}{ Analyte } & \multirow[b]{2}{*}{$\begin{array}{l}\text { Deteat } \\
\text { Irequency }\end{array}$} & \multirow[b]{2}{*}{$\begin{array}{l}\text { Minimum } \\
\text { detect }\end{array}$} & \multirow[b]{2}{*}{$\begin{array}{c}\text { Maxdinum } \\
\text { defect }\end{array}$} & \multirow{2}{*}{$\begin{array}{l}\text { Location(s) of } \\
\text { maximum detect }\end{array}$} & \multirow{2}{*}{$\begin{array}{c}\text { Average } \\
\text { detected } \\
\text { result }\end{array}$} & \multicolumn{6}{|c|}{ Nomber of ntalypes excediteg criterin } \\
\hline & & & & & & $\begin{array}{c}\text { Max } \\
\text { RL }\end{array}$ & $\begin{array}{l}\text { Avg } \\
\text { RL }\end{array}$ & $\begin{array}{c}\text { lod } \\
\text { rREC }\end{array}$ & Blog & $\begin{array}{l}\text { GW } \\
\text { SL }\end{array}$ & $\begin{array}{c}\text { Res } \\
\text { PRG }\end{array}$ \\
\hline Cesium-137 & $2 / 3$ & 0155 & 06236 & KAH-SS-S8I & 0389 & $\overline{0}$ & 0 & 0 & $N A$ & NA & 2 \\
\hline Techinetlưr-9y & $2 / 3$ & $0 \mathbf{I I J}$ & 02773 & KAH-SS-SB] & 0190 & NA & NA & 0 & NA & NA & ] \\
\hline Thonum-228 & $1 / 1$ & 1067 & 1067 & KAF-SSSBI & 107 & NA & NA & ] & 0 & NA & 1 \\
\hline Thonum-232 & ll & 1057 & $105\}$ & KAH-S\$-S81 & 106 & NA & NA & 1 & $\theta$ & NA & 1 \\
\hline Utanum-233 & $3 / 3$ & 0885 & 1723 & KAH.SS-581 & 119 & 0 & 0 & 0 & l & 0 & 3 \\
\hline \multicolumn{5}{|c|}{ 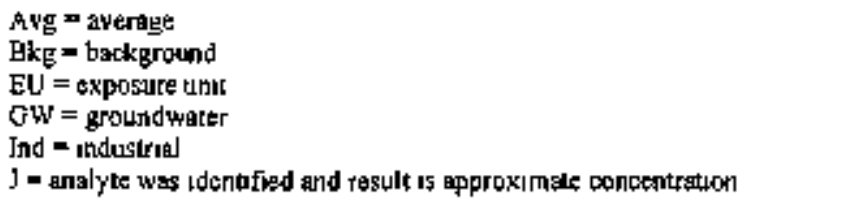 } & \multicolumn{5}{|c|}{ 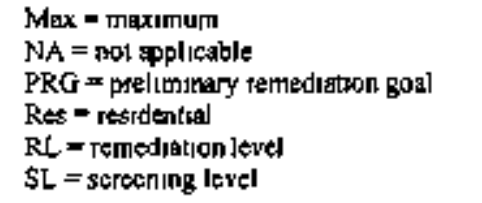 } & & \\
\hline
\end{tabular}




\begin{tabular}{|c|c|c|c|c|c|c|c|c|}
\hline \multirow[b]{2}{*}{ Analyte } & \multirow[b]{2}{*}{$\begin{array}{c}\text { Detect } \\
\text { frequency }\end{array}$} & \multirow[b]{2}{*}{$\begin{array}{c}\text { Mfioimam } \\
\text { detect }\end{array}$} & \multirow[b]{2}{*}{$\begin{array}{c}\text { Mininum } \\
\text { detect }\end{array}$} & \multirow{2}{*}{$\begin{array}{l}\text { Lacstion(s) of } \\
\text { thingimnm deteel }\end{array}$} & \multirow{2}{*}{$\begin{array}{l}- \\
\text { hrerage } \\
\text { detectigh } \\
\text { retult }\end{array}$} & \multicolumn{3}{|c|}{$\begin{array}{l}\text { Niteber of anslyat } \\
\text { exceetipg criterin }\end{array}$} \\
\hline & & & & & & $\begin{array}{l}\text { Ind } \\
\text { PEG }\end{array}$ & SL & $\begin{array}{l}\text { Res } \\
\text { PRG }\end{array}$ \\
\hline Acenophthylent & $2 \sqrt{3}$ & $56]$ & $97 \mathrm{~J}$ & $\mathrm{~K} 1006-01$ & 765 & 0 & NA & 0 \\
\hline Bєпz'alanthracene & $3 \sqrt{3}$ & 931 & [90] & $\mathrm{K} 1006-0]$ & 131 & 0 & $N A$ & 0 \\
\hline Benzo(a)pynese & $3 \sqrt{3}$ & $120 \mathrm{~J}$ & $240 \mathrm{~J}$ & $\mathrm{~K} 1006-01$ & 177 & 0 & NA & 3 \\
\hline Benzo(b) fituranthent & $3 / 3$ & 1105 & 2001 & $k 1006-[p]$ & $15\}$ & 0 & NA & 0 \\
\hline Benzo(ghi)perylene & $3 \sqrt{3}$ & $100 \mathrm{~S}$ & $190 J$ & $\mathrm{~K} .006-\mathrm{bl}$ & 147 & 0 & $N_{A}$ & 0 \\
\hline Benzo(k)fituoranthent & $3 \sqrt{3}$ & $110 \mathrm{~J}$ & $2\lfloor 0\rfloor$ & $\mathrm{K}(006-01$ & 153 & 0 & $\mathrm{Nh}$ & 0 \\
\hline Chrorsent & $3 \sqrt{3}$ & 1105 & 2|DJ & $\mathrm{K}(006-5]$ & 153 & 0 & NA & 0 \\
\hline Dibenz(ah)anthracene & $1 / 3$ & 501 & $50 \mathrm{~N}$ & $\mathrm{~K} 1006-0]$ & 30 & 0 & $N A$ & 0 \\
\hline Fluoranthent & $3 / 3$ & $120 \mathrm{~J}$ & $340 \mathrm{~J}$ & $\mathrm{~K} 1006-01$ & 193 & 0 & NA & 0 \\
\hline Endeno(] 2,3-cd\}pyrene & $3 / 3$ & 120 & $240)$ & Kl006-0] & 130 & 0 & NA & 0 \\
\hline Phenanthrene & $1 / 3$ & 1105 & \rfloor$\lfloor 0\rfloor$ & $\mathrm{K}(006-0)$ & 110 & 0 & $\mathrm{NA}$ & 0 \\
\hline Pyrent & $3 \sqrt[3]{3}$ & 97 & 2501 & $\mathrm{~K} 10006-0]$ & 159 & 0 & $\mathrm{NA}$ & 0 \\
\hline $\begin{array}{l}\text { EU = exposure unit } \\
\text { GW = eroutidwater } \\
\text { [nd = industral } \\
\text { J - anaidyte was sdentolit } \\
\text { NA = not applicable }\end{array}$ & 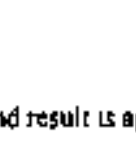 & t. & 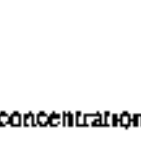 & $\begin{array}{l}\text { PRG = prebur } \\
\text { Res = residen } \\
S L=\text { swetenr } \\
\text { SYC = stem }\end{array}$ & $\begin{array}{l}\text { anary rome } \\
\text { tial } \\
\text { ig level } \\
\text { ivolatile or }\end{array}$ & Aigtict: & npound & \\
\hline
\end{tabular}

VOCs were analyzed for but were not detected.

K-1015 Laundry Facility* The K-1015 Laundry facility concrete pad was recommended for biased sampling in the Assessment Report based on site knowledge regarding former use of the facility. Three DVS biased sample locations were identified (Sect. 2.2.3) and three soil and two concrete samples were collected. In addition, there were several historical sample locations associated with this facility (Sect. 2.2.3). The concrete pad was removed during D\&D after samplong had been conducted as were a number of sample locations (Table 3). Analyucal results from DVS and historical soil sample locatjons representative of current conditions (see Table 3) summarized below show radionuclide ind PRG exceedances, metal and radionuclide $\mathrm{Bkg}$ exceedances, and PCB detections.

EU 22-33 K-IF]5 LAUNDRY FACILCTY SOLL METALS WITH BACKGROUND, PRG, GW SL, AND/OR RL EXCEEDANCES (mekg) 0-10 I!

\begin{tabular}{|c|c|c|c|c|c|c|c|c|c|c|c|}
\hline \multirow[b]{2}{*}{ Arelyte } & \multirow[b]{2}{*}{$\begin{array}{c}\text { Detect } \\
\text { Irequeлcy }\end{array}$} & \multirow[b]{2}{*}{$\begin{array}{l}\text { Migimum } \\
\text { detect }\end{array}$} & \multirow[b]{2}{*}{$\begin{array}{c}\text { Maximun } \\
\text { detect }\end{array}$} & \multirow{2}{*}{$\begin{array}{c}\text { Lateationd (f) of } \\
\text { merimam } \\
\text { detect }\end{array}$} & \multirow{2}{*}{$\begin{array}{l}\text { Arerape } \\
\text { detected } \\
\text { - result }\end{array}$} & \multicolumn{6}{|c|}{ Number of and lyses exreedias criterit } \\
\hline & & & & & & $\begin{array}{l}\text { Max } \\
\text { II }\end{array}$ & $\begin{array}{l}\text { Avi: } \\
\text { RL }\end{array}$ & $\begin{array}{l}\text { Ind } \\
\text { PRG }\end{array}$ & B. & $\begin{array}{l}\text { GW } \\
\text { \$SL. }\end{array}$ & $\begin{array}{l}\text { REs } \\
\text { PRG }\end{array}$ \\
\hline Altrminum & $4 \sqrt{4}$ & 8,560 & $J \mathrm{~B}, 000$ & $22-E[33-2016$ & 14,375 & NA & $N A$ & 0 & 0 & NA & 4 \\
\hline Arstonic & $4 / 4$ & 36 & 8 & $27-E U 33-2014$ & 615 & b & $\theta$ & 0 & 0 & 0 & 4 \\
\hline Cadmum & $4 / 4$ & 15 & 2 & Z2-EU33.2016 & $\perp \mathrm{B3}$ & NA & NA & 0 & 4 & NA & 0 \\
\hline Calcum & $4 / 4$ & 3,400 & $14,000]$ & $22-E U 333-2016$ & 5125 & NA & NA & NA & 2 & NA & NA \\
\hline Chromium & $4 \sqrt{4}$ & 19 & 23 & $\mathrm{Z2} 2-\mathrm{EU} 33-2017$ & 2] 3 & NA & $N A$ & 0 & 0 & 0 & $\mathbf{I}$ \\
\hline Copper & $4 \sqrt{4}$ & E I & 26 & $22-E \bigcup 33-2017$ & 208 & $\mathrm{NAS}$ & $\mathrm{NA}$ & 0 & 2 & NA & to \\
\hline Iт̣ா & $4 \sqrt{4}$ & 41,000 & 54,000 & Z2-EU33-2017 & 48,000 & $\mathrm{NA}$ & $\mathrm{NA}$ & 0 & 0 & $\mathrm{NA}$ & 4 \\
\hline Manganese & $4 \sqrt{4}$ & 290 & 470 & Z2-EU33.2014 & 365 & $\mathrm{~N} /$ & $N A$ & 0 & 0 & NA & 4 \\
\hline Selenium & 314 & $1\rfloor$ & 21 & 22-Eบ33-2017 & 147 & $\mathrm{NA}$ & $\mathrm{NA}$ & 0 & 1 & NA & 0 \\
\hline Vanadium & $4 / 4$ & 23 & 33 & Z2-EU33-2017 & 29 & NA & NA & 0 & $\theta$ & NA & 4 \\
\hline \multicolumn{5}{|c|}{ 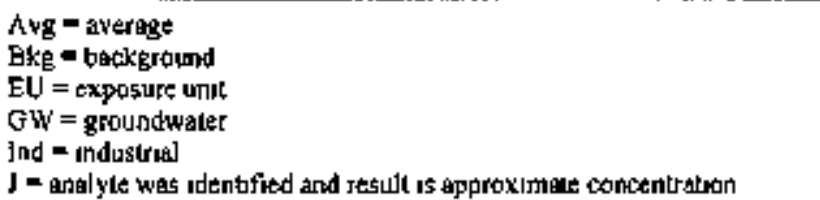 } & \multicolumn{7}{|c|}{ 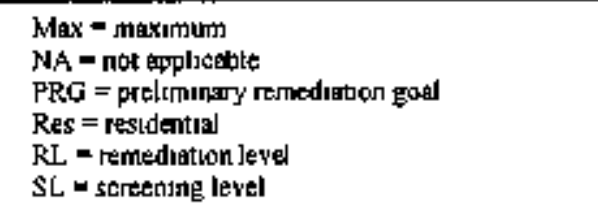 } \\
\hline
\end{tabular}

PCBs were analyzed for in four samples but were not detected. 
EU Z2-33 K-1015 LAUNDRY FACTLITY \$OTL RADIONUCEIDES WITH

GACKGROUND, PRG, ANDOR RL EXCEEDANCES (pCL) 0-10 A

\begin{tabular}{|c|c|c|c|c|c|c|c|c|c|c|c|}
\hline \multirow[b]{2}{*}{ Anglyte } & \multirow{2}{*}{$\begin{array}{c}\text { Detcet } \\
\text { Irtequexcy }\end{array}$} & \multirow[b]{2}{*}{$\begin{array}{l}\text { Milsimumm } \\
\text { detect }\end{array}$} & \multirow{2}{*}{$\begin{array}{c}\text { Mrrimum } \\
\text { detect }\end{array}$} & \multirow{2}{*}{$\begin{array}{l}\text { Location(s) of } \\
\text { meximare detect }\end{array}$} & \multirow{2}{*}{$\begin{array}{l}\text { Averagt } \\
\text { detectod } \\
\text { result }\end{array}$} & \multicolumn{6}{|c|}{ 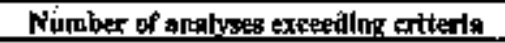 } \\
\hline & & & & & & $\underset{\mathbf{R} \mathbf{L}}{\operatorname{Max}}$ & $\begin{array}{l}\text { Ars } \\
\text { RL }\end{array}$ & $\begin{array}{c}\text { Yad } \\
\text { PRG. }\end{array}$ & Bks. & $\begin{array}{l}\mathbf{G W} \\
\text { SL }\end{array}$ & $\begin{array}{c}\text { Res } \\
\text { PRG }\end{array}$ \\
\hline Poiassum -40 & $4 / 4$ & 169 & $\overline{272}$ & Z2-EU33B-301 & 224 & NA & NA & 4 & 0 & NA & 4 \\
\hline Radiun-226 & Ald & 0416 & 102 & 27-EU33B-302 & 0749 & $\mathrm{NA}$ & $N A$ & 4 & 0 & NA & 4 \\
\hline Thoriust-228 & $4 / 4$ & 」 07 & I B3 & Z2-EU33B-301 & 156 & NA & NA & 4 & 0 & WA & 4 \\
\hline Thonum-230 & $4 / 4$ & 075 & 189 & 22-EЏ33-2014 & 135 & NA & NA & 0 & 3 & NA & 0 \\
\hline Thorump-232 & $4 / 4$ & 101 & 175 & 22 -EU33.2014 & 149 & NA & $\mathrm{NA}$ & 4 & 0 & NA & 4 \\
\hline Urantum-235 & $2 / 4$ & 0.132 & 029 & Z2-EU33B-302 & 0211 & 0 & 0 & 0 & NA & 0 & 1 \\
\hline Liancum-238 & $4 / 4$ & 066 & 171 & Z2-EU33B-302 & 117 & 0 & 0 & 0 & $\mathrm{t}$ & 0 & 3 \\
\hline
\end{tabular}

Avg = aqeragt

$\mathrm{Bkg}=$ bacizground NA = not appliceble

EVI $=$ exposure unit

$\mathrm{G} \psi \mathrm{H}=$ groundwater

$P R G=$ prediminary remediahon goal

Ind $=$ tndustrial

Max $=$ maxmum

$\mathrm{RL}=$ remediabon level

\$L = sereening leved

SVOCs and VOCs were analyzed for in one sample but were not detected.

K-1205-A Facility Locations: The K-1205-A Condensate Station was not recomunended for biased sampling in the Assessment Report. However, there were several historical soil sample locations around K-1205-A (Sect. 2.2.3) that are summarized in this report.The purpose of the facility was to collect condensate from the plant's steam heating system for recycling back into the system. Analytical results for the historical samples summarized below show metal $\mathrm{Bkg}$ exceedances.

EU Z2-33 K-1205-A FACILITY SOLL METALS WITH BACKGROUND, PRG, GW \$L, ANDIOR RL EXCEEDANCES (四/R) 0-10 ft

\begin{tabular}{|c|c|c|c|c|c|c|c|c|c|c|c|}
\hline \multirow[b]{2}{*}{ Anolyte } & \multirow[b]{2}{*}{$\begin{array}{l}\text { Detect } \\
\text { trequedcy }\end{array}$} & \multirow[b]{2}{*}{$\begin{array}{l}\text { Minimum } \\
\text { detect }\end{array}$} & \multirow[b]{2}{*}{$\begin{array}{l}\text { Maxlminn } \\
\text { detect }\end{array}$} & \multirow{2}{*}{$\begin{array}{l}\text { Locadon(s) of } \\
-\begin{array}{c}\text { merlmumat } \\
\text { detect }\end{array}\end{array}$} & \multirow{2}{*}{$\begin{array}{l}\text { Ayertgét } \\
\text { delected } \\
\text { resolt }\end{array}$} & \multicolumn{6}{|c|}{ Nupher of nualyges excesding criteris } \\
\hline & & & & & & $\underset{\mathbf{R l}}{\mathbf{M g x}}$ & $\begin{array}{l}\text { Avg } \\
\text { RL }\end{array}$ & $\begin{array}{l}\text { Ind } \\
\text { PRG }\end{array}$ & Bl: & GW & $\begin{array}{l}\text { Res } \\
\text { PRG }\end{array}$ \\
\hline Alum|mum & $3 / 3$ & 8,500 & 11,000 & $\mathrm{ZZ}-\mathrm{EU} 33-2 \mathrm{LO} 2$ & $9,700^{\circ}$ & $\overline{\mathrm{NA}}$ & NंA & 0 & 0 & NA & 3 \\
\hline Arsenic & $3 B$ & $5]$ & 61 & 22-EนI33-2003 & 567 & 0 & 0 & 0 & 0 & 0 & 3 \\
\hline Cadraums & $3 / 3$ & 221 & 32 & $\mathrm{Z2}-\mathrm{EU} 333-2002$ & 257 & NA & NA & 0 & 3 & $\mathrm{NA}$ & 0 \\
\hline Całcıum & $3 / 3$ & 6,100 & 68,000 & $22-E 033-20433$ & 31,367 & NA & NA & NA & 3 & $\mathrm{Na}$ & NA \\
\hline Iron & $3 / 3$ & 20,000 & 25,600 & Z2-EU33-20013 & 22,333 & $N A$ & $\mathrm{NA}$ & 0 & 0 & $M A$ & 3 \\
\hline Megneșyum & $9 / 3$ & 1,600 & 9,500 & 22-EU33-20043 & 4,367 & NA & $\mathrm{NA}$ & NA & $\mathbf{I}$ & $\mathbf{N A}$ & NA \\
\hline Minganese & $3 / 3$ & 920 & 2,600 & 27-EU33-2002 & 1,640 & $\mathrm{NA}$ & $\mathrm{NA}$ & 0 & 1 & $N A$ & $\exists$ \\
\hline Utânium & $3 / 3$ & 099 & 17 & $\begin{array}{l}\text { Z2-EU33-2001 } \\
22-E U 33-20013\end{array}$ & 146 & $\mathrm{NA}$ & NA & 0 & NA & $\mathbf{N A}$ & 2 \\
\hline Vanaditum & $3 / 3$ & 21 & 26 & Z2-EU33-2002 & 23 & $\mathrm{NA}$ & $\mathrm{NAA}$ & 0 & D & NA & 3 \\
\hline$Z_{\text {Istc }}$ & $3 / 3$ & 32 & 110 & $22-E \cup 33-200 k$ & 683 & NA & NA & 0 & $\mathbf{i}$ & NA & 0 \\
\hline \multicolumn{5}{|c|}{$\begin{array}{l}\text { Avg = average } \\
\text { Bkg = background } \\
\text { EU = exposure unit } \\
\text { GW = groundwater } \\
\text { Ind = tndugtrial } \\
\text { J = analyte was tdentied }\end{array}$} & \multicolumn{7}{|c|}{$\begin{array}{l}\text { Max = mexumurd } \\
\text { NA = not applicadble } \\
\text { PRG = prelinarary remediation goal } \\
\text { Res = residential } \\
\text { RL = remediatuon level } \\
\text { SL = screenmg level }\end{array}$} \\
\hline
\end{tabular}

PCBs were analyzed for in thet samples but were not detected.

Substation Facilities: Three electrical substation facilities were recommended for biased sarnpling in the Assessment Report based on site knowledge regarding former uses of the facilities (K-700-A-13 Substation, K-700-A-I7 Substation, and K-700-A-74 Substation). Three DVS biased soil sample locations were identified (Sect. 2.2 3). Analytical results summarized below show PCB detections at one location. 
EU 22-33 SUPSTATJON SOIL PPCB DETECTS (ag)/

\begin{tabular}{|c|c|c|c|c|c|c|c|c|c|}
\hline \multirow[b]{2}{*}{ Anelyte } & \multirow[b]{2}{*}{$\begin{array}{l}\text { Defeet } \\
\text { treguersy }\end{array}$} & \multirow[b]{2}{*}{$\begin{array}{c}\text { Misimum } \\
\text { defect }\end{array}$} & \multirow{2}{*}{$\begin{array}{c}\text { Mavinam } \\
\text { Jetext } \\
\end{array}$} & \multirow{2}{*}{$\begin{array}{c}\text { Locotion(c) of } \\
\text { moriman } \\
\text { deteet }\end{array}$} & \multirow{2}{*}{$\begin{array}{l}z \\
\text { Average } \\
\text { detected } \\
\text { result }\end{array}$} & \multicolumn{4}{|c|}{$\begin{array}{c}\text { Nowber af abtyyts } \\
\text { expepting Giterin }\end{array}$} \\
\hline & & & & & & $\begin{array}{l}\text { Max } \\
\text { BI }\end{array}$ & $\begin{array}{l}\text { Avt } \\
\text { RL }\end{array}$ & $\begin{array}{l}\text { Ind } \\
\text { PRG }\end{array}$ & $\begin{array}{l}\text { RE: } \\
\text { PRG }\end{array}$ \\
\hline PCB-I2SA & $1 / 3$ & 1,400 & 1,400 & Z2-EU33B-323 & 1,400 & 0 & 0 & 0 & 1 \\
\hline Polychlorthated Buphendy| & $1 / 3$ & 1,400 & 1,400 & Z2-EU33B-323 & 1,400 & 0 & $\theta$ & 0 & [ \\
\hline
\end{tabular}

\begin{tabular}{|c|c|}
\hline $\begin{array}{l}\text { Avg = average } \\
\text { EU = exposure urt } \\
\text { Ind = urdustral } \\
\text { Max = maxumptn }\end{array}$ & $\begin{array}{l}\text { PPCB - pestictide and polychlorinaledbiphenyl } \\
\text { PRO - preliminary remediation goal } \\
\text { Res = rasidented } \\
\text { RL = remediation level }\end{array}$ \\
\hline
\end{tabular}

EU Z2-33 Summary: This section presents a summary of the current nature and extent of contamination in the 0 - $10 \mathrm{ft}$ depth interval by combining all analytical data for this EU (focused investigation summaries above and FFA site summaries in Sect. 2.2.6). In addition, four other historical sample Jocations not assigned to a focused investigation area or FFA site also are included (Sect. 2.2.3). A total of 172 historical and DVS sample locations in this EU have been sampled in the $0-10 \mathrm{ft}$ and $\geq 10 \mathrm{ft}$ depth intervals (Sects. 2.2.1, 2.2.2, and 2.2.3). Details of the sarnpting and analysis are presented in Table 2 and sample locations are shown on Fig. A.13. Several sample locations were remoyed during remedial actions or $\mathrm{D} \& \mathrm{D}$ (Table 3). The following sumgnary includes all solid matrix samples (i.e., soil, sediment, concrete, brick, and mortar) that are representative of current conditions. Also, the summary includes soil samples collected from $\geq 10 \mathrm{ft}$ bgs if those samples were collected to document the effectiveness of a remedial action or a facility demolition (Table 3), or if the sample documented possible contaminant leakage from a subsurface structure. This summary does not include data from historical locations KAH-SS-B22 and KAH-SS-S3l because DVS confirmation sampling did not confirm the historical analytical results. EU-wide compositional characteristics are evaluated in lerms of human health risk and groundwater protection in Sect. 3.

Analytical results summarized below for current conditions in the 0 - $10 \mathrm{ft}$ depth nterval in this EU show two RaTTh decay series Max and Avg RL exceedarces; four PCB, one Cs-137, two U-235, and three U-238 Avg RL exceedatices; one arsenic, two chromitm, four U-234, and three U-238 GW SL exceedances; metal, PCB, radionuclide, and SVOC Ind PRG exceedances; anA DRO, GRO, PCB, SVOC, and VOC detections.

Sexeral RL and $\mathrm{OW}$ SL exceedances occurred in the two sediment samples from the K-1066 Facility north sump (sample locations Z2-EU33B-128 and Z2-EU33B-327). These exceedances included all Ra/Th decay series Max and Avg RL exceedances; one U-238 Avg RL exceedance; one PCB-1254 and one PCB Avg RL exceedance; atrd one arsenic, one chrotnium, one U-234, and one U-238 GW SL exceedances.

The remaining three PCB-1254 and PCB Avg RL. exceedances oceurred at three concrete sample locations Z2-EU33-2004, Z2-EU33-2005, and Z2-EU33-2006 in the K-1004-D Facility basement.

One U-235 Avg RL exceedance, one U-238 Avg RL exceedance, one U-234 GW SL exceedance, and one U-238 GW SL exceedance occured in the sediment sample (sample location Z2-EU33B-334) from the storm drain adjacent to the gravel wash area (referted to as Brick-Lined Drain Pit).

One U-235 Avg RL exceedance, one U-238 Avg RL exceedance, one U-234 GW SL exceedance, and one U-238 GW SL exceedance occurred al a brick and mortar sample location inside a manhole adjacent to the K-1015-A Laundry Ptt (sample location Z2-EU93B-235).

The Cs-137 Avg RL exceedance, which is representative of current conditions, occurred in the K-I004-J Lab South Class 1 SU step-put sample from outside the area of contamination defined by the BAR survey (sample location Z2-EU33B-130). T wo other Cs-137 Avg RL exceedances originally recognized in the K,AH-\$S-B22 and KAH-SS-S31 Class 2 SUs (historical sample locations KAH-SS-B22 and KAH-SS-S31, respectively) were not mcluded in this sumrnary because contimnation sampling and BAR surveys failed to confirm the presence of Cs-137 concentrations in excess of the Avg RL.

The remaning chromium $\mathrm{GW}$ SL exceedance occured in a sediment sample coliected from a manhole east of the acid djlution pit, which is south of K-1004- $\mathrm{L}$ (sample location 22-EU33B-365). The remaining U-234 GW SL exceedance occurred in historical soil sample location KAH-SS-\$1l from the K-1015 Class 1 SU/K-1015-A Laundry Pít FFA Site. 
Ind PRG exceedarces fell into three groups: (1) exceedances associated with the RL and GW SL exceedances described above; (2) exceedances for K-40, Ra-226, Th-228, Th-230, and Th-232, which are evaluated for risk using the Ra/Th decay series RLs or under special circumstances as described in Sect. 3, or (3) other Ind PRG exceedances. The other Ind PRG exceedances occurred in styen focused investigation areas in this EU. The U-238 Ind PRG was exceeded in one soil sample from the K-1015 Class 1 SU/K-1015-A Laundry Pit FFA Site. Arsenic (one sample), U-238 (two samples), and benzo(a)pyrene (one sampie) exceeded their Ind PRGs in the K-1004 Dreit Line Class 2 SU soits. The benzo(a)pyrene Ind PRG was exceeded in one soil sampls from the K-1004-F Facility, iron Ind PRG was exceeded in two sedirnent samples from the $\mathrm{K}$-1006. Facility (one in the noth sump and one in the south sump), U-238 Ind PRG was exeeeded in two soil samples from the K-1004-L facility, Ind PRGs for total uranium, benz(a)anthracene, benzo(a)pyrent, benzo(b)flupranthene, dibenz(a,h)anthracene, and indeno $(1,2,3-c d)$ anthracene were exceeded in one sediment sample from the Brick-Lined Drain Pit at the Gravel Wash Area, and arsenic and iron exceed their Ind PRGs in a sediment sample from the manhole east of the dilution pit south of K-1004-L.

DRO (7500 $\mathrm{mg} / \mathrm{kg})$ and GRO $(0.47 \mathrm{mg} / \mathrm{kg})$ were detected at historical sample location Z2EU33-K $1004 \mathrm{D}$, which was located in a sewer ejector sump pit in the K-1004-D Facility basement. The DRO and GRO data are reported here but the sample location (Z2EU33-K1004D) was removed when D\&D Operations removed the sump pit sediment after production of the initial draft of this TM.

EU 22-33 METALS WTH BACKGROUND, PRG, GW SL, ANDHOR RL EXCEEDANCES (WRAG) O-10 H

\begin{tabular}{|c|c|c|c|c|c|c|c|c|c|c|c|}
\hline \multirow[b]{2}{*}{ Aaplytyt } & \multirow[b]{2}{*}{$\begin{array}{l}\text { Detcet } \\
\text { frequency }\end{array}$} & \multirow[b]{2}{*}{$\begin{array}{c}\text { Mijijum } \\
\text { detect }\end{array}$} & \multirow[b]{2}{*}{$\begin{array}{l}\text { Marlonum: } \\
\text { detoct }\end{array}$} & \multirow[b]{2}{*}{ 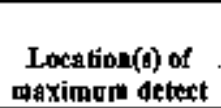 } & \multirow{2}{*}{$\begin{array}{l}\text { A pertige } \\
\text { detected } \\
\text { result }\end{array}$} & \multicolumn{6}{|c|}{ 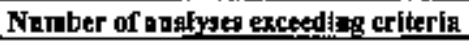 } \\
\hline & & & & & & $\begin{array}{l}\text { Max } \\
\text { RL }\end{array}$ & $\begin{array}{l}\text { AvE } \\
\text { aL }\end{array}$ & $\begin{array}{l}\text { Ind } \\
\text { PRG }\end{array}$ & Bise & $\begin{array}{l}\text { GW } \\
\text { ȘL: }\end{array}$ & $\begin{array}{l}\text { Rea } \\
\text { PRG }\end{array}$ \\
\hline A]итапил & $97 / 87$ & $2,520 \mathrm{~J}$ & 29,400 & K]004D-\$3 & $1], 964$ & NA & NA & 6 & 0 & NA & 70 \\
\hline Antrmony & 6477 & $001 B \mathrm{~J}$ & 19 & Z2EU33-K.10D4D & 0594 & NA & NA & b & 4 & 0 & 3 \\
\hline Arstenis & $87 / 87$ & 12 & 931 & Z2-EU33B-327 & 682 & 0 & 0 & 4 & 4 & $\mathbf{I}$ & 87 \\
\hline Вэгтा & 87187 & 19 & 346 & Z2-EU33E-327 & 942 & $\mathrm{NA}$ & NA & 0 & 16 & D & 0 \\
\hline Berylluum & 86187 & 0 12] & 107 & 414 & 112 & 0 & 0 & 0 & 6 & NA & 0 \\
\hline Cedmium & 82187 & $0028 \mathrm{~J}$ & 242 & $22-E \cup 138-327$ & $18 \hat{8}$ & $\mathrm{NA}$ & $\mathrm{NA}$ & 6 & $\$ 4$ & NA & 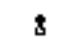 \\
\hline Calcutrs & $87 / 87$ & 7671 & $291,000 \mathrm{~J}$ & 22-EU33B-36A & 33,196 & NA & NA & $\mathrm{NA}$ & 72 & $\mathrm{NA}$ & NA \\
\hline Chromnum & 87187 & 75 & $238 \mathrm{~J}$ & Z2-EU33B-327 & 295 & NA & NA & 0 & 8 & 2 & 29 \\
\hline Cobalt & $87 / 87$ & 215 & 2833 & $22-E \cup J 33 M-212$ & 155 & NA & NA & 0 & 1 & NA & 1 \\
\hline Copper & $87 / 87$ & 385 & 24,0063 & Z2-EU33B-365 & 328 & $N A$ & NA & 0 & 29 & NA & 4 \\
\hline Iron & $87 / 87$ & 4,700 & $510,000 \mathrm{~J}$ & Z2EU33-K 1004D & 44,434 & $N /$ & NA & 4 & $s$ & NA & 87 \\
\hline Lead & $\$ 7 / 87$ & 355 & 1,300 & Z2EU33-K1004D & 689 & NA & NA & 1 & 23 & 0 & 4 \\
\hline Lithiutn & $6 \mathrm{~B} / 76$ & 3 & 515 & Z2-EU33B-32T & 126 & NA & NA & $\theta$ & ] & NA & D \\
\hline Magnesum & $87 / 87$ & 4301 & 63,0000 & $\begin{array}{l}\mathrm{Z2}-E U 33-2006 \\
\text { Z2-EU33-2026 }\end{array}$ & 7,726 & NA & NA & NA & 26 & $\mathrm{NA}$ & NA \\
\hline Manganese & $87 / 87$ & I]5J & 4,350 & K1004D-S3 & 945 & NA & NA & 0 & 5 & NA & 87 \\
\hline Mercury & $71 / 82$ & $0012 J$ & 30 & Z2EU33-K1004D & 0948 & 0 & 0 & 0 & 30 & NA & 3 \\
\hline Nıckel & $87 / 87$ & 47 & $\$ \$ 2$ & K]004D-\$3 & 331 & $N A$ & $\mathrm{NA}$ & 0 & 20 & NA & 3 \\
\hline Selenium & $42 / 87$ & $\theta 13 \mathrm{~J}$ & $14 J$ & Z2EU33-K I004D & 160 & NA & NA & 0 & 15 & NA & 0 \\
\hline Silvet & $43 / 87$ & 0 ดाइ & 130 & Z2E E (133-K1004D & 789 & NA & NA & 0 & 10 & $\mathrm{NA}$ & 3 \\
\hline Sodiums & 69187 & 159 & 1,260 & Z2-EU33B-334 & 138 & NA & NA & NA & 3 & $N A$ & NA \\
\hline That|3 & $55 / 87$ & ( & $049 \mathrm{~J}$ & 22-EU33E-116 & 0187 & $N A$ & NA & 0 & 2 & 0 & 0 \\
\hline Drasium & $76 / 76$ & 033 & 6921 & Z2-EU33日-394 & $14 !$ & $N A$ & NA & 1 & $\mathrm{NA}$ & NA & 34 \\
\hline Vartadium & B.s? & $54 \mathrm{~J}$ & $75 \mathrm{~J}$ & Z2-EU33B-I16 & 251 & NA & NA & 0 & 2 & NA & 83 \\
\hline Znec & 87187 & 11 & 1,9001 & $22-5433-2006$ & 149 & $N A$ & $\mathrm{NA}$ & 0 & 21 & $\mathrm{NA}$ & 0 \\
\hline 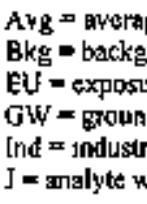 & $\begin{array}{l}\text { Id } \\
\text { Iert } \\
\text { Ier }\end{array}$ & 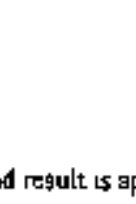 & & & $\begin{array}{l}\text { Mux }= \\
N A=n \\
P R G=1 \\
\operatorname{Res}=r \\
R L=r e \\
\$ L=S C\end{array}$ & 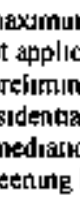 & $\begin{array}{l}\text { ble } \\
y \text { Teा }\end{array}$ & allat & god & & \\
\hline
\end{tabular}




\section{EU Z2-33 OTHER ORGANICS DETECTS (mgkg) a-10 a}

\begin{tabular}{|c|c|c|c|c|c|}
\hline Analyte. & $\begin{array}{c}\text { Detect } \\
\text { Frequency }\end{array}$ & $\begin{array}{l}\text { Minimum } \\
\text { Detect }\end{array}$ & $\begin{array}{l}\text { Madnan } \\
\text { Petet }\end{array}$ & $\begin{array}{c}\text { Locitiou(c) of } \\
\text { Meximon Detect }\end{array}$ & $\begin{array}{l}\text { Average } \\
\text { Detected } \\
\text { Befolt }\end{array}$ \\
\hline Dieset Range Organics & $1 / 3$ & 7,500 & 7,500 & 22EU33-K1004D & 7,500 \\
\hline Gasolune Ramge Orgence & $1 / 3$ & (4) 47J & (0 A7! & ZZEU3 3-K1004D & 047 \\
\hline
\end{tabular}

EU = expogure tumts

J = analyte was identfied and result is approximate concentratiou

EU Z2-33 PPCB bETECTS (ux/kg) -10 ft

\begin{tabular}{|c|c|c|c|c|c|c|c|c|c|}
\hline \multirow[b]{2}{*}{ Anplyty } & \multirow[b]{2}{*}{$\begin{array}{c}\text { Deteet } \\
\text { frequenay }\end{array}$} & \multirow[b]{2}{*}{$\begin{array}{c}\text { Minimuri } \\
\text { detect }\end{array}$} & \multirow[b]{2}{*}{$\begin{array}{l}\text { Mammom } \\
\text { detect }\end{array}$} & \multirow{2}{*}{$\begin{array}{c}\text { Encrition(1) of } \\
\text { pाaximatill } \\
\text { detect }\end{array}$} & \multirow{2}{*}{$\begin{array}{l}\text { Average } \\
\text { detected } \\
\text { reault }\end{array}$} & \multicolumn{4}{|c|}{$\begin{array}{l}\text { Namber af anolyses } \\
\text { exceedlng critterio }\end{array}$} \\
\hline & & & & & & RL & Ang & $\begin{array}{l}\text { Ind } \\
\text { PRG }\end{array}$ & $\begin{array}{l}\text { Res } \\
\text { PRG }\end{array}$ \\
\hline 4,4 & $1 / 9$ & 150 & 150 & $\mathrm{~K} 1004 \mathrm{D}-\mathrm{S}_{3}$ & 150 & $\overline{\mathrm{NA}}$ & NA & $\overline{0}$ & $\overline{N A}$ \\
\hline 4,4'-DDT & 49 & 19] & $230 J$ & K1004D-S] & 145 & NA & NA & 0 & $\mathrm{NA}$ \\
\hline alphe-Chordene & $1 / 9$ & 851 & $85 \mathrm{~J}$ & K.]0040-\$1 & 85 & $N A$ & $N A$ & 0 & NA \\
\hline gamma-Glordane & 19 & $6]$ & $6 \mathrm{~J}$ & KJ004D-SI & 6 & NA & NA & 0 & $\mathrm{NA}$ \\
\hline Endosulfan sulfate & $1 / 9$ & $250 \mathrm{~J}$ & $250 \mathrm{~F}$ & K1004D-SI & 250 & $\mathrm{NA}$ & NA & 0 & $N A$ \\
\hline Endmn & 36 & $20 J$ & 2301 & $k] 0040-\$ 2$ & 112 & NA & NA & 0 & NA. \\
\hline Heptachlor & 19 & $65 \mathrm{~J}$ & 655 & K1004D-SI & 65 & NA & NA & 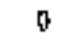 & $N A$ \\
\hline Heptachlor epoxide & $3 / 9$ & 35J & $95 \mathrm{~J}$ & K1004D-S2 & 707 & NA & NA & 0 & $\mathrm{NA}$ \\
\hline PCE-1254 & $22 / \$ 6$ & 21 & 51,0000 & Z2-EU33-2004 & 5,788 & $\theta$ & 4 & 4 & 14 \\
\hline $\mathrm{PCB} \cdot 1260$ & $12 / 86$ & 613 & $920 \mathrm{~J}$ & Z2-EU33B-334 & 106 & 0 & 0 & 巾 & ] \\
\hline Polychlorinsted Biphenyl & $25 / 78$ & 611 & 51,000 & 22-EU33-20104 & 5,010 & 0 & 4 & 4 & $\sqrt{2}$ \\
\hline 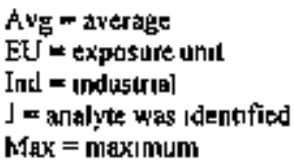 & & & & $\begin{array}{l}\text { NA }=\text { nol } \\
\text { PPCB }=p \\
\text { PRG = pr } \\
\text { Res = ress } \\
\text { RL = rem }\end{array}$ & $\begin{array}{l}\text { iusary } \\
\text { tial } \\
\operatorname{tin}(\operatorname{con} \text { is }\end{array}$ & edi & & & \\
\hline
\end{tabular}

EU $\not 2$-33 BADIONiKCLUES WITH BACKGROUND, PRG, ANDOR RL EXCEEDANCES (pCUE) 0-10 I

\begin{tabular}{|c|c|c|c|c|c|c|c|c|c|c|c|}
\hline \multirow[b]{2}{*}{ Analyte } & \multirow[b]{2}{*}{$\begin{array}{c}\text { Detect } \\
\text { Irequency }\end{array}$} & \multirow[b]{2}{*}{$\begin{array}{c}\text { Minimina } \\
\text { Sedect }\end{array}$} & \multirow[b]{2}{*}{$\begin{array}{c}\text { Maxlmum } \\
\text { detect }\end{array}$} & \multirow[b]{2}{*}{$\begin{array}{l}\text { Locetion(s) of } \\
\text { marymum detect }\end{array}$} & \multirow{2}{*}{$\begin{array}{l}\text { Average } \\
\text { detected } \\
\text { result }\end{array}$} & \multicolumn{6}{|c|}{ Number of anglocke extocding criterin } \\
\hline & & & & & & $\begin{array}{l}\text { Max } \\
\text { RL }\end{array}$ & $\begin{array}{l}\text { AvE } \\
\text { RL }\end{array}$ & $\begin{array}{l}\text { IFd } \\
\text { PRG }\end{array}$ & Bkg & $\begin{array}{l}\text { GW } \\
\text { SL }\end{array}$ & $\begin{array}{l}\text { Reg } \\
\text { PRG }\end{array}$ \\
\hline Cesturti-137 & $16 / 71$ & 0 IIJ & $54 !$ & $22-\mathrm{EV} 333 \mathrm{~B}-130^{-}$ & 0784 & 0 & ] & 2 & NA & $\overline{N A}$ & 16 \\
\hline Neptunium-237 & $4 / 66$ & (1) 17751 & 13 & $22-E \cup 33 B-327$ & 0817 & 0 & 0 & 0 & NA & $\mathrm{NA}$ & 4 \\
\hline Potassium-40 & $56 / 60$ & $3 B$ & 545 & Z2-EU33-200B & 171 & NA & NA & 56 & 3 & $N A$ & 56 \\
\hline Redutum:226 & 4346 & 0163 & 218 & Z2-EU33B-327 & $0 \$ 25$ & NA & NA & 39 & 3 & NA & 43 \\
\hline RerTh decay series & $30 / 64$ & 002 & 4164 & $22-E U 33 B-327$ & 259 & 2 & 2 & NA & NA & NA & $\mathrm{NA}$ \\
\hline Technetitum-99 & 100 & $0111]$ & 267 & $22-E U 33 \mathrm{E}-327$ & 355 & $\mathrm{NA}$ & NA & 0 & NA & NA & 9 \\
\hline Thorsum-22B & $64 / 69$ & 037 & 385 & 22-Ev33日-327 & 30 & $N A$ & NA & 63 & 5 & $\mathrm{NA}$ & 64 \\
\hline Thorlum-230 & $62 / 69$ & 0452 & 405 & Z2-EU33B-327 & 229 & NA & NA & 0 & $3 I$ & $\mathrm{NA}$ & 3 \\
\hline Thonum-232 & 66169 & 0179 & 429 & $22-5 U 33$ B-327 & | 2 | & $\mathrm{NA}$ & $N A$ & 66 & 2 & NA & 66 \\
\hline Uranium-234 & $75 / 76$ & 03921 & 387 & Z2-EU33B-235 & 150 & 0 & 0 & 1 & NA & 4 & 20 \\
\hline Urumium-235 & 46777 & 003311 & 186 & 22-E்133B-235 & 122 & 0 & 2 & 3 & NA & 0 & 97 \\
\hline Vгврлит-238 & $36 \sqrt{76}$ & $02 \mathrm{~B} 8$ & 244 & Z2-EU33B-334 & 943 & 0 & 3 & B & 35 & 3 & 65 \\
\hline 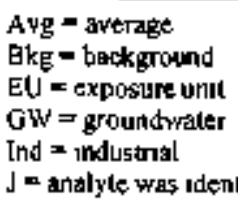 & ed and & 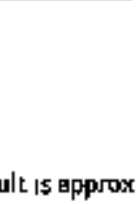 & 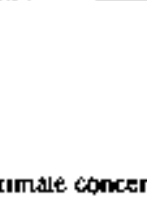 & & 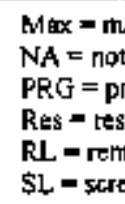 & $\begin{array}{l}\text { amum } \\
\text { Pplicat } \\
\text { iminar } \\
\text { ential } \\
\text { dielion } \\
\text { ning le }\end{array}$ & reme & aluos: & & & \\
\hline
\end{tabular}




\begin{tabular}{|c|c|c|c|c|c|c|c|c|}
\hline \multirow[b]{2}{*}{ Anahyte } & \multirow[b]{2}{*}{$\begin{array}{c}\text { Detiect } \\
\text { frequency }\end{array}$} & \multirow[b]{2}{*}{$\begin{array}{c}\text { MTnimurn } \\
\text { deteet }\end{array}$} & \multirow[b]{2}{*}{$\begin{array}{l}\text { Moximam } \\
\text { detect }\end{array}$} & \multirow{2}{*}{$\begin{array}{l}\text { Location(s) of } \\
\text { manomum dẹtret }\end{array}$} & \multirow{2}{*}{$\begin{array}{l}\text { Atarafe } \\
\text { detected } \\
\text { resoft }\end{array}$} & \multicolumn{3}{|c|}{$\begin{array}{l}\text { Namber of enmlyse } \\
\text { exceeding crtterlis }\end{array}$} \\
\hline & & & & & & $\begin{array}{l}\text { lad } \\
\text { PRG }\end{array}$ & $\begin{array}{l}\text { GW } \\
\text { SE }\end{array}$ & $\begin{array}{l}\text { Res } \\
\text { PRG }\end{array}$ \\
\hline 3-Methylphenol & $1 / 27$ & $130 \mathrm{~T}$ & 1300 & $22-E U 33 \mathrm{~B}-374$ & 130 & 0 & $\overline{\mathrm{NA}}$ & 4 \\
\hline $\begin{array}{l}\text { 4-Eromophenyl phenyl } \\
\text { ether }\end{array}$ & $1 / 67$ & $97 \mathrm{~J}$ & $97 J$ & KI004D-S1 & 97 & NA & $\mathbf{N A}$ & $\mathrm{NA}$ \\
\hline Actsuaphthene & $9 / 67$ & $27 \mathrm{~J}$ & 38,000 & Z2-EU33B-334 & 4,396 & 0 & NA & 0 \\
\hline Acenaphthylene & 9167 & $47 \mathrm{~J}$ & 1,400 & Z2-EU33B-325 & 306 & 0 & NA & 0 \\
\hline Anthracese & 13367 & $46 \mathrm{~J}$ & 82,000 & Z2-EU33B-334 & 6,711 & 0 & $\mathrm{NA}$ & 0 \\
\hline Benga(a) anuluricene & $28 / 67$ & 46] & $\mathrm{I} 90,000$ & 22-Eบ336-334 & 7,372 & 1 & MA & 6 \\
\hline Benzo(a)pyrene & 28167 & 45] & 170,000 & Z2-EU33B-334 & 6,637 & 3 & NA & 22 \\
\hline Benzo(b)Alwor anthene & 29167 & 48 & 170,000 & Z2-EU33E-334 & 6,587 & $\mathbf{I}$ & NA & 7 \\
\hline Benzo(ghi)perylene & $22 / 67$ & $42 J$ & 92,000 & 22-EU33B-334 & 4,690 & 0 & NA & 0 \\
\hline Benzo(k)fluortanthene & 2767 & $57]$ & 170,000 & Z2-EU33B-334 & 6.766 & 0 & NA & ] \\
\hline Eenzort acid & $1 / 57$ & 5,500 & 5,500 & 22-EU93B-327 & 5,500 & 0 & MA & 0 \\
\hline B।s(2-ethy|hexyl)phthalate & $18 / 67$ & 44」 & $66,000 \mathrm{~J}$ & Z2-EU33B-327 & 5,441 & 0 & 0 & 1 \\
\hline Butyl benzyl phathelate & 867 & 49J & $29,000 \mathrm{~J}$ & Z2-EU33B-327 & 6.128 & 0 & NA & 0 \\
\hline Carbazole & {$[3 / 67$} & $41]$ & 53,000 & 22-EU333-334 & 4,291 & 0 & NA & $\mathbf{I}$ \\
\hline Chrysent & $30 / 67$ & $44]$ & 220,000 & Z2-EบЭ3B-334 & 7,915 & 0 & NA & $\mathbf{I}$ \\
\hline Dibenas $(a, h)$ anthusente & $1] / 67$ & $50 \mathrm{~J}$ & 23,000 & 22-EU33E-334 & $2,3] 2$ & 1 & NA & 10 \\
\hline Dibenzofuran & 667 & $55 \mathrm{~J}$ & 23,000 & 22-EL13B-334 & 4,108 & 0 & NA & 1 \\
\hline Di-nbutyl plsthalate & $5+55$ & I]OH & 1,2000 & Z2-EU33B-32 T & 456 & 0 & NA & 0 \\
\hline D1-ת-octylphthalate & $2 / 67$ & $\mathrm{t} 20 \mathrm{f}$ & 1,400 & Z2-EU33B-32\} & 760 & 0 & Na & 0 \\
\hline Fluoranthene & $33 / 67$ & 671 & 500,000 & 27-EЏ33B-334 & 16,288 & 0 & NA & 1 \\
\hline Fluorene & 1267 & 48] & 29,000 & Z2-EU33B-334 & 3,043 & 0 & NA & $\mathfrak{b}$ \\
\hline Hexachlorobenzene & $1 / 67$ & $3-40 \mathrm{~J}$ & $340 \mathrm{~J}$ & Z2-EU33B-327 & 340 & 0 & NA & ! \\
\hline Indeno( $1,2,3-4 d) p y r e n s$ & 22167 & 491 & 77,000 & 22-Eบ33B-334 & 4,012 & 1 & NA & 5 \\
\hline$m+p$ Medhy Lhenol & 127 & $450 \mathrm{~S}$ & $450 \mathrm{~J}$ & Z2-EU33B-334 & 450 & $\mathrm{NA}$ & NA & NA \\
\hline Nophthalent & $9 / 87$ & 94 & 31,000 & 22-EU33B-334 & 5,438 & 0 & NA & 2 \\
\hline N-Notrosadiphenylarrune & $1 / 61$ & 17 & נก & Z)-EU33-2012 & 17 & 0 & NA & 0 \\
\hline Pentrchlorophenol & $1 / 66$ & 741 & 74 & K1004D-S2 & 74 & 0 & NA & 0 \\
\hline Phenenthrens & $26 / 67$ & $45 J$ & 370,000 & Z2-EЏ33B-3:-4 & $15,15]$ & 0 & NA & l \\
\hline Phenol & $3 / 66$ & 961 & $260 \$^{\prime}$ & 22-EU39日-334 & 175 & 0 & NA & 0 \\
\hline Pyrone & $33 / 67$ & d3J & 340,000 & Z2-EU33B-334 & $11,19 \mathrm{~d}$ & 0 & $\mathrm{NA}$ & l \\
\hline
\end{tabular}

EU $=$ exposure untt

$\mathrm{GWW}=\mathrm{ground} w \mathrm{Gtes}$

Ind a inductrial

J a analyte was Idenefied and result is approxımete concentrostion

NA = not applicable
PRC = pre[rthinary remedianon $\mathrm{gos}$

Res = residental

$S L=$ scretenjing level

$\$ V O C=$ semryolatile orgtic tampourhd

EU 2.2-33 VOC DETECTS (uflke) o 10 it

\begin{tabular}{|c|c|c|c|c|c|c|c|c|}
\hline \multirow[b]{2}{*}{ Anolyte } & \multirow[b]{2}{*}{$\begin{array}{l}\text { Detect } \\
\text { freyuetiog }\end{array}$} & \multirow[b]{2}{*}{$\begin{array}{l}\text { Minımura } \\
\text { detect }\end{array}$} & \multirow[b]{2}{*}{$\begin{array}{l}\text { Maximow } \\
\text { detect }\end{array}$} & \multirow{2}{*}{$\begin{array}{c}\cdot \dot{y} \\
\text { Location(g) of } \\
\text { neximentedted }\end{array}$} & \multirow{2}{*}{$\begin{array}{l}\text { Avergage } \\
\text { de1tetcd } \\
\text { resatt }\end{array}$} & \multicolumn{3}{|c|}{$\begin{array}{l}\text { Number of unatyses } \\
\text { exceeding criterig }\end{array}$} \\
\hline & & & & & & $\begin{array}{l}\text { Ind: } \\
\text { PAG }\end{array}$ & $\begin{array}{l}\text { GW } \\
\text { SL }\end{array}$ & $\begin{array}{l}\text { Hes } \\
\text { PRG }\end{array}$ \\
\hline l,1,1-Truchloroethane & $2 / 4 !$ & 96 & 4,300 & Z2.EU33B-113 & 2,198 & 0 & 0 & 0 \\
\hline $\begin{array}{l}\text { 1, }, \text {, -Trichloro-1,2,2- } \\
\text { tuflud rocthane }\end{array}$ & $3 / 23$ & $25 J$ & 150 & $22-E \cup 33 E-113$ & 578 & 0 & NA & 0 \\
\hline 1,1,2-Trichloroethane & ]$/ 41$ & 74 & 74 & Z2-EU33B-113 & 74 & 0 & 0 & 0 \\
\hline l,1-Dichlorcethane & $2 / 4 !$ & 42 & 480 & $22 \cdot E \cup 335 \cdot 113$ & 261 & 0 & NA & 0 \\
\hline I,I-D|chlorothene & $3 / 41$ & 31 & 320 & 22-EU33E-1I3 & 120 & 0 & 0 & 0 \\
\hline 1,2,3-Trichlorobenzene & $\mathrm{I} / 2 \mathrm{I}$ & 273 & $27 \mathrm{~J}$ & $22 \cdot E U 33 \mathrm{~B}-117$ & 27 & NA & NA & $\mathbf{N A}$ \\
\hline 1,2-Dhchlorethane & $1+41$ & 11 & $1 \mathrm{I}$ & 22-EU33E-] l\$ & II & 0 & NA & 0 \\
\hline 2-Bubanone & ]$/ 4 !$ & ]6) & 【6」 & ZZ-EU33-2I] & 16 & 0 & NA & 0 \\
\hline Acclone & $5 / 41$ & $10 !$ & 110 & $\mathrm{Z2}-\mathrm{EU} 33 \mathrm{~B}-383$ & $\$ 28$ & 0 & $N A$ & 0 \\
\hline Benzene & $2 / 41$ & $22 J$ & 353 & Z2-EU33E-346 & 285 & 0 & $\theta$ & 0 \\
\hline Carbon dısulfidt & $2 / 41$ & 69 & 12 & $22-E \bigcup 33 B-383$ & 945 & 0 & $\mathrm{NA}$ & 0 \\
\hline Cabon tetrachioride & $4 / 41$ & 121 & 67 & Z2-EU33B-123 & 338 & 0 & 0 & 0 \\
\hline Chloroform & 4/4] & 381 & 140 & Z2خ-EЏ33日-383 & 472 & 0 & 0 & 0 \\
\hline
\end{tabular}


EU Z2-33 VOC DETECTS fug/ $\mathrm{kg}$ ) 0.10 ft (sant'd)

\begin{tabular}{|c|c|c|c|c|c|c|c|c|}
\hline \multirow{2}{*}{ Antyle } & \multirow{2}{*}{$\begin{array}{c}\text { Detect } \\
\text { Ireịutengy } \\
\end{array}$} & \multirow[b]{2}{*}{$\begin{array}{l}\text { Minimum } \\
\text { detect }\end{array}$} & \multirow[b]{2}{*}{$\begin{array}{c}\text { Mefilmón } \\
\text { detect }\end{array}$} & \multirow{2}{*}{$\begin{array}{c}\because \div \\
\text { Lochtion[s] of } \\
\text { maximum dituet? }\end{array}$} & \multirow{2}{*}{$\begin{array}{l}\text { Arcragk } \\
\text { detecterd } \\
\text { tedult }\end{array}$} & \multicolumn{3}{|c|}{$\begin{array}{c}\text { Nomber of andyoes } \\
\text { exceeiving criteria }\end{array}$} \\
\hline & & & & & & $\begin{array}{l}\text { Imd } \\
\text { PRG }\end{array}$ & $\begin{array}{l}\text { GWF } \\
\text { sl. }\end{array}$ & $\begin{array}{l}\text { Res } \\
\text { PRG }\end{array}$ \\
\hline eLs+1,2-Dichlidothent & $9 / 40$ & $12 \mathrm{~J}$ & 1,300 & $\overline{22}$-EX)3B-383 & 222 & 0 & $\mathrm{NA}$ & 0 \\
\hline Ethylbenzents & $2 / 41$ & 74 & נן & Z2-ЕU33В-.27 & $1 \% 7$ & 0 & $\mathrm{NA}$ & 0 \\
\hline Methylene chlonde & $3 / 41$ & 71 & 40 & 72-EU33B-113 & 260 & 0 & 0 & 0 \\
\hline Tetrexhlorocthene & $4 / 41$ & 235 & 29 & Z2-EU3引B-383 & 163 & 0 & 0 & 0 \\
\hline Toluen & 944 & ]J & 30 & 2?-Eบ33B-113 & 12 \& & 0 & 0 & 0 \\
\hline Total Xylene & 212 & 18 & 2900 & 72-EU33B-327 & 154 & 0 & NA & NA \\
\hline teans-1,2-Dichioroethene & $4 / 39$ & I IJ & 11 & 22-E\33日-383 & 438 & 0 & NA & 0 \\
\hline Trehlorcethene & 10442 & $19 \mathrm{~J}$ & 580 & Z2-EU33B-113 & 125 & D & 0 & 4 \\
\hline Ytuyl chlartde & $4 / 41$ & 82 & 120 & Z2-EU33B-383 & 456 & 0 & 0 & 1 \\
\hline 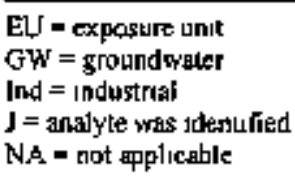 & and result to & proximlire & centrations & \multicolumn{5}{|c|}{ 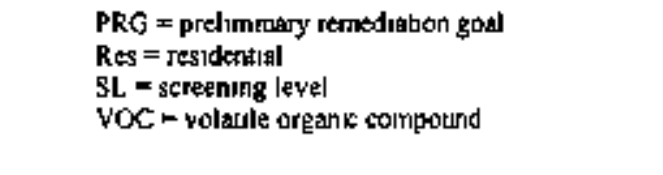 } \\
\hline
\end{tabular}

\subsection{6}

ZONE 2 ROD APPENDIX A FFA SITES EVALUATION

This section presents chafacterization summaries for FFA sites in EU 22-33. FFA characterization area sites listed in Appendix A of the Zone 2 ROD are the primary concem. However, other FFA sites also may be addressed. Information included in the summaries for the FFA sites also is included in the summary for Z2.EU33 presented in Sect. 2.2.5.

\section{K*]004-L Recirculating Codling Water (RCW) Lines Leak Sites}

During DQO scoping, it was decided that sampling in the K-1004-L RCW Lines Leak Sites FFA site was unnecessary. Provious sampling at other RCW lines leak sites in Zone 2 demonstrated that the RCW lines leak sites were not sources of contamination.

\section{K-1015-A Laundry Pit FFA Site}

The K-1015-A Laundry Pit in the K-J015-A Laundry Pit FFA site received wash water from the K-1015 Laundry Facility. Analytical results from DVS sampling of pit sediment [Z2-EU33B-223, Z2-EU33B-225, Z2-EU33B-227, and Z2-EU33B-235) showed metal GW SL exceedances, PCB Avg RL exceedances, radionuclide GW SL, Avg RL and $\operatorname{Max} R L$ exceedances. In addition, historical soil sample locations (KAH-SS-B 12 and KAH-SS-B13) around the pit had radionuclide Avg RL and Max RL exceedances. The K-1015-A Laundry Pit was removed during a remedial action. Th1s remedial action, and the K-1015 Class 1 SU remedial action (Sect. 2.2.5), also removed soils surounding the pit. During process of these two remedial actions, several sample locations also were removed (Table 3). Following remedial action, a confirmation sample was collected at the base of the excayation at sample location 22-EU33B-382. Sample locations representative of current conditions at the K-1015-A Laundry Pit FFA site are presented in Table 3. These locations had samples taken from $>10 \mathrm{ft}$ bgs and included Z2-EU33B-229 and confirmation sample location 22-EU33B-382. Sample locations representative of current conditions at the K-1015-A Laundry Pit FFA site are the same as locations representative of the K-1015 Class 1 SU (Sect. 2.2.5), except for the confirmation sample location at the FFA site and brick and mortar sample Z2-EU33B-235 taken from instde a manhole adjacent to the FFA site. Analytical restilts sumumarized below for samples representative of carrent conditions at the K-1035-A Laundry Pit FFA site include U-235 and U-238 Avg RL exceedances in the brick and mortar sample from the manhole; radionuclide Ind PRG exceedances; two U-234 and one U-238 GW SL exceedances; metal and radionuclide Bkg exceedances; and PCB, SVOC, and VOC detections. 
EU Z2-33 K-1015 LAUNDRY PJT FFA SITE METALS WTH BACKGROUND, PRG, GW SL, AND/OR RL EXCEEDANCES (bo/kg) (a-10 it

\begin{tabular}{|c|c|c|c|c|c|c|c|c|c|c|c|}
\hline \multirow[b]{2}{*}{ Antyly } & \multirow[b]{2}{*}{$\begin{array}{l}\text { Detect } \\
\text { frequency }\end{array}$} & \multirow[b]{2}{*}{$\begin{array}{c}\text { Minum uाB } \\
\text { deteet }\end{array}$} & \multirow[b]{2}{*}{$\begin{array}{c}\text { Maximan } \\
\text { detect }\end{array}$} & \multirow{2}{*}{$\begin{array}{c}\text { Localion(s) of } \\
\text { nisimemi } \\
\text { detett }\end{array}$} & \multirow{2}{*}{$\begin{array}{l}\text { Averige } \\
\text { detected } \\
\text { regult }\end{array}$} & \multicolumn{6}{|c|}{ Nenber of enolpoct exteding tritaria } \\
\hline & & & & & & $\begin{array}{l}\text { Mrx } \\
\text { RL }\end{array}$ & $\begin{array}{l}\text { AFg } \\
\text { RL }\end{array}$ & $\begin{array}{l}\text { Ind } \\
\text { PRG }\end{array}$ & Bkg & $\begin{array}{l}\text { CWW } \\
\text { SL. }\end{array}$ & $\begin{array}{l}\text { Reg } \\
\text { PRG }\end{array}$ \\
\hline A Àminum & $9 / 9$ & $7,600 \mathrm{~F}$ & $-18,800 \mathrm{~J}$ & 22-EU33B-309 & 13,278 & $\mathrm{NA}$ & $\mathrm{NA}$ & 0 & 0 & $\mathrm{NA}$ & 8 \\
\hline Arsentic & $9 / 9$ & $3 \mathrm{~J}$ & 78 & $22-E U 33-20] 8$ & 489 & 0 & 0 & 0 & Q & 0 & 9 \\
\hline Ваглшm & $9 / 9$ & so J & $170 \mathrm{~J}$ & Z2-EU33B-229 & 100 & NA & NA & $\theta$ & 2 & 0 & 0 \\
\hline Berуyllıum & $\$ 19$ & 033 & 23 & 22-EU33E-229 & $1 O B$ & 0 & 0 & 0 & $\mathbf{I}$ & NA & 0 \\
\hline Cedurium & 39 & 0079 & 39 & 22-EU33-2018 & 6687 & $\mathrm{NA}$ & $\mathrm{NA}$ & 0 & I & NA & 1 \\
\hline Celturmt & $9 / 9$ & 11403 & 65,200 & Z2-EU33B-306 & 14,984 & $\mathrm{NA}$ & NA & $N A$ & 7 & NA & NA \\
\hline Chromum & 919 & $\mid 2 J$ & 343 & 425 & 216 & $N A$ & $N / 2$ & 0 & 0 & $\theta$ & 4 \\
\hline Copper & 919 & 86 & 33. & Z2-EU33E-229 & 178 & NA & $\mathrm{NA}$ & 0 & 2 & $\mathrm{NA}$ & 6 \\
\hline Iron & $9 / 9$ & {$[6,000]$,} & 57,0000 & Z2-EU33B-229 & 34,267 & $N_{A}$ & NA & 0 & 0 & NA & 9 \\
\hline Load & $9 / 9$ & $168 \mathrm{~J}$ & $51 \mathrm{f}$ & Z2-EU33B-309 & 294 & $\mathrm{NA}$ & NA & 0 & 3 & 0 & 0 \\
\hline Mangantst & 919 & $320 \mathrm{~J}$ & 3.510 & Z2-EL $33 \mathrm{~B}-3169$ & 1364 & NA & $\mathrm{NA}$ & 0 & 2 & $\mathrm{NA}$ & 9 \\
\hline Mertury & 818 & 0053.1 & 121 & 27-E人33日-307 & 0251 & 0 & 0 & 0 & 3 & NA & 0 \\
\hline Nockel & $9 / 9$ & 6 & 57 & Z2-EU33-2018 & 233 & NA & NA & 0 & 4 & $\mathrm{NA}$ & 0 \\
\hline Selên sum & $3 / 3$ & 1 & I 8 & Z2-EU33E-3B2 & 13 & NA & NA & 0 & $\mathbf{I}$ & $N A$ & 0 \\
\hline Stver & 50 & 00721 & 12 & $22-E \cup 33-2018$ & 03 & NA & NA & 0 & $\mathbf{I}$ & $\mathrm{NA}$ & 0 \\
\hline Uranium & $\pi$ & 04 & 34 & $\mathrm{Z2}-\mathrm{EU} 33-20 \mathrm{JB}$ & 136 & $\mathrm{NA}$ & NA & 0 & NA & $N A$ & 3 \\
\hline Vandưfmpt & 99 & 13 & $40 \mathrm{~J}$ & Z2-EU33B-309 & 272 & $N_{A}$ & $\mathrm{NA}$ & 0 & 0 & $\mathrm{Na}$ & 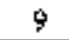 \\
\hline
\end{tabular}

Avg $=$ average

$\mathrm{Bkg}=$ background

$E U=$ exposure undt

FFA = Federal Facilıcy Azratement

Max $=$ maximum

GW = errundwaler

NA $=$ not applucable

PRG = prefintitsary temediation goal

[กd = industrat:

Res a residentual

RL in remediation level

$\mathrm{J}=$ analyte was identified and result is approximate concentration

$S L=$ screening level

EU Z2-33 K-1015 LAUNDRY PIT FFA 8ITE PPCB 3)ETECTS (uvelka) 0-10 ft

\begin{tabular}{|c|c|c|c|c|c|c|c|c|c|}
\hline \multirow[b]{2}{*}{ Analyte } & \multirow[b]{2}{*}{$\underset{\text { Trequeticy }}{\text { Detect }}$} & \multirow[b]{2}{*}{$\begin{array}{l}\text { Mininam } \\
\text { defect }\end{array}$} & \multirow[b]{2}{*}{$\begin{array}{l}\text { Mlanimanm } \\
\text { detect }\end{array}$} & \multirow{2}{*}{$\begin{array}{l}\text { Locintion(s) of } \\
\text { mozimaum } \\
\text { detect }\end{array}$} & \multirow{2}{*}{$\begin{array}{l}\text { Averige } \\
\text { detected } \\
\text { result }\end{array}$} & \multicolumn{4}{|c|}{$\begin{array}{l}\text { Namber of analyges } \\
\text { exceeing crilterie. }\end{array}$} \\
\hline & & & & & & $\begin{array}{l}\text { Max } \\
\text { EL }\end{array}$ & $\begin{array}{l}\text { Avi } \\
\text { RI }\end{array}$ & $\begin{array}{l}\text { Ind } \\
\text { PRG }\end{array}$ & $\begin{array}{l}\text { Tteg } \\
\text { PRG }\end{array}$ \\
\hline PCB-I254 & $1 / 8$ & 307 & 507 & 22-EU33B-235 & 507 & 0 & 0 & 0 & 0 \\
\hline PCB-1260 & 1 is & 39 & $\exists 9$ & 22-EU33B-235 & 39 & 0 & 0 & 0 & 0 \\
\hline Polychlorınated Bipheny' & $1 / 6$ & 897 & 897 & Z2-EU33B-235 & 897 & 0 & 0 & 0 & 0 \\
\hline
\end{tabular}

AYS $=$ average $\quad$ PPCB $=$ pesticide ard polychlonnaled bophenyl

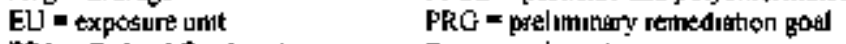

PFA = Federal Fachlity Agreement Res $=$ ressidentral

lnd = industrial $\quad R L=$ remediation leved

Max $=$ maxımunt

EU Z2-33 K-L015 LAUNDRY PJT FFA STTE RADTONUCLIDES WITH

BACKGROUND, PRG, WNDOR RL EXCEEDANCES (pCvg) 0-10 ft

\begin{tabular}{|c|c|c|c|c|c|c|c|c|c|c|c|}
\hline \multirow[b]{2}{*}{ Antylyte } & \multirow[b]{2}{*}{$\begin{array}{c}\text { Detect } \\
\text { frequescy }\end{array}$} & \multirow[b]{2}{*}{$\begin{array}{l}\text { Mavnum } \\
\text { detect }\end{array}$} & \multirow[b]{2}{*}{$\begin{array}{c}\text { Maximand } \\
\text { derect }\end{array}$} & \multirow[b]{2}{*}{$\begin{array}{l}\text { Locatton(s) of } \\
\text { moneaum detect }\end{array}$} & \multirow{2}{*}{$\begin{array}{l}\text { Average } \\
\text { detected } \\
\text { result }\end{array}$} & \multicolumn{6}{|c|}{ Ningber of anealyoses excerding critería } \\
\hline & & & & & & $\begin{array}{l}\text { Mtax } \\
\text { RL }\end{array}$ & $\begin{array}{l}\text { AYg } \\
\text { RL }\end{array}$ & $\begin{array}{l}\text { Ind } \\
\text { PRG }\end{array}$ & Ekg & $\begin{array}{l}\text { GW } \\
\text { SL }\end{array}$ & $\begin{array}{l}\text { Res } \\
\text { PRG }\end{array}$ \\
\hline Cestum-137 & $1 / 10$ & 0564 & 0564 & KAH-SS.S11 & 9564 & 0 & 8 & 0 & $\mathrm{NA}$ & NA & 1 \\
\hline Neptualum-237 & $1 / B$ & 05896 & 05896 & KAH-SS-SII & 0590 & 0 & 0 & 0 & NA & NA & I \\
\hline Potassjum-40 & 77 & 71 & 278 & Z2.EU33B-229 & 193 & NA & Nh & 7 & 0 & $\mathbf{N A}$ & 7 \\
\hline Radıum-226 & sis & 0776 & 099 & Z2-EU33B-369 & 0899 & NA & $\mathrm{NA}$ & 5 & 0 & NA & 5 \\
\hline Technetım-99 & $w ! \theta$ & (1) 3807 & $0 \$ 307$ & KAH-SS-SII & 0381 & NA & NA & 0 & NA & $\mathbf{N} / A$ & 1 \\
\hline Thomum-22s & $10 / 10$ & 0727 & 178 & Z2.EU33B-229 & 131 & NA & $N A$ & 10 & 0 & NA & 10 \\
\hline Thotum-230 & 10150 & 0452 & $6+48$ & KAH-\$\$-\$1 1 & $1 \mathrm{~d} 8$ & NA & $\mathrm{NA}$ & 0 & 3 & $\mathrm{NA}$ & 1 \\
\hline Thonum-732 & I0/EO & 0543 & 16 & $72-E U 33 B-382$ & 121 & NA & $N A$ & 10 & 0 & NA & 10 \\
\hline Utantum-234 & IOHI & 0735 & 387 & Z2-EV/33B-235 & 481 & 0 & $\theta$ & 1 & NA & 2 & 2 \\
\hline
\end{tabular}


EU Z2-33 K-101\$ LAUNDRY PIT FFA SITE RADIONUCLIDES WOTH BACKGROUND, PRG, AND/OR RE, EXCEEDANCES (pCirg) 0-10 ft (cont'd)

\begin{tabular}{|c|c|c|c|c|c|c|c|c|c|c|}
\hline \multirow[b]{2}{*}{ Amabyte } & \multirow{2}{*}{$\begin{array}{l}\text { Miniman } \\
\text { detect }\end{array}$} & \multirow{2}{*}{$\begin{array}{c}\text { Mininum } \\
\text { detect }\end{array}$} & \multirow{2}{*}{$\begin{array}{l}\text { Locstibn(s) of } \\
\text { naxilaman detect }\end{array}$} & \multirow{2}{*}{$\begin{array}{l}\text { Awerage } \\
\text { defected } \\
\text { resalt }\end{array}$} & \multicolumn{6}{|c|}{ 'Number of undigges excesding criterin - } \\
\hline & & & & & $\begin{array}{c}\text { MLx } \\
\text { RL }\end{array}$ & $\begin{array}{l}\text { Ave } \\
\text { Rí }\end{array}$ & $\begin{array}{l}\text { Ind } \\
\text { pakc }\end{array}$ & Blky & $\begin{array}{l}\text { GW } \\
\text { s!! }\end{array}$ & $\begin{array}{c}\text { Rtal } \\
\text { Pkt }\end{array}$ \\
\hline Uזапाum-235 & 0058 & 186 & 27-EU33日-235 & 367 & $\phi$ & I & I & NA & 0 & 2 \\
\hline Uranium-238 & 0321 & 633 & Z2-EU33B-235 & 844 & 0 & $\mathbf{I}$ & 2 & 3 & 1 & 9 \\
\hline 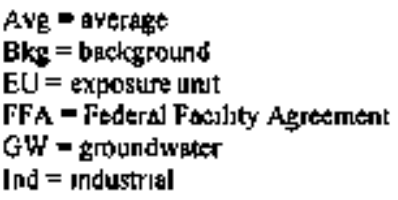 & $\begin{array}{l}\text { Mfax } \\
\text { NA }= \\
\text { PRG } \\
\text { Res }= \\
\text { RL = } \\
\text { SL = }\end{array}$ & $\begin{array}{l}\text { - makctmum } \\
=\text { not applicst } \\
=\text { prelıminar } \\
\text { = residentua] } \\
\text { remediation } \\
\text { screening ke }\end{array}$ & $\begin{array}{l}\text { ble } \\
\text { y remediation goal } \\
\text { level } \\
\text { wel }\end{array}$ & & & & & & & \\
\hline
\end{tabular}

EU Z2-33 K-1015 LAUNDRY PCT FFA STTE SVOC DETECTS (UgRGg) 0-10 At

\begin{tabular}{|c|c|c|c|c|c|c|c|c|}
\hline \multirow[b]{2}{*}{ Analylt } & \multirow[b]{2}{*}{$\begin{array}{c}\text { Detect } \\
\text { Irtequency }\end{array}$} & \multirow[b]{2}{*}{$\begin{array}{c}\text { Minlonan } \\
\text { detect }\end{array}$} & \multirow[b]{2}{*}{$\begin{array}{l}\text { Mastmurs } \\
\text { detect }\end{array}$} & \multirow[b]{2}{*}{$\begin{array}{c}\text { Loceiloa(s) of } \\
\text { meximsm detect }\end{array}$} & \multirow{2}{*}{$\begin{array}{l}\text { Avernge } \\
\text { detected } \\
\text { regult }\end{array}$} & \multicolumn{3}{|c|}{$\begin{array}{l}\text { Nerwer of anglyses } \\
\text { exceeting criterin }\end{array}$} \\
\hline & & & & & & $\begin{array}{c}\text { IDd } \\
\text { PRG }\end{array}$ & $\begin{array}{l}\text { GW } \\
\text { SL }\end{array}$ & $\begin{array}{l}\text { Res } \\
\text { PRG }\end{array}$ \\
\hline Acenaphahene & $6 / 4$ & $7 \mathrm{BJ}$ & $78 \mathrm{~J}$ & Z2-EU33B-307 & 78 & 0 & $N A$ & 0 \\
\hline Anthracecte & $1 / 4$ & $110+$ & 100 & 22-EV33月-307 & 110 & 0 & NA & 0 \\
\hline Benz(a)aathracene & $1 / 4$ & $240 \mathrm{~J}$ & 2101 & Z2-EU33B-307 & 240 & 0 & $N A$ & 0 \\
\hline Benro(a)pyrtente & $1 / 4$ & $180 \mathrm{~J}$ & IBOJ & Z2-EU33B-307 & 180 & 0 & NA & 1 \\
\hline Benzo(b)fliorshthene & $1 / 4$ & $210\rfloor$ & $210 \mathrm{~J}$ & $22-E[333-307$ & 210 & 0 & NA & 0 \\
\hline Benzo(ghi)peryleng & $1 / 4$ & $130 \mathrm{~J}$ & $130 \mathrm{~J}$ & $22-E U 33 \mathrm{~B}-367$ & 130 & 0 & $N A$ & 0 \\
\hline Berrza(k) luxprantuene & $1 / 4$ & $190 \mathrm{~J}]$ & 1900 & $22-E U 33 B-307$ & 190 & 0 & $\mathrm{NA}$ & 0 \\
\hline Bls(2-ethylhexyl)phthal ate & $1 / 4$ & 1,8000 & 1,800 & Z2-E:J33-2018 & 1,800 & 0 & 0 & 0 \\
\hline Buty] bengyl phithalate & $1 / 4$ & 69J & $69 \mathrm{~J}$ & Z2-EU33-20!B & 69 & 0 & NA & 0 \\
\hline Cerrbazole & $1 / 4$ & 783 & $78 \mathrm{~J}$ & Z2-EU33B-307 & 78 & 0 & NA & 0 \\
\hline С̆гугепе & $1 / 4$ & $28[\mathrm{~J}]$ & $2 \mathrm{BOJ}$ & Z2-EU33B-397? & 280 & 0 & NA & 0 \\
\hline Dh-ת-octylphhatate & $1 / 4$ & $120 \mathrm{~J}$ & 1201 & Z2-EU33-2018 & 120 & 0 & $\mathrm{NA}$ & 0 \\
\hline Filuorarthene & $1 / 4$ & 590 & 590 & Z2-EU33B-307 & 590 & 0 & $\mathrm{NA}$ & 0 \\
\hline Fluarese & $1 / 4$ & 635 & 63 & $22-E \amalg 33 B-307$ & 63 & 0 & NA & 0 \\
\hline 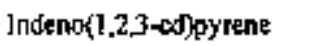 & $1 / 4$ & $320 \mathrm{~J}$ & I201 & Z2-EU33B-347? & 120 & 0 & NA & 0 \\
\hline Phenanchrente & $1 / 4$ & 520 & $\$ 20$ & 22-EU13,3E-307 & 520 & 0 & NA & 0 \\
\hline Рутепе & $1 / 4$ & d70 & 470 & Z2-EU33B-307 & 470 & 0 & NA & 0 \\
\hline
\end{tabular}

$E U=$ exposure umit

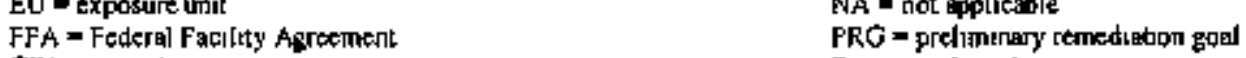

GW $=$ ground water

lind = indusurtal

J - analyte wat identafied and result is approxumate contentrallou

Res $=$ ress|d|der|t|al

$\mathrm{SL}=$ screening level

SVoc $=$ temrolatile organte tompound

EU Z2-33 K.](15 LAUUNORY PET FFA SETE VOC DETECTS (LG/kg) 0. 30 ft

\begin{tabular}{|c|c|c|c|c|c|c|c|c|}
\hline \multirow[b]{2}{*}{ Anslyte } & \multirow[b]{2}{*}{$\begin{array}{l}\text { Detect } \\
\text { Irisutency }\end{array}$} & \multirow[b]{2}{*}{$\begin{array}{l}\text { Munnium } \\
\text { detect }\end{array}$} & \multirow[b]{2}{*}{$\begin{array}{l}\text { Masimnn } \\
\text { detect }\end{array}$} & \multirow[b]{2}{*}{$\begin{array}{l}\text { Lacatian(s) of } \\
\text { nevl anum detect }\end{array}$} & \multirow{2}{*}{$\begin{array}{l}\text { Average } \\
\text { dictected } \\
\text { regult }\end{array}$} & \multicolumn{3}{|c|}{$\begin{array}{l}\text { Number of andlyses } \\
\text { erceeting criteng }\end{array}$} \\
\hline & & & & & & $\begin{array}{l}\text { Ind } \\
\text { PRG" }\end{array}$ & $\begin{array}{l}\text { G巾 } \\
\text { 9L }\end{array}$ & PRG \\
\hline $\begin{array}{l}\text { 1,1,2-Trichloro-1,2,2- } \\
\text { trifueroethane }\end{array}$ & $1 / 5$ & 21 & $2 !$ & 424 & 21 & 10 & NA & 0 \\
\hline Toluene & $2 / 5$ & 9 & 22 & 425 & 15.5 & 0 & 0 & 0 \\
\hline $\begin{array}{l}\text { EU a exposure unit } \\
\text { FFA = Federal Facility } \\
\text { GW' = groundwater } \\
\text { Ind = Industnal } \\
\text { NA = nol applicable }\end{array}$ & estentictil & \multicolumn{7}{|c|}{ 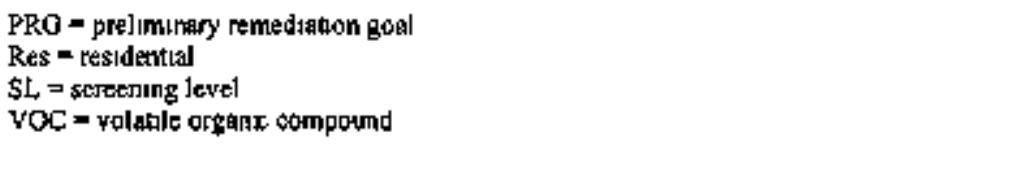 } \\
\hline
\end{tabular}




\section{K-1044 Heavy Equipment Repair Shop FFA Site}

The K-1044 Heavy Equipment Repair Shop FFA site is located in the northeast comer of EU Z2-33. The shop itself was demolished in 1958 and its footprint is now partially covered by Bldg. K-1225. Two biased sample Iocations were selected at the FFA site (Sect. 2.2.3). Analytical results surtumarized below from these samples show metal Bkg exceedances and PCB detections.

\begin{tabular}{|c|c|c|c|c|c|c|c|c|c|c|c|}
\hline \multirow[b]{2}{*}{ Anabyte } & \multirow[b]{2}{*}{$\begin{array}{c}\text { Detect } \\
\text { freg nency }\end{array}$} & \multirow{2}{*}{$\begin{array}{c}\text { Milinum } \\
\text { defect }\end{array}$} & \multirow[b]{2}{*}{$\begin{array}{l}\text { Moxtuum } \\
\text { Eectecf }\end{array}$} & \multirow{2}{*}{$\begin{array}{c}\text { Eocetion(s) of } \\
\text { mirimint } \\
\text { defect }\end{array}$} & \multirow{2}{*}{$\begin{array}{l}\text { Avetrige } \\
\text { detectud } \\
\text { result }\end{array}$} & \multicolumn{6}{|c|}{ Nuriber of anglybes ercecting criterls } \\
\hline & & & & & & $\begin{array}{l}\mathbf{R p x} \\
\mathbf{R l}\end{array}$ & $\begin{array}{l}\text { AF } \\
\text { RL }\end{array}$ & $\begin{array}{l}\text { Ind } \\
\text { PRE }\end{array}$ & Bly & $\begin{array}{l}\text { GW } \\
\text { StL }\end{array}$ & $\begin{array}{l}\text { Rts } \\
\text { PRG }\end{array}$ \\
\hline Aluminintm & $2 / 2$ & 12,000 & 13,000 & Z2-EU93B-232 & 12,500 & NA & $N A$ & 0 & 0 & $\overline{W A}$ & 2 \\
\hline Asserine & $2 / 2$ & 4 & 96 & Z2-EU33B-232 & 68 & 0 & 0 & 0 & 0 & 0 & 2 \\
\hline Calciurn & $2 / 2$ & 2,500 & 11,000 & $22 \times E U 33 \mathrm{~B}-233$ & 9,750 & NA & $\mathrm{NA}$ & NA & 2 & NA & NA \\
\hline Chromiturn & $2 / 2$ & 17 & 33 & $22-6 U 33 B-232$ & 25 & $\mathrm{NA}$ & $N A$ & 0 & b & 0 & 1 \\
\hline Lton & $2 / 2$ & 38,0005 & $42,000 \mathrm{~J}$ & $\mathrm{Z2}-\mathrm{EU} 33 \mathrm{~B}-232$ & 40,000 & NA & NA & 0 & 0 & NA & 2 \\
\hline Manganese & $2 \pi$ & 6]0J & $1,100 J$ & Z2-EU33B-232 & 855 & NA & NA & 0 & 0 & NA & 2 \\
\hline Selenium & $2 / 2$ & 25 & 35 & Z2-EU33B-232 & 3 & NA & $\mathrm{NA}$ & 0 & 2 & NA & 0 \\
\hline Vanadium & $2 / 2$ & 265 & $52 \mathrm{~J}$ & $\mathrm{Z2}-\mathrm{EU} 33 \mathrm{~B}-232$ & 39 & $\mathrm{NA}$ & $\mathrm{NA}$ & 0 & 0 & $N A$ & 2 \\
\hline \multicolumn{5}{|c|}{ 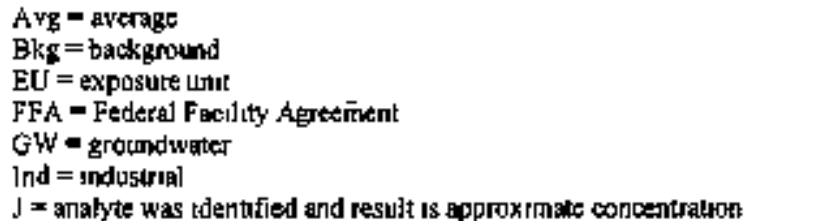 } & \multicolumn{6}{|c|}{ 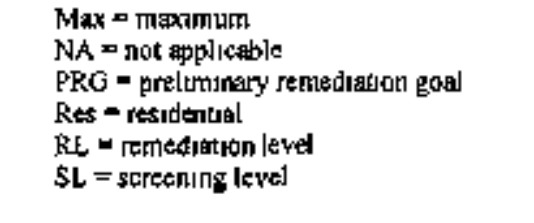 } & \\
\hline
\end{tabular}

\section{EU $Z 2-33$ K-[044 HEAVY LOULPMENT REPA]R SHOP FFA SITE PRCB DETECTS (ue/kg) 0-10 ft}

\begin{tabular}{|c|c|c|c|c|c|c|c|c|c|}
\hline \multirow[b]{2}{*}{ Analyte } & \multirow[b]{2}{*}{$\begin{array}{c}\text { Detect } \\
\text { frequency }\end{array}$} & \multirow[b]{2}{*}{$\begin{array}{l}\text { Mialmum } \\
\text { detect. }\end{array}$} & \multirow[b]{2}{*}{$\begin{array}{l}\text { Maxlmum } \\
\text { detecl }\end{array}$} & \multirow{2}{*}{$\begin{array}{c}\text { Location[s] of } \\
\text { naxinum } \\
\text { detect }\end{array}$} & \multirow{2}{*}{$\begin{array}{l}\text { Averige } \\
\text { detected } \\
\text { remult }\end{array}$} & \multicolumn{4}{|c|}{$\begin{array}{l}\text { Number of analywes } \\
\text { exuedúg crilterba }\end{array}$} \\
\hline & & & & & & Max & AH & $\begin{array}{l}\text { lind } \\
\text { PRTG }\end{array}$ & $\begin{array}{l}\text { Res } \\
\text { PRG }\end{array}$ \\
\hline PCB-I2S4 & $1 / 2$ & 21 & 21 & $22-e_{U} 33-233$ & $2 \mathrm{~F}$ & 0 & 0 & $\frac{10}{10}$ & 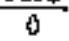 \\
\hline Polychlormated Bipheny] & $1 / 2$ & 21 & 21 & Z2-EU33B-233 & $2 I$ & 0 & 0 & 0 & 0 \\
\hline
\end{tabular}

Avg - aresuge $\quad$ PPCB * pestueide and polychlorınated biphenyt

EU * exposure undt PRG $*$ prel mininary remediation goal

FFA = Federal Facility Agreement Res = resident|g]

Ind = mdustral $\quad \mathrm{RL}=$ temedistion level

Mix = maxumpurs

SVOCs were analyztd for but were not detected.

\begin{tabular}{|l|l|}
\hline 3.0 & RISK EVALUATION AND ACTION/NO FURTHER ACTION DECISION \\
\hline 3.1 & INTRODUCTYON \\
\hline
\end{tabular}

In this section, data are evaluated in terms of the four decision rules presented in the Zone 2 RAWP. The decision rules include:

- Doss the concentration of any Zone 2 contaminant of concen (COC) exceed its maximum RL?

- Does the mean concentration of any Zone 2 COC exceed its average RL across the EU?

- Does the EU pose a risk exceeding an industrial I $\times 10^{-1}$ excess lifetime cancer risk (ELCR) or target organ hazard index (HI) of 1 ?

- Does the site pose a threat to groundwater based on MCL exceedances or soil RLs for protection of groundwater?

Table 3 presents results fiom comparison of the data to Zone 2 soils RLs, Ind PRGs (set at an ELCR of $1 \times 10^{-5}$ or a HI of (1), and background levels. In addition, the EU summary in Sect. 2.2 .5 presents an evaluation of EU data by analyte group. The following table summarizes the conclusions for current conditions in EU Z2-33. 


\begin{tabular}{|c|c|c|c|c|c|}
\hline EU H & $\begin{array}{l}\text { Max RL } \\
\text { exceeded? }\end{array}$ & $\begin{array}{l}\text { Average RL over } \\
\text { EU exceeded? }\end{array}$ & $\begin{array}{l}\text { Industrial risk } \\
\text { above } 1 \times 10^{-47}\end{array}$ & $\begin{array}{l}\text { Potential source } \\
\text { to groundwater? }\end{array}$ & $\begin{array}{l}\text { Action } \\
\text { required? }\end{array}$ \\
\hline $22-33$ & No & $\mathrm{No}$ & No & $\mathrm{N}_{0}$ & No \\
\hline
\end{tabular}

| DATA EVALUATION FOR THE ACTION/NO FURTHER ACTION DECISION

The requirements for determining NFA in the Zone 2 EUs are stated in the protection goals of the Zone 2 ROD remedial action objective. Four decision rules developed in the DVS DQDs state the specific criteria against which each EU must be compared to make the NFA decision. These four decisjon rules are presented in Sect. 3.2 of this PCCR and the way the decigion rule evaluations are conducted and special datn handlitg requirements are discussed in Sect 33. In summary, the decision rule criteria for NFA are that each EU must meet each of the following compositional constraints:

- Zone 2 soils Max RLs-maximum allowable concentrations of Zone 2 soils COCs. Zone 2 soils Max RLs are presented in the Zone 1 ROD and Sect 3.2 of this PCCR.

- Zone 2 soils Avg RLs-limit on the allowable average concentrations of Zone 2 soils COCs across an EU. Zone 2 soils AYg RLs are preserted in the Zone 1 ROD and Sect. 3.2 of this PCCR.

- Cunulative risk across the EU-curnulative risk across an EU cannot exceed $1 \times 10^{-1}$ ELCR or HI of 1. A stepuise evaiuation of culmulative risk is performed by comparing EU data to $1 \times 10^{-5}$ intustrial PRGs. The $1 \times 10^{.5}$ Ind PRGs for the analytes required by the RDRRAWP are presented in Sect. 3.2 of this PCCR

- Groundwater protection goals - composition of Zone 2 soils cannot pose a threat to groundwater. This evaluation is conducted by assessing local groundwator monitoring results and comparing soils composition to calculated SLs. Groundwater SLs are presented in Sect. 3.2 of this PCCR.

\begin{tabular}{l|l}
3.3 & SUMMARY AND CONCLUSIONS \\
\hline
\end{tabular}

EU Z2-33

In this section, soil compositions from the $0-10 \mathrm{ft}$ depth interval are evaluated in terms of the decision rule criteria diseussed in Sect. 3.2 of this PCCR, The data evaluated reflect current conditions that are post-remedial actions and post-D\&D in EU Z2-33. The same remedial action that addressed the K-1004-I Lab Soruth Class 1 SU in EU Z2-33 addressed soil contamination associated with the K-1004-J Laboratory in EU Z2-42. For EU Z2-33, data evaluated include soil samples collected from a depth of $\geq 10 \mathrm{ft}$ bgs if the samples were collected to confirm the results of a remedial action or D\&D, or if the samples were collected to document contatrinant leakage from a subsurface structure. Also, data for concrete left on site was evaluated with the soil data because the concrete will remain a permanent soltid matrix of the site.

Maximum $\mathrm{RL}$ screening. The Ra/Th decay seties Max $\mathrm{RL}$ was exceeded in two samples of sediment collected from the K-1006 north sump. The K-1006 Developrnent Laboratory is an active facility. The RA Core Team agreed the K-1006 noth surep would not be addressed at this time.

Average RL screening. The Avg RL screening process included the requirements of the Zone 2 ROD, which stated the weighted average concentrations of Zone 2 COCs across the EU could not exceed their respective Avg RLs. The screening process began by documenting the individual locations of Avg RL excerdances in the EU. Next, the average detected concentration of any $\mathrm{COC}$ with an Avg RL exceedance was compared to the Avg RL. (Where noted betow, the average detected concentration included dala for soil and concrete samples, therefore, data will not match the data summaries that present tither soil or concrete data.) If the detected average concentration was less than the Avg RL, the COC was dropped from further screening. If a COC's average detected concentration exceeded the average $\mathrm{RL}$, then a new average concentration was calculated where half the value of the detection limit was used for nondetects. If the new average exceeded the Avg RL, then a weighted averge concentration for the COC was calculated and the weighted average concentration was compared to the Avg RL.

The Avg RL for PCB-1254 was excteded in four soil and concrete samples. The average detected concentration of PCB-12\$4 in EU soil and concrete was $5788 \mathrm{ug} / \mathrm{kg}$, which was less than the Avg RL of $10,000 \mathrm{ug} / \mathrm{kg}$. 
The Avg RL for polychlorinated biphenyl (total PCB) was exceeded in four soil and concrete samples. The average detected epncentration of total PCB in EU soil and concrete was $5010 \mathrm{ug} / \mathrm{kg}$, which was less than the Avg RL of $10,000 \mathrm{ug} / \mathrm{kg}$.

The Avg RL for Cs-197 was exceeded in one soil sample (historical locations KAH-SS-B22 and KAH-SS-S31 were not included becaluse DVS sampling did not confirm Cs-i37 Avg RL exceedances). The averafe detected concentration of Cs-137 in EU soil was $0.784 \mathrm{pCi} / \mathrm{g}$, which was less than the Avg RL of $2 \mathrm{pCi} g$.

The Ra/Th decay series Avg RL, was exceeded in two samples fron the $\mathrm{K}$-1006 north sump. The RA Core Team has agreed that the $\mathrm{K}-1006$ north sump will not be addressed at this time.

The Avg RL for $U-235$ was exceeded in a soil and a concrete sample. The average detected concentration of $U-235$ in $\mathrm{EU}$ soil and concrete is. $1.22 \mathrm{pCi} / \mathrm{g}$, which was less than the $\mathrm{Avg} \mathrm{RL}$ of $8 \mathrm{pCi} / \mathrm{g}$.

The Avg RL for $\mathrm{U}-238$ was exceeded in soil and concrete samples. The average detected concentration of $\mathrm{U}-238 \mathrm{in}$ EU soil and concrete was $8.32 \mathrm{pCi} / \mathrm{g}$, which was less than the Avg RL of $50 \mathrm{pCi} / \mathrm{g}$.

It was concluded that no average $C O C$ concentration across EU Z2-33 exceeded its Avg RL.

Risk evaluation. The $1 \times 10^{-5}$ Ind PRGs were used as an initial screen to test for the possibility that a $1 \times 10^{-4}$ industrial risk would be exceeded. The first step in the risk screen was to document all of the chemicals and radienuclides with $1 \times 10^{-5}$ Ind PRG exceedances. The $1 \times 10^{-5}$ Ind PRGs for Ra-226, Th-228, Th-230, and Th-232 were not considered in the risk eveluation becalnse tisk for those radionuclides was evaluated with the Ra/Th decay series RLs, and K-40 was considered in the risk evaluation only if its average detected concentration exceeded its background concentration. The second step in the risk screer was to compare the average detected concentrations of chemicals and radionuclides with individual Ind PRG exceedances to the $1 \times 10^{-5}$ Ind PRGs. If the average detected concentration of a chemical or radiontuclide was less than the $\mathrm{I} \times 10^{-5}$ Ind PRG, that chemical or radionuclide was no longer evaluated for risk. If the average detected concentration of a chemical or radionnclide exceeded the $1 \times 10^{-5}$ Ind PRG, then the average concentration was recalculated using one-half the detetion limit for nondetects. If the recalculated average concentration exceeded the $1 \times 10^{-4}$ Ind PRG (i.e., 10 times the $1 \times 10^{-5}$ [nd PRG), then a weighted average caleulation was performed (weighted average is explained in the PCCR). If the weighted average exceeded the $1 \times 10^{-4}$ Ind PRG, then a quantitative risk assessment was performed. Lastly, all chernicals and radionuclides with individual $1 \times 10^{-9}$ Ind PRG exceedances were evaluated for their combined impact on cutrulative risk. An estimate of cumulative risk was made by calculating the fraction each average concentration was of its $1 \times 10^{.5}$ Ind PRGs, then summing those fractions. If the sum was $>7.5$ (i.c., approximately $75 \%$ of the $1 \times 10^{-4}$ Ind PRGs), then a quantitative risk assessment was performed.

The data summaries in Sect. 2.2 .5 illustrates that there were several Ynd PRG exceedances. As described above, the Ra-226, Th-228, Th-230, and Th-232 Ind PRG exceedances are not considered and, because the average detectedf concentration was less than the background concentration $(32.12 \mathrm{pCi} / \mathrm{g})$, the $\mathrm{K}-40$ Ind PRG exceedances also were not considered. Among the remaining chemicals and radionuclides with Ind PRG exceedances, only the average detected concentrations of benzo(a)pyrese $(6637 \mathrm{ug} / \mathrm{kg})$ and dibenz $(\mathrm{a}, \mathrm{b})$ anthracene $(23 \mathrm{l} 2 \mathrm{ug} / \mathrm{kg}$ ) exceeded their $1 \times 10^{-5}$ Ind PRGs (2110 ug $/ \mathrm{kg}$ for both).

Recalculating the EU Z2-33 average concentrations for benzo(a)pyrene and fibenz(a, $h$ )anthracene by using one half the detection limit for non-detects resulted in new averages of $2799 \mathrm{ug} / \mathrm{kg}$ and $47 \mathrm{l} u \mathrm{~g} / \mathrm{kg}$, respectively. Thus, neither the recaiculated average concentration of benzo(a)pyrene or benz(a,th)anthracene exceeded the $1 \times 10^{-4}$ Ind PRG, although the bento(a)pyrene recalculated everage concentration exceeded the $\mathrm{I} \times 10^{-5}$ Ind PRG.

The fraction of each average detected concentration relative to the respective $\mathrm{I} \times 10^{-5}$ Ind PRG was calculated for all chemicals and radionuclides with $1 \times 10^{-3}$ Ind PRG exceedances, except for benzo(a)pyrene and dibenz(a,h)anthracene. For these two chernicals, the recalculated averages were used (sec above). Summing the fractions resulted in a value of 6.5 . It was concluded that if all nondetects were to be accounted for and their weighted averagos were calculated, the cumulative risk over EU Z2-33 would not exceed $1 \times 10^{-4}$.

In conclusion, the industrial risk for EU Z2-33 was calculated to be less than $1 \times 10^{-4}$ ELCR, with a target organ $\mathrm{HI}$ of $\mathrm{I}$.

Threat to groundwater. The threat to groundwater from an EU was evaluated by looking at MCL exceedances in local groundwater wells and comparing the chemicals and radionuclides with MCL exceedances to chemicals and radionuclides with GW SL exceedances. If there were matches between the two sets of analytes, then the mobilities 
of the matching analytes were evaluated, the volumetric extent of their GW SL exceedances were estimated, and a conclusion was drawn regarding whether any of the matching analytes was a source of groundwater contamination.

As discussed in the groundwater evaluation in Sect 2.2.5, MCLs in local groundwater wells were exceeded by VOCs. No VOC GW SLS exceedances were observed in the EU Z2-33 data, however, one arsenic, two chromium, four U-234, and three U.238 GW SL exceedances were observed. The 10 GW SL exceedances occurred in five samples from locations KAH-SS-S1 1, Z2-EU33B-235, Z2-EU33B-327, Z2-EU33B-334, and Z2-EU33B-365. The sample from Z2-EU33B-235 was brick and concrete ftom a mantiole while samples from Z2-EU33B-327, Z2-EU33B-334, and Z2-EU33B-365 were sediment from subsurface enclosures (sump, stomn drain, and manhole, respectively). These sample locations represented 9 of the $10 \mathrm{GW}$ SL exceedances. The last GW SL exceedance was KAH-SS-S1J, which was a surface soit sample location. Arsenic, chromiurn, and uranium had low mobilities in aqueous environments, therefore, they adhered to the soil, sediment, and concrete/brick surfaces representing the matrices of the various samples with $\mathrm{GW} \mathrm{SL}$ exceedances and did not represent a threat to groundwater.

Both DRO and GRO were detected in a sediment sample at historical location Z2EU33-K1004D. The sample was from a sewer ejector surnp pit in the basement of the K-1004-D Facility. Although there were no site-specific or action-specific criteria in the Zone 2 ROD that pertained to DRO and GRO, underground stotage tank rules of the Tenressee Department of Ervironment and Conservation Chap. 1200-1-15-06(7)(e)(4) state site-specific, risk-based cleanup levels may be used where appropriate. In the case of these DRO and GRO detections, the sample location was removed when D\&D Operations removed the surap pit sediment after production of the fnitial draft of this TM.

Qualitative risk screening for unrestricted use. There was a low probability that EU Z2-33 acreage could be released with to land use testrictions. Avg RL exceedances for radionuclides and PCBs, and ind and Res PRG exceedances for metals, radionuclides, PCBs, SVOCs, and VOCs occurred in this EU. Specific chemicals and radionuclides with criteria exceedances are presented in Sect, 2.2.5. An appropriate evaluation of residential risk should be conducted to make a definitive conclusion.

\section{Zone 2 ROD Appendix A FFA Sites}

Based on sarnpling analytical results at the EU Z2-33 FFA sites (Sect. 2.2.6) and an evaluation of the EU-wide contaminant profile (above), soils in the following Zone 2 ROD Appendix A FFA sites do not pose a potential threat to the future industrial worker or groundwater:

- K-1004-L RCW Lines Leak Site FFA site,

- K-1015-A Laundry Pit FFA Site, and

- K-1044 Heavy Equipment Repair Shop FFA Site.

\begin{tabular}{|l|l|}
\hline 4.0 & RECOMMENDATION FOR ACTION/NO FURTHER ACTION \\
\hline 4.1 & DECISION AND REMEDIATION ACTIVITIES \\
\hline
\end{tabular}

EU Z2-33: Based on the analytical results of DVS and historical samples collected in EU Z2-33 and the Class 3 SU walkover assessment in the EU, the U.S. Department of Energy (DOE) recommends that NFA is appropriate under the Zone 2 ROD to meet industrial land use for the 18 acres of ETTP Zone 2 EU33.

There are 20 DVS and historical sample locations in EU Z2-33 with samples from $\geq 10 \mathrm{ft}$ bgs. Anafytical results summarized in Table 5 showet sporadic radionuclide lnd PRG exceedances; metal, radionuclide, and VOC Res PRG exceedances; and numerous metal and radionuclide Bkg exceedances, In addition, one or more groundwater contaminant plumes occumed under portions of this EU. Based prinarily on the existence of known groundwater contamination, DOE does not recommend the 10-fi-depth use restriction be lifted.

FFA Sites: Based on sampling analytical results and the recommendation for EU Z2-33, DOE reconmends NFA as appropriate for the following FFA sites:

- K-1004-L RCW Lines Leak Sile FFA site,

- K-1015-A Laundry Pit FFA Site, and

- K-1044 Heavy Equipment Repair Shop FFA Site. 
Data and observations recorded in this TM reflect current conditions in EU Z2-33 (i.e., post-remedial action and post-D\&D conditions). Data evaluations in Sect 3.3 conchude there are no average $R L$ or trisk exceedances and no threats to groundwater in soils of the 0-10-ft-depth interval in the EU. Two maximum RL exceedances oceu in the north sunp of the active K-1006 Development Laboratory but the RA Core Team hos agteed to defer actions until a later time. Therefore, no excavation activities or confirmation sampling is planned for EU Z2-33. 


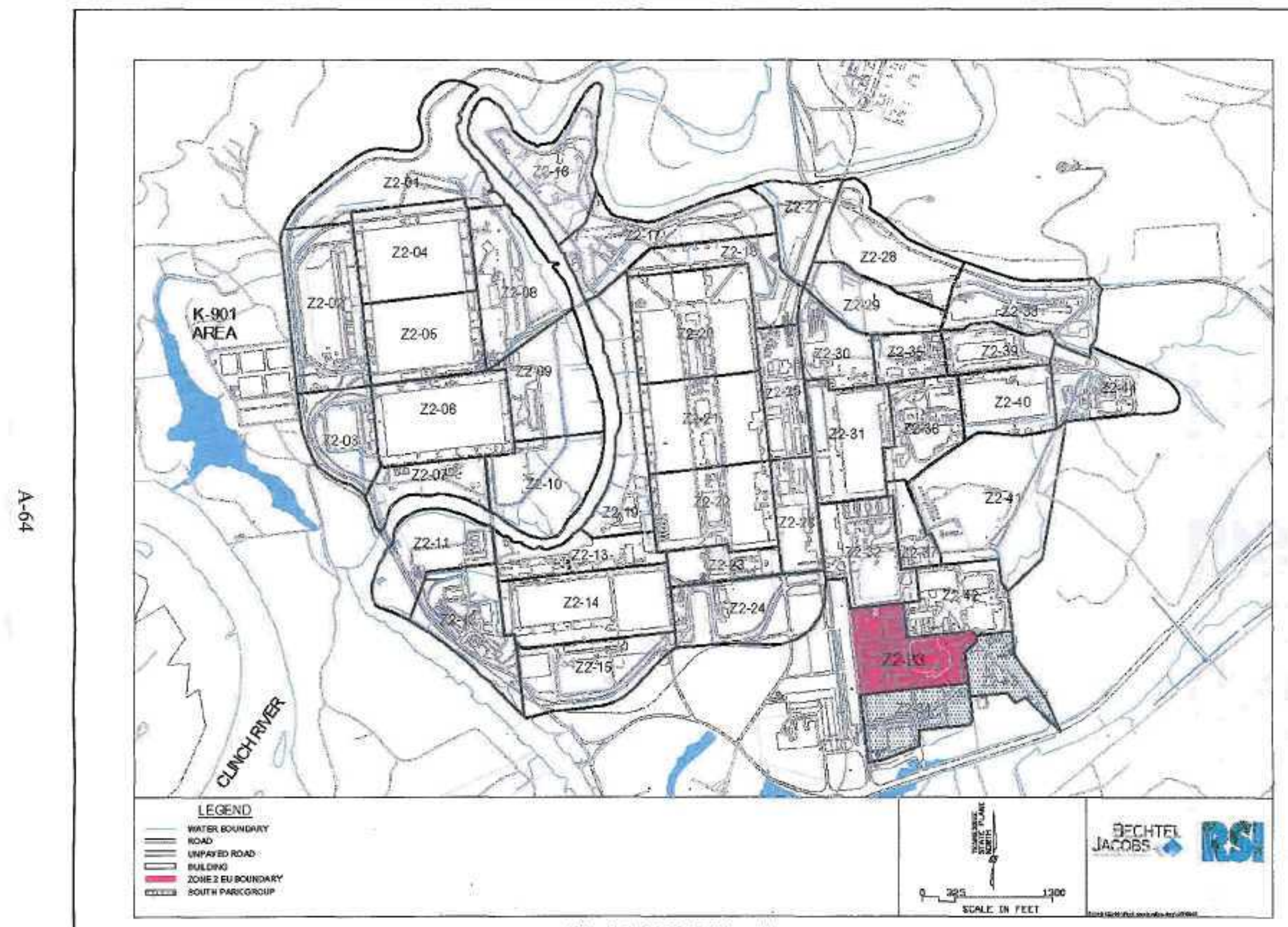

Fig. A.1. EU Z2-33 location map. 


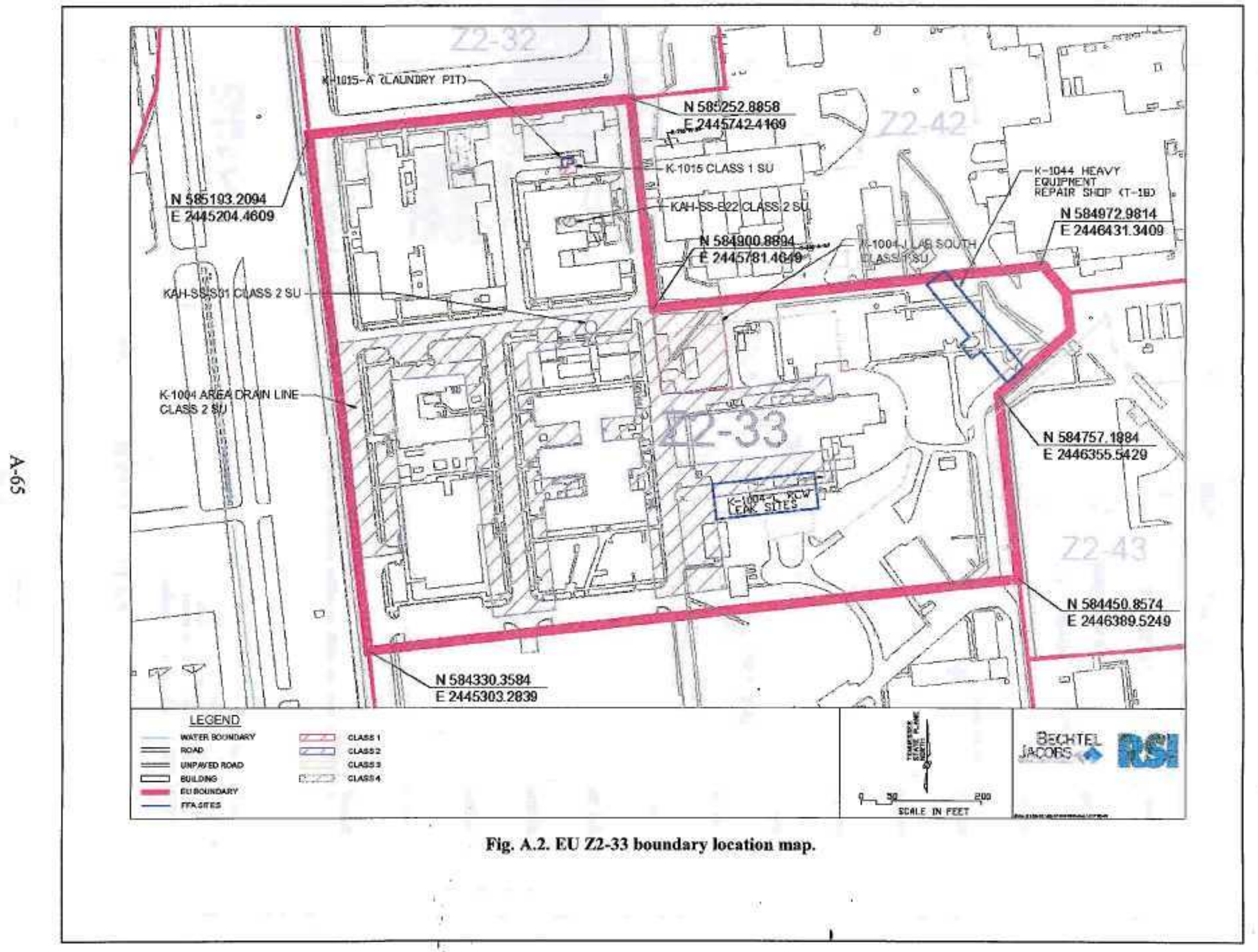




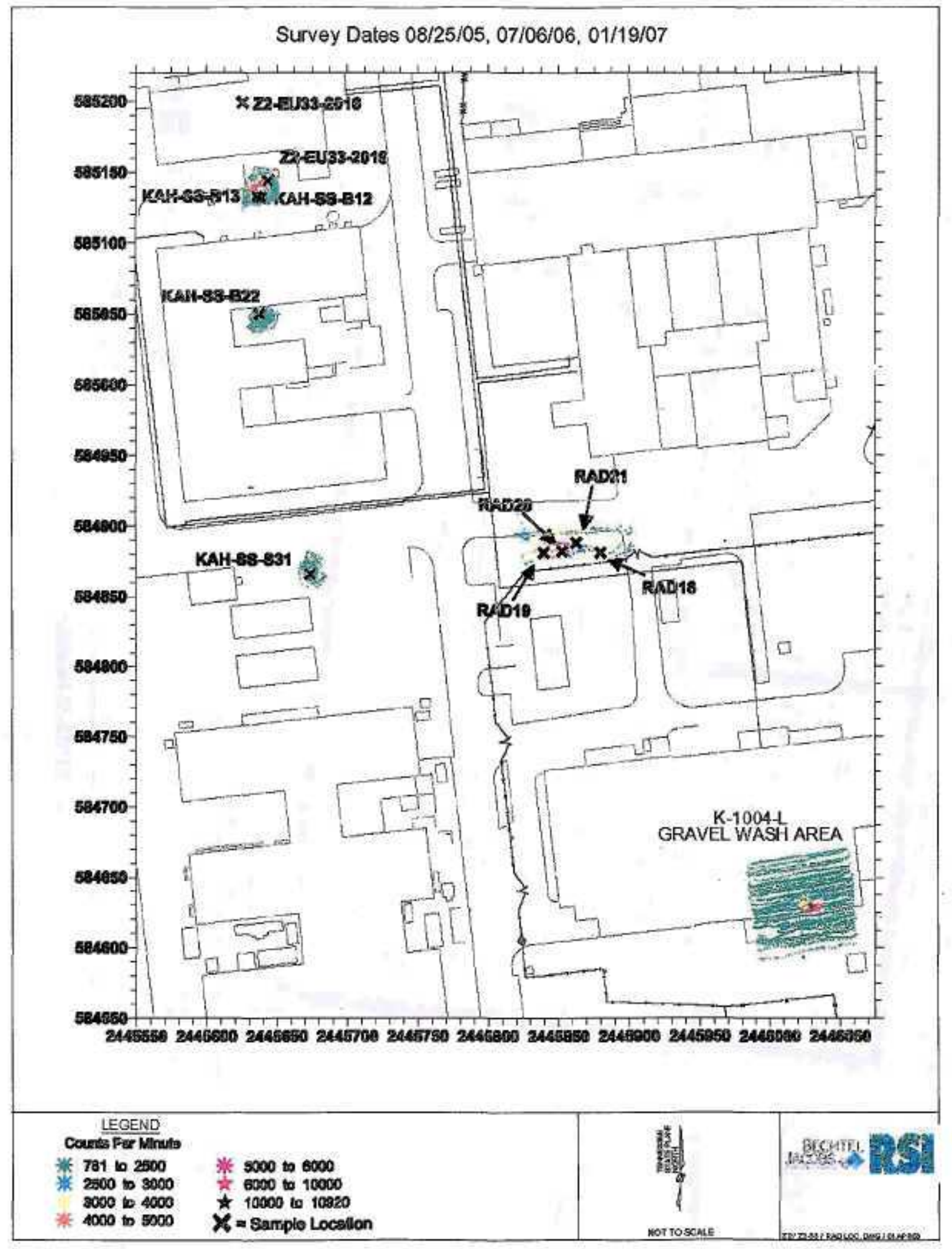

Fig. A.3, EU Z2-33 BAR survey locations. 


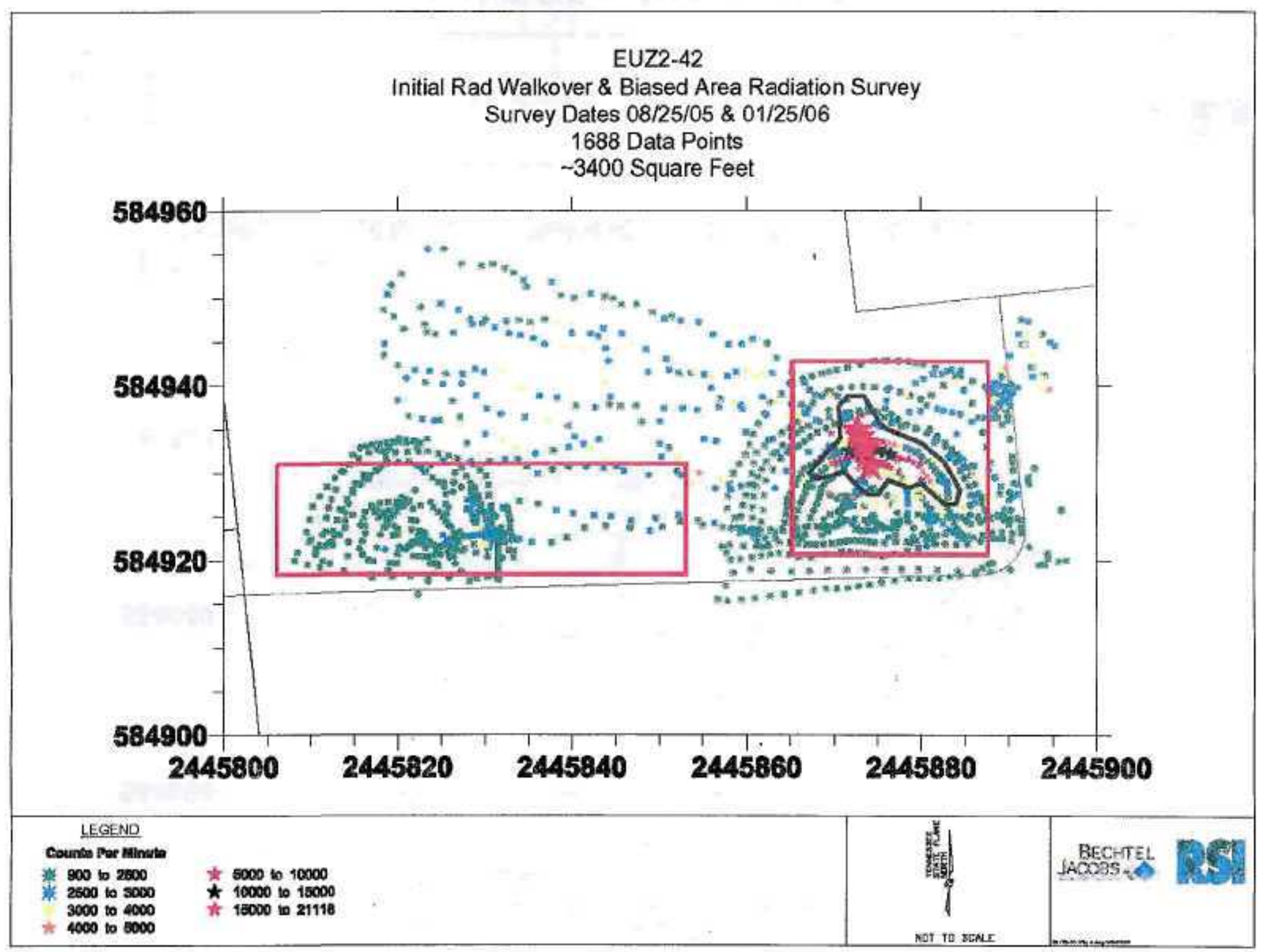

Fig. A.4, EU Z2-42 initial BAR survey results. 


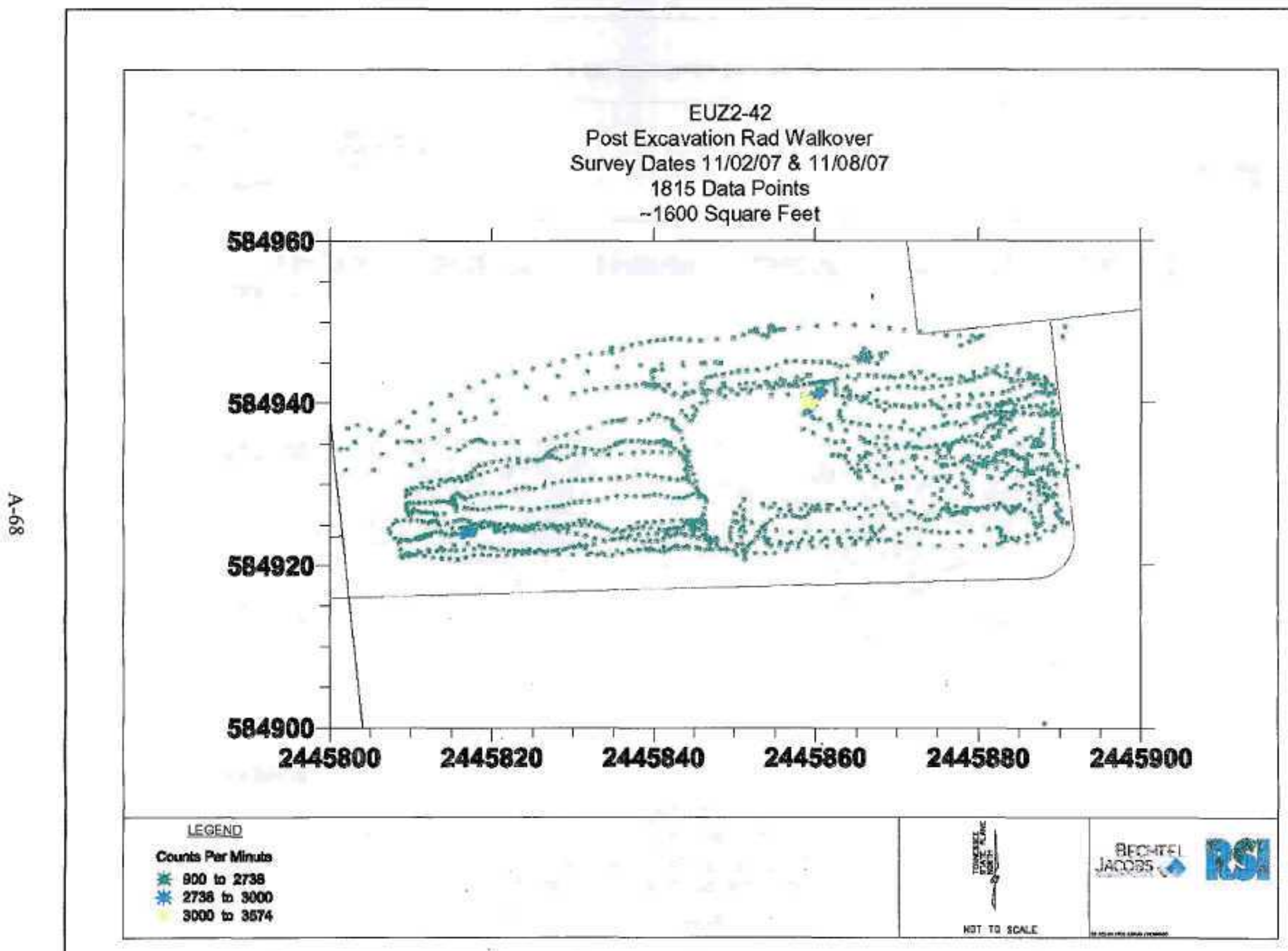

Fig. A.5. EU Z2-42 post-RA BAR survey results. 


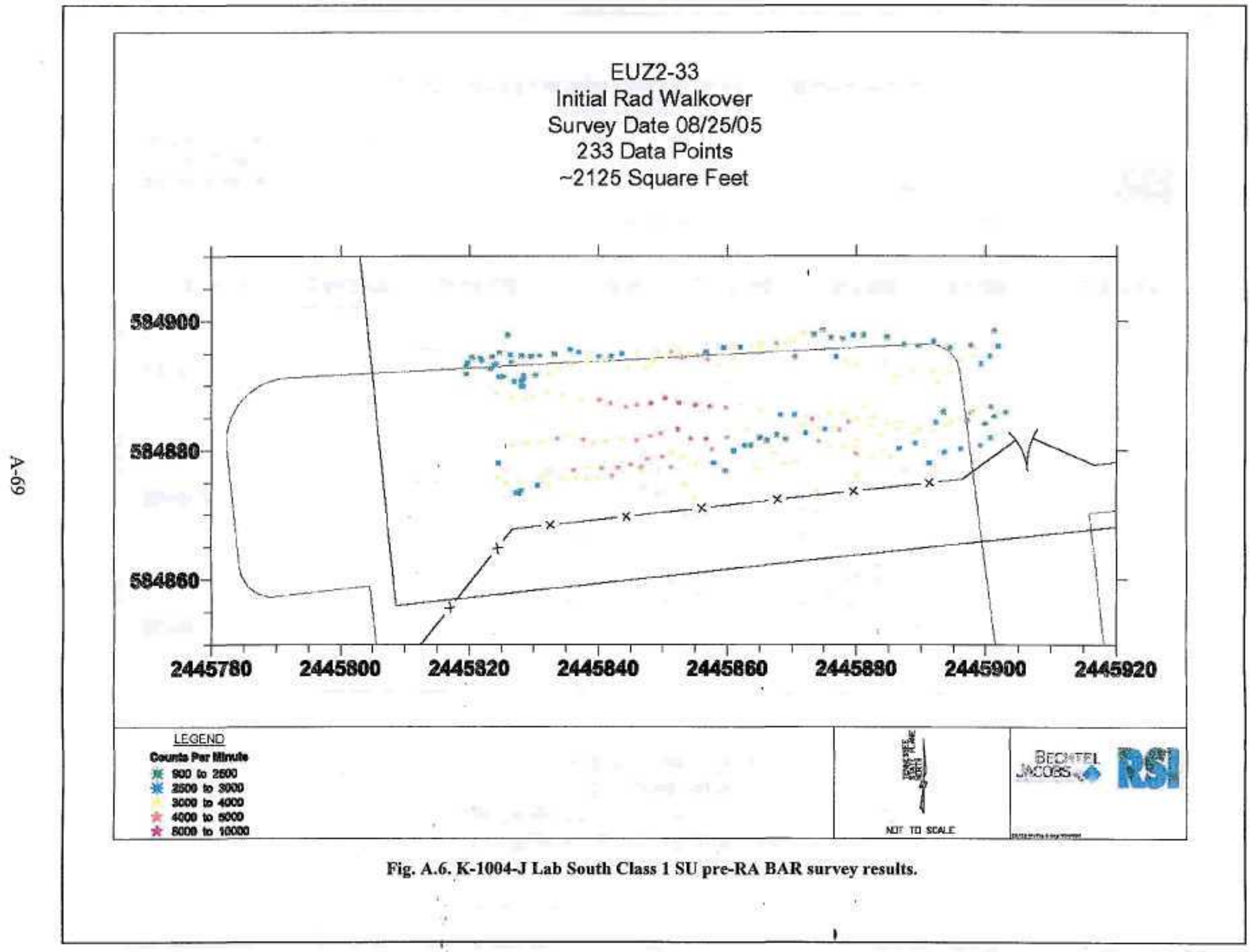



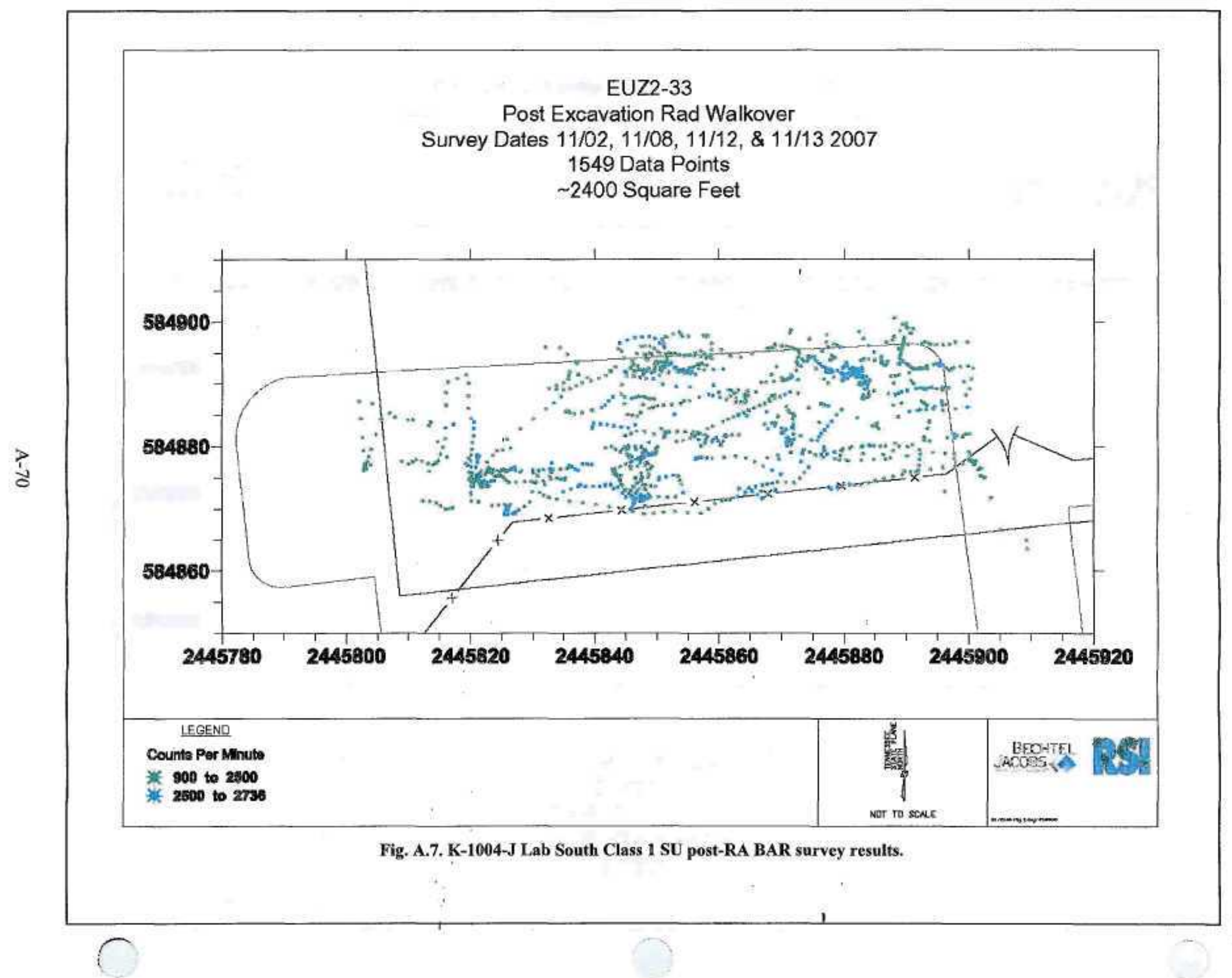


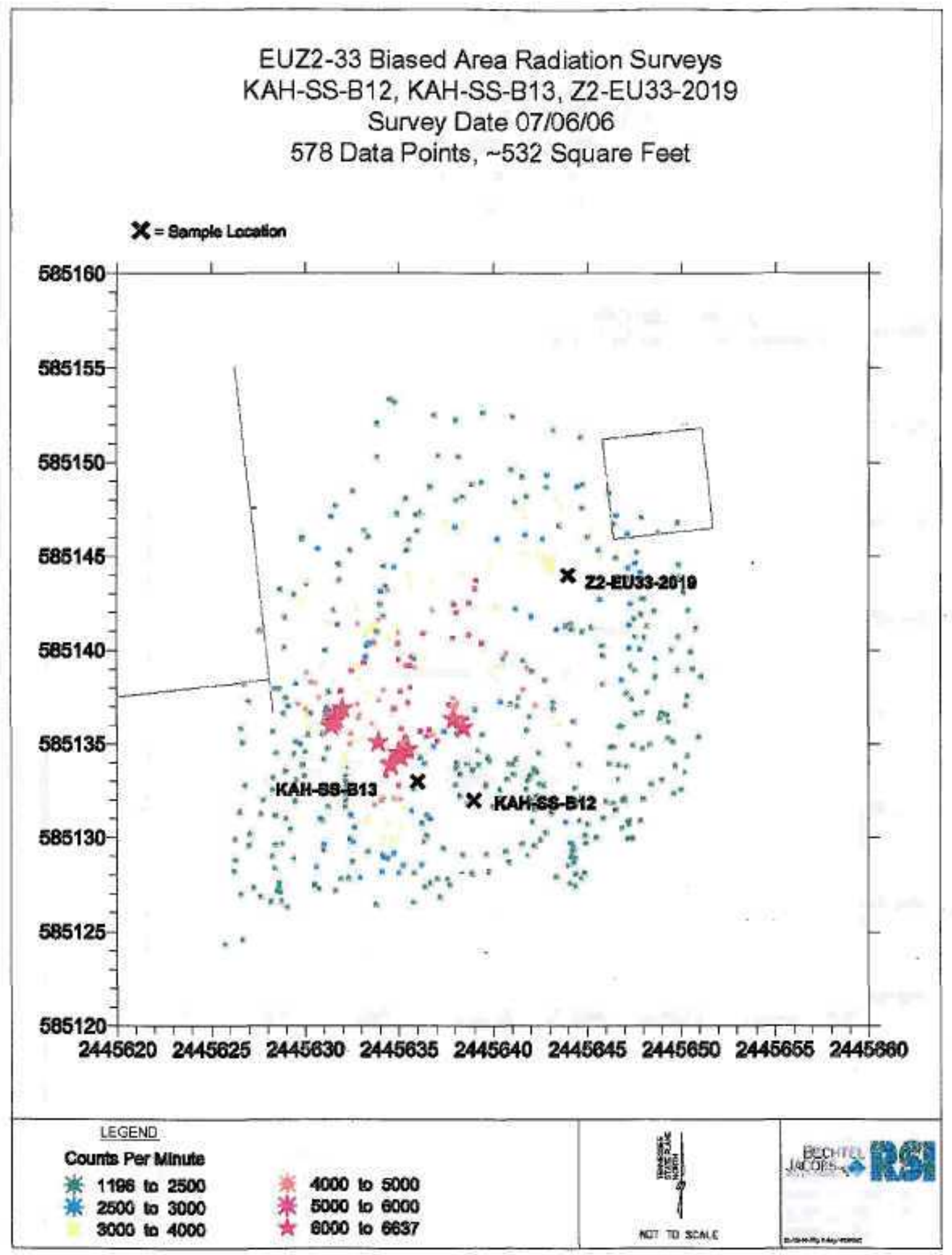

Fig. A.8. K-1015 pre-RA BAR survey results. 


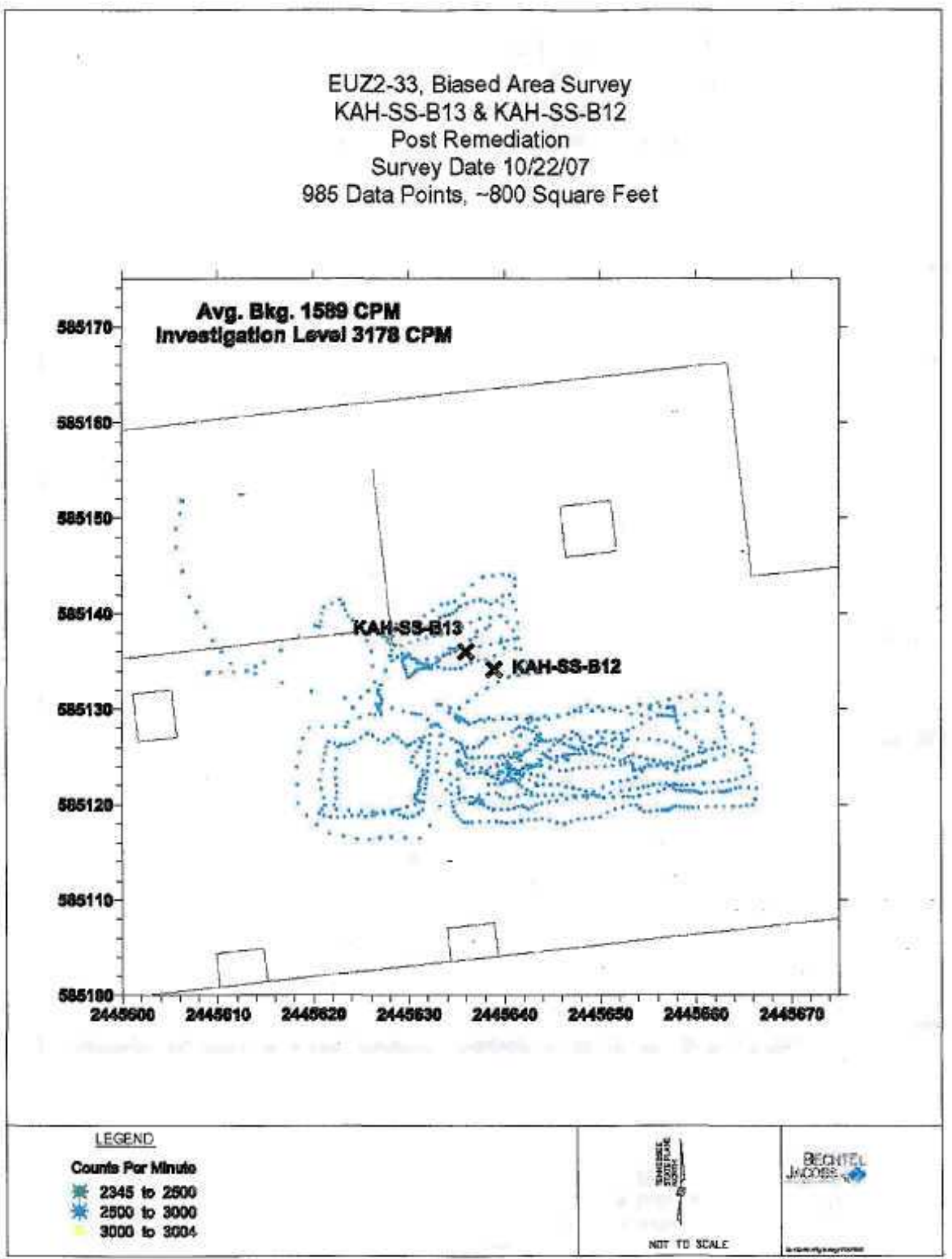

Fig. A.9. K-1015 post-RA BAR survey results. 


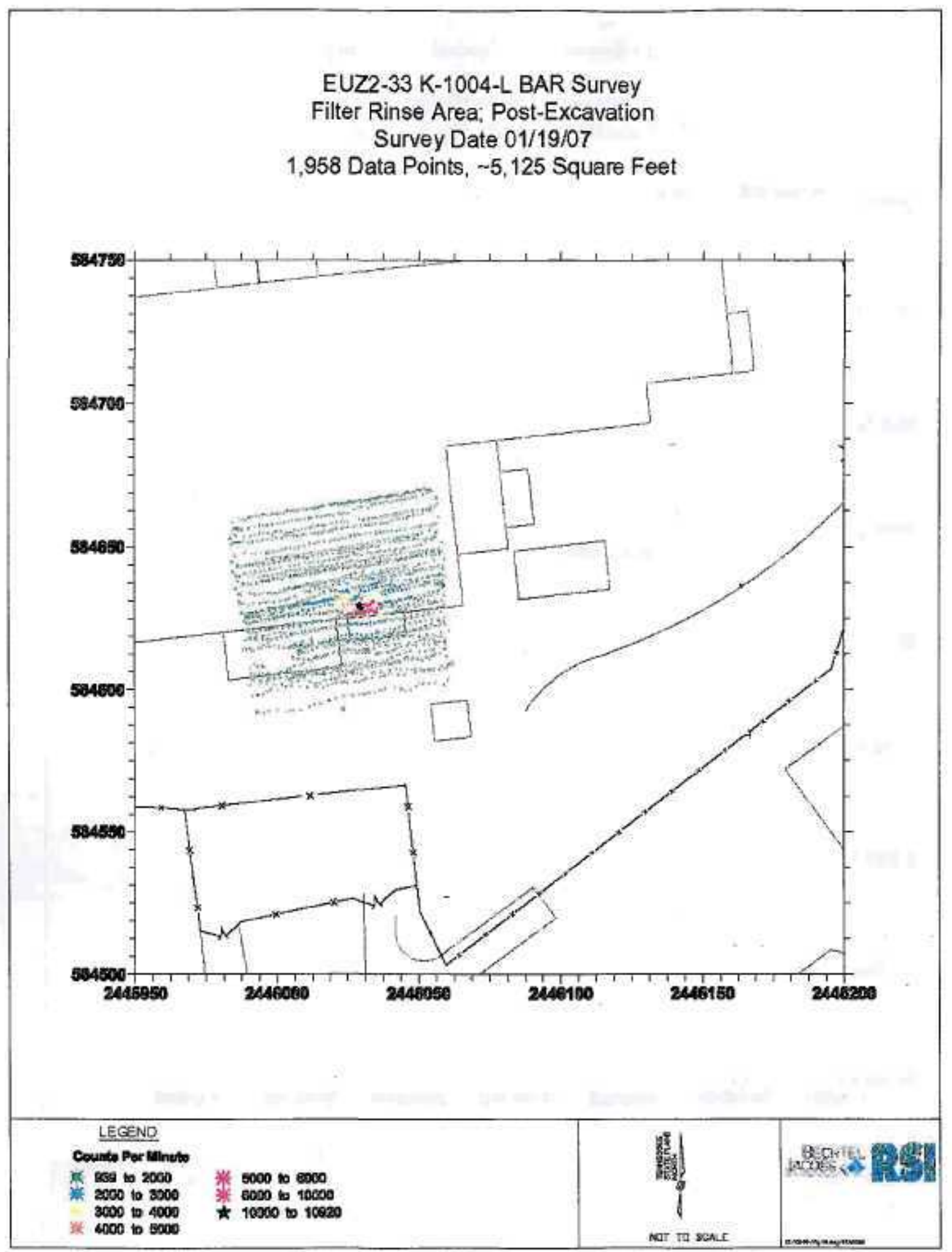

Fig. A.10. K-1004-L gravel wash area post-RA BAR survey results. 


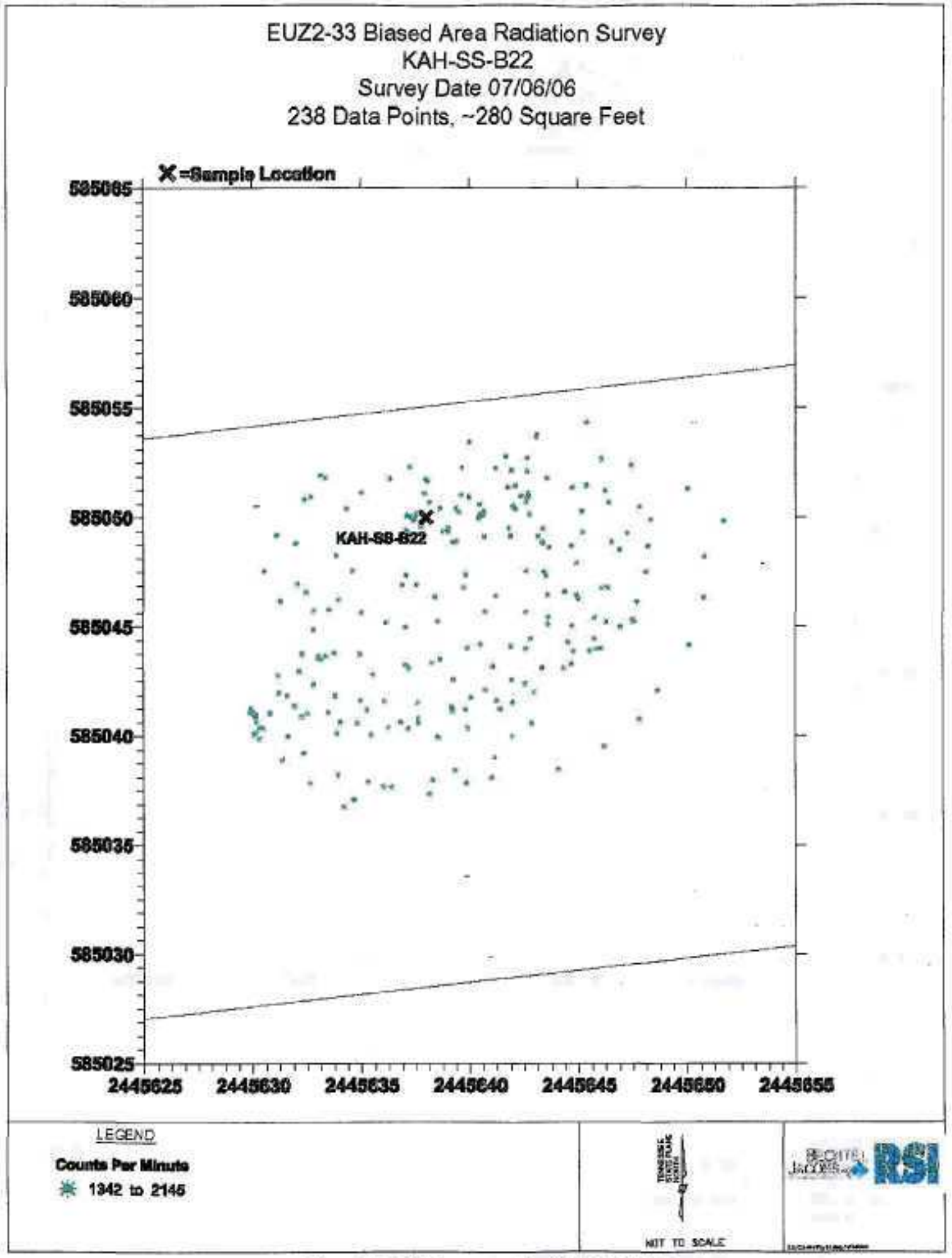

Fig. A.11. BAR survey for KAH-SS-B22. 


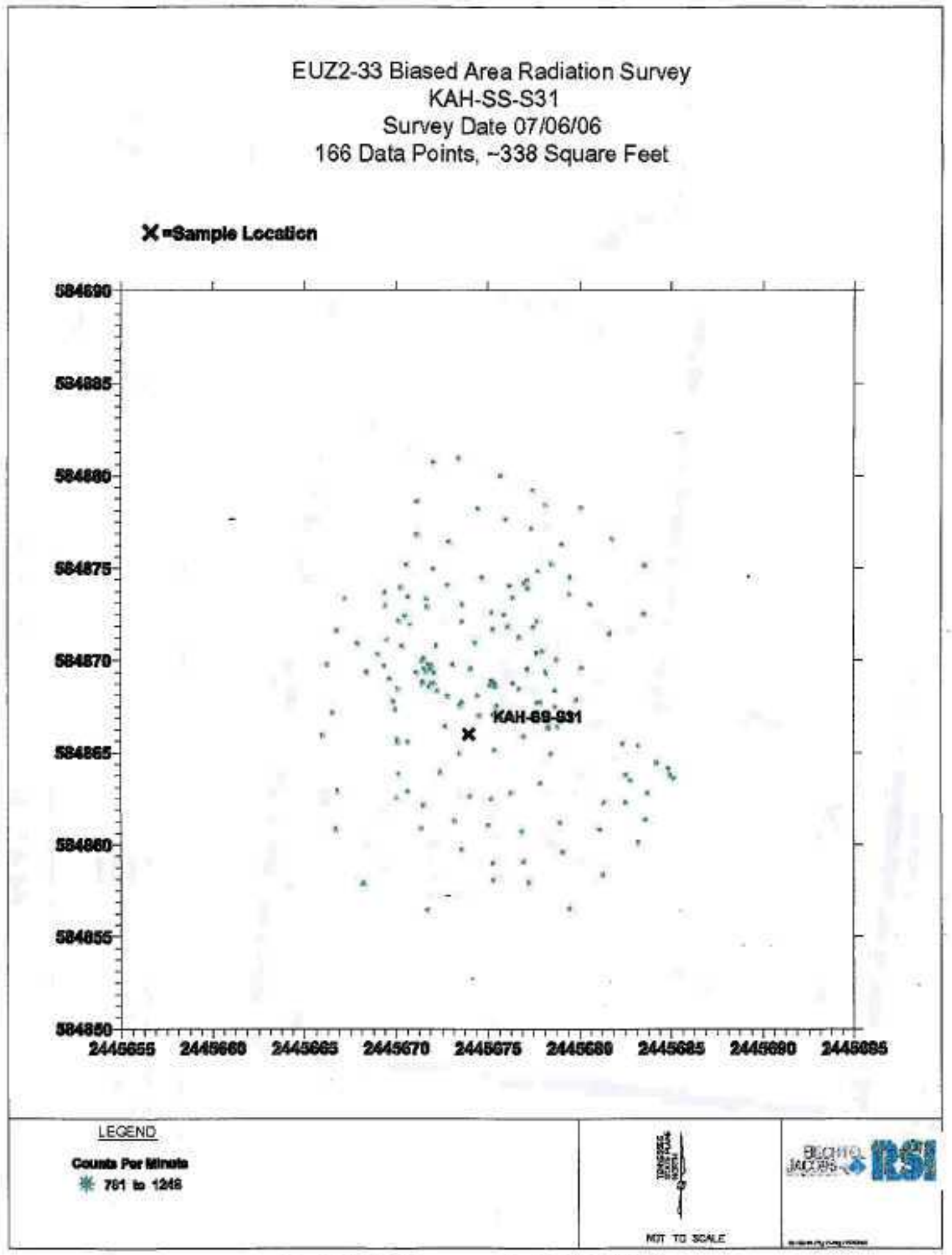

Fig. A.12. BAR survey for KAH-SS-S31. 


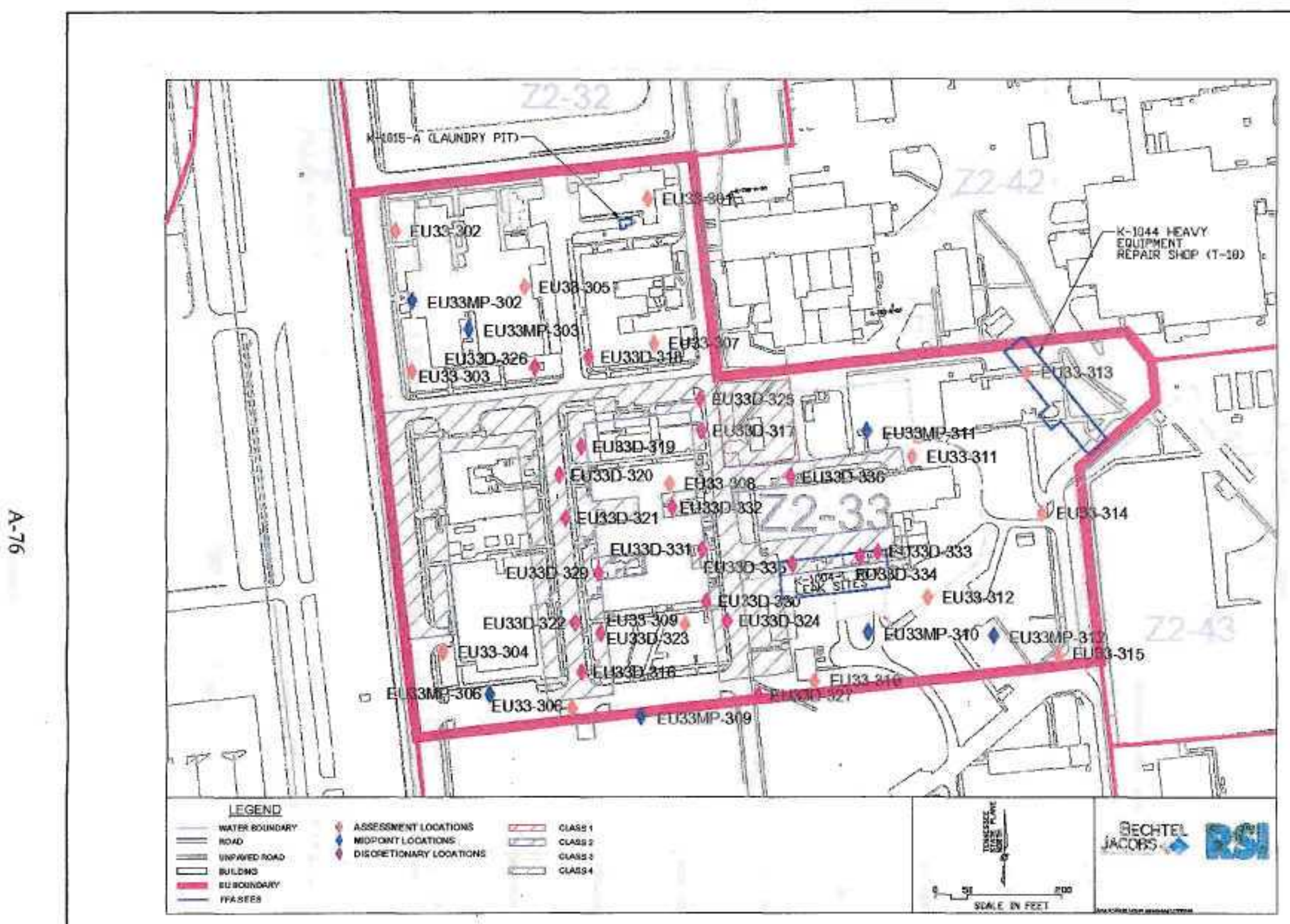

Fig. A.13. EU Z2-33 assessment locations. 


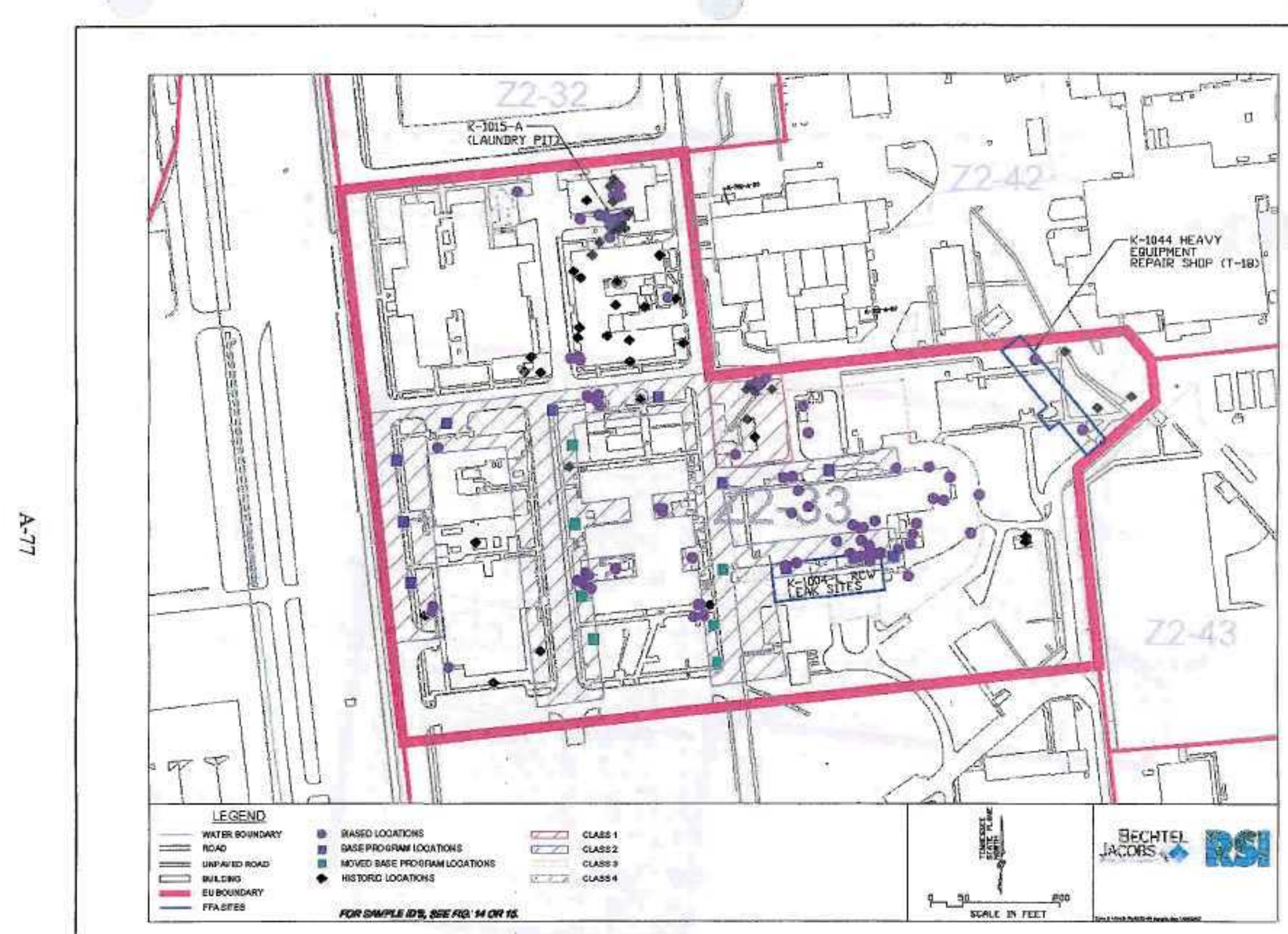

Fig. A.14. All EU Z2-33 DVS and historical sample locations from all depths. 


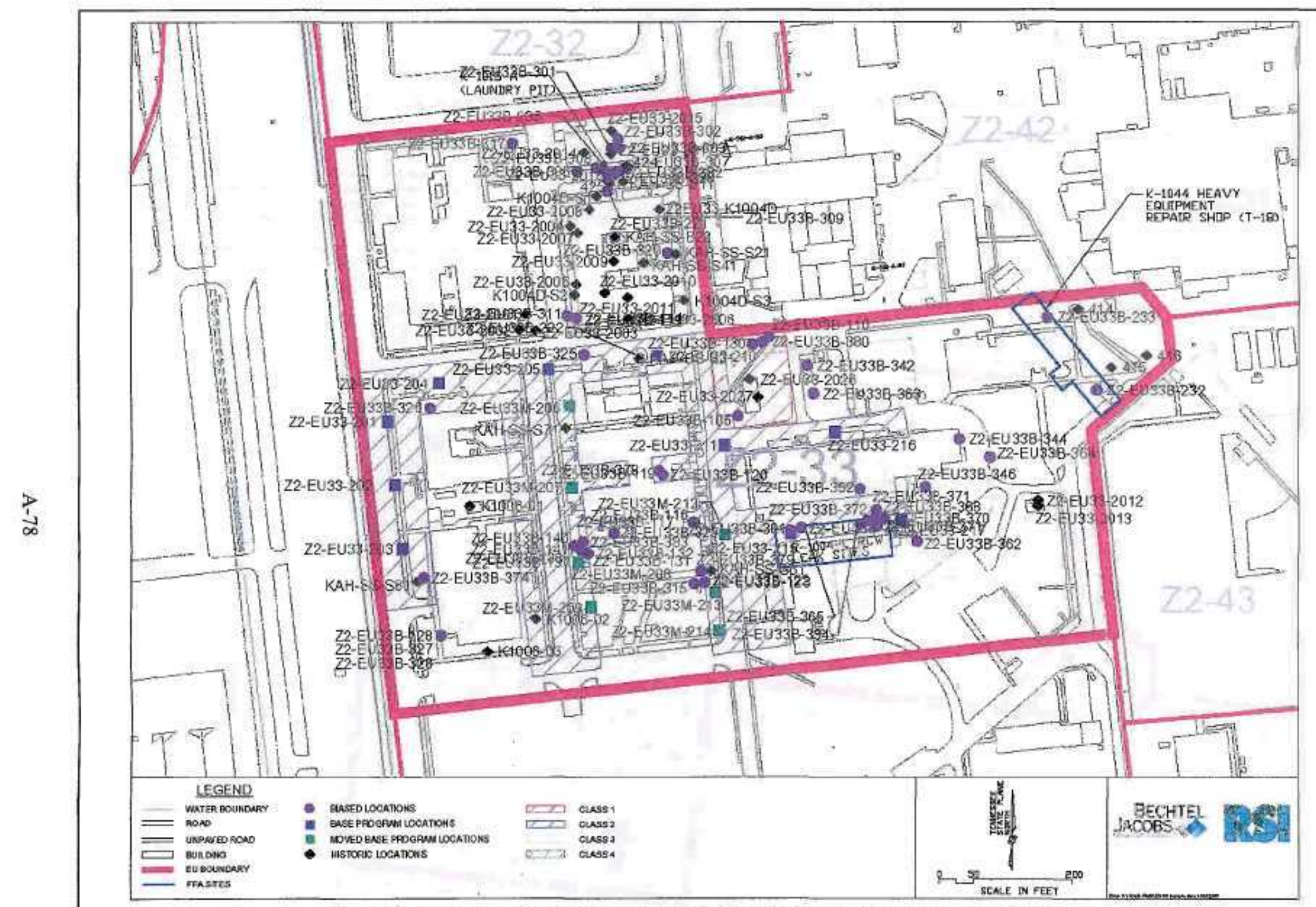

Fig. A.15. EU Z2-33 DVS and historical sample locations representative of current conditions.

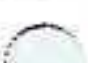




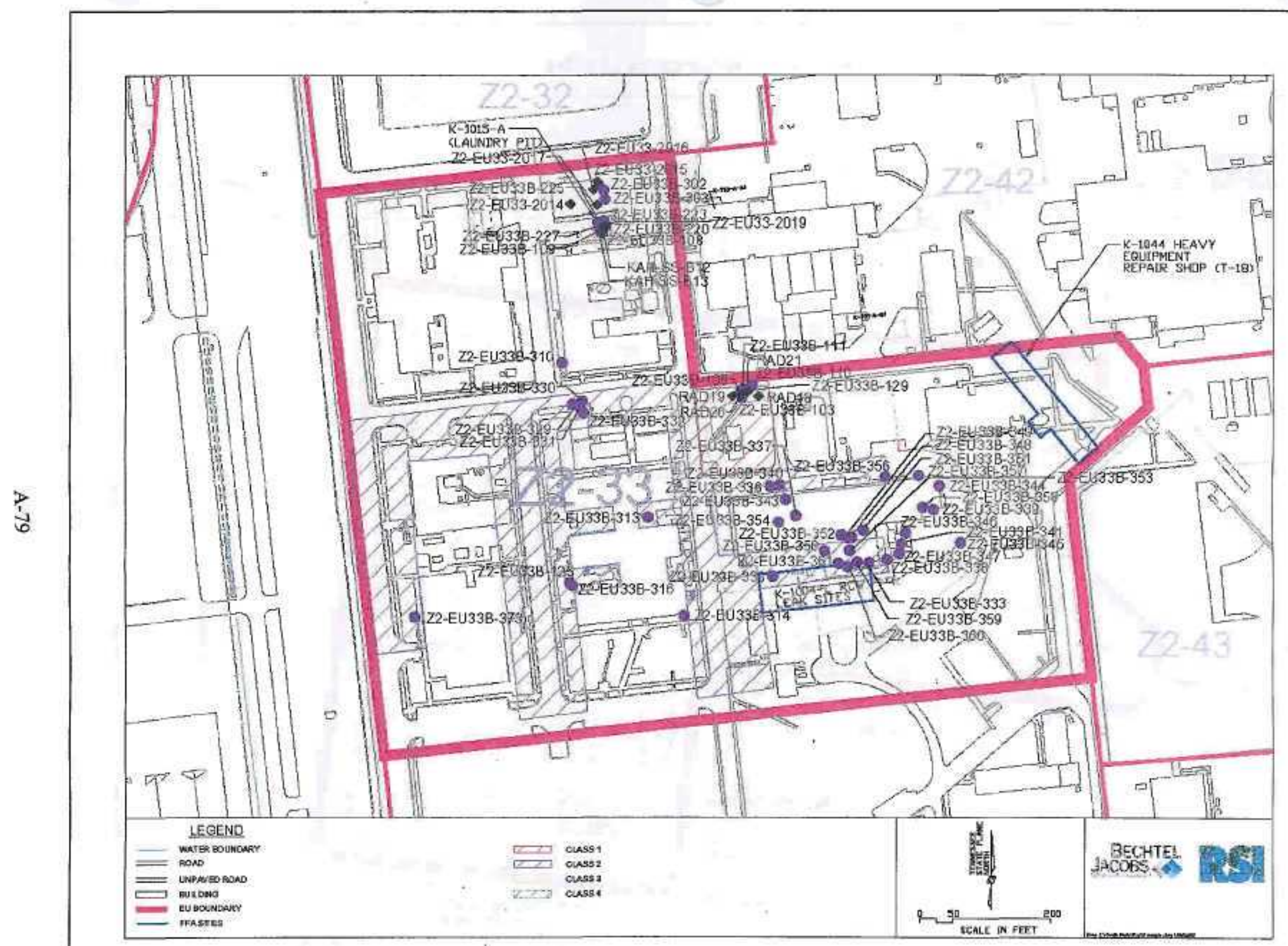

Fig. A.16. EU Z2-33 sample locations removed during a remedial action or D\&D. 


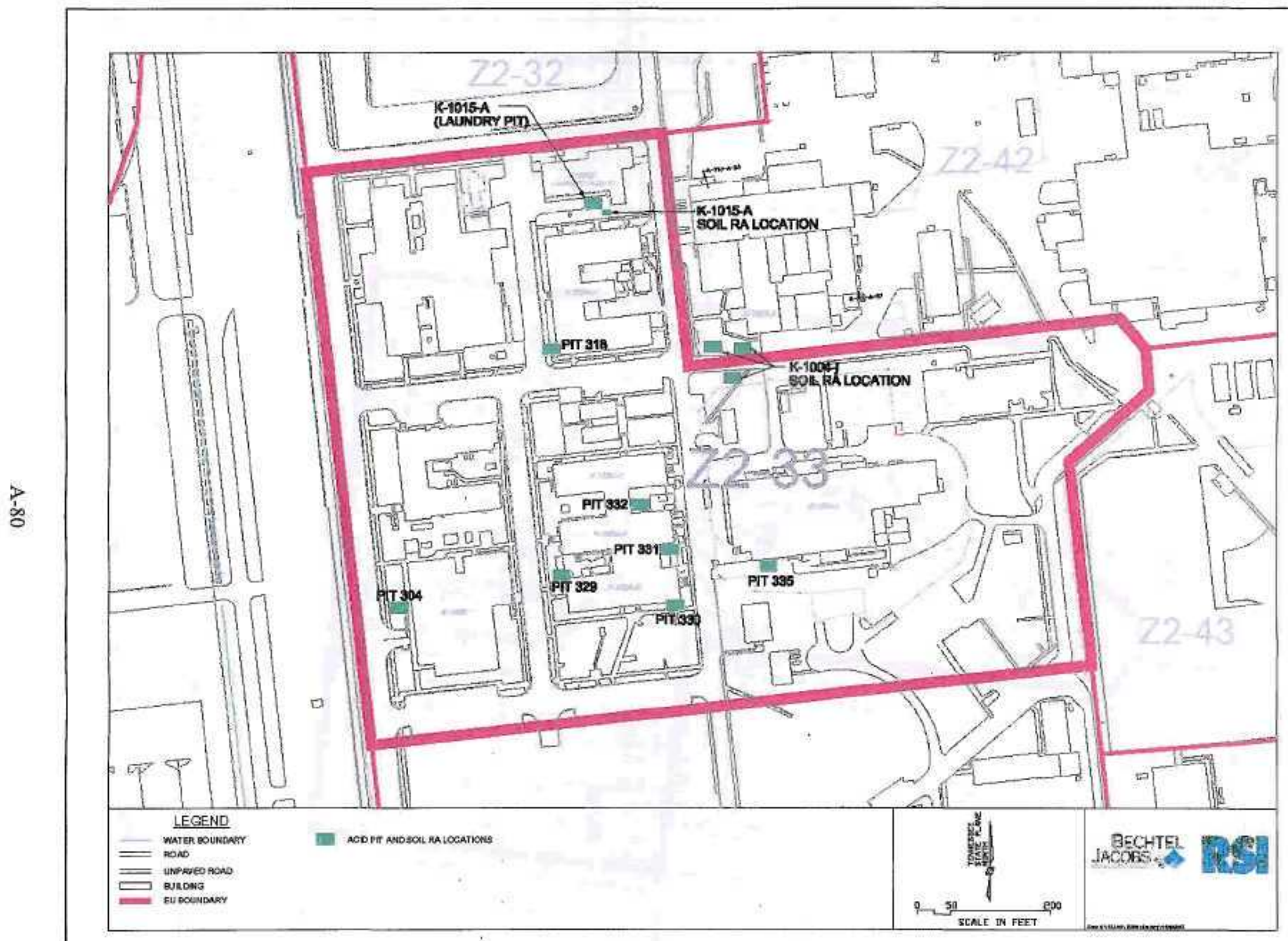

Fig. A.17. EU Z2-33 acid pit locations. 
Table A.1. EU Z2-33 facillty and FFA site list

\begin{tabular}{|c|c|c|c|}
\hline \multirow[b]{2}{*}{ Facility name DQO scoping } & \multicolumn{2}{|c|}{ Facility assessed? } & \multirow[b]{2}{*}{ Comments } \\
\hline & Yes & No & \\
\hline $\mathrm{K}-700-\mathrm{A}-13$ Substation & $\mathrm{X}$ & & \\
\hline K-700-A-15 Substation & & $\mathrm{X}$ & No longer exists \\
\hline K-700-A-16 Substation & & $\mathrm{x}$ & No lonker exists \\
\hline K-700-A-17 Substation & $\mathrm{x}$ & & \\
\hline K-700-A-26 Substationt & $\mathrm{x}$ & & \\
\hline K-700-A-50 Sabstation & $\mathrm{x}$ & & \\
\hline K-700-A- 62 Substation & $\mathrm{x}$ & & \\
\hline K-700-A-74 Substation & $\mathrm{x}$ & & \\
\hline K-1002 Cafeteria & $\mathrm{x}$ & & \\
\hline K-1003 Dispensary & $X$ & & \\
\hline K-10004-A Laboratory & & $\mathrm{x}$ & No longer exists \\
\hline K- 1004-B Laboratory & & $\mathrm{x}$ & No longer exists \\
\hline $\mathrm{K}-1004-\mathrm{C}$ Laboratory & & $\mathrm{x}$ & No longer exists \\
\hline K-J004-[D Laboratory & $\mathrm{x}$ & & \\
\hline K-]004-E Laboratory Storage Building & & $\mathrm{x}$ & No longer exists \\
\hline K-1004-F Lahoratory Storage Building & $\mathrm{X}$ & & \\
\hline K-1004-H Liquid Gas Storage Shed & & $\mathrm{x}$ & No longer exists \\
\hline K-1004-L Laboratory Pllot Plant & $\mathrm{x}$ & & Only concrete pad remains \\
\hline K-1004-L RCW Lines Leak Site & & $\mathrm{x}$ & $\begin{array}{l}\text { FFA site included in DVS systematic } \\
\text { sanpling }\end{array}$ \\
\hline K-I004-M Electrical Switchgear Room & $\mathrm{x}$ & & \\
\hline K-I004-N Cooting Tower & $\mathrm{x}$ & & Only gravel pad remains \\
\hline K-1004-P Test Facility - Isostatic & & $\mathrm{x}$ & No longer exists \\
\hline K-1004 Area Drain Line & & $\mathrm{x}$ & Included in DVS systematic sampling \\
\hline K-1006 Development Laboratory & $\mathrm{x}$ & & \\
\hline K-1006-A Cooling Tower & & $\mathrm{X}$ & No longer exists \\
\hline K-1006-C Chiller Building & $\mathrm{X}$ & & \\
\hline K-1006-D Boiler Building & $\mathrm{x}$ & & \\
\hline K-1015-A Laundry Pit & $\mathrm{x}$ & & FFA site \\
\hline K-1018 Emergency Generator Building & $\mathrm{x}$ & & \\
\hline K-1019-2B Bus Shelter & & $\mathrm{x}$ & No longer exists \\
\hline K-I028-62 Guard Portal - Portable & & $\mathrm{x}$ & No longer exists \\
\hline K-1039 Telephone Building & $x$ & & \\
\hline K-1039-1 lntegrated Communication Office & $x$ & & \\
\hline K-1044 Heavy Equipment Shop & & $\mathrm{X}$ & FFA site under Bldg. K-1225 \\
\hline K-1204-4 Sewage Ejector Station & $\mathrm{X}$ & & \\
\hline K-1205-A Condensate Station & $\mathrm{x}$ & & \\
\hline K-1225 Office Building & $\mathrm{x}$ & & \\
\hline$K=1310-C$ Office Trailer & $\mathrm{x}$ & & \\
\hline K-13]0-D Office Trailet & $\mathrm{x}$ & & \\
\hline K-1310-EE Storage Shed & & $\mathrm{x}$ & No longer exists \\
\hline K-1310-KJ Office/Break Trailer & & $\mathrm{x}$ & No longer exists \\
\hline K-1310-JC Shower Trailer & & $x$ & No longer exists \\
\hline K-1310-JJ Tech. Traiter & $\mathrm{x}$ & & \\
\hline K-1310-IN Construction Breakroom Trailer & $\mathrm{X}$ & & \\
\hline K-1310-U Storage Trailer & & $\mathrm{x}$ & No longer exists \\
\hline K-1310-JV Storage Trailer & & $x$ & No longer exists \\
\hline K-1544 Sanitary Water Meter Pit & $\mathrm{x}$ & & \\
\hline K-1546-C Office Trailer & & $\mathrm{x}$ & No longer exists \\
\hline K-1550-J Engineerng Office Trailer & & $\mathrm{x}$ & No longer exists \\
\hline K-1550-K Engineering Office Trailer & & $\mathrm{X}$ & No longer exists \\
\hline K-1550-L Engineering Office Trailey & & $\mathrm{x}$ & No longer exists \\
\hline K-1550-N Engineering Office Trailer & & $\mathrm{X}$ & No longer exists \\
\hline
\end{tabular}


Table A.1. (continued)

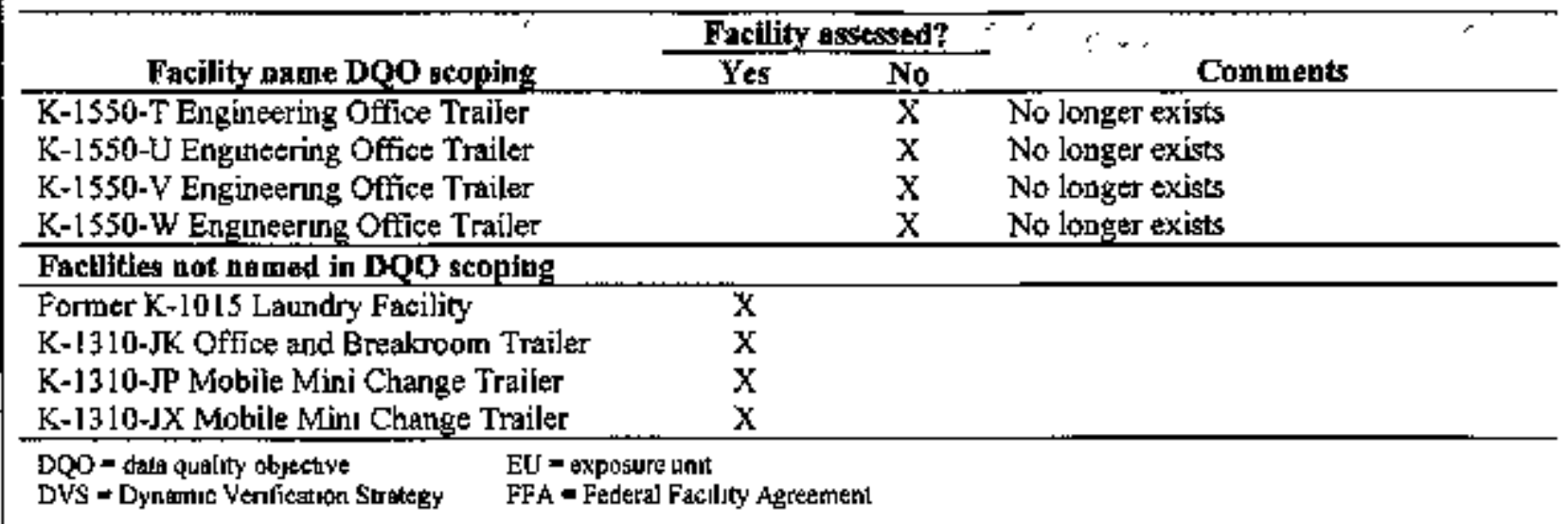


Toble A.2. EU Z2-33 sample summary

\begin{tabular}{|c|c|c|c|c|c|c|c|c|c|c|c|c|c|c|c|c|}
\hline \multirow[b]{2}{*}{ sit } & \multirow[b]{2}{*}{ 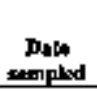 } & \multirow[b]{2}{*}{ FIU } & \multirow[b]{2}{*}{ Loendas $\mathbf{m}$} & \multicolumn{2}{|c|}{ Lonativen } & \multirow[b]{2}{*}{ 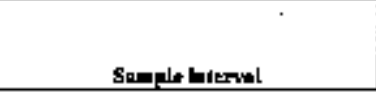 } & \multicolumn{2}{|c|}{ Sithon } & \multicolumn{7}{|c|}{ 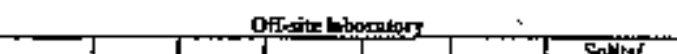 } & \multirow{2}{*}{ 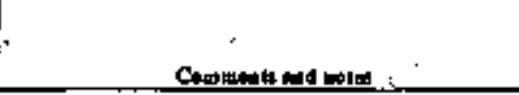 } \\
\hline & & & & Mothis. & Eatins & & RAD & voc & Koins s & PtB & RAD & swoc & woC & Oofer & 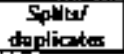 & \\
\hline \multicolumn{17}{|c|}{ DNs suples } \\
\hline 2 & 7 Thx & 27-93 & 21-EV]33-201 & $\sin \pi$ & $2+15295$ & 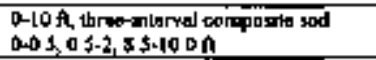 & 1 & 1 & $T$ & $\mathbf{I}$ & & $\bar{t}$ & & & & 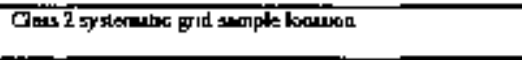 \\
\hline 3 & $\pi \operatorname{Tin}$ & $\overline{27.33}$ & $\overline{22 . E 0133-2002}$ & 596675 & 2945304 & 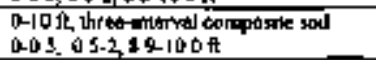 & 1 & $\mathbf{T}$ & $T$ & $\mathbf{I}$ & $T$ & $T$ & T & & D & 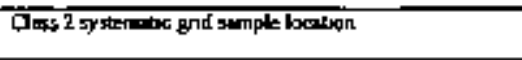 \\
\hline 2 & 71206 & $22-33$ & $22.6133-2019$ & 5305 sid & 2665315 & 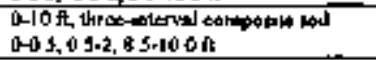 & $T$ & T & 1 & T & 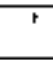 & $\mathrm{T}$ & & & & 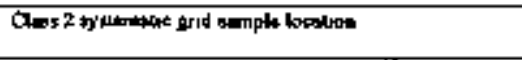 \\
\hline 2 & Thath & $23-33$ & 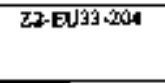 & $9 \$ 4829$ & $24 \% 53 \pi 0$ & 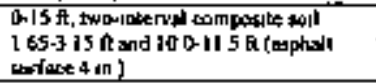 & 1 & I & 1 & 1 & & $\mathrm{~T}$ & & & & 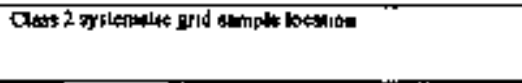 \\
\hline$\frac{1}{2}$ & TQSOE & $22-99$ & $22-E \sqrt{33-2015}$ & 534849 & $24+55 \bar{b} 6$ & 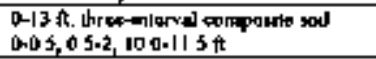 & 1 & I & 1 & $T$ & & l' & & & & 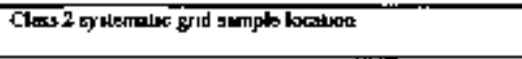 \\
\hline 2 & $\pi / 6 \sin$ & ¿3-33 & $22-0 \sqrt{35}+\mathrm{M}-206$ & $59+794$ & 2445565 & 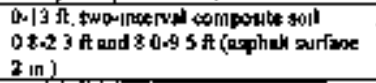 & 1 & $T$ & 1 & $T$ & & $\mathrm{I}$ & & & & 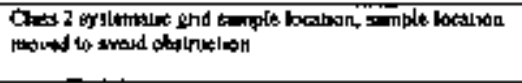 \\
\hline 2 & $7 / 6+60$ & 23.33 & 27.PLLSSM-201] & 580671 & 2445572 & 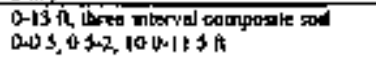 & Ti & T & $T$ & $T$ & T & $T$ & & & & 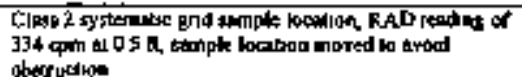 \\
\hline 2 & 176ios & $27-33$ & 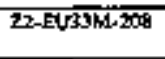 & 984535 & 2445353 & 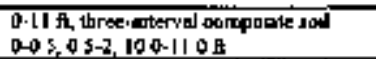 & $T$ & I & $T$ & $T$ & $\mathrm{I}$ & 1 & & & D & 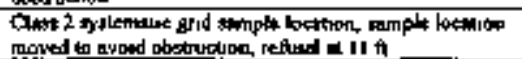 \\
\hline 2 & TFSOT6 & 22.39 & 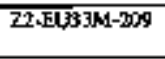 & 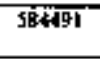 & 245601 & 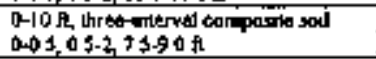 & $\mathrm{J}$ & $\mathbf{T}$ & $T$ & 1 & & $T$ & & & & 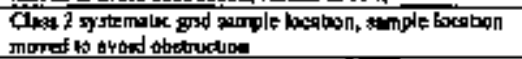 \\
\hline$\overline{2}$ & $77 \pi 6$ & $22-33$ & 22-EUT3-310 & 58689 & 244502 & 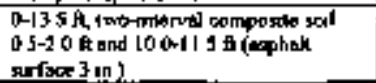 & 1 & $\mathbf{T}$ & ] & 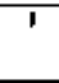 & & $T$ & & & & 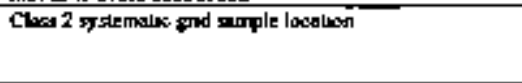 \\
\hline 2 & GHano & 25.39 & $22-5(33-211$ & 5B4735 & 2445802 & 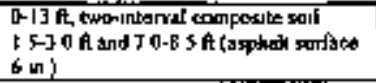 & $\mathbf{T}$ & $T$ & I & 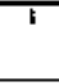 & $T$ & $T$ & 1 & & MSTMSO & 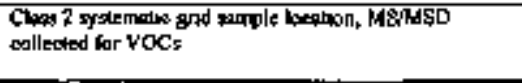 \\
\hline$\frac{1}{2}$ & की०स & 27.39 & 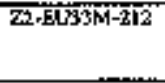 & $3+600$ & 2015BOA & 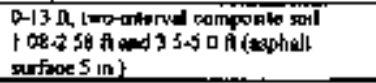 & $T$ & $\overline{3}$ & $T$ & $\mathbf{T}$ & $T$ & $\mathrm{t}$ & & & & 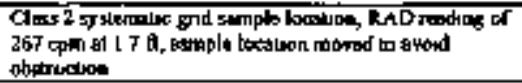 \\
\hline 2 & $7 / 3 \$ 05$ & $22-33$ & 27-EOP3M-213 & SSAst3 & 244580 & 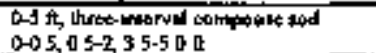 & $T$ & $\pi$ & $T$ & T & & $T$ & & & & 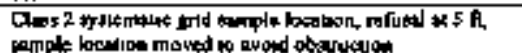 \\
\hline $\mathbf{z}$ & 5/406 & $22-33$ & $22-E U \$ 3)-214$ & t84asta & 2445794 & 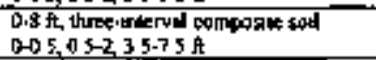 & 1 & 9 & 1 & $T$ & & $\mathbf{T}$ & & & & 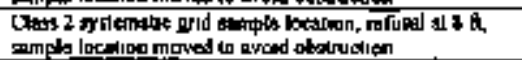 \\
\hline 2 & $\overline{10 B}$ & 22.33 & 22-E[ज]-2]5 & 584601 & $24+5906$ & 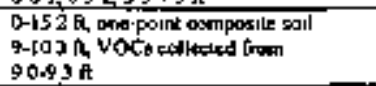 & $T$ & $\mathrm{~J}$ & $T$ & $T$ & & $\hat{t}$ & 1 & & & 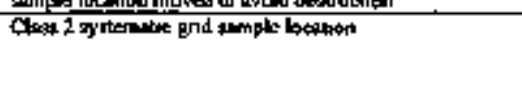 \\
\hline 2 & Itidet & $23-33$ & $22-60133.216$ & Istris & $34596 \%$ & 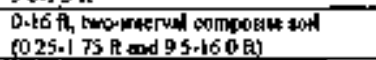 & $T$ & $\mathrm{t}$ & l & 1 & & t & & & $s$ & 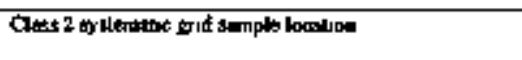 \\
\hline $\mathbf{z}$ & JÜSTÉ & 22.33 & $72.81033-217$ & 594621 & $\operatorname{sen} 0 \sec x$ & 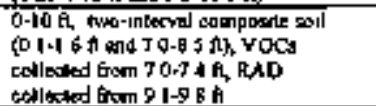 & $T$ & $T$ & 1 & I & T & $\mathbf{I}$ & 1 & & 8 & 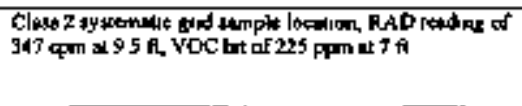 \\
\hline
\end{tabular}




\begin{tabular}{|c|c|c|c|c|c|c|c|c|c|c|c|c|c|c|c|c|}
\hline \multirow[b]{3}{*}{$\begin{array}{l}\text { So } \\
\text { dan }\end{array}$} & \multicolumn{16}{|c|}{ Tiple A2 (conctinued) } \\
\hline & \multirow{2}{*}{ 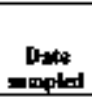 } & \multirow{2}{*}{$\mathbf{w}$} & & \multicolumn{2}{|c|}{ Leather } & \multirow{2}{*}{ Sample biorenal } & \multicolumn{2}{|c|}{ Stapalies } & \multicolumn{7}{|c|}{$\therefore$} & \multirow[b]{2}{*}{ 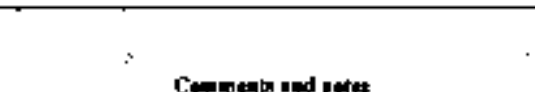 } \\
\hline & & & & Mettice & Sostiog & & $\mathbf{M A P}$ & voc & Mrotedi & $\mathrm{CCB}$ & xan & svoce & yoc & Otter & Splition & \\
\hline & & & 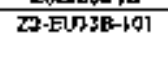 & seres & & Proped & & & & & & & isc & & & 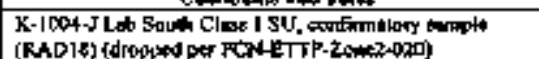 \\
\hline $\mathrm{t}$ & & & $2-\mathrm{E}[\mathrm{n3} 3 \mathrm{~B}-102$ & & & Dropedat & & & & & & & & & & 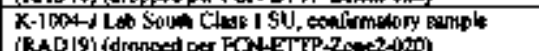 \\
\hline 1 & 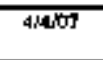 & 22.33 & $27-61038-103$ & 534679 & 2445894 & 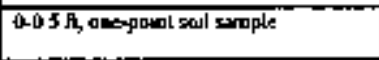 & & דו & & & $T$ & & & & & 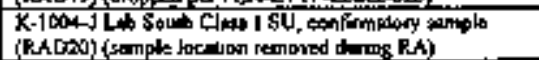 \\
\hline 1 & & & $23-E 0336-194$ & & & Droppest & & & & & & & & & & - \\
\hline $\mathrm{t}$ & $9 / 26066$ & 22.33 & Z2-EUt3B-i0s & 584778 & 2445823 & 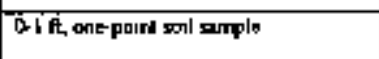 & & $\mathrm{T}$ & & & $T^{3}$ & & & & & 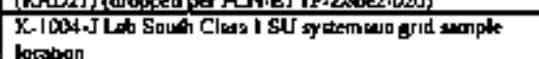 \\
\hline 1 & $\mathbf{d}(40,03$ & 222.37 & 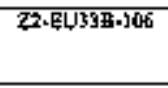 & Statikg & $24 \times 5832$ & 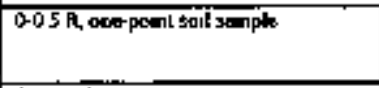 & $T$ & $T$ & & & $T$ & & & & & 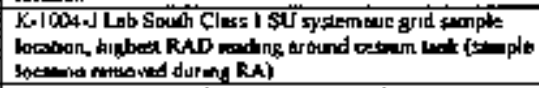 \\
\hline 1 & & & 22-EN33B-107 & & & mopoped & & & & & & & & & & 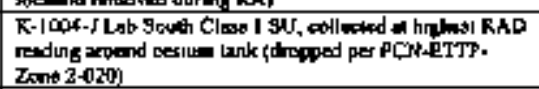 \\
\hline 1 & 7 7ow6 & 27.37 & Z2-EJJ338-100 & 585132 & 7403653 & 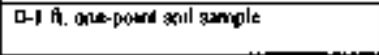 & & $T$ & & & 1 & & & & & 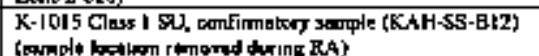 \\
\hline 1 & $7 / 0006$ & 22.37 & $22-E \mathrm{EN} 33 \mathrm{~B}-109$ & 365137 & 2445637 & D. I ilh ons poinl soll sompte & & $\mathrm{T}$ & & & $T$ & & & & & 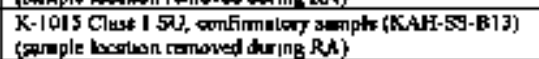 \\
\hline 3 & N1507 & $22: \cdot 33^{3}$ & $27-[]_{3} 33 \mathrm{~B}-1 / 3$ & sta929 & $24+155 \%$ & 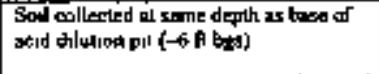 & $T$ & $\mathrm{~T}$ & $T$ & $T$ & 1 & $T$ & $T$ & & & 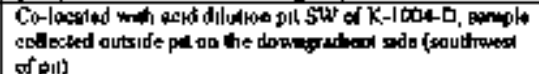 \\
\hline 3 & $A(1007$ & $27-37$ & $22-E N 333 B-1 / 4$ & 27A92T & 2405198 & 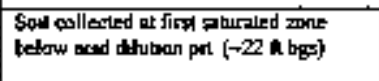 & $T$ & I & $\mathrm{t}$ & $\mathrm{T}$ & I & 1 & 1 & & $\$$ & 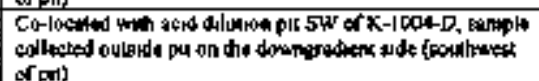 \\
\hline 5 & Wt:k07 & $22: 93$ & 22-Eப53B-16 & $58+6|t|$ & 2445736 & 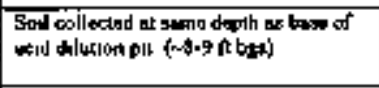 & $T$ & $T$ & $T$ & $T$ & $T$ & $T$ & J & & & 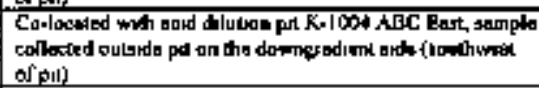 \\
\hline 3 & 41707 & $22-33$ & 22 -EU338-117 & 584618 & $24+5936$ & 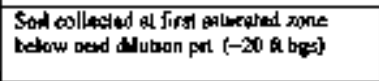 & 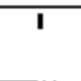 & $T$ & $\mathrm{t}$ & 1 & 1 & 1 & 1 & & & 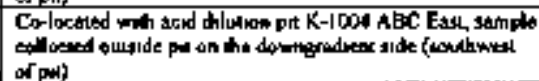 \\
\hline 1 & $4 / 1807$ & 22.33 & 72. EU:3B.119 & 584696 & 2445709 & 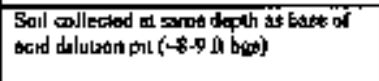 & 1 & $T$ & J & $T$ & $T$ & $T$ & $\pi$ & & & 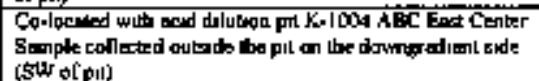 \\
\hline$\overline{3}$ & $N^{\prime \prime} 1307$ & $22-33$ & 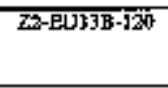 & $5 \neq 4650$ & 24157989 & 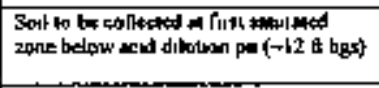 & $T$ & $t$ & $\mathrm{~T}$ & 1 & $T$ & $T$ & $\mathrm{~J}$ & & & 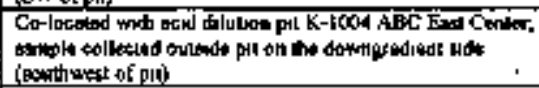 \\
\hline 3 & Altwom & 72.33 & 22-EU\}3G-1212 & 3EAS2t & 2445794 & 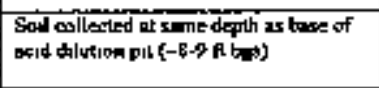 & I & I & $T$ & T. & I & $T$ & 1 & & & 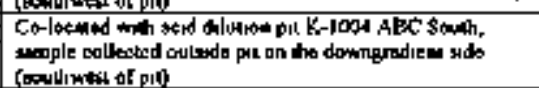 \\
\hline 3 & 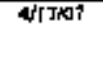 & $22-33$ & Z2-ELJ33B-123 & P्A52x & 2405774 & 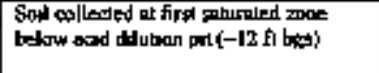 & $\mathrm{I}$ & 1 & $\mathrm{l}$ & 1 & 1 & 1 & 1 & & & 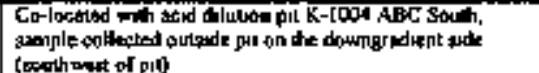 \\
\hline 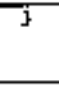 & $4 / 1367$ & $22-33$ & 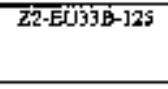 & SEASPS & 24+55s? & 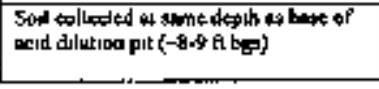 & $T$ & $T$ & $t$ & $T$ & $T$ & $T$ & $\mathrm{~J}$ & & & 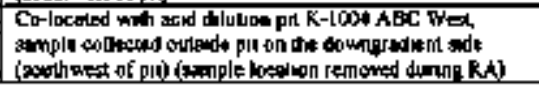 \\
\hline
\end{tabular}


Toble A.2, (conlinneds)

\begin{tabular}{|c|c|c|c|c|c|c|c|c|c|c|c|c|c|c|c|c|}
\hline \multirow[b]{2}{*}{$\begin{array}{l}80 \\
\text { daten }\end{array}$} & \multirow[b]{2}{*}{ Date } & \multirow[b]{2}{*}{ ET } & \multirow[b]{2}{*}{ laeallin DD } & \multicolumn{2}{|c|}{ lacention } & \multirow[b]{2}{*}{ 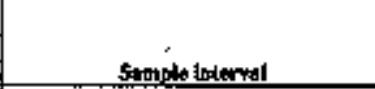 } & \multicolumn{2}{|c|}{ Sareennim } & \multicolumn{7}{|c|}{ 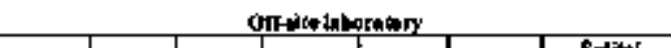 } & \multirow{2}{*}{ " Conerentemed moln } \\
\hline & & & & Nerthiog & Entin: & & RAD & YOC: & Meten & PCP & RAD & spoc & woc & onther. & 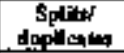 & \\
\hline 3 & Wron? & 22-93 & 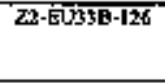 & 554595 & $34+5589$ & 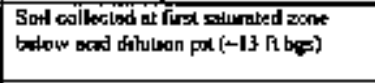 & 1 & $i$ & $\frac{1}{1}$ & 1 & 1 & $T$ & $\mathrm{l}$ & & & 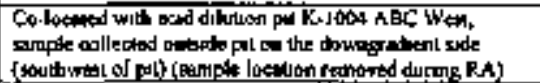 \\
\hline $\overrightarrow{9}$ & Ang & $2-33$ & 2Z-EU33B-I28 & 584448 & 2615374 & Grab tandith & & $\mathbf{I}$ & & & 1 & & & & & 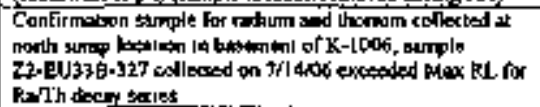 \\
\hline$T$ & 4400 & 22-33 & $\overline{Z 2-E C 3 B-12 \overline{9}}$ & 584891 & 7455855 & 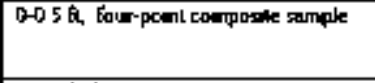 & & $\mathbf{T}$ & $\mathrm{J}$ & T & $T_{1}$ & $\mathrm{t}$ & i & & $\mathbf{D}$ & 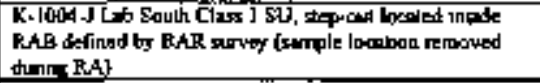 \\
\hline$T$ & WhisT & $22-33$ & 20-EUSB-130 & $53 \times 697$ & 2465843 & 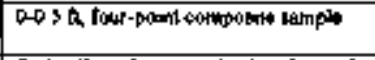 & & $T$ & & & $T$ & & & & & 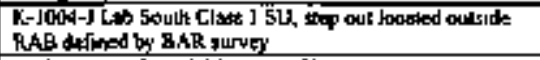 \\
\hline 3 & Stlistit & 22.15 & 2 23-EU33B-|3| & SeASti & 2445597 & 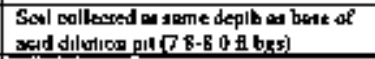 & & $T$ & & & & & $\mathrm{~T}$ & & & 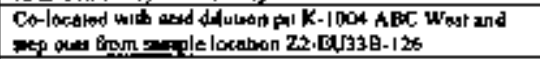 \\
\hline 3 & जille? & $\overline{Z 2-33}$ & 22 -EU99E-132 & 584571 & 245359 & 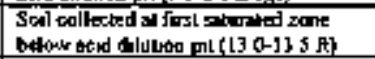 & & $T$ & & & & & $T$ & & D & 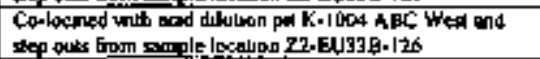 \\
\hline 3 & 51007 & $27-33$ & $22-6033 \mathrm{~B}-137$ & 584577 & J45SBE & 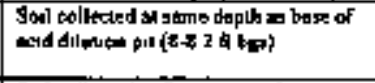 & & 1 & & & & & $\mathbf{I}$ & & & 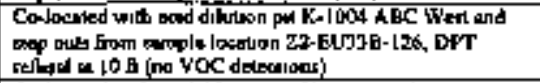 \\
\hline 3 & $5 / 1007$ & 20,53 & 22 Eख/39E.]38 & 584517 & $24+5386$ & 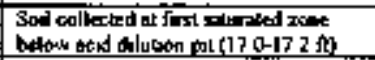 & & 1 & & & & & $T$ & & & 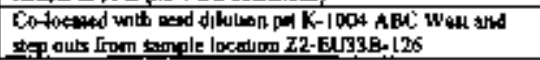 \\
\hline 3 & $\sin x=$ & 츄-53 & 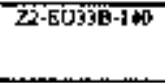 & 384583 & 245576 & 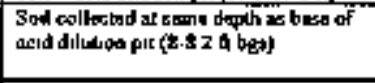 & & $T$ & & & & & $\mathrm{~T}$ & & & 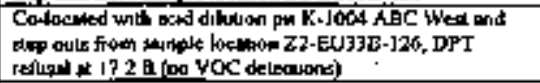 \\
\hline 3 & S/1047 & 2031 & 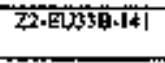 & 584583 & 2क्य5576 & 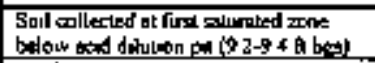 & & $T$ & & & & & $T$ & & & 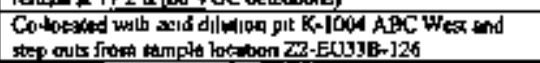 \\
\hline 1 & HLL̈ & $\mathrm{Z}^{-j-j]}$ & $\overline{\mathrm{z}}-\overline{\mathrm{E}} \mathrm{d} 3 \mathrm{BB}-2 \mathrm{2N0}$ & $5 B 5] 42$ & $24+56+4$ & 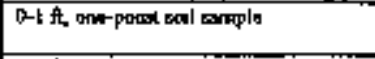 & $\mathrm{J}$ & $\mathbf{T}$ & & & $T$ & & & & & 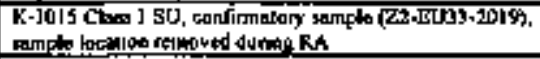 \\
\hline 2 & $7 / \sqrt{1 \times 6}$ & $222-33$ & 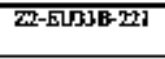 & 585050 & $34+5638$ & 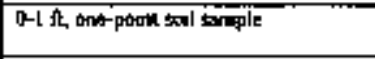 & 1 & $\mathbf{T}$ & & & 1 & & & & & 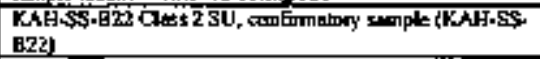 \\
\hline$\overline{2}$ & 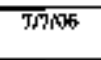 & $22-33$ & Z2-ECS3E-2n2 & 584866 & $24656 \mathrm{~T} 4$ & 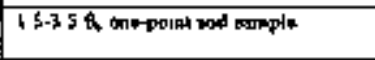 & 1 & 1 & & & $\mathbf{l}$ & & & & & 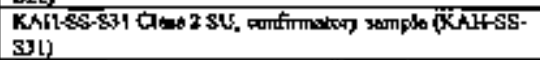 \\
\hline$\overline{3}$ & T5507 & $22-33$ & $28-E U 338-223$ & 575150 & 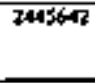 & 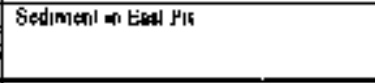 & & 1 & $\mathrm{~T}$ & $\mathbf{T}$ & 2 & & & & & 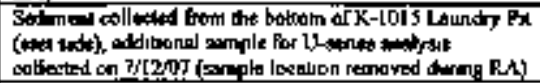 \\
\hline 7 & $25+07$ & $27-13$ & $27-[0130.229$ & 565146 & $\overline{245632}$ & 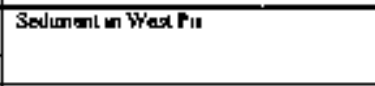 & & $T$ & $T$ & T & 2 & & & & & 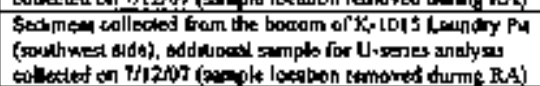 \\
\hline 3 & $45 \times 1$ & $22-33$ & $27-8 d, 3,8-227$ & 刺|41 & 243645 & 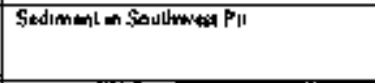 & & 1 & I & $!$ & 2 & & & & & 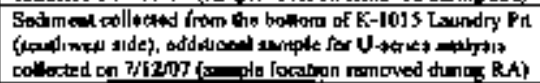 \\
\hline 3 & काज्ञा? & $20-33$ & 72-EU339-229 & 585139 & 24565 & 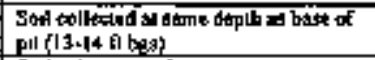 & $T$ & 3 & $T$ & $T$ & $T$ & & $T$ & & & 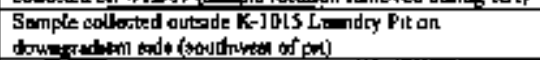 \\
\hline$\overline{3}$ & सारण & $22-33$ & ZD-EUJ3B-320 & $\$ 75139$ & 244657 & 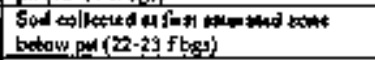 & $T$ & $\mathrm{a}$ & $\mathrm{T}$ & $\mathbf{T}$ & I & & $T$ & & & 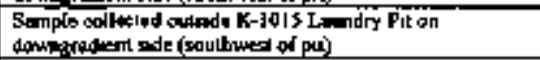 \\
\hline 3 & $4[3 \times 0]$ & 20.31 & 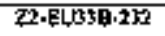 & $\operatorname{sen} 4 \mid \frac{1}{2}$ & $2 \pi+6364$ & D-10 fi, trete-intaval cosmpessile ample & $T$ & T & 1 & $\mathbf{T}$ & & T & & & to & K-1044 LPA SILF \\
\hline
\end{tabular}




\begin{tabular}{|c|c|c|c|c|c|c|c|c|c|c|c|c|c|c|c|c|}
\hline \multicolumn{17}{|c|}{ Table A.2. (continued) } \\
\hline \multirow{2}{*}{$\begin{array}{c}\text { so } \\
\text { das }\end{array}$} & \multirow{2}{*}{ 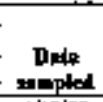 } & \multirow[b]{2}{*}{$\mathbf{E}$} & \multirow[b]{2}{*}{ Eocebou $\mathbf{m}$} & \multicolumn{2}{|c|}{ Loenioge } & \multirow[b]{2}{*}{ Suople Golurval } & \multicolumn{2}{|c|}{ Sangen } & \multicolumn{7}{|c|}{ 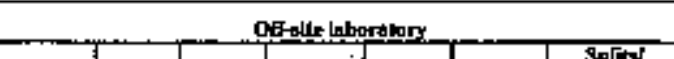 } & \multirow{2}{*}{ 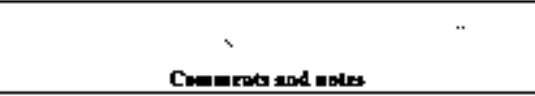 } \\
\hline & & & & Norting & Testios & & RAM & Yoc & Mesth & $\mathbf{F C B}$ & RAD & sroc: & voc & Olnew & 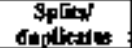 & \\
\hline & & $22-33$ & $27 \pm 0738-233$ & $5 \$ 20$ & $24+6250$ & 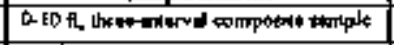 & 1 & 1 & 1 & 1 & & 1 & & & & R-104+FRA Silk \\
\hline $\mathrm{J}$ & $7 / 1 \mathrm{BOT}$ & 27.93 & T2-8US3B-235 & 585151 & 2445620 & Solid sample from Mranbole ST & & & & $T$ & 1 & & & & & 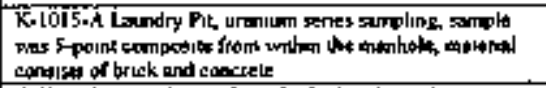 \\
\hline 3 & $T / 2606$ & 22-33 & $23-20038-30]$ & 535184 & 24,9692 & 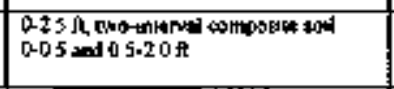 & $T$ & $T$ & & & $\mathbf{I}$ & & & & & 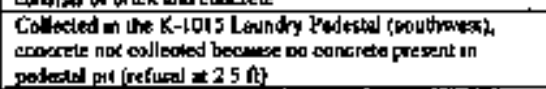 \\
\hline 1 & T/2606 & 27,31 & 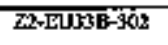 & $5 \$ 519 \pi$ & $24+565+1$ & 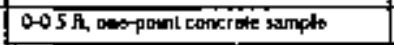 & & & & & $T$ & & & & & 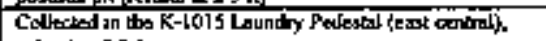 \\
\hline & & & & & & 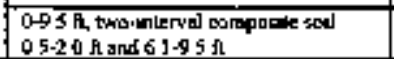 & $\overline{1}$ & $T$ & & & 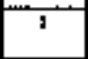 & & & & & retusal at $95 \mathrm{n}$ \\
\hline 1 & $7 / 2806$ & 22.31 & 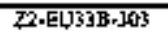 & 585LI8A & $2456+3$ & 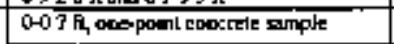 & & & & & $T$ & & & & & 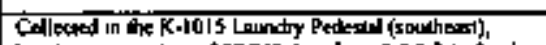 \\
\hline & & & & & & 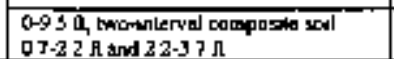 & I & 1 & & & 1 & & & & & 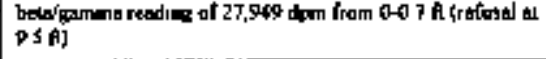 \\
\hline$T$ & 710\%5 - & $\frac{27.35}{23}$ & 22-EU33B.516 & $\mathbf{5 8 5 1 4 8}$ & 2445580 & 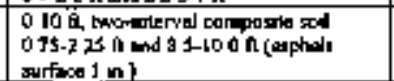 & $T$ & 1 & 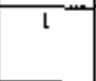 & $\mathrm{t}$ & 1 & $T^{-}$ & & & & 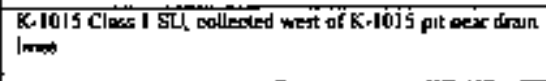 \\
\hline 1 & 701006 & 21,31 & Z27.E[15]6-907 & $\$ \$ 5154$ & $2+15652$ & 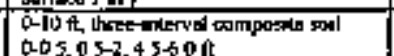 & $T$ & 5 & $T$ & T & 1 & 1 & & & & 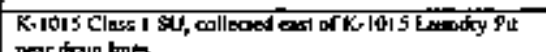 \\
\hline 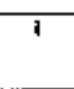 & 7 than 6 & 22:-33 & E2-EUY3E-30B & 585154 & 2401605 & 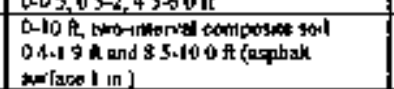 & 1 & $\mathrm{t}$ & 1 & & $\mathrm{~T}$ & & & & & 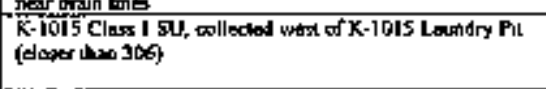 \\
\hline $\mathrm{T}$ & $7 / 106$ & 22:31 & $72 \cdot 5033 \mathrm{~B} \cdot 309$ & 5\$5ाi9 & 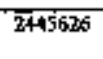 & 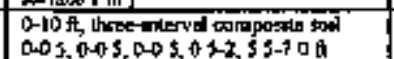 & $T$ & 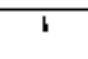 & 1 & & $T$ & & & & & 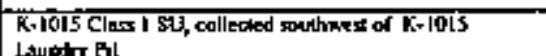 \\
\hline I & $6292966^{\circ}$ & 22-3] & Z2-EU\}SB-3in & $57+9933$ & 240 SST & 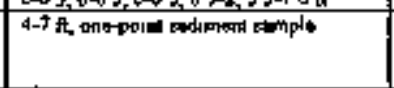 & & 1 & 1 & 1 & $\mathbf{T}$ & 1 & 3 & & & 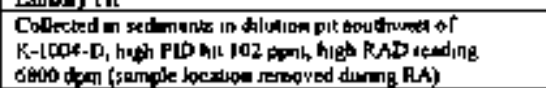 \\
\hline 1 & & $22-37$ & $22-\varepsilon U, 36-312$ & & & Nox solllased & & & & & & & & & & 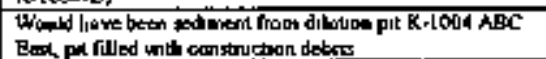 \\
\hline 3 & 7RGA & 22.31 & $22 \cdot E$ [353B:-133 & $5+5695$ & 245970 & 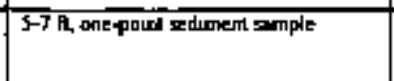 & & $T$ & $T$ & 1 & 1 & $t$ & 1 & & & 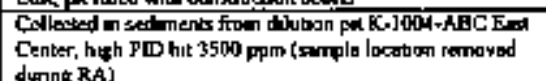 \\
\hline $\mathrm{s}$ & $628 \times 106$ & $22-33$ & Z2-EJJ38-3/4 & SEAS43 & 724575s & 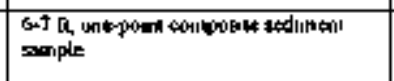 & & 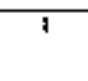 & 1 & $\mathrm{l}$ & 1 & 1 & 1 & & & 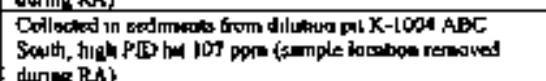 \\
\hline$\overline{3}$ & $7 \sin 6$ & 22,53 & 27.EU93B-315 & 584526 & 2445758 & 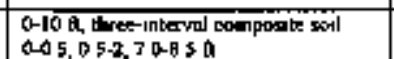 & $t$ & 1 & $\mathrm{t}$ & $T$ & $T$ & $T$ & $T$ & & $\bar{s}$ & 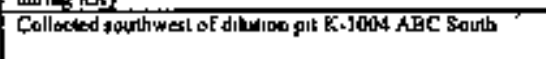 \\
\hline 3 & 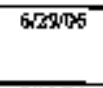 & $22 \cdot 33$ & Z2-Eं & 584591 & 2445593 & 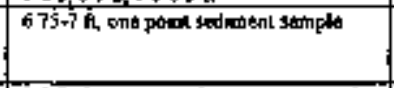 & & 1 & 1 & $T$ & T & $T$ & $T$ & & & 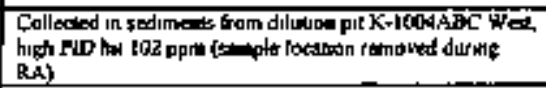 \\
\hline 3 & $2 \pi 12 \times 6-6$ & 22,33 & 22.EU39D.137? & 585591 & $24+5431$ & 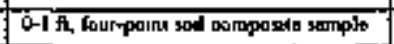 & & $T$ & & $i$ & & & & & & 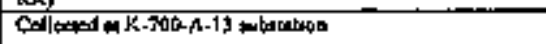 \\
\hline 1 & 7MाNO & $22-33$ & 27-EU33B.220 & 5850125 & 244577 & 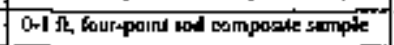 & $\overline{1}$ & $T$ & & $T$ & & & & & & 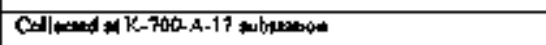 \\
\hline 1 & 77706 & 2233 & 22.805393232 & 581602 & $24+15636$ & 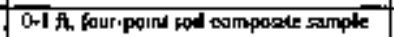 & & 1 & & $\mathrm{~T}$ & & & & & & 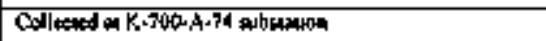 \\
\hline
\end{tabular}




\begin{tabular}{|c|c|c|c|c|c|c|c|c|c|c|c|c|c|c|c|c|}
\hline \multirow{4}{*}{$\begin{array}{ll}s t \\
\text { dem } \\
3\end{array}$} & \multirow[b]{3}{*}{ Nots } & \multirow[b]{3}{*}{$\mathbf{v}$} & \multirow[b]{3}{*}{ Loulloe W } & \multicolumn{12}{|c|}{ Table A,2 (continued) } & \multirow[b]{3}{*}{ Conngats iod tods } \\
\hline & & & & Lenc. & & \multirow[b]{2}{*}{ Susple bitenal } & \multicolumn{2}{|c|}{ Strowing. } & \multicolumn{7}{|c|}{ 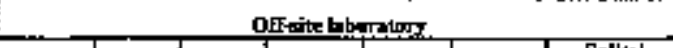 } & \\
\hline & & & & Stmite & tosing & & $\mathbf{k}+\mathbf{n}$ & yoc & Mertols & $\mathrm{PCB}$ & RAt & syoc & Yoc & Other & 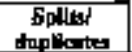 & \\
\hline & 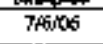 & $22-33$ & 27-EVA3B-3725 & $5 \$ 24871$ & 2455500 & 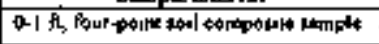 & & 1 & $\mathrm{l}$ & 1 & & 1 & & & & 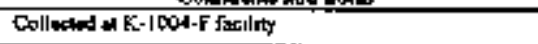 \\
\hline 3 & जin 2106 & $22-33$ & $22-E$ U33E-326 & 534791 & 2M45357 & 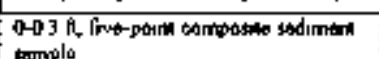 & & 1 & 1 & 1 & & 1 & & & & Collocted in sedimestif at north \\
\hline 9 & 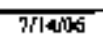 & $23-33$ & 22-EWS3E-327 & $53+448$ & 2445374 & 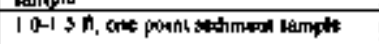 & & $\mathbf{I}$ & $i^{-}$ & $\mathbf{I}$ & 1 & 1 & 1 & & & 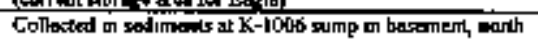 \\
\hline 3 & II19/6 & $22-53$ & 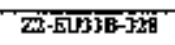 & $58+4+18$ & 2115379 & 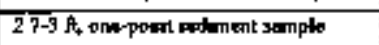 & & $T$ & $T$ & $\mathbf{I}$ & $i$ & $i$ & $T$ & & & 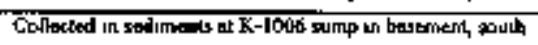 \\
\hline 3 & $\operatorname{stzing}$ & 22.59 & 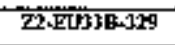 & 584869 & 2445593 & Ded $25 \mathrm{fl}$, ame-pant concrete sample & & & $T$ & 1 & -1 & $T$ & & 1 & & 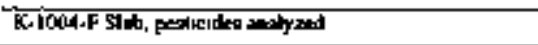 \\
\hline 3 & orima & 23.59 & 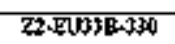 & 584873 & 2445608 & 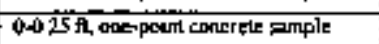 & & & $T$ & 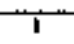 & 1 & $T$ & & $T$ & & 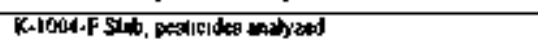 \\
\hline 3 & 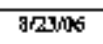 & $27 \cdot 33$ & $27 \cdot$ QUnJ)-331 & $93+4663$ & $244 \$ 064$ & 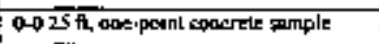 & & & 1 & I & 1 & $\mathrm{I}$ & & 1 & & 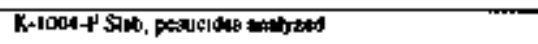 \\
\hline 3 & 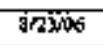 & 27-33 & 27-E1031:-332 & ss+ess & 2445610 & 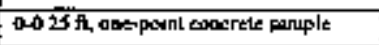 & & & 1 & I & 1 & 1 & & 1 & & 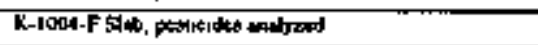 \\
\hline 3 & Lorsmos & 22.-13 & 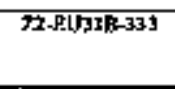 & $\$ 34626$ & 2446050 & 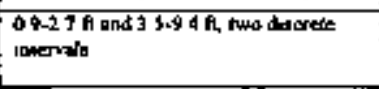 & $\mathrm{z}$ & $\mathrm{z}$ & 3 & 2 & 2 & 2 & 7 & & & 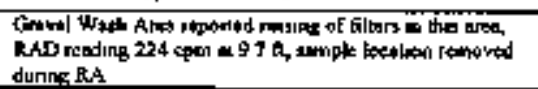 \\
\hline 3 & 929,00 & $22-33$ & $\overline{Z 2-E U 33 E-334}$ & $\$ \$ 4616$ & 24+61078 & 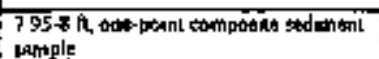 & & $T$ & $T$ & $\mathbf{T}$ & $T$ & $T$ & $T$ & & & 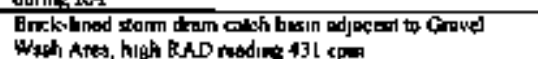 \\
\hline$\overline{2}$ & 9/29106 & $22-33$ & $27-E U 33$-335 & 584605 & 2455901 & 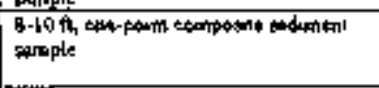 & & 1 & I & T & $\mathrm{T}$ & I & $\mathrm{l}$ & & D & 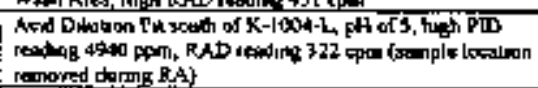 \\
\hline 3 & Tिजक & $2 \mathrm{z}+\mathrm{ij}$ & 22-EU33日-536 & 584743 & 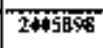 & 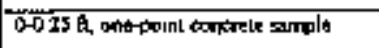 & & & $T$ & $\mathbf{I}$ & $i$ & & & & & 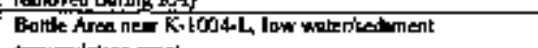 \\
\hline 3 & $9 / 25,066$ & $22-33$ & 28-E0338-337? & $57169 \%$ & 2415937 & 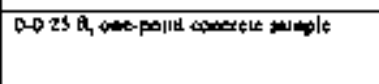 & & & l & I & 1 & $\mathrm{r}$ & & & & 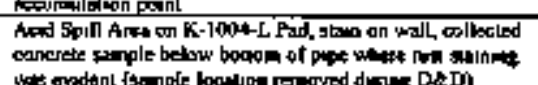 \\
\hline 3 & $8 / 27 \times 36$ & 22.93 & Z2.E[33E-338 & $3 \%+691$ & 2446077 & 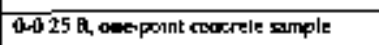 & & & 1 & $\mathrm{I}$ & $T$ & & & & & 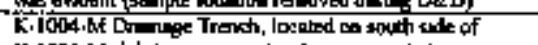 \\
\hline & & & & & & 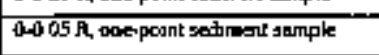 & & $T$ & $T$ & $T$ & T & $T$ & $T$ & & MSIMSD & 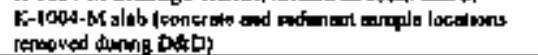 \\
\hline$\overline{3}$ & $\cos 12 x$ & $22-33$ & ZZ-EU]3E-339 & 386703 & $24+6145$ & 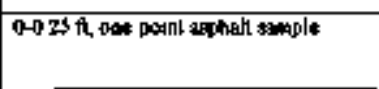 & & & & & 1 & & & & & 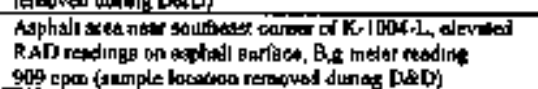 \\
\hline${ }^{3}$ & 9125506 & 23.13 & 22.50550 .540 & $18+794$ & 2449912 & 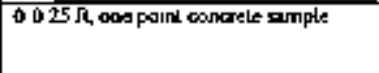 & & & $T$ & $T$ & & & & & & 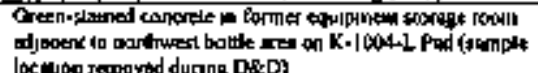 \\
\hline$\overline{3}$ & 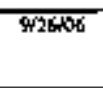 & 22-33 & Z2-EUJyE-3Al & 5i657 & 246i50 & 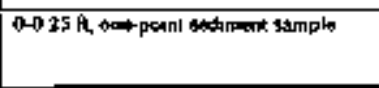 & & $\mathbf{T}$ & $T$ & $\mathbf{T}$ & $\mathrm{T}$ & 1 & 7 & & & 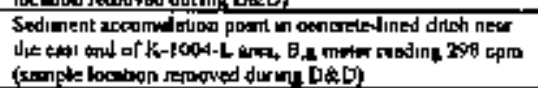 \\
\hline 3 & Fुसाम & 27.39 & 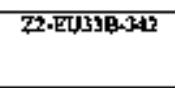 & $58 \times 6854$ & $24+5998$ & 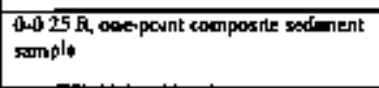 & & 1 & & . & 1 & & & & & 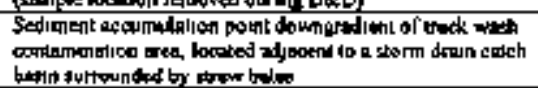 \\
\hline 3 & $\sin 2 \sin 6$ & 23.13 & 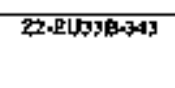 & $13 \sin 73$ & 2445921 & 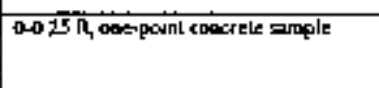 & & & $\mathrm{I}$ & & & & & & & 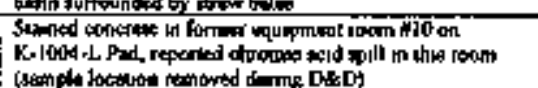 \\
\hline 3 & 1003916 & $22-33$ & $22-6 \sqrt{338-344}$ & 589744 & 244615 & and $x S$, antopoint & & & $i$ & & $\mathrm{I}$ & & & & & 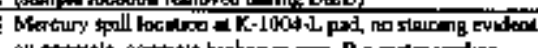 \\
\hline & & & & & & 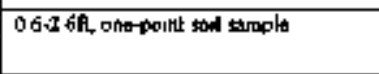 & $\mathrm{T}$ & $\mathrm{J}$ & 1 & & & & & & $\mathbf{s}$ & 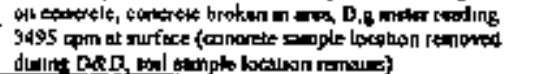 \\
\hline
\end{tabular}




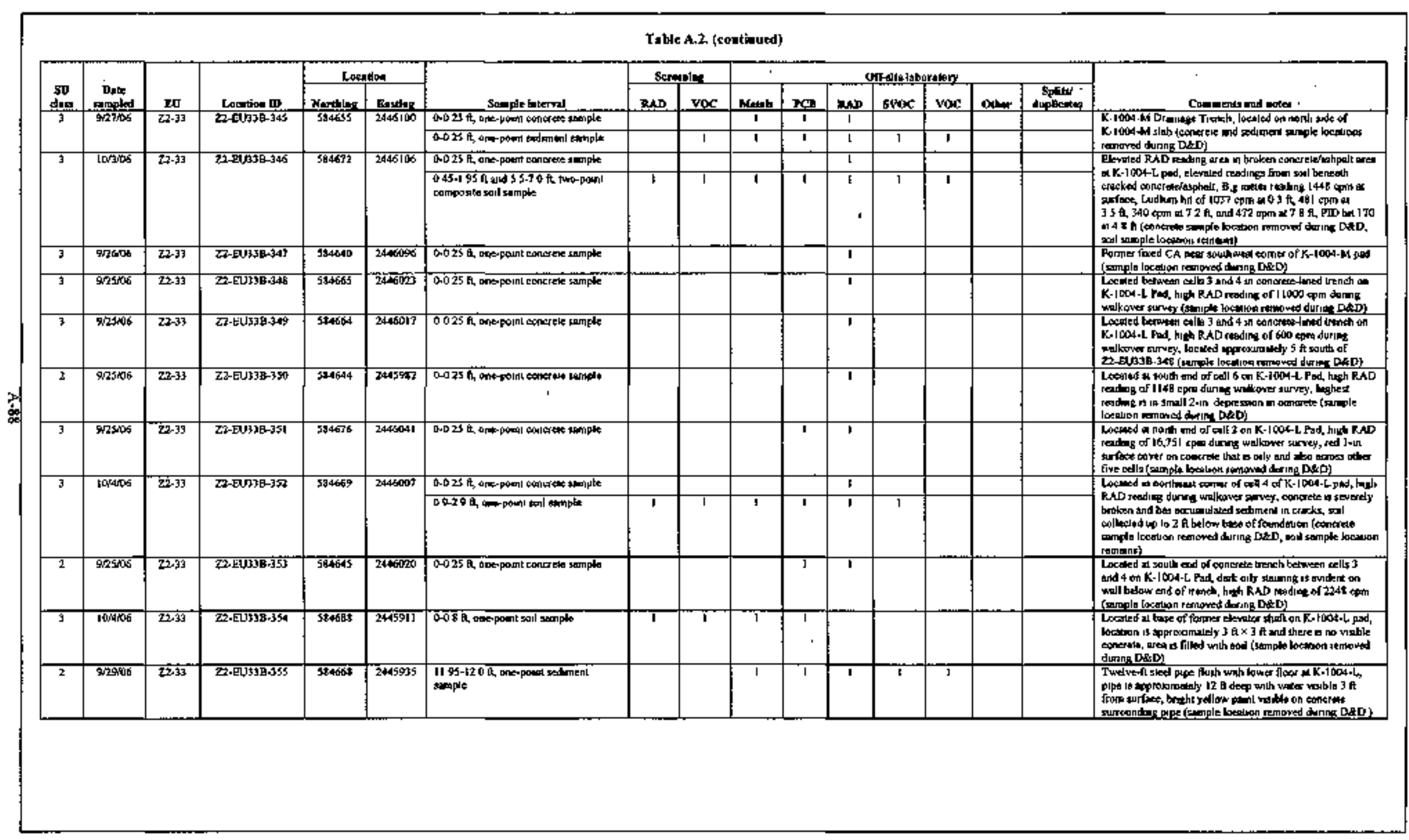




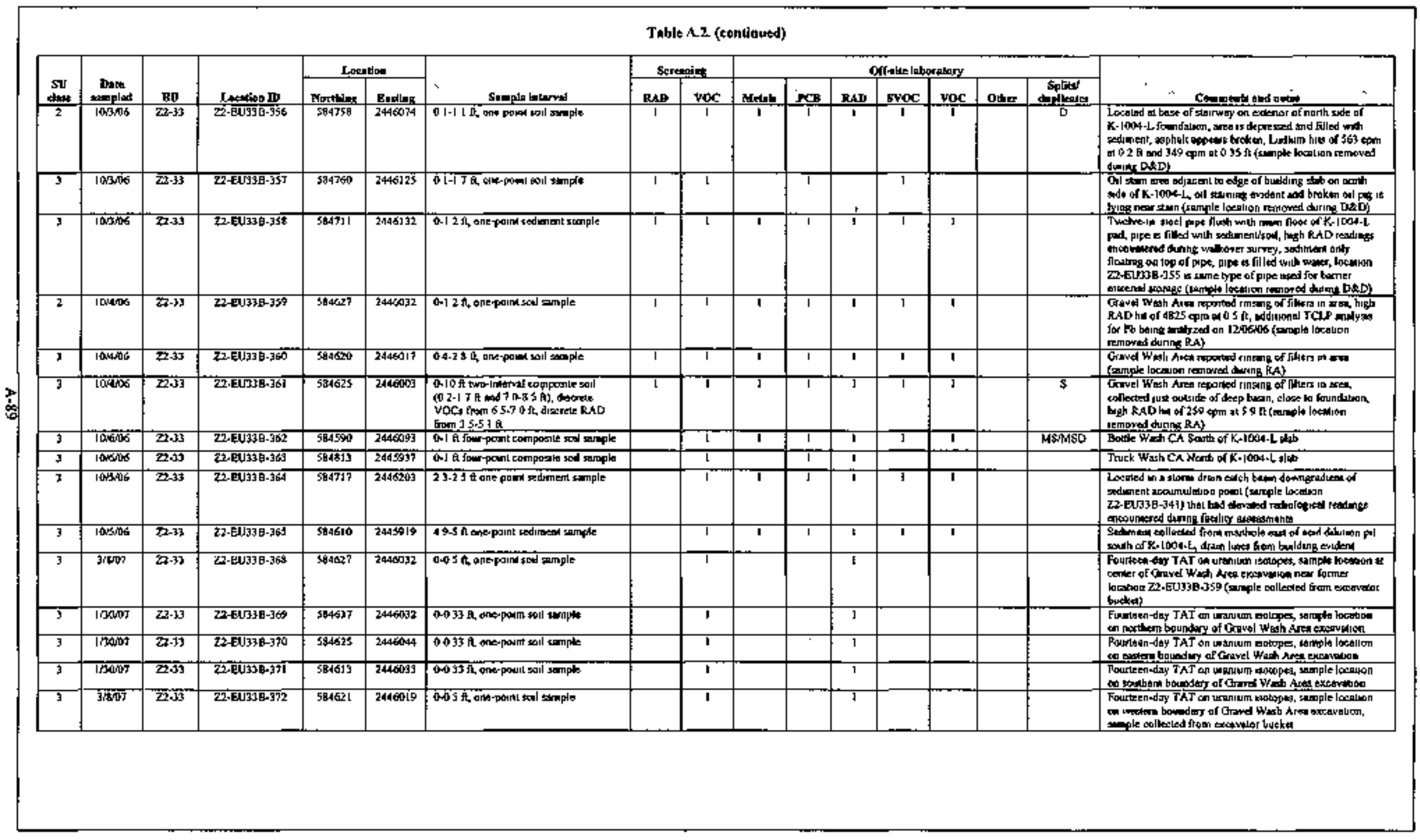




\begin{tabular}{|c|c|c|c|c|c|c|c|c|c|c|c|c|c|c|c|c|}
\hline \multicolumn{17}{|c|}{ Tabk A.2. (montinued) } \\
\hline \multirow{2}{*}{ 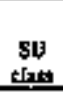 } & \multirow{2}{*}{ 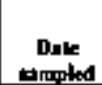 } & \multirow[b]{2}{*}{$\mathbf{2 0}$} & \multirow[b]{2}{*}{ Lotation In } & \multicolumn{2}{|c|}{ Loendom } & \multirow[b]{2}{*}{ 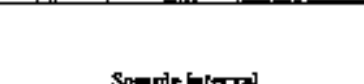 } & \multicolumn{2}{|c|}{ Serentace } & \multicolumn{7}{|c|}{ 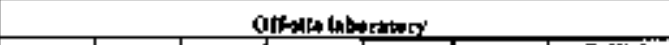 } & \multirow[b]{2}{*}{ 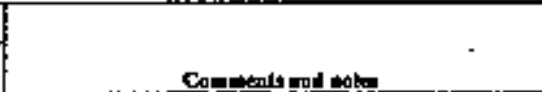 } \\
\hline & & & & Nentalese & Foultog & & pal & $\operatorname{voc}$ & Mntely & ree & RAT & svoc & thos & 0 & Splitiks & \\
\hline$\frac{i}{2}$ & $1,1240+5$ & 22,39 & 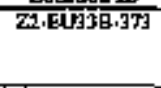 & 584491 & 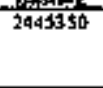 & 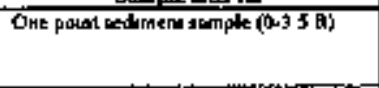 & & 1 & $\frac{1}{1}$ & 1 & $\frac{1}{1}$ & 1 & 1 & nim & & 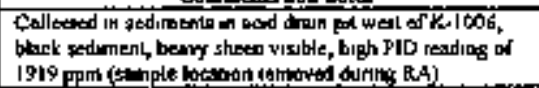 \\
\hline 2 & $5 / 24007$ & 2233 & 22EEUT3E-3TA & 584555 & 3445349 & 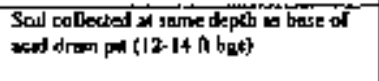 & $T$ & $\mathrm{~J}$ & 1 & $\overline{\mathbf{T}}$ & Ti & $\mathbf{T}$ & 1 & & & 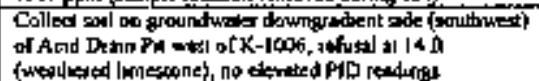 \\
\hline 3 & Filest & 25-33 & $22-E U 338-577$ & SE459] & 7*45391 & 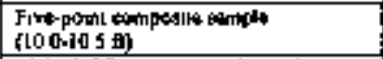 & 1 & $\mathbf{T}$ & $T$ & $T$ & 1 & & & & & 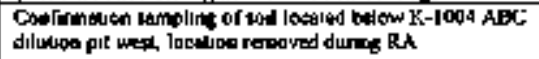 \\
\hline & & & & & & 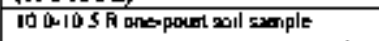 & $\mathrm{J}$ & $\mathbf{T}$ & & & & & 1 & & & \\
\hline 3 & N1909 & $27-37$ & $22 \cdot 8 \mathrm{ed} 33 \mathrm{E}-37 \mathrm{8}$ & Sta6ss & 20453004 & 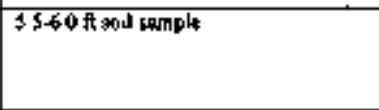 & 1 & i & t & $\mathrm{T}$ & $T$ & & & & & 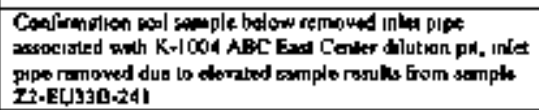 \\
\hline 3 & [01'107) & $28-\pi x$ & $22-E(3330-379$ & 584543 & 2445759 & 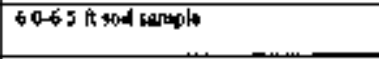 & $\mathrm{T}$ & $\mathrm{T}$ & $\mathrm{I}$ & $\mathrm{T}$ & $T$ & $\mathbf{T}$ & & & & 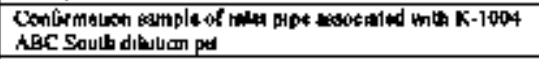 \\
\hline 3 & $11 / 13 \% 5$ & 22.35 & 27.EU336-380 & \$E4391 & $2043260^{2}$ & 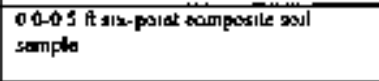 & $T$ & 1 & & & $T$ & & & & & 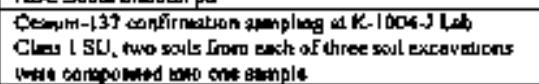 \\
\hline 3 & 10,4007 & 272-33 & 22-EUT36-331 & 5648266 & 2045902 & 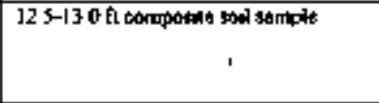 & $T$ & 1 & $\mathrm{l}$ & $\mathbf{T}$ & $\mathrm{T}$ & & $T$ & & & 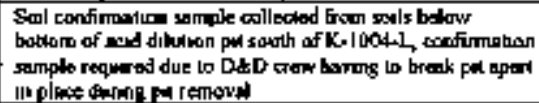 \\
\hline 3 & Twision & 222-33 & $22+10336-332$ & इ55 & 244638 & 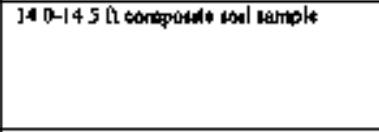 & $T$ & $\mathrm{~J}$ & $\mathrm{l}$ & $\mathbf{T}$ & $T$ & $\mathbf{T}$ & $T$ & & & 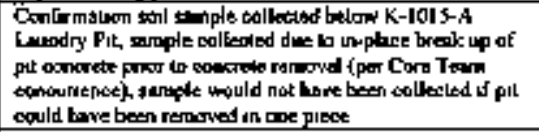 \\
\hline 3 & 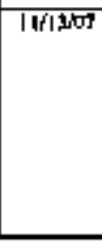 & 22.53 & $22 \cdot$ EU338.383 & 584429 & 2041689 & 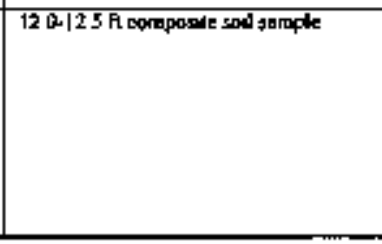 & & 1 & & & & & $T$ & & & 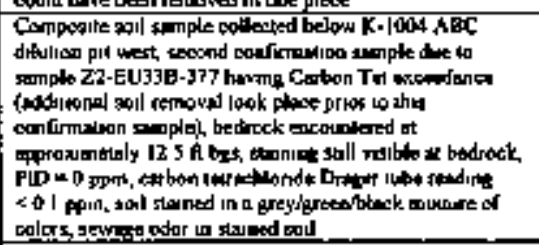 \\
\hline \multirow{2}{*}{\multicolumn{17}{|c|}{ blutorienl snmptes }} \\
\hline & & & & & & & & & & & & & & & & \\
\hline 3 & $3 / 194$ & 27.39 & $\frac{4 x^{2}}{2}$ & $944390^{\circ}$ & $244 \sqrt{3} 36$ & 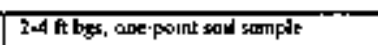 & & & $T$ & & & $\mathrm{~J}$ & & & & \\
\hline$\overline{3}$ & jrias & 222-33 & 415 & $5 \overline{84852}$ & $2 A+6285$ & 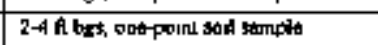 & & & 3 & & & $\mathrm{~J}$ & & & & \\
\hline 3 & MIIS4 & $22-33$ & 416 & 584570 & $24+6439$ & $2-4 \mathrm{nbys}$, ond & & & 1 & & & 1 & & & & \\
\hline 3 & $302 \mathrm{st}$ & $22-33$ & 424 & 595157 & 2445656 & 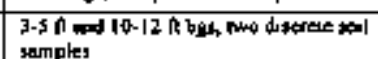 & & & $z$ & $\mathbf{z}$ & 2 & & $\overline{2}$ & & & 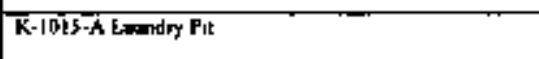 \\
\hline 3 & $3 \sqrt{2 / 92}$ & 22.33 & 425 & 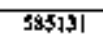 & 24456960 & 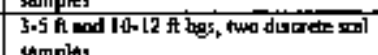 & & & 2 & 2 & 2 & & 2 & & & K-10FI-A Lemodry Pit \\
\hline
\end{tabular}


T*G Ge R2 (continued)

\begin{tabular}{|c|c|c|c|c|c|c|c|c|c|c|c|c|c|c|c|c|}
\hline \multirow[b]{2}{*}{ șl } & \multirow[b]{2}{*}{ Dats } & \multirow[b]{2}{*}{ EO } & \multirow[b]{2}{*}{ 14ater III } & \multicolumn{2}{|c|}{ Locutian } & \multirow{2}{*}{ Sunpialeterngl } & \multicolumn{2}{|c|}{ Sergats. } & \multicolumn{7}{|c|}{ Off-the bortiony } & \multirow[b]{2}{*}{ Coprogent and unew } \\
\hline & & & & Nortings: & Enediut & & Ran & $\sec$ & Metnb & $\mathbf{K O}$ & nan & svoc & yoc & Other & 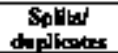 & \\
\hline 1 & 2liso & $2,32-33$ & $\mathrm{~K} \mid 004 \mathrm{D}-31$ & $585[1]$ & 244510 & Surfasen soll stmph & & & 1 & 1 & & 1 & 1 & & & 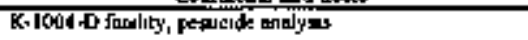 \\
\hline 3 & Fin & 22.53 & 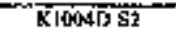 & $584 \overline{962}$ & 2445576 & Suffact soll somple & & & $\mathbf{T}$ & 1 & & 1 & $\mathbf{I}$ & & & 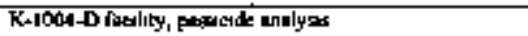 \\
\hline 3 & 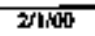 & $2 \overline{2}-53$ & K100.40-53 & 584953 & 2945742 & Śrfíce sall samphe & & & $\bar{T}$ & $\mathrm{~J}$ & & 丁 & T & & & 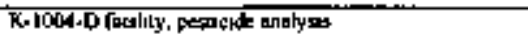 \\
\hline 3 & चल & $272+\sqrt{3}$ & 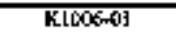 & 539643 & 24454]B & Sirfisce soul = = liple & & & 1 & $\frac{1}{3}$ & $T$ & נו & I & & & 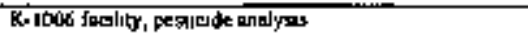 \\
\hline 3 & एयफ & $22-3]$ & K. $100-\infty 2$ & 584473 & 2445518 & Surfter toil ample & & & $\mathbf{I}$ & J & $\mathbf{I}$ & 1 & $\mathbf{T}$ & & & 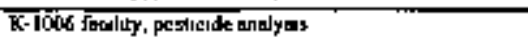 \\
\hline 3 & 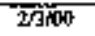 & $27-33$ & KID06 00 & SEA424 & 2405445 & Surfiest soll timple & & & $\mathbf{T}$ & $\mathrm{J}$ & 1 & J & $\mathbf{T}$ & & & K-1006 roolluy, pesticide andlysst \\
\hline t & $5 \sqrt{29} 6$ & $2-33$ & 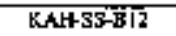 & क्ष5i 32 & $\overline{24+5649}$ & Surilat soll eumpin & & & & & I & & & & & 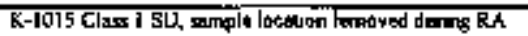 \\
\hline $\mathrm{t}$ & $\sqrt{x 31} \times 6$ & 22.33 & KAH-SE-AI3 & \$क्ष\$133 & 240363 & Suriscet soll sample & & & & & I & & & & & 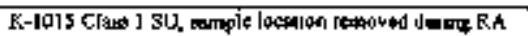 \\
\hline 2 & $5 / 29 \times 6$ & $22-\$ 3$ & KAHASE-E2Z & stsoso & 7445638 & Surficet goil 2ample & & & & & I & & & & & KAHSS-B22 Chts 250 \\
\hline 3 & अ1696 & 72.13 & KAH-8S-S11 & Stsbs & 2445650 & Surface sati somple & & & & & 1 & & & & & 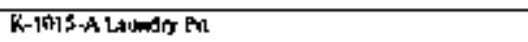 \\
\hline 3 & 3/16/9 & 27.59 & KAH-SS-SII & 581043 & $244 \$ 570$ & Sufuace sod sampice & & & & & $T$ & & & & & \\
\hline 7 & $3 / 6 / 96$ & $72-9$ & KAH+SS-SI & $58 d 366$ & 2945574 & Surfares sonl somplo & & & & & $T$ & & & & & KAH.ST_\$31 Class 2\$V \\
\hline$\overline{3}$ & 3/696 & $22-33$ & KAㅏ-55-SAl & 585010 & 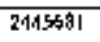 & 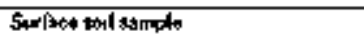 & & & & & 1 & & & & & 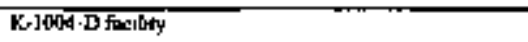 \\
\hline$\overline{2}$ & I/1696 & $23-33$ & KCH+55-SG| & 584565 & $24 \sqrt{5794}$ & Sarbat sod semtat: & & & & & ] & & & & & 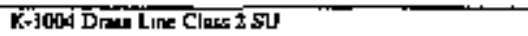 \\
\hline$\frac{\pi}{2}$ & 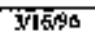 & 27,53 & KAHSS-S7I & $5 \$ 4760$ & 2045563 & Sturfooe sopl sample & & & & & 1 & & & & & 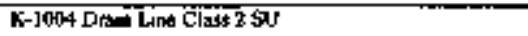 \\
\hline 3 & 7/1696 & $22-31$ & KAH.SSSAI & 584379 & 2445399 & Strfout soul somple & & & & & $\mathrm{J}$ & & & & & K-1006 furlatery \\
\hline I & $7 / 2004$ & $22 \cdot 33$ & W高它18 & $5848 \&]$ & $3445 \times 80$ & Surface soll somple & & & & & 3 & & & & & 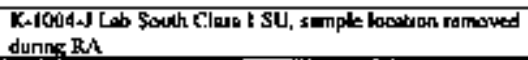 \\
\hline 1 & $7 \sqrt{20134}$ & $\overline{22-53}$ & RAD̈19 & $584 \dot{31}$ & $2 \sqrt{415416}$ & Sw fiot soll stmpt & & & & & $\mathbf{T}$ & & & & & 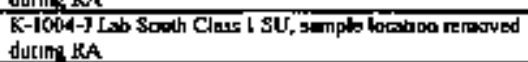 \\
\hline i & 7rotida & $\overline{z-33}$ & RAD20 & $5848 \times 2$ & 24d4\$5; & 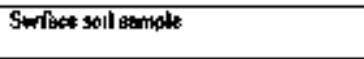 & & & & & $\mathbf{I}$ & & & & & 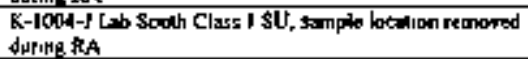 \\
\hline$T$ & $3 / 20 \times 49$ & 22-33 & RADAI & 584988 & 2445365 & Serfese soll smome & & & & & I & & & & & 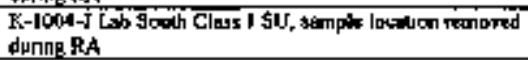 \\
\hline 3 & Bons & $22-33$ & Z2E $20133-K 10000$ & & & 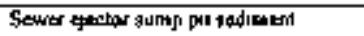 & & & 1 & $\mathrm{~T}$ & $\mathbf{I}$ & 1 & & & & DROGGRO, TCLP model \\
\hline 3 & liforiog & $27-35$ & 2.5635 .2001 & $5 \$ 9932$ & 244550 & 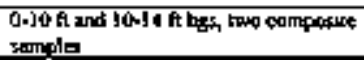 & & & 2 & 2 & & & & & & K-I203-4 Rtality \\
\hline 3 & $10 / 265$ & 22.33 & 2Z-81/31-200/2 & 504909 & $244 \operatorname{sing}$ & 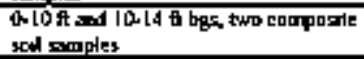 & & & $\overline{2}$ & $\frac{1}{2}$ & & & & & & K-1zos-A Anty \\
\hline 3 & $10 \mathrm{~d}$ thas & 23.39 & 72.हण133-200 & 584908 & 2445518 & 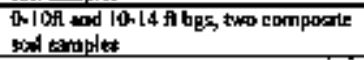 & & & 2 & $\overline{2}$ & & & & & & K-J $20 \%-A M=1 M Y$ \\
\hline 5 & sistos & $22-33$ & $22-80639-20014$ & 58506 & 2445570 & 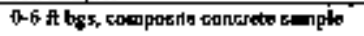 & & & 1 & $T$ & $T$ & $\mathrm{~T}$ & & $\mathrm{~T}$ & & 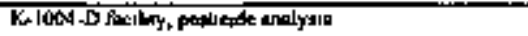 \\
\hline 3 & $9460 \%$ & 23-33 & $20-E U 33-20055$ & 584978 & $24+5579$ & 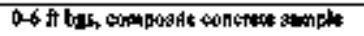 & & & $\mathrm{J}$ & $\mathbf{T}$ & $T$ & $\mathrm{l}$ & & $\mathrm{l}$ & & 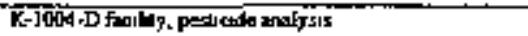 \\
\hline 3 & 26ios & $27-33$ & 23-EU33-2005 & 584925 & 244 G618 & 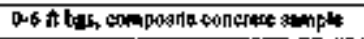 & & & 1 & $\mathrm{~s}$ & $\mathrm{I}$ & $T$ & & 1 & & 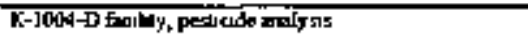 \\
\hline \multirow[t]{2}{*}{3} & श्रrणी & 27.31 & 22-EL/33-2001] & $58 \leqslant 0 \leqslant 6$ & $244 \$ 58 \mathrm{BL}$ & 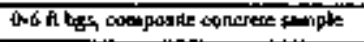 & & & $\mathrm{J}$ & 1 & 1 & $\mathrm{I}$ & & & & \multirow[t]{2}{*}{ K-1004-D Facildy } \\
\hline & Tantes & & & & & 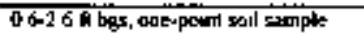 & & & נ] & $\mathrm{l}$ & $T$ & $\mathrm{I}$ & $\mathrm{I}$ & & & \\
\hline
\end{tabular}




\begin{tabular}{|c|c|c|c|c|c|c|c|c|c|c|c|c|c|c|c|c|}
\hline \multirow{3}{*}{$\begin{array}{c}\text { su } \\
\text { dared }\end{array}$} & \multicolumn{16}{|c|}{ Table A.2. (contined) } \\
\hline & \multirow[b]{2}{*}{ 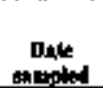 } & \multirow[b]{2}{*}{$\mathbf{y 0}$} & \multirow[b]{2}{*}{ 10eatton D } & \multicolumn{2}{|c|}{ Locuster } & \multirow[b]{2}{*}{ 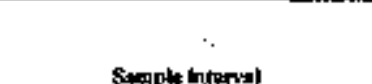 } & \multicolumn{2}{|c|}{ soreentiog } & \multicolumn{7}{|c|}{ 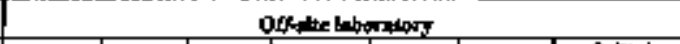 } & \multirow[b]{2}{*}{. Cormeats and rover } \\
\hline & & & & \multirow{3}{*}{ Northing } & \multirow{3}{*}{$\begin{array}{l}\text { Vunting } \\
24+55999\end{array}$} & & EAD & yoc & sidets & PCT & BAn & 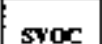 & voc & Othar & 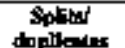 & \\
\hline & ต़/Nós & $22-3 \overline{3}$ & Z2. ELIS13.20064 & & & 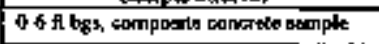 & & & 15 & $i$ & 1 & 1 & & & & \multirow{2}{*}{ 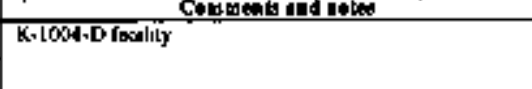 } \\
\hline & 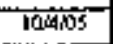 & & \multirow{3}{*}{ 22.EJ]3 2009 } & & & 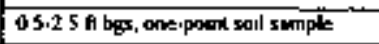 & & & $i$ & $\bar{\tau}$ & آ- & & & & & \\
\hline \multirow[t]{2}{*}{3} & $997 \times 15$ & \multirow[t]{2}{*}{$22 \cdot \sqrt{33}$} & & \multirow[t]{2}{*}{385013} & \multirow[t]{2}{*}{2445636} & 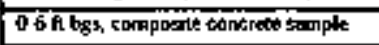 & & & $T$ & $T$ & $T$ & $T$ & & & & \multirow[t]{2}{*}{ Krocos, D forhty } \\
\hline & Tutanios & & & & & 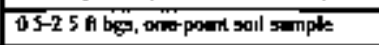 & & & $T$ & $\mathrm{~T}$ & $T$ & & & & & \\
\hline \multirow[t]{2}{*}{3} & 9रतबi5 & \multirow[t]{2}{*}{$22-3 \overline{3}$} & \multirow[t]{2}{*}{ 22-EU33-2010 } & \multirow[t]{2}{*}{$58+965$} & \multirow[t]{2}{*}{ 34156272 } & 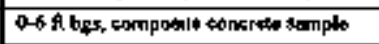 & & & 1 & $\mathrm{l}$ & 1 & $\mathrm{t}$ & & & & \multirow[t]{2}{*}{ K-1004-D foxality } \\
\hline & 3010405 & & & & & 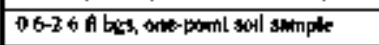 & & & 1 & $\mathrm{E}$ & 1 & & & & & \\
\hline \multirow[t]{2}{*}{$\overline{3}$} & 9תN5 & $22-33$ & 27-ED3.3011 & $58 \mathrm{~s}$ & Z245657 & 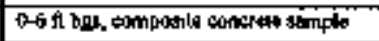 & & & $\mathrm{l}$ & $t$ & 1 & 1 & & & & 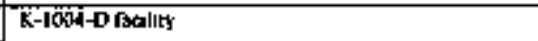 \\
\hline & 100405 & & & & & 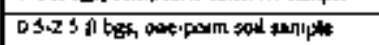 & & & 1 & I & & & & & & \\
\hline 3 & 82905 & $22-35$ & 2ZEU33-2012 & 584652 & 2446276 & 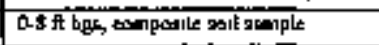 & & & 1 & I & 1 & $\mathrm{t}$ & $T$ & $\mathrm{t}$ & & 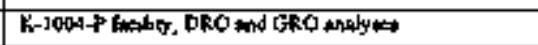 \\
\hline 3 & 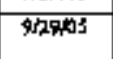 & 72-33 & $27-E[53-2013$ & \$84643 & 2406276 & 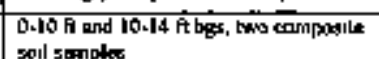 & & & 2 & 2 & & & & 2 & & 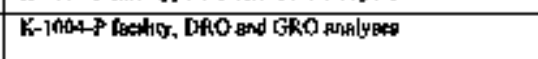 \\
\hline 3 & F्राM & 22,57 & 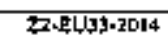 & 969157 & 29435940 & 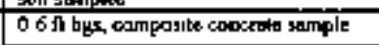 & & & $T$ & $\pi$ & $T$ & $T$ & & & & 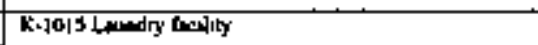 \\
\hline & 10015065 & & & & & 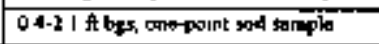 & & & $\mathbf{T}$ & נ & 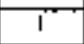 & $\mathrm{I}$ & $\mathrm{T}$ & & & \\
\hline $\mathbf{3}$ & 9monos & $2-3 \overline{3}$ & 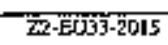 & 585310 & 2445612 & 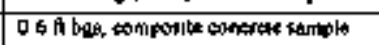 & & & $\mathbf{I}$ & $\mathrm{J}$ & 1 & $\mathbf{I}$ & & & & 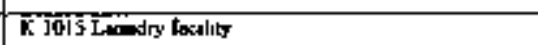 \\
\hline & IOSSOS & & & & & 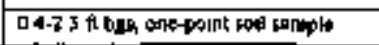 & & & $\mathbf{I}$ & 1 & & & & & & \\
\hline 3 & posons & 27.33 & Z2-E(393-2016 & SES 199 & 2441620 & 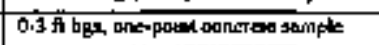 & & & I & 1 & $\mathrm{~T}$ & 1 & & & & 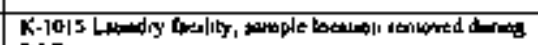 \\
\hline & 1001SWOA & & & & & 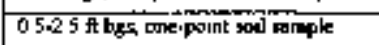 & & & $\mathrm{I}$ & 1 & & & & & & \\
\hline 3 & 9isios & 22-33 & 72.5033.2013 & 585975 & $244563]$ & 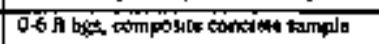 & & & $T$ & $\mathrm{~J}$ & $T$ & $T$ & & & & 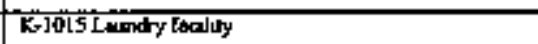 \\
\hline & TQW50NS & & & & & 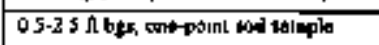 & & & $T$ & I & & & & & & \\
\hline 3 & $10 \times 201 \bar{b}$ & $22 \cdot \sqrt{3}$ & $252-\mathrm{EU} 93-2018$ & 585175 & 24156236 & 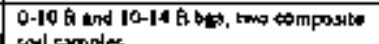 & & & 2 & 2 & 2 & 2 & 2 & & & 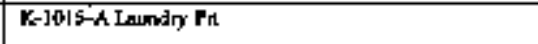 \\
\hline$T$ & jossos & $22-3 \sqrt[3]{3}$ & 22-ELI3-20 19 & 585142 & 3405644 & 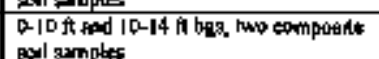 & & & 2 & 2 & 1 & 1 & & & & 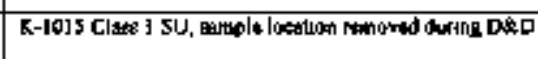 \\
\hline $\mathrm{J}$ & 9'llols & $22-3 \overline{3}$ & 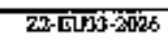 & 584834 & $20 \mathrm{SBA+1}$ & 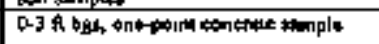 & & & $\mathrm{l}$ & 1 & 1 & 1 & & - & & 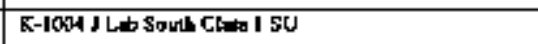 \\
\hline 1 & Pflatos & $22-93$ & $22-6103-2027$ & $58+907$ & 760594 & 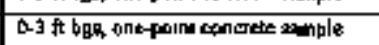 & & & $\mathrm{l}$ & $\mathrm{I}$ & $\mathrm{T}$ & $T$ & & & & K-1004 J Lob Sould Ca:s I SU \\
\hline$i$ & $100260 \mathrm{ds}$ & $22-3 \sqrt[3]{3}$ & 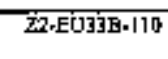 & 584899 & 2445370 & 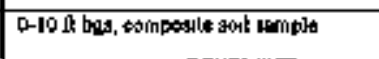 & & & $\mathrm{l}$ & $\mathbf{I}$ & 1 & $\mathrm{l}$ & & & & 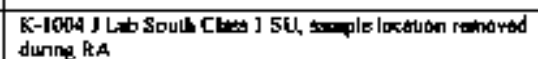 \\
\hline$T$ & 10026005 & $22-33$ & $22-\mathrm{EN} 333 \mathrm{\theta}-11 \mathrm{~L}$ & 584392 & 244556 & 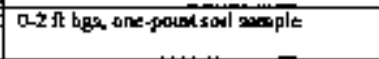 & & & $\mathbf{E}$ & 1 & 1 & ' & $\mathrm{T}$ & & & 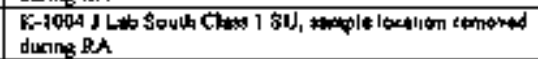 \\
\hline 3 & 8:1305 & 22.43 & 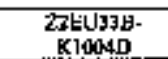 & 549691 & 2445705 & 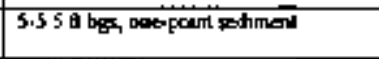 & & & 1 & 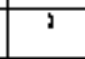 & $T$ & $T$ & & $\mathrm{I}$ & & 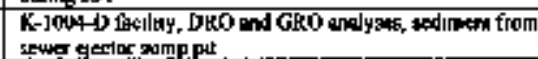 \\
\hline & & & & & & 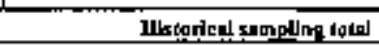 & & & $\mathbf{5 s}$ & 5 & 46 & $\mathbf{3 s}$ & 16 & IG & & \\
\hline 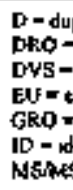 & 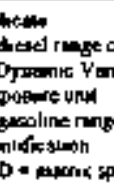 & 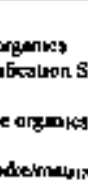 & 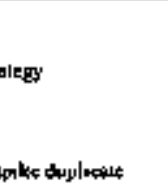 & 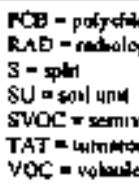 & 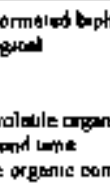 & 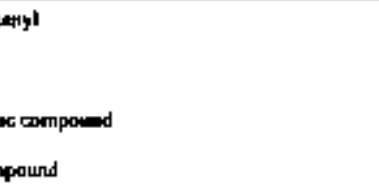 & & & & & & & & & & \\
\hline
\end{tabular}


Table A.3. EU Z2-33 sample bocathens tenoved turing remedtal astions and D\&D

\begin{tabular}{|c|c|c|c|}
\hline $\begin{array}{c}-\cdot \\
\text { Location } \\
\text { dententfed in TM }\end{array}$ & 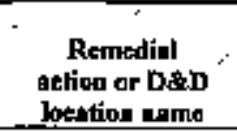 & 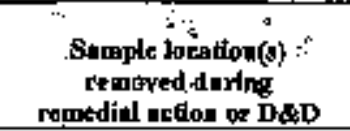 & 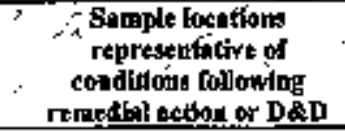 \\
\hline $\begin{array}{l}\text { EU33D-3I B Dilution PIt } \\
\text { sorulhwegt of K-1004-D }\end{array}$ & 72.EU33B.316 & Z2-5U333日-310 & 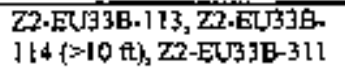 \\
\hline $\begin{array}{l}\text { EU330-329 K-11014-A, } \\
\text { B, CDilutson Fit West }\end{array}$ & Z2.EU33B-316 & 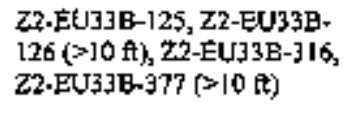 & $\begin{array}{l}22-E U 33 B-131,22-E U 33 B- \\
137, Z 2-E U 33 B-140, \\
Z 2-E U 33 B-(41, Z 2-E U 33 \mathrm{~B}- \\
383(310 \mathrm{ft})\end{array}$ \\
\hline $\begin{array}{l}\text { EUT33D-330 K-1004A, } \\
\text { B, C Dilution Pit South }\end{array}$ & Z2-EU333-314 & 22.EU33R-314 & $\begin{array}{l}\text { Z2.EU33B-122, Z2-EU33B. } \\
\text { 123 (> 10 ft), Z2-EU33B-315. } \\
\text { Z2.EU33B-379 }\end{array}$ \\
\hline 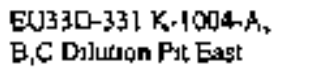 & 22-EU33B-312 & $\begin{array}{l}\text { Z2.EU33B-312 (5ample nof } \\
\text { collected) }\end{array}$ & $\begin{array}{l}\text { Z2.EU33E-116, Z2-Et333E. } \\
117(>10 \mathrm{ft})\end{array}$ \\
\hline $\begin{array}{l}\text { EU330.332 K-1004A, } \\
\text { B, C Dilution Plt East } \\
\text { Center }\end{array}$ & $22 \cdot$ EU33B-313 & Z2.-EU33E-313 & $\begin{array}{l}\text { Z2.EU33E. 119.22.EU33E- } \\
120(>10 \mathrm{ft}), 22 \text {-EU33B-378 }\end{array}$ \\
\hline $\begin{array}{l}\text { Euj3D-333 Gravel wash } \\
\text { area south of the K-1004-L } \\
\text { part }\end{array}$ & None given & $\begin{array}{l}\text { 22-EU33B-333, 22-EU33B- } \\
359, \angle 2-E U 33 B-360, Z 2- \\
\text { EU33B-36I }\end{array}$ & $\begin{array}{l}\text { 22-EU33B-368, 22-EU33B- } \\
369,22-E U 33 \mathrm{~B}-370 \\
22 \text {-EU33B-371, 22-EU33B- } \\
372\end{array}$ \\
\hline $\begin{array}{l}\text { EUJ33D-395 Acid dilution } \\
\text { pit gouth of K-1004-L- }\end{array}$ & Z2̂-EUJ3B-335 & Z2.EU/33B-335 & $\begin{array}{l}\text { 22-EU33B-365, 22-EU33B- } \\
38][>10 \mathrm{ft})\end{array}$ \\
\hline Eu330-336 Botlle Arte & None grven & 22.EU33B-336 & Sapne as for K. $1004-\mathrm{L}$ \\
\hline $\mathrm{K} \cdot 1004-\mathrm{F}$ Facilaty & None grven & $\begin{array}{l}\text { 22.EU3,3-329, Z2-EU33B- } \\
\text { 330, Z2-EU338-331, } \\
\text { 22-EU336-332 }\end{array}$ & Z2-EU33E-325 \\
\hline $\begin{array}{l}\text { K-1004-L Facilicy (whtere } \\
\text { concrete sample locations } \\
\text { werte temoved, co-localed } \\
\text { solisediment locations } \\
\text { remann at Z2-EUJ3B-344, } \\
\text { Z2-EU33B-346, } \\
\text { Z2-EU33B-353) }\end{array}$ & None given & 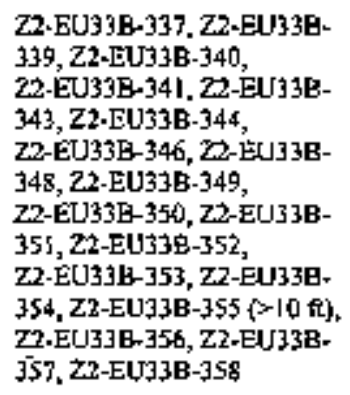 & $\begin{array}{l}\text { Z2.EU33B-344. Z2.EU33日. } \\
\text { 346. Z2-EU33B-352. } \\
\text { Z2-EU33E-362. Z2.EU39E. } \\
\text { 363. Z2-EU33E-364 }\end{array}$ \\
\hline$K \cdot 1004-M$ & None givent & $\begin{array}{l}\text { 22-EU33B-336, 22-EU33B- } \\
\text { 345, Z2-EU33B-347 }\end{array}$ & Same ts for K. $100 \mathrm{~d}-\mathrm{L}$ \\
\hline $\begin{array}{l}\text { K-1006 Facility (acud } \\
\text { dran pit) }\end{array}$ & Z2.EU33B.373 & 22.40338 .373 & Z2-EU33B.374 (3 L0 ft) \\
\hline 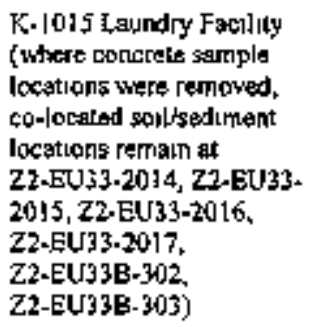 & Nane givern & $\begin{array}{l}\text { Z7-EU33-2014, Z2-EU33- } \\
2015,22-E U 33-2016, \mathrm{Z2}- \\
\text { EU3-2017, Z2-EU33B-302, } \\
\text { Z2.EU33E-303 }\end{array}$ & $\begin{array}{l}\text { Z2-EU33-2014, ZZ-EU33- } \\
2015, Z 2-E U 33-2016, \\
\text { Z2-EU33-2017, ZZ-EU33B- } \\
301, Z 2-E U 33 B-302, \\
\text { Z2-EU33B-303 }\end{array}$ \\
\hline
\end{tabular}


T. ble A.3. (contunued)

\begin{tabular}{|c|c|c|c|}
\hline $\begin{array}{c}\text { Locston } \\
\text { identfunof in TM }\end{array}$ & $\begin{array}{c}\text { Remedial } \\
\text { ectdon or D\&D } \\
\text { lecution Berint: }\end{array}$ & $\begin{array}{l}\text { Sumplo lacitian(s) } \\
\text { reinoved durlas } \\
\text { remetimal actien or } 5 \& D\end{array}$ & 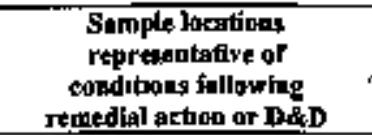 \\
\hline 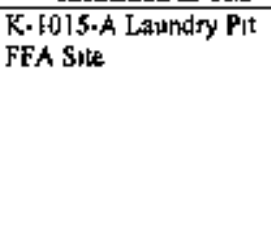 & None guven & $\begin{array}{l}\text { KAH-SS-B12, KAH-SS. } \\
\text { B13, Z2-EU33-2019, Z2. } \\
\text { EU33B-108, Z2-EU33B-109, } \\
\text { Z2-EU33B-220, Z2-EU33B- } \\
\text { 223, Z2-EU33B-225, } \\
\text { EU33B-227 }\end{array}$ & 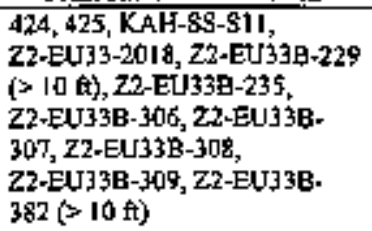 \\
\hline K-l0]5 Clags i su & None given & $\begin{array}{l}\text { KAH-SS-BI2, KAH-SS- } \\
\text { B13, Z2-EU13-2019, } \\
\text { Z2-EUJ3B-108, Z2-EU33B- } \\
\text { I09, Z2-EU331-220 }\end{array}$ & $\begin{array}{l}\text { 424, 425, KAH-BS-SII. } \\
\text { Z2-EU33-2018, Z2-EU33E-229 } \\
\text { (? 10 Al), Z2-EU33B-306. } \\
\text { Z2-EU33B-307, Z2-EU33B- } \\
\text { 308, Z2-EU33B-309 }\end{array}$ \\
\hline $\begin{array}{l}\text { K-1004.J Lab South } \\
\text { Class I SU }\end{array}$ & None given & $\begin{array}{l}\text { RADI8, RADI9, RAD70, } \\
\text { RAD21, Z2-EU33B-103, } \\
\text { Z2-EU33B-ID6, Z2-EU33E- } \\
\text { I10, Z2-EU33B-111, } \\
\text { Z2-EU33B-129. }\end{array}$ & $\begin{array}{l}\text { Z2-EU33-2026, Z2-EU33. } \\
2027,22-E U 33 \mathrm{~B}-105, \\
\text { Z2-EU33B-130, Z2-EU33B- } \\
380\end{array}$ \\
\hline
\end{tabular}

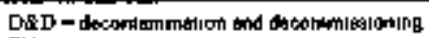
EUل = exposult unit

SU a soil unit

FFA - Foderal Focildty Aorumant

THA = techuoad mereorabdum 


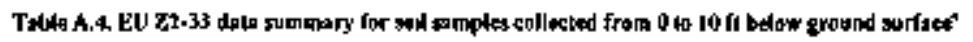

\begin{tabular}{|c|c|c|c|c|c|c|c|c|c|c|c|c|c|}
\hline Aaplyte & $\begin{array}{l}\text { Frequend } \\
\text { of detpot }\end{array}$ & 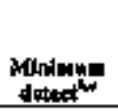 & 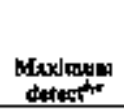 & 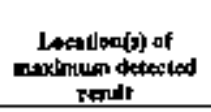 & $\begin{array}{l}\text { Avernet } \\
\text { detexted risplt }\end{array}$ & $\begin{array}{c}\text { Maximann } \\
\text { RL }\end{array}$ & 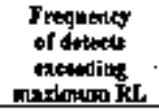 & $\begin{array}{c}\text { Arestoto } \\
\text { RL }\end{array}$ & 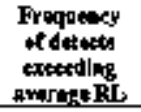 & 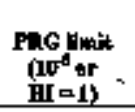 & 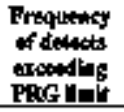 & 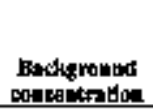 & 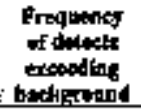 \\
\hline \multicolumn{14}{|l|}{ 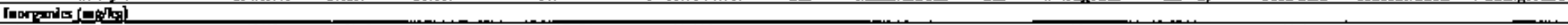 } \\
\hline Aformeng & 6969 & 2,52 , & $29, A Q 0$ & X]1004D-S3 & 12,209 & & $\mathrm{NA}_{\mathrm{A}}$ & & $\mathrm{NA}$ & 100,000 & thos & 40300 & 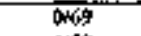 \\
\hline Amomany & *tyg & 00311 & 19 & $22 \mathrm{EU} 33-\mathrm{K} L(0 \mathrm{C}) \mathrm{D}$ & 074 & & NA & & $\mathrm{NA}$ & 100 & cots & 152 & 4t9g \\
\hline Anente & 6989 & 12 & I) & Z2EU3 B -327 & 764 & xoth & Q699 & 300 & a149 & 159 & $* 6 \%$ & $14 \mathrm{ss}$ & 469 \\
\hline Bmun & 69169 & 19 & 346 & 22 EUa3B-327 & 959 & & $\mathrm{NA}$ & & $\mathrm{NA}$ & 6,577 & $\cos \theta$ & 12493 & J1\%9 \\
\hline Berydhw: & 6869 & 0125 & 103 & 414 & 108 & 6000 & $0 \leftrightarrow 0$ & 2,000 & 269 & 1,941 & $\omega$ & 22 & 3169 \\
\hline Borod & 31,58 & 0.535 & 1631 & 22 EUOISB-334 & 369 & & $\mathrm{Nh}$ & tho & $\mathrm{NA}$ & J00,000 & 058 & & WA \\
\hline Cudmum & $66 \times 69$ & 0.0285 & 242 & 22EUU33B-327 & 178 & & $\mathrm{NA}_{\mathrm{A}}$ & & $\mathrm{NA}$ & $45+$ & 169 & 0220 & 12469 \\
\hline Cakcium & 69969 & $767 \mathrm{I}$ & $291,000 \mathrm{OS}$ & 72. Eu33 B-36d & 21,866 & & NA & & wh & & WA & 2,400 & 57869 \\
\hline Cowemilom & 6969 & $98 \mathrm{gJ}$ & 2381 & Z2-EU3]B-327 & 315 & & NA & & tes & $G+4$ & 269 & 448 & 7869 \\
\hline Cobleh & 69469 & $2 y$ & $2 \mathrm{~B} 3 \mathrm{~J}$ & $22-60193 M-212$ & ITI & & NA & & Wh & 131,310 & 069 & 42 & IN69 \\
\hline Coppo & 6969 & $3 \mathrm{BJ}$ & $21,0000]$ & $22+E L 33 \mathrm{~B}-365$ & $40 y$ & & No & & MA & 40,877 & w69 & $22 d 8$ & $24 / 69$ \\
\hline Iron & 69 & 9240] & s10,000] & 22EU33-K10040 & $\operatorname{sog}, 000$ & & NA & & $\mathrm{NA}$ & 100,000 & 469 & 58,600 & 5669 \\
\hline Leod & 6960 & 37 & $1,3 \infty$ & $22 E U 33-K, 10040$ & $s 11$ & & NA & & $\mathrm{NA}$ & 2000 & 1,169 & 3791 & $22 / 69$ \\
\hline Loulmum & $\$ 1 / 95$ & 3 & $\$ 1 \$$ & 22 - $2031[-127$ & 134 & & $N_{A}$ & & NA & 20,439 & oh's & 1594 & $1+56$ \\
\hline Magotshora & 6909 & 4301 & $\$ 9,600)$ & 2280393.964 & 4,929 & & $N_{A}$ & & NA & & $\mathrm{N}_{\mathrm{A}}$ & 3,300 & 1809 \\
\hline Menparase & 69.69 & IISI & 4,550 & $\mathrm{~K}$ 10040.53 & 1,050 & & $\mathrm{NA}$ & & $\mathrm{NA}$ & 19.458 & 0169 & 3,200 & 5069 \\
\hline Mereury & 57868 & yoly & 30 & Z2EL/33+K1004D & I l2 & $\mathbf{I t 0 0}$ & arts & 600 & o'68 & 307 & 068 & דון & 29.68 \\
\hline Molstodenum & 5758 & 0165 & 294 & $22-E U, 3] \mathrm{B}-3$-3H & 229 & & $N A$ & & $M$ & 5,110 & 058 & & WA \\
\hline Nockel & 6969 & 49 & 452 & K.joeso-s 3 & 379 & & $\mathrm{NA}$ & & MA & 20,439 & tos & 2607 & LBR69 \\
\hline Potessum & 6969 & 2605 & 3270 & KJDot-i I & $[1]\}$ & & $\mathrm{NA}$ & & $\mathrm{NA}$ & & Wh & 5,07469 & 1669 \\
\hline Selenumer & 35.469 & 0131 & 115 & $22 \mathrm{E}-133-\mathrm{K} 10 \mathrm{0}-\mathrm{D}$ & 149 & & $\mathrm{Ns}$ & & $\mathrm{MA}$ & $5,1] 0$ & Dite9 & 147 & נ] \\
\hline Siture & +1069 & Q ot & 130 & 223EU33-K10001D & 643 & & NA & & NA & 5,160 & $0+6 \%$ & 060 & 9169 \\
\hline Sodum & 56669 & 119 & 1260 & 22-EL31B.354 & 996 & & NA & & $\mathrm{NA}$ & & $\mathrm{NA}$ & $49 \mathrm{~T}$ & $1+64$ \\
\hline Thálomrar & 37169 & 0071 & [0.43] & $20-E \cup 933-116$ & 0228 & & NA & & NA & 673 & 069 & 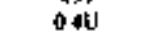 & 3,69 \\
\hline Uranran & strst & 057 & 6921 & $\overline{22}-\mathrm{E} \cup 93 \mathrm{~B}-3 \div 4$ & 178 & & NA & & NA & 240 & L15B & & $\mathrm{NA}$ \\
\hline Yanathum & 64tos & $54 J$ & $\mathrm{rj}$ & 22-EU13E-116 & 268 & & $N_{A}$ & & NA & 1,022 & $00 \%$ & 6517 & 2169 \\
\hline & 69699 & 13 & 1,600 & $228 \cup 33-K 10040$ & 126 & & $\mathrm{Na}$ & & $\mathrm{NA}_{\mathrm{A}}$ & 100,000 & 669 & 89 7 & 1769. \\
\hline \multicolumn{14}{|l|}{ Other oriandes ( 0 pikg) } \\
\hline Dresed Rumge Ongers & II & 7,509 & 7,500 & Z2ELI3]-KIDOAD & $7.50 \times 1$ & & NA & & NA & & MA & & NA \\
\hline 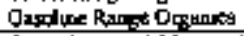 & 183 & $047 \mathrm{~J}$ & $0+\pi J$ & ZZEUIZ-KIDOOAD & 047 & & NAA & & $\mathbf{N A}_{\boldsymbol{A}}$ & & MA & & $\mathrm{MA}$ \\
\hline \multicolumn{14}{|c|}{ 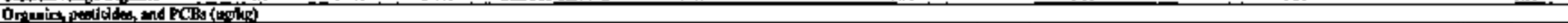 } \\
\hline $4, \mathrm{ADOD}$ & ovo & ND & ND & & ND & & NA & & NA & $E[0,000$ & Date & & $\mathrm{HA}$ \\
\hline $4,4 \cdot D O D E$ & 150 & 150 & Lot & KlootD-sy & 150 & & NA & & NA & $\pi 0,000$ & 016 & & WA \\
\hline $4,4-0 \mathrm{OT}$ & $4 \sqrt{6}$ & $19 \mathrm{~J}$ & 230] & K L $1004 \mathrm{D}-\$ 1$ & 143 & & NA & & NA & 70,000 & DNG & & NA \\
\hline Aldna & ais & ND & ND & & ND & & NA & & NA & 6,900 & ON6 & & $\mathrm{NA}$ \\
\hline aLha.EHC & ats & ND & ND & & ND & & Na & & $\mathrm{NA}$ & 3,600 & Dr6 & & $\mathrm{NA}$ \\
\hline alphumetbondtume & Ith & 851 & 355 & KIONAD-SI & as & & $\mathrm{NA}_{\mathbf{A}}$ & & NA & 65,000 & Dor & & $\mathrm{NA}$ \\
\hline betaAC & dis & $\mathrm{N}[\mathrm{r}$ & ND & & ND & & Na & & $N_{A}$ & 13,000 & ONG & & $\mathrm{NA}$ \\
\hline dethe-BWC & 016 & ND & ND & & ND & & NA & & $\mathrm{NA}$ & & $\mathrm{NA}$ & & $\mathrm{Nh}$ \\
\hline Dedidtw & ass & ND & ND & & ND & & NA & & $n$ & 1,100 & or & & NA \\
\hline Endowilien I & aro & ND & ND & & ND & & NA & & $\mathrm{MA}$ & $3,700,000$ & ore & & Nh \\
\hline Endosulfrom II & ars & $\mathrm{ND}$ & ND & & ND & & NA & & NA & $3,700,000$ & aro & & $\mathrm{NA}$ \\
\hline Endoralfing galfote & 15 & 250נ & 250 & X10000-5I & 250 & & $\mathrm{NA}$ & & MA & $3,700,000$ & Dos & & wA \\
\hline Eumn & $3 / 6$ & $2 \mathrm{WJ}$ & च01 & KJo000-5i & 312 & & NA & & MA & LBO 0.000 & DRE & & $\mathrm{WA}$ \\
\hline Endun aldebyto & $0 / 6$ & $\mathrm{ND}$ & ND & & ND & & NA & & $\mathrm{NA}_{A}$ & lBo, 000 & DOE & & Wh \\
\hline Extor ketous & $0 \times 6$ & ND & ND & & No & & $\mathrm{NA}$ & & $\mathrm{N}_{\mathrm{A}}$ & LEOQ0,000 & 0,06 & & NA \\
\hline gan-nh-OJlordene & $1 / 56$ & 6 & b] & $x] 0040.51$ & 6 & & NA & & M & 65.000 & a.6 & & wh \\
\hline Geptechlor & $1 / 6$ & 651 & 655 & XJOCADSE & 65 & & NA & & NA & 3,000 & 0.64 & & $N A$ \\
\hline Hep(unt)y spoxude & 36 & 351 & $95 J$ & $K 1004 D-S 2$ & 307 & & $\mathrm{NA}$ & & $\mathrm{NA}$ & 1,900 & 0,16 & & $\mathrm{NA}$ \\
\hline
\end{tabular}




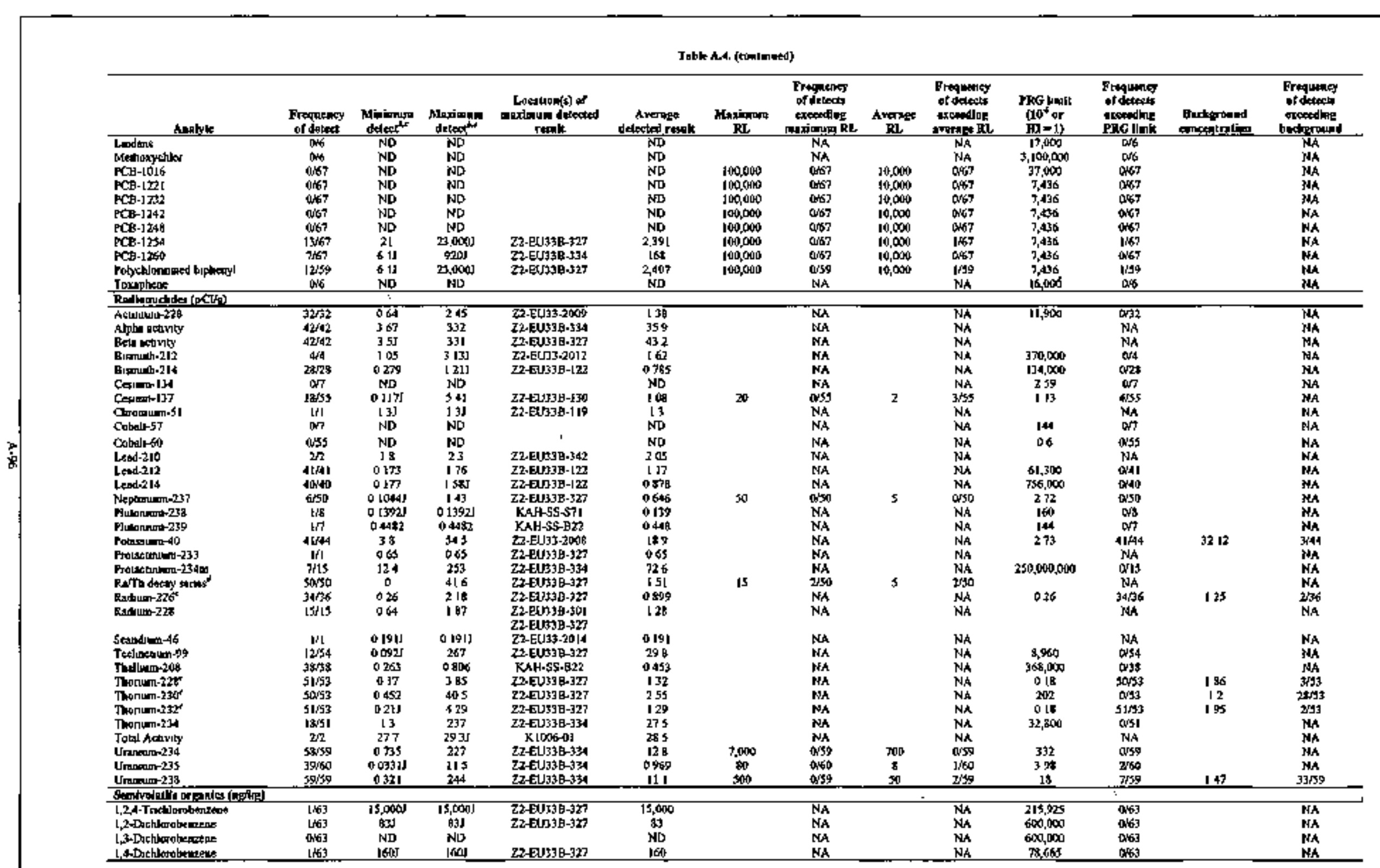


Toble A.4, (coudmaed)

\begin{tabular}{|c|c|c|c|c|c|c|c|c|c|c|c|c|c|}
\hline Andyts & $\begin{array}{l}\text { Frequenosy } \\
\text { ofdetect }\end{array}$ & $\begin{array}{l}\text { Malmon } \\
\text { detection }\end{array}$ & Maximun & 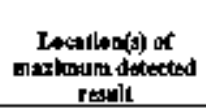 & $\begin{array}{c}\text { Anerposs } \\
\text { Atrected resul }\end{array}$ & $\begin{array}{c}\text { Markmous } \\
\text { Ml }\end{array}$ & 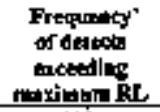 & ArL & 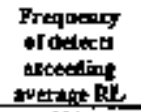 & 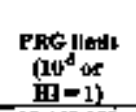 & 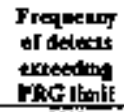 & 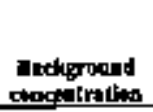 & 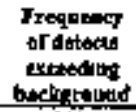 \\
\hline 2,3,4,6-Tetrarhlaropdenol & d/ L & ND & ND & & ND & & $\mathrm{NA}$ & & $M A$ & $18,468,189$ & क्वाi & & $\mathrm{NB}$ \\
\hline 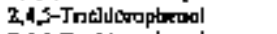 & a/o & No & ND & & ND & & NA & & $\mathrm{NA}$ & $61,560,629$ & orso & & $\mathrm{NA}$ \\
\hline 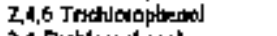 & $0 \$ 50$ & ND & ND & & ND & & NA & & $N_{A}$ & 61,561 & 0,50 & & $N A$ \\
\hline 24-Deblocopliented & asso & NO & ND & & ND & & NA & & NA & $1,846,910$ & $0 \times 150$ & & $N_{A}$ \\
\hline 3,4-Butedhytathetol & Q & ND & ND & & ND & & $\mathrm{NA}$ & & $\mathrm{NA}$ & $12,312,126$ & abso & & $\mathrm{NA}$ \\
\hline Z,4-Drumoplesteol & 247 & ND & ND & & ND & & NA & & $\mathrm{NA}$ & $1,231,213$ & Dors 7 & & NA \\
\hline 2,4-Dewroulutense & ast & ND & ND & & NO & & $\mathrm{NA}$ & & $N A$ & 25,348 & DtsI & & NA \\
\hline 3,6-Dusurotuluene & ast & ND & ND & & ND & & $\mathrm{N} / \mathrm{A}$ & & $\mathrm{NA}$ & 25,348 & ars 1 & & NA \\
\hline 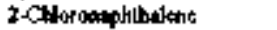 & ayl & ND & ND & & ND & & NA & r & $N_{A}$ & $2,3,362,3,32$ & Dors I & & N.a \\
\hline 2-Chorophersol & 240 & ND & HD & & ND & & $N_{A}$ & & $N A$ & $233_{1} 166$ & arso & & NA \\
\hline 2 -Wethyl-4,6-duarophesol & 0,49 & ND & ND & & ND & & NA & & $\mathrm{NA}$ & 61,561 & $0 / 49$ & & NA \\
\hline if Methylauphthatent & $3 \mathrm{SI}$ & 451 & J 1,000 & Z2-PJ]35P:534 & 1,758 & & NA & & $\mathrm{NA}$ & 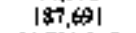 & I & & NA \\
\hline $2+$ Wethylphenof & asso & ND & ND & & ND & & $\mathrm{NA}$ & & $\mathrm{NA}$ & $30,760,315$ & arso & & NA \\
\hline 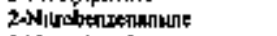 & $\cos 1$ & ND & ND & & ND & & $\mathrm{NA}$ & & NA & $1,050,202$ & as & & $\mathrm{NA}$ \\
\hline 2) Norsephenod & $\cos \theta$ & ND & ND & & ND & & NA & & $N A$ & & $\mathrm{NA}$ & & NA \\
\hline 3,3'-Dichlanobearadine & aso & ND & ND & & ND & & NA & & $N A$ & 3E:304 & asso & & NA \\
\hline 3-3Aethylphenof & $0 / 1$ & ND & ND & & ND & & NA & & NA & J0,7e0,315 & arll & & NA \\
\hline 3-Nutrobenuenamaure & 어5I & ND & ND & & $N D$ & & MA & & NA & 18,468 & QSS & & $\mathrm{NA}$ \\
\hline 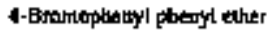 & וצמו & $97]$ & 97ग & K.10040-5] & 9) & & MA & & No & & NA & & $\mathrm{NA}$ \\
\hline 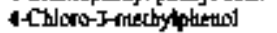 & (N9) & No & ND & & ND & & $N A$ & & NA & & $\mathrm{NA}$ & & NA \\
\hline 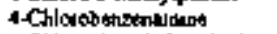 & 0 1 1 & ND & ND & & WF & & $\mathrm{NA}$ & & NA & $2,462,425$ & I I & & $\mathrm{NA}$ \\
\hline 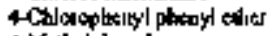 & as 1 & ND & ND & ' & $\mathrm{ND}$ & & $\mathrm{NA}$ & & NA & . & $\mathrm{NA}$ & & $\mathrm{NA}$ \\
\hline 4. Metuylphenot & aßi & ND & ND & & ND & & NA & & MA & $3,100,000$ & ois 1 & & NA \\
\hline 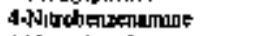 & $\operatorname{arsi}$ & ND & ND & & ND & & $\mathrm{Nh}$ & & NA & LBA,648 & QSSI & & $\mathbf{N A}$ \\
\hline d Wistrephengia & $\cos 0$ & ND & ND & & ND & & NA & & $N / k$ & & NA & & $\mathbf{N h}$ \\
\hline Acepenhuthene & 85 & 271 & 38,000 & Z2-EU13B-334 & 4,930 & & $\mathrm{NA}$ & & $\mathrm{mA}$ & $29,2] 9,327$ & ars I & & HA \\
\hline 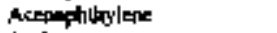 & $9 / 5 \mathrm{~L}$ & 47J & $\int 400$ & Z2-EU133-325 & 306 & & $N_{A}$ & & NA & $29,2] 9,327$ & orsi & & NA \\
\hline Anokre & $0 / 42$ & ND & ND & & No & & $\mathrm{NA}$ & & NA & $3,024,03]$ & ONd2 & & $\mathrm{NA}$ \\
\hline Ambirocene & $|2 / 5|$ & $46 \mathrm{~J}$ & 32,000 & 22-EU33B-334 & 3.255 & & NA & & NA & $100,000,000$ & 0,51 & & $\mathrm{NA}$ \\
\hline Beux(d)anthrocane & $26 / 51$ & 46J & 190,000 & Z2-EU33B-334 & 3,910 & & $\mathrm{HA}$ & & NA & $21,0 \%$ & ||$S \mid$ & & $\mathrm{N} / \mathbf{a}$ \\
\hline Gearenermethamol & $0 / 41$ & NO & NO & & ND & & NA & & NA & $100,000,000$ & DaI & & NA. \\
\hline 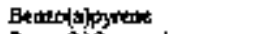 & 26151 & 45] & 170.000 & Z2-EN33E-334 & 7,139 & & NA & & NA & 之ेlo & H's! & & NA \\
\hline 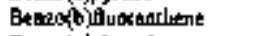 & 27951 & 4\$1 & 170,000 & Z2-EU33B-334 & 7045 & & $\mathrm{NA}$ & & $\mathrm{NA}$ & $21,0 \%$ & $|H|$ & & NA \\
\hline 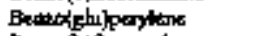 & $22 / 51$ & $47 J$ & 92000 & Z2-EN1330-334 & 1,690 & & $x_{A}$ & & NA & $29,126,201$ & $a / s 1$ & & $\mathrm{NA}$ \\
\hline 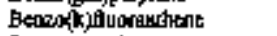 & 泣s & $17 \pi$ & $3 \pi, 000$ & 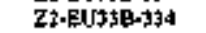 & 8,234 & & $N_{A}$ & & $\mathrm{NA}$ & $214,9,2$ & $\alpha=1$ & & $N_{A}$ \\
\hline Bearouc atd & 141 & 3.500 & 5,500 & Z2.EU $33 \mathrm{~B}-327$ & 5,500 & & $\mathrm{NA}$ & & NA & $100,000,000$ & $\$ 41$ & & NA \\
\hline 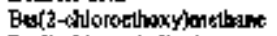 & insi & ND & ND & & No & & $\mathrm{NA}$ & & $\mathrm{NA}_{A}$ & & NA & & NA \\
\hline 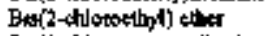 & 0 & ND & ND & & $\mathbf{k D}$ & & NA & & $\mathrm{NA}$ & 5,738 & QS1 & & NA \\
\hline Bus(2-chlorolsopropyl) edres & 0151 & ND & ND & & ND & & $\mathrm{NA}$ & & $\mathrm{NA}$ & $7,3,38$ & Quyl & & NA \\
\hline 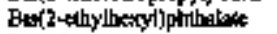 & \415! & 44 & 66,000 & Z2-EUU33E-327 & 6,916 & & $\mathrm{NA}$ & & NA & $1,291,213$ & Qyil & & NA \\
\hline Butyl benzyl ghathalete & $6+51$ & $49]$ & 29,0000 & Z2.EU33E-327 & $B, \infty 60$ & & $\mathrm{Na}$ & & NA & $100,000,0 \times 1$ & oy & & NA \\
\hline Carbazolk & 12151 & $4 I J$ & 53,000 & Z2.EU33E.334 & 4,636 & & whe & & $\mathrm{NA}$ & 861,249 & ordi & & NA \\
\hline Chryole & $2815 \mathrm{~L}$ & $44 \mathrm{~J}$ & 220,000 & Z2-EUS3E-93d & 8,450 & & $N A$ & & $\mathrm{NA}$ & $2,109,629$ & orsi & & $\mathrm{NA}$ \\
\hline Dibenas & 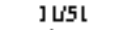 & sol & 23,000 & 227-EU33E-334 & 2,312 & & wet & & $\mathrm{NA}$ & 2,110 & I/SI & & $\mathrm{NA}$ \\
\hline Dibanimpiren & $6+51$ & $55\rfloor$ & 23,000 & $72-60039-334$ & 4,109 & & $N A$ & & NA & $1,563,342$ & QS1 & & NA \\
\hline Dieffryl phitalrte & 0151 & ND & $\mathrm{N}$ & & N[] & & $\mathrm{MA}$ & & NA & $100,000,000$ & ass & & HA \\
\hline Dunóblbyl phathake & 0151 & ND & $N D$ & & WD & & $N A$ & & NA & 100,0000000 & ats] & & NA \\
\hline [? $\neg$ - -buxyl parchalare & 239 & IJol & $1,7 \infty 000$ & $22-20153,3-327$ & 655 & & $\mathrm{NA}$ & & NA & $61, \$ 60,629$ & ary & & $\mathrm{Na}$ \\
\hline Dr-n-octy] phaldate & 251 & $120]$ & 1,400 & $22-50333 \mathrm{~B}-327$ & 760 & & $\mathrm{NA}$ & & NA & $24,624,252$ & Q5: & & $\mathrm{NA}$ \\
\hline Dipbeylyanimes & 066 & ND & ND & & ND & & $\mathrm{N} A$ & & $\mathrm{NA}$ & $15,000,000$ & ax & & $\mathrm{NA}$ \\
\hline Dipteriddurente & Who & ND & HD & & $\mathrm{ND}$ & & ies & & $N A$ & {$[5,70]$} & 0,00 & & $\mathrm{NA}$ \\
\hline
\end{tabular}


Tulte Aet (sondrowed)

\begin{tabular}{|c|c|c|c|c|c|c|c|c|c|c|c|c|c|}
\hline Aabyose & $\begin{array}{l}\text { Eropuency } \\
\text { of delest }\end{array}$ & 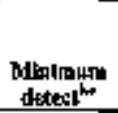 & $\begin{array}{c}\text { Maxinuon } \\
\text { Anleet" }\end{array}$ & 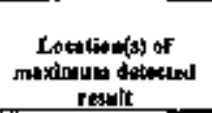 & 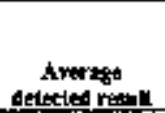 & Maxtrown & 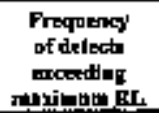 & $\begin{array}{c}\text { Aversog } \\
\text { Th }\end{array}$ & 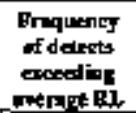 & $\begin{array}{l}\text { PHG holt } \\
\text { (J06 or } \\
\text { Ht: } 1 \text { ) }\end{array}$ & 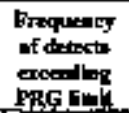 & Butagroutd & 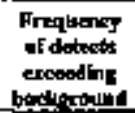 \\
\hline Fluomedivene & 30 ors I & का & 500,000 & Z7.EU338.334 & $17, \mathrm{~B} 5 \mathrm{~F}$ & & NA & & $\mathrm{dA} \Lambda$ & $22,000,353$ & AISI & & in \\
\hline Furveac & $\mid \mathbf{I} 5 \mathbf{|}$ & $48]$ & 29,000 & Z2-e0n-3B-534 & $3,3] 0$ & & HA & & $\mathrm{NA}$ & $26,281,433$ & 051 & & iA \\
\hline 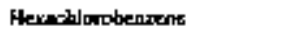 & $\mid / S t$ & 3AOS & $940 I$ & Z2-EU3JE-327 & 390 & & $\mathrm{NA}$ & & NA & to, 773 & osj & & MA \\
\hline 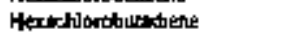 & 0663 & No & ND & & ND & & $\mathrm{NA}$ & & NA & $\mathrm{JB4}, 682$ & 0 & & $N_{A}$ \\
\hline Herechlorocy doptumodi=s & 0150 & ND & ND & & Nb & & NA & & NA & $3,658,717$ & $\cos 0$ & & WA \\
\hline Heranticocethanat & $0 / 5 \mathrm{~L}$ & ND & ND & & NB & & $\mathrm{NA}$ & & ies & 615,606 & oss & & NA \\
\hline Lodero $(1,2,3$ - sul pynent & 22751 & 491 & 37,000 & $27-E D 33 B-334$ & 4017 & & NA & & in & $2 \mathrm{t}, 095$ & us & & NA \\
\hline Lsopherde & Wht & ND & ND & & No & & NA & & is & $5,119,093$ & os 51 & & HA \\
\hline mop Metuylphenoll & 127 & $150 \mathrm{~J}$ & $450 J$ & 22-E[J33B-334 & 450 & & $\mathrm{NA}$ & , & MA & & $w_{A}$ & & BA \\
\hline Noptthidare & 9,63 & 94 & 35,000 & $22-E \mathrm{E} / 33 \mathrm{e}-334$ & S438 & & NA & & $\mathrm{NA}$ & 187,691 & 063 & & MA \\
\hline Notrobeminns & WSI & ND & $N D$ & & ND & & $\mathrm{NA}_{\mathrm{A}}$ & & $\mathrm{NA}$ & {$[02,935$} & 251 & & $\mathbf{M A}_{A}$ \\
\hline 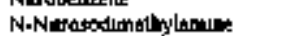 & anso & ND & NU & & No & & MA & & $N A$ & 358 & Do30 & & $\mathrm{NA}$ \\
\hline 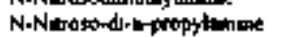 & Disi & ND & NO & & ND & & $N_{A}$ & & $\mathrm{~N}$ & 1,462 & 0.5: & & $N A$ \\
\hline 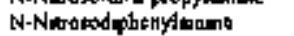 & {$[, 43$} & נדון & [ง] & $22-E U 33-2312$ & 17 & & NA & & $\mathrm{NA}$ & $3,317,7$, th & Das & & $\mathrm{NA}$ \\
\hline 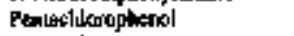 & $1 / 50$ & 345 & $74 \mathbf{J}$ & K 10040.52 & $f_{4}$ & & NA & & $\mathrm{NA}$ & 39,4 & Qxis & & NA \\
\hline Patenumibres: & 24,51 & 451 & 370,000 & $22.015 .13 \mathrm{~B} \cdot 334$ & 16,358 & & $\mathrm{NA}$ & & $N_{A}$ & $\$ 0,126,201$ & $\cos 1$ & & wA \\
\hline Ptientol & $1+B 0$ & $260 \mathrm{H}$ & $260 \mathrm{~J}$ & 7. 2 .E[133B.394 & 200 & & $\mathrm{NA}$ & & $\mathrm{NA}$ & 100,0000000 & 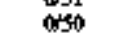 & & $M_{A}$ \\
\hline Pyтен: & 30,51 & $4 \mathrm{JJ}$ & 340,000 & Z2.EU13P.394 & 12,250 & & NA & & NA & $29,136,201$ & ays & & $\mathrm{Na}$ \\
\hline Pyndure & 0,042 & $\mathrm{ND}$ & ID & & ND & & $\mathrm{NA}$ & & $\mathrm{NA}$ & $6 \mid 5,000$ & $a_{42}$ & & NA \\
\hline \multicolumn{14}{|l|}{ 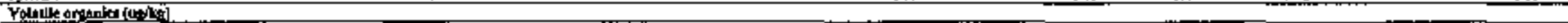 } \\
\hline 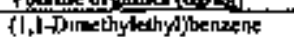 & âj 12 & wD & Wi & & ND & & NA & & $\mathrm{Nk}$ & 390,000 & $\mathbf{Q} \backslash 2$ & & NA \\
\hline 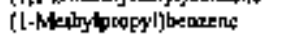 & o' 2 & $\mathrm{WD}$ & ND & ' & $\mathrm{ND}$ & & HA & & $\mathrm{NA}$ & 220,000 & 畨/2 & & $\mathrm{Nk}$ \\
\hline$[, 1,1,2, I$ en andoroeshane & WrLZ & $\mathrm{ND}$ & $\mathbf{N D}$ & & $\mathrm{MD}$ & & $\mathrm{HA}$ & & $\mathrm{Nh}$ & 72,755 & (12 & & $N A$ \\
\hline $1,1,1$. Thatlocoesthent & $\operatorname{Lsz}$ &,+ 300 & 1,700 & Z2-EU33H-113 & 1,300 & & NA & & $\mathrm{NA}$ & $1,200,000$ & 0237 & & $\mu_{\mu}$ \\
\hline 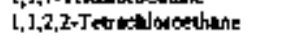 & I & $\mathrm{ND}$ & ND & & ND & & $N_{A}$ & & $\mathrm{NA}$ & 9.294 & 0031 & & $M$ \\
\hline $1,1,2-T_{\text {trebl }}$ of $0-1,2,2-$ & 24 & 21 & 150 & 22.EU53B-LI3 & 855 & & NA & & $\mathrm{NA}$ & $3,600,0000$ & ond & & $\mathrm{NA}$ \\
\hline 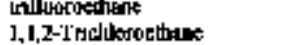 & 132 & 74 & 74 & Z3-EU1338-413 & 74 & & $\mathrm{NA}$ & & MA & 16,050 & 032 & & NA \\
\hline 1, If Destloncediente & 1052 & $A B D$ & 400 & $\mathrm{Z}-\mathrm{E}[\mathrm{3} 3 \mathrm{~B}-413$ & 180 & & $\mathrm{NA}$ & & $x_{A}$ & $1,736,654$ & $0 \sqrt{32}$ & & $\mathrm{NA}_{A}$ \\
\hline l,I-Drehlowotedietie & 102 & 320 & 320 & 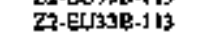 & 520 & & $N_{A}$ & & NA & $4,3,321$ & a 32 & & $\mathrm{~N}_{\mathrm{A}}$ \\
\hline L, I-Dresloropsopente & $0+12$ & & & & ND & & $\mathrm{NA}$ & & NA & & & & NA \\
\hline 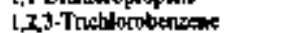 & 0 & ND & ND & & ND & & NA & & $N_{A}$ & & $N_{A}$ & & NA \\
\hline 1.3)-Trebtoropropane & 供12 & ND & ND & & ND & & $\mathrm{NA}$ & & $\mathrm{NA}$ & 7 (n) & 013 & & NA \\
\hline 1,2,-Trumethy lestreace & 粗 & $\mathrm{ND}$ & ND & & ND & & NA & & $\mathrm{Nk}$ & $1 \pi 0,2 \pi 2$ & 012 & & $N_{A}$ \\
\hline 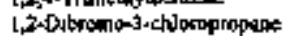 & $0 r^{\prime} \mid z$ & $\mathrm{l}$ & ND & & ND & & NA & & $\mathrm{Nk}$ & 11,000 & W/12 & & $N A$ \\
\hline 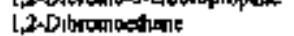 & $0 \times 12$ & WD & $\mathrm{ND}$ & & ND & & $N \wedge$ & & NA & 650 & w12 & & $N A$ \\
\hline 1,2-Dichloroethene & $L_{132}$ & ii & II & 72-E) $33 \mathrm{E}-\mathrm{E} \mathbf{1 3}$ & 11 & & NA & & $N_{\alpha}$ & 6,033 & 10 & & $N A$ \\
\hline b,2-Duchluroetberece & $a_{2}$ & ND & ND & & MD & & $\mathrm{NA}$ & & NA & $1,50,000$ & $a / 2$ & & $\mathrm{NA}$ \\
\hline 1,2-Dichlarepopans & 0,32 & $\mathrm{MD}$ & ND & & $\mathrm{MD}$ & & $\mathrm{HA}$ & & NA & 7,422 & $\log _{2}$ & & $\mathrm{WA}$ \\
\hline 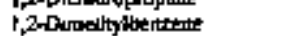 & W'I & $N$ & $\mathrm{ND}$ & & ND & & wA & & NA & $42 \pi, 0 \infty 0$ & QN & & $w_{k}$ \\
\hline 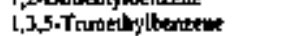 & 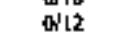 & $\mathrm{ND}$ & MO & & NAD & & $N_{A}$ & & $\mathrm{Nh}$ & 69,712 & 田12 & & $n$ \\
\hline 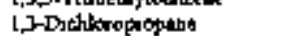 & and 2 & $\mathrm{ND}$ & ND & & $M D$ & & NA & & $\mathrm{NA}$ & 3601,521 & DXI2 & & sh \\
\hline 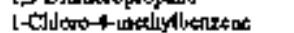 & of 12 & ND & NO & & ND & & NA & & $\mathrm{NA}$ & & $\mathrm{NA}$ & & $\mathrm{NA}$ \\
\hline l-qulowaheswane & $0 \times 12$ & ND & ND & & ND & & $N_{A}$ & & $\mathrm{NA}$ & & $N A$ & & $N A$ \\
\hline [-Metyldal:- & WN12 & $\mathrm{ND}$ & ND & & $\mathrm{ND}$ & & NA & & $\mathrm{N} \hat{k}$ & & $\mathrm{NA}$ & & $\mathrm{NA}$ \\
\hline 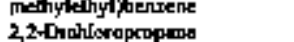 & $0 \times 12$ & ND & $\mathrm{ND}$ & & MD & & HA & & $\mathrm{N}_{\mathrm{H}}$ & & $\mathrm{ran}$ & & $\mathrm{NA}$ \\
\hline 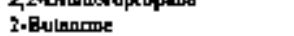 & Lis? & [6] & (6) & Z2-EU33-217 & 16 & & $N_{A}$ & & Nk & $1 / 3,264,3 \mathrm{gB}$ & 132 & & WA \\
\hline 2-Hekerone & WN5? & ND & ND & & ND & & NA & & $\mathrm{N} k$ & & $\mathrm{NA}$ & & NA \\
\hline 2-Netluxxy-2-methydpopht & of 12 & ND & ND & & ND & & NA & & $\mathrm{N} k$ & $700,000+$ & wit & & $\mathrm{NA}$ \\
\hline 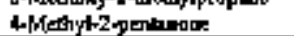 & WN2 & ND & ND & & N & & $N_{A}$ & & $\mathrm{NA}$ & $47,000,434$ & $\alpha \geq 3$ & & $\mathrm{NA}$ \\
\hline
\end{tabular}


Toble A, (coptinued)

\begin{tabular}{|c|c|c|c|c|c|c|c|c|c|c|c|c|c|}
\hline Aneyte & 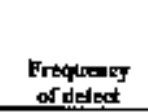 & $\begin{array}{c}\text { DHimianuta } \\
\text { detect }\end{array}$ & 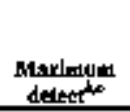 & 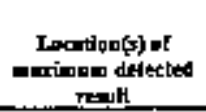 & $\begin{array}{c}\text { Average } \\
\text { sedeled renuth }\end{array}$ & 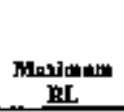 & 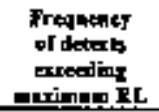 & $\begin{array}{c}\text { Averdpo } \\
\text { RLE }\end{array}$ & 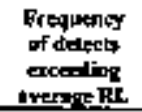 & 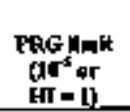 & 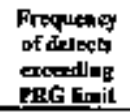 & 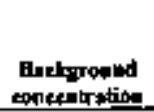 & 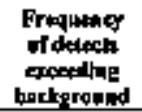 \\
\hline Acerdont & $4 \sqrt{2}$ & 101 & 64 & $27.6039-113$ & 385 & & NA & & WA & $94,320,986$ & $0 \% 3$ & & $\mathrm{NA}$ \\
\hline Eetratest & $2 / 32$ & 225 & 35 & $22 \cdot \ln 38-346$ & 285 & & $N A$ & & k & $14,0,044$ & 0,32 & & NA \\
\hline Eromoleprene & $a$ & ND & ND & & ND & & $\mathrm{NA}$ & & $\mathrm{NA}$ & 92.152 & 0,12 & & NA \\
\hline Bronanchlowongeahane & ariz & ND & ND & & ND & & $\mathrm{Nk}$ & & $\mathrm{NH}$ & & $\mathrm{Nh}$ & & NA \\
\hline Bropraptatioramelhere & Q 322 & HD & ND & & ND & & $\mathrm{NA}$ & & $\mathrm{MA}$ & 18,306 & 032 & & NA \\
\hline Bromolorm & $\cos 2$ & $\mathrm{KQD}$ & ND & & ND & & NA & & $\mathrm{mA}$ & $2,131,99$ & $\cos 2$ & & NA \\
\hline Bramornothane & Das & ND & ND & & ND & & NA & & $2 \pi$ & 13,078 & 032 & & $\mathrm{HA}$ \\
\hline Butylbeourne & ONL2 & סונ & No & & No & & $N_{A}$ & & WhA & 240,000 & o'iz & & NA \\
\hline Carteon dystide & 1,92 & 69 & 69 & 22-EU338-11引 & 69 & & $N_{*}$ & 1 & $\mathrm{HA}$ & 720,000 & $0+32$ & & NA \\
\hline 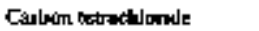 & 392 & ] 2 & 3 & $22-E 19330-32 t$ & 227 & & $N_{*}$ & & $W_{A}$ & 5,493 & 632 & & $N_{A}$ \\
\hline Oalowobertent & ANO2 & NO & ND & & $\mathrm{AD}$ & & $\mathrm{NA}$ & & WA & 530,466 & 632 & & NA \\
\hline Olonediante & $(x) 3$ & ND & ND & & $\mathrm{ND}$ & & NA & & WA & 64,855 & 032 & & NA \\
\hline Olomelestik & $2 \tan 2$ & (10 & 41 & Z2EU33日-113 & 21 & & $N A$ & & $\mathrm{NA}$ & $1,69 \mathrm{~A}$ & 632 & & $\mathrm{Na}$ \\
\hline Dheremetiane & arti & $N D$ & ND & & ND & & NA & & $\mathrm{MA}$ & $2 \leq 3,746$ & OH & & $N_{A}$ \\
\hline c15-1,2-Dechloroetheos & $3 /$ & $|2|$ & 570 & 22.ELI35-137 & 983 & & NA & & $N_{A}$ & {$[46,3131$} & $03 !$ & & $N_{A}$ \\
\hline c1:-1.3. Dochlomopropene & as & ND & ND & & ND & & Na & & NA & 17,643 & $0 \times 32$ & & NA \\
\hline Cumene & $\alpha / 2$ & ND & ND & & ND & & NA & & $\mathrm{NA}$ & 520,000 & WI2 & & $N_{\lambda}$ \\
\hline 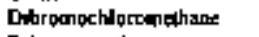 & as 2 & ND & $\mathrm{ND}$ & & ND & & $\mathrm{NA}$ & & $\mathrm{Nh}$ & 28,547 & an? 3 & & $i n$ \\
\hline Dtroppomethope & 0,12 & ND & ND & & ND & & NA & & MA & 297,550 & W'? & & $\mathrm{NA}$ \\
\hline Dnd lorod ffhuocrome thute & ariz & No & $\mathrm{ND}$ & & ND & & $\mathrm{NA}$ & & $\mathrm{NA}$ & GQ8 058 & $\mathbf{Q}] 2$ & & $m_{k}$ \\
\hline Elypherizang & 237 & 74 & 301 & $23-E \cup 330-321$ & IE? & & $\mathrm{NA}$ & & $\mathrm{NA}_{\mathrm{A}}$ & 595,000 & 0,32 & & NA \\
\hline Iodoractume & WLI & No & ND & & $\mathrm{ND}$ & & $\mathrm{NA}_{\mathrm{A}}$ & & $W_{A}$ & & NA & & NA \\
\hline$M+P X y k=0$ & 620 & ND & No & & No & & Na & & $N A$ & 420.000 & 60 & & NA \\
\hline Mehylewe chlondt & $3 \sqrt{2}$ & 71 & 10 & 22E013B-1:3 & 260 & & $\mathrm{NA}$ & & $\mathrm{NA}$ & 2002369 & 033 & & NA \\
\hline OC-Chlarotoduluen & or 12 & מאו & ND & & ND & & $\mathbf{N k}$ & & NA & 560,010 & $0 / 12$ & & $N_{A}$ \\
\hline Propothenaref & wh2 & $\mathrm{Mg}$ & ND & & No & & sth & & FA & 240.000 & 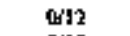 & & $\mathrm{NA}$ \\
\hline Styrext & ors 2 & No & ND & & ND & & $\mathrm{NA}$ & & $3 \mathrm{HA}$ & $1,700,000$ & 037 & & NA \\
\hline Tetrocklomethente & $3 / 32$ & 23) & 261 & 22-EU/33B-327 & 12 & & $\mathrm{NA}$ & & int & 13,086 & 037 & & $\mathrm{NA}$ \\
\hline $\begin{array}{l}\text { Taluene } \\
\text { Thesis }\end{array}$ & $7 / 32$ & u & 30 & 22- EU $U 3 \mathrm{E}-313$ & in 3 & & $\mathrm{NA}$ & & $W_{A}$ & 520,000 & $0 \times 32$ & & $N_{A}$ \\
\hline Talol Xylene & $2 \vdash 2$ & 18 & 2901 & 22EEบIJB-321 & 154 & & $N n$ & & HA & $\$ 20,060$ & Q12 & & NA \\
\hline 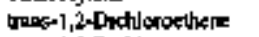 & $3 / 30$ & $|7|$ & 255 & 22E EU93日-137 & 217 & & NA & & WA & 239,829 & 030 & & $N A$ \\
\hline 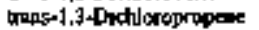 & $\operatorname{Los} 2$ & $\mathrm{MD}$ & ND & & ND & & $\mathrm{NA}$ & & $\mathrm{WA}_{\mathrm{A}}$ & J7.645 & 632 & & $\mathrm{NA}$ \\
\hline Tromlormeshere & $7 m I$ & I I I & 580 & 22.EU33B-113 & jos & & $\mathrm{NA}$ & & $\mathrm{HA}$ & 1,147 & 033 & & NA \\
\hline Jochloroflupromethere & $\$ 12$ & $\mathrm{ND}$ & ND & & ND & & NA & & $\mathrm{mA}$ & $1,276,074$ & 6'12 & & $\mathrm{NA}$ \\
\hline Voyl axzale & Q 12 & $\mathrm{ND}$ & ND & & ND & & $\mathrm{NA}$ & & $M A$ & $1,996,422$ & 6)12 & & NA \\
\hline Verylajoxide & 3,92 & 82 & 37 & $22+20133-217$ & 207 & & $\mathrm{NA}$ & & $\mathrm{MA}$ & 7,461 & 632 & & $\mathrm{NA}$ \\
\hline \multirow{2}{*}{\multicolumn{14}{|c|}{ 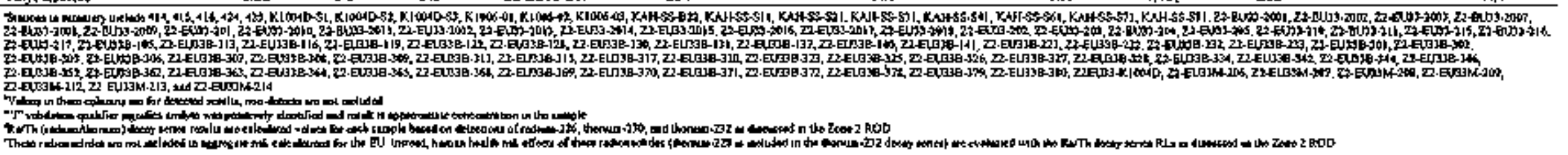 }} \\
\hline & & & & & & & & & & & & & \\
\hline 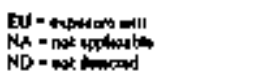 & \multicolumn{13}{|c|}{ 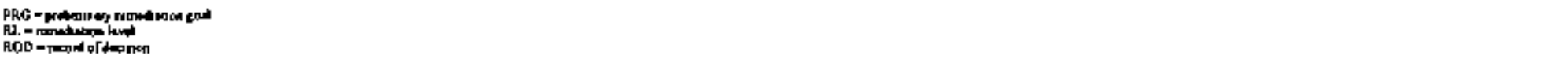 } \\
\hline
\end{tabular}


Tablo A.5. ED Z2-13 conerete date qumary"

\begin{tabular}{|c|c|c|c|c|c|c|c|c|c|c|c|c|c|}
\hline Antyls & $\begin{array}{l}\text { Erupuars; } \\
\text { of detists }\end{array}$ & $\begin{array}{c}\text { Mladmen } \\
\text { detect }\end{array}$ & $\begin{array}{c}\text { Marionifm } \\
\text { detest }\end{array}$ & 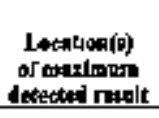 & $\begin{array}{l}\text { Averase } \\
\text { deteded routt }\end{array}$ & $\begin{array}{c}\text { Maximanum } \\
\text { R2 }\end{array}$ & 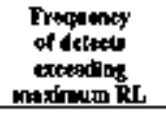 & $\operatorname{Arm}_{\mathrm{RL}}$ & 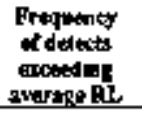 & $\begin{array}{c}\text { PBG Ulmi } \\
\text { (10 dor } \\
\text { HIIn 1) }\end{array}$ & 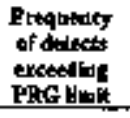 & $\begin{array}{l}\text { Bectagroud } \\
\text { enceitintion }\end{array}$ & 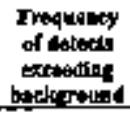 \\
\hline \multicolumn{14}{|l|}{ Inoreanite } \\
\hline Ahulariang & IO'LO & 3,600 & 13,000 & $22-601532004$ & $\$, 100$ & & NA & & $N_{A}$ & 100,000 & \%10 & 40,300 & W \\
\hline Anceltaony & $\$ 10$ & $001 \$$ & 0261 & Z2-E039-2011 & 0063 & & NA & & $\mathrm{NA}$ & ADB 8 & (t) & 152 & $\$ 10$ \\
\hline Anseture & Lor 10 & 23 & 49 & Z2-EIY33-2027 & 32 & 900 & oro & 300 & w10 & 159 & of 10 & 1493 & 010 \\
\hline Bonuth & bosta & 251 & 210 & 22 Ely53-2004 & 406 & & $\mathrm{NA}$ & & $N_{A}$ & 66,577 & \$10 & 12493 & अ \\
\hline Beryyllawh & IG'10 & 079 & $\$ 1$ & $2260113-2006$ & 106 & 6,000 & $\$ 10$ & 2,0000 & N & 1.991 & 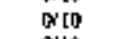 & 22 & 310 \\
\hline Eห⿻日⺈ & torto & 51 & 17 & 22EU33.20106 & 182 & & NA & , & NA & 100,000 & $\$ 10$ & & NA \\
\hline Cunnum & iovía & 023 & 13 & 22EU33.2006 & 347 & & NA & 1 & NA & $\$ 51$ & $9 \times 10$ & 0220 & Ioflo \\
\hline Calkium & iorio & 31,000 & 230,000 & 220039.2006 & 131,700 & & $\mathrm{NA}$ & & $N A$ & & $\mathrm{NA}$ & 2,400 & 1010 \\
\hline Chromitan & a & i1 & 171 & 22 EU3s.2016 & 163 & & $\mathrm{NA}_{\mathrm{A}}$ & & $N A$ & 640 & n'to & 44 & 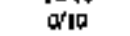 \\
\hline Cobath & |arto & $2 \mathrm{LJ}$ & 81 & 22 EU3 3.2007 & 437 & & $\mathrm{NA}$ & & NA & t37,310 & 0.10 & 12 & $\alpha 10$ \\
\hline Copper & iario & 52 & 52 & 7.2. Fus3.2003 & 144 & & $\mathrm{NA}$ & & NA & 40,877 & inlo & 2342 & $2 \pi$ \\
\hline Iron & Iorlo & 4,700 & 11,0000 & Z2.EU33-2709 & 7,610 & & NA & & wh & 100,000 & ato & $5 x, 600$ & orio \\
\hline Leaph & 10rio & 35 & 37 & Z2-EU3\}-2012 & 159 & & $\mathrm{HA}$ & & NA & 900 & $0 \times 10$ & 3791 & o10 \\
\hline Lothem & IW10 & 35 & 20 & $\begin{array}{l}22-E U 33-2004 \\
2 \geq-E U 33-2006\end{array}$ & 83 & & NA & & $\mathrm{NA}$ & 20,439 & $\alpha 10$ & 489 & $\$ 10$ \\
\hline Mapulezum & $10 / 10$ & 1,70051 & 63,000 & $\begin{array}{l}\text { 22-EU13-2006 } \\
\text { Z2EU3 }\end{array}$ & $\$ 1,000$, & & NA & & $\mathrm{Nk}$ & & $\mathrm{NA}$ & 3,300 & $*^{\prime \prime \prime}$ \\
\hline Mmprenes & 10010 & $130 \mathrm{~J}$ & T:ter & $2,2-6 \mathrm{U}\} 3-2006$ & 402 & & NA & & $\mathrm{N} / \mathrm{k}$ & 19,ASt & $\infty \times 10$ & 2,100 & 210 \\
\hline Magany & 606 & 0 ty & 0.551 & 22,EU33-20103 & 0353 & 1,800 & QW & $6 D$ & Def6 & 307 & off & ót? & SNO \\
\hline blolyhdenam & Arlo & 12 & 22 & $22-\mathrm{a} / 39-200 \%$ & 155 & & $N_{A}$ & & NA & 5,110 & wiv & & $\mathrm{Nh}$ \\
\hline Nwikel & IWIO & 5 & I65 & $\begin{array}{l}22-a 103-2007 \\
22-a 153-2010\end{array}$ & di & & $\mathrm{NA}$ & & NA & 20,439 & ajo & 2607 & Dיו" \\
\hline Pocesturar & IS/IEI & $T k_{0}$ & $3,6001)$ & $2 \geq-E U 53-2006$ & $150 \mathrm{~d}$ & & $\mathrm{NA}$ & & $N A$ & & NA & 5,07469 & WID \\
\hline Selenuam & 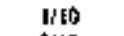 & 0473 & 0.7] & Z2-EU\}3-20104 & 047 & & $\mathrm{NA}$ & & $\mathrm{NA}$ & 5,110 & Dו & 147 & 0 \\
\hline Sluver & 210 & o[ & Q OUI & 22 Evots-200 & $0 \operatorname{tos}$ & & $\mathrm{NA}$ & & $\mathrm{NA}_{\mathrm{A}}$ & 5,110 & W10 & $06 \mathrm{U}$ & סואס \\
\hline Sodhur. & ID & 180 & 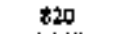 & 22 Elat3-2004 & 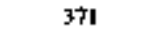 & & $\mathrm{NA}$ & & $N_{A}$ & & $\mathrm{NA}$ & 497 & 김 \\
\hline Tulluen & סו & 00 o[g] & 0064 & $22+2153-2027$ & 0030 & & $\mathrm{NA}$ & & $\mathrm{NA}$ & 679 & do & DAU & WID \\
\hline Total Uramum & If & 199 & 197 & $22-$ EU33B 535 & 197 & & NA & & $N_{A}$ & 2004 & o'l & & $\mathrm{NA}$ \\
\hline Urarum & Lóld & 05 & 12 & Z2-Eus $3-2004$ & 175 & & NA & & $N_{A}$ & 204 & $\omega, 0$ & & $N_{A}$ \\
\hline 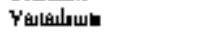 & 100 & 33 & It & 22 EUpg-2026 & $i \pi$ & & NA & & $N_{A}$ & 1,022 & ore & 6547 & $D 50$ \\
\hline Zanc & 10010 & 13 & 9001 & Z2EUU3.2027 & $\geq 8$ & & NA & & N & 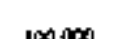 & (2) & \pm 97 & s \\
\hline \multicolumn{14}{|c|}{ 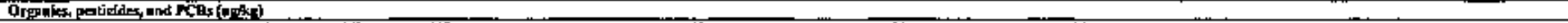 } \\
\hline 4,4-DDD & ab & NO & ND & & No & & NA & & $\mathrm{NA}$ & 1000,0061 & ow & & NA \\
\hline A,A $\mathrm{BDE}$ & as & ND & ND & & ND & & $\mathrm{NA}$ & & $\mathrm{NA}$ & $\pi 0,000$ & 样 & & $N A$ \\
\hline 4.4-DDT & a & ND & ND & & ND & & $\mathrm{NA}$ & & $\mathrm{NA}$ & $\pi, 000$ & arl & & $N A$ \\
\hline Aldet & as & ND & ND & & ND & & NA & & Nh & 1,000 & W & & $\mathrm{JAA}$ \\
\hline घlphu-BHC & as & ND & ND & & ND & & NA & & Mh & 3,600 & ory & & $\mathrm{NA}$ \\
\hline Alphatchontane & QI & ND & ND & & ND & & $\mathrm{NA}$ & & $\mathrm{NA}$ & 63000 & the 3 & & $N A$ \\
\hline Beta- $\mathrm{BHC}$ & to & ND & $\mathrm{ND}$ & & No & & NA & & $\mathrm{NA}$ & $1+000$ & a. & & $\mathrm{NA}$ \\
\hline deltar. Bi $\mid$ C & Q3 & ND & $\mathrm{ID}$ & & $\mathrm{GD}$ & & NA & & NA & & $\mathrm{Nh}$ & & NA \\
\hline Ibeddre & 63 & ND & ND & & $\mathrm{kD}$ & & NA & & $\mathrm{N} / \mathrm{A}$ & 1,100 & ars & & $\mathrm{NA}$ \\
\hline Endosulfan! & (b3 & Nu & ND & & No & & $\mathrm{NA}$ & & $\mathrm{NA}$ & $3,700,000$ & or 3 & & $\mathrm{NA}$ \\
\hline Endosulfital Ji & 63 & ND & ND & & ND & & $\mathrm{NA}$ & & $\mathrm{NA}$ & $3,700,000$ & ons & & $N A$ \\
\hline Eotosulfar oulfare & $a+3$ & ND & ND & & ND & & NA & & NA & $3,700,000$ & Q & & $N A$ \\
\hline Eadrun & $Q 3$ & $\mathrm{NDF}$ & ND & & ND & & NA & & $N_{A}$ & 130,000 & Q63 & & $\mathrm{NA}$ \\
\hline Eadrus adebyde & $\omega_{3}$ & ND & ND & & ND & & NA & & $\mathrm{Nh}$ & 130,060 & 吸 & & $N A$ \\
\hline Eutrn katowe & $a / 3$ & $\mathbf{N D}$ & ND & & ND & & NA & & NA & 180,000 & $0 \sqrt{3}$ & & WA \\
\hline stmina Chlordans & 67 & $\mathrm{ND}$ & $\mathrm{ND}$ & & ND & & $\mathrm{NA}$ & & $\mathrm{NA}$ & 65,000 & \$3 & & $\mathrm{NA}$ \\
\hline
\end{tabular}




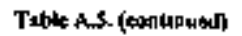

\begin{tabular}{|c|c|c|c|c|c|c|c|c|c|c|c|c|c|}
\hline - Aoulote & 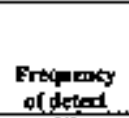 & 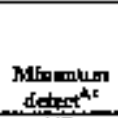 & 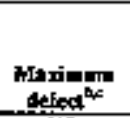 & 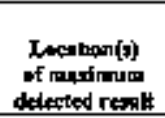 & 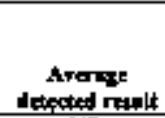 & $\begin{array}{c}\text { Marimann } \\
\text { RL }\end{array}$ & 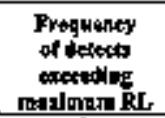 & $\begin{array}{c}\text { Awante } \\
\text { Rl }\end{array}$ & 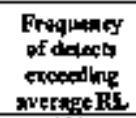 & 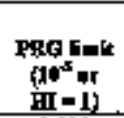 & 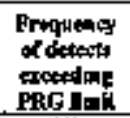 & 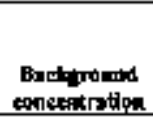 & 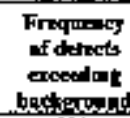 \\
\hline Hepl*acldor & Q⿳亠口冋丁口 & ND & ND & & ND & & $N_{A}$ & & $N / A$ & 3,800 & ors & & NA \\
\hline 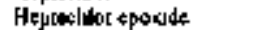 & 0 & ND & wD & & ND & & NA & & inh & 1,900 & 躬 & & $\mathrm{HA}$ \\
\hline Condene & 就 & ND & WD & & ND & & NA & & $n$ & 17,000 & 的 & & Wh \\
\hline Metioxychlor & $0 n$ & ND & ND & & ND & & NA & & $\mathrm{NA}$ & $3,10,000$ & 0,13 & & $\mathrm{kH}$ \\
\hline PCE-1016 & OII & ND & ND & & ND & 100,000 & a/1 & 10,000 & I & 37,000 & on & & NA \\
\hline PCPE-1221 & WII & ND & WD & & ND & 100,0006 & at1 & 10,000 & I I I & 7,436 & i & & MA \\
\hline PCE-1202 & o'li & ND & NO & & ND & 100,0015 & â1 & 10,000 & IוI & 7,436 & M1i & & NA \\
\hline PLO-1242 & oni & ND & mo & & ND & 100,000 & a & 10,000 & וונו & 7436 & Wi & & MA \\
\hline$P C H+124 B$ & ol [ & ND & $M D$ & & ND & 100,000 & טוור & 10,000 & DII & 7,436 & Wi & & NA \\
\hline PCR.12S4 & git & 421 & 51,000 & ZZ7.EUJ]-200d & 12,025 & 100,000 & L & 10,000 & 则 & 7,436 & Iוזו & & NA \\
\hline $\mathrm{PCB} 1260$ & $3 / 11$ & 693 & 39 & Z2-EU338-225 & 200 & 100,000 & till & 10,000 & Q & 7,436 & III I I I & & NA \\
\hline Polyat) comoled bupbaryl & $10 x+1$ & 69! & 51,000 & 27-EU133-2004 & 9,626 & 100,900 & וֹו' & t0,000 & 则 & 7,436 & $3 r i$ & & $N A$ \\
\hline Towphere & $\mathrm{CO}^{\mathrm{S}}$ & NO & $\mathrm{Na}$ & & ND & & $\mathrm{NA}$ & & $\mathrm{NA}$ & 60,000 & $\mathrm{DM}$ & & $\mathrm{NA}$ \\
\hline \multicolumn{14}{|l|}{ 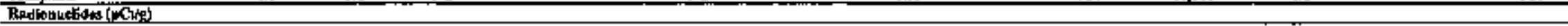 } \\
\hline Alphas octivity & Thlo & 130 & $8 \mathrm{~B} 5$ & 277 -EU33-2004 & 524 & & SNA & & NA & & Nं太 & & $\mathrm{NA}$ \\
\hline Beali axtrity & 610 & 2 & 865 & 27-EU133-2010 & 394 & & $\mathrm{NA}$ & & NA & & NA & & $\mathrm{NA}$ \\
\hline B|toreth-2it & 3 & $123 \mathrm{JJ}$ & 146 & $2 \vec{b}$-EN\}-2009 & 131 & & $N_{\Lambda}$ & & $N_{A}$ & $136, \infty 00$ & ans & & $\mathrm{NA}$ \\
\hline Cotalunt- $\{3\}$ & W10 & NO & ND & & $\mathrm{ND}$ & 20 & 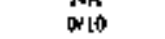 & $i$ & alo & 113 & - & & NA \\
\hline Coball- 60 & oito & $\mathrm{ND}$ & $\mathrm{ND}$ & & WD & & NA & & NA & 06 & o $J 0$ & & NA \\
\hline$L_{\text {end }}-212$ & 878 & 0275 & 0939 & $27 \cdot[2] 133.2006$ & 0467 & & $\mathrm{NA}$ & & $\mathrm{NA}$ & 61,300 & 0,18 & & int \\
\hline Lend-214 & $4 / 4$ & 0 526 & Jו1 & $\mathrm{T2} \cdot \mathrm{E} \cup 133 \times 2006$ & 0 ogd & & NA & & $\mathrm{NA}$ & 756,000 & 0,4 & & $\mathrm{Nh}$ \\
\hline Nopturiom:-237 & Q & ND & WD & & ND & 50 & w/o & 5 & onto & 272 & or & & NA \\
\hline Polass: & 399 & 33 & 932 & $27-E 033-2011$ & 625 & & $\mathrm{NA}$ & & $\mathrm{NA}$ & $2 \pi$ & $8 \times 9$ & $32 \mathrm{E2}$ & 00 \\
\hline $\mathrm{Ra} / \mathrm{Th}$ dtcay sencos $\mathrm{s}^{\mathrm{H}}$ & $|0| 0$ & 0 & $16 \mathrm{l}$ & 22-EU33-21004 & 0295 & 15 & Wio & 1 & 则䧄 & & NA & & $\mathbf{N} \mathbf{k}$ \\
\hline Reshum-225 & 9iv & 0 L 65 & 127 & 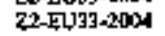 & 0 5ad & & NA & & wak & 026 & 6010 & 125 & $|r| 0$ \\
\hline Technadure-gs & $0+10$ & ND & WD & & ND & & NA & & $i=$ & 8,960 & 010 & & Nh \\
\hline Thenum-23\% & mo & 0.464 & 100 & Z2-EU33-2005 & 0.731 & & NA & & $\mathrm{NA}$ & 018 & 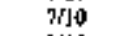 & 186 & $W_{N} \mid 0$ \\
\hline Thenuna-230 $d^{\prime *}$ & 6190 & $0558 \mathrm{~J}$ & 281 & $72-\mathrm{EO} 33-2000$ & 142 & & $\mathrm{NA}$ & & juk & 2012 & N110 & 12 & YIID \\
\hline Thenumb-zy $y^{3 *}$ & 9110 & 0159 & 134 & 22-EU13-2004 & 072 & & NA & & $\mathrm{NA}$ & 018 & $8+10$ & 194 & $0 \times \mid 0$ \\
\hline Thoorumb-394 & 010 & ND & $\mathrm{ND}$ & & ND & & $\mathrm{NA}$ & & $\mathrm{NAn}$ & 32,800 & 010 & & $\mathrm{NA}$ \\
\hline Uгвлет-żज-4 & IIII & 0.992 & 387 & 22.EU336.235 & 361 & 7000 & $\left.\omega^{\prime}\right] 1$ & $m \infty 0$ & QII & 332 & IIII & & NA \\
\hline 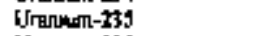 & 4III & 0136 & $1 \pm 6$ & $72.6 U 336.225$ & 48 & $\mathrm{Bo}$ & will & 8 & ini & J 98 & Hi & & $\mathrm{NA}$ \\
\hline 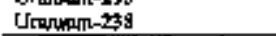 & IIrkI & 0228 & 633 & Z2-EU33E-225 & 640 & 500 & யاl & 50 & wtI & 18 & ini & 147 & $2 \pi 1$ \\
\hline \multicolumn{14}{|l|}{ 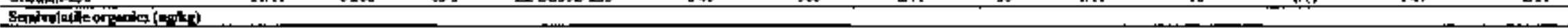 } \\
\hline 1,2,4-Tneflocobenzente & (1010 & ND & Na & & M & & $N_{A}$ & & NA & 215,925 & $1 \% 10$ & & $\mathrm{~min}$ \\
\hline 1.2-Dichlonobengene & ario & ND & ND & & ND & & NA & & NA & 600,6000 & wilo & & $\mathbf{N A}$ \\
\hline 1,3-Dichlorobeacene & orlo & WD & No & & $\mathrm{ND}$ & & we & & NA & 604000 & wio & & HA \\
\hline 1,A-Durblorobeareat & arlo & $\mathrm{ND}$ & ND & & $\mathrm{ND}$ & & $\mathrm{ju}$ & & NA & 78,655 & arto & & NA \\
\hline 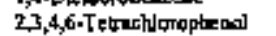 & ano & WD & ND & & $\mathrm{ND}$ & & $\mathrm{NA}$ & & $\mathrm{NA}$ & $18,468,189$ & of & & NA \\
\hline 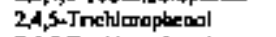 & orlo & MD & ND & & No & & $\mathrm{Nh}$ & & NA & $61,560,629$ & ovio & & $\mathrm{NA}$ \\
\hline 2,1,6-Tochloroptsoal & Q 110 & ND & ND & & ND & & $\mathrm{NA}$ & & NA & 6],561 & 0,10 & & $\mathrm{NA}$ \\
\hline 2,4:Dublboropherof & 0.10 & ND & ND & & ND & & $\mathrm{MA}$ & & NA & $1,846,819$ & orlo & & $N A$ \\
\hline 2.4.Duneliylphenot & ON10 & N1 & ND & & $\mathrm{ND}$ & & $\mathrm{NeS}$ & & NA & $12,332,126$ & DID & & NA \\
\hline 2,4.Dunatrophentiol & Dו & $A D$ & $\mathrm{ND}$ & & ND & & $\mathrm{Nh}$ & & $N_{A}$ & $1,231,213$ & वा० & & $\mathrm{NA}$ \\
\hline 2,4-Duntrotalectat & \$10 & ND & No & & $\mathrm{ND}$ & & $\mathrm{NA}$ & & $\mathrm{NA}$ & 25.348 & Dito & & $\mathrm{NA}$ \\
\hline 2,6-Dunueroolwent & N10 & ND & ND & & wo & & $N_{A}$ & & $\mathrm{NAB}$ & 2534 & $\begin{array}{ll}1 \\
0\end{array}$ & & $\mathrm{NA}$ \\
\hline 2 Chlemergp thakew & W10 & ND & $\mathrm{ND}$ & & WD & & $N \hbar$ & & $\mathrm{NA}$ & $23,3 \pm 2,732$ & סואט & & $N A$ \\
\hline 2-Cherophemol & wio & No & NL & & no & & $N_{\Lambda}$ & & $\mathrm{NA}$ & 235,765 & os & & NA \\
\hline 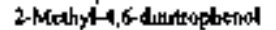 & No & ND & ND & & ND & & $\mathrm{NA}$ & & NA & 61,561 & orlo & & $N A$ \\
\hline 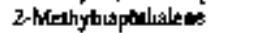 & o & $\mathrm{AD}$ & MD & & ND & & wh & & $N A$ & {$[37,69]$} & Drlo & & NA \\
\hline 2-Medhutphescol & 0,10 & ND & ND & & $\mathrm{ND}$ & & NA & & $\mathrm{NA}$ & $30,300,315$ & OSIO & & NA \\
\hline
\end{tabular}




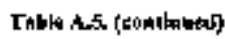

\begin{tabular}{|c|c|c|c|c|c|c|c|c|c|c|c|c|c|}
\hline . Anchodf & $\begin{array}{l}\text { Iroquency } \\
\text { M Idetery }\end{array}$ & 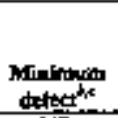 & Mhrinum & 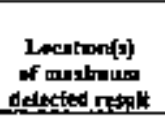 & 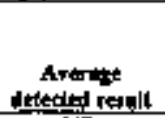 & 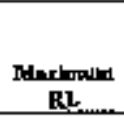 & 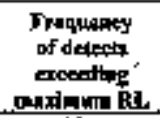 & $\underset{R I}{\text { Arasese }}$ & 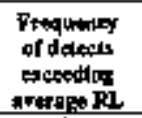 & $\begin{array}{c}\text { FRG lundt } \\
\left(10^{4} \mathrm{or}\right. \\
\text { HI }=5)\end{array}$ & 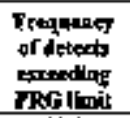 & 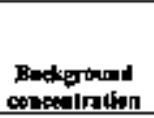 & 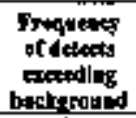 \\
\hline 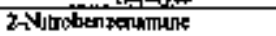 & बाँ́ & ND & ND & & ND & & NA & & NA & $1,830,232$ & 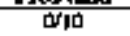 & & $\mathrm{NA}$ \\
\hline 2ANucphenot & oilo & ND & ND & & ND & & NA & & $\mathrm{NA}$ & & NA & & $\mathrm{NA}$ \\
\hline 3.3'-0xaldotobenzidune & 0,10 & $\mathrm{ND}$ & ND & & ND & & NA & & $N_{A}$ & $9 \$, 304$ & orlo & & $N_{A}$ \\
\hline H-Mechylphenol & 0,10 & No & ND & & ND & & NA & & $N A$ & $30,70,315$ & Orio & & $\mathrm{NA}$ \\
\hline $3-\mathrm{N}_{1}$ trobe & arlo & ND & ND & & ND & & $N_{A}$ & & NA & 18464 & $\alpha / 0$ & & $\mathrm{NA}$ \\
\hline 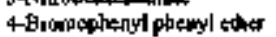 & OSto & ND & ND & & ND & & $N_{A}$ & & $\mathrm{NA}$ & & NA & & $\mathrm{NA}$ \\
\hline $4-1$ tore s-medhylphenot & ailo & ND & ND & & ND & & $N_{A}$ & & $N_{A}$ & & NA & & $\mathrm{Na}$ \\
\hline 4CWorobongewing & ando & ND & ND & & ND & & $N A$ & & $N_{A}$ & 2462,425 & orlo & & NÁ \\
\hline 4 C) Mrophanyl pheays etber & wito & ND & ND & & ND & & NA & . & $\mathrm{NA}$ & & NA & & NA \\
\hline 4-Nitrobenzanumune & Drio & ND & ND & & MD & & NA & & NA & LBA, 648 & arto & & $N_{A}$ \\
\hline 4Nitrophenol & orlo & ND & ND & & ND & & WA & & $\mathrm{N}$ & & NA & & $\mathrm{NA}$ \\
\hline Acenaphiterace & $1 / 6$ & 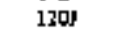 & [ZD] & $22+1033-2007$ & 120 & & NA & & $N A$ & $29,219,327$ & $\begin{array}{l}-10 \\
0\end{array}$ & & NA \\
\hline Acenupbulyyletent & oflo & $\mathrm{ND}$ & ND & & ND & & NA & & $\mathrm{NA}$ & $29,2] 9,32 T$ & OFID & & NA \\
\hline Ambre & W'เด & ND & WD & & ND & & B HA & & NA & $3,024,031$ & who & & $\mathrm{NA}$ \\
\hline Asuracente & j/10 & 2101 & 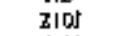 & $22-E 033-2007$ & 210 & & its & & $N_{A}$ & $100,000,000$ & orlo & & $\mathrm{Nm}$ \\
\hline Etrti(i) andhrocent & ZJu & I I & 3soj & $22-E U U_{33}-2005$ & $3 \pi$ & & HA & & NA & 21,096 & ơ & & NA \\
\hline Bertentemesiviol & Wio & ND & ND & & ND & & $N_{A}$ & & $\mathrm{NA}$ & $100,000,000$ & $0 / 10$ & & NA \\
\hline Bentot(0)pyrence & $2 / 10$ & 1601 & 3000 & 22-EVas-2009 & 30 & & th & & $\mathrm{NA}$ & 2,110 & d/10 & & $\mathrm{NA}$ \\
\hline 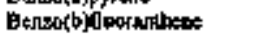 & 210 & $\$ 201$ & 5005 & zx-Eupl-2007 & 410 & & NA & & NA & $21,0 \% 6$ & oro & & $\mathrm{NA}$ \\
\hline Bensol(poloperyle= & ailo & ND & ND & & ND & & $N_{A}$ & & NA & $29,126,201$ & Orlo & & NA \\
\hline 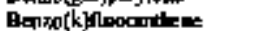 & sito & 2301 & 420] & $22-80333-20093$ & 306 & & NA & & NA & 210,062 & orio & & $\mathrm{NA}$ \\
\hline Bensogr atud & Orlo & סבני & ND & 1 & ND & & NA & & in & $10,0,00,000$ & orlo & & $N_{A}$ \\
\hline 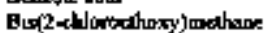 & 0 & ND & ND & & ND & & HA & & $\mathrm{NA}$ & & NA & & $\mathrm{NA}$ \\
\hline 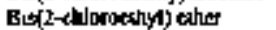 & Q & ND & NO & & ND & & NA & & $\mathrm{NA}$ & $5,75 s$ & $\$ 10$ & & NA \\
\hline 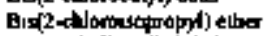 & Who & ND & ND & & ND & & $\mathrm{HA}_{\mathrm{A}}$ & & $N A$ & 73,518 & - & & $\mathrm{NA}$ \\
\hline 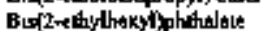 & $4 / 10$ & J60J & $510 \mathrm{l}$ & $22+00 \times 3-2010$ & 280 & & NA & & NA & $1,231,213$ & 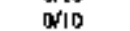 & & $\mathrm{NA}$ \\
\hline 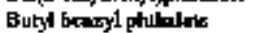 & $2 / 10$ & 240 & 430) & $22-4133-2007$ & t35 & & $\mathrm{NA}_{\mathrm{A}}$ & & $M A$ & $100,000,000$ & OrLO & & NA \\
\hline 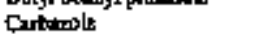 & Ito & $150 \mathrm{~J}$ & |190| & Z2-eU35-2007 & 390 & & NA & & NA & 861,849 & 0 & & $\mathrm{NA}$ \\
\hline Suryenes & 210 & $290 \%$ & $970]$ & 22. EU133-2007 & 450 & & NA & & $x_{A}$ & 2100,623 & 0 & & NA \\
\hline 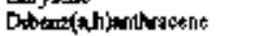 & W & 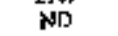 & ND & & No & & $\mathrm{NA}$ & & $\mathrm{NA}_{\mathrm{A}}$ & 2,110 & 0 & & $N A$ \\
\hline 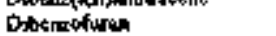 & orlo & $\mathrm{S} D$ & ND & & ND & & NA & & MA & $1,563,3,12$ & W & & $\mathrm{NA}_{\mathbf{H}}$ \\
\hline Diethyl phithalowe & $0 / 10$ & $\mathrm{ND}$ & ND & & ND & & $\mathrm{NA}$ & & $N_{A}$ & ] $10,000,000$ & WL & & $\mathrm{NA}$ \\
\hline 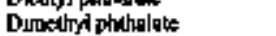 & orto & $\mathrm{Na}$ & ND & & ND & & NA & & $\mathrm{NA}$ & $100,000,000$ & arlo & & $N A$ \\
\hline 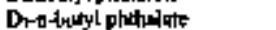 & $3 / 10$ & [40] & 3905 & 22.E1353.2004 & 373 & & NA & & $\mathrm{NA}_{A}$ & $61,460,625$ & טן & & NA \\
\hline 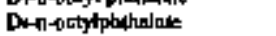 & who & $\mathrm{NOB}$ & ND & & ND & & $N_{A}$ & & $N_{A}$ & $2 A_{1}, 6 t+2 \leq 2$ & w/o & & $\mathrm{NA}$ \\
\hline Depheoyidumara & anto & ND & ND & & ND & & NA & & $N_{A}$ & 156,704 & 0 & & $\mathrm{NA}$ \\
\hline Flumerellire & Wo & נסדון & 1,50003 & $2,-2033-2007$ & 673 & & $\mathrm{NA}$ & & $N A$ & $22,000,353$ & arlo & & $N_{A}$ \\
\hline Flumeree & Ifo & ito & 1105 & $2.26033-2007$ & 10 & & Ne & & $N A$ & $26,211,473$ & ario & & NA \\
\hline Hexanhloroberione & orio & Ny & WD & & HD & & Na & & NA & 10,773 & arto & & $\mathrm{NA}$ \\
\hline Hexarblocobulanthems & w10 & ND & ND & & ND & & $\mathrm{EHA}$ & & $N \Lambda$ & $1 \pm 4,02$ & orio & & NA \\
\hline 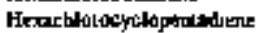 & ख10 & ND & $\mathrm{END}$ & & ND & & WA & & $\mathrm{NA}$ & $3,65 \mathrm{~B}, 7 \mid 7$ & ono 10 & & $\mathrm{NA}$ \\
\hline Hecarblomentitos & W10 & ND & ND & & ND & & NA & & NA & 615,606 & arto & & $\mathrm{NA}$ \\
\hline Inteno $(1,2,2,-d)$ pyretre & dilo & ND & ND & & ND & & WA & & $N A$ & 11,0966 & arto & & NA \\
\hline Inopherione & od 10 & No & ND & & ND & & $\mathrm{N}_{A}$ & & NA & $5,119,795$ & 0 & & NA \\
\hline Napulualem: & 吸住 & $\mathrm{SAD}$ & ND & & ND & & NA & & $N A$ & {$[37,69]$} & 0 & & $\mathrm{NA}$ \\
\hline Notobertente & W10 & ND & ND & & ND & & $N_{A}$ & & NA & 102,935 & Ól(t) & & NA \\
\hline 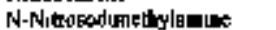 & orto & $\mathrm{ND}$ & ND & & ND & & NA & & $N A$ & 351 & $0 \times 10$ & & $\mathrm{NA}$ \\
\hline 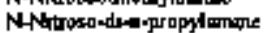 & oin & ND & ND & & ND & & $w_{A}$ & & $N_{A}$ & $2+162$ & orio & & $N_{A}$ \\
\hline N-Aktrosodo phenylunure & o/10 & No & ND & & ND & & $N A$ & & $N_{A}$ & $3,317,790$ & W10 & & NA \\
\hline Pentathlaraptea ol & orlo & ND & ND & & ND & & $N_{A}$ & & $N A$ & 89,9az & 足 & & $\mathrm{NA}$ \\
\hline Phenanturene & $2 / 10$ & 1201 & $1,200 \mathrm{~J}$ & 22-6utso.20,07 & 660 & & NA & & NA & $29,126,201$ & $\$ 10$ & & NA \\
\hline
\end{tabular}




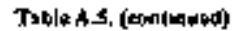

\begin{tabular}{|c|c|c|c|c|c|c|c|c|c|c|c|c|c|}
\hline Antrote & $\begin{array}{l}\text { Frequenty } \\
\text { of peled }\end{array}$ & Merimum & Mnimegre & 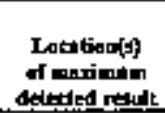 & 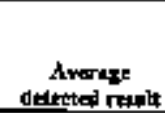 & $\begin{array}{c}\text { Mrximum } \\
\text { RX. }\end{array}$ & 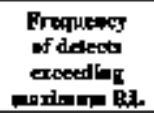 & $\underset{\text { AL }}{\text { Awerego }}$ & 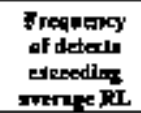 & $\begin{array}{c}\text { FRE] }]_{\text {mil }} \\
\left(10^{-5} \text { or }\right. \\
\text { EII - L })\end{array}$ & 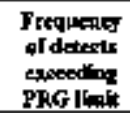 & Getproved & 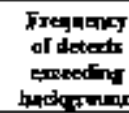 \\
\hline $\begin{array}{l}\text { Prenol } \\
\text { Pyreas }\end{array}$ & $\begin{array}{l}3 / 10 \\
3 / 10\end{array}$ & $\begin{array}{l}901 \\
1500\end{array}$ & $\begin{array}{c}176 J \\
1,300 \mathrm{~J}\end{array}$ & 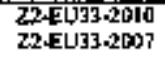 & $\begin{array}{l}133 \\
593\end{array}$ & & $\begin{array}{l}\mathrm{NA} \\
\mathrm{NA}\end{array}$ & & $\mathrm{H}_{3+\Lambda}$ & $\begin{array}{l}100,000,000 \\
29,126,201\end{array}$ & $\begin{array}{l}\text { o'10 } \\
\text { o'so }\end{array}$ & & $\mathrm{Nh}$ \\
\hline pyndes & Qítio & $\mathrm{ND}$ & ND & & ND & & $\mathrm{NA}$ & & MA & $6 \mid S, 600$ & ond & & $\mathrm{mA}$ \\
\hline
\end{tabular}

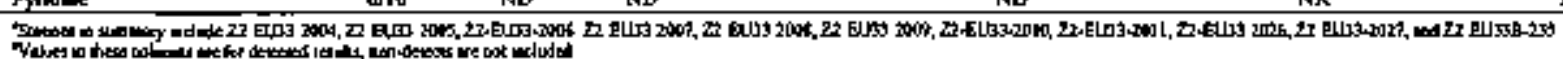

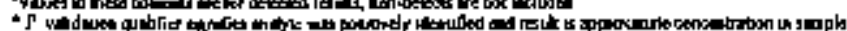

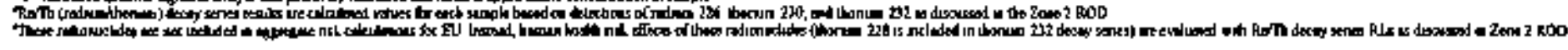

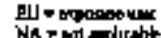

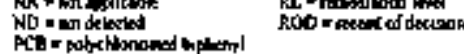

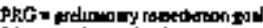

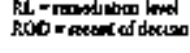




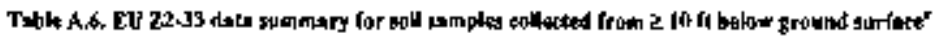

\begin{tabular}{|c|c|c|c|c|c|c|c|c|c|c|c|c|c|}
\hline Andits & $\begin{array}{c}\text { Frequeng } \\
\text { nf delect }\end{array}$ & $\begin{array}{c}\text { Mimimange } \\
\text { desect } \\
\end{array}$ & 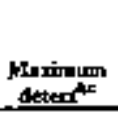 & 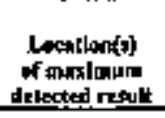 & $\begin{array}{c}\text { Aversos } \\
\text { detacted reoul }\end{array}$ & 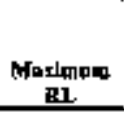 & 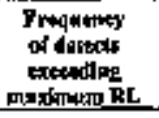 & $\begin{array}{c}\text { Averasoso } \\
\mathrm{RI}\end{array}$ & 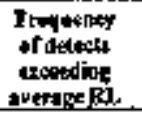 & 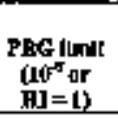 & 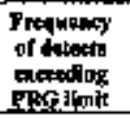 & $\begin{array}{l}\text { Backgrowid } \\
\text { consenlratien }\end{array}$ & 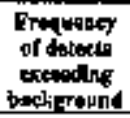 \\
\hline \multicolumn{14}{|l|}{ Inorraniss (molke) } \\
\hline 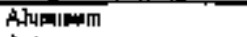 & LËL & 7,500 & 2,000 & $22 \cdot D_{033}^{3}-2013$ & 15,199 & & $\sqrt{\mathrm{A}}$ & & 萩 & 100,000 & कि 16 & 40,300 & Dit6 \\
\hline Antomesty & IIFLE & 0.0351 & $068 \mathrm{BJ}$ & 425 & 0211 & & NA & & $N$ & 1080 & $0+16$ & 192 & $0 \times 16$ \\
\hline Arrolic & 16756 & 17 & 91 & Z7.EUY39.2013 & 49 & 900 & an's & 300 & $0 \times 16$ & 139 & orts & 1495 & orla \\
\hline Вепши & L6Fl6 & $32 \mathrm{IJ}$ & 170 & $272-[10318.229$ & t30 & & NA & & NA & 66,577 & Orito & 12495 & $3 / 6$ \\
\hline Berylloun & $16 r 16$ & 034 & 25 & Z27-EU398-220 & 142 & 6,000 & QY6 & 2,000 & 象 16 & 1,941 & ON'L6 & 22 & 狛同 \\
\hline Borro & $14 / 14$ & 0321 & 33 & Z2-EU35B-230 & 200 & & NA & 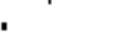 & NA & 100,000 & Q/14 & & NA \\
\hline $\operatorname{Cod}=1-m$ & $12: 16$ & 1) & 25 & 2-feut3-2001 & $0 \% 36$ & & NA & & NA & 451 & Q/16 & $022 \mathrm{~L}$ & $9 / 16$ \\
\hline Calcram & $16 / 16$ & 920 & 18,000 & $22-E \cup 33 \mathrm{~B}-123$ & 4, 观 & & NA & & $\mathrm{NA}$ & & NA & 2,400 & $9 / 6$ \\
\hline Chromunum & 16156 & 13 & 130 & $22-\mathrm{E} \cup 33 \mathrm{~B}-123$ & 320 & & NA & & NA & $6+1$ & $Q 16$ & 9488 & $2 / 16$ \\
\hline Cotath & $16 \mid 6$ & 45 & 23 & $\begin{array}{l}\text { 22EU33-20101 } \\
72-E U 336-374\end{array}$ & 191 & & NA & & NA & {$[33,310$} & $\alpha^{\prime \prime} 16$ & 42 & ONES \\
\hline Coppest & Lo'to & $4 t$ & $\mathbf{3}$ & 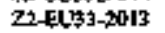 & 197 & & $\mathrm{NA}_{\mathrm{A}}$ & & NA & 40,877 & 0,16 & 2248 & 616 \\
\hline Iron & LE'L 6 & 21,00이 & 66,000 & $22 \cdot E(1) 3-2013$ & 45,844 & & $N_{A}$ & & $\mathrm{NA}$ & {$[(\mathbb{x}, 0001$} & $W^{\prime} \in G$ & 38,600 & $3 / 66$ \\
\hline Legl & $16 / 6$ & 99 & 61 & 22.84318 .123 & 236 & & $N_{A}$ & & NA & Wo & oito & 3791 & 1816 \\
\hline J.|lhulum & 13/14 & 56 & 23 & Z2-EU33B.230 & 194 & & NA & & NA & 10,439 & o/4 & 489 & $\$ / 14$ \\
\hline Mиgp=14 & $16 \sqrt{16}$ & 262 & 3,200 & Z2-EU33B.229 & 1,268 & & NA & & NA & & NA & $\$, 300$ & 016 \\
\hline Wunganese & [6/16 & 150 & 1,300 & Z2-EU39-2002 & $7 \times$ & & $\mathrm{NA}$ & & $\mathrm{NA}$ & 19,458 & $0 / 16$ & 2,200 & $8 / 16$ \\
\hline Meraury & $16 / 16$ & 0032 & D 535 & Z2-EL13B-123 & 0114 & 1,800 & 016 & $6 \infty 0$ & arl6 & 3007 & $8 / 16$ & 013 & 1/1: \\
\hline Asolybdetant & $12 / 4$ & 02 & 0865 & $\overline{z z}-E L\} 3 \mathrm{~B}-123$ & of 360 & & NA & & NA & SIto & OHili & & $\mathrm{Nh}$ \\
\hline Nathol & $16 \mid 6$ & 46 & 31 & 22-EU33B-1 14 & $31 \%$ & & N. & & $N A$ & 20,439 & OrI6 & 2607 & 116 \\
\hline Portstseold & L6il6 & 450 & 1,800 & 23-EU330-200 & 1306 & & NA & & $N A$ & & NA & 5,07469 & to't6 \\
\hline Scherum & $\mid 1 / 16$ & I t) & 42 & $\begin{array}{l}22-E U 538-129 \\
22 \mathrm{EU} 33 \mathrm{~B}-220\end{array}$ & 27 & & $N_{A}$ & & $N A$ & 5,310 & orlo & 147 & $10 \times 16$ \\
\hline Sulvex & 216 & 052 & 21 & Z2.EU33-123 & I 21 & & NA. & & Na & 5,110 & OFl6 & 060 & $1 / 16$ \\
\hline Sodulun & $9 / 6$ & $26 \mathrm{~J}$ & 925 & 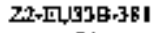 & 534 & & NA & & NA & & NA & 493 & $0 \times 16$ \\
\hline Thallern & 1516 & $013 \mathrm{~J}$ & 14 & 424 & 0303 & & $\mathrm{NA}$ & & $N_{*}$ & 679 & oite & $04 \mathrm{U}$ & Ifló \\
\hline Uranurura & $14 \sqrt{ } \mid 4$ & 0,33 & 15 & 27.5437 B.123 & 187 & & $\mathrm{NA}_{\mathrm{A}}$ & & $N A$ & 204 & $\operatorname{art} 4$ & & $\mathrm{NA}$ \\
\hline Yanadilim & เER & $23 j$ & $49 \mathrm{~J}$ & $22 . \pm \cup 33 E_{-123}$ & 312 & & NA & & NA & 1,021 & orto & 6547 & arle \\
\hline Zins & 16516 & II & L05 & 424 & 526 & & $N_{A}$ & & jNk & 100,000 & arti & 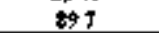 & $1 / 6$ \\
\hline \multicolumn{14}{|l|}{ 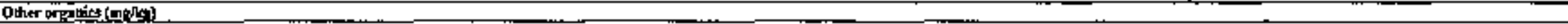 } \\
\hline Dreed Rupe Ongens & orl & No & ND & & ND & & NA & & $\mathrm{NA}$ & & $N_{A}$ & & NA \\
\hline 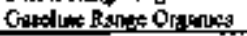 & arl & No & ND & & ND & & $\mathrm{NA}$ & & NA & & $\mathrm{NA}$ & & NA \\
\hline \multicolumn{14}{|c|}{ 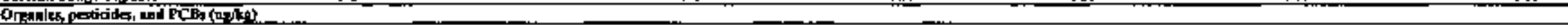 } \\
\hline PCB-1016 & क्षा & ND & NDD & & ND & $\overline{00,0 N Q}$ & Q/16 & 10,000 & Q/1 $1 \delta$ & $37,0 \%$ & \$/16 & & NA \\
\hline $\mathrm{PCB}-1221$ & oilo & ND & ND & & ND & 100,000 & W/6 & 10,000 & a/16 & 7.436 & dit 16 & & NA \\
\hline $\mathrm{PCB}-1232$ & Wis & No & ND & & ND & 100,000 & $0 / 16$ & 10,000 & anto & 7,436 & Q/16 & & NA \\
\hline $\mathrm{PCQ}-1242$ & $\$ 16$ & ND & ND & & ND & 100,000 & W/16 & 10,000 & orle & 7,036 & $\alpha / 16$ & & $N A$ \\
\hline $\mathrm{PCB}-1243$ & wit & $\mathrm{ND}$ & ND & & ND & 100,000 & Q & 10,000 & ait6 & 7,436 & \$/16 & & NA \\
\hline PCE-1254 & $1 / 16$ & 60 & 60 & 72-EU)38-123 & 60 & $100, \infty+0$ & \$1 16 & 10,000 & DIG & 7,436 & a/16 & & $\mathrm{NA}$ \\
\hline$P C D-1260$ & $2 / 6$ & [9] & 2015 & 22. Eบ138.117 & 195 & $100,0 \times 0$ & or 16 & 10,000 & 0,16 & 7,436 & of 16 & & $\mathrm{NA}$ \\
\hline Pollydulcemolex[ bupbenyl & $3 r 14$ & 19J & 60 & $22-E \cup 33 \mathrm{~B}-123$ & 33 & 100,000 & o14 & 10,000 & $\hat{W}<14$ & 7,436 & Qils & & Nh \\
\hline \multicolumn{14}{|l|}{ 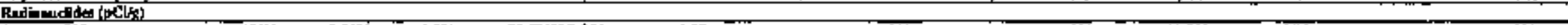 } \\
\hline Actanur-228 & IEIto & $0963 j$ & 1521 & 22-EU33B-391 & 329 & & $\overline{\mathrm{N} \Lambda}$ & & $\overline{\mathrm{NA}}$ & 81,9000 & wio & & NA \\
\hline Alphas acLrvity & II/IJ & 421 & 3 & 22-EU338-123 & 559 & & NA & & $\mathrm{NA}$ & & NA & & NA \\
\hline Beat teranty & {$[0 / 1]$} & 363 & 613 & $22-E \cup 338-114$ & 40 & & NA & & $\mathrm{NA}$ & & NA & & NA \\
\hline Bitgmath-2IZ & $2 / 2$ & 335 & 38 \& & 27-EL」33B.250 & 36 & & NA & & N* & 370,000 & $0 / 2$ & & NA \\
\hline B|काषणत-2I4 & B & $0.521 \mathrm{~J}$ & (2) हागJ & 22. ELI33B.123 & 0 OSA & & NA & & $\mathrm{NA}$ & 194,000 & $a$ & & NA \\
\hline Cesilum.137 & orla & ND & ND & & ND & 30 & $d^{\prime} 13$ & 2 & orl3 & 113 & $\alpha+13$ & & $\mathrm{NA}$ \\
\hline
\end{tabular}


Tabk A-6. (eoninowed)

\begin{tabular}{|c|c|c|c|c|c|c|c|c|c|c|c|c|c|}
\hline Anatyote & $\begin{array}{l}\text { Trequepry } \\
\text { of diftedet }\end{array}$ & $\begin{array}{l}\text { Minfroum } \\
\text { dedect }\end{array}$ & $\begin{array}{c}\text { Maximuse } \\
\text { delector }\end{array}$ & 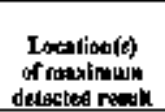 & $\begin{array}{c}\text { bverpese } \\
\text { detertud rosul| }\end{array}$ & $\begin{array}{c}\text { Mexilotom } \\
\text { RL }\end{array}$ & 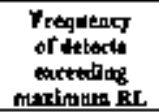 & 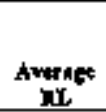 & 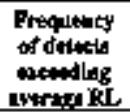 & 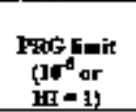 & 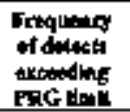 & $\begin{array}{l}\text { Bnckerownd } \\
\text { concentintlen }\end{array}$ & 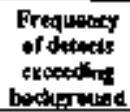 \\
\hline Coballe-60 & $1 / 13$ & 02725 & 027 & $22-\mathrm{EU} J 33 \mathrm{~B}-230$ & 0272 & & NA & & NA & 06 & $00^{\prime} 13$ & & $N A$ \\
\hline Eигориш-152 & $1 / 1$ & I Ot & I 1020 & $22-\mathrm{EU} 33 \mathrm{~B}-120$ & 104 & & $\mathrm{NA}$ & & NA & 073 & III & & $\mathrm{NA}$ \\
\hline Leas-212 & I U'll & 6987 & (s) & $2260133-2018$ & 123 & & $N A$ & & NA & 65,300 & Oill & & in \\
\hline Leatiti4 & 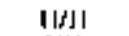 & 0 S.9 & 0952J & $\mathrm{Z2} \cdot \mathrm{EU33 \textrm {E } - 1 1 0}$ & 0 वा० & & $\mathrm{NA}$ & & $\mathrm{NA}$ & 796,000 & 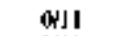 & & $N *$ \\
\hline NLph=um-23\}? & Oill & ND & $\mathrm{ND}$ & & ND & 50 & onil & $s$ & וורז0 & 272 & Wili & & $N A$ \\
\hline Podenemuna 40 & 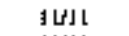 & $\sqrt{112}$ & 322 & Z2.EU13E.230 & 204 & & $\mathrm{NA}$ & & $\mathrm{NA}$ & 27 & $\|F\|$ & 32 เ2 & IFII \\
\hline 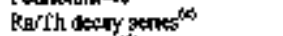 & dull & 0 & $0 ; 5$ & Z2. & 0 (II & 15 & \$11 & 5 & L & & $\mathrm{M}$ & & $\mathrm{NA}$ \\
\hline 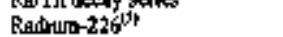 & $2 n$ & 0749 & (0) & 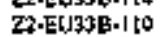 & $0 \mathrm{Bg}$ & & $\mathrm{NA}$ & & $N A$ & 0.26 & $2 \pi$ & 125 & on \\
\hline Tethnebaum-as & Q15 & $\mathrm{ND}$ & $\mathrm{NT}$ & $\Rightarrow$ cons & ND & & $\mathrm{NA}$ & 1 & $m_{k}$ & $R, 960$ & WII & 10 & $\mathrm{NA}$ \\
\hline Thellium-20t & Jutt & 0308 & oxsJ & Z2.EU33E. 114 & 0419 & & $\mathrm{NA}$ & & wA & $96 \pm 000$ & Oill & & $\mathrm{NA}$ \\
\hline Thenum-22s $s^{10}$ & IMI3 & 102 & 207 & Z2. EUU33B. 12 & 145 & & $\mathrm{NA}$ & & $\mathrm{MA}$ & 018 & $13(1]$ & 186 & $2 / 13$ \\
\hline Thenum-230 $0^{40}$ & $1\} 13$ & 0194 & 155 & 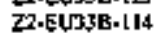 & 112 & & NA & & NAs & 202 & arla & 32 & $5 \mathrm{NIJ}$ \\
\hline 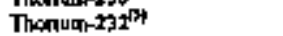 & 13113 & 075 & 172 & Z2.EUS3E. II & 132 & & NA & & $\mathrm{NA}$ & 018 & $13 / 13$ & 195 & ovis \\
\hline Thonum-2? & ons & ND & $\mathrm{ND}$ & & $\mathrm{ND}$ & & Nik & & NA & $32,8 \infty 0$ & arto & & $\mathrm{NA}$ \\
\hline 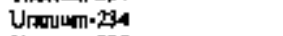 & $13 / 6$ & 0628 & 437 & $22.603358 \cdot 120$ & 150 & 7,000 & o's & 200 & QII & 332 & $0+13$ & & NA \\
\hline 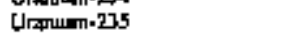 & 6013 & 0 IUTJ & O lde & 22 -E)з39y- 117 & 0121 & Bo & wis & 8 & DNI3 & 398 & DrT3 & & NA \\
\hline Ltroman.278 & $13 / 13$ & 0,353 & 785 & $22 . E U 133 \mathrm{~B}-123$ & 1 is & 500 & Qull & 50 & $0 \times 13$ & 18 & 0.13 & Id7 & 기 \\
\hline \multicolumn{14}{|l|}{ 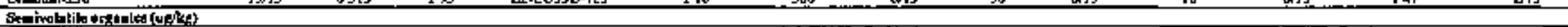 } \\
\hline 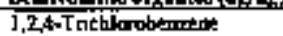 & 019 & ND & AD & & ND & & NA & & NA & 215,925 & 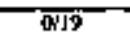 & & NA \\
\hline 1,2-Dudilerobenzent & bils & ND & $\mathrm{HB}$ & & ND & & $\mathrm{NA}$ & & $\omega_{A}$ & 600,0100 & 0.19 & & NA \\
\hline 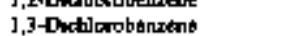 & orlo & ND & ND & & ND & & NA & & $N_{A}$ & 600,000 & N19 & & $\mathrm{NA}_{\mathrm{A}}$ \\
\hline 1,4-Dedidoroletuzent & 019 & ND & ND & . & ND & & $N_{A}$ & & NA & 78,665 & W & & NA \\
\hline $2,3,4,6$ - Terombloruphenol & $\alpha ?$ & ND & ND & & ND & & NÁ & & $w / A$ & $18,468,188$ & ant & & $\mathrm{NA}_{\mathrm{A}}$ \\
\hline $2,4 \times$-Tnchlorephenof & wh & ND & $\mathrm{ND}$ & & ND & & NA & & NA & $61,960,629$ & W & & ik \\
\hline $3,4,6$-T nchloropheont & W & ND & $\mathrm{ND}$ & & ND & & $N_{A}$ & & $\hat{w n}$ & $6 \mid, 561$ & art & & $N_{k}$ \\
\hline 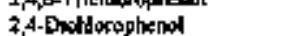 & un & ND & ND & & ND & & $\mathrm{Nh}$ & & $\mathrm{HA}$ & $1.846,8,9$ & trit & & $m$ \\
\hline 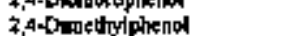 & 政 & ND & ND & & ND & & NA & & N/A & $12,312,126$ & on & & $N A$ \\
\hline 3,400urophenol & a & ND & $\mathrm{ND}$ & & ND & & $\mathrm{NA}$ & & NA & 1.231 .243 & ar & & NA \\
\hline 3,4-Denutrotohuene & $a n$ & ND & ND & & ND & & $N_{A}$ & & NA & 29,342 & on & & $\mathbf{N A}$ \\
\hline 3, GD Devorotoluene & $\mathbb{a n}$ & ND & ND & & ND & & NA & & MA & 29,748 & or & & $N_{A}$ \\
\hline 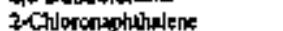 & 07 & ND & ND & & ND & & Nh & & MA & $25,351,732$ & art & & $\mathrm{NA}_{A}$ \\
\hline 2-Chlorcobenol & W & ND & ND & & ND & & $\mathrm{NA}$ & & MA & 235,765 & טי & & NA \\
\hline 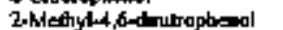 & wh & ND & ND & & ND & & $\mathrm{NA}_{\mathrm{A}}$ & & $m_{A}$ & 61,561 & QR & & NA \\
\hline 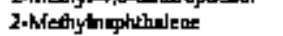 & 07 & ND & שי & & ND & & NA & & $\mathrm{MA}$ & 187,691 & 97 & & NA \\
\hline 2. Methythotenol & 8 & No & ND & & $N+D$ & & NA & & NA & 30,780,3]5 & QT & & NA \\
\hline 2. Nurobenortentanture & aT & ND & ND & & W & & WA & & NA & $\mathrm{L}, 830,212$ & प7 & & NA \\
\hline Z.Nutuphomol & or & $\mathrm{ND}$ & ND & & No & & NA & & WA & & $N A$ & & NA \\
\hline 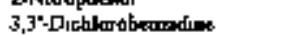 & w) & No & No & & WD & & NA & & $N_{A}$ & 30,304 & 07 & & $N_{A}$ \\
\hline 3-Medty loluenio] & vin & 1301 & 130 & $22-\mathrm{EU}_{3} 3 \mathrm{~B}-374$ & 130 & & $\mathrm{NA}$ & & NA & $30, \pi 0,315$ & ort & & NA \\
\hline 3-Nurobobzenanume & 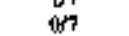 & ND & $N D$ & & ND & & $\mathrm{NA}$ & & $N_{A}$ & 12,469 & ont & & $N A$ \\
\hline A-Bromeghenyl pbecyil cher & w & ND & No & & WD & & NA & & $N_{A}$ & & NA & & $N k$ \\
\hline 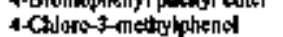 & ib & ND & ND & & ND & & NA & & $w a$ & & $N$ & & $N A$ \\
\hline 4-Chlordbermenamune & af & ND & DO & & $\mathrm{kD}$ & & $N_{A}$ & & $m a$ & $7,467,475$ & art & & $\mathrm{NA}$ \\
\hline 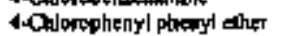 & ar & ND & ND & & ND & & NA & & $m$ & & NA & & $\mathrm{NA}$ \\
\hline 4 Niltrabenuenarause & 07 & ND & ND & & ND & & NA & & $m_{A}$ & 184,64t & कर & & is \\
\hline A-Abroghened & an & No & 210 & & ND & & $N_{A}$ & & $M A$ & & $\mathrm{NA}$ & & NA \\
\hline Acentphthent & the & ND & $N D$ & & NO & & $\mathrm{NA}$ & & $N_{A}$ & $29,219,327$ & WT & & NA \\
\hline 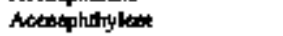 & 07 & ND & ND & & NO & & NA & & HA & $29,219,327$ & on & & NA \\
\hline Ardilat & 07 & ND & no & & ND & & WA & & $N A$ & $3,024,031$ & ont & & NA \\
\hline 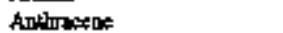 & ตT & ND & ND & & WD & & NA & & NA & $100,000,000$ & ONT & & MA \\
\hline 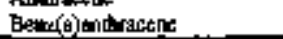 & \&7 & ND & No & & 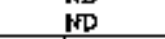 & & NA & & $\mathrm{N} / \mathrm{A}$ & $310 \%$ & 07 & & NA \\
\hline
\end{tabular}


Table A.C. (cominuod)

\begin{tabular}{|c|c|c|c|c|c|c|c|c|c|c|c|c|c|}
\hline Anatyve & $\begin{array}{l}\text { Preprency } \\
\text { of defted }\end{array}$ & $\begin{array}{c}\text { Melnalmum } \\
\text { dotetets }\end{array}$ & 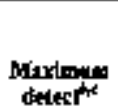 & 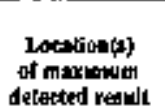 & Anterat: & $\begin{array}{c}\text { Maxjmon } \\
\text { pl }\end{array}$ & 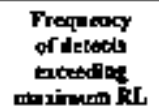 & 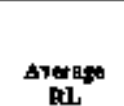 & 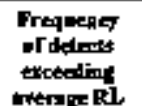 & 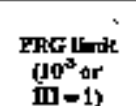 & 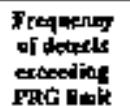 & 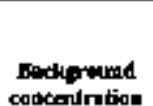 & 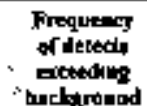 \\
\hline 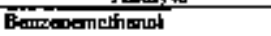 & $\frac{0}{07}$ & $\mathrm{ND}$ & ND & & ND & & $\frac{N A}{N A}$ & & Nh & 106000000 & क्षे & & $\mathrm{N}+\mathrm{A}$ \\
\hline Bercoldapyrene & $0 / 7$ & ND & ND & & ND & & NA & & NA & 3,110 & $\alpha \pi$ & & WA \\
\hline 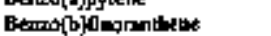 & ar & No & ND & & ND & & $N_{A}$ & & NA & $2 i, 096$ & ar & & WA \\
\hline Bemom $(g(0)$ peryleat & $a r$ & No & ND & & ND & & $\mathrm{NA}$ & & $\mathrm{NA}$ & $29,126,201$ & ar & & W \\
\hline 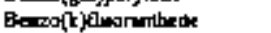 & an & NO & ND & & ND & & Nh & & NA & 210,962 & of & & NA \\
\hline Benow ard & or & No & ND & & ND & & NA & & NA & $300,000,000$ & art & & $N_{A}$ \\
\hline 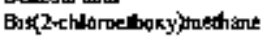 & at & $\mathrm{NU}$ & No & & ND & & NA & & $N_{A}$ & & NA & & NA \\
\hline 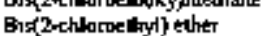 & ar & No & ND & & $\mathrm{ND}$ & & NA & & NA & 5.755 & or & & $N_{A}$ \\
\hline Bas $\{2$-chlorossopopsi) thes & or & ND & ND & & ND & & NA & 1 & NA & 73,518 & art & & NA \\
\hline 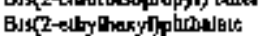 & $1 / \pi$ & 391 & 390 & 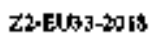 & 39 & & NA & & NA & $1,231,213$ & ant & & $N_{A}$ \\
\hline 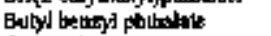 & 听 & ND & No & & ND & & NA & & NA & $100,000,000$ & ONT & & $N_{A}$ \\
\hline Combete & 初 & $\mathrm{AD}$ & ND & & No & & $\mathrm{NA}_{A}$ & & NA & $361,4 \%$ & ar & & $N_{A}$ \\
\hline Chryete & 67 & ND & $\mathrm{ND}$ & & ND & & $N_{A}$ & & Na & $2,109,623$ & ar & & NA \\
\hline 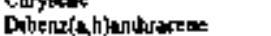 & 01 & ND & $\mathrm{ND}$ & & ND & & $N_{A}$ & & NA & $=2,110$ & on & & $N_{A}$ \\
\hline $\begin{array}{l}\text { Dobenzofium } \\
\text { Dus }\end{array}$ & 007 & ND & ND & & ND & & $N_{A}$ & & NA & $1,569,7-12$ & or & & $N_{A}$ \\
\hline Dethyl phlakate & os & $\mathrm{Na}$ & ND & & No & & NA & & $N_{A}$ & 102000,000 & (5) & & NA \\
\hline Dumettryl pithalase & 05 & $\mathrm{ND}$ & ND & & ND & & $\mathrm{NA}_{\mathrm{A}}$ & & $N_{A}$ & $100,000,000$ & a) & & NA \\
\hline Dowaturyl phthulate & 67 & ND & No & & ND & & $\mathrm{HA}$ & & $N_{A}$ & $6,1560,629$ & Tדו & & $N A$ \\
\hline Dinnoctyspbuhalate & $a r$ & ND & ND & & ND & & $W_{A}$ & & NA & $2,4624,257$ & an & & $N_{A}$ \\
\hline 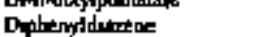 & an & ND & ND & & No & & NA & & $\mathrm{NA}$ & Istinat & ar & & $\mathrm{NA}$ \\
\hline Flnoromberse & ar & NG & ND & & ND & & NA & & $N_{A}$ & $22,000,353$ & $0 \pi T$ & & NA \\
\hline Flutace & 听 & NO & ND & ' & ND & & NA & & NA & $26,281,433$ & OPT & & NA \\
\hline Hewecthocobeavene & (ז' & NO & ND & & No & & Na & & tis & (ט,7) & an & & NA \\
\hline 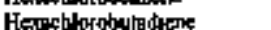 & oilg & $\mathrm{ND}$ & ND & & ND & & NA & & NA & 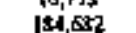 & ais & & NA \\
\hline 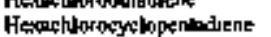 & an & ND & ND & & ND & & NA & & $N_{A}$ & $3,658,517$ & ast & & NA \\
\hline 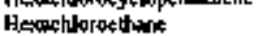 & an & ND & ND & & ND & & NA & & NA & $615,0 \times 0$ & or & & NA \\
\hline Indeno( $(1,2,5$-ad)pyreace & ar & ND & ND & & ND & & $N_{A}$ & & NA & 21,0906 & an? & & $\mathrm{NA}$ \\
\hline Inothore & ar & $\mathrm{ND}$ & ND & & ND & & NA & & NA & $5,119,795$ & on & & MA \\
\hline Nophthalewe & و & NO & ND & & ND & & NA & & $N A$ & 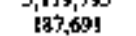 & w19 & & $N_{A}$ \\
\hline Notobetare & ar & No & ND & & ND & & NA & & NA & ED2935 & the & & $N_{A}$ \\
\hline N.Notrasodmethylamont & art & $\mathrm{No}$ & ND & & ND & & WA & & NA & 338 & an & & $\mathrm{NA}_{A}$ \\
\hline 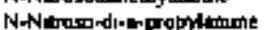 & on & NG & ND & & ND & & NA & & NA & 2,467 & an & & sik \\
\hline 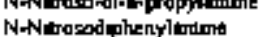 & an & No & No & & No & & $N_{A}$ & & NA & 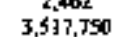 & $\begin{array}{l}\text { ant } \\
\text { ont } 19\end{array}$ & & $w_{A}$ \\
\hline Ponthoblorophengt & art & ND & ND & & ND & & $N_{\Lambda}$ & & NA & 89,9e2 & $0 \times 7$ & & MA \\
\hline Ptemathrents & 05 & ND & $\mathrm{ND}$ & & $\mathrm{ND}$ & & $\mathrm{NA}$ & & NA & $29,126,201$ & or & & NA \\
\hline 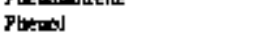 & 67 & ND & $\mathrm{NZ}$ & & No & & $N_{A}$ & & NA & $100,000,000$ & an & & NA \\
\hline Pronts & 07 & ND & ND & & $\mathrm{ND}$ & & $N_{A}$ & & NA & $29,126,2911$ & ar & & $N_{A}$ \\
\hline Gyadian & 07 & ND & ND & & $M D$ & & NA & & $\mathrm{N} n$ & 615,606 & on & & $N_{A}$ \\
\hline \multicolumn{14}{|l|}{ 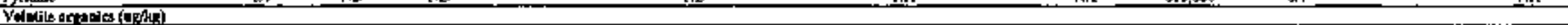 } \\
\hline 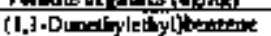 & WI3 & ND & ND & & ND & & WA & & $\mathrm{NA}$ & $390,0 \times 0$ & $\overline{\mathrm{Q}} \overline{\mathrm{T}}$ & & $\mathrm{NA}$ \\
\hline 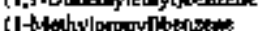 & 年 & ND & ND & & ND & & $N_{A}$ & & $\mathrm{NA}$ & 20,000 & $x+3$ & & NA \\
\hline 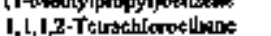 & 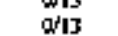 & $\mathrm{ND}$ & ND & & ND & & NA & & NA & $\pi, 7 s 5$ & W' & & $N_{A}$ \\
\hline I. I-Tnchloroedlane & j/5 & 96 & $\infty$ & 22.Eฏ) & so & & $\mathrm{NA}_{\mathrm{H}} \mathrm{a}$ & & NA & $1,200,00000$ & QXI & & NA \\
\hline i, i,2-Trtrecbleroetlane & Q/15 & ND & ND & & ND & & NA & & $N_{k}$ & 9,294 & orly & & NA \\
\hline $1,1,2$-Trechlorent $1,2,2$. & ias & 251 & 25 & 72-EU33B:AL4 & 25 & & NA & & $x \in$ & $5,6 \infty 0, \infty)$ & on 15 & & NAB \\
\hline 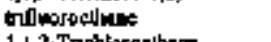 & & & & & & & & & & & & & \\
\hline 1, 1,2-TTholisoroethane & H15 & ND & $\mathrm{ND}$ & & NOD & & $m / A$ & & N\$ & 16,050 & \$13 & & $\mathrm{NA}$ \\
\hline i, 1-Dkitoroed ane & $1 / 5$ & $d 2$ & 42 & Z2-EUB3E-1 I4 & 42 & & $\mathrm{nn}$ & & $\mathrm{NA}$ & $1,738,654$ & Q 15 & & $\mathrm{NA}$ \\
\hline i.-Dechloroedtene & $2 / 5$ & 3 & 37 & $\mathrm{Z2} \cdot \mathrm{EU} 33 \mathrm{~B} \cdot 1 \mathrm{L4}$ & 201 & & $\mathbf{w}$ & & NA & 413,325 & (x) & & NA \\
\hline 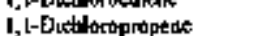 & 过 & ND & $\mathrm{ND}$ & & $\mathrm{ND}$ & & $\mathrm{NA}$ & & NA & & NA & & NA \\
\hline 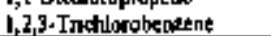 & $1 / 3$ & 27 & 23 & Z2-E[/33E- $1[7$ & 23 & & $N_{A}$ & & $N A$ & & $N A$ & & NA \\
\hline
\end{tabular}


Tabk A 6.6. (momlmed)

\begin{tabular}{|c|c|c|c|c|c|c|c|c|c|c|c|c|c|}
\hline Aralyte & $\begin{array}{l}\text { Trequency } \\
\text { of deted }\end{array}$ & $\begin{array}{l}\text { Mtinimerer } \\
\text { delest }\end{array}$ & 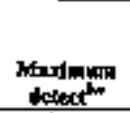 & 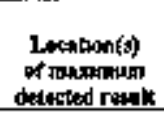 & $\begin{array}{l}\text { Awerpe } \\
\text { drtected ranult }\end{array}$ & $\begin{array}{c}\text { Mprlmpm } \\
\text { BLr }\end{array}$ & 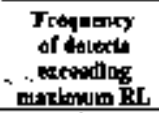 & $\begin{array}{c}\text { Averpe } \\
\text { PL }\end{array}$ & $\begin{array}{l}\text { Froquewey } \\
\text { of detests } \\
\text { arewdlog } \\
\text { wertade BL }\end{array}$ & 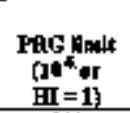 & 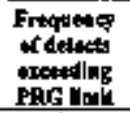 & 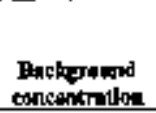 & 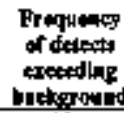 \\
\hline 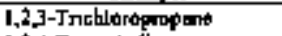 & $0 / 13$ & ND & MD & & ND & & $\mathrm{NA}$ & & $N_{A}$ & 760 & 0.13 & & $\mathrm{NA}$ \\
\hline 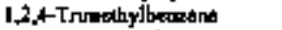 & a/12 & ND & HOD & & ND & & $\mathrm{NA}$ & & $\mathrm{NA}$ & 170,272 & o']2 & & $\mathrm{NA}$ \\
\hline 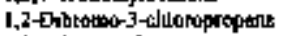 & o/13 & ND & No & & ND & & $\mathrm{NA}$ & & NA & 31,000 & $6] 3$ & & $\mathrm{NA}$ \\
\hline 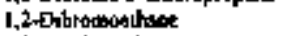 & $0 / 13$ & ND & $\mathrm{WD}$ & & ND & & $\mathrm{Nk}$ & & NA & 630 & 6] & & $\mathrm{NA}$ \\
\hline 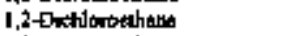 & QIIS & ND & WD & & ND & & $\mathrm{NA}_{\mathrm{A}}$ & & $N A$ & 6,055 & ols & & $N_{A}$ \\
\hline 1,2-Dnthunixdhelit & $0 / 2$ & ND & HO & & ND & & NA & & $N A$ & 150,000 & 0,2 & & $\mathrm{NA}$ \\
\hline 1,2-0nthosoptopane & $0 / 15$ & ND & ND & & ND & & NA & & $\mathrm{NA}$ & 7,472 & o's & & $\mathrm{NA}$ \\
\hline 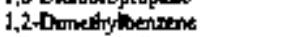 & 0113 & ND & ND & & ND & & NA & & $N A$ & $\$ 20,000$ & 31 & & NA \\
\hline 1,3,5.Trmollyblbetsan & Qilis & ND & WD & & ND & & $\mathrm{NA}$ & 1 & $\mathrm{NA}$ & 69,712 & 做3 & & NA \\
\hline 1,3-Dochlompropent & 01 13 & ND & ND & & ND & & NA & & $\mathrm{JA}$ & 760,321 & [13 & & NA \\
\hline 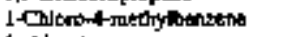 & Oil3 & ND & ND & & ND & & $\mathrm{NA}$ & & $\mathrm{NA}$ & & $\mathrm{NA}$ & & NA \\
\hline 1-endwohexarie & $0+13$ & ND & $\mathrm{ND}$ & & ND & & NA & & NA & & $\mathrm{NA}$ & & NA \\
\hline 1-Mentyles (1- & $0^{4} 3$ & ND & $\mathrm{ND}$ & & ND & & $\mathrm{NA}$ & & NA & & $\mathrm{NA}$ & & NA \\
\hline 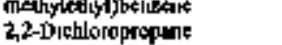 & N13 & WD & NE & & WD & & NA & & NÁ & & NA & & Na \\
\hline 2-Bubase & Wis & ND & ND & & ND & & NA & & $N_{A}$ & $11,3,264,388$ & oris & & NA \\
\hline 5. Hexwanare & 015 & WD & ND & & ND & & $\mathrm{NA}$ & & $\mathrm{N} 2$ & & NA & & Na \\
\hline 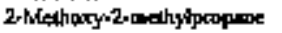 & 에기 & MD & No & & MD & & NA & & NA & 700,000 & arla & & NA \\
\hline 1Afethyl-2-penlanare & otis & ND & $\mathrm{MD}$ & & WD & & $\mathrm{NA}$ & & $N A$ & $4, \pi 00[, 434$ & E15 & & NA \\
\hline Actoos & ]/15 & 110 & $1] 0$ & $22-E$-EJ56-383 & $110-3-10$ & & $\mathrm{NA}$ & & NA & $54,320,406$ & Euts & & NA \\
\hline Betrense & Oils & ND & W0 & & NO & & NA & & NA & 14,004 & oxts & & NA \\
\hline 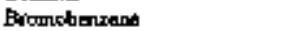 & \$13 & ND & WD & . & ND & & $N_{A}$ & & NA & $\$ 2,192$ & (0) 3 & & NA \\
\hline Bromicentoromethane & Q13 & ND & WO & & HE & & NA & & in & & na & & $\mathrm{NA}$ \\
\hline Bromedichtordonetbere & ois & ND & WD & & ND & & NA & & $\mathrm{NA}$ & 18,306 & 015 & & N4 \\
\hline Evosination & it's & ND & ND & & ND & & NA & & $\mathrm{NA}$ & $2,181,998$ & פ'ו't & & $\mathrm{NA}$ \\
\hline Brodionotethan & oils & ND & ND & & ND & & NA & & Fa & 13,078 & 9 & & $\mathrm{NA}$ \\
\hline Beny buelizene & 013 & ND & WD & & ND & & NA & & ins & 240,000 & \&广了 & & $N_{A}$ \\
\hline Cortion desulliots & 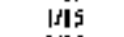 & 12 & 12 & 27.EU33B.383 & 12 & & Nh & & $N A$ & 720,000 & 015 & & $\mathrm{NA}$ \\
\hline Crubon temochlonds & J/Is & 67 & 67 & Z2.EU33B-12] & 67 & & NA & & NA & 5,493 & 015 & & NA \\
\hline Chorobenseste & o'ls & ND & MD & & ND & & NA & & $\mathrm{NA}$ & 530,466 & 015 & & NA \\
\hline Dh]oredure & bالt5 & ND & $\mathrm{MD}$ & & ND & & NA & & $N A$ & 64,855 & orts & & WA \\
\hline Odoroficrn & 235 & 381 & 240 & Z2.EUJ3E-3B3 & 719 & & NA & & NA & 4,698 & W5 & & NA \\
\hline Qjoromethe & o's & WD & $\mathrm{MD}$ & & ND & & $\mathrm{NA}$ & & $N A$ & 155,746 & wis & & MA \\
\hline ct-1,2-Duphlorpethene & 3133 & $9 z$ & 1300 & Z2.EUV33E-383 & 441 & & NA & & NA & {$[46,30]$} & WN] & & MA \\
\hline cLs:1, & a's & WD & ND & & ND & & $\mathrm{NA}$ & & NA & 17,645 & oris & & NA \\
\hline Carrene & QN13 & ND & ND & & ND & & NA & & NA & 520,0100 & 0,13 & & $\mathrm{NA}$ \\
\hline Othroosochloromedume & onds & WD & ND & & הN & & ies & & NA & 25,543 & DN15 & & WA \\
\hline Derocenowethnne & 0113 & WD & ND & & $\sqrt{\mathrm{N}}$ & & $\mathrm{MA}$ & & $\mathrm{NA}$ & 237,590 & DrI3 & & NA \\
\hline 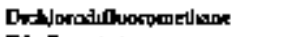 & arl3 & MD & ND & & $N$ & & $H A$ & & $\mathrm{NA}$ & 3005,058 & Dris & & NA \\
\hline Ehyphenzunt & Dils & ND & ND & & $\mathrm{ND}$ & & NA & & $\mathrm{NA}$ & 395,000 & oris & & NA \\
\hline lodoredhante & aill & $\mathrm{ND}$ & No & & $\mathrm{ND}$ & & MA & & $\mathrm{Na}$ & & $\mathrm{NA}$ & & $\mathrm{NA}$ \\
\hline$M+P$ Kyleas & 013 & ND & ND & & ND & & $N_{A}$ & & $N A$ & 120,000 & $0^{\prime} 15$ & & $\mathrm{NA}$ \\
\hline 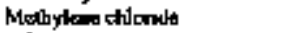 & oils & $\mathrm{ADD}$ & ND & & ND & & $\mathrm{NA}$ & & $\mathrm{NA}$ & 205.264 & ans & & NA \\
\hline oclaleratoluten: & $0 \times 13$ & ND & NE & & ND & & NA & & NA & 360,010 & ovi3 & & WA \\
\hline Proptwotsrante & Q13 & ND & NE & & ND & & $\mathrm{NA}$ & & $\mathrm{NA}$ & 240.000 & 013 & & $\mathrm{NA}$ \\
\hline Styom & 0.15 & ND & no & & ND & & $\mathrm{NA}$ & & $\mathrm{Nk}$ & $1,700,0 \times 0$ & $0 \times 19$ & & $\mathrm{NA}$ \\
\hline Tetrochlorethenes & b]s & $2 \mathrm{~s}$ & 29 & Z2-ELY338-383 & 29 & & $\mathrm{NA}$ & & $\mathrm{NA}$ & 15,0066 & W'S & & Wh \\
\hline Toluene & Sני & $26 \mathrm{~J}$ & 24 & 425 & 987 & & WA & & $\mathrm{NA}$ & $520,0 \times 0$ & Wris & & ext \\
\hline 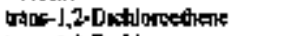 & t/13 & 1] & II & 22-90338.383 & 11 & & NA & & NA & 274,823 & or 13 & & Nh \\
\hline 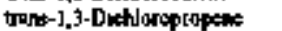 & 에 5 & ND & ND & & mo & & NA & & Nk & 17,645 & orls & & NA \\
\hline Ttufloposthene & $3 / 15$ & 20 & 3000 & 22EU13B-381 & igi & & $\mathrm{NA}$ & & NA & 1,147 & No1s & & NA \\
\hline
\end{tabular}


Tabte A,6. \{ooptouned)

\begin{tabular}{|c|c|c|c|c|c|c|c|c|c|c|c|c|c|}
\hline Analyte & $\begin{array}{l}\text { Fropuens } \\
\text { of dited }\end{array}$ & $\begin{array}{l}\text { Minianum } \\
\text { deletrt }\end{array}$ & $\begin{array}{c}\text { Mardanan } \\
\text { detector }\end{array}$ & 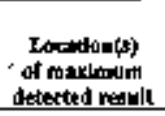 & $\begin{array}{l}\text { Axarage } \\
\text { detested tewall }\end{array}$ & $\underset{\text { RL }}{\text { Mingiman }}$ & 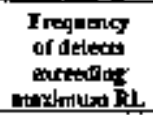 & $\begin{array}{c}\text { Antents } \\
\text { RL }\end{array}$ & 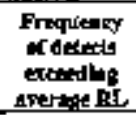 & $\begin{array}{l}\text { PRG fluit } \\
\left(10^{\mathrm{a}} \text { ar }\right. \\
\text { III-1) }\end{array}$ & 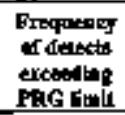 & 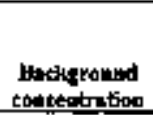 & 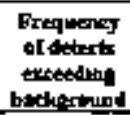 \\
\hline Treshloroflusmowechans & $\mathbb{W} / 3$ & $\mathrm{MD}$ & ND & & ND & & NA & & $\mathrm{N} \Omega$ & $\mathrm{i}, 27 \mathrm{k}, 0 \mathrm{~A}$ & w'13 & & $\mathrm{Nh}$ \\
\hline YLryl Abediti & o 13 & ND & No & & $\mathrm{No}$ & & $\mathrm{NA}$ & & NA & $1,396,422$ & (b) & & NA \\
\hline Yoritedoute & $2+13$ & 37) & 120 & $27-E U 1338-363$ & 619 & & $\mathrm{NA}$ & & NA & 7,461 & 에 5 & & $\mathrm{NA}$ \\
\hline \multicolumn{14}{|c|}{ 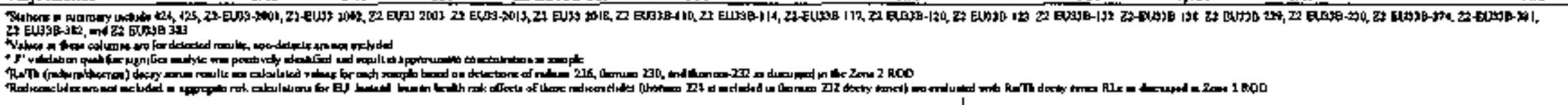 } \\
\hline 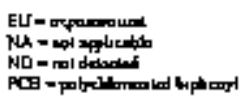 & 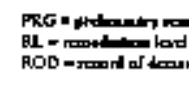 & 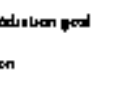 & & & & & & & & & & & \\
\hline
\end{tabular}


